Logos der Vernunft - Logos des Glaubens 


\section{Millennium-Studien}

zu Kultur und Geschichte des ersten Jahrtausends n. Chr.

\section{Millennium Studies}

in the culture and history of the first millennium C.E.

Herausgegeben von / Edited by

Wolfram Brandes, Alexander Demandt, Helmut Krasser,

Hartmut Leppin, Peter von Möllendorff

Band 31

De Gruyter 


\title{
Logos der Vernunft - Logos des Glaubens
}

\author{
Herausgegeben von \\ Ferdinand R. Prostmeier \\ und \\ Horacio E. Lona
}

De Gruyter 
Diese Publikation wurde im Rahmen des Fördervorhabens 16TOA021 - Reihentransformation für die Altertumswissenschaften („Millennium-Studien“) mit Mitteln des Bundesministeriums für Bildung und Forschung im Open Access bereitgestellt. Das Fördervorhaben wird in Kooperation mit dem DFG-geförderten Fachinformationsdienst Altertumswissenschaften - Propylaeum an der Bayerischen Staatsbibliothek durchgeführt.

\section{(cc) BY-NC-ND}

Dieses Werk ist lizenziert unter der Creative Commons Attribution-NonCommercial-NoDerivatives 4.0 International Lizenz. Weitere Informationen finden Sie unter http://creativecommons.org/licenses/by-nc-nd/4.0/.

Die Bedingungen der Creative-Commons-Lizenz gelten nur für Originalmaterial. Die Wiederverwenung von Material aus anderen Quellen (gekennzeichnet mit Quellenangabe) wie z.B. Schaubilder, Abbildungen, Fotos und

Textauszüge erfordert ggf. weitere Nutzungsgenehmigungen durch den jeweiligen Rechteinhaber.

ISBN 978-3-11-024726-8

e-ISBN 978-3-11-024727-5

ISSN 1862-1139

\section{Library of Congress Cataloging-in-Publication Data}

A CIP catalogue record for this book is available from the Library of Congress.

Bibliografische Information der Deutschen Nationalbibliothek

Die Deutsche Nationalbibliothek verzeichnet diese Publikation in der Deutschen Nationalbibliografie; detaillierte bibliografische Daten sind im Internet über http://dnb.d-nb.de abrufbar.

(C) 2010 Walter de Gruyter GmbH \& Co. KG, Berlin/New York

Satz: fpf, Freiburg im Breisgau

Druck: Hubert \& Co. GmbH \& Co. KG, Göttingen

$\infty$ Gedruckt auf säurefreiem Papier

Printed in Germany

www.degruyter.com 
Edgar Früchtel zum 8o. Geburtstag 



\section{Inhalt}

Einleitung

Peter von Möllendorff

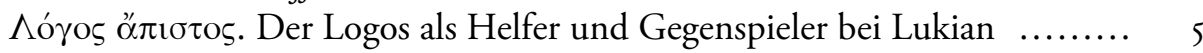

Horacio E. Lona

Wahrer Logos - Logos der Wahrheit.

Der Umgang des Kelsos mit der Bibel

Jörg Ulrich

Widersprüchlichkeit und Kohärenz. Beobachtungen zu einem Argument

der Polemik und Apologetik im zweiten Jahrhundert

\section{Thomas Johann Bauer}

Einen missglückten Auftritt retten.

2 Kor Io,Iof. und die rhetorische Kultur der frühen Kaiserzeit $\quad$............ 77

\section{Thomas M. Böhm}

Ptolemäische Gnosis bei Hegel? Anmerkungen zur Interpretation

des Johannesprologs durch Amelius

Josef Lössl

Zwischen Christologie und Rhetorik.

Zum Ausdruck „Kraft des Wortes“ (

in Tatians „Rede an die Griechen“

\section{Thomas Lechner}

Süße Lust des Logos. Die Vorrede zum Protreptikos

des Clemens von Alexandrien und die prolaliai der Zweiten Sophistik

Ferdinand R. Prostmeier

Der Logos im Paradies. Theophilos von Antiochia

und der Diskurs über eine zutreffende theologische Sprache 207

\section{Uta Heil}

Menschenliebe im Superlativ. Zur Rezeption der christlichen Lehre von der Feindesliebe bei Athenagoras 
Christoph Schubert

Ein stummer Gott? Beobachtungen zur Verteilung von Reden und Schweigen im Octavius des Minucius Felix

Tobias Georges

Die Philosophen in Tertullians Apologeticum.

Ihre Bedeutung für den Epilog und das gesamte Werk 287

Jutta Tloka

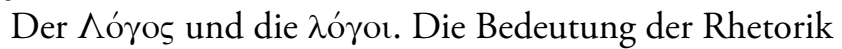

für die Konstituierung der christlichen Elite in der Spätantike 301

Hanns Christof Brennecke

Homöismus und Logostheologie 


\section{Einleitung}

Wer sich mit der geistigen Auseinandersetzung im Abendland während des zweiten Jahrhunderts beschäftigt, wird ein Phänomen nicht übersehen können: Eine von ihrer Herkunft her unbedeutsame jüdische Sekte - in Antiochia wurden ihre

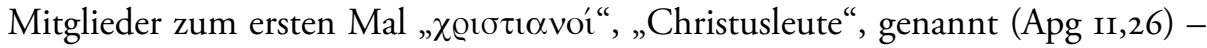
breitet sich in allen Schichten der Gesellschaft aus, gewinnt dort Anhänger und fängt an, sich mit der im römischen Reich vorherrschenden Kultur auseinanderzusetzen. In Folge eines schnellen Wachstumsprozesses gesellten sich zu dieser Gruppe auch gebildete Menschen heidnischer Herkunft, die ihren Glauben in den Denkkategorien der hellenistisch-römischen Kultur zur Sprache brachten.

Es überrascht nicht, dass der Begriff „Logos“ in dieser Auseinandersetzung eine zentrale Rolle spielte. Für die Vertreter der klassischen Überlieferung bot seine semantische Multivalenz die Möglichkeit, mit „Logos“ wesentliche Inhalte der eigenen Überzeugung auszudrucken: die Kraft des Verstands, den Primat der Vernunft, das Prinzip der Verständlichkeit der Welt, das Wort, die Rede, die Lehre u. a. Gebildete Christen konnten zu dieser Vielfalt einen spezifischen Inhalt ihres Glaubens hinzufügen: Der Logos war am Anfang bei Gott (Joh I,I), und der Logos ist Fleisch geworden (Joh I,I4).

Der Titel des vorliegenden Werkes - „Logos der Vernunft - Logos des Glaubens“ - trägt dieser Begegnung Rechnung. Im weitesten Sinne handelt es sich um einen „Dialog“ ( $\delta\llcorner\alpha ́ \lambda o \gamma o \varsigma)$, obwohl die Gesprächspartner in diesem Fall nicht gerade bereit sind, einander zu zuhören.

Die Beiträge lassen sich in zwei Gruppen einordnen, wenngleich die Trennungslinie nicht immer klar und eindeutig zu ziehen ist. Zur ersten Gruppe gehören jene Aufsätze, die sich vornehmlich mit Vertretern der römisch-hellenistischen Kultur befassen, unabhängig davon, ob sie den christlichen Glauben anvisieren. Die schillernde Mehrdeutigkeit des Logos-Begriffs wird von Lukian von Samosata exemplarisch demonstriert. Die Macht und zugleich die Unverfügbarkeit des Logos, die von den handelnden Personen in seinen Dialogen vorgetragen werden, bleiben in ständiger Spannung und führen immer wieder zu unlösbaren Widersprüchen: der Logos als Helfer und Gegenspieler. - Der platonische Philosoph Kelsos zeigt in seinem „Alethes Logos“ erstaunlich gute Kenntnisse über das Alte Testament und die neutestamentliche Überlieferung. Wie hat er den „Logos" von Juden und Christen verstanden und welches ist seine Absicht bei einer derart breiten Rezeption der Schrift? - Die Behauptung der Widersprüchlichkeit gegnerischer und der Kohärenz eigener Positionen gehört zu den Argumenten der Polemik und Apologetik, die von mehreren Autoren des zweiten Jahrhunderts - Christen, Heiden und Juden - in Anspruch genommen wird. Die Aus- 
tauschbarkeit der Argumente erforderte ein hohes Maß an apologetischem Geschick, wenn es galt, die eigene Seite gegen entsprechende Kritik zu verteidigen.

Zur zweiten Gruppe der Beiträge gehören die Aufsätze, die zunächst auf einen christlichen Autor Bezug nehmen, um dann eine Brücke zum jeweiligen kulturellen Hintergrund zu schlagen. - Ob Paulus von Tarsus über eine rhetorische Ausbildung verfügte oder nicht, ist eine in der Forschung umstrittene Frage. Der Abschnitt 2 Kor Io,Iof wird hier als Beleg dafür analysiert, dass Paulus sehr wohl Kenntnisse über die Anforderungen an einen perfekten rhetorischen Auftritt besaß. - Der Johannesprolog nahm nicht nur in der Großkirche, sondern auch bei gnostischen Gruppierungen eine besondere Stellung ein. Das Interesse anderer Gruppen an diesem Text ist durch die neuplatonische Interpretation dokumentiert, die Amelios, in der Schule Plotins, nach einer von Euseb von Cäsarea bezeugten Tradition zugeschrieben wird. - In seiner "Rede an die Hellenen“ ver-

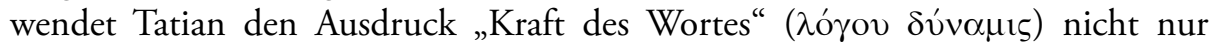
logostheologisch, sondern auch rhetorisch im Hinblick auf die Wirkung der christlichen Verkündigung und auch des eigenen $\lambda$ ó $\gamma o \varsigma$ an die Adresse der Hellenen. - In der Vorrede zu seinem „Protreptikos“ zieht Clemens von Alexandrien alle Register seiner rhetorischen Kompetenz, die ihn als einen herausragenden Vertreter der ,Zweiten Sophistik' ausweisen. Die christliche Lehre wird als politisch relevante und philosophisch attraktive Lebensform vorgestellt, und zwar als kulturkritische, aber keineswegs kulturfeindliche Alternative. - Eindrucksvoll zeigt Theophilos von Antiochia die Leistungsfähigkeit des Logos-Begriffs, um zum einen die christliche Gottesvorstellung mit dem Logos-Begriff der kaiserzeitlichen Tradition in Einklang zu bringen, zum anderen, um das christliche Gottes-, Menschen- und Weltbild als die grundlegende Selbstoffenbarung Gottes darzustellen, die in der Sprache der Schrift erschlossen wird. - In seiner an den Kaiser Marc Aurel und seinen Sohn Commodus gerichteten Apologie widmet Athenagoras dem Gebot der Feindesliebe einen ausführlichen Abschnitt. Welche Bedeutung hat das Thema im Rahmen der sogenannten „Hellenisierung des Christentums", die durch den Beitrag der Apologeten geleistet wird? Welcher historischen Hintergrund lässt sich für die Behandlung des Themas herausstellen? - Es fällt auf, dass im „Octavius“ des Minucius Felix das für das Christentum so wichtige Wort Gottes wie ausgeblendet erscheint. Im Unterschied zu den in Orakeln und Träumen redenden Göttern, spricht Gott durch seine Werke oder mit sich selbst. Wollte der Verfasser den Lesern nur den Bereich christlicher Überzeugung zumuten, der den Horizont der verbreiteten stoisch-platonischen Philosophie nicht überschritt? - In den letzten Kapiteln („Peroratio“ oder Epilog) seines „Apologeticum“ führt Tertullian eine scharfe und erregte Polemik gegen die Philosophen - wiewohl auch der Verfasser zu den Gebildeten gehörte -, weil sie die Wahrheit vom Endgericht verstellen. An die Adresse der Regierenden ergeht der Appell, jetzt diese Wahrheit anzuerkennen, um nicht später zum Opfer 
des Gerichts zu werden. - Nach der „konstantinischen Wende“ am Anfang des vierten Jahrhunderts ändert sich die Lage der Christen in der Gesellschaft, aber das bedeutet nicht das Ende der Auseinandersetzung auf dem Gebiet der Kultur. Der Rhetor Libanius und sein Schüler Johannes Chrysostomus belegen die Kontroverse um Bildungsinhalte im Licht des christlichen Glaubens. - In einem innerkirchlichen Raum entfaltet sich schließlich die christologische Diskussion um das richtige Verständnis des Logos in seinem Verhältnis zum Vater, das im Konzil von Nicäa eine verbindliche Bestimmung bekommen hatte, der aber in den folgenden Jahrzehnten häufig widersprochen wurde. Die Übernahme griechischer Begrifflichkeit, um die Wahrheit des Glaubens auszudrücken, erweist sich als problematisch und als Quelle für neue Auseinandersetzungen.

Der Überblick lässt eine reiche thematische Vielfalt erkennen, die aber kein disparates Konglomerat bildet. Der „Logos“ in seiner semantischen Mehrdeutigkeit dient als verbindender Leitfaden oder, anders ausgedrückt, als Leitmotiv, das zu vielen Variationen anregt. Nur der „Logos“ kann sinnvolle Worte erzeugen.

Festschriften sind von ihrer Entstehungsgeschichte und von ihrem potentiellen Leserkreis her kein leichtes Unterfangen. Die Herausgeber von solchen - literarisch gesehen - recht merkwürdigen Werken könnten darüber viel erzählen.

Auch die vorliegende Festschrift, die Edgar Früchtel zu seinem 8o. Geburtstag überreicht wird, hat ihre eigene Geschichte, und sie ist mit der Person des Jubilars untrennbar verbunden. Als im September 1992 die Vertreter der Bayerischen Fakultäten sich in Benediktbeuern für die erste Sitzung der „Arbeitsgemeinschaft Zweites Jahrhundert" trafen, wusste niemand ganz genau, ob dieses Treffen vielleicht doch eine einmalige Begegnung bleiben würde oder ob es der erste Schritt für eine weitere Entfaltung war. Das Zweite ist geschehen und die Teilnehmer konnten jährlich den Fortschritt in wissenschaftlichen Vorhaben und die Entstehung von neuen Projekten verfolgen. Bei diesem ersten Treffen war Edgar Früchtel dabei und seitdem hat er mit seinem Wissen, Rat und seiner überaus sympathischen Art den Weg der Arbeitsgemeinschaft begleitet und mitbestimmt. Der Sammelband ist ein Ausdruck der Dankbarkeit dafür.

Das Thema entspricht der Breite seines wissenschaftlichen Interesses, das ihn nicht nur als „Philologen“ und „Philosophen“ im strengen Sinne des Wortes auszeichnet, sondern auch als einen Gelehrten, der gerne im Grenzgebiet zwischen der klassischen Antike und der altchristlichen Literatur sachkundig zu wandern weiß.

Mit dem Wort des Demokritos: „Ein Leben ohne Festfeier ist ein langer Weg ohne Gasthäuser" - das Edgar Früchtel gern zitiert -, wünschen wir dem Jubilar zu diesem festlichen Anlass viel Freude und Kraft und bleiben mit ihm herzlich verbunden. 
Dass dieser Sammelband erscheinen konnte, ist vor allem den Beiträgern zu danken. Folgende Personen sollen aber hervorgehoben werden: Zuallererst mein ehemaliger Gießener Kollege am Fachbereich „Geschichts- und Kulturwissenschaften" der Justus-Liebig-Universität Gießen, Prof. Dr. Peter von Möllendorff, der es namens der Herausgeber der Millennium-Studien ermöglicht hat, unseren Sammelband in dieser Reihe erscheinen zu lassen. Großer Dank gilt Herrn Dr. Thomas Johann Bauer, Akademischer Rat am Arbeitsbereich ,Neutestamentliche Literatur und Exegese' in der Theologischen Fakultät der Albert-Ludwigs-Universität Freiburg im Breisgau, und Frau Valeska Prenschke, studentische Mitarbeiterin, die das Werden des Projekts auf vielfältige Weise begleitet haben, sowie Frau Christina Fehrenbach, studentische Mitarbeiterin, die die Beiträge Korrektur las und den Band für den Satz vorbereitet hat. Frau Sabine Vogt, Frau Katrin Hofmann und Frau Sabina Dabrowski haben im Verlag Walter de Gruyter die Veröffentlichung betreut. Ihnen allen gilt unser herzlicher Dank.

Die Herausgeber 


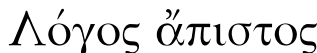

\section{Der Logos als Helfer und Gegenspieler bei Lukian}

\section{Peter von MÖllendorff}

Auftritte eminent gebildeter Rhetoren und Philosophen müssen einen bedeutenden Faktor des kulturellen Lebens der frühen und hohen Kaiserzeit dargestellt haben. Berichte von solchen performances, wie wir sie in der Literatur der Kaiserzeit finden oder doch aus ihr erschließen können, zeigen, mit wieviel Spannung und öffentlicher Anteilnahme jene Sophisten erwartet, bei ihren Auftritten begleitet und frenetisch gefeiert wurden, und zwar nicht nur von einer kleinen, gebildeten Oberschicht, sondern von großen Teilen der Bevölkerung der Städte, die sie bereisten oder in denen sie wirkten. Für die Publikumswirkung der rhetorisch bis in kleinste ausgefeilten Vorträge war entsprechend nicht nur die Wortgewalt des Redners, sondern auch seine körperliche und äußerliche Selbststilisierung von herausragender Bedeutung. Entsprechende Aufmerksamkeit wendeten die Sophisten daher nicht nur an ihre rhetorische Perfektion, sondern auch an die Zurichtung ihres Äußeren. So prägte sich etwa seit Hadrian ein ideal-physiognomisches ,Intellektuellen-Zeitgesicht' aus, dessen genauer ,Zuschnitt' Gegenstand modischer Konkurrenz war. Insbesondere Intensität und Façon der Kopfbehaarung - Haupthaar und Barttracht - waren offensichtlich umstritten. ${ }^{\mathrm{I}}$ De facto ging es bei diesen Diskussionen, die noch verstärkt wurden durch entsprechende Debatten über die angemessene Kleidung, ${ }^{2}$ um die Frage nach einer Angemessenheit der gebildeten Selbstdarstellung: Wie man von einem Gebildeten verlangte, daß er seine Sprache und sein Denken nicht nur okkasionell, sondern im ganzen Lebensvollzug auf das aus der Tradition gewonnene Vorbild hin ausrichtete,

\footnotetext{
Vgl. hierzu grundsätzlich Zanker 1995, v. a. 190-251.

2 Vgl. Dion or. 70,8 und v. a. or. 72; außerdem etwa Lukian RhPr. isf. In diesen Zusammenhang gehört auch die komplexe Argumentation, die Tertullian in De pallio entfaltet, wo der von ihm provokativ anstelle der römischen Toga getragene Mantel in schnellen Wechseln bald für Griechentum (vs. Romanität), für den Philosophen (statt des Alltagsbürgers), für den Kyniker (statt des gemäßigten Philosophen), für den Priester (statt des Laien) und schließlich für den Angehörigen einer eigenen afrikanischen Oberschicht (wiederum statt des Römertums) steht; ein Ausspielen einer spezifisch christlichen (anstelle einer paganen) Identität kommt hingegen erst ganz am Ende und in aller Kürze ins Spiel. Vgl. hierzu jetzt Wilhite 2007, 139-I45; dort auch weitere Literatur.
} 
sich - wie mit Bezug auf das Platonische Färbergleichnis bisweilen formuliert wurde $^{3}$ - mit seiner Bildung vollständig durchtränkte, so daß sie sich nicht mehr ablegen ließ, keine bloße Rolle, sondern Identität war, stoisch formuliert: von der Schésis zur Héxis wurde, so erwartete man auch im Äußeren eine Anpassung des Körpers des Gebildeten: Banal formuliert, sollte man sehen können, daß es sich bei dem Gegenüber um einen Gebildeten handelte. Der Körper mußte also als Zeichen, vielmehr als ein Konglomerat von Zeichen gelesen und auf einen Bildungsanspruch bezogen werden können. Zu diesem Zweck mußten die Zeichen lesbar sein. Lesbarkeit heißt: Die Zeichen mußten entweder formal auf einen allgemein verständlichen Code verweisen oder als Symbole aufgefaßt werden können.

Das Aussehen des gesamten Körpers, seine Oberfläche, seine Haltung, seine Bewegung ebenso wie Stimme und Blick konnten als Zeichen für die geistig-seelische Beschaffenheit des betreffenden Individuums gelesen werden. Physiognomie spielte im kaiserzeitlichen Bildungsdiskurs eine wichtige Rolle. ${ }^{4}$

Zugleich gelangte die grundsätzliche Agonalität der antiken Kultur hier erneut zu einem Höhepunkt: Der öffentliche Auftritt des Gebildeten fand grundsätzlich in der Atmosphäre eines Wettbewerbes statt, wurde immer direkt oder indirekt mit dem anderer Aspiranten auf kulturelles Ansehen verglichen. Um hier zu reüssieren, genügte es keineswegs, einfach sehr gut zu sein. Vielmehr war Einzigartigkeit gefragt. Die Exponenten der kaiserzeitlichen Bildungskultur mußten den Anspruch erheben, nicht austauschbar, sondern einmalig zu sein. Die Souveränität, ja die Virtuosität der intellektuellen Bildung war ihnen mehr oder weniger allen gemeinsam. Hier konnte man sich höchstens punktuell und graduell von anderen unterscheiden. ${ }^{5}$ Verlangt war darüber hinaus eine Ausnahmepersönlichkeit, die zudem sichtbar gemacht werden mußte, und dies konnte und mußte in erster Linie über das körperliche Erscheinungsbild gehen, denn dieses bestimmte nicht nur den ersten Eindruck beim rhetorischen Auftritt, sondern auch die allgemeine öffentliche Wahrnehmung. ${ }^{6}$

$\mathrm{Da}$ nur wenige zu wirklich radikalen Weisen der Selbstverformung bereit und fähig waren, liegt auf der Hand. Ebenso evident ist allerdings auch, daß das öffentliche Interesse, daß solchen Phänomenen extremer Körperlichkeit entgegengebracht wurde, so hoch war, daß wir berechtigt sein dürften, hier von einem Diskurs zu sprechen: Daß wir nur von den Ausnahmepersönlichkeiten hören,

3 Etwa Luk. BisAcc. 8.

4 Vgl. hierzu grundlegend Gleason 1995.

5 Nicht zuletzt dieser hohe Druck, der auf den eminenten Vertretern der Bildungskultur lastete, erklärt die Häme und die Vehemenz, mit der man selbst über kleine Ausrutscher der anderen herfiel; vgl. etwa Luk. Laps. und Pseudol.

6 Vgl. etwa den Auftritt der (als Verkörperung der Paideia anzusehenden; s.u. S. Iof.) Panthea in Luk. Imagines I-IO. 
liegt in der Natur unserer Quellen, während die diskursive Qualität körperlicher Selbststilisierung dafür Sorge getragen haben wird, daß auch ihre reduktiven Formen durchaus wahrgenommen wurden.

Es ist hier nicht der Ort, um dieses Thema weiter zu verfolgen. Die obigen Ausführungen dienen vielmehr dem Zweck der Skizzierung eines kulturellen Hintergrundes, vor dem nun umso mehr auffällt, daß - auf der Basis dessen, was uns bekannt ist - unter den nachhaltig bedeutenden Vertretern der Paideia einzig Lukian sich diesem Zwang zur körperlichen Selbst(ver)formung weitgehend entzogen zu haben scheint. In einigen Texten scheint Lukian sogar direkt an dessen Demontage zu arbeiten. Als ethisch defizient wird das Interesse am Körper desavouiert, wenn etwa in Dial.Mort. 20,3.5.9 Charmoleos seine körperliche Schönheit, der Athlet Damasias seine Muskelpakete und schließlich ein Philosoph seinen Bart ablegen muß, bevor sie den Fährkahn in die Unterwelt betreten dürfen; dies ist allerdings ganz dem Diatribenstil und damit einer Topik der generellen Abwertung von Körperlichkeit verpflichtet. Subtiler wird das Problem im Eunuchus verhandelt. Bei einem - so die Fiktion dieses Dialogs - öffentlich ausgetragenen Disput um die Besetzung des peripatetischen Lehrstuhls zu Athen streiten Diokles und Bagoas um den Vorrang. Bagoas wird sein Eunuchentum zum Vorwurf gemacht. Ein Eunuch, so Diokles, könne nicht beanspruchen, als Philosoph angesehen zu werden: Auf den Bart komme es an, ein Eunuch sei nichts halbes und nichts ganzes und könne daher nicht respektiert werden. Bagoas repliziert, er immerhin würde den von ihm unterrichteten Knaben nicht gefährlich werden, und wenn es nur um die Länge des Bartes ginge, müsse ein Ziegenbock den Lehrstuhl erhalten (Eun. 8f.). Schließlich tritt jedoch ein Dritter auf, der Bagoas entlarvt: Er sei gar kein Eunuch, sondern im Gegenteil sexuell aktiv und habe als Beklagter in einem Ehebruchsprozeß das Eunuchentum nur erfunden, um der Verurteilung zu entgehen. Das Ende des Streits bleibt offen. Denn Diokles muß einerseits auf dem Eunuchentum seines Gegners beharren, um sein Tauglichkeitsargument aufrechterhalten zu können, andererseits wäre ihm daran gelegen, Bagoas mithilfe des Ehebruchvorwurfs als moralisch verwerflich aus dem Weg zu räumen. Bagoas geht es ähnlich, nur aus den genau umgekehrten Gründen, wobei er sich nun vor allem darum bemüht, Proben seiner Männlichkeit abzulegen, um als rechter Anwärter auf den Lehrstuhl gelten zu können. Daß mit der Figur des Bagoas eine Anspielung auf den berüchtigten Sophisten Favorinus v. Arelate gegeben sein könnte, ist recht wahrscheinlich. ${ }^{7}$ Aber der Sprecher Lykinos richtet seinen Spott nicht auf dessen physische Besonderheit. Vielmehr wird beider Philosophen Körperlichkeit lächerlich gemacht: Diokles ist bei all seiner Männlichkeit am Ende philosophisch nicht begabter als ein Ziegenbock, Bagoas

7 Hierfür spricht auch das Motiv des Ehebruchprozesses, von dem wir für Favorinus durch Philostrat (VS 489) erfahren. 
hingegen ist entweder ein Lügner oder ein Ehebrecher, scheidet als Philosoph also ebenfalls aus. Ihre tatsächliche Körperlichkeit spielt, anders als ihr Lebenswandel, gar keine Rolle für die Frage nach ihrer philosophischen Tauglichkeit. Aber gerade dies - und hierin besteht eine wichtige satirische Pointe des Textes - vermag die Umwelt, die mit dem Entscheid in dieser Sache betraut ist, nicht zu sehen, weshalb sie den Fall an den Kaiser als höchste Instanz verweist. ${ }^{8}$ Selbst eine außerordentlich komische Situation beläßt also im Blick der Umwelt der Körperlichkeit ihre hohe axiomatische Stelle; der Satiriker Lykinos hingegen spricht ihr jede Bedeutsamkeit ab.

Auch im Rhetorum Praeceptor wird einer ,favorinischen' Gestalt einiger Platz eingeräumt. Ein anonymer Sprecher stellt einem angesprochenen rhetorischen Adepten zwei Modelle vor, an denen er sich orientieren könne: Einem an Favorinus gemahnenden, körperlich ambivalenten Redner mit stark femininen Zügen, dessen Auftreten und Äußeres genauestens beschrieben werden und der auch selbst in einer sermocinatio das Wort erhält, um seine Lehren von der öffentlichen Attraktivität eines möglichst unverschämten und unmoralischen Lebenswandels zu formulieren, ${ }^{9}$ wird in kurzen Zügen ein anderer, betont viriler ${ }^{\text {Io }}$ Rhetoriker gegenüber gestellt. Nur: Keinen der beiden von ihnen vorgeschlagenen, ganz unterschiedlichen Wege zur vollendeten Rhetorik hält der anonyme Sprecher für wirklich geeignet: Denn der virile Rhetoriker behaupte die Notwendigkeit harter Arbeit, was unter den aktuellen Umständen gar nicht zutreffe, aber viel Geld koste (Rh.Pr. 9 Ende), während der androgyne Rhetoriker mit seiner faszinierenden und schillernden Persönlichkeit leicht zum Ziele komme, ohne aber über wirkliche Rednerqualitäten zu verfügen. Am Ende erklärt der Sprecher, selbst an seinen Zielen zu verzweifeln und sich aus dem Rhetorikbetrieb zurückzuziehen (Rh.Pr. 26), ist also selbst kein hilfreicher und nicht einmal ein verläßlicher Ratgeber. Der Text erlaubt es uns auch nicht - und das dürfte der eigentliche Zweck der Einführung dieser Figur sein -, als brave und diatribisch geschulte Rezipienten doch lieber die Lehren des virilen Rhetorikers zu beherzigen, denn er steht zwar auf der populärethisch und pädagogisch abgesicherten Seite des harten, steinigen Weges, wird aber von der schnöden Wirklichkeit widerlegt, die zwar vielleicht verwerflich, aber eben erfolgsorientiert ist: Moralische Sieger sind zugleich leider oft auch triste Gestalten.

8 Eun. I2.

9 Seine Beschreibung erhält den größten Raum im Text: Rh.Pr. II-25; die Aufforderung zu einem unmoralischen Lebenswandel ebd. 23. Wie Favorinus ist der androgyne Rhetoriker in Prozesse um Erbschleicherei und Giftmischerei verwickelt (Rh.Pr. 24); darin ähnelt er einem weiteren extremen Vertreter der sophistischen Epideiktiker, Skopelian (vgl. Philostrat VS 516-518), der überhaupt einen auffälligen und auf skandalöse Sichtbarkeit bedachten Lebenswandel pflegte.

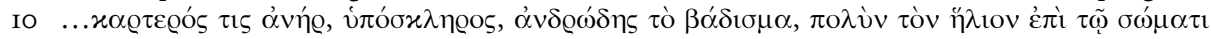

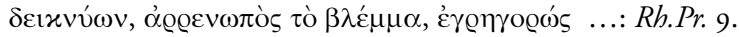


Diese Fragwürdigkeit des anonymen Sprechers in der Sache scheint mir aber auch vor dem Hintergrund der Frage nach der Relevanz auffälliger Körperlichkeit von Interesse zu sein. Während er sich nämlich, wie dargelegt, ausgiebig bei der Körperlichkeit seiner beiden Kontrahenten aufhält und sich über beide teils direkt, teils indirekt zu mokieren scheint, bleibt er selbst, physisch gesehen, ein Schemen. Diese Eigenschaft nun teilt er mit ausnahmslos allen übrigen Sprechern des Lukianischen Euvres: Lykinos, Tychiades, Parrhesiades, ,Lukianos', weiteren anonymen ,Ich'-Sagern, dem Syrer. „Le ,Je“ de Lucien“, so der Titel eines Beitrags von Suzanne Said, ${ }^{\text {II }}$ hat keinen Körper und hebt sich nicht zuletzt dadurch von nahezu allen seinen dialogischen Gegenübern ab. Auch eine entsprechende Charakterisierung durch andere Figuren findet nicht statt.

Mir scheint dabei signifikant, daß Lukians Sprecher diese Körperlosigkeit mit ihrem biographischen Autor teilen, über den selbst der anekdotensüchtige Philostrat nichts zu sagen weiß und von dessen Lebensweg wir, wie schon Barry Baldwin hervorhob, ${ }^{\mathrm{I}}$ im Grunde nichts wissen. Versuche, seine Biographie zu skizzieren, bleiben bekanntlich rudimentär oder stützen sich auf auktoriale Eigenaussagen aus fiktionalen Kontexten. Es liegt daher nahe, angesichts des bisher erhobenen Befundes die These zu formulieren, daß Lukians spezifische Modellierung seines epideiktischen Körpers - aus welchen biographischen Gründen auch immer - darin bestand, ihn der sophistischen Öffentlichkeit zu entziehen, und das heißt de facto: nicht (mehr) zu deklamieren oder jedenfalls bei solchen Auftritten auf eine exorbitante, auf Partikularität zielende körperliche Selbststilisierung weitgehend zu verzichten, aus seinem Leben - anders als viele seiner sophistischen Kollegen - kein Spektakel zu machen. ${ }^{13}$ Eine solche Entscheidung bedeutete unter diesen Umständen zwar einerseits einen weitgehenden Verzicht auf Renommée, eröffnete aber auf der anderen Seite erst eigentlich die Erschaffung einer solchen Vielzahl elaborierter auktorialer Masken, wie es anderen Sophisten viel weniger möglich war. Lukian war hierbei dann primär auf das Medium der Buchpublikation angewiesen, während ihm die Wirkung durch faszinierende Auftritte versagt blieb; die Publikation wiederum bot die Chance der Kreation vielfältiger literarischer Querbezüge und einer auf einen Leser berechneten mimetischen Vielschichtigkeit, wie sie dem Redner notwendigerweise versagt blieben. Auch agonale Einmaligkeit war auf diese Weise - allerdings zu einem hohen persönlichen Preis - zu erzielen: Dieser Preis bestand, zugespitzt formuliert, in einer weitgehenden epideiktischen Selbstauslöschung, in dem Verzicht auf herausgehobene Ego-Repräsentation und zugleich in der figuralen Fragmentarisierung.

II Saïd I993.

I2 Baldwin 1973 , I8.

I3 In einigen Texten - etwa in der Apologie und im Herakles - ist von Deklamationen in Gallien die Rede. Ob sie fingiert sind oder wirklich stattgefunden haben, ist nicht definitiv zu entscheiden, wenngleich die Wahrscheinlichkeit eher auf der Seite realer Deklamationen liegen dürfte. 
Überprüfen wir diese - zugegeben: provokative - These an zwei Texten: dem ,autobiographischen' Somnium sowie dem Dialogpaar Imagines / Pro Imaginibus. Das Somnium - ,Lukian' erzählt hier seinen Werdegang: Nach einer wegen Mißerfolg schon nach einem Tag abgebrochenen Steinmetzlehre erschienen ihm die allegorischen Figuren Frau Techne und Frau Paideia im Traum, er wählte die Karriere der Paideia, die ihm sodann in einem kosmischen Flug die Welt und seine zukünftigen Erfolge zeigte - ersetzt jedwede realistische Narration durch eine Reihe von biographischen Imitationen unterschiedlicher Couleur: der historischen Figur des Sokrates (Lukian: Neffe eines Steinmetzen) gesellen sich die mythischen Figuren Herakles (Lukian: Entscheidung zwischen Frau Téchne und Frau Paideía) und Triptolemos (Lukian: Himmelswagenfahrt über die Erde) bei, zugleich wird mit Rhetorik und Philosophie (Somn. Io) ein universalistisches Bildungsziel benannt. Gerade weil dieser Text sich so ausdrücklich autobiographisch gibt, unterstützt er m. E. die oben vorgetragene These: Lukian' ist nicht faßbar, seine epideiktische persona eröffnet sich nur im Gang durch seine Texte, nur im Vollzug des Leseaktes. Das von Lukian gewählte Verfahren läßt sich also als eine Performativisierung der Persönlichkeit im Medium des Texts verstehen.

Imagines führt mit Lykinos und Polystratos zwei pepaideuménoi vor, die versuchen, die charakterliche, intellektuelle und körperliche Schönheit der Panthea zu beschreiben. Die ältere Forschung hat sich mit biographischer Lust auf die Frage gestürzt (und sie prinzipiell bejaht), ob es sich bei dieser Frauengestalt um die gleichnamige Favoritin des Kaisers Lucius Verus handelt. Wenn dem so ist - wogegen nichts spricht -, dann ist gleichwohl interessant, daß Lukian selbst eine solche historische Identifikation vermeidet, ja selbst den Namen Panthea nicht explizit nennt, der vielmehr durch den Leser über die Identifikation einer Xenophon-Anspielung erschlossen werden muß. ${ }^{14}$ Diese Abkehr von einer historisch greifbaren Realität und biographischen Identität wird dadurch unterstützt, daß Panthea selbst als sprechende Figur in beiden, Bilder'-Dialogen nicht auftritt: Ist sie in Imagines ausschließlich Objekt der Beobachtung und Beschreibung, so hören wir ihre Replik auf jenen Text in Pro Imaginibus nur durch den Mund des Polystratos. Zugleich wird jedoch gerade ihre fulminante körperliche Erscheinung und Präsenz im ersten Teil der Imagines (4-IO) eingehend beschworen. Um seinem Freund Polystratos ihre Schönheit zu beschreiben und sie so ihm gegenüber zu identifizieren, beschreibt er Details ihres Körpers, insbesondere ihres Gesichts und ihrer Haare, indem er auf Polystratos' Erinnerung an fünf klassische Frauenstatuen rekurriert, ihnen jeweils eine Einzelheit entnimmt und sie ,verbal ${ }^{\text {' }}$ $(\lambda o ́ \gamma \omega)$ zusammensetzt. Eine solche Ekphrasis, die mimetische Darstellung und physiognomische Analyse miteinander verbinden will, muß scheitern und scheitert auch in der Tat, weil Lykinos über die Heterogenität der einzelnen schönen

I4 Zu Details der intertextuellen Arbeit sowie auch zum Folgenden vgl. Möllendorff 2004, I-24. 
Zeichen hinaus die Totalität der Schönheit nur zu beschwören, nicht aber zu evozieren vermag: Entsprechend identifiziert Polystratos die schöne Unbekannte in subtilster Parodie gerade in dem Augenblick, als Lykinos von ihren herrlichen Zähnen spricht und damit von jenem Körperteil, der weder im kunsttheoretischen noch im physiognomischen Diskurs eine wirkliche Rolle spielt.

Lykinos und Polystratos gehen noch einen Schritt weiter, indem sie ihr Loblied auf Panthea am Ende von Imagines explizit verschriftlichen und es der Nachwelt auf diese Weise zukommen lassen. Wie Pantheas Antwort auf die Lektüre des Buches dann in Pr.Im. von Polystratos dem Lykinos ausgerichtet wird, so setzt dieser den Freund ebenfalls als Boten seiner Replik auf Pantheas Antwort ein. Das Dialogpaar vermeidet also den Einsatz direkten Kontakts, wie sie die epideiktische Kommunikation bestimmt, und bedient sich statt dessen eines medial vermittelten. Dabei erscheint als der eigentliche Adressat entsprechend nicht mehr ein zeitlich oder räumlich unmittelbar anwesendes Publikum, sondern aus-

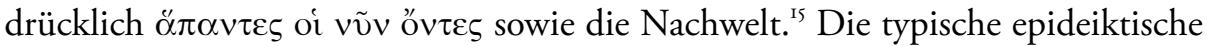
Kommunikationssituation (der Vortrag) wird also in diesem Text von Lukian zwar noch aufgerufen, dann aber ebenso ad acta gelegt wie die Bedeutung physischer Außergewöhnlichkeit, die hier durch die Abwesenheit sowie die physiognomische Unzugänglichkeit der einzigartigen Schönen desavouiert wird, deren körperliche Schönheit durch die Schönheit intertextueller Schichtungen ersetzt ist.

Dies alles gewinnt dadurch Relevanz für die bisher verhandelte Frage, daß wie oft bei Lukian - die ideale Frauengestalt, hier die der Panthea, wohl allegorisch aufzufassen und als Sinnbild der Paideia anzusehen ist. ${ }^{16}$ Lukian hätte also, wenn man der oben formulierten These folgt, diese Allegorie so auftreten lassen, wie er sich auch selbst modelliert: als ein ,körperloses' Ideal, das sich der fixierenden Wahrnehmung durch ein Publikum und seiner Einordnung durch die Konkurrenten stets entzieht, das vielmehr nur durch die permanente Auseinandersetzung mit seiner medialen Manifestation, den publizierten Texten, erfahrbar wird. Bildung, dies legt auch Lukians Wahl seiner präferierten literarischen Gattung, des zutiefst performativen Dialogs, nahe, wird hier entmonumentalisiert. An die Stelle des Staunens über den Glanz und den Prunk der epideiktischen Inszenierung und der Präsentation des Körpers des Epideiktikers tritt bei ihm die nicht endende Konfrontation mit dem Text, tritt die Arbeit des lógos an der Bildung. ${ }^{17}$

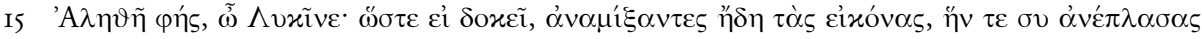

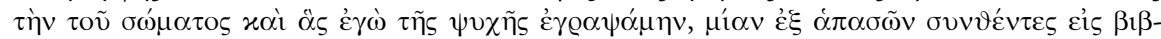

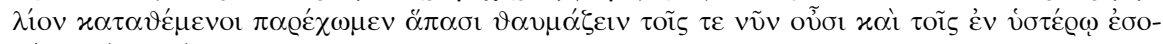
$\mu \varepsilon ́$ vols (Im. 23).

I6 Vgl. hierzu insbesondere Bretzigheimer 1992, I6I-I87, sowie Möllendorff 2004, I3f.

I7 $\mathrm{Zu}$ Verfahrensweisen Lukians, seine Texte rekursiv zu gestalten, also mit einem Modell-Leser zu operieren, der in zyklischen Bewegungen innerhalb des textlichen Universums verharrt, vgl. Möllendorff 2000a, 26. 507f., sowie ders. 2004, I4f. 17. 
Um dies zu konkretisieren, möchte ich im folgenden dem Lukianischen Verständnis eines solchen lógos etwas genauer nachgehen und ihn als diskursive Figur verstehen: Wie imaginiert Lukian seinen textuellen Zugriff auf die Welt der Bildung, was für ein Bild entwirft er vom logos, das diesem eine der epideiktischen Selbstinszenierung vergleichbare (und damit im kulturellen Kontext konkurrenzfähige) Aura der Einmaligkeit verleiht? Als erster Ausgangspunkt von Überlegungen bietet sich hier der Blick auf eine literarische Innovation an, auf die Lukian, wie er mehrfach explizit hervorhebt, ${ }^{18}$ selbst stolz war. Denn mit einer solchen Innovation könnten wir ein textuelles Pendant zu der Originalität des Auftretens erfassen, auf deren Herausarbeitung die anderen Sophisten hinwirkten. Dies gilt umso mehr, wenn wir an die plakatierte Bisexualität eines Favorinus denken, dem geradezu daran gelegen war, seine Person und sein Erscheinen und Reden in der Öffentlichkeit zu einem prekären Ereignis werden zu lassen. Denn auch Lukians literarische Erfindung zeichnete sich durch die Prekarität aus, genuin Unvereinbares zu einer hybriden Form verschmelzen zu lassen, nämlich zwei traditionelle Genres, deren Gattungsbezeichnungen zudem auch noch unterschied-

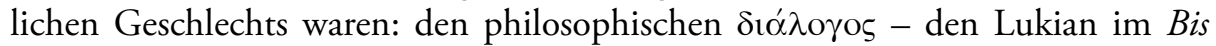
accusatus sogar als eigenen Sprecher auftreten läßt - und die $x \omega \mu \omega \delta$ '́ $\alpha$ im alten Stile eines Aristophanes. Damit ist über die Figurationen seiner Texte bereits im Vorfeld einiges gesagt, was sich auch unmittelbar in der Lektüre bestätigt: Lukians Dialogfiguren zeichnen sich einerseits (der Tradition des philosophischen Dialogs insbesondere Platonischer Provenienz gemäß) durch oft geradezu existentielle, jedenfalls aber hochrelevante Anliegen aus, andererseits - dramengemäß durch einen hohen Grad an argumentativer Eigenständigkeit, womit ich eine weitgehende Unverrechenbarkeit auf eine auktoriale Position meine, die im Dia$\log$ naturgemäß nicht im gleichen Maße gegeben ist und gegeben sein kann wie in einem Text mit einer einzelnen Sprecherinstanz. Hinzu kommt - und dies entspricht sowohl dem komödischen als auch dem philosophischen Anteil (wiederum vor allem in der Platonischen Tradition) - eine Ad-hoc-Bereitschaft zur verbalen Attacke, sei es in Gestalt wenig urbaner Direktheit, sei es gar in Gestalt heftiger Polemik. Lukians Rekurs auf die philosophische Tradition bedeutet darüber hinaus, daß seine Texte einen Anspruch auf ein höheres Erkenntnisziel erheben, dessen Bestand diskursiv abzusichern ist. Diese diskursive Absicherung ist zweigestaltig. Einerseits geht es darum, daß in der agonalen Auseinandersetzung der Dialogfiguren eine von ihnen mit ihrer Position den Sieg erringt (wie auch in der Alten Komödie stets einer der Akteure, nämlich der Protagonist, den Streit gewinnt: Ziel des dramatischen Dialogs ist entschieden nicht ein Kompromiß). Andererseits soll dieser Sieg nicht nur Ergebnis rhetorischer Überlegenheit, son-

I8 Vgl. Prom.Es 5, BisAcc. 33 f. 
dern auch eines argumentativen Fortschritts sein, also das dialogische Gegenüber „mitnehmen“ (wie es der Tradition des philosophischen Dialogs entspricht).

Nun gehen jedoch Erkenntnissuche und agonaler Überlegenheitswille, Überzeugung und Verbalattacke nicht in jedem Falle zusammen und können nicht immer leicht koordiniert werden. Die Prekarität der Lukianischen Neuschöpfung, seiner Hybride aus Dialog und Komödie, liegt also nicht nur im Formalen und im Thematischen, sondern auch ganz grundsätzlich im Kommunikativen. Die Gefahr des Scheiterns eines solchen hybriden lógos - damit ist gemeint: die Gefahr, daß ein ästhetisch defizienter Text entsteht oder daß, wie in Zeux. I. 7. IIf. ausgeführt, die Besonderheit und spezifische Schönheit des hybriden Textes von den Rezipienten nicht wahrgenommen, nicht gewürdigt oder falsch gewürdigt wird - ist nicht gering. Die Frage, der ich im folgenden nachgehen will, ist, ob und wie Lukian diese spezifische Prekarität reflektiert.

Ich beginne, um den Fokus der Untersuchung nicht allzu vage werden zu lassen, mit einem Blick auf die unterschiedlichen Verwendungsweisen des Begriffes $\lambda$ ójos. Dabei untersuche ich natürlich nicht alle Belegstellen, sondern nur diejenigen, an den lógos als textuelle Instanz, sei es als eigenständige Figur, sei es als organisierendes Subjekt von Aussagen erscheint. Unauffällig, gleichwohl häufig,

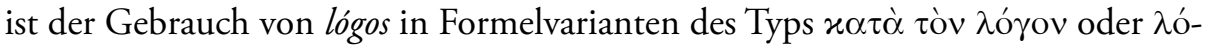

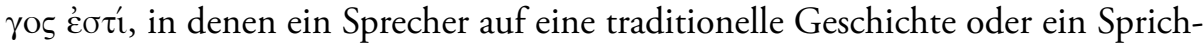
wort rekurriert, um seine Argumentation auf diese Weise mit einer a priori unhinterfragbaren Autorität abzusichern. In einer zweiten Stufe bezeichnet der Begriff die Argumentation selbst, der auf diese Weise eine beweiskräftige Geschlossenheit attestiert wird. An diesen Stellen fällt auf, daß die jeweils verwendeten Formulierungen (insbesondere die hier zum Einsatz kommenden Verben;

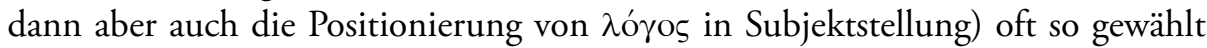
sind, daß der Eindruck entsteht, jener lógos trete geradezu selbstständig auf und spreche in eigenem Recht; auch hier scheint ein Bemühen um Gewinnung von

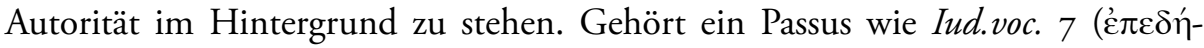

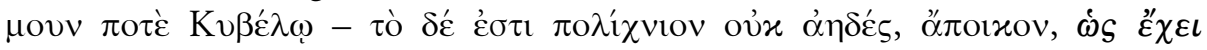

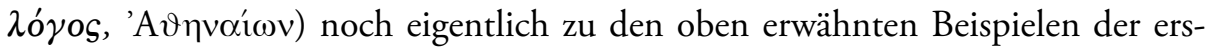
ten Stufe, so gewinnt der Logos an Autarkie etwa in Conv. 3, in der er eingeführt wird, um zu begründen, warum man den Bericht von dem ausartenden Symposi-

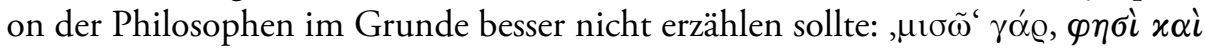

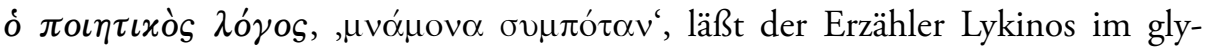
koneischen Versmaß den Logos sagen, der hier als Vertreter des eigentlichen Sprechers, eines anonym bleibenden Lyrikers, gleichsam als eigene Figur auftritt

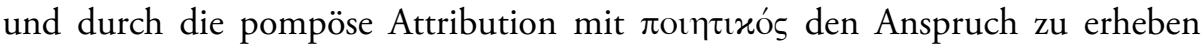
scheint, mit genereller, quasi die gesamte Literatur hinter sich wissender Autorität seine Maxime zu formulieren. ${ }^{19}$ Genauso drückt sich der Hahn in Gall. 5 aus, der Mikyllos davon überzeugen will, seinen früheren Traum als nichtig und wert- 
los zu vergessen und seine Aufmerksamkeit allein ihm und seiner Erzählung zu-

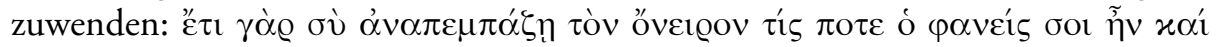

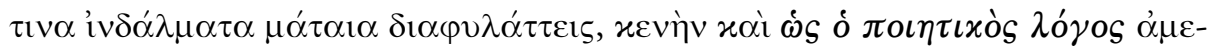

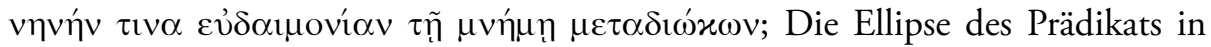
dem den Logos als sprechendes Subjekt einführenden Korrelativsatz erhöht den Autoritätsanspruch von dessen Auftritt m. E. noch, weil sie ihn nicht auf die Prädikatshandlung (und gar die eines blassen $\varphi \eta \sigma \mathrm{u}$ wie in Conv. 3) reduziert, sondern die Möglichkeiten umfänglicherer Ergänzungen und jedenfalls der Verwendung prägnanterer Verben offenhält.

Einen Schritt weiter geht Lukian im Pseudologista. Hier läßt er zur Abschmetterung seines verhaßten Gegners, der ihm einen - in attizistischen Kreisen strenger Observanz unverzeihlichen - falschen Wortgebrauch vorgeworfen hat, einen Prologsprecher aus einer Menandrischen Komödie auftreten, den "E $\lambda \varepsilon \gamma \chi 0 \varsigma$

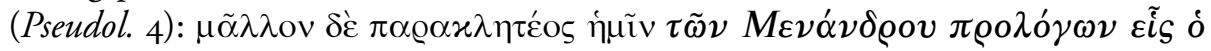

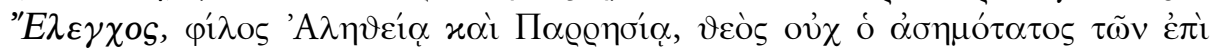

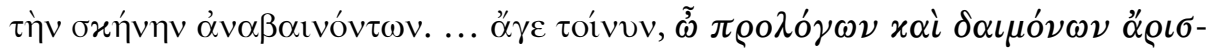

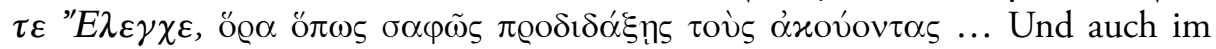
späteren Verlauf der Darlegungen wird daran erinnert, daß Elenchos der Sprecher von immerhin sechs Kapiteln und damit fast einem Fünftel des gesamten Textes ist. ${ }^{20}$ Hier ist nun die figurale Qualität des Logos unbestreitbar, immerhin handelt es sich um eine dramatische Persona. Es ist aber auffällig, daß Lukian immer

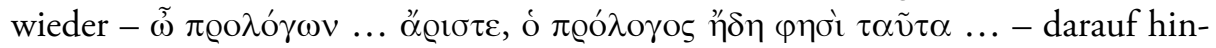
weist, daß es sich bei Elenchos um einen speziellen Logos handelt, um Gestalt gewordene Sprache, Gestalt gewordenen Text. Elenchos ist dabei ein spezifischer Charakter, wie sein Name zeigt: Sein Sprechen dient allein der Kritik, der Widerlegung, dem Vorwurf, und seine diesbezügliche Autorität zieht er aus seiner literarischen Herkunft, seiner Abstammung von Menander, die er in seiner in Pseu-

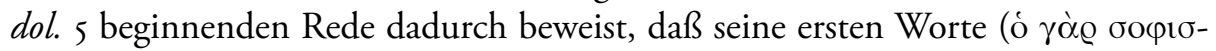

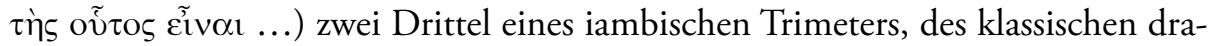
matischen Sprechverses, bilden, die gleichwohl kein Menandrisches Zitat darstellen: Der Logos argumentiert also gewissermaßen eigenständig, er ist trotz seiner Abkunft nicht an seinen ,Originaltext ${ }^{\text {gebunden. }}{ }^{21}$

I9 Durchaus vergleichbar ist Sacr. I4, wo die Tatsache, daß in Ägypten die Priester und Propheten zwar freiwillig geheimes Wissen über ihre Götter preisgeben, dies jedoch stets mit der - hier dann nur pseudo-autoritären - Formel einleiten, alle Unreinen sollten sich fernhalten, mithilfe

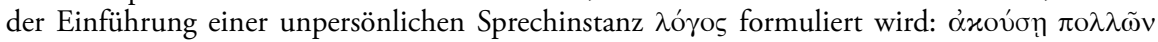

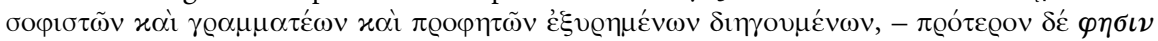

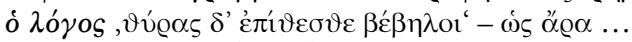

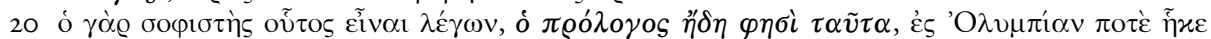

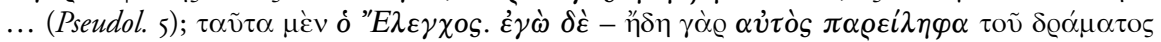

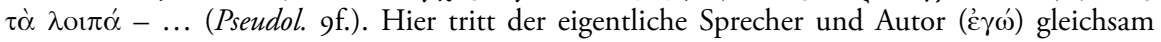
gleichberechtigt seinem früheren Stellvertreter "E $\lambda \varepsilon \gamma \chi 0 \varsigma$ gegenüber. 
Als ein solcher selbständiger Gesprächsteilnehmer entpuppt sich der Logos auch in Iup. conf. 6. Zeus muß sich hier von einem Vertreter des Kynismus belehren lasse, daß ihm, da ihm die Moiren doch überlegen seien, eigentlich keine göttlichen Ehren gebührten, und reagiert auf solche Fragen verständlicherweise unwirsch und unterstellt dem Frager sophistische Umtriebe. Der Kyniker lehnt

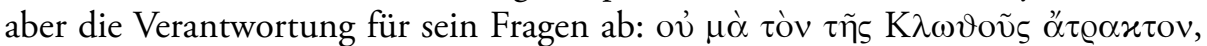

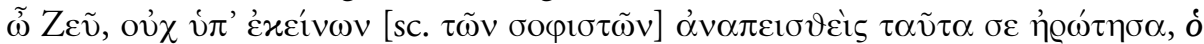

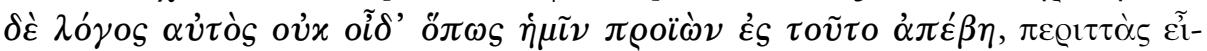

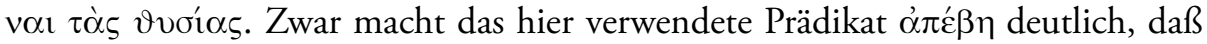
es sich bei diesem Logos nicht um eine Figur, sondern um die Argumentation als solche handelt. Aber auch hier beweist der Logos doch eine beachtliche Autarkie, verfügt über eine inhärente, pragmatisch unkontrollierbare rationale Macht, die moralisch fundierten Vorwürfen - hinsichtlich dessen, was ,man' sagen oder fragen ,darf' und was nicht - nicht zugänglich und daher auch nicht rechenschaftspflichtig ist. Ähnlich ist es der Logos, im Sinne der sich im Gespräch manifestierenden Rationalität der Argumentation, der als Verbündeter des Sprechers in Merc. cond. 4 herausfindet, wie es um die Arbeitsverhältnisse gebildeter Griechen in römischen Diensten steht, und auch er ist für die Ergebnisse ,seiner ' Argu-

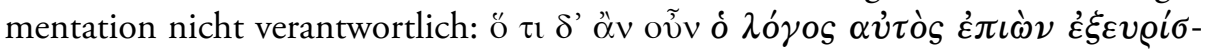

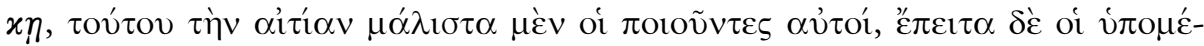

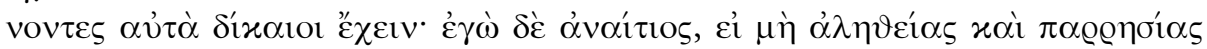

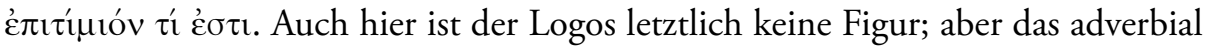

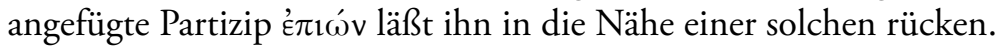

Zwei Charakteristika weist also, wie die bisherige Übersicht über entsprechende Verwendungsweisen zeigt, die von Lukian immer wieder eingesetzte, mehr oder weniger figural-autarke Sprecherinstanz eines Logos auf: Sie gibt sich - entweder mit Rekurs auf eine affirmierte Tradition oder auf unwiderlegbare ratio zum einen unhinterfragbar autoritär, zum anderen lehnt sie eine moralisch einklagbare Verantwortung für das von ihr Angeführte ab.

Beide Züge finden sich auch in zwei weiteren Texten, die zudem thematisch eng miteinander zusammenhängen, nämlich im Nigrinus und im Hermotimus. Der Erzähler des Nigrinus hat sich bei einem Besuch in Rom auch auf den Weg zu dem berühmten Philosophen Nigrinos gemacht, ihn zuhause angetroffen und eine lange Rede des weisen Mannes über den verkommenen Zustand der Welt und die Rolle des Philosophen darin angehört. Nigrinos' Worte haben ihn tief

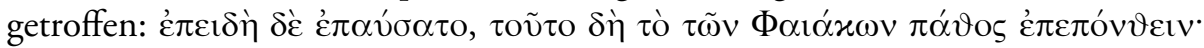

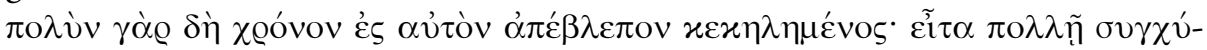

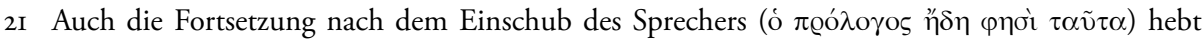
iambisch an: $\dot{\varepsilon} \varsigma$ 'O $\lambda \nu \mu \pi i \alpha \nu \pi \mathrm{o} \tau \dot{\varepsilon} \tilde{\eta} \varkappa \varepsilon$, und zwar mit regulärer, aber deutlicher und also komödientypischer Auflösung im jeweils ersten Anceps. 


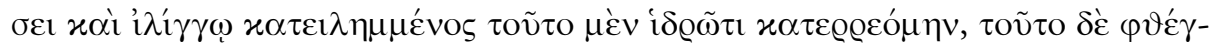

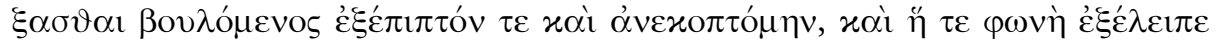

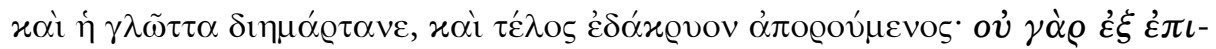

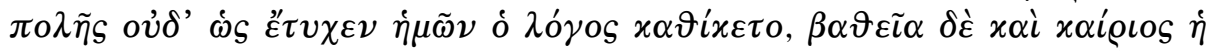

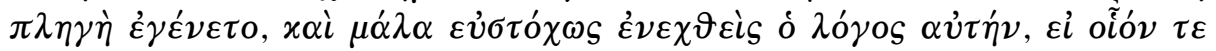
$\varepsilon i \pi \varepsilon \tilde{\imath} \nu, \delta\left\llcorner\varepsilon ́ x o \psi \varepsilon \tau \dot{\eta} \nu \psi v \chi \chi \eta^{\prime} \nu\right.$... (Nigr. 35). Dieser Logos - hier zunächst einmal nur gleichzusetzen mit „Nigrinos' Worten“ - gibt sich so eindeutig und unhinterfragbar in seinem Urteil, daß dem Sprecher - in den Handschriften heißt er sogar Lukian - die Tränen kommen und er sich nicht nur oberflächlich, sondern tief getroffen, versehrt, seelisch durchbohrt fühlt. Und auch dieser Logos, dessen Wirkung immerhin mit der Kampfkraft eines Kriegers metaphorisch gleichgesetzt wird, legt über sein Tun keine Rechenschaft ab: Zu einem Gespräch über das Gehörte kommt es nicht, der Logos des Philosophen läßt sich nicht auf eine Diskussion ein, die sein Zuhörer aber auch gar nicht führen will. Und dies mutet nun gerade deshalb, weil dieser Zuhörer den Namen Lukian trägt, doch zumindest leicht ironisch an, nämlich als plakative Naivität und dann letztlich als Warnung, sich den Sturzfluten des Logos, wie sie aus Nigrinos (ganz ungefragt) hervorbrechen, so unreflektiert hinzugeben, wie es jener ,Lukianos' tut. Daß ein solcher ironischer Gestus hier vorhanden ist, darauf weisen einige Details des Berichtes hin: Nicht nur tritt Nigrinos mit einem aufgeschlagenen Buch in der Hand auf (Nigr. 2), was bei Lukian sonst grundsätzlich als Hinweis auf bloße Bildungsprätention zu verstehen ist, auch die - so ganz unsokratische - Wortflut selbst macht mißtrauisch, ${ }^{22}$ und wenn ,Lukianos ${ }^{6}$ eingangs die Wirkung des $\mathrm{Ni}$ grinos auf ihn mit dem odysseischen Lotos vergleicht (Nigr. 3), so sollte man nicht vergessen, daß im Epos die Gefährten des Helden nur mit Schlägen zur Vernunft gebracht werden konnten. Zuletzt wird ,Lukianos' die verbalen Pfeilschüsse des Philosophen mit der Bogenkunst des Teukros vergleichen und dabei (Nigr. 37) sehr konkret aus Homer (Ilias 8,282) zitieren: Dort fordert Agamemnon Teukros auf, Hektor zu erschießen - jedoch verfehlt ihn Teukros dann zweimal hintereinander und wird zudem von ihm selbst mit einem Steinwurf zu Boden gestreckt. Auch hierin mag man also eine Ironisierungsstrategie erkennen, deren Höhepunkt vielleicht am Ende des Textes erreicht ist, wenn der Gesprächspartner, dem ,Lukianos' die Tirade des Nigrinos berichtet hat, sich von einer ansteckenden Krankheit befallen wähnt (Nigr. 38). ${ }^{23}$

Wenn denn also dieser scheinbar protreptische Text tatsächlich unterschwellig ironisiert ist, dann erweist sich Nigrinos' verletzender, treffender, durchschlagender Logos als tatsächlich unzuverlässig und nicht wirklich vertrauenswürdig. Da-

22 Philosophisches Vorbild Lukians - und in seiner häufig verwendeten Figur ,Lykinos‘ gespiegelt - ist ohne Zweifel der Protoethiker Sokrates und damit dessen dezidiert dialogisch und geradezu antimonologische Gesprächsführung; vgl. hierzu grundlegend Dubel 1994.

23 Vgl. insgesamt Möllendorff 2006, 310-312. 
mit ist nun eine weitere Stufe des Einsatzes des Logos erreicht. Denn an den bislang betrachteten Stellen gab es keinen Anlaß, dem Logos zu mißtrauen und seine Autorität anzuzweifeln. Ein Grund hierfür mag aber dann vorliegen, wenn sich der Logos zu einem Übermaß an Gewalttätigkeit versteigt, wie es im Nigrinos formuliert ist und wie er es auch im Hermotimus, dem vielleicht wichtigsten philosophischen Werk Lukians, tut, einem Dialog, in dem Lykinos seinem 6ojährigen Freund Hermotimos auf dem Weg zu seinem Philosophielehrer begegnet, ihn in ein Gespräch über seine Lebenswahl und die Wahl seiner philosophischen Schule, der Stoa, verwickelt und ihn schließlich argumentativ dazu bringt, eingestehen zu müssen, daß diese Wahl verfrüht und im letzten unreflektiert gewesen ist. Zu dem Zweck, Hermotimos immer weiter in die Aporie zu treiben, führt Lykinos im letzten Viertel des Textes, als Hermotimos sich immer stärker auch persönlich attackiert und hintergangen fühlt, einen personifizierten

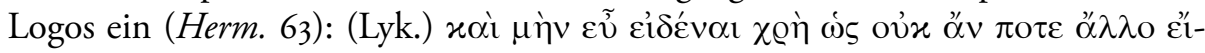

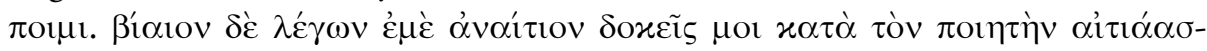

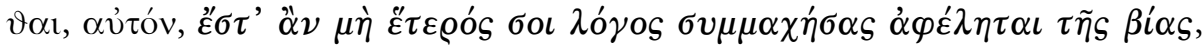

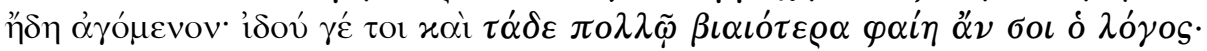

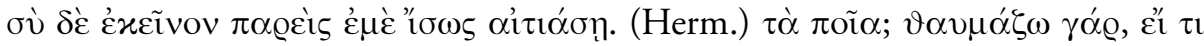

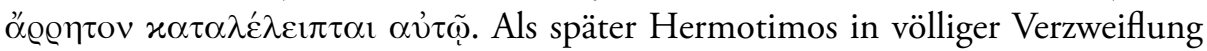
fragt, ob man denn als Philosoph nicht einmal dann, wenn man alle Wege der Philosophie abgeschritten habe, sicher sein könne, die Wahrheit zu finden, verweist Lykinos erneut auf den Logos (Herm. 66): $\mu \grave{\eta} \dot{\varepsilon} \mu \dot{\varepsilon}^{\prime}, \tilde{\omega} \gamma \alpha \vartheta \dot{\varepsilon}, \dot{\varepsilon} \rho \omega \dot{\tau} \tau \alpha, \dot{\alpha} \lambda \lambda \dot{\alpha}$

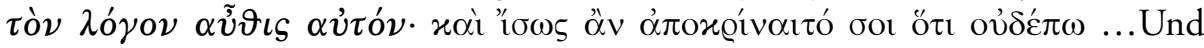
noch am Ende kann Lykinos darauf hinweisen, sein Logos sei keineswegs speziell

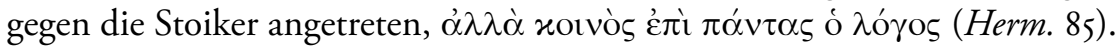

Die Besonderheit des Auftrittes eines autoritären, sich auf rationale Argumentation stützenden Logos im Hermotimus liegt ganz offenkundig darin, daß er zwar nur auf der Ebene des Zitats verbleibt, nun aber - anders als bei seiner Verwendung durch den Kyniker im Iuppiter confutatus - als angreifbar, als moralisch fragwürdig desavouiert werden kann, daß man sich vorstellen könnte - auch

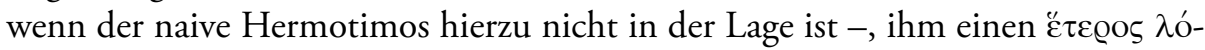
yos gegenüber treten zu lassen: Jedenfalls sollte sich der nicht ganz so naive Leser hierzu aufgefordert fühlen und dürfte sich dann nicht allen - primär skeptischen Positionen entnommenen - Argumenten des Lykinos beugen müssen, die keineswegs alle so unanfechtbar sind, wie es zunächst (und vor allem für Hermotimos) den Anschein hat. Der Logos wird hier, unter Ausweitung der uns schon bekannten militärischen Metaphorik, als ,Verbündeter ${ }^{\varsigma}(\sigma \nu \mu \mu \alpha \chi \eta \dot{\sigma} \sigma \varsigma)$ verstanden, ja als der eigentliche Kriegsgegner, hinter dessen ,Gründe` sich der Sprecher, Lykinos,

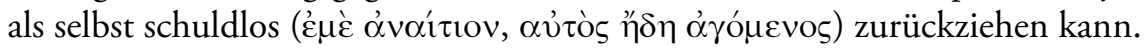

Der existentiell motivierte und leidenschaftliche Widerstand, den Hermotimos der Zerstörung seines Lebenszieles entgegenzusetzen versucht, der sokra- 
tisch-elenktische Gestus, der Lykinos' Gesprächsführung bestimmt, die Tatsache, daß Hermotimos am Ende des Gesprächs mit wehenden Fahnen zu Lykinos überläuft und seine philosophische Karriere abbricht, verbunden mit der Imagi-

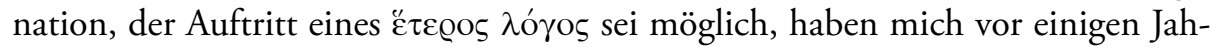
ren zu der Annahme geführt, hinter diesem ganzen Motivkomplex stecke eine ex-

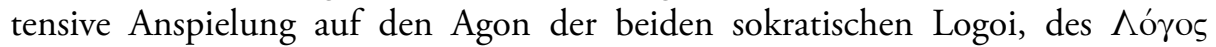

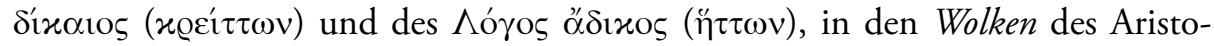
phanes (aufgeführt 423 v. Chr.); ich stelle diese Deutung im folgenden abgekürzt vor. $^{24}$

In den Wolken führt Sokrates als Haupt des sophistischen Phrontisterions dem aus niederen Motiven um rhetorische Ausbildung nachsuchenden Protagonisten Strepsiades und dessen Sohn Pheidippides den Wettstreit zweier in seinem

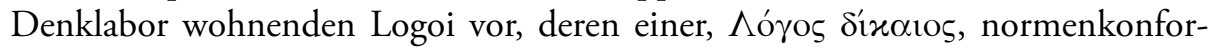

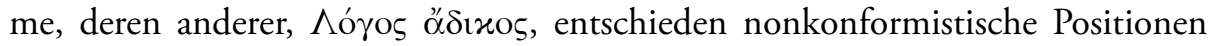
vertritt. Der ,gerechte Logos', der seine Auffassungen als naiver Konservativer nur als selbstverständlich und als, schon immer so gewesen ' affirmieren, nicht aber begründen kann, ist bald den intrikaten Nachfragen und Sondierungen seines ,ungerechten' Gegners unterlegen, der keine diskursiven Tabus kennt und seinen Kontrahenten daher leicht aushebeln kann. Logos Dikaios wirft, als er seine Niederlage - und damit die Niederlage einer Argumentation, die sich auf Äußerlichkeiten, Herkommen und gegebene, nicht erworbene Autorität stützt - seinen Mantel $\mathrm{ab}$ und läuft in das Lager des Gegners über (Wo. IIOzf.). Das Abwerfen des Mantels als Symbol für den Wechsel der Einstellung ist nun aber auch der Gestus, mit dem Hermotimos im Finale des Dialogs (Herm. 86) das Gespräch beendet: Er beschließt, fortan einen purpurnen Mantel zu tragen und damit auch nach außen zu demonstrieren, daß das armselige, von Kasteiung und Lebensfeindlichkeit geprägte Philosophenleben - das ihn, wie er nun zu verstehen

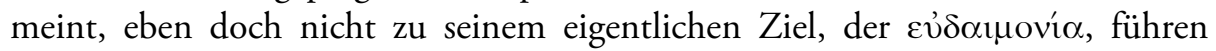
wird - jetzt ein Ende haben wird, daß er sich vielmehr der Lebensfreude und dem Lebensgenuß hingeben wird. So wie Lykinos im Dialog die Position des Protophilosophen Sokrates einnimmt, steht also Hermotimos für den Logos Dikaios und steht dann natürlicherweise der von Lykinos angeführte Logos für den Aristophanischen Logos Adikos. Entsprechend sind wir berechtigt, Aristophanische Wertungen und Positionierungen auf unseren Text zu beziehen, und hier zeigt sich dann, daß Hermotimos offenkundig seinen ideologischen Lagerwechsel allzu schnell und unüberlegt, letztlich aus intellektueller Schwäche, vollzieht. Denn der Logos Dikaios der Wolken läuft in dem Augenblick über, in dem er erkennen muß, daß die Zuschauer längst alle auf der Seite des Adikos stehen, ${ }^{25}$ er

24 Vgl. ausführlicher Möllendorff 200ob, 2IO-2I8, v. a. 2I2-2I5.

25 Wo. IO83-IIO2. 
mit seiner wertkonservativen Position also allein ist, was einen Widerspruch in sich darstellt, basiert doch (naiver) Wertkonservatismus darauf, zwar nicht reflektiert zu werden, aber auf die (unreflektierte) Zustimmung der sozialen Mehrheit bauen zu können. In gewisser Weise hat auch Hermotimos darauf gebaut, daß die Hinwendung zur spekulativen Philosophie eine allgemein für wertvoll gehaltene Lebenswahl ist, muß aber jetzt sehen, daß sie sich rational nur schwer vertreten läßt, oder besser: Daß sie anders umgesetzt, in eine ethisch fundierte Lebensgestaltung übersetzt werden müßte. $\mathrm{Zu}$ der Entwicklung einer Argumentation, die seine Lebensführung, seine Wertsetzung rechtfertigen würde - im Sinne des Themas meines Beitrages formuliert: Einen Logos auftreten zu lassen, der seine Einstellung argumentativ stützen und vertreten könnte -, ist er hingegen nicht in der Lage.

Brisanter ist aber meines Erachtens, daß durch diese Aristophanesanspielung auch der Logos des Lykinos fragwürdig wird, der es sich ja nun gefallen lassen muß, auf seine Affinitäten zu einem Logos befragt zu werden, der in der Komödie den desavouierenden Namen Adikos trägt. Dessen ,Ungerechtigkeit' besteht darin, daß er grundsätzlich keine Werte anerkennt, und Lykinos ist ihm insofern vergleichbar, als er an die Stelle der von ihm zerstörten Bemühungen um Erkenntnis nichts eigentlich Positives setzt. Denn er stellt zwar den metaphysischen Spekulationen des Hermotimos und seines Lehrers eine pragmatische Ethik des Gemeinsinns entgegen (Herm. 7I-79), ohne aber eigentlich zu konkretisieren, auf welchen Prämissen und wesentlichen Erkenntnissen - wie sie der Platonische Sokrates in seinen Gesprächen zu erarbeiten suchte: als Abstraktion, die über eine Alltagsbegrifflichkeit hinausreicht - ein solches Handeln eigentlich beruhen soll. Entsprechend kann die Bekehrung des Hermotimos zu einem ,besseren' Leben nur oberflächlich sein; und auch dies scheint ja sein Entschluß, von nun an einen purpurnen Mantel zu tragen, zumindest anzudeuten.

Es ist also der Hermotimus, in dem sich die oben beschriebene Prekarität des Lukianischen Diskurses - das Gegenüber von Erkenntnissuche und agonalem Überlegenheitswillen, Überzeugung und Verbalattacke - am deutlichsten manifestiert; sie ist aber vorbereitet und flankiert in den weniger drastischen Verwendungsweisen einer autarken oder doch zur Autarkie tendierenden Logos-Figur, wie ich sie zuvor beschrieben habe. Der offensichtlich nicht völlig vertrauenswürdige Logos des Lykinos ist gewalttätig und gibt sich schließlich damit zufrieden, die schwächere, zu wenig reflektierte und ihrer selbst ohne Grund allzu sichere Argumentation des Hermotimos überwinden zu können; das Erkennen muß im Zuge dieses Agons letzlich auf der Strecke bleiben, aber frappierend ist m. E., daß Lukian durch die plakative Anspielung auf die Wolken des Aristophanes ja eine Ebene einzieht, auf der der Rezipient um ein Bedenken der Positionen, um eine kritische Sichtung dieses Überzeugungsvorganges, der auch vor herbem Spott nicht zurückschreckt, nicht herumkommt. Die Frage, ob Lukian die aus 
der Hybride von philosophischem Dialog und Komödie resultierende prekäre Diskursivität bedenkt und zum Gegenstand seines Schreibens macht, läßt sich also - in diesem impliziten Sinne - bejahen.

Weniger existentiell als im Hermotimus, dafür aber dramatisch lebendiger operiert der Logos schließlich in der Prolalia De Domo, einem der bedeutenderen ästhetiktheoretischen Werke Lukians. Der Sprecher trägt seine Rede offensichtlich in einem architektonisch gelungenen, in seiner Bildausstattung eindrucksvollen Saal vor und denkt in dieser Prolalia laut darüber nach, wie man in einem ästhetisch so vollendeten Raum eigentlich adäquat sprechen könne; er diskutiert also letztlich die Frage, wie das Sprechen in einem solchen Raum ein bimediales Gesamtkunstwerk, ein ästhetisch vollendetes ikonotextuelles Ensemble hervorbringen könne. Der Redner behauptet, daß dies nur gelingen könne, wenn er sich nicht bemühe, den Raum und die Bilder in seinen Worten zu beschreiben, sondern wenn er deren spezifische ästhetische Qualitäten in Sprache transformiere. In der Mitte des Textes geschieht nun aber etwas Ungewöhnliches (Dom. I4f.):

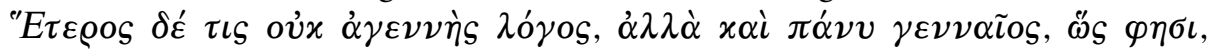

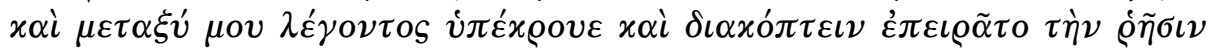

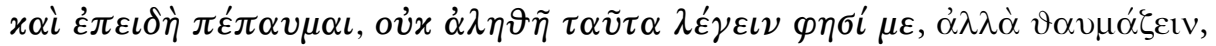

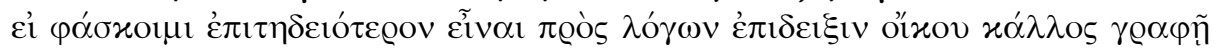

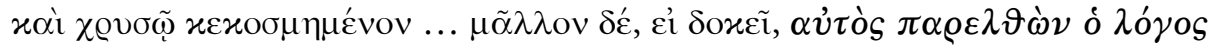

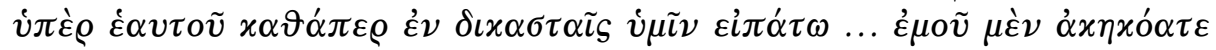

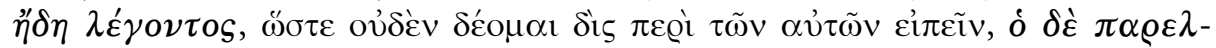

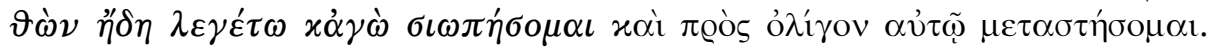

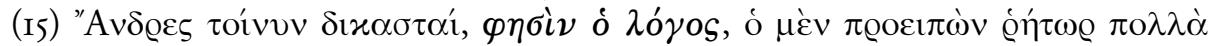

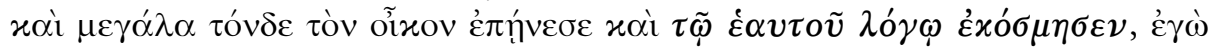

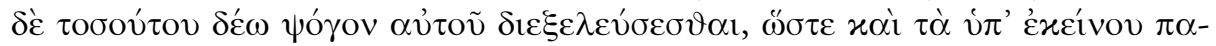

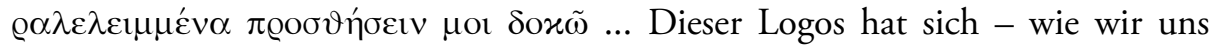
vorstellen müssen - offensichtlich schon während der einleitenden Rede des Sprechers kaum zurückhalten können, hat Lärm gemacht und ihn zu unterbrechen versucht. Es mag zu weit hergeholt erscheinen, aber es könnte einem hier das Verhalten des Aristophanes in Platons Symposion in den Sinn kommen, der während der Rede seines Vorgängers Eryximachos damit beschäftigt ist, lautstarke Versuche zur Beseitigung seines Schluckaufs zu unternehmen ${ }^{26}$ damit wäre auch hier ein komödisches Element in Szene gesetzt und in der Prolalia, in der es, wenn auch nicht um eine genuin philosophische Fragestellung, so doch um ein höheres Verständnis eines nicht unwesentlichen medial-ästhetischen Problems geht, ließe sich somit ein weiteres Exempel jenes hybriden Lukianischen Diskurses sehen. Dieser dreist auftretende, die Rede usurpierende Logos spricht bis zum Ende der Prolalia, okkupiert, aufs Ganze betrachtet, mehr als die Hälfte

26 Plat. Symp. I85c4-e5. I89aI-b2. 
des Textes und ist auch derjenige, der die Prolalia beendet, ohne daß der erste Sprecher noch einmal zu Wort käme, und dies entgegen seiner noch am Ende

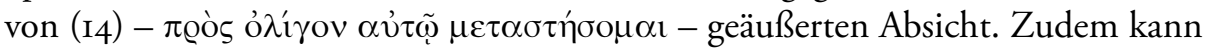
er eigenständig Zeugen aufrufen, die innerhalb seiner Rede explizit und eigenständig zu Wort kommen. ${ }^{27} \mathrm{Er}$ ist nicht eigentlich ein Gegner des ersten Sprechers, gibt er doch zu Protokoll, daß er ihm nicht widersprechen, aber doch einiges von jenem Ausgelassenes hinzufügen wolle; allerdings propagiert er schließlich doch ein ganz anderes Modell, nämlich das einer medialen Unterlegenheit der Sprache, die sich nur in den Dienst des Sichtbaren stellen kann, indem sie es beschreibt, weshalb den größeren Teil seiner Ausführungen eine Ekphrasis der Bilderreihe einnimmt, die an den Wänden des Saales hängt. Damit gewinnt er jedenfalls eine bisher ungesehene Unabhängigkeit von dem ersten Sprecher: Trat der Logos bislang als zwar selbständiger, aber doch getreuer Unterstützer des Sprechers auf, so ist er hier ein (lästiger) Konkurrent, den der Sprecher noch nicht einmal abschließend aus dem Felde zu schlagen vermag.

Es ist somit Aufgabe des Rezipienten, aus der Antithese zur (vom Autor nun definitiv nicht vorgegebenen, auch nicht insinuierten) Synthese zu gelangen, das Urteil bleibt ihm überlassen. Lukian vermag auf diese Weise die ideologische Offenheit seines hybriden Dialogs zu wahren und ihm so eine wirkliche dramatische Qualität zu verleihen: Dramatisch in dem Sinne, daß sich die Polyphonie der Figurenreden nicht auf die Eindeutigkeit und Zurechenbarkeit zu einer auktorialen Instanz reduzieren läßt. Prekär ist hieran, daß Lukian diese Qualität seiner Texte zu dem Preis erkauft, daß er auch dem Erkenntnisprozeß eine ernsthafte Dialogizität einschreiben muß, das heißt: Die Verantwortung für das Gelingen dieses Prozesses verschiebt sich vom Autor auf den Rezipienten, der sich mit den Ansprüchen der Figuren und nicht zuletzt der Logos-Figuren, autoritativ sprechen zu können, auseinanderzusetzen hat. ${ }^{28}$

Ich möchte diesen Beitrag nicht schließen, ohne auf einige weitere Figuren des Lukianischen Euvres zumindest aperçuhaft hinzuweisen, die ohne Zweifel die Qualität von Logos-Figuren besitzen und deren Verhältnis zum Autor Lukian unterschiedlich und insgesamt schwer bestimmbar ist: Die Figur des $\Delta$ tó $\lambda$ oyos

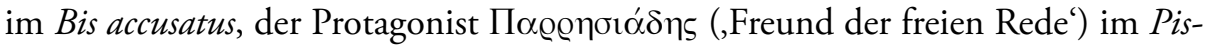
cator sowie die verschiedentlich auftretende Personifikation der kritischen Ein-

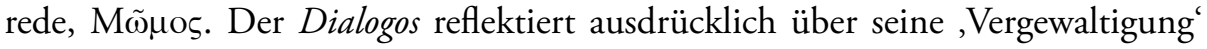
durch den ,Angeklagten' Lukian, nämlich seine Verbindung mit der Komödie, die er als dysfunktional beschreibt: dysfunktional gleichwohl nicht etwa ästhetisch, sondern ethisch, womit er in einen - dem Procedere in De Domo vergleich-

27 Dom. 20 (Zeugnis Herodots zur Richtigkeit der Behauptungen des Logos hinsichtlich der Überlegenheit des Sehens über das Hören).

28 Hieraus ergibt sich auch ein ethisches Problem, nämlich das der Verantwortung für die ,Botschaft' eines Textes; vgl. hierzu Möllendorff 2010. 
baren - Widerspruch und Gegensatz zu Lukian tritt, der sich doch für die Erschaffung gerade dieser Verbindung besonders rühmt. Parrhesiades ist, wie Dialogos, eine genuin dem Traditionsstrang des philosophischen Gesprächs zuzuordnende Figur, rekurriert sein Name doch auf die parrhesia als eine Einstellung der angstlosen Freimütigkeit des Philosophen gegenüber den Herrschenden, wie sie einschlägig von Flinterman dargelegt worden ist. ${ }^{29}$ Zugleich gibt es hier eindringliche intertextuelle Referenzen auf eine weitere problematische Aristophanische Figur, den Dikaiopolis der Acharner. Problematisch ist diese Figur deshalb, weil sie zwar - wie der Parrhesiades im Piscator - einen ethisch prätentiösen Namen trägt, sich aber im Verlauf des Dramas als keineswegs verläßliche ethische Instanz erweist: Der attische Bauer Dikaiopolis schließt im Peloponnesischen Krieg mithilfe eines magischen Friedensweines einen Privatfrieden mit Sparta, sorgt aber auf egoistischste Weise dafür, daß niemand außer ihm davon profitieren kann..$^{30}$ Wie im Hermotimus ließe sich fragen, ob und wenn ja: welche Rückschlüsse auf die Lukianische Figur Parrhesiades hieraus zu ziehen sind, dem eine gewisse Prä-

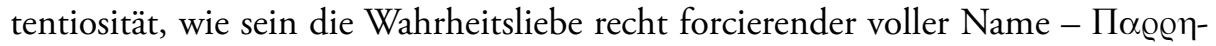

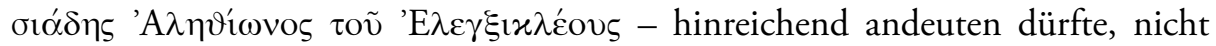
gänzlich fern ist. Momos schließlich ist zweifellos eine hybride Figur, die dem Lukianischen Anspruch der Verbindung von derber komischer Kritik und philosophischem Verbesserungswollen am ehesten entspricht, wenn auch gleichwohl aufgrund seiner grundsätzlichen Haltung, stets nur das Negative zu sehen, ebenfalls ein ironisches Schlaglicht auf die auktoriale Persona fällt.

Nimmt man die oben teils ausführlicher, teils summarisch vorgestellten Instanzen von Logos-Figuren zusammen, so zeigt sich, daß Lukian ein ganzes Arsenal von unterschiedlich elaborierten und funktionalisierten Lógoi in seinem Werk zum Einsatz bringt. Diese treten teils als seine Stellvertreter oder Helfer auf, teils entpuppen sie sich aber auch als heimliche oder sogar offene Gegenspieler. Lukian, schon biographisch nicht greifbar, ist es auch nicht in seinem Werk. Der Grund für eine solche Strategie könnte, wie ich thesenhaft formulieren möchte, gerade mit seiner spezifischen Selbstverortung in der epideiktischen Kultur seiner Zeit zusammenhängen, deren Besonderheiten ich oben skizziert habe. Wenn die körperliche Selbstinszenierung der herausragendsten Sophisten gerade darauf abzielte, sich zu tatsächlich einzigartigen Gestalten zu stilisieren, und wenn es richtig ist, die plakative ,Unkörperlichkeit' Lukians als analoge Strategie sophistischer Positionsnahme anzusehen, dann dürfte diese Vielfalt von auktorialen Sprechern und schwer einzuordnenden Logoi-Figuren dem Zweck dienen, gerade den Vorzug einer vor allem textuellen Existenz auszuspielen: Denn während jene anderen

29 Flinterman 2004.

30 Vgl. Bowie I993, 33, sowie Möllendorff 2002, 65f. 
Sophisten, und selbst Favorinus, doch am Ende nur einen Körper haben, kann Lukian sich in eine quasi unbegrenzte Zahl textueller Instanzen einspiegeln und auf diese Weise eine Polyphonie erzeugen, hinter der er selbst unauffindbar und damit uneinholbar wird. 


\section{Literaturverzeichnis}

Baldwin (1973): B. Baldwin, Studies in Lucian, Toronto.

Bowie (1993): Angus M. Bowie, Aristophanes. Myth, Ritual and Comedy, Cambridge.

Bretzigheimer (1992): G. Bretzigheimer, Lukians Dialoge EIKONE $\Sigma$ - ҮПEP T $\Omega N$ EIKON $\Omega N$. Ein Beitrag zur Literaturtheorie und Homerkritik, $R h M$ I35, I6I-I87.

Dubel (1994): Sandrine Dubel, Dialogue et autoportrait: les masques de Lucien, in: Alain Billault (Hg.), Lucien de Samosate. Actes du colloque international de Lyon organisé au Centre d'Etudes Romaines et Gallo-Romaines les 30 septembre $-I^{\text {er }}$ octobre 1993, Lyon, 19-26.

Flinterman (2004): Jan J. Flinterman, Sophists and emperors: A reconnaissance of sophistic attitudes, in: B. Borg, Paideia. The World of the Second Sophistic, Berlin / New York, 359-376.

Möllendorff (200oa): Peter von Möllendorff, Auf der Suche nach der verlogenen Wahrheit. Lukians Wahre Geschichten, Tübingen.

Möllendorff (200ob): Peter von Möllendorff, Lukian. Hermotimos oder Lohnt es sich, Philosophie zu studieren? Hg., übers. u. komm. v. ders., Darmstadt [TdF 74].

Möllendorff (2002): Peter von Möllendorff, Aristophanes, Darmstadt.

Möllendorff (2004): Peter von Möllendorff, Puzzling Beauty. Zur ästhetischen Konstruktion von Paideia in Lukians ,Bilder'-Dialogen, Millennium I, I-24.

Möllendorff (2006): Peter von Möllendorff, Lukian. Gegen den ungebildeten Büchernarren, Düsseldorf / Zürich.

Möllendorff (20Io): Peter von Möllendorff, Das A und $O$ des Zitierens. Zur ethischen Dimension beschnittener Zitate, in: J. Jacob, M. Mayer (Hgg.), Im Namen des anderen. Die Ethik des Zitierens, München, I89-202.

Saïd (1993): Suzanne Saïd, Le ,je' de Lucien, in: M.-F. Baslez u. a. (Hgg.), L'invention de l'autobiographie d'Hésiode à saint Augustin. Actes du deuxième colloque de l'Equipe de recherche sur l'hellénisme post-classique, Paris, 253-270.

Wilhite (2007): David E. Wilhite, Tertullian the African. An anthropological reading of Tertullian's Context and Identities, Berlin / New York.

Zanker (1995): Paul Zanker, Die Maske des Sokrates. Das Bild des Intellektuellen in der antiken Kunst, München. 


\title{
Wahrer Logos - Logos der Wahrheit
}

\author{
Der Umgang des Kelsos mit der Bibel
}

\author{
HoraCio E. LONA
}

„Wahrer Logos - Logos der Wahrheit“: Hinter der Formulierung, die auf den ersten Blick nur als ein Wortspiel erscheinen könnte, verbirgt sich eine Auseinandersetzung, die einen Wendepunkt in der Geschichte der abendländischen Kultur einleiten wird.

Gemeint ist, einerseits, das Werk des platonischen Philosophen Kelsos, der mit erstaunlich genauen Kenntnissen über die Bibel und über die Christen in der Gesellschaft, in der Zeit von ca. I77-I8o diese darstellt und sich mit ihnen auseinandersetzt. Der gegen Vernunft und Sitten verstoßenden christlichen Lehre

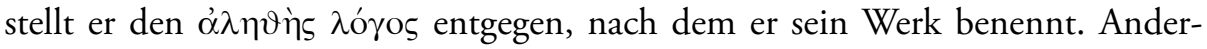
seits steht der Logos der Wahrheit ( $\lambda$ ó 2 Tim 2,15) als zusammenfassende Bezeichnung der christlichen Botschaft mit ihrem Anspruch, die Wahrheit über Gott, den Menschen und die Welt in unüberbietbarer Dichte zu verkünden.

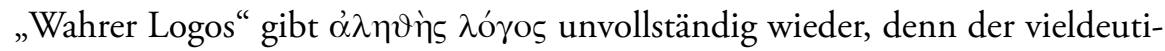
ge Begriff $\lambda$ ó $\gamma$ os verlangt nach einer genauen Übersetzung. Bekanntlich handelt es sich um eine Wendung platonischer Herkunft ${ }^{\mathrm{I}}$, die Plato oft und mit unterschiedlichen Inhalten verwendet. Einige Beispiele dazu: In Cra. 385b.c; 408c; Sph. 264a; Ti. 37b.52c; Lg. 698d wäre „wahre Rede“ angebracht; in Phdr. 270c; in Lg. 783a geht es eher um die „richtige Vernunft“, während in Lg. 653d „wahrer Gedanke" in Frage kommt. An anderen Stellen dürfte eine inhaltliche Komponente miteingeschlossen sein, die auf „weise Männer und Frauen“ (Men. 8Ia), auf eine ,alte und wahre Lehre“ (Lg. 757a) oder auf die „Lehre aus einer alten Überlieferung" (Ti. 2od) zurückgeführt wird. Daraus lässt sich die Absicht des Kelsos

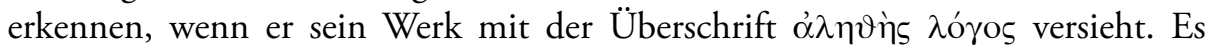
handelt sich wahrscheinlich nicht um einen präzisen Inhalt ${ }^{2}$, sondern allgemein

I Vgl. Wifstrand I942, I-4I, bes. 7-II.

2 Wifstrand I942, 22f. vertritt eine andere Meinung. Kelsos meine damit einen klaren Inhalt, der von einem anderen Platoniker, Maximos von Tyros, zusammengefasst sei: „Mitten in einem solchen Kampf und Streit sollst du die eine einstimmige Satzung und Lehre (vó $\mu$ ov xò $\lambda$ óyov) erkennen, dass es einen Gott gibt, den König und Vater aller Dinge, und viele Götter, 
um die Gültigkeit der antiken Überlieferung, so wie sie in der Tradition der hellenistischen Kultur verankert, aufbewahrt und verstanden wurde. Die „altehrwürdige von Anfang an herrührende Lehre" (Cels. I,I4c: $\alpha \varrho \chi \alpha \tilde{i o s ~ \alpha ̋ v \omega \vartheta \varepsilon v ~} \lambda$ ó-

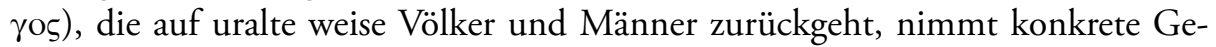
stalt an in der Lehre des Platonismus des zweiten Jahrhunderts, der sich somit als Erbe und Wächter einer unantastbaren Überlieferung darstellt.

Vorliegender Beitrag beabsichtigt nicht, den Verlauf dieser Auseinandersetzung darzustellen oder gar zu skizzieren. Einiges aus der Sicht des Kelsos wurde in der Kommentierung des „Alethes Logos“ dargelegt”, die dem Jubilar viele Anregungen und reiche Belehrung verdankt. Als Zeichen des Dankes und der Anerkennung seiner wissenschaftlichen Leistung sind ihm diese Seiten gewidmet.

Erfahrungsgemäß weiß der Verfasser jedes umfangreichen Kommentars erst nach Abschluss des Werkes besonders deutlich, wie viele offene Fragen geblieben sind, die einer eingehenden Behandlung bedürfen. Die Beschäftigung mit den Fragmenten des Kelsos macht dazu keine Ausnahme, und das Thema dieses Aufsatzes ist nur ein Versuch, einer von diesen Fragen nachzugehen.

In diesem Fall nehmen wir eine Frage auf, die zunächst das Selbstverständnis

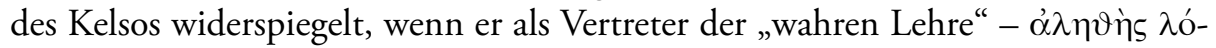

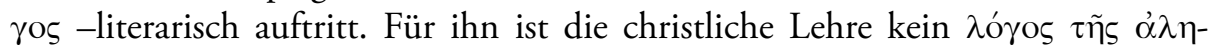

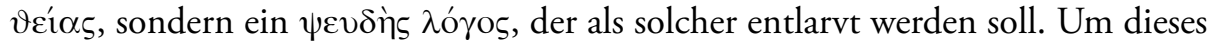
Ziel zu erreichen, zieht Kelsos alle Register seiner Gelehrsamkeit und seines Scharfsinnes, um das Christentum nicht nur als Bewegung von Sklaven und Ungebildeten darzustellen (Cels. 3,44-55; 3,72-78), sondern darüber hinaus als subversive Kraft in der Gesellschaft (Cels. 8,2.9.17), die den Bestand des Reiches gefährden wird (Cels. 8,69.7I), falls es sich ausdehnt und Anhänger gewinnt.

Uns interessiert in diesem Zusammenhang der Umgang des Kelsos mit der Heiligen Schrift der Christen, wie dieser sich auch in der Struktur des „Alethes Logos" niederschlägt. Daher werden wir einfach nach dieser Struktur vorgehen, um die wesentlichen Aspekte und das Anliegen in der Rezeption der christlichen Bibel bei Kelsos hervorzuheben. ${ }^{4}$

Söhne Gottes, Mitregenten Gottes“ (Diss. II,5). Selbstverständlich gehört die Anschauung über Gott und die Götter zu den Inhalten der „wahren Lehre“, aber sie beschränkt sich nicht auf Theologisches, sondern bietet darüber hinaus eine Gesamtsicht der Wirklichkeit. - Nach Bader

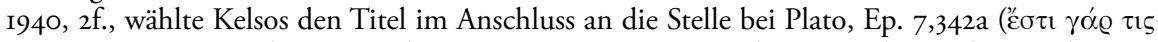

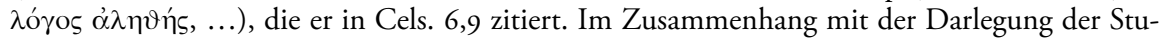

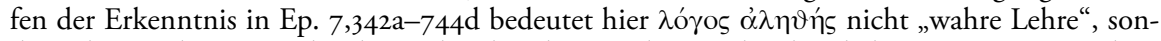
dern eher „wahrer Grund“, aber Kelsos hat die Wendung wahrscheinlich im Sinne von „wahrer Lehre“ verstanden. Vgl. Lona 2005, 323-325.

3 Ebd.

4 Einen Überblick über das Gesamtmaterial bietet Cook 2000; ders. 2004. 
Drei Vorbemerkungen dazu: I. Über die Struktur des „Alethes Logos“ gehen die Meinungen der Forschung auseinander. Wir unterscheiden einen einleitenden Teil, zu dem die Fragmente in Cels. I,I-27 gehören. Dem folgen drei große Abschnitte: Der erste Teil $(\mathrm{I}, 28-2,79)$ enthält die jüdische Kritik an Jesus und am christlichen Glauben; der zweite Teil $(3, \mathrm{I}-5,65)$ behandelt die Welt ohne Logos und Nomos der Juden und Christen; im dritten Teil $(6, I-8,75)$ geht es um den Logos und den Nomos der griechischen Überlieferung'; 2. nicht alle biblische Zitate und Anspielungen werden hier untersucht. Im Rahmen eines Aufsatzes ist nur ein selektives Verfahren möglich. Es geht um die Bedeutung der Bibel und ihrer Rezeption für das Anliegen des Kelsos in seinem Werk; 3. zuerst schenken wir unsere Aufmerksamkeit einigen ausgewählten Fragmenten des „Alethes Logos", in denen sich die Rezeption der Bibel widerspiegelt. In einem zweiten Moment stellen wir in einigen Bemerkungen zum betreffenden Abschnitt die hermeneutischen Grundsätze dar, welche die vorgelegte Interpretation leiten. ${ }^{6}$ Es geht also nicht allein um die Frage, „wie“ Kelsos die Schrift interpretiert, sondern um die Frage, „warum“ er den Text so interpretiert. Das Verfahren verfolgt ein elementares hermeneutisches Anliegen: Wir wollen den Kelsos verstehen, auch wenn er die Schrift in einer Art liest, die uns fremd, anstößig oder einfach ungewöhnlich vorkommt.

\section{Biblische Zitate und Anspielungen in Cels. I,28-2,79.}

Die Kritik eines fiktiven Juden an Jesus (I,28-7I) und an den Judenchristen (2,I79) bildet eine erste thematische Einheit, die aus zwei Teilen besteht. ${ }^{7}$ Der erste Teil $(\mathrm{I}, 28-7 \mathrm{I})$ wird als Tadelrede oder „vituperatio" gestaltet, die aufgrund der Herkunft, der Lebensführung und der Taten eines Menschen ein durchgehend negatives Urteil über ihn abgibt. Im zweiten Teil (2,I-79) überwiegt stilistisch die „disputatio“, wie sie im Rahmen eines Strafprozesses geübt wurde. Sie erreicht ihr

5 Zur Begründung dieser Teilung vgl. Lona 2005, 23-27.

6 Das bedeutet nicht, dass diese Grundsätze ausschließlich in diesem Abschnitt gelten, sondern dass sie dort besonders deutlich hervortreten.

7 Genau gesehen, darf nicht übergangen werden, dass Kelsos schon in der Einleitung Aussagen der Christen zitiert, die ihre Leichtgläubigkeit und ihre Ablehnung der Vernunft offenbaren

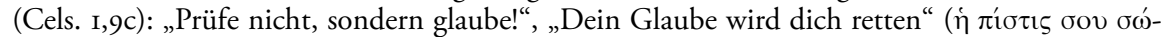
$\sigma \varepsilon(\sigma \varepsilon)$; „Ein Übel ist die Weisheit in der Welt, ein Gut aber ist die Torheit“. Die zwei letzten Aussagen nehmen in freier Form neutestamentliche Stellen auf. „Dein Glaube hat dich geret-

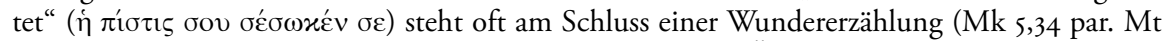
9,22; Lk 8,48; Mk I0,52 par. Lk 18,42; Lk 7,50; 17,19). „Ein Übel ist die Weisheit in der Welt,

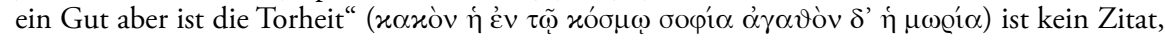
sondern eine den ursprünglichen Sinn entstellende Variation über I Kor I,I8.2If.; 3,I8f. („,.. denn die Weisheit dieser Welt ist eine Torheit vor Gott"). I Kor 3,19 wird in Cels. 6,I2a genauer zitiert. 
Ziel, wenn der Angeklagte die verdiente Verurteilung bekommt. ${ }^{8}$ Es ist nicht so, dass die zwei Teile sich stilistisch voneinander sauber unterscheiden. Elemente der "vituperatio“ kommen auch in der "disputatio“ vor. Dennoch rechtfertigen die stilistischen Merkmale die hier vorgenommene Bestimmung.

Dass Kelsos seine Kritik am Christentum zuerst durch einen Juden vortragen lässt, den er als literarische Gestalt schafft, ist mehr als der Ausweis stilistischer Breite und schriftstellerischen Könnens. Für die Adressaten seiner Schrift, die zu den gebildeten Heiden, wohl in Alexandria, gehörten, war es sicherlich ein überzeugendes Argument, wenn die erste Ablehnung des Juden Jesus - an Heftigkeit kaum zu überbieten -, durch einen anderen Juden erfolgte. Als Volksgenosse war er besonders geeignet, die negativen Aspekte einer jüdischen Gestalt ans Licht zu bringen, und dies umso mehr, wenn er über solche Kenntnisse verfügte, wie sie bei ihm vorhanden waren.

In diesem Abschnitt häufen sich mehr als in den anderen Teilen des „Alethes Logos" die Anspielungen auf die Evangelien. Es sind keine wörtlichen Zitate, aber ihre Verwendung setzt unbedingt Kenntnisse der biblischen Überlieferung voraus, die jetzt in den Dienst der Polemik gegen Jesus gestellt wird. Wie Kelsos, der seine literarische Schöpfung so sprechen lässt, zu diesen Kenntnissen kommen konnte, ist eine noch ungeklärte Frage. ${ }^{9}$

$$
\text { I.I Die „vituperatio“ (I,28-7I) }
$$

Um der Tadelrede zusätzliche Überzeugungskraft und literarische Attraktivität zu verleihen, spricht der Jude des Kelsos abwechselnd in der Form der Rede in der dritten Person ( $\mathrm{I}, 28.32 .39 \cdot 49 \cdot 54 \cdot 58.62 .67 \mathrm{a} .70-7 \mathrm{I})$ und der direkten Anrede in der zweiten Person (I,4I.50.57a.6I.66.67b.68a.69). Seine Absicht dabei ist klar erkennbar: Er will die wahre Gestalt Jesu demaskieren als die „eines gottverhassten und verworfenen Zauberers" (I,7I).

Um dieses Ziel zu erreichen, versucht seine Tadelrede die ganze Geschichte Jesu, von den Umständen seiner Geburt bis hin zu seinem Tod, zu erfassen, und sie im Zeichen der kritischen Aufklärung neu zu erzählen. Die in diesem Abschnitt aufgenommenen neutestamentlichen Motive, die wichtige Etappen der Geschichte Jesu dokumentieren, sind diesem Ziel untergeordnet. ${ }^{\text {Io }}$

- Jesus selbst eröffnet die Reihe der fehlerhaften Angaben, indem er die Geschichte seiner Geburt aus einer Jungfrau erdichtet $(\mathrm{I}, 28 \mathrm{a})$, während in Wahrheit

8 Pichler 1980, I24-I32, hat zuerst auf den stilistischen Hintergrund aufmerksam gemacht. Vgl. auch Lona 2005, 173-175.

9 Am Schluss dieses Beitrags werden wir auf die Frage zurückkommen.

IO Für eine detaillierte Analyse der herangezogenen Abschnitte aus dem Alethes Logos verweisen wir auf den in Anm. 2 angegebenen Kommentar. 
seine Mutter, eine arme Handarbeiterin, „von ihrem Mann, der von Beruf Zimmermann war, des Ehebruchs überführt und verstoßen wurde. ${ }^{\text {II }}$ Der Beruf des Vaters Jesu wird in Mk 6,3 und Mt 13,55 angegeben. Nach Mt I,I8f denkt auch Josef an einen möglichen Ehebruch. Aus der Möglichkeit wird hier Gewissheit, indem der Jude sogar den Namen des wahren Vaters Jesu überliefert, mit dem seine Mutter Ehebruch trieb: „Ein Soldat Namens Panthera“ (Cels. I,32). Um die christliche Version von der Geburt Jesu als falsch hinzustellen, greift Kelsos auf Einzelheiten der jüdischen Polemik gegen die Christen zurück, von der er wahrscheinlich in Alexandria Kenntnis nehmen konnte. ${ }^{\text {I2 }}$

- Die Geschichte von der Anbetung der Weisen aus dem Morgenland (Mt 2,I-I2) wird nicht deswegen erwähnt, weil sie jeder historischen Grundlage entbehrt und darum als falsch abzulehnen ist, sondern weil sie einen Widerspruch offen legt, der den Glauben an Jesus als den Messias gravierend in Frage stellt. Die überlieferten Fragmente enthalten die wesentlichen Züge der Erzählung: Der Stern, der bei der Geburt Jesu aufgegangen ist (Cels. I,34; vgl. Mt 2,2.9); die Ankunft der "Chaldäer"13 mit der Absicht, das Kind als einen König anzubeten (Cels. I, 58 ; vgl. Mt 2,2); die Mitteilung ihrer Absicht an den "Tetrarchen Herodes"14 (vgl. Mt 2,2); die Tötung aller Kinder, die in dieser Zeit geboren wurden, um zu verhindern, dass Jesus als König herrschen würde (vgl. Mt 2,I6-I8). - Der Widerspruch geht aus der „unmessianischen“ Geschichte Jesu hervor. Wenn er als Kind seine messianische Würde so weit offenbaren konnte, dass die fremden Chaldäer sie anerkannten, warum trat er nicht als erwachsener Mensch als König hervor und

II Kelsos weiß, dass der Name der Frau Maria war (vgl. Cels. 5,52b), aber hier wird er nicht genannt.

I2 Nach Maier 1978, 257 sind die Stellen im Talmud, die einen gewissen Ben Panthera (oder auch Panderas, Pantheros) erwähnen (bSabb Io4b; bSanh 67a), ursprünglich nicht auf Jesus bezogen. Wenn es sich aber so verhält, kann man nicht erklären, warum ein anfangs eindeutig gegen die Christen gerichtetes Motiv - der Vater Jesu war Panthera -, das hier in den Mund eines Juden gelegt wird, in der späteren Zeit diese ursprüngliche Verwurzelung im Judentum so weit verliert, dass es in der talmudischen Überlieferung wieder aufgenommen wird, aber ohne jeden Bezug auf Jesus. Gegen die Annahme eines weitgehenden Schweigens der talmudischen Literatur über die Gestalt Jesu - nach der Analyse von J. Meier - hat P. Schäfer eine ganz andere Deutung vorgelegt: „Der Jude in Kelsos’ Bericht vom späten zweiten Jahrhundert n. Chr. und der babylonische Talmud mit seiner wohl aus dem frühen vierten Jahrhundert $\mathrm{n}$. Chr. stammenden Überlieferung beziehen sich beide auf dieselbe polemisierende Gegenerzählung zu Jesu Familienhintergrund, die den neutestamentlichen Bericht in ihr Gegenteil verkehrt" (vgl. Schäfer 2007, 4I).

I3 Mt 2,I bezeugt nicht $\chi \alpha \lambda \delta \alpha \alpha_{101}$, sondern $\mu \alpha \dot{\gamma} \gamma o$, aber die Angabe in Cels. I,58 ist nicht falsch. Die „Chaldäer" waren durch ihre astrologischen Kenntnisse berühmt; die „Magier" gehörten zu einer persischen Priesterklasse. Cels. 6,80 benennt die beiden Gruppen getrennt, neben den Ägyptern und Persern.

I4 Es liegt eine Verwechslung vor. Mt 2,I erwähnt den König Herodes, nicht seinen Sohn, den Tetrarchen Herodes, der später in Galiläa herrschte (vgl. Lk 3,I). 
herrschte? Die anschließende Frage an Jesus bedarf keiner Antwort: „Warum bettelst so unwürdig, du, der Sohn Gottes, und ziehst gebeugt vor Angst elend landauf und landab herum?" (Cels. I,6I).

- Die Flucht nach Ägypten, um der Hand der Herodes zu entkommen (Mt 2,I3f), ist das Thema von zwei Fragmenten. Cels. I,66 bleibt dem Text des Evangelisten näher: „Aber ein Engel kam vom Himmel her und gebot dir und deinen Angehörigen zu fliehen, damit ihr, wenn ihr zurückbleibt, nicht sterben müsstet." Es ist verständlich, dass nicht Josef als Empfänger der Botschaft des Engels (vgl. Mt 2,13) erwähnt wird. Nach dem Ehebruch seiner Frau hat er Maria verstoßen (Cels. I,32), und vom wahren Vater Jesu sind nur der Name und der Beruf bekannt: ein Soldat namens Panthera. Konsequent wendet sich der Engel an Jesus

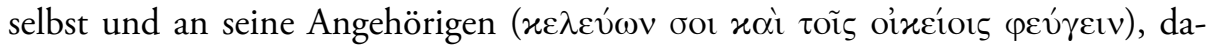
mit sie nach Ägypten fliehen. - Die Kritik betrifft in diesem Fall nicht Jesus, sondern Gott, dessen Sohn er angeblich ist. Denn der „große Gott“ ist offenbar nicht mächtig genug, um seinen eigenen Sohn zu schützen. Der Befehl des Engels, sie sollen nach Ägypten fliehen, um am Leben zu bleiben, zeigt die unbegreifliche Schwäche des christlichen Gottes. Wie in Cels. I,6I formuliert Kelsos seine Kritik durch die ironische Frage seines ,jüdischen Sprechers": „Konnte aber der große Gott, der deinetwegen schon zwei Engel ${ }^{15}$ geschickt hatte, dich, den eigenen Sohn, an Ort und Stelle nicht schützen?"

In Cels. I,28b erfährt der Bericht des Evangelisten eine ganz andere Deutung. Danach ging Jesus nach Ägypten „wegen der Armut“ ( $\left.\delta \grave{\iota} \alpha \varepsilon v v^{i} \alpha v\right)$, und dort ver-

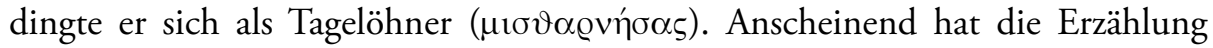
von der Flucht nach Ägypten auch diese Version hervorgebracht, die im Vergleich zur Fassung in Cels. I,66 stark „entmythologisiert“ wirkt. Die Notiz baut auf dem Kontrast zwischen der sozialen Wirklichkeit - ein Jude muss wegen der Armut nach Ägypten auswandert, und dort verdient er sein Brot als Tagelöhner und dem religiösen Vorgang, der sich unter diesen Umständen abspielt. Durch die Aneignung der magischen Kräfte der Ägypter, kehrt nämlich die gleiche Person, Jesus, in seine Heimat zurück, und erklärt sich öffentlich als Gott. Der angegebene Ort bildet den passenden Hintergrund für das Geschehen. Ägypten galt als das Land der Magie und Zauberei. Cels. I,68 beschreibt die Taten der „Schüler der Ägypter", die wunderbare Dinge versprechen und vollbringen. - Das Fragment Cels. I,28b bereitet ein Thema vor, das in I,68 ausführlicher behandelt wird, und die Charakterisierung der Gestalt Jesu als eines Zauberers bzw. Gauk-

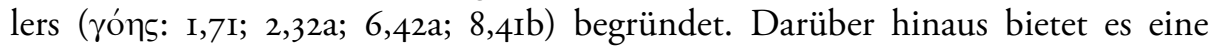
„psychologische“ Erklärung für die Wundererzählungen der Evangelien. Jesus erlernte seine Zauberkunst in Ägypten, und darauf gehen die scheinbaren Wunder

I5 Gemeint sind die zwei Engel nach Mt I,20; 2,I3. Kelsos kennt die Stellen. Vgl. Cels. 5,52b. 
zurück. Sie haben also keinen Wert als Beweis für das Wirken Gottes durch Jesus, seinen Sohn.

- Die Geschichte von der Taufe Jesu, bei der Jesus selbst als Erzähler erscheint (Cels. I,4I), entspricht in ihrem Grundbestand äußerlich der Fassung der Synoptiker. Es geht um Johannes, um einen aus der Luft herabfallenden Vogel und um eine Stimme vom Himmel, die Jesus als Sohn Gottes adoptiert. Beim genauen Zuschauen lassen sich die parodistischen Züge der Wiedergabe erkennen. In der Handlung kommt nicht $\beta \alpha \pi \tau^{\prime} \zeta \omega$ vor (Mk I,9; Mt 3,I3.I4.I6; Lk 3,2I), sondern $\lambda$ ov́ $\omega$, das zuerst „reinigen“, „baden“ bedeutet, wenngleich es im christlichen Sprachgebrauch oft als Metapher für die Taufe verwendet wird (Apg 22,I6; Justinus, I apol. 6I,IO; 65,I; 66,I). Für den Leser, dem diese Diktion fremd ist, schildert der Text eine Szene, bei der Jesus „bei Johannes badete“. Die tiefere Dimension der Taufe ist nicht unmittelbar erkennbar. - Auch die nächste Einzelheit enthält eine subtile Sinnverschiebung. Es ist von der „Erscheinung eines Vogels“

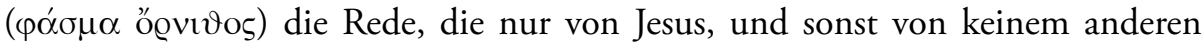
glaubwürdigen Zeuge gesehen wurde. Der Vogel fiel „aus der Luft herab“ (’ $\xi \xi$

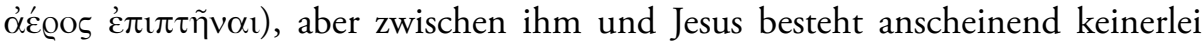
Kontakt. Die Synoptiker sprechen von dem Heiligen Geist, der „wie eine Taube“

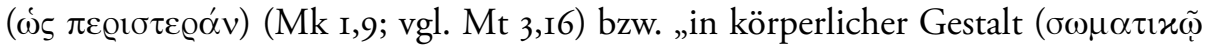

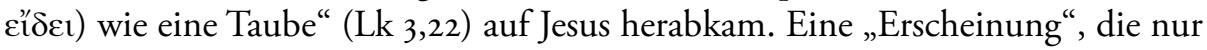
von dem gesehen wurde, der das Geschehen erzählt, bleibt im Rahmen einer subjektiven Wahrnehmung, deren Wahrheitsgehalt von der Glaubwürdigkeit dessen abhängt, der es bezeugt. Im Zusammenhang mit den bisherigen Aussagen über Jesus liegt auf der Hand, dass die „Erscheinung eines Vogels“ in den Bereich der Erfindung und der Phantasie gehört. -Beim Wort über die himmlische Stimme, die Jesus als Sohn Gottes adoptiert, besteht eine sachliche Entsprechung mit dem Bericht der Synoptiker (Mt 3,I7; Mk I,II; Lk 3,22), wenngleich die literarische Form eine andere ist. Aber auch in diesem Fall wird das Ereignis durch einen nicht zu beseitigenden Zweifel überschattet: Nur Jesus kann das bezeugen, und darüber hinaus nur einer von denen, die mit ihm bestraft worden sind $(\tau \tilde{\omega} v$ $\mu \varepsilon \tau \grave{\alpha} \sigma o \tilde{v} \varkappa \varepsilon \varkappa 0 \lambda \alpha \sigma \mu \varepsilon ́ v \omega v)$. Der abrupte Wechsel in der Zeitperspektive, der mit dem Hinweis auf das Ende Jesu und auf das Schicksal der Christen sichtbar wird - gegen Ende des zweiten Jahrhunderts war dies keine Zukunftsweissagung, sondern Bestandteil konkreter Erfahrung -, bringt Gewissheit über den nichtigen Wert der von Jesus erzählten Geschichte über seine Begegnung mit Johannes.

- Jesus und seine Jünger werden in zwei Fragmenten in ähnlicher Form kurz charakterisiert. Nach Cels I,62 sind es zehn oder elf Männer, nach 2,46 nur zehn, die Jesus nachfolgten. ${ }^{16}$ An beiden Stellen gelten sie beruflich als „Z̈̈llner und

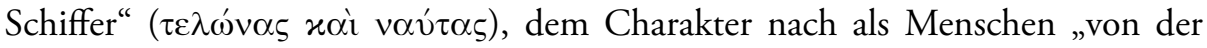




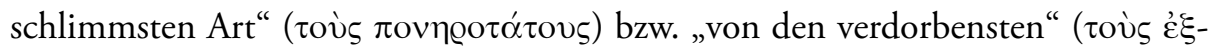
$\left.\omega \lambda \varepsilon \sigma \tau \tau^{\prime} \tau o \cup \varsigma\right)$. Dass die Jünger Jesu Zöllner waren, geht wahrscheinlich auf den Einfluss des Matthäusevangeliums zurück. Der Zöllner Levi, Sohn des Alphäus (Mk 2,I4), heißt nach Mt 9,9 Matthäus, und der Name kommt in der Liste der zwölf Apostel vor (Mk 3,I8; Mt IO,3; Lk 7,I5). Mk 2,I5 notiert, dass viele Zöllner und Sünder Jesus nachfolgten. Nirgends in den Evangelien werden die Jünger Jesu als "Schiffer" bezeichnet, aber in der Berufung der ersten Jünger wird auch ein $\pi \lambda$ oĩov erwähnt, das in diesem Zusammenhang „Boot“ bedeutet, das aber allgemein als „Schiff“ aufzufassen ist. Von hier aus könnte man erklären, dass neben den Zöllnern hier die "Schiffer" auftauchen. - Mit meisterlicher Prägnanz beschreibt Kelsos ferner das Leben der Jünger Jesu mit seinem Meister. Es sind

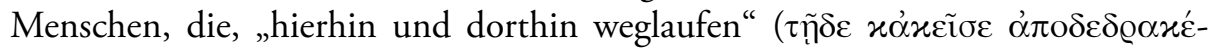
$v \propto$ l), als wären sie ständig auf der Flucht, während er „schmählig und kümmer-

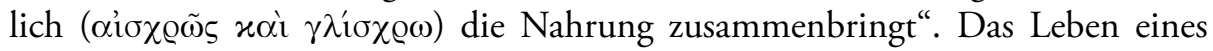
Wanderpredigers, der in Begleitung seiner Jünger, durch das Land umherzieht, und dabei bettelnd auf die Hilfe der Sympathisanten angewiesen ist, wird in wenigen, durch herabsetzende Distanz geprägten Zügen zusammengefasst.

- Dass die Wunder Jesu die in Ägypten bekannte und ausgeübte Praxis der Magie bzw. Zauberei fortsetzt, hat der Jude des Kelsos am Anfang seiner Aussagen über Jesus dargelegt (vgl. Cels. I,28b). Cels. I,68 betrachtet den gleichen Gegenstand aus einer anderen Perspektive. Hier erzählen die Jünger Jesu von seinen Wundern: Heilungen, Auferstehung und über eine Brotvermehrung, von der viele ernährt wurden, sodass viele Reste übrig geblieben sind. So weit die summarischen Angaben über die Wundertätigkeit Jesu, die inhaltlich grundsätzlich mit den Berichten der Evangelien übereinstimmt. In einem zweiten Schritt kommt die kritische Überlegung zum Ausdruck, um den Angaben jede Glaubwürdigkeit weg zu nehmen. Was Jesus getan hat, unterscheidet sich nicht von dem, was die „Schüler der Ägypter“ „auf den Märkten für wenig Geld“ vollbringen. Der Argumentation der Christen, die Wunder Jesu würden ihn als den Sohn Gottes beglaubigen, wird die Grundlage entzogen. Mit dem gleichen Recht müsste man auch die anderen, die ähnliches tun, für Söhne Gottes halten. Die offensichtliche Schlussfolgerung wird dem Leser überlassen.

I6 Die Angabe ist rätselhaft. Hängt Kelsos von einer apokryphen Quelle mit einer Fehlinformation ab? Es fällt auf, dass nirgendwo von den Zwölf die Rede ist. 


\section{I.2 Die „disputatio“ (2,I-79)}

Der Grund, weswegen Jesus angeklagt und verurteilt werden soll, ist der Betrug, durch den er einen Teil der Juden an sich zog, sodass sie sich vom Judentum trennten und an ihn glaubten (Cels. 2,I). Der Jude des Kelsos wendet sich nicht an Jesus, sondern an die Judenchristen, die diesen Schritt vollzogen haben, mit der Absicht, die Wahrheit über die Person offen darzulegen, die mit dem falschen Anspruch, als Gott aufzutreten, sie in die Irre geführt hat. Von diesem Anliegen her versteht es sich, dass in diesem Abschnitt die biographischen Motive zum Tragen kommen, die geeignet sind, als Anklage gegen Jesus vorgebracht zu werden, ohne die klassischen Themen der „vituperatio“ - Herkunft, Taten, Lebensführung - in den Vordergrund zu stellen.

- Der Verrat. Der Name Judas kommt nirgendwo vor, aber die Tatsache, dass Jesus verraten wurde, wird an mehreren Stellen erwähnt. Nach Cels. 2,9a wurde Je-

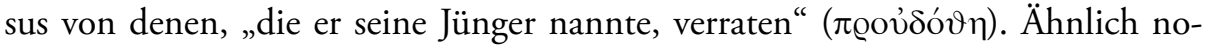
tiert Cels. 2,9b, dass er „von seinen Genossen, die persönlich alles mit ihm teilten

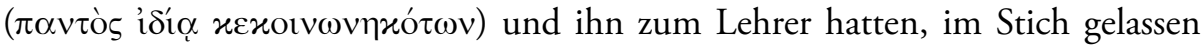
und ausgeliefert wurde“ ('่x $\delta^{\prime} \delta \sigma \sigma \vartheta \alpha \mathrm{l}$ ). In beiden Stellen soll der Verrat beweisen, dass Jesus unmöglich für Gott gehalten werden darf. Jesus erscheint als der Ahnungslose, der nicht weiß, wen er für seinen Jünger hält bzw. mit wem er das Ideal der Freundschaft - alles ist den Freunden gemeinsam - verwirklichen will. Ferner ist der Verrat nicht die Tat eines Einzelnen, sondern all seiner Jünger. Das Scheitern Jesu geht nicht auf die Ablehnung seitens der jüdischen Behörden zurück, sondern vollzieht sich zuerst in kläglicher Art im Kreis seiner Jünger. - Nur aus einer Stelle kann man schließen, dass Kelsos nicht unüberlegt oder aus mangelnder Information den Verrat so darstellt, sondern dass er die Fassung der Evangelien gekannt hat. Seinen Juden lässt er folgende Überlegung anstellen: „Wenn er schon vorausgesagt hat, wer ihn verraten ( $\tau$ òv $\pi \varrho o \delta \omega \sigma o v \tau \alpha)$ und wer ihn verleugnen wird ( $\tau$ òv $\alpha \varrho \vee \eta \sigma o ́ \mu \varepsilon v o v)$, wieso haben diese ihn nicht wie einen Gott gefürchtet, sodass der eine ihn dann gar nicht verraten und der andere ihn nicht verleugnet hätte? Aber sie haben ihn verraten und verleugnet, ohne sich um ihn zu kümmern" (Cels. 2,I8). Die Angaben sind differenzierter als in den zuvor zitierten Aussagen. Neben dem Verrat wird auch die Verleugnung genannt, und in beiden Fällen erscheint nur eine Person als Täter. In den Einzelheiten spiegelt sich die wie auch immer vermittelte Kenntnis der Evangelienüberlieferung wider, und zwar sowohl betreffend der Ankündigung als auch des Geschehens selbst. ${ }^{17}$

I7 Es ist anzunehmen, dass Kelsos auch die Namen der involvierten Personen gekannt hat. Für das argumentative Anliegen seines Juden waren sie aber irrelevant. Das dürfte das Schweigen über ihren Namen erklären. Zur Ankündigung des Verrats vgl. Mt 26,2I-23; Mk I4,I8-20; Lk 22,2I; Joh I3,26; zum Geschehen vgl. Mt 26,47-50; Mk I4,43-45; Lk 22,47f.; Joh I8,2f. Zur An- 
Beides, Verrat und Verleugnung, werden in Cels. 2,19b herangezogen, um die angebliche Voraussage Jesu über die Ereignisse als unmöglich zu erweisen. „Diese Dinge sind nicht so geschehen, weil sie vorausgesagt wurden - denn das war unmöglich -, sondern weil sie geschehen sind, darum wird die Voraussage als Lüge erwiesen. Es ist nämlich völlig unbegreiflich, dass die, welche das vorher gehört hatten, ihn dennoch verraten und verleugnen." - Aber auch im Fall, dass man das Vorauswissen Jesu, das seine Voraussagen begründet, für wahr hält und infolgedessen auch seine göttliche Würde annimmt, würde sich daraus eine schwerwiegende Folgerung unvermeidlich ergeben. Kelsos bezeichnet sie als „mehr als

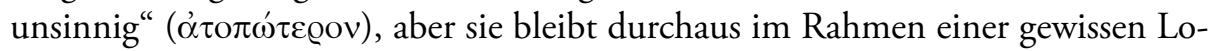
gik. Da die Voraussage eines Gottes auf jeden Fall in Erfüllung gehen muss, hat also Gott in der Gestalt Jesu ,seine Jünger und Propheten, mit denen er gemeinsam aß und trank, dazu irregeführt, sodass sie zu Gottlosen und Frevlern wurden“" (Cels. 2,20a). Gott selbst wäre schuldig am Verrat seiner Jünger, weil er sie durch sein das Schicksal der Menschen bestimmendes Wissen dazu geführt hat. In der Geschichte der Kirche hat sich immer wieder gezeigt, dass der Verrat des Judas untrennbar mit der Frage nach der menschlichen Freiheit und der Vorherbestimmung - Variationen über die Theodizeefrage - verbunden ist. Kelsos ist diese Dimension nicht entgangen, aber für ihn bedeutet dies keine Frage. So unsinnig wie der Gedanke, dass Gott seine Tischgenossen zum Bösen verführen könnte, ist die Vorstellung, Jesus sei mit Gott gleich zu setzen.

- Die Klage und die Bitte in der Stunde des Leidens. Nach der synoptischen Überlieferung hat Jesus in Getsemani zu seinem Vater gebetet, dass der Kelch des Leidens, falls möglich, an ihn vorübergehen möge (vgl. Mt 26,39; Mk I4,36; Lk 22,42). Kelsos kennt die matthäische Fassung, und zitiert daraus die Bitte: „O Vater, wenn es möglich wäre, dass dieser Kelch vorüberginge" (Cels. 2,24), als Teil einer Frage: „Warum also jammert er und klagt und bittet um das Vorbeigehen der Todesangst, indem er ungefähr so sagt ... " Die Frage ist durch die Überlegung in Cels. 2,23 motiviert: "Wenn all dies von ihm selbst beschlossen, und er, seinem Vater gehorsam, bestraft wurde, ist es klar - da er Gott war und es so gewollt hatte -, dass das, was ihm nach seinem Entschluss zugefügt wurde, weder schmerzlich noch leidvoll war." - Die Übernahme einer Christologie monarchianischer Prägung, die Jesus als Gott einfach hin betrachtet, lässt der scheinbare Widerspruch aufkommen, der in der gestellten Frage zutage tritt. Es ist richtig, dass Jesus gegenüber seinem Vater gehorsam war (vgl. Mt 26,39), aber als Gott war er der Herr seines Schicksals. Wenn er also bestraft werden sollte, dürfte dies „weder schmerzlich noch leidvoll“ sein. Daher weist die zitierte Bitte auf eine

kündigung der Verleugnung des Petrus vgl. Mt 26,33-35; Mk I4,29-3I; Lk 22,33f.; Joh I3,37f.; zum Geschehen vgl. Mt 26,69-75; Mk I4,66-72; Lk 22,5-62; Joh I8,25-27. 
gründliche Unstimmigkeit hin. Die Bitte hat erst einen Sinn, wenn Jesus nicht Gott war, und wenn er als einfacher Mensch um Befreiung von dem künftigen Leiden bittet. Im Sinne einer induktiven Rhetorik wird hier nur die Frage gestellt. Der anvisierte kluge Leser wird die richtige Antwort finden.

- Die Verspottung Jesu. Kelsos lässt sich durch seinen frei erfundenen Juden vertreten, aber er kümmert sich nicht immer darum, den Rahmen der literarischen Fiktion genau zu beachten. Die Fragmente in Cels. 2,33f. sind ein Beweis für diese Schwankungen. - Der Abschnitt schließt mit einer beschreibenden Bemerkung zur Verspottung Jesu ab: „Sie haben ihn verspottet, mit dem Purpurgewand bekleidet, den Kranz aus Dornen aufgesetzt und das Rohr in die Hand gegeben" (Cels. 2,34b). Der Text nimmt in freier Form Einzelheiten aus Mt 27,28f. wieder auf. Der Abschnitt ist Teil einer scharfen Gegenüberstellung, die den Kontrast zwischen der souveränen Haltung des Bakchos in der Stunde der Gefährdung und dem erbärmlichen Verhalten Jesu bei seiner Verspottung verdeutlichen soll. Damit offenbart Kelsos seine Vertrautheit mit dem Thema, das durch das Werk des Euripides zu einem Klassiker der griechischen Literatur geworden war. Die knappe Bezugnahme auf das Drama zeigt noch einmal, dass er sich an die Gebildeten in der Gesellschaft wendet, von denen er erwarten konnte, für sie würden die wenigen Hinweise ausreichen, um den Sinn seiner Kritik an die Gestalt Jesu zu erfassen. - In der Begegnung zwischen Bakchos und dem König Pentheus begegnen sich der göttliche und der menschliche Machtbereich. An sich sind sie nicht vergleichbar, aber einmal beide gegenüber gestellt, muss jeder von ihnen die eigene Stärke entfalten, um den Kontrahenten eindeutig seine Grenzen zu zeigen. Das tut ein echter Gott wie Bakchos. Als er vor dem König Pentheus gefesselt geführt wurde, lachte und ließ zu, dass man ihn abführte (Ba. 439). Die Überlegenheit des Bakchos rührt von seiner Verbindung mit der göttlichen Macht her. Kelsos zitiert das Wort: „Der Gott selbst wird mich erlösen, sobald

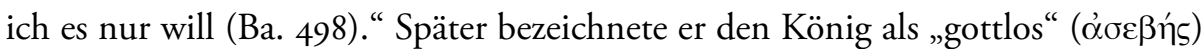
(Ba. 503), der seinerseits sich von ihm verachtet vorkam (Ba. 504). Der Frevel von Pentheus, der gewagt hatte, den Gott gefangen zu nehmen, wurde furchtbar bestraft, als er „verrückt geworden, zerrissen wurde“ (Cels. 2,34b; vgl. Ba. II4-II52). Ganz anders verhält es sich mit Jesus, der sich ohne jeden Widerstand verspotten ließ, und seine Peiniger in keinerlei Weise zur Rechenschaft zog. Er handelte nicht nach dem eigenen Willen, sondern überließ alles dem Willen seines Vaters (Mt 26,39), aber dieser hat ihn nicht geschützt und nicht gerettet. - Das klassische Erbe bietet das entscheidende Argument, um Klarheit im Hinblick auf die Gestalt Jesu zu schaffen. ${ }^{18}$

I8 Das wäre ein Beispiel für das Prinzip der „Privilegierung der eigenen Überlieferung“ in der Auslegung (s.u.). 
- Bemerkungen zum Umgang mit der Bibel in Cels. I-2: Wesentliche Aspekte der jüdischen Kritik an Jesus zeigen die Wirkung von Texten der Evangelien, die dadurch nicht der Verkündigung des christlichen Glaubens dienen, sondern das Material für dessen Widerlegung liefern. Wie der fiktive Jude sagt: „All dieses gegen euch ist euren Schriften entnommen, zu denen wir keinen weiteren Zeugen brauchen. Ihr widerlegt also euch selbst" $(2,74 a)$. Diese Einschätzung, die das ursprüngliche Ziel christlicher Verkündigung in ihr Gegenteil verkehrt, ergibt sich aus einem umfassenden interpretativen Verfahren, das auf verschiedenen Ebenen abläuft. Drei Elemente spielen dabei eine zentrale Rolle.

I. Die Evangelien sind von ihrer Entstehung her nicht glaubwürdig. Sie enthalten frei erfundene Geschichten (Cels. 2,26), sie sind Produkte der Phantasie der Jünger $(\mathrm{I}, 68 \mathrm{a})$, und sie wurden nach der ersten Fassung dreifach und vierfach und vielfach umgeprägt $(2,27)$. Eine streng historisch orientierte Hermeneutik vermag hier Wahrheit von Unwahrheit zu unterscheiden. Der jüdische Kritiker beansprucht für sich ein Wissen über die tatsächlichen Ereignisse, das bei diesem fragwürdigen Stand der Quellen den Weg zur Wahrheit öffnet: „Vieles und Wahres könnte ich über die Ereignisse um Jesus sagen, das mit den Aufzeichnungen der Jünger Jesu nicht übereinstimmen“ (Cels. 2,Iza). Die „Wahre Lehre“ des Kelsos offenbart auch die „wahre Geschichte“ Jesu.

2. Die historische Hermeneutik baut auf dem Verdacht gegenüber der gegenwärtigen Gestalt der Überlieferung bzw. des Textes auf. Als ein wirksames Mittel, um den Verdacht zu erhärten und dadurch die ursprüngliche Wahrheit von ihrer Hülle zu befreien, erweist sich eine „psychologisierende“ Annäherung an den Stoff, die zu einer ganz anderen Deutung führt, als es in der jetzigen Fassung der Fall ist. Wenn die Mutter Jesu eine Ehebrecherin war und von ihrem Mann verstoßen wurde, versteht sich, dass Jesus seine Geburt aus einer Jungfrau erdichtet hat (Cels. I, 28a). - Hinter den angeblichen Wundern Jesu, die ihn als Gott ausweisen sollen, verbirgt sich lediglich die von den Ägyptern praktizierte Magie, die er sich während seines Aufenthaltes in Ägypten angeeignet hatte (Cels. I,28b), und die auch von vielen anderen ausgeübt wird (Cels. I,68b). - Wenn die Jünger in den Evangelien aufschreiben, Jesus habe von seiner Verurteilung und von seinem Leiden im Voraus gewusst, tun sie das zur Entschuldigung dessen, was mit Jesus geschehen ist (Cels. 2,I6a). - Auch der Kern des christlichen Glaubens, die Auferstehung Jesu, wird einer solchen Interpretation unterzogen und damit völlig entwertet. „Als Bestrafter wurde er von allen gesehen, als Auferstandener nur von

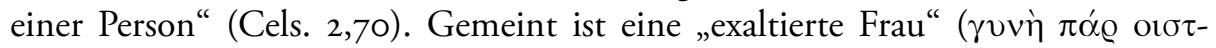
@os) - Maria Magdalene (vgl. Lk 8,2) -, „und vielleicht ein anderer von denen, die von der gleichen Zauberei abhängig sind, der entweder durch eine gewisse 
Veranlagung zu Träumereien neigt, und durch die eigene Absicht in seiner verirrten Einsicht sich dem Phantasieren hingibt" (Cels. 2,55b). Die Diagnose über die Verfassung der Zeugen der Auferstehung verweist den Auferstehungsglauben in den Bereich des krankhaften Imaginären, dem keine Wahrheit zugesprochen werden kann, es sei denn, dass man auch zu diesem Bereich gehört.

3. Auf ihre Art interpretieren auch die Christen die Angaben der Überlieferung. Aber diese „christliche Hermeneutik“ kann nicht auf dem Prüfstand der von Kelsos vertretenen kritisch-historischen Hermeneutik bestehen, die den Anspruch des christlichen Glaubens mit den historischen Gegebenheiten konfrontiert. Die feststellbaren Fakten entscheiden über die Wahrheit der Interpretation. Die Christen verkünden Jesus als den von den Propheten angekündigten Gottessohn (Cels. I,49-50.57), aber die Weissagung lässt sich ebenso auf tausend andere beziehen, die mit dem gleichen Anspruch aufgetreten sind (Cels. 2,28). Die Propheten haben das Kommen eines großen und mächtigen Herrn angekündigt, nicht einen „solchen Unglücklichen“ wie Jesus (Cels. 2,29). - Die Christen halten Jesus für den Sohn Gottes und für den Logos selbst (vgl. Joh I,If.). Der „reine und heilige Logos“ darf aber mit einem Menschen, „der auf die schändlichste Art abgeführt und ans Kreuz gebracht wurde“, nicht gleichgesetzt werden (Cels. 2,3Ia). - Es ist eine Frechheit, wenn die Verfasser des Stammbaums Jesu seine Herkunft „auf den ersten Menschen und auf die jüdischen Könige“ zurückführen. Die Begründung für dieses Urteil sieht die Dinge sehr realistisch: „Die Frau des Zimmermanns wäre nicht in Unkenntnis geblieben, wenn sie eine solche Abstammung gehabt hätte" (Cels. 2,32). - Die Behauptung, Jesus sei in die Unterwelt hinab gestiegen, „um die Leute dort zu überzeugen“ (vgl. I Petr 3,I9), erweist sich als unglaubwürdig durch die Tatsache, dass er die Menschen hier auf Erden nicht überzeugen konnte (Cels. 2,43). - Schließlich blieb Jesus nach dem Zeugnis der Evangelien eine Antwort schuldig in der entscheidenden Stunde seines Todes. „Wenn Jesus wirklich seine göttliche Macht offenbaren wollte, hätte er vor denen, die ihn verachteten, und vor dem, der ihn verurteilte und überhaupt vor allen Menschen erscheinen müssen" (Cels. 2,63). Die Verborgenheit des Auferstandenen (Cels. 2,73) stellt die Wirklichkeit der Auferstehung massiv in Frage.

\section{Biblische Zitate und Anspielungen in Cels. 3,I-5,65.}

Im zweiten Teil des Werkes verlässt Kelsos den Rahmen der Fiktion und tritt selbst in den Vordergrund, um Christen und Juden zu attackieren. Im Vergleich zum ersten Teil wird die Schrift nicht so oft herangezogen, wobei die Anspielungen auf das Alte Testament überwiegen. Dass beide Gruppen sich vom Logos und vom Nomos der klassischen Überlieferung entfernt haben, wird anhand von 
wenigen, aber gut ausgewählten Texten demonstriert. Jeder von ihnen bringt einen bestimmten Aspekt dieser Entfernung zum Ausdruck.

- Die Herkunft der Juden und ihre Wirkungsgeschichte. Kelsos kennt die wichtigsten Etappen der Geschichte Israels. Die Juden sind ägyptischer Herkunft. Sie dienten dort als Sklaven, aber sie lehnten sich gegen das Gemeinwesen der Ägypter auf, und sind geflohen. Danach „zogen sie nach Palästina, und sie wohnten im Land, das jetzt Judäa genannt wird“ (Cels. 3,5f.; vgl. 4,31a). Die summarischen Angaben entsprechen den Eckdaten der biblischen Überlieferung (Exodus, Josua). Daraus entwickelt Kelsos in wenigen Worten eine historische Betrachtung, die sowohl das Judentum als auch das Christentum charakterisiert und den eigenen Standpunkt gegenüber den beiden erkennen lässt. Das Stichwort dabei ist

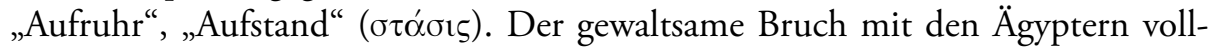
zog sich auf einer zweifachen Ebene: Die Juden lehnten sich gegen das Gemein-

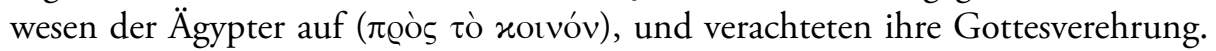
Das Ereignis blieb nicht isoliert im Hinblick auf das Judentum. Was die Juden den Ägyptern angetan haben, mussten sie später von den Anhängern Jesu erleiden, die sich ebenso gegen ihr Gemeinwesen auflehnten. Dass dazu auch der Bruch in der Frage der Gottesverehrung gehört, weiß der Leser aus dem ersten Teil des Werkes, in dem ein Jude dies zum Thema seiner Kritik an Jesus und an die Christen macht. Die Reihenfolge des Geschehens und die bleibende Ursache wird in der Aussage zusammengefasst: „Der Aufruhr ( $\sigma \tau \alpha \dot{\sigma}, \varsigma)$ ist damals die Ur-

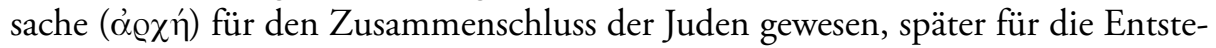

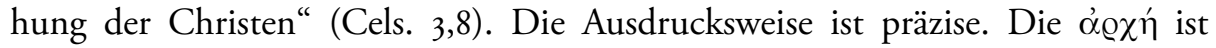
nicht nur der Anfang, sondern vor allem die Macht des Ursprungs, die für jeden weiteren Verlauf maßgebend bleibt, und darum nicht aufhören kann, immer neu

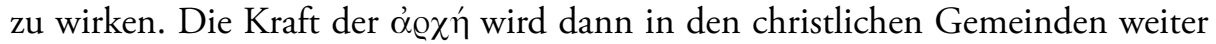
wirken, wie es sich in ihren ständigen Spaltungen und Streitigkeiten zeigt (Cels. 3,IO.I2; 5,6I-64). ${ }^{\text {19 }}$ - Diesem Überblick über Vergangenheit und Gegenwart liegt eine Interpretation der Geschichte zugrunde, die einem klaren Deutungsprinzip verpflichtet ist. Wahr und echt ist nur das, was in ungebrochener Kontinuität mit seinem Ursprung steht. Der Aufruhr zerstört diese Kontinuität und bringt eine Neuerung hervor, die nichts Positives beinhaltet, sondern vielmehr die Entfernung aus dem Ursprung markiert.

- Die Erschaffung des ersten Menschen und die Übertretung (Cels. 4,36a). Vor den Augen eines Gebildeten, der mit den verschiedenen Erzählungen von der Ent-

I9 Hierzu gehört das paulinische Zitat Gal 6,I4 in Cels. 5,64: „Für mich ist die Welt gekreuzigt und ich für die Welt“. Kelsos führt die Stelle an als Beleg für die schlimmen Streitigkeiten in kirchlichen Kreisen. Durch Irenäus, der den Text als Wort der Valentinianer aus der ptolemäischen Schule zitiert (haer. I,2,5), lässt sich die Angabe des Kelsos bestätigen. 
stehung des Menschen in der klassischen Tradition vertraut war, musste Gen 2-3 literarisch grob und mangelhaft erscheinen. Dementsprechend ist die Reaktion des Kelsos vor der Erzählung von einem Menschen, „der von den Händen Gottes gebildet von ihm auch angehaucht wurde, und von einer Frau, die aus seiner Seite gebildet wurde und von einer Schlange, die gegen diese wirkte und sich über die Gottesgebote überlegen zeigte" (vgl. Gen 2,7.21; 3,4-6). ${ }^{20}$ Seine Kritik beschränkt sich aber nicht auf die Ebene des ästhetischen, literarischen Empfindens. Richtig erkennt Kelsos, dass die Erzählung mit einem bestimmten Gottes-

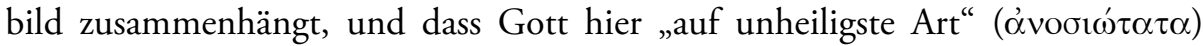
dargestellt wird. Er ist nämlich „von Anfang an schwach und unfähig, nicht einmal den einzigen Menschen, den er selbst gebildet hatte, zu überzeugen." - Der Vorwurf an die Adresse der biblischen Überlieferung betrifft die Art der Rede über Gott. Ein solcher Gott, der in der Welt wirkt und mit seinen eigenen Händen den Menschen bildet, würde im Widerspruch mit dem Recht und dem Anspruch des Göttlichen stehen, wenn er sich gegenüber seinem Geschöpf soweit ohnmächtig zeigt, dass es sich gegen ihn wenden kann. Darum muss diese Rede über Gott verurteilt und abgelehnt werden. Die Distanz zwischen dem biblischen Gottesbild und dem der griechischen Überlieferung lässt sich hier nicht überbrücken. Dass damit auch die Frage nach dem jeweiligen Menschenbild untrennbar verbunden ist, braucht nicht hervorgehoben zu werden.

- Die Übernahme und Verfälschung der klassischen Überlieferung (Cels. 4,2I). Möglicherweise hat Origenes die Aussagen des Kelsos in diesem Abschnitt verkürzt, aber auch in der vorliegenden Form ist der ursprüngliche Sinn erkennbar. Es handelt sich um kurze Anspielungen auf die Erzählungen von der Sintflut (Gen 6-8) ${ }^{21}$, vom Turmbau zu Babel (Gen II) und von der Vernichtung von Sodom und Gomorra (Gen I8-I9). Nach einem in Cels. 4,20 zitierten Wort der Juden geschah die erste Sintflut zur Bestrafung der Ungerechten. Nach Cels. 4,2I bewirkte die Sintflut die Reinigung der Erde. Das gleiche Ziel verfolgte die Zerstörung des Turms. Sodom und Gomorra wurden schließlich wegen der Sünde durch das Feuer vernichtet. - Die drei Geschichten von Zerstörung werden erwähnt, weil sie alle die mangelnde Originalität der biblischen Überlieferung bezeugen, die das Überkommene nicht einmal richtig weitergibt, sondern verfälscht. Die griechische Überlieferung weiß darüber Bescheid: „Weltbrände und viele Überflutungen hat es seit aller Zeit gegeben, und jüngst die Überschwem-

20 Auch Cels. 6,49 berichtet über das Geschehen: „Das von Gott gepflanzte Paradies und das erste Leben des Menschen darin und das, was aus dem Umstand geworden ist, als er wegen der Sünde daraus vertrieben wurde und gegenüber dem Paradies der Wonne wohnte."

2I Cels. 4,4I ergänzt die Angaben: „Es geht ferner um eine Sintflut und eine eigenartige Arche, die alles drinnen hatte, und um eine Taube und eine Krähe als Boten, mit denen sie die Geschichte von Deukalion umbilden und leichtsinnig behandeln." 
mung unter Deukalion, der Weltbrand unter Phaëthon “22 (Cels. I,I9). Mose hat diese Lehre „bei weisen Völkern und berühmten Männern gehört“ und übernommen (Cels. I,2Ia), aber offenbar nicht alles richtig verstanden. Die Geschichte vom Turm ist eine verfälschte Variation über die Geschichte von den Söhnen des Aloeus. Der Leser wird wissen, dass sie, bei ihrem Versuch in den Himmel zu steigen, von Apollon vernichtet wurden (vgl. Homer, Od. II,305-320). Ähnlich verhält es sich mit der Geschichte von Sodom und Gomorra, welche die Geschichte von Phaëthon, dem Sohn des Helios ${ }^{23}$, entstellt. ${ }^{24}$

- Der beschämende Inhalt der Patriarchengeschichte (Cels. 4,43-47). Leider hat Origenes wenig von den Aussagen des Kelsos zur Geschichte der Patriarchen überliefert. Nur isolierte Wendungen weisen auf Episoden dieser bewegten Geschichte hin $^{25}$, auch wenn nicht immer deutlich wird, was eigentlich gemeint ist. In Cels. 2,43: „... eine ganz unsinnige und unzeitige Kinderzeugung“, geht es um Abraham und Sarah (Gen 2I,I-7). Was nachher folgt: „... die Nachstellungen der Brüder ... die Trauer des Vaters ... Hinterlist der Mütter ... der Unsinn: Gott lebte mit allen diesen in der innigsten Beziehung zusammen", bezieht sich auf mehrere Einzelheiten: der Konflikt zwischen Jakob und Esau (Gen 27,34-45), die Trauer Jakobs bei der Nachricht vom Tod des Josef (Gen 37,34f.), wahrscheinlich die Rolle der Rebekka in Gen 27,5-17. Die abschließende Bemerkung über die enge Beziehung Gottes zu diesen Menschen zeigt noch einmal, dass Kelsos den theologischen Sinn der Patriarchengeschichte richtig verstanden hat, und darum ihn nicht für sinnvoll halten konnte. Gott offenbart sich in der Verborgenheit der durchaus „weltlichen“ Geschichte der Patriarchen - wahrlich menschlich all$\mathrm{zu}$ menschlich -, indem er in den verschlungenen Wegen des Weltgeschehens sein Volk führt und das Geschick der Menschen leitet.

22 Die Quelle ist Plato, Ti. 22a-d.

23 Vgl. Plato, Ti. 22c-d: Phaëthon verbrannte alles, was auf der Erde war, weil er auf dem Sonnenwagen die Bahn seines Vaters, Helios, nicht einhalten konnte, und von einem Blitz getroffen den Tod fand. Plato erklärt den Mythos durch eine astronomische Überlegung: In großen zeitlichen Abständen werden die Dinge auf Erde durch Feuer vernichtet.

24 Nicht nur die drei Geschichten offenbaren das Missverständnis der klassischen Überlieferung. Auch die jüdische und christliche Lehre von der Bestrafung der Sünder durch göttliches Feuer geht auf das gleiche Missverständnis zurück (vgl. Cels. 4,II.2O).

25 Nur im Abschnitt über Josef überliefert Origenes eine größere Texteinheit: „Den Brüdern, die ihn verkauft hatten, erwies sich der Verkaufte bei der Wiedererkennung gütig - unsinnige Wiedererkennung -, als sie unter Hungersnot leidend mit den Eseln gesandt waren, um Handel zu treiben. Der als Knecht Verkaufte und jetzt Befreite kehrte in feierlichem Zug zum Grab seines Vaters zurück" (Cels. 4,47a). Der Text begründet die Annahme, dass Kelsos die Patriarchengeschichte gut kannte, und dass die Bruchteile des überlieferten Textes auf die Kürzungen des Origenes zurückgehen. 
- Bemerkungen zum Umgang mit der Bibel in Cels. 3-5: Die Stellen des „Alethes Logos“, die im zweiten Teil einen Bezug zur Bibel erkennen lassen, sind nicht viel. Die kritische Rezeption betrifft weder Jesus noch das Christentum, sondern das Judentum in seiner Herkunft, Geschichte und Überlieferung. Auch in diesem Abschnitt beruht die Interpretation der biblischen Themen auf einigen Grundpfeilern.

I. Die Trennung der Juden von den Ägyptern, der die Trennung der Christen von den Juden folgt, sind historische Fakten, deren echte Tragweite erst dann erkannt wird, wenn man sie mit dem festen Prinzip von der notwendigen Kontinuität mit dem Ursprung konfrontiert. Jeder Bruch mit dieser Kontinuität ist ein Verstoß gegen die Ordnung der Dinge, die zwei schwerwiegende Folgen hat: Zum einem geht dadurch der Zugang zur Überlieferung der „wahren Lehre“ der „weisen Männer und Völker“ verloren, wie die vielen Missverständnisse der alten Tradition bei Juden und Christen reichlich belegen. Zum anderen entsteht durch diesen Bruch eine fremde gesellschaftliche Größe (Cels. 8,I7), die sich mit den anderen Völkern, welche die Kontinuität mit dem Ursprung bewahrt haben, nicht vertragen wird. Den Juden ist nicht einmal eine Scholle noch eine Feuerstätte geblieben, die Christen irren heimlich herum, sie werden gesucht und zum

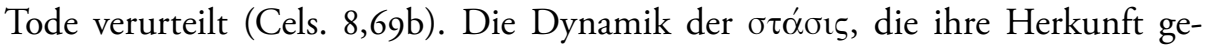
prägt und ihre Geschichte weiterhin bestimmt hat, verhindert gesellschaftliche Integration: „Das ist die Stimme des Aufruhrs von denen, die sich von den anderen Menschen abgrenzen und trennen" (Cels. 8,2a). Gerade die Christen, auf die sich die Polemik des Kelsos vornehmlich richtet, stellen durch den ausschließenden Charakter ihres Monotheismus eine akute Gefährdung der antiken Gesellschaft dar. Die von ihnen verkündete und verteidigte Exklusivität in ihrer Gottesverehrung würde Aufruhr im himmlischen Bereich stiften (Cels. 8,II.I5b). Auf dem irdischen Bereich würde dies das Ende des Römischen Reiches, des Trägers der antiken Kultur, bedeuten (Cels. 8,68-69.7I).

2. Die dezidierte Behauptung: „Den Menschen hat Gott nicht nach seinem Abbild gemacht" (Cels. 6,63), weist darauf hin, dass Kelsos auch die Stelle Gen I,27 gekannt hat. ${ }^{26}$ Wenn er sich dann in Cels. 4,36a mit der volkstümlichen Version von Gen 2,7 beschäftigt, dann weil diese polemisch leichter angreifbar war als die „erhabene“ Diktion in Gen I. ${ }^{27}$ Einleitend zum zitierten Abschnitt Cels.

26 Es ist nicht das einzige Indiz. In Cels. 6,6oa kritisiert Kelsos die Erschaffung der Welt in einigen Tagen, bevor es überhaupt Tage gab. In Cels. 6,6ob-6I macht er sich darüber lustig, dass Gott jeden Tag nur etwas durch seine Schöpfung anfertigt, und dass er zum Schluss Ruhe zur Erholung braucht. Die Christen der Großkirche glauben, „dass die von den Juden vorgetragene Lehre von der Erschaffung der Welt, von den sechs Tagen und von dem siebten Tag, an dem Gott ruhte, wahr ist" (Cels. 5,59). 
4,36b schreibt Kelsos: „Die Juden, in irgendeinem Winkel Palästinas zusammengeduckt, in jeder Hinsicht ungebildet und ohne vorher gehört zu haben, dass diese Dinge längst von Hesiod und tausend anderen gottbegeisterten Männer besungen wurden, haben auf unglaublichste und unfeinste Art die Erzählung von einem Menschen zusammengestellt ..." Unmittelbar zuvor spricht er von den Völkern, die ein hohes Alter für sich beanspruchen, wie die Athener, Ägypter, Arkader und Phrygier. Sie erzählen, „dass einige Erdgeborene bei ihnen entstanden sind, und sie bringen im Einzelnen die Beweise dafür" (Cels. 4,36a). - Die Selbstverständlichkeit, mit der die mythischen Legenden von den Erdgeborenen erwähnt werden, macht deutlich, dass die Kritik an die biblische Erzählung letztlich nicht in der Materialität der ganzen Szene begründet ist. Um die Sache mit anderen Worten auszudrücken: Die „wahre Lehre“ des Kelsos ist nicht die Lehre der reinen Vernunft, frei von Mythen und Legenden. Glaubwürdig sind aber die Mythen und Legenden, die in der „wahren Lehre“ der weisen Männer und Völker überliefert wurden. Und dazu zählen die jüdischen und christlichen Mythen und Legenden nicht. Über die biblische Erzählung von der Entstehung der Menschheit fällt das Urteil dementsprechend negativ: „In unverschämter Weise haben sie versucht, ihren Stammbaum vom ersten Geschlecht der Gaukler und Betrüger herzuleiten" (Cels. 4,33). Somit kommt ein weiteres Prinzip der Hermeneutik des Kelsos zum Tragen: Wahr sind die Mythen und Legenden der eigenen Überlieferung, die darin enthalten und tradiert wurden. ${ }^{28}$ Diese Privilegierung der Überlieferung hängt mit der eigenen kulturellen Identität zusammen, die in der Überlieferung ihren Bestand hat, zu der aber auch ein bestimmtes Gottesbild gehört. Die "Schwäche“ Gottes in Gen 3, die sich in seinem Unvermögen zeigt, den Menschen derart zu überzeugen, dass er das Gebot nicht übertritt, ist die „notwendige“ Schwäche, welche die Freiheit der Kreatur gegenüber seinem Schöpfer ermöglicht. Von Sünde kann nur sinnvoll die Rede sein, wenn die menschliche Entscheidung gegen Gott sich im Rahmen einer endlichen Freiheit vollzieht. Die reine Notwendigkeit oder der blinde Beschluss der Gottheit würden das Spiel der Freiheit nicht aufkommen lassen. - Wenn Kelsos diese Rede von Gott entschieden zurückweist, urteilt er im Sinne der klassischen Überlieferung.

27 Überschwänglich äußert sich Philo dazu: „Die Schönheit der Gedanken dieser Weltschöpfung vermöchte kein Dichter und kein Schriftsteller würdig zu preisen: Denn sie gehen über das Sprach- und Gehörvermögen hinaus und sind zu groß und zu erhaben, als dass sie mit den Organen eines Sterblichen erfasst werden könnte" (Op. 4).

28 Cels. 6,50 hebt den Unterschied hervor: „Einige der schon erwähnten altehrwürdigen Gestalten haben verschiedene Berichte über die Entstehung der Welt und der Menschen verfasst. Auch Mose und die Propheten haben Bücher hinterlassen, aber da sie nicht wussten, was immer die

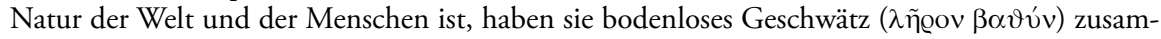
mengestellt." 
3. Die Privilegierung der eigenen Überlieferung macht sich in den folgenden Abschnitten - die Sintflut, der Turmbau, die Zerstörung von Sodom und Gomorra - besonders bemerkbar. Weil nur diese Überlieferung kanonischen Wert besitzt, ist jede andere Tradition, die ein ähnliches Motiv enthält, nur eine untaugliche, degradierte Verfälschung des Originals. Nachahmung bedeutet in diesem Fall zugleich Un- und Missverständnis des Ursprünglichen. Das „Vorrecht“ der eigenen Überlieferung - das ist das Privileg - braucht keine nähere Begründung. - Vergleicht man den Inhalt der Patriarchengeschichte mit den vielen Geschichten der griechischen Götter, die hier auf Erden wirkten, würde die erste ohne weiteres unter der Kategorie des Harmlosen ihren Platz finden. Kelsos kennt die griechische Mythologie und bezieht sich bedenkenlos auf einige ihrer Gestalten. Im Zusammenhang mit der Jungfrauengeburt stehen die Namen von Danae, Melanippe, Auge und Antiope (Cels. I,37). Wahrscheinlich wurden sie dort zitiert, um zu zeigen, dass die von Jesus erdichtete Geschichte von seiner Geburt aus einer Jungfrau von dem alten, mit den vier Frauennamen verbundenen Motiv abhängt. Ihre Verbindungen mit göttlichen Gestalten sind alles andere als erbaulich, aber dies steht nicht zur Diskussion. Lukian von Samosata wird solche Geschichten in seinen Dialogen stilisierend aufnehmen, um sein Publikum zu unterhalten und sich über die traditionelle Religiosität lustig zu machen. Kelsos nimmt sie auf den ersten Blick ernst, aber wahrscheinlich nicht ganz wörtlich. Auf jeden Fall wäre er imstande, die alten Erzählungen allegorisch zu deuten, wie er es in Cels. 6,42 anhand der Überlieferung über den Streit zwischen Hera und Zeus tut. Mit der Patriarchengeschichte verhielt es sich freilich anders. Wenige Generationen vor ihm hatte ein anderer Alexandriner, der Jude Philo, aus diesen Erzählungen, ebenfalls durch die Kunst der Allegorie, einen reichen Sinn gefördert. Für Kelsos wäre ein solches Vorgehen indes nicht möglich. Die Patriarchengeschichte war nämlich eine fremde Überlieferung, kein Bestandteil des Kanonischen.

\section{Biblische Zitate und Anspielungen in Cels. 6,I-8,75.}

Es versteht sich, dass im dritten Teil des Werkes, in dem Kelsos die „wahre Lehre" darstellt, die Schrift kaum gebraucht wird. Im Unterschied zum zweiten Teil überwiegen Worte aus dem Neuen Testament, die oft sehr nah am biblischen Text zitiert werden.

- Die Weisheit dieser Welt (Cels. 6,I2a). Im Abschnitt Cels. 6,I-2I legt Kelsos wesentliche Inhalte der Lehre Platos dar. Die dort angeführten Missverständnisse der Christen dienen, einerseits, zum Erweis der defizitären Bildung der Christen, anderseits zur Verdeutlichung der „wahren Lehre“ - Kelsos zitiert als Meinung 
der Christen: „Die Weisheit unter den Menschen ist eine Torheit bei Gott“ ( $\tau \eta \nu$

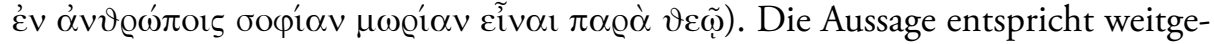
hend dem paulinischen Wort in I Kor 3,19: „Denn die Weisheit der Welt ist eine

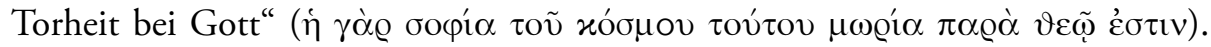
Nach Kelsos gehört dieses Wort in die Strategie der Christen, um Anhänger unter den Ungebildeten und Toren zu gewinnen. ${ }^{29}$ Darüber hinaus wurde es aus der griechischen Tradition übernommen, die vom Unterschied zwischen der menschlichen und der göttlichen Weisheit gewusst hat. Das Missverständnis der Überlieferung besteht darin, dass die Griechen die Erhabenheit der göttlichen Weisheit haben, während die Christen "die Lehren von der göttlichen Weisheit den Ungebildetsten oder Sklaven oder Unwissendsten darlegen“ (Cels. 6,13).

- Das Wort Jesu gegen die Reichen (Cels. 6,16). Mit kleinen formalen Änderungen zitiert Kelsos das Wort Jesu in Mt 19,24 wörtlich: „Es ist leichter, dass ein Kamel durch ein Nadelöhr geht, als dass ein Reicher in das Reich Gottes eingeht." Es handelt sich in diesem Fall um die Verfälschung einer Aussage Platos: „Dass einer, der überragend gut ist, auch hervorragend reich sei, ist unmöglich" (Lg. 743a). Der radikale Ton des Wortes Jesu wird mit dem Prinzip der Mäßigkeit der griechischen Ethik konfrontiert, und dadurch als eine Verfälschung eingestuft.

- Der Mensch als Abbild Gottes (Cels. 6,63). Unter klarer Bezugnahme auf Gen I,27 hält Kelsos dem biblischen Wort entgegen: „Den Menschen hat Gott nicht

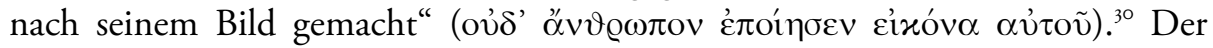
Abschnitt Cels. 6,62-65, zu dem die zitierte Aussage gehört, stellt die ,via negationis" dar, die alles im Bereich der menschlichen Erfahrung Wahrnehmbare negiert, wenn es darum geht, zur Erkenntnis Gottes zu gelangen: „Gott hat weder Mund noch Stimme. Gott hat auch nichts von dem, was wir kennen" (Cels. 6,62). ". „Aus Gott ist alles entstanden, aber Gott hat keinen Ursprung. Er ist auch nicht durch das Wort zu erreichen, da er keinen Namen hat" $(6,65) .^{32}$ In diesem Rahmen bleibt kein Raum mehr für die Sprache des Bildes und der Metapher.

29 Das Thema kam schon in der Einleitung vor; vgl. Anm. 7.

30 Philo differenziert: „Diese Ähnlichkeit darf man aber nicht in der Eigentümlichkeit des Körpers vermuten; denn weder hat Gott menschliche Gestalt noch ist der menschliche Körper gottähnlich“ (Op. 69).

3I Vgl. Philo, Conf. 98: „Dabei braucht er weder Füße noch Hände noch irgendwelchen anderen Teil der Erschaffenen."

32 Vgl. Philo, Abr. 5I: „Denn Gott bedarf keines Namens.“ Ähnlich Justinus, I apol. IO,I: „Er kann von keinem Namen genannte werden“; I apol. 6I,I: „Denn niemand vermag, dem unaussprechlichen Gott einen Namen zu geben“; 2 apol. 5,I: „Der Vater des Alls hat, weil ungezeugt, keinen ihm beigelegten Namen." 
- Die Unstimmigkeiten in der Botschaft des Mose und in der Verkündigung Jesu (Cels. 7,18). Dem aufmerksamen Leser der Bibel - und Kelsos war einer von ihnen - entgehen manche Eigentümlichkeiten der Botschaft Jesu nicht, die in unübersehbarem Gegensatz zum Alten Testament stehen, zumal er selbst - in der Fassung des Matthäusevangeliums - diesen Unterschied betont: „Ihr habt gehört, dass zu den Alten gesagt worden ist ... Ich aber sage euch ..." (Mt 5,21.27.33.38. 43). Die Anspielungen auf die Schrift befinden sich im Zusammenhang mit der Polemik gegen die biblischen Weissagungen, um den Wert der antiken Orakel hervorzuheben (Cels. 7,2-I8). Neben diesem polemischen Ziel gibt es ein anderes, das durch eine Streitfrage unter den Christen nahe gelegt wurde: die Lehre Markions vom bösen Schöpfer Gott und vom guten Erlöser Gott. In Cels. 7,I8 spiegelt sich die Auseinandersetzung wider: „Wenn die Propheten des Gottes der Juden vorhergesagt haben, dieser wird der Sohn von jenem sein, wieso ordnet jener durch Mose an, dass sie reich und stark sein sollen, und die Erde erfüllen und die Gegner umbringen, die Jugendlichen und jegliches Geschlecht töten, was auch er selbst vor den Augen der Juden, wie Mose sagt, tut, und dazu noch, wenn sie nicht gehorchen, ausdrücklich androht, ihnen das gleiche wie den Gegnern anzutun?" Im Gegensatz dazu verordnet Jesus, „dass der Reiche oder der Herrschsüchtige oder wer Weisheit oder Ruhm beansprucht, keinen Zugang zum Vater haben soll. Man solle sich um Nahrung und Vorratskammer nicht mehr kümmern, als die Raben es tun, und um die Kleider noch weniger als die Lilien. Dem, der einmal geschlagen hat, soll man sich zu einem anderen Schlag anbieten." - Das zitierte Wort des Mose gibt keine alttestamentliche Stelle wieder, wohl aber die konkrete Ausrichtung der Verheißungen Gottes. Das Wort Jesu vom "Zugang zum Vater" spielt auf das Wort gegen die Reichen an, das in Cels. 6,16 zitiert wurde (s.o.). Die zweifache Aufforderung zum Vertrauen in der Vorsehung steht der lukanischen Fassung (vgl. Lk 12,24 und 12,26) näher als der matthäischen (vgl. Mt 6,28 und 6,29). ${ }^{33}$ Auch beim Wort zum Verzicht auf Vergeltung ist dies der Fall (vgl. Lk 6,29). ${ }^{34}$

- Derselbe Mensch kann nicht mehreren Herren dienen (Cels. 7,68). Das Wort in Mt 6,24; Lk I6,13, das fast wörtlich aus der Logienquelle übernommen wurde, war auf die Unmöglichkeit bezogen, Gott und dem Geld zugleich zu dienen. Kelsos erwähnt es als Aussage eines Christen als Beweis für das unsinnige Festhalten der Gläubigen am Monotheismus.

33 Die Forschung hat oft die Meinung vertreten, Kelsos würde in diesem Abschnitt eine markionitische Quelle wiedergeben. Die Verwendung des Lukasevangeliums stützt die Annahme.

34 Die Stelle wird wörtlicher in Cels. 7,58a zitiert: „Und wenn einer dich auf die eine Backe schlägt, halte die andere hin." 
- Bemerkungen zum Umgang mit der Bibel in Cels. 6-8: Kelsos betrachtet sich mit seiner „Wahre Lehre" als Träger der klassischen Überlieferung, aber er beabsichtigt nicht, ein enzyklopädisches Wissen mit der Lehre der alten Völker zu erfassen und zu vereinheitlichen, sondern er orientiert sich an der ,platonischen Lehre" als unerlässlich inhaltliche Referenz, so wie sie im zweiten Jahrhundert allgemein verstanden wurde. ${ }^{35}$ Die Anspielungen auf die Schrift in diesem Abschnitt sind daher auf diesem Hintergrund zu verstehen.

I. Dass Plato den Maßstab der Interpretation der biblischen Worte bestimmt, wird im Zitat über die Weisheit der Menschen, die bei Gott eine Torheit ist, besonders deutlich. Die Ablehnung dieser Einsicht geht auf den platonischen Gedanken zurück, dass das Erste Gute "auf keinen Fall aussagbar" ist (Ep. 7,34Ic), der in Cels. 6,3 wörtlich zitiert wird. Die platonische Haltung vor der letzten Wahrheit der Dinge unterscheidet sich von der der Christen, die „auf sofortigem Glauben bestehen" (Cels. 6,7a), statt „den lang währenden Umgang" mit dem Unaussagbaren (Ep. 7,34IC) zu pflegen, aus dem allein echte Erkenntnis hervorgeht. Auch der Unterschied zwischen dem erbärmlichen Wert der menschlichen Weisheit im Vergleich zur göttlichen Weisheit ist nicht neu. Das in Cels. 6,I2b zitierte Wort des Heraklit belegt das: „Denn menschliches Wesen hat keine Erkenntnisse, wohl aber göttliches“ (Fr. 78). Die bekannte Zurückhaltung des Sokrates hinsichtlich tieferer Erkenntnis bestätigt die Verankerung dieser Idee in der Tradition der griechischen Philosophie. Im beinahe grotesken Kontrast dazu

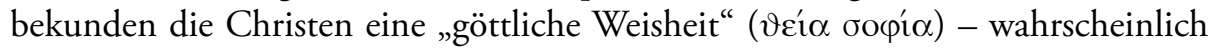

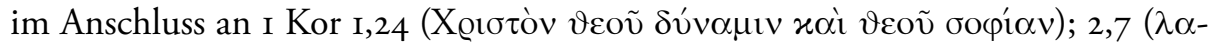

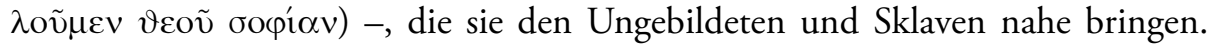
Nach der Kritik im ersten und im zweiten Teil des Werkes braucht man keine weitere Erläuterung über die Qualität der „göttlichen Weisheit“ der Christen. Eine ähnliche Gegenüberstellung eines christlichen Wortes mit einem Zitat aus dem Werk Platos liegt in der zweiten zitierten Stelle (gegen die Reichen). ${ }^{36}$ In beiden Fällen verkörpert die Lehre Platos die kanonische Überlieferung, die der Beurteilung über die christliche Botschaft die letzte, nicht mehr hinterfragbare Gewissheit verleiht. Kelsos hat schon vorher über andere Themen von Juden und Christen ähnlich geurteilt. Er nimmt hier expliziten Bezug auf Plato im Einklang mit der positiven Zielsetzung des dritten Teiles des „Alethes Logos“, den Logos und den Nomos der griechischen Überlieferung darzustellen.

35 Der so genannte „Mittelplatonismus“ ist kein einheitliches Phänomen. Die Autoren, die dazu gerechnet werden, zeigen beachtliche Unterschiede untereinander. $\mathrm{Zu}$ einem Überblick vgl. Dillon 1977.

36 Ein weiteres Beispiel für die gleiche Art der Darstellung bietet Cels. 7,58a-b. Dem Wort Jesu: „Und wenn einer dich auf die eine Backe schlägt, halte die andere hin“ (Lk 6,29), wird das Gespräch des Sokrates mit Kriton nach Cri. 49b-c gegenübergestellt. 
2. Gerade in der Frage nach Gott bekennt sich Kelsos offen zu Plato als dem noch „tüchtigeren Lehrer“ im Vergleich zu den vielen gottbegeisterten Dichtern, Weisen und Philosophen (Cels. 7,4I-2). Auf ihn führt er die im Mittelplatonismus verbreitete Lehre von den drei Wegen zur Erkenntnis Gottes zurück ${ }^{37}$ : die via eminentiae, die via abstractionis bzw. negationis und die via analogiae. Im Namen der „via negationis“ war eine Aussage wie die von der Erschaffung des Menschen nach dem Abbild Gottes (Gen I,27) leicht abzulehnen. - Die philosophische Rede über die verschiedenen Wege, die zur Erkenntnis des unaussprechlichen Jenen führen, „der jenseits von allem ist“ (Cels. 7,45a), wollte und konnte die Sprache des Mythos nicht ersetzen, die in vielen Geschichten etwas von der Erfahrung des Göttlichen mitzuteilen versuchte. Kelsos selbst ist ein Beispiel für das problemlose Ineinander der zwei Sprachebenen in der Rede von Gott. Aber wenn es darum geht, gegen Aussagen der Bibel Stellung zu nehmen, tut er das aus der Ebene der philosophischen Sprache heraus. Darum zitiert als christliche Behauptung die Aussage: „Gott hat Anteil an Gestalt oder Farbe, Anteil an Bewegung, Anteil an einer Seinsweise“ (Cels. 6,64), um zugleich die Jenseitigkeit des Ersten Gutes zu betonen. - Das von Philo repräsentierte alexandrinische Judentum und die christlichen Autoren des zweiten Jahrhunderts, die zum ersten Mal versuchten, ihren Glauben mit den Mitteln der griechischen Philosophie darzulegen, zeigen die andere Seite in dieser geistigen Auseinandersetzung. Wie bei den zitierten Stellen Philos sichtbar wird, ${ }^{38}$ haben nicht alle Juden die Schrift wörtlich ausgelegt. Sofern die philosophischen Denkvoraussetzungen gleich waren, haben sie solche Stellen wie Gen I,27 ähnlich ausgelegt wie ihre Gegner. Die christliche alexandrinische Schule geht auf dem gleichen Weg. So wie Kelsos diese Seite des Problems ignoriert, werden auch die christlichen Apologeten ignorieren, als sie immer wieder gegen die grobe Materialität der Götterbilder polemisierten ${ }^{39}$, dass die griechische Philosophie eine andere Rede von Gott pflegte, von der sie selbst unendlich viel profitiert hatten. Die Privilegierung der eigenen Überlieferung kann zu Einseitigkeiten führen.

3. Über den Streit zwischen den Christen der Großkirche und den Markioniten ist Kelsos gut informiert. Er nimmt davon reichlich Kenntnis (vgl. Cels. 5,54.

Vgl. Alkinoos, Didask. I0,5; Maximos von Tyros, Diss. II,9.

Vgl. Anm. 30 und $3 \mathrm{I}$.

In der Frage der Götterbilder vertritt Kelsos eine aufgeklärte Haltung, und bezeichnet die christliche Kritik als eine „lächerliche Weisheit“. Nur ein ganz „kindischer Mensch“ könnte die Götterbilder „,für Götter halten und nicht für Weihgeschenke und Statuen von Göttern“ (Cels. 7,62b). In seiner Erwiderung verwendet er Gen I,27 als Argument gegen die Christen: Wenn diese die Götterbilder ablehnen, „weil keine göttliche Abbildung angenommen werden soll, da Gott eine andere Gestalt hat ..., dann merken sie selbst nicht, dass sie sich widersprechen,

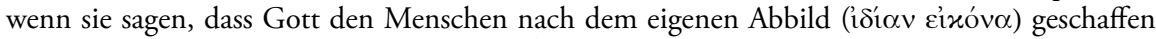

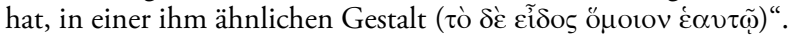


59.62; 6,27-29.5I-53; 7,I8; 8,15b) als Beweis für die tiefen Widersprüche in der christlichen Botschaft ${ }^{40}$ und für die blasphemische Neuheit ihres Inhaltes. Die Vorstellung von einem „großen Gott“, dem sich ein Schöpfergott entgegen stellte, musste den Vertretern eines "philosophischen“ Monotheismus, die sich ebenfalls zu einem "großen Gott" bekannten, aber in Begleitung von vielen anderen ihm untergeordneten göttlichen Gestalten, zutiefst absurd erscheinen. ${ }^{41}$ Jede Annahme eines Widersachers Gottes würde bedeuten, Aufruhr zu stiften, indem man das Reich Gottes teilt (Cels. 8,II). Dass ausgerechnet die Christen, welche die gestufte Wirklichkeit des Göttlichen im Sinne des Mittelplatonismus ablehnen, dennoch an solchen dualistischen Formen festhalten, ist für Kelsos ein Zeichen ihrer Verblendung. Die festgestellten Widersprüche in den Worten des Mose und Jesu sind ein weiteres Beispiel dafür.

\section{Schluss}

Beim Durchgang durch die drei Teile des „Alethes Logos“ haben wir am Ende jedes Abschnitts einige zusammenfassende Bemerkungen zum Umgang des Kelsos mit der Bibel gemacht. Es ist daher nicht notwendig, die Ergebnisse noch einmal zusammenzufassen. Stattdessen wenden wir uns zwei Fragen zu, über die es sich lohnt, weiter nach zu denken. Bei der Tragweite des Themas beschränken wir uns auf wenige Aussagen, die das Problem verdeutlichen und den Weg auf eine mögliche Antwort andeuten.

- Es geht zuerst um die Frage nach dem Ort der Aneignung der biblischen Inhalte. Wer den „Alethes Logos“ aufmerksam liest, stellt Kenntnisse der Bibel fest, die bei einem heidnischen Verfasser gegen Ende des zweiten Jahrhunderts in diesem Ausmaß sehr ungewöhnlich sind. Die Beherrschung der Materie erlaubt ihm, die biblischen Themen und Texte je nach dem argumentativen Duktus des Werkes auszuwählen und zu integrieren, wie es sich in jedem der drei Teile beobachten lässt. Kelsos kann sich manchmal mit knappen Andeutungen begnügen, wie im Hinblick auf Jonas „bei dem Kürbis“ (Jon 4,6 LXX), oder auf Daniel, „der aus den Tieren befreit wurde" (Dan 6,17-23) (Cels. 7,53c). Offensichtlich rechnet er mit Lesern, die mit der Bibel so vertraut sind wie er selbst, für die ein kurzes Wort genügt, um die Aussage zu verstehen. Die gestellte Frage verlangt die Berücksichtigung von manchen Einzelheiten, die den kulturellen Hintergrund der Auseinandersetzung des Kelsos mit den Christen präzisieren. Er kennt nicht nur

40 Cels. 6,29 schildert im leicht theatralischen Ton die gespannte Lage eines Gläubigen, der sich, wenn er von den Juden genötigt wird, zum Schöpfergott bekennt, wenn er aber die Unterschiede zwischen Jesus und Mose feststellt, sich dem anderen Gott zuwendet.

4I Ähnliches gilt für die Einsicht, dass der höchste Gott im Teufel einen Gegner hat, vor dem er machtlos ist (Cels. 6,42a). 
die Bibel. Darüber hinaus hat er sich mit Werken der altchristlichen Literatur beschäftigt, wie die Hinweise auf das „Streitgespräch zwischen Papiskos und Jason“ (4,52a), auf die „Sibyllinischen Orakel“ mit den christlichen Zusätzen $(7,53 \mathrm{C})$ und auf den gnostischen „Himmlischen Dialog“ (8,15a) beweisen.

Doch der Kontakt betrifft nicht nur die Literatur. Die detaillierte Unterscheidung zwischen den Christen der "Großkirche“ (5,59) und den Christen anderer Gruppen, die sich um irgendeine markante Gestalt gesammelt haben (5,6I-64), geht nicht auf literarische Quellen zurück, sondern auf mündliche Information bzw. auf die unmittelbare Begegnung mit solchen Gruppierungen. Dass die Markioniten dabei einen besonderen Platz einnehmen, wurde oben vermerkt.

Der im ersten Teil auftretende Jude ist gewiss die literarische Schöpfung des Kelsos, aber die Themen der durchdachten scharfen Polemik gegen Jesus und die Judenchristen sind nicht seine Erfindung, sondern spiegeln vielmehr den Ton der Streitigkeiten zwischen Juden und Christen im zweiten Jahrhundert wider. Einiges davon - die Geburt aus einer Jungfrau, der Wert der prophetischen Weissagungen als Beweis für die Messianität Jesu usw. - begegnet auch im „Dialog mit Trypho" des Justin. Der Jude des Kelsos kennt zwar die Evangelien viel besser und macht von ihnen weit intensiver Gebrauch als Trypho, aber beide wirken als literarische Gestalten nur stellvertretend für eine Kontroverse, die sich in den Gemeinden abspielte.

Ob Kelsos ein weit gereister Gebildeter war - in der Zeit der zweiten Sophistik wäre das keine Seltenheit -, der all dies an verschiedenen Orten des römischen Reiches beobachten und aufnehmen konnte, lässt sich weder bestätigen noch zurückweisen. Es kann aber als sicher gelten, dass der Entstehungsort des „Alethes Logos" Alexandria war ${ }^{42}$, und von hier aus lassen sich weitere Überlegungen anstellen.

Die Namen von Pantainos und Klemens stehen für eine besondere Art der christlichen Präsenz in Alexandria. Im gleichen Zeitraum wie Kelsos schaffen sie den Raum für eine offene Auseinandersetzung mit der hellenistischen Kultur. Von Pantainos ist nichts Schriftliches überliefert, dafür aber bietet das umfangreiche Werk des Klemens einen breiten Einblick in die geistige Atmosphäre dieses Kreises. Es handelt sich um eine christliche Einrichtung für die Vertiefung und Weitergabe der Glaubens an die Gebildeten, die dazu freien Zugang hatten. Andernfalls wäre eine Begegnung mit ihnen nicht möglich gewesen. ${ }^{43}$ Auch Klemens hätte sein Ziel verfehlt, wären die Adressaten des „Propreptikos“ und „Paidagogos" und der „Stromateis" nur auf die entsprechenden Schriften angewiesen,

42 Zur Begründung vgl. Lona 2005, 56f..

43 Euseb von Cäsarea spricht schon in dieser Zeit von einer „Katechetenschule“ (hist. 6,6.8), aber die Bezeichnung ist nicht streng wörtlich zu nehmen. Sicherlich ging es um die Verkündigung des Glaubens, aber ohne eine feste kirchliche Bindung. Vgl. Scholten 1995, 16-37; Fürst 2007, 249-277, hier 264-268. 
um von deren Inhalt Kenntnis zu nehmen. Im Sinne der klassischen „Paideia“ muss man eher mit einem lebendigen Austausch rechnen, zu dem auch das gesprochene Wort in der Form von Vorträgen, Vorlesungen oder Diskussionen gehörte. Nur unter diesen Voraussetzungen wird man hier von der „alexandrinischen Schule" sprechen dürfen.

Mit der gebotenen Vorsicht und im Bewusstsein des hypothetischen Charakters der Rekonstruktion lässt sich diese Einrichtung als der Ort bestimmen, in dem Kelsos nicht nur von den biblischen Inhalten Kenntnis nehmen konnte ${ }^{44}$, sondern auch von der Polemik zwischen Juden und Christen, von den unterschiedlichen christlichen Gruppen, von ihrem jeweils eigenen Profil und von ihren Streitigkeiten und gegenseitigen Beschimpfungen.

- Die zweite Frage steht im Zusammenhang mit der Hermeneutik des Kelsos im Umgang mit der Bibel. Um diese Hermeneutik zu charakterisieren, haben wir solche Kategorien wie „Verdacht“, „psychologisierende Erklärung“, „kritisch-historische Hermeneutik“ und „feststellbare Fakten“ verwendet. Sie klingen sehr modern und in der Tat sind sie mit der Entstehung der historisch-kritischen Methode und ihrer Anwendung an der Auslegung der Bibel im 19. Jahrhundert und in der folgenden Zeit verbunden.

Es wäre ein naiver Anachronismus, Kelsos als Vorbote der historisch-kritischen Forschung hinzustellen. Dafür sind die kulturellen Voraussetzungen zu unterschiedlich, um hier enge Verbindungen herstellen zu wollen. Anderseits lässt sich nicht leugnen, dass die Haltung des Kelsos vor der Bibel durch diese Kategorien erfasst werden kann. Es stellt sich die Frage nach der Verwandtschaft in der Geisteshaltung allen kulturellen Unterschieden zum Trotz.

Der gemeinsame Nenner dürfte die Erfahrung der Fremdheit des Textes sein, die ähnliche Reaktionen hervorbringt. ${ }^{45}$ Im Fall der historisch-kritischen Exegese geht ihr Aufkommen auf mehrere Faktoren zurück. Dazu gehören unter anderen das aufklärerische Streben nach Befreiung aus dem Diktat der Tradition und der Dogmen - auch aus der traditionellen Bibelauslegung -, das historische Bewusstsein von der Einmaligkeit der eigenen Situation im Verhältnis zur Vergangenheit, der Traum des Historismus und die Wiederentdeckung der Antike. Unter diesen Voraussetzungen wird die Bibel mit neuen Augen gelesen, die ihre Fremdheit feststellen.

Im Fall des Kelsos ist die Lage einfacher. Die Fremdheit der Bibel geht aus der unerträglichen Neuheit der judenchristlichen Botschaft hervor, die in drei zentra-

44 Eine andere Möglichkeit der Vertrautheit mit biblischen Texten, z. B. dass Kelsos einiges davon als persönlichen Besitz hatte, kann man ausschließen.

45 Die Bedeutung der „Fremdheit“ in der Frage der Hermeneutik ist längst erkannt worden. Neu ist hier nur die Übertragung auf einen Verfasser der Spätantike, um die „modernen“ Züge seines Ansatzes zu erklären. 
len Bereichen der klassischen Überlieferung, wie sie im Platonismus des zweiten Jahrhunderts verstanden wurde, gründlich widerspricht: I. im Hinblick auf Gott, indem die Christen einen Gott verkünden, der sich in der Geschichte eines Volkes offenbart, und schließlich in der Gestalt seines Gesandten eine menschliche Gestalt annimmt. Die Spannung von Transzendenz und unfassbarer Nähe wird in einer Form dargestellt, die sowohl der Religiosität als auch dem philosophischen Denken fremd ist; 2. im Hinblick auf den Kosmos, indem er als Gottes Geschöpf und der Vergänglichkeit geweiht radikal „weltlich“, fern von jeder Sakralität gedacht wird; 3. im Hinblick auf den Menschen, indem er als gefallenes Wesen auf göttliche Erlösung angewiesen ist, die in der Gestalt einer eigenen verklärten Leiblichkeit ihre Vollendung findet.

Die Erfahrung der Fremdheit mit der christlichen Botschaft schlägt bei Kelsos in konsequente Ablehnung um. Dort, wo keine Annährung möglich schien, wurde die unüberbrückbare Distanz zum Fremden durch das Festhalten an der eigenen Überlieferung als der „wahren Lehre“ begründet. Dem „Verdacht“, „der psychologischen Deutung", dem Pochen auf die Fakten, um danach die Wahrheit eines Textes zu messen, geht die tiefe Überzeugung voraus, dass nichts von diesem Inhalt wahr sein kann. Wo diese Schritte nicht weiter führen konnten, wurde die eigene Überlieferung als Richtschnur der Wahrheit hingestellt.

Der Umgang des Kelsos mit der Bibel ist der erste Fall einer durchgehend „negativen“ Rezeption ihres Inhalts. Der Grund für diese Negativität ist nicht mangelndes Verständnis oder eine unaufrichtige Einstellung zu Wahrheit - wie Origenes ihm vorwirft ${ }^{46}$-, sondern seine Zugehörigkeit zu einem spezifischen Kulturbereich, aus dem er die Prinzipien seiner Interpretation ableitet. Auch hier bekommt der bekannte Grundsatz volles Recht, dass Verstehen nur im Rahmen einer bestimmten Überlieferung möglich ist.

Die Bibel, als Fundament und Richtlinie des Glaubens, wurde von Kelsos als Quelle und Hauptzeugnis für eine irreparable Entfernung aus der Wahrheit aufgestellt. Um auf den Titel dieses Aufsatzes zurück zu kommen: Der „Alethes Logos" und der „Logos der Wahrheit" der Christen sind an sich nicht kompatibel. ${ }^{47}$

46 Die Heftigkeit des Angriffs gegen Juden und Christen entspricht der Heftigkeit, mit der Origenes versucht, Kelsos zu widerlegen. In beiden Fällen geht es um die leidenschaftliche Verteidigung einer Interpretation der Wirklichkeit, welche die Gültigkeit des Kanonischen für sich beansprucht.

47 Es bleibt dennoch zu bedenken, dass nur die Platoniker sich für das Christentum ernsthaft interessiert haben - auch um es zu bekämpfen, wie später Porphyrios -, und dass die Christen spätestens nach Justin - immer wieder versuchten, die Nähe der christlichen Botschaft zum Platonismus glaubhaft zu machen. 


\section{Literaturverzeichnis}

Bader (1940): R. Bader, Der A $\Lambda \mathrm{H} \Theta \mathrm{H} \Sigma \Lambda \mathrm{O} \Gamma \mathrm{O} \Sigma$ des Kelsos, TBAW 33, Stuttgart / Berlin.

Cook (2000): J. G. Cook, The Interpretation of the New Testament in Greco-Roman Paganism, STAC 3 , Tübingen.

Cook (2004): J. G. Cook, The Interpretation of the Old Testament in Greco-Roman Paganism, STAC 23, Tübingen.

Dillon (1977): J.Dillon, The Middle Platonists. A Study of Platonism 80 B.C. to A.D. 220, London.

Fürst (2007): A. Fürst, „Der junge Origenes im Bildungsmilieu Alexandrias“, in: F. R. Prostmeier (Hg.), Frühchristentum und Kultur, KfA.E 2, Freiburg, 249277.

Lona (2005): H.E. Lona, Die, Wahre Lehre' des Kelsos, KfA.E I, Freiburg.

Maier (1978): J. Maier, Jesus von Nazareth in der talmudischen Überlieferung, EdF 82, Darmstadt.

Pichler (1980): K. Pichler, Streit um das Christentum. Der Angriff des Kelsos und die Antwort des Origenes, RSTh 23, Frankfurt a. M. / Bern.

Schäfer (2007): P. Schäfer, Jesus im Talmud, Tübingen [= Jesus in the Talmud, Princeton].

Scholten (1995): C. Scholten, Die alexandrinische Katechetenschule, in: JAC 38 , I6-37.

Wifstrand (1942): A. Wifstrand, Die wahre Lehre des Kelsos. Boulletin de la Société Royale des Lettres de Lund 1942, Lund. 


\title{
Widersprüchlichkeit und Kohärenz
}

\author{
Beobachtungen zu einem Argument der Polemik und Apologetik \\ im zweiten Jahrhundert
}

\section{JÖRG ULRICH}

In der Auseinandersetzung konkurrierender Wahrheitsansprüche von Christen, Heiden und Juden in der Antike kommt den verwendeten Argumentationsmustern naheliegenderweise eine hohe Bedeutung zu. In diesem Zusammenhang hat Peter Pilhofer im Jahre 1990 eine viel beachtete Analyse des so genannten Altersbeweises vorgelegt, ${ }^{\mathrm{I}}$ der zu den am meisten beanspruchten Denkfiguren in der Literatur des zweiten Jahrhunderts (und späterer Zeiten) zählt. Vergleichbar eingehende Detailuntersuchungen anderer, ebenso wichtiger Argumentationsmuster stehen noch aus. ${ }^{2}$ Nun hat uns aber gerade die neuere wissenschaftliche Diskussion vor Augen geführt, dass sich die antike Apologetik vor allem als Denk- und Argumentationsmodus zu verstehen empfiehlt. ${ }^{3}$ Die Dringlichkeit detaillierter Untersuchungen zu einzelnen apologetischen Argumenten hinsichtlich ihrer Herkunft, Anwendung und Ausrichtung liegt somit auf der Hand.

Im folgenden seien einige Beobachtungen zu einer polemisch-apologetischen Argumentationsfigur mitgeteilt, die im Kampf konkurrierender Wahrheitsansprüche im zweiten Jahrhundert offenbar eine große Rolle gespielt hat: der Behauptung der Widersprüchlichkeit gegnerischer und der Kohärenz eigener Lehre. Mit diesem Argument korrespondiert die Polemik gegen die Diversität gegnerischer Institutionen und die protreptisch ausgerichtete Betonung der Einheitlichkeit der eigenen. Zwar lassen sich in der bunten Wirklichkeit des zweiten Jahrhunderts weder bei Christen noch bei Juden noch bei Heiden eine echte Kohärenz der Lehre und auch keine institutionelle Geschlossenheit ihrer Vertreter erkennen - die Quellen zeigen, dass eher das Gegenteil der Fall ist -, aber gerade deshalb eignete sich der Vorwurf der Widersprüchlichkeit gut für den Angriff auf die gegnerische Seite. Andererseits bedurfte es auch eines hohen Maßes

I Pilhofer 1990; Zur Bedeutung des Altersbeweises im Zusammenhang der christlich-paganen Auseinandersetzung über das Alte Testament vgl. Ackermann 1997.

2 Für die ältere Literatur ist immer noch auf Harnacks kleine Abhandlung über den Atheismusvorwurf zu verweisen, die freilich auch einer intensiven, die politischen und geistesgeschichtlichen Voraussetzungen gründlich erhellenden Revision bedürfte: Harnack 1905.

Klostergaard Petersen 2009, I5-4I. 
an apologetischem Geschick, wenn es darum ging, die eigenen Reihen gegen entsprechende Kritik zu verteidigen. Im folgenden soll zunächst ein Anzahl einschlägiger Stellen für die polemische Verwendung des Widersprüchlichkeitsarguments durch die Christen gesichtet (I.) und nach dessen Hintergründen gefragt (II.) werden, sodann soll auf die gegen die Christen gerichtete Inanspruchnahme des Arguments durch die Heiden (III.) und auf die Verteidigung der Christen hiergegen (IV.) eingegangen werden, ehe ein zusammenfassender Ausblick die Beobachtungen abrundet (V.).

\section{I.}

In seiner handlichen Überblicksdarstellung der frühchristlichen Apologetik hat Michael Fiedrowicz dem Widersprüchlichkeitsargument zu Recht einen prominenten Platz im Disput um Wahrheitsansprüche in der Antike eingeräumt: Unter den christlicherseits geltend gemachten Differenzen zwischen Christentum und paganer Philosophie steht es an erster Stelle. ${ }^{4}$

Dabei lassen sich graduelle Unterschiede in der Verwendung erkennen: Während die einen nämlich den paganen Philosophen mit dem Inkongruenz-Vorwurf „nur" defizitäre Explikationen bestimmter Sätze attestieren, zugleich aber deren Übereinstimmung mit bestimmten christlichen Grundwahrheiten positiv vermerken, betonen andere mit demselben Argument die grundsätzliche Unterschiedenheit von Christentum und Philosophie und stellen das Christentum exklusiv als einzig konsistente Lehre dar. Je nachdem, ob man eher an einer Annäherung oder an einer Abgrenzung von den paganen Philosophen interessiert war, änderte sich die Ausrichtung, die man dem Widersprüchlichkeitsvorwurf gab.

Als Vertreter einer differenziert-konstruktiven Inanspruchnahme des Arguments ist Justin zu nennen, der sich als christlicher Philosoph verstand und in seinen Apologien` auf die wechselseitige Anschlussfähigkeit zwischen Christentum und Philosophie setzte. Typisch für seine Position ist r apol. 44,9f.:

Alles, was Philosophen und Dichter über die Unsterblichkeit der Seele (...) gesagt haben, das haben sie nur aufgrund der von den Propheten empfangenen Anhaltspunkte erkennen können und ausgeführt. Daher scheinen bei allen Keime der Wahrheit zu sein; man kann ihnen aber auch nachweisen, dass sie dieselbe nicht

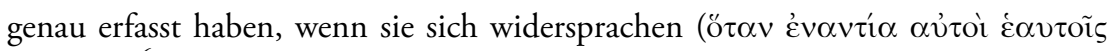

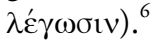

4 Fiedrowicz 200I, 292f.

5 Minns u. Parvis 2009.

6 Minns u. Parvis 2009, I94, I7-22. - Die Herausgeber machen darauf aufmerksam (a.a.O. I95

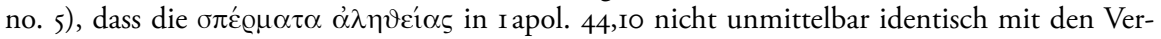
nunftkeimen gemäß der Logos-spermatikos-Theorie Justins sein müssen; es könnten auch ein- 
Justin geht aus von einer Inspirierung der Philosophen und Dichter durch die Worte der Propheten. Bezüglich einiger zentraler Lehren wie der von der Unsterblichkeit der Seele hatten die Philosophen an der Wahrheit Anteil, weil sie von den Propheten Anhaltspunkte erhalten haben. Eine basale Erkenntnis der Wahrheit wird den Philosophen zugestanden. Andererseits fehlt ihnen die vollständige Erkenntnis der Wahrheit, was daran deutlich wird, dass sie sich widersprechen, d.h. gegensätzliche Meinungen zu bestimmten Themen vertreten, sobald sie über die von den Propheten übernommenen Erkenntnisse hinausgehen. Das Widersprüchlichkeitsargument dient Justin nicht dazu, die Philosophen und Dichter in toto zu widerlegen, sondern beweist nur, dass die vollständige Wahrheit bei ihnen nicht zu finden ist. Ihre Einsichten sind korrektur- und vervollkommnungsbedürftig. So auch in 2 apol. 13,2-6:

Indem ich darum bete und inständig ringe, als Christ befunden zu werden, bekenne ich nicht, dass die Lehren Platons den Lehren Christi fremd seien, sondern dass sie ihnen nicht in jeder Hinsicht gleichkommen, wie auch die der anderen nicht, der Stoiker und Dichter und Prosaschreiber. Denn jeder von ihnen hat gut argumentiert, indem er auf Grund des Anteils am samenausstreuenden göttlichen Logos das (diesem) Verwandte gesehen hat. Da sie aber in den wesentlicheren

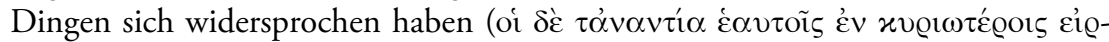

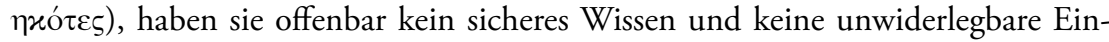
sicht gehabt. All das nun, was bei ihnen allen recht gesagt worden ist, eignet uns Christen: (...) Denn alle jene Schriftsteller konnten durch den in ihnen befindlichen eingepflanzten Keim des Logos das, was ist, schemenhaft sehen. Denn das eine ist der Keim einer Sache und das Abbild, das gemäß der Fähigkeit (des jeweiligen Menschen) gegeben wird, ein anderes ist die Sache selbst, an der Anteil zu haben und die nachzubilden der Gnade Gottes obliegt. ${ }^{7}$

Justin kombiniert hier das Widersprüchlichkeitsargument mit seiner Theorie von den allen Menschen innewohnenden Samenkörnern der Wahrheit. ${ }^{8}$ Aufgrund des ihnen innewohnenden Logoskeimes haben die Philosophen' durchaus Richtiges, d.i. dem Logos Entsprechendes gesehen, wenngleich schemenhaft. Eine sichere, unwiderlegbare Einsicht können sie hingegen nicht gehabt haben, da sie ja einander widersprachen. Sie hatten nicht Anteil am ganzen Logos, der Christus selbst ist. ${ }^{\text {Io }}$ Die richtigen Einsichten, die die Philosophen hier und da hatten, fü-

fach „Ausgangspunkte“ (starting points) für die Wahrheit gemeint sein.

7 Minns u. Parvis 2009, 320, 9-23.

$8 \mathrm{Zu}$ dieser These vgl. Ulrich 2005, 3-16; außerdem Minns u. Parvis (2009), Introduction, 65f.

9 Der gelegentliche Wechsel und unterschiedliche Kombinationen in der Bezeichnung der paganen Gruppen (Philosophen, Dichter, Prosaschreiber) bei Justin und anderen Apologeten kann hier außer Betracht bleiben: Es geht generell um die prominenten Texte und Lehrmeinungen aus der paganen antiken Tradition.

IO In dieselbe Linie gehört 2 apol. IO,I-3: „Unsere Lehren aber scheinen herrlicher als jede menschliche Lehre dadurch, dass das gesamte Vernunftgemäße Christus geworden ist, der für uns, Leib, Vernunft und Seele, erschienen ist. Denn was auch immer die Denker und Gesetzge- 
gen sich erst in der wahren christlichen Philosophie zu einem vollständig kohärenten Bild zusammen. Das Widersprüchlichkeitsargument ist bei Justin Teil eines Überbietungsmodells, nach welchem trotz zugestandener Übereinstimmungen mit der Philosophie in basalen Fragen die vollständige, logosgemäße Wahrheit nur von den Christen beansprucht werden kann.

Auch Athenagoras ist zu den Vertretern einer grundsätzlichen Harmonie zwischen Christentum und Philosophie zu rechnen. ${ }^{\text {II }}$ Er geht von der Basis gemeinsamer Überzeugungen aus und operiert dann mit dem Widersprüchlichkeitsargument, um die Überlegenheit des auf klarer göttlicher Offenbarung gründenden Christentums gegenüber der auf Vermutungen basierenden und in ihren Aussagen vieldeutigen Philosophie zu beweisen. Nachdem er in leg. 5 f. die Übereinstimmung aller Philosophen in der Lehre von der Einzigkeit Gottes dargelegt hat, schreibt er in leg. 7,If.:

Fast alle, die auf die Weltprinzipien zu sprechen kommen, sind selbst gegen ihren Willen darüber einig, dass die Gottheit nur eine ist (...).Wenn aber dann wir behaupten, dass der Ordner dieses Alls der eine Gott ist, so steht uns unbegreiflicherweise ein Gesetz entgegen, obwohl wir das von uns Erkannte und richtig Geglaubte, nämlich die Einheit Gottes, mit sicheren Argumenten und Gründen zu belegen vermögen. Dichter und Philosophen nämlich traten (...) auch an dieses Thema nur mit Vermutungen heran (...) wobei jeder doch nur so viel Erfolg hatte, dass er sich allerlei Gedanken machte, ohne aber das Seiende wirklich zu finden; denn er suchte nicht bei Gott Belehrung über Gott, sondern nur bei sich selbst. Daher hat auch jeder von ihnen auf andere Weise über Gott und Materie

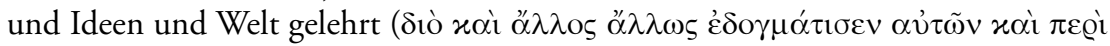

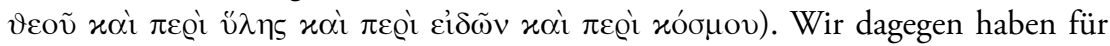
unsere Erkenntnis und unseren Glauben die Propheten zu Zeugen, die in der Kraft des göttlichen Geistes über Gott und göttliche Dinge Offenbarungen gegeben haben. ${ }^{12}$

ber jemals Treffliches gesagt und gefunden haben, das ist von ihnen mit Mühe erarbeitet worden durch Forschen und Anschauen gemäß dem Logos. Da sie aber nicht das Ganze des Logos,

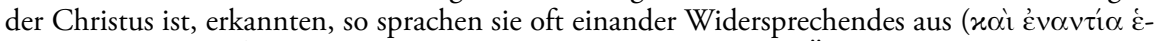

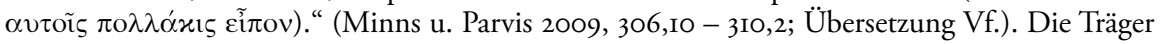
der Bemühungen um die Wahrheit sind hier nicht Philosophen und Dichter wie oben, sondern Denker und Gesetzgeber. Ansonsten ist das Argument dasselbe: Die Denker und Gesetzgeber besitzen einen Teil des Logos, aber jeder eben nur einen Teil, nicht das Ganze (= Christus); der Teil Logos, der in ihnen ist, befähigt sie, unter Mühen hier und da Treffendes zu erkennen. Aber es fehlt ihnen die Erkenntnis des Ganzen. So entstehen die Widersprüche. Ob Justin meint, dass einige Philosophen sich selbst widersprachen (Widersprüchliches lehrten) oder ob er darauf hinweist, dass die Philosophen einander widersprachen und aus diesem Phänomen die defizitäre Erkenntnis ihrer alle sich zeigt, ist nicht sicher zu entscheiden. Beide Deutungen schließen einander aber auch keineswegs aus, wie z. B. Pseudo Justins Cohortatio ad Graecos (coh. Gr. 35,2) zeigt: Die Philosophen sind nicht nur untereinander zerstritten, sondern jeder von ihnen legt die eigene Meinung einmal so und einmal anders aus.

II Barnard 1972a; Barnard I972b, 3-I6. 
Hier ist der Gegensatz von Menschenmeinung und geistgewirkter Offenbarung entscheidend. Die Meinungen der Philosophen rühren daher, dass sich ,jeder so seine Gedanken macht." Aber eben dadurch, dass die Philosophen die Wahrheit bei sich selbst suchen, ist die Vielfalt ihrer Meinungen so groß wie die Zahl ihrer selbst. Sie kommen über Vermutungen nicht hinaus, weshalb ,jeder auf andere Weise" lehrt. Athenagoras expliziert nicht ausdrücklich den Vorwurf der Widersprüchlichkeit, aber er diagnostiziert bei den Philosophen eine unüberschaubare Vielfalt von verschiedenen Ansichten, die kein auch nur annähernd kohärentes Bild ergeben. Das ist die Folge dessen, dass jeder von ihnen sich selbst als Erkenntnisquelle hat. Dem stellt Athenagoras die von Gottes Geist gewirkte Offenbarung an die Propheten entgegen. Der Glaube, der auf dem Zeugnis der Propheten bzw. der göttlichen Offenbarung beruht, unterscheidet sich von der verwirrenden Vielfalt philosophischer Vermutungen durch sein Gegründetsein auf einer einheitlich-kohärenten, göttlich autorisierten Überlieferung.

Schärfer gegen die paganen Philosophien richten sich der Verfasser des Diognetbriefs, Tatian und Theophilus von Antiochien. Entsprechend polemischer ist bei diesen Autoren der Gebrauch des Widersprüchlichkeitsarguments. In Diogn 8,If. heißt es:

Wer von den Menschen hat denn überhaupt gewusst, was Gott ist, bevor er gekommen ist? Oder billigst du etwa die leeren und läppischen Reden jener so glaubwürdigen Philosophen? Einige von ihnen sagten, das Feuer sei Gott - sie nennen Gott das, wohin sie gelangen werden - andere meinen, das Wasser sei Gott, andere aber irgendeines der von Gott geschaffenen Elemente. ${ }^{\mathrm{I}}$

Der Widersprüchlichkeitsvorwurf wird hier nicht expliziert, steht aber im Hintergrund. Der Verfasser will die Philosophen lächerlich machen, die über Gott die unterschiedlichsten Meinungen vertreten. Die Vielfalt der philosophischen Lehren wird als Argument für die Falsifikation jeder dieser Lehren benutzt: Die einen halten die Elemente für Götter, und dann sogar noch für unterschiedliche. Andere setzen das Feuer und Gott gleich, wieder andere identifizieren das Wasser mit Gott. ${ }^{14}$ In ihrer beliebigen Unterschiedlichkeit erweisen sie selbst alle ihre Lehren als läppisch. Auffällig ist die ironische Färbung.

Ähnlich verhält es sich bei Tatian, bei dem sich auch die im Diognetbrief erkennbare ironische Note findet. In orat. 25,3f. heißt es:

I2 Athenagoras, leg. 7, I-3 (PTS 3I, 34,I-35,2 Marcovich) - Übersetzung nach ,Athenagoras, Apologie`, aus dem Griechischen übersetzt von P. Anselm Eberhard, in: Frühchristliche Apologeten und Märtyrerakten Bd. I, BKV I2, Kempten I9I3, 28If. (leicht geändert).

I3 Übersetzung nach dem Kommentar ,An Diognet', übersetzt und erklärt von Horacio E. Lona, KfA 8, Freiburg 200I, 234.

I4 Vgl. hierzu Lona in seinem Kommentar An Diognet (wie vorige Anm.), 236f.; im einen Fall könnte auf Heraklit oder dessen Schüler, den Stoiker Zenon, der den feurigen voũ s der Welt für Gott hält, angespielt sein, im anderen Fall auf Poseidon. 
Du folgst den Lehren Platons, da tritt dir ein Schüler Epikurs mit lauter Stimme entgegen; willst du dich wiederum nach Aristoteles richten, so verhöhnt dich irgendein Anhänger Demokrits. (...) Da die philosophischen Systeme, die ihr habt,

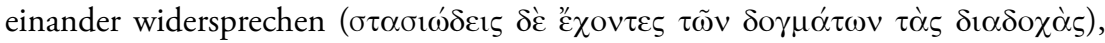
so kämpft ihr, unter euch uneins, gegen diejenigen, die unter sich einig sind. ${ }^{\text {I5 }}$

Hier ist keine Teilmengen- und Überbietungsvorstellung im Visier wie bei Justin, sondern eine strikte Grenze gezogen: ${ }^{16}$ Tatian befehdet die griechische Denkweise und Kultur insgesamt. ${ }^{17}$ Die Philosophen offenbaren ihre Unfähigkeit zur Wahrheit nicht nur durch widersprüchliche Lehren, sondern noch mehr dadurch, dass sie Vertreter jeweils anderer Positionen verhöhnen und ihre Uneinigkeit offen zur Schau stellen. Dieser Uneinigkeit der Philosophen wird die Einigkeit der Christen entgegengestellt. Dass die Christen im Unterschied zu den Philosophen untereinander einig sind, ist ihr wichtigstes Identitätsmerkmal und legitimiert ihren Wahrheitsanspruch. Das Einigkeitsargument wird zu dem Wahrheitskriterium des Christentums schlechthin. In der Einigkeit der Christen liegt zugleich der Grund dafür, dass sie angegriffen und verfolgt werden: Die Uneinigen können die Einigkeit der sich Einigen nicht ertragen und müssen sie demzufolge bekämpfen.

Bei Theophilus findet sich unser Gedanke an zahlreichen Stellen in seinen drei Büchern Ad Autolycum, z. B. 2,4; 2,8f.; 3,3; 3,7 u.ö. In Einklang mit Tatian und im Unterschied zu Justin nutzt Theophilus das Widersprüchlichkeitsargument, um die griechischen Philosophen, Dichter oder Geschichtsschreiber grundsätzlich zu diskreditieren: Sie alle haben über alle möglichen Themen unterschiedlichste Auffassungen vorgelegt, weswegen ihre Meinungen offenbar töricht sind. In Autol. 2,8,2-9,2 heißt es:

Auch über den Ursprung der Welt haben sie einander widersprochen und törichte Meinungen vertreten. Denn erstens haben einige die Welt für ewig erklärt, wie wir oben gezeigt haben. Und die, die sie für ungeworden und die Natur für ewig erklären, haben Dinge gesagt, die mit den Aussagen derer, welche die Welt für einmal geworden erklären, völlig unvereinbar sind.

(Es folgen Zitate von Aratus, Sophokles, Homer, Simonides, Euripides, Menander, Thestius und Theophilus summiert:)

I5 Tatianus, orat. 25,3f. (PTS 43, 48,II-49,I7 Marcovich). - Übersetzung nach Tatian, Rede an die Bekenner des Griechentums, eingeleitet und übersetzt von R.C. Kukula, in: Frühchristliche Apologeten und Märtyrerakten Bd. I, BKV I2, Kempten 1913, 234 (leicht verändert).

I6 Differenziert dargestellt wird das Verhältnis beider bei Hanig 1999, 3I-73.

I7 Was nichts daran ändert, dass Tatian bei aller Bekämpfung paganer Philosophien der Logoslehre stoischer und mittelplatonischer Provenienz verpflichtet bleibt. Immer noch instruktiv hierüber ist die über Ioo Jahre alte und nur 36 Seiten starke Dissertation von Carl Willibald Steuer, Die Gottes- und Logoslehre des Tatian in ihren Berührungen mit der griechischen Philosophie: Steuer 1892. Die bis heute beste monographische Behandlung Tatians ist von Martin Elze: Elze 1960. 
Dergleichen sich selbst widersprechende Aussagen ( $\alpha \sigma u ́ \mu \varphi \omega v \alpha)$ tun sie zu Tausenden ...

(Dem stellt Theophilus dann die Lehre der Männer Gottes entgegen und resümiert:)

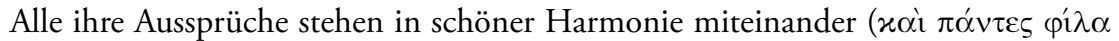

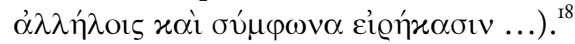

Die Schrift „Ad Autolycum“ will ihren Adressaten für das Christentum gewinnen. In diesem Kontext spielt das Gegenüber von Widersprüchlichkeit der philosophischen Lehren und Harmonie der christlichen Überlieferung eine entscheidende Rolle. Autolykos wird aufgefordert, die einhelligen Aussagen der einfachen, ungebildeten, aber inspirierten biblischen (= alttestamentlichen) Autoren mit den widersprüchlichen, unsicheren, irrigen Ansichten der paganen Dichter, Philosophen und Historiker zu vergleichen (Autol. 2,34,I; 2,35,I4f.; 3,I7,4f.). Einhelligkeit der Meinung und Kohärenz der Aussagen gelten auch hier als entscheidendes Wahrheitskriterium, umgekehrt wird die widersprüchliche Vielfalt philosophischer Auffassungen zum Beweis ihrer Unbrauchbarkeit. Nur am Rande wird eingeräumt, dass unter den Philosophen und Dichtern die eine oder andere treffende Ansicht sich auch einmal finden kann - und zwar da, wo sie mit den Meinungen der inspirierten biblischen Autoren übereinstimmen; ein Argument, das wir schon bei Justin sahen. Theophilus bringt in diesem Zusammenhang die These vom „Diebstahl der Hellenen“" auf (3,I,I4; 3,2,37). Dem Grunde nach aber wird bei ihm der paganen Philosophie keine Teilhabe an der Wahrheit zuerkannt, weil diese nur bei den Christen zu finden ist (2,33). Hier hat das Widersprüchlichkeitsargument die Funktion, die Philosophie in toto als falsch zu erweisen und zu verabschieden.

Bei Tertullian zeigt sich, wie geläufig die Verwendung des Arguments am Ende des zweiten Jahrhunderts auch im lateinischen Sprachraum ist. Im Apologeticum schreibt er:

Denn nachdem diese Menschen Gott lediglich gefunden hatten, haben sie nicht so von ihm gesprochen, wie sie ihn gefunden hatten, so dass sie in Folge auch über sein Wesen und seine Natur und seinen Wohnort verhandeln. Die einen behaupten, er sei unkörperlich, die anderen, er sei körperlich, wie es die Platoniker und die Stoiker tun; die einen behaupten, er bestehe aus Atomen, die anderen, aus Zahlen, wie es Epikur und Pythagoras tun; ein anderer, aus Feuer, wie es dem Heraklit schien; und die Platoniker freilich behaupten, er sorge für alle Dinge, er sei der Schöpfer und Antreiber aller Dinge, hingegen die Epikureer, er sei müßig und untätig, und, um es so zu sagen, für die menschlichen Angelegenheiten ein

I8 Theophilus, Autol. 2,8,2-2,9,2 (PTS 44, 49,7-52,I3 Marcovich). Übersetzung nach Theophilus, Drei Bücher an Autolykus, übersetzt und eingeleitet von J.Leitl u. Andreas Freiherr von di Pauli, in: Frühchristliche Apologeten und Märtyrerakten Bd. 2, BKV I4, Kempten 1913, 34-37 (leicht geändert). 
Niemand; sein Platz sei aber außerhalb der Welt, behaupten die Stoiker, und nach Art eines Töpfers lasse er diese Weltmasse von außen kreisen; innerhalb der Welt, behaupten die Platoniker, und in der Manier eines Steuermanns verweile er innerhalb dessen, was er lenkt. So sind sie auch im Blick auf die Welt selbst geteilter Meinung (uariant), ob sie geworden oder ungeworden sei, ob sie untergehen oder fortbestehen werde; so auch im Blick auf das Wesen der Seele, das die einen als göttlich und ewig, die anderen als der Auflösung geweiht ausgeben: je nachdem, wie ein jeder gedacht hat, so hat er entweder etwas eingefügt oder umgestaltet. ${ }^{19}$

Die Aufzählung philosophischer Schulen und ihrer Meinungen wirkt hier schon routiniert-traditionell. Tertullian deutet deren Widersprüchlichkeiten als Entstellungen der eigentlich einheitlich-einfachen Überlieferung der christlichen Bibel. Mit ihren „eigenen Beiträgen“ haben die Philosophen eine unübersehbare Fülle verschiedener Meinungen produziert. In zentralen Fragen wie denen von Wesen, Natur und Wohnort Gottes gelangen sie so zu unterschiedlichen Auffassungen, gleiches gilt für die Fragen nach der Entstehung und Bewahrung der Welt und nach dem Wesen der Seele. Damit ist ihre Unglaubwürdigkeit offensichtlich.

Wohl vom Anfang des dritten Jahrhunderts datiert schließlich die Spottschrift gegen die heidnischen Philosophen, deren Verfasser Hermias fast ausschließlich auf dem Widersprüchlichkeitsargument aufbaut und eine satirisch-literarische Inszenierung desselben bietet. ${ }^{20}$ Der Text dokumentiert die offenbar stetig steigende Beliebtheit des Arguments und die Selbstverständlichkeit seiner Verwendung. In beißend-polemischer, ironischer Kritik werden die einander widersprechenden Lehrmeinungen der Philosophen verhöhnt. Hermias stellt Aussagen u. a. von Anaxagoras, Parmenides, Thales, Anaximenes, Archelaos, Plato, Aristoteles, Pherekydes, Leukippos, Demokrit, Epikur, Karneades, Klitomachus und Pythagoras zusammen, ${ }^{2 \mathrm{I}}$ um so ihre unterschiedlichen und widersprüchlichen Meinungen gegeneinander auszuspielen ${ }^{22}$. Das Widersprüchlichkeitsargument eignete sich in besonderem Maße für satirische Verarbeitungen: Bei Hermias finden sich Tendenzen gesteigert, die schon im Diognetbrief und bei Tatian anklangen und auch in späteren Texten zum Tragen kommen. Die in der Forschung immer wieder diskutierten Parallelen zwischen dem Hermias-Traktat und PseudoJustins Cohortatio ad Graecos ${ }^{23}$ sind möglicherweise als Teil der Wirkungsge-

I9 Tertullian, Apol. 47, 4-8 (CChr.SL I, I63,15-164,32 Dekkers). Für die Übersetzung verweise ich auf Tobias Georges, dessen Habilitationsschrift über Tertullians Apologeticum mitsamt einer neuen deutschen Übersetzung und Kommentierung in der Reihe KfA gedruckt werden wird.

20 Hermias, Satire des philosophes païens, ed. Richard Patrick Crossland Hanson u. a., SC 388, Paris 1993; vgl. dazu die Besprechung von Christoph Riedweg: Riedweg 1995, I8I-I83. Zu Hermias vgl. Waszink 1988, 808-815; Riedweg 2000, I673; Skeb 2002, 320f.

2I Er erwähnt nicht die Philosophen des Mittel- und Neuplatonismus, was als Indiz für die relative Frühdatierung des Werkes ins Feld geführt werden kann.

22 So die ausdrückliche Zielsetzung der gesamten Schrift, wie Hermias sie in der Zusammenfassung beschreibt: Hermias, irris. I9.

23 Christoph Riedweg hat die Cohortatio ad Graecos vorschlagsweise Markell von Ancyra zuge- 
schichte des Traktats oder seiner literarischen Vorlagen zu deuten. Dies gilt auch hinsichtlich der Verwendung des Widersprüchlichkeitsarguments. ${ }^{24}$

\section{II.}

Die intensive Inanspruchnahme des Widersprüchlichkeitsarguments durch die christliche Polemik und Apologetik ist nur dadurch zu erklären, dass das Argument und seine Explikation zum zeitgenössischen intellektuellen Gemeingut zählten, dessen sich die Christen naheliegenderweise bedienten. Schon ein kurzer vergleichender Blick auf die in etwa zeitgenössische jüdische Apologetik zeigt eine ähnliche Selbstverständlichkeit bei seiner Anwendung. Bei Philo von Alexandrien findet sich gleich zum Eingang seiner Werbeschrift für das kontemplative Leben eine Aussage, mit der er die eigene einfache, schlichte ( $\dot{\tau} \tau \varepsilon \chi v \tilde{\omega} \varsigma)$ Orientierung an der Wahrheit den Darstellungen der Poeten und Schriftsteller entgegensetzt. ${ }^{25}$ Die Aussagen, die er in diesem Zusammenhang über bestimmte Auffassungen der Philosophen macht, ähneln denen, die wir christlicherseits im Diognetbrief vorgefunden hatten. ${ }^{26}$ Noch deutlicher ist der Befund bei Josephus. Er betont in seiner Verteidigungsschrift gegen Apion ${ }^{27}$ ausdrücklich die einheitsstiftende Kraft des jüdischen Gesetzes und setzt die Vielfalt der Meinungen der Philosophen kritisch hiervon ab:

Dies hat vor allem anderen die bewundernswerte Eintracht bei uns zustande gebracht: Dass wir ein und dieselbe Auffassung von Gott haben, aber auch in der Lebensführung und in unseren Gedanken nicht voneinander unterschieden sind, bewirkt die schönste Übereinstimmung der Menschen in ihrem Ethos. Denn nur bei uns wird man weder Reden über Gott hören, die einander widersprechen - so wie bei den Übrigen nicht nur von irgendwelchen Leuten je nachdem, wie jeder gerade empfindet, geredet wird, sondern sogar von einigen Philosophen verantwortungslos gelehrt worden ist, von denen die einen die Natur Gottes mit ihren Argumenten aufheben, die anderen die Vorsorge für die Menschen ihm absprechen möchten -, noch wird man in den Alltagsgeschäften einen Unterschied sehen, sondern gemeinsam sind bei uns die Verrichtungen aller und eine ist die

wiesen: Riedweg 1994; Pseudo-Justin, Cohortatio ad Graecos. De monarchia. Oratio ad Graecos.

24 Ad Graecos de vera religione 3,2-4,I und 8,If. - Zu den Stellen und ihrer Deutung vgl. die Übersetzung und die Kommentierung von Christoph Riedweg (vgl. vorige Anmerkung).

25 Philo cont. I (Cohn / Reiter).

26 Philo cont. 3f. im Vergleich zu Diogn. 8,If.

27 Ausgabe: Flavius Josephus, Über die Ursprünglichkeit des Judentums (Contra Apionem), Bd. I und 2. Erstmalige Kollation der gesamten Überlieferung (griechisch, lateinisch, armenisch), literarkritische Analyse und deutsche Übersetzung, hg. Folker Siegert, Schriften des Institutum Judaicum Delitzschianum 6,I / 6,2, Göttingen 2008. - Vgl. zu „Contra Apionem“ auch die Einleitung in Labow 2005, sowie Haaland 2007; Gerber 1997; Feldman 1996. 
Lehre, die mit dem Gesetz übereinstimmt, was Gott betrifft, indem sie besagt, dass jener alles beaufsichtigt. ${ }^{28}$

Durch ihre „bewundernswerte Eintracht“ (

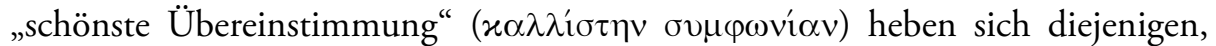
die sich am göttlichen Gesetz ausrichten, von allen anderen Menschen positiv ab. Die kollektive Identität gründet auf die Übereinstimmung in der Lebensführung und darauf, dass alle „ein und dieselbe Auffassung von Gott haben.“ Die Einheitlichkeit wird als Alleinstellungsmerkmal profiliert: Von dem am Kohärenzkriterium orientierten Idealbild werden die anderen Völker abgesetzt, bei denen sich widersprechende Ansichten über Gott finden. Solche im Judentum vorfindliche Argumentationsfiguren machte sich die christliche Apologetik natürlich zu eigen. ${ }^{29}$

Unbeschadet dieser und anderer Belegstellen aus der frühjüdischen Apologetik ist zum zeitgenössischen Hintergrund des Widersprüchlichkeitsarguments aber nicht auf die Traditionen der Apologetik, sondern auf die philosophische Skepsis zu verweisen. Darauf hat Christoph Riedweg hingewiesen. ${ }^{30}$ Bei den Skeptikern war das Widersprüchlichkeitsargument von zentraler Bedeutung für ihre Option zugunsten der દ̇ $\pi \circ \chi \eta ́$, des Zurückhaltens der Meinung: Wenn im Laufe der Geschichte bei allen prominenten Bemühungen um die großen Fragen der Philosophie nichts weiter herausgekommen war als eine kaum mehr überschaubare Vielfalt verschiedener einander widersprechender Meinungen, dann musste eine gewisse Selbstfestlegungsreserve in diesen Fragen die einzig verantwortbare Haltung sein. Riedweg hat mit Recht unterstrichen, dass dies auch für theologische Fragen galt. ${ }^{3}$ Riedweg hat ferner gezeigt, dass der Rückgriff auf doxographische Zusammenstellungen von philosophischen Meinungen zu einschlägigen Themen fester Bestandteil skeptischer Argumentationstechnik war. Er verweist beispielsweise auf den Akademiker bei Cicero, der aus einer Zusammenstellung über die Prinzipienlehre der Philosophen eine riesige Bandbreite der Meinungen unter den großen Denkern nachweist, um dann zu folgern, dass man aus dieser Vielfalt nicht die eine oder die andere Meinung begründet als richtig identifizieren könne. ${ }^{32}$ Natürlich findet sich der Hinweis auf die Problematik der

28 Josephus C. Ap. II I79-I8I (Übersetzung nach Siegert, Bd. I, I92).

29 Vgl. hierzu die Bemerkungen von Martin Vogel in Siegert, Bd. I, 63f.: „Noch im 2. Jahrhundert eröffneten Quadratus, Aristides und Justin die Reihe der christlichen Apologeten, die sich - ob nun schon unter dem Einfluss des Josephus oder nicht - jüdischer Standardargumente bedienen. Ab Pseudo-Justin (Cohortatio ad gentiles) wird Josephus' Einfluss angenommen, ab Theophilos ist er sicher." - Zur Thematik vgl. Meiser 2000, I55-184.

30 Riedweg 1994, I09-II5; vgl. auch Fiedrowicz 200I, 292f., der sich auf die Analysen Riedwegs bezieht.

3I C. Riedweg (vgl. vorherige Anmerkung), II3. Riedweg zitiert als Beleg S.E. Pyrrhon, hyp III 2, der das Widersprüchlichkeitsargument zunächst entfaltet und dann folgert: „Aus diesem Grunde ist es also nicht zu erfassen, ob Gott existiert." 
Vielfalt unterschiedlicher Meinungen schon seit Platon. ${ }^{33}$ Und dem alten sophistischen Anspruch auf Wahrheit auch entgegengesetzter Meinungen ${ }^{34}$ suchten Platon mit der scharfen Unterscheidung von Meinen und Wissen und Aristoteles mit dem Satz vom Widerspruch ${ }^{35}$ zu begegnen. Die Skeptiker zogen aus dem

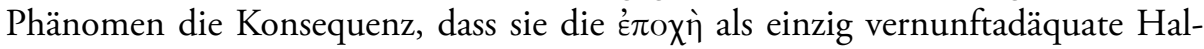
tung auf den Schild hoben und zum Beleg auf einschlägige Textsammlungen zurückgriffen bzw. diese teils erweiterten, teils selbst erstellten.

Neben dem Verweis auf den historisch gewachsenen skeptisch-philosophischen Hintergrund des Widersprüchlichkeitsarguments ist zu beachten, dass es während der zweiten Sophistik zu einer spezifischen Färbung bei seiner Anwendung kommt. Denn zu dieser Zeit fallen ironisch-satirische Explikationen besonders auf. Berühmt und bei einer großen Leserschar bis heute beliebt sind die beißenden Demaskierungen des zeitgenössischen Philosophenbetriebes aus der Feder des Lukian von Samosata, ${ }^{36}$ die literarisch brillant in die Form parodistischer Dialoge gegossen sind. Die Vielfalt der Meinungen ist ein wichtiges Argument für Lukian, um den Philosophen Scharlatanerie nachzuweisen. ${ }^{37}$ Es liegt auf der Hand, dass christliche Apologeten sich durch diese Texte zu eigenen Versuchen inspirieren ließen, zumal sie damit auf den Beifall des zeitgenössischen $\mathrm{Pu}$ blikums hoffen konnten. Insbesondere für Hermias lässt sich nachweisen, dass er sich für seine „Verspottung der heidnischen Philosophen“ am konkreten literarischen Modell des Spötters Lukian von Samosata orientiert hat. ${ }^{38}$

Die Verarbeitung solcher Vorlagen auf christlicher Seite hat sowohl rezeptive als auch eigenständige Aspekte. Auf der einen Seite griffen die christlichen Autoren den Grundgedanken wie auch das bereitstehende literarische Material zu seiner Entfaltung und die ironisch-satirischen Tendenzen bei seiner Explikation auf ${ }^{9}$ und schlossen sich so an zeitgenössische pagane Autoren an, die sich ihrer-

32 C. Riedweg (vgl. vorherige Anmerkung, II2) zitiert Cicero, Acad. II II7ff. und bezieht sich dabei auch auf die Analysen zur Stelle von A.-J. Festugière (1949), hier bes. 363.

33 C. Riedweg (vgl. vorherige Anmerkung, II2) verweist auf Platon, Soph. 26a4-5.

34 Platon, Euthyd. 285d7-287a5.

35 Platon, Theiat. I5Ie9-I52c7. I6Id2-e2; Aristoteles, metaph. IV 3-8.

36 Vgl. u. a. Möllendorf 2000; Dazu: Möllendorf 2007, 3I-45.

37 Die hoch komplexe Frage der Imitation und Aneignung klassischer Literatur durch die Vertreter der zweiten Sophistik kann hier natürlich nicht behandelt werden. Einschlägig sind die Ergebnisse des Giessener SFB „Erinnerungskulturen“ mit dessen von Peter von Möllendorf geleiteten Teilprojekt Aıo „Ästhetik und Bildung in der Zweiten Sophistik.“

38 Vgl. Hanson/Joussot 1993, I6. 66. - Für die ältere Literatur zu Hermias vgl. Di Pauli 1907, 4052. - Zum hier nicht weiter zu verfolgenden Motiv des Falls der Engel als Grundlage aller Philosophie bei Hermias vgl. Richard Bauckham 1985, 313-330.

39 In diesem Punkt besteht eine Kontinuität auch innerhalb der christlichen Apologetik bis ins 5 . Jahrhundert, vgl. hierzu meinen Beitrag (Ulrich 2009a), II3-I30. Wir verzeichnen erstens die Benutzung doxographischer Handbücher, in denen einschlägige Stellen der Philosophen aufgeführt waren, und zweitens die Etablierung einer binnenchristlichen Belegstellenkultur, die bei Eusebius einen Höhepunkt erreicht und am Ende bei Theodoret weidlich, aber eben oft auch 
seits über den Philosophenbetrieb lustig machten. Auf der anderen Seite blieben sie aber nicht bei der destruktiven Ausrichtung stehen, die das Argument bei den Skeptikern hatte. Zwar nutzten sie die vorliegenden Traditionen zur Kritik oder Destruktion paganer philosophischer Entwürfe, aber zugleich setzten sie dem einen positiven Entwurf entgegen, der einen unbeirrbaren Wahrheitsanspruch erhob. Für die Christen folgte aus dem Tatbestand vorliegender unterschiedlicher und widersprüchlicher philosophischer Meinungen zwar, dass die überkommenen Philosophien nur teilweise oder gar nicht tragfähig waren, aber daraus ergab sich nun gerade nicht das skeptische Plädoyer für die Meinungszurückhaltung, sondern die Notwendigkeit der Hinwendung zu einer tragfähigen philosophischen Alternative, nämlich der christlichen Lehre, ${ }^{40}$ von der dann freilich innere Kohärenz unabdingbar zu behaupten war, um sie nicht dem gerade ausgesprochenen Verdikt über einander widersprechende philosophische Meinungen auszusetzen. Die Polemik gegen die Widersprüchlichkeit paganer Philosophen diente den Christen nicht nur zur Zurückweisung von deren Lehren, sondern war zugleich eine bewusst eingesetzte dunkle Folie, vor der die eigene Lehre umso heller aufstrahlen und ihre Überzeugungskraft erweisen sollte.

\section{III.}

Nun war es gegen Ende des zweiten Jahrhunderts für niemanden zu übersehen, dass auch das Christentum dem Phänomen einer Diversifizierung von Meinungen bis hin zu Aufspaltungen in verschiedene Gruppen, Kirchen und Konfessionen unterlag. ${ }^{4 I}$ Und die Quellen zeigen, dass die Inkohärenz der Lehre und die

nur noch wiederholend, benutzt wird. Die doxographischen Handbücher bestimmen die Auswahl der Zitate und deren Anordnung, ihre Benutzung machte es den Apologeten natürlich leicht, schnell ein paar Stellen zusammenzusuchen, mit denen evident zu machen war, dass unterschiedliche Meinungen vorlagen. Aetius' Placita waren außerordentlich beliebt; Theodoret benutzt und empfiehlt nach eigener Aussage auch Plutarch, Placita Philosophorum, und Porphyrius' Geschichte der Philosophie, so Theodoret, cur. 4,31. Zugleich entwickelt sich eine binnenchristliche apologetische Belegtradition, die mit festen Argumentationsmustern arbeitete und dabei auch bestimmte Textanthologien produzierte, die die Nachfolgenden dann benutzten. Hier waren Clemens von Alexandriens Teppiche und Eusebs Praeparatio Evangelica die wichtigsten christlichen Sammlungen heidnischer Quellen, die ihrerseits wieder zur Quelle für die apologetischen Arbeiten des vierten (Athanasius) und fünften (Theodoret) Jahrhunderts wurden.

40 Auch Josephus falsifiziert mit dem skeptischen Argument der Meinungsvielfalt unter Philosophen nicht zu zuletzt auch die Skeptiker unter den Philosophen, indem er ihnen die Einheitlichkeit der jüdischen Lehre und Lebensführung entgegenstellt, C. Ap. II 179-I8I (vgl. hierzu die Bemerkungen von Manuel Vogel in Siegert, Bd. 2, Ir7). - Für die christlichen Texte vgl. entsprechend die oben zitierten Stellen Tatianus, orat. 25,3f. und Theophilus, Autol. 2,82,-9,2.

4I Auch Josephus, der die Einheitlichkeit des Judentums aus apologetischen Gründen gegenüber Apion ins Feld führt, wusste natürlich um die tatsächliche Vielfalt des Judentums, wie Bell. 
Aufspaltung in eine Vielzahl sich christlich nennender Gemeinschaften von heidnischer Seite sofort kritisiert wurden. Das ergibt sich sowohl aus christlichen Verteidigungsanstrengungen gegen eben diese Einwände als auch aus Zitaten heidnischer Kritiker, die zum Zwecke anschließender Widerlegung in christlichen Texten erhalten sind.

Unmittelbar an die oben zitierte Passage aus Tertullians Apologeticum ${ }^{42}$ anschließend finden wir einen ersten Beleg. Nachdem Tertullian das Widersprüchlichkeitsargument polemisch gegen die paganen Philosophen eingesetzt hat, verteidigt er sich sogleich gegen Vorwürfe, die auf die offensichtliche Pluralität christlicher Gruppierungen zielten oder zielen konnten:

Das erwähnen wir darum, damit nicht jemand angesichts der bekannten Meinungsverschiedenheit in unserer Gemeinschaft denkt, dass wir auch darin den Philosophen gleichkommen (ne cui nota uarietas sectae huius in hoc quoque nos philosophis aequare uideatur), und aufgrund der Meinungsverschiedenheit eine Schwäche der Wahrheit beanstandet. Kurzerhand aber wenden wir gegen unsere Verfälscher ein, dass jene die Richtschnur der Wahrheit ist, welche von Christus kommt und durch seine Gefährten überliefert worden ist, denen gegenüber sich diese abweichenden Ausleger als bedeutend später erweisen. ${ }^{43}$

Tertullian räumt die „bekannten Meinungsverschiedenheiten in unserer Gemeinschaft" (an denen er bekanntlich nicht ganz unbeteiligt war) ein und versucht dennoch, die Christen in diesem Punkt von den heidnischen Philosophen zu unterscheiden. Er tut dies, indem er die anderen Christen, aus seiner Sicht die „Häretiker“, ${ }^{44}$ als Dissidenten diskreditiert, die von der einheitsstiftenden Richtschnur abgewichen seien und die Tradition verlassen und Neuerungen eingeführt hätten. Die wahren Christen sind hingegen die, die sich auf die Tradition berufen können. Diese allein werden dem Anspruch auf Kohärenz der Lehre und Einheit der Gemeinschaft gerecht - im Unterschied zu den Abweichlern. Man sieht, wie sehr die Christen angesichts ihrer von ihnen behaupteten, aber offensichtlich nicht vorhandenen Einheit unter apologetischem Druck standen, gerade wenn sie selbst das Widersprüchlichkeitsargument zur Falsifizierung paganer Philosophien einsetzten. War das Problem der vielfältigen Gemeinden, Schulen, Zirkel, die sich alle als christlich ansahen, schon aus inneren Gründen eine massive Anfrage an die frühen Christen, so gerieten sie umso mehr in Erklärungszwang, wenn sie selbst mit dem etablierten Argument „Gegensätzlichkeit - falsch / Ein-

Iud. II II9-I6I oder Antiq. I8, II-2I zeigen. Manuel Vogel in Siegert, Bd. 2, II7, erklärt sich dies so, dass Josephus die apologetisch behauptete „bewundernswerte Eintracht" für die Juden weit gefasst habe. Das mag sein. Wie überzeugend das für nichtjüdische Leser war, ist eine andere Frage.

42 Tertullian, Apol. 47, 4-8. Vgl. oben Anm. I9.

43 Tertullian, Apol. 47, 9f. (CChr.SL I, I64,37-43 Dekkers). - Übersetzung nach T. Georges (vgl. Anm. 19).

44 Vgl. hierzu Tertullians Entwurf De praescriptione haereticorum. 
heitlichkeit - wahr" operierten, um ihren Wahrheitsanspruch geltend zu machen. Aus Perspektive eines heidnischen Kritikers ${ }^{45}$ traf die verwirrende Vielfalt, die Tertullian den Philosophen anlastete, auf die Christen in gleichem Maße zu. Tertullian hält demgegenüber an dem Anspruch der Christen auf Einheitlichkeit fest und "löst" das Problem, indem er die christlichen „Abweichler" nicht als Christen anerkennt. Ein ähnliches Vorgehen finden wir bei Justin, der Christen, die in Lehre und Lebenswandel Christus nicht entsprechen, im Grunde nicht mehr als Christen anerkennt bzw. sie als bloße „Namenschristen“ diskreditiert. ${ }^{46}$ Der apologetische Hintergrund dieser Aussagen ist mit Händen zu greifen. ${ }^{47}$

Eine genüssliche heidnische Polemik gegen die Diversität christlicher Lehre und Institutionalität finden wir bei Kelsos, dem großen Christentumskritiker am Ende des 2. Jahrhunderts. ${ }^{48}$ In seiner in der Apologie des Origenes referierten „Wahren Lehre" ${ }^{49}$ kritisiert er an drei Stellen die augenfällige Uneinigkeit der Christen. In Kels. 2,27 nimmt er die Vielzahl der Evangelien aufs Korn. Das Vorhandensein verschiedener Evangelien bei verschiedenen christlichen Gruppen sei ein Versuch, die Kritik am Christentum unter Hinweis auf das je eigene, „wahre“ Evangelium zu entkräften. Kelsos führt den Gebrauch verschiedener Evangelien und anderer kanonischer Texte bei den vielen sich christlich nennenden Gruppierungen als Beleg an, dass Hass und Streit, Spaltungen und Parteienwesen im Christentum an der Tagesordnung seien, womit dieses sich selbst diskreditiere. ${ }^{50}$ In Kels. 3,IO-I4 wird den Christen unterstellt, dass nur noch der Name, die Tendenz zum Aufruhr und die gemeinsame Furcht vor den äußeren Feinden als gemeinsamer Nenner erscheine, während sie sich angesichts ihrer zahlreichen Trennungen und Spaltungen letztlich gegenseitig widerlegen. ${ }^{\text {II }}$ Die christlicherseits als

45 Mit dem ,jemand“ (cui) in apol. 47,9 ist sicher keine bestimmte Person im Blick, sondern verallgemeinernd die Außenperspektive auf das Christentum eingeholt.

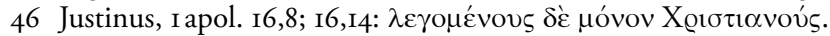

47 Es handelt sich offensichtlich um eine Verteidigung gegen den Vorwurf der Inkohärenz der Lebensweise verschiedener Christen. Im Hintergrund steht der moralische Wahrheitsbeweis, den Justin unter Verweis auf die Bergpredigt zu Gunsten des Christentums zu führen versucht. Vgl. Ulrich 2006, 2I-28 und Ulrich 2009b, 209-229 (214f.).

48 Vgl. Frede 1994, 5183-5213.

49 Die, Wahre Lehre' des Kelsos, übersetzt und erklärt von Horacio E. Lona, KfA.E ı, Freiburg 2005 .

50 Dass die vielfältige Institutionalität konkurrierender christlicher Gruppen mit dem Vorhandensein unterschiedlicher kanonischer Texte in diesen Gruppen korrespondieren konnte, hat Kelsos völlig richtig gesehen - ein Beleg dafür, dass er das Christentum, gegen das er polemisiert, einigermaßen gut gekannt haben muss.

5I Kels. 3,IO-I4: „Am Anfang waren sie wenige und eines Sinns. Nachdem sie aber zu einer Menge angewachsen sind, trennen und spalten sie sich wieder, und jeder will seine eigene Partei haben. Denn danach verlangten sie von Anfang an. Infolge der Menge haben sie sich wieder voneinander getrennt und widerlegen sich gegenseitig; sie haben sozusagen nur eines noch gemeinsam, wenn sie es überhaupt gemeinsam haben: den Namen. Das ist doch das Einzige, das sie sich schämen aufzugeben; was den Rest anbelangt, organisiert sich jede Gruppe jeweils 
Wahrheitskriterium geltend gemachte Eintracht existiert in Wirklichkeit nicht, der damit verbundene Anspruch entfällt. Zum Beweis präsentiert Kelsos die berühmte lange Liste einander unerbittlich bekämpfender christlicher Gruppen, ${ }^{52}$ in der man cum grano salis das heidnische, gegen die Christen polemisierende Pendant zu Tatians und Hermias' christlicher, gegen die Heiden polemisierender Liste verschiedener Philosophengruppen erblicken kann. Kelsos will die Christen angesichts ihrer vielfältigen Zerstrittenheit lächerlich machen und ihren Wahrheitsanspruch durch den Hinweis falsifizieren, dass sie sich untereinander alle beschimpfen, hassen und sich in ihren Streitereien gegenseitig widerlegen:

Niemand soll meinen, ich wisse nicht, dass die einen unter ihnen darin übereinstimmen, ihr Gott sei derselbe wie jener der Juden, andere hingegen meinen, ihr Gott sei ein anderer - ein Gegner des Ersten -, und von dem sei der Sohn gekommen. Es gibt auch ein drittes Geschlecht derer, die einige als Psychiker bezeichnen, andere als Pneumatiker. Einige stellen sich als Gnostiker vor. Einige anerkennen Jesus, aber sie wollen nach dem jüdischen Gesetz weiter leben wie die Masse der Juden. Einige sind Sibyllisten. Ich kenne auch die Simnoianer, welche die Helena oder den Helenos als Lehrer verehren und auch Helenianer genannt werden. Ich kenne auch die Markellianer, die von Markellina, und die Harpokratianer, die von Salome, und andere von Mariamme und andere von Martha, und die Markioniter, deren Vorsteher der Markion ist. Einige haben diesen, andere jenen Lehrer und Dämon als Vorsteher gefunden, indem sie in übler Weise umherirren und sich in großer Finsternis herumwälzen, gesetzloser und verworfener als die Vereinsgenossen des Ägypters Antinoos. Sie beschimpfen sich gegenseitig auf übelste Weise mit sagbaren und unsagbaren Ausdrücken und sie würden nicht nachgeben, auch nicht im Hinblick auf die Eintracht, denn sie hassen sich gegenseitig durchaus. Einige nennen sie Kirken und listige Unruhestifter. Einige werden Brandmale der Ohren genannt; einige Rätsel; einige hinwegtanzende und sophistische Sirenen, die die Ohren der Gläubigen versiegeln und mit einem Schweinskopf versehen. Auch wenn sie sich voneinander distanziert haben und sich selbst in ihren Streitigkeiten in der schlimmsten Form widerlegen, so hört man dennoch von allen sagen: „Für mich ist die Welt gekreuzigt, und ich für die Welt." “\$3

Ein kurzer Blick auf die spätere pagane Christentumskritik zeigt, dass der Inkohärenzvorwurf auch im 3. und 4. Jahrhundert noch von paganer Seite gegen die Christen erhoben fortbestand - das Christentum bot an diesem Punkte hinreichend Angriffsflächen. Christoph Riedweg hat in diesem Zusammenhang auf das

anders. Ihre Verbindung ist umso erstaunlicher, je weniger sie, wie man nachweisen kann, auf einer zuverlässigen Grundlage beruht. Die zuverlässige Grundlage aber ist nur der Aufruhr und der von ihm bedingte Vorteil, sowie die Furcht vor den äußeren Feinden. Dies allein befestigt ihren Glauben." - Übersetzung nach H. Lona (vgl. Anm. 49), i8I; zur Kommentierung der Passage vgl. ebd. I8I-183.

52 Kelsos 5,6I-64.

53 Übersetzung von Horacio E. Lona, a.a.O. 310.; zur Kommentierung dieser Passage vgl. ebd. 3IO-3I4. 
bei Clemens von Alexandrien Referierte aufmerksam gemacht, wo den Christen

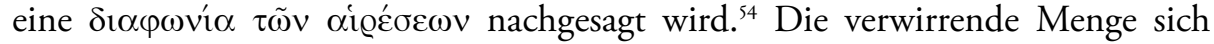
christlich nennender, aber einander befehdender Parteien, war für Beobachter von außen befremdlich und falsifizierte jegliche christliche Wahrheitsansprüche. Neben der institutionellen Mannigfaltigkeit scheint inhaltlich v.a. die Inkohärenz der biblischen Zeugnisse immer von neuem Zielscheibe der Kritik an den Christen gewesen zu sein. Eine große Rolle spielen dabei, wie schon bei Kelsos gesehen, die Vielzahl verschiedener Evangelien bei verschiedenen christlichen Gruppen, aber auch die Vierzahl der Evangelien in der sich etablierenden Großkirche. Die tatsächliche oder vermeintliche Widersprüchlichkeit der Jesusüberlieferung wurde von Porphyrius ebenso vorgetragen ${ }^{5 s}$ wie von Hierokles, dem von Diokletian mit der Abfassung einer christentumskritischen Schrift beauftragten bithynischen Statthalter. ${ }^{56}$ Bis ins 5. Jahrhundert hinein konfrontierten die heidnischen Gegner des Christentums die nun zur führenden Größe im Imperium Romanum aufgestiegene christliche Religion mit diesem Vorwurf, was sich an apologetischen Bemühungen Theodorets im Osten und Augustins im Westen indirekt ablesen lässt. ${ }^{57}$

\section{IV.}

Das Widersprüchlichkeitsargument besaß in der zeitgenössischen intellektuellen Umwelt hohe Akzeptanz und große Beliebtheit in der wechselseitigen Polemik und Apologetik. Wie aber reagierten nun die Christen, die das Widersprüchlichkeitsargument in ihrer Polemik gegen die paganen Philosophen verwendeten, darauf, dass eben dasselbe Argument ihnen von paganer Seite mit durchaus nachvollziehbaren Gründen vorgehalten wurde? Bei Tertullian sahen wir, dass er anders denkenden Christen mit Hilfe einer Traditionskonstruktion die Authentizität und damit das Christsein abspricht. Ähnlich verhält es sich bei Justin, der Abweichlern von einer als kohärent dargestellten christlichen Ethik abspricht,

54 Clemens Alexandrinus, str. VII 89,2, zitiert bei Riedweg (vgl. Anm. 23), Iı3f. mit Anm. 468.

55 Porphyrius, Adv. Christ. fr. I5 Harnack.

56 Abzulesen in den Fragmenten bei Laktanz, inst. V 2f. und in der Gegenschrift des Eusebius von Caesarea, Contra Hier.; insbesondere Hier. 2. Hierokles' Traktat widerlegt die Christen durch Erweis der Überlegenheit des Apollonius von Tyana gegenüber Christus und durch den Nachweis von Widersprüchen im Neuen Testament.

57 Theodoret, cur. 5,49: „Den Gesetzgeber Mose nämlich und den Propheten David, den hochherzigen Ijob, Jesaja, Jeremia, und überhaupt den ganzen Chor der Propheten ebenso wie Matthäus, Johannes, Lukas, Markus, Petrus, Paulus und die Schar der Apostel, sie alle kann man in völliger Übereinstimmung über die menschliche Natur zu den Leuten sprechen sehen." - Augustinus, Civ. 18,4I: „Dagegen sind unsere Schriftsteller, die man mit gutem Grund zum fest abgegrenzten Kanon heiliger Schriften zusammengefasst hat, weit entfernt davon, irgendwie voneinander abzuweichen." 
Christen zu sein..$^{8}$ Das apologetisch geforderte Bemühen um den Erweis von Einheit verstärkt ohnehin bestehende Tendenzen, abweichende Lehren und andere sich als christlich verstehende Gemeinschaften nicht als zugehörig zur christlichen Gemeinschaft anzuerkennen. Das Problem von „Häresie und Orthodoxie“ erfährt mit dem Widersprüchlichkeits- und Kohärenzargument eine erhebliche Verschärfung. Die Notwendigkeit des Nachweises eigener Lehrkohärenz erforderte es, klare Abgrenzungen vorzunehmen von allen, die von den jeweiligen Konsensen abwichen. Zusätzlich zu derartigen Abgrenzungsmanövern verzeichnen wir verstärkte apologetische Bemühungen der Christen um den Nachweis eigener Lehrkohärenz. Behauptete man, eine evident überlegene Alternative aufzeigen zu können, die positive, widerspruchsfreie philosophische und theologische Aussagen ermöglichte und sich genau darin von der verwirrenden Vielfalt philosophischer Versuche positiv unterschied, musste man dies belegen und gegen Kritik schützen. Bemühungen um den Erweis innerer Einheit mussten die Folge sein. Von besonderer Bedeutung wurde das Insistieren auf der Einheitlichkeit der eigenen Offenbarungsüberlieferung. Dies konnte auf unterschiedliche Weise geschehen: Meist unter Hinweis auf die göttliche Inspiration der Schrift bzw. ihrer Verfasser, häufig mit Hilfe der typologischen und allegorischen Auslegungsmethode(n), oft durch Verwendung oder Aufstellung von Chroniken und Chronologi$\mathrm{en}^{59}$ und in manchen Milieus mit Anstrengungen hinsichtlich der christlichen Hermeneutik. ${ }^{60}$ Für die heiligen Schriften des Alten Testaments konnte man hierzu teils auf entsprechenden apologetischen Anstrengungen jüdischer Autoren aufbauen. Im Blick auf den werdenden neutestamentlichen Kanon ergaben sich aber neue Schwierigkeiten wie das Problem mehrerer Evangelien, das von Gegnern wie Kelsos aufgespießt wurde. Irenäus argumentiert zugunsten der Vierzahl der Evangelien, indem er einerseits das „vierfältige Evangelium“ gerade gegen die Zersplitterung geltend macht, die andere durch die Beschränkung auf nur ein Evangelium verursacht hätten ${ }^{61}$ und andererseits in weitreichenden allegorischen Deutungen der Vierzahl gerade die Einheit des Kosmos bzw. Einheit der Heilsordnung in dieser Vierheit symbolisiert sieht.

Warum sollte die Zahl der Evangelien größer oder kleiner sein? Da die Welt, in der wir leben, sich in vier Gegenden teilt und weil es vier Hauptwindrichtungen gibt, die Kirche aber auf der ganzen Erde verbreitet ist, Säule und Stütze der Kirche das Evangelium und der Geist des Lebens sind, so hat sie plausiblerweise vier Säulen, die von allen Seiten Unvergänglichkeit atmen und die Menschen immer

58 Vgl. hierzu oben Anm. 46.

59 Z.B. Julius Africanus oder Eusebius von Caesarea; vgl. auch Theophilus, Autol. 3,16-30, wo die Chronologie die Funktion der Absicherung des Altersbeweises durch einen Kohärenznachweis erfüllt.

60 Z.B. Augustinus, De doctrina Christiana; zuvor schon Tyconius.

6I Irenäus, haer. 3,II,7. 
neu beleben. Da leuchtet es ein, dass der Erbauer des Alls, der Logos, „der auf den Kerubim thront“ und „das All zusammenhält“, uns bei seinem Erscheinen vor den Menschen das Evangelium in vierfacher Gestalt gab, aber zusammengehalten von einem Geist. ${ }^{62}$

Irenäus begründet den Vierevangelienkanon mit dem Hinweis auf die Komplementarität der Vierzahl, die, wie bei den vier Himmelsrichtungen, nur zusammen ein einheitliches Ganzes ergeben; die Vierzahl verdankt sich dem Willen des Schöpfungsmittlers, von dessen Erscheinen bei den Menschen dann auch in vierfacher Weise die Rede sein muss, wobei die Vierheit von dem einen Geist zusammengehalten wird (uno spiritu continetur). Der Vierevangelienkanon ist nicht eine Sammlung von vier Evangelien, sondern eine logos- und schöpfungsgemäße Viergestaltigkeit des einen Evangeliums. Irenäus' Begründung läuft darauf hinaus, die Vierzahl als Einheit zu interpretieren und so die Kohärenz der Offenbarungsüberlieferung zu erweisen.

Dabei muss man allerdings sehen, dass, auch wenn sich langfristig der Vierevangelienkanon durchgesetzt hat, die Überzeugungskraft der Ausführungen eines Irenäus unter den frühen Christen nicht überall gleichermaßen hoch war. Vor dem Hintergrund des Widersprüchlichkeits- und Kohärenzarguments wird jedenfalls gut verständlich, dass in einigen christlichen Kreisen verstärkt Bemühungen um eine Evangelienharmonie sichtbar werden. ${ }^{63}$ Diese konnte apologetisch die Funktion erfüllen, den christlichen Wahrheitsanspruch und seine Begründung aus der Einheitlichkeit der christlichen Lehre zu unterstreichen und ihn in Abgrenzung von der Vielfalt und Gegensätzlichkeit der Meinungen bei den Heiden zur Geltung zu bringen. Das apologetisch motivierte Interesse am Aufweis von Einheitlichkeit und Kohärenz hat dem Diatessaron offenbar doch in weiten Kreisen der frühen Christenheit erheblichen Erfolg ermöglicht. Gerade in denjenigen christlichen Milieus, in denen das Argument von Widersprüchlichkeit und Kohärenz den Heiden besonders radikal entgegengehalten wurde, so wie etwa bei Tatian, fand der Vierevangelienkanon keine Freunde, sondern es wurde die Notwendigkeit gesehen, ein einheitliches, verbindliches Evangelium zu erstellen. Das Entstehen des Diatessaron gerade in den Kreisen um Tatian verdankt sich auch dem apologetischen Bemühen, paganer Kritik an der Vielfalt christlicher Überlieferung den Wind aus den Segeln zu nehmen. Hier konnte eine Evangelienharmonie überzeugender erscheinen als der noch so kongruent verstandene Vierevangelienkanon.

Neben den apologetischen Bemühungen um Kohärenzerweise sei aber auch auf eine grundsätzlich andere Strategie hingewiesen, sich gegen den Vorwurf in-

62 Irenäus, haer. 3,II,8. Ich zitiere die Übersetzung von Norbert Brox: Irenäus von Lyon, Adversus Haereses. Gegen die Häresien, übersetzt und eingeleitet von Norbert Brox, FC 8/3, Freiburg I995, I09-III.

63 Vgl. hierzu Petersen 1994 (Lit!); Baarda 1994 (Lit!). 
nerchristlicher Meinungsvielfalt zu verteidigen. Diese finden wir bei Origenes, der in seiner Auseinandersetzung mit der "Wahren Lehre" des Kelsos die Vielfalt innerhalb des Christentums ausdrücklich zu rechtfertigen versucht. Während Tertullian und andere apologetisch auf Bestreitung der Vielfalt innerhalb des Christentums setzten, betreibt Origenes ihre Legitimierung. Freilich hatte Origenes das Widersprüchlichkeitsarguments auch nicht polemisch gegen die Heiden in Anschlag gebracht. Origenes reagiert jedenfalls auf die Kritik des Kelsos, ${ }^{64}$ indem er die Verschiedenheit christlicher (und sonstiger) Theorien nicht als Widersprüchlichkeit, sondern als legitime Vielfalt interpretiert. So wie es in der Heilkunst, aber auch in der Philosophie und in der jüdischen Theologie verschiedene Schulen gab und gibt, verhält es sich eben auch im Christentum. Origenes hält Kelsos entgegen:

Es wäre aber doch wenig vernünftig, wenn man von der Heilkunde wegen der in ihr vorhandenen verschiedenen Richtungen nichts wissen wollte, oder wenn man nach würdigen Zielen streben und sich doch mit Hass von der Philosophie abwenden und diesen Hass damit rechtfertigen würde, dass die Philosophen unter sich vielfach nicht einig seien. Ebensowenig darf man die heiligen Bücher des Moses und der Propheten wegen der Sekten verdammen, die unter den Juden entstanden sind. Hat es hiermit seine Richtigkeit, warum sollten wir dann nicht in gleicher Weise auch das Vorhandensein von Sekten unter den Christen rechtfertigen können? ${ }^{65}$

Damit nimmt Origenes innerhalb des zeitgenössischen Denkens wie innerhalb der christlichen Apologetik freilich insofern eine gewisse Sonderstellung ein, als er die Vielfalt von Meinungen nicht als Widersprüchlichkeit diskreditiert, sondern positiv deutet.

\section{$\mathrm{V}$.}

Wie beim Alters- oder beim moralischen Beweis handelt es sich auch beim Widersprüchlichkeits- und Kohärenzargument um eine in der Antike konsensuell etablierte, in ihrer Gültigkeit nicht bestrittene Denkfigur. Es besteht auf allen Seiten Einigkeit darüber, dass Widersprüchlichkeit in den Aussagen gegen und dass Kohärenz in den Aussagen für die Wahrheit einer Lehre sprechen. Die Wahrheit muss in sich stimmig sein, während die Unwahrheit in Widersprüche zerfällt, weil sie sowohl mit der Wahrheit als auch mit sich selbst im Streit ist.

64 Vgl. hierzu oben Anm. 53.

65 Origenes, Cels. III I2 (GCS Origenes I, 2II,25-2I2,I3 Koetschau). - Übersetzung nach Origenes, Acht Bücher gegen Kelsos, I. Teil Buch I-IV, aus dem Griechischen übersetzt von P. Koetschau, BKV 52, München 1926, 219 (leicht geändert). 
$\mathrm{Zu}$ verzeichnen ist eine gewisse Traditionsbildung in der Verwendung des Arguments, die auch literarischen Niederschlag findet in der doxographischen $\mathrm{Zu}-$ sammenstellung von Textbelegen und durch die offenbar beliebte Inanspruchnahme in der Satire. Die inkohärente Vielzahl philosophischer Meinungen konnte benutzt werden zur Selbstkritik, als kritisches Argument gegenüber jeweils anderen Auffassungen, als polemische Verspottung des real existierenden zeitgenössischen Philosophenbetriebes, aber auch als ernstes philosophisches Argument zur Meinungszurückhaltung in stoischem Sinne. Juden und Christen übernahmen die vorgeformte Denkfigur und machten sie sich in der Polemik gegen die Heiden zunutze, um sodann der paganen Philosophie die eigene Lehre als überzeugende Alternative entgegenzuhalten. Aus diesem Verfahren ergab sich freilich ein erheblicher apologetischer Druck, wenn es darum ging, angesichts der offensichtlichen Vielfalt eigener Lehre und Institutionalität für das eigene Lager Einheitlichkeit und Widerspruchsfreiheit zu behaupten. Die einschlägigen Texte zeigen, dass es eher leicht war, das Argument polemisch einzusetzen, dass sich die Apologetik aber schwer tut, entsprechende Vorwürfe gegen die eigene Seite zu entkräften. Neben der entschiedenen polemischen Abgrenzung von anders denkenden Christen um der äußeren Einheit willen zeigen sich vor allem argumentative Bemühungen um den Erweis der Einheitlichkeit der eigenen Offenbarungsüberlieferung. Stimmen, die die Vielfalt sowohl der christlichen Institutionen als auch der kanonischen Texte positiv deuten und als Mannigfaltigkeit legitimieren, sind demgegenüber in der Minderheit geblieben.

Das Bewusstsein, dass die Einheitlichkeit von Lehre Bedingung für das Erheben von Wahrheitsansprüchen war, scheint im Vollzug wechselseitiger Polemik wie Apologetik weiter geschärft worden zu sein und mit der Zeit auch Niederschlag institutionellen Gestaltwerdungsprozessen gefunden zu haben. Ab der Mitte des dritten Jahrhunderts absorbiert der Neuplatonismus viele der übrigen philosophischen Schulen, wodurch die griechische Philosophie im Vorfeld der „Konstantinischen Wende“ ein deutlich einheitlicheres Bild abgibt. Im Christentum entsteht trotz zahlreicher Spaltungen und Lehrdifferenzen zeitgleich eine als solche immer deutlicher kenntlich werdende allgemeine Kirche, die nicht zuletzt aufgrund ihrer relativen Einheitlichkeit in Struktur und Lehre zu einem gesellschaftlich maßgeblichen Faktor im Imperium Romanum aufsteigen konnte. Dass Konstantin der Große in seinem Kirchen- und Theologieverständnis immer wieder auf die Einheitlichkeit als entscheidenden Faktor abhob, ist Ausweis dieser Entwicklung und hat sie zugleich abermals befördert. 


\section{Literaturverzeichnis}

Ackermann (1997): Sonja Ackermann, Christliche Apologetik und heidnische Philosophie im Streit um das Alte Testament, SBB 36, Stuttgart.

Baarda (I994): Tjitze Baarda, „Essays on the Diatessaron“, Contributions to Biblical Exegesis and Theology II, Kampen.

Barnard (1972a): Leslie W. Barnard, Athenagoras. A Study in Second Century Christian Apologetic, ThH i8, Paris.

Barnard (I972b): Leslie W. Barnard, „The Philosophical and Biblical Background of Anthenagoras“, in: Jacques Fontaine u. Charles Kannengießer (Hgg.), Epektasis. Mélanges patristiques offerts au Cardinal Jean Daniélou, Paris, 3-16.

Bauckham (1985): Richard Bauckham, „The Fall of the Angels as the Source of Philosophy in Hermias and Clement of Alexandria“, in: VigChr 39, 313-330.

Di Pauli (1907): Andreas Freiherr von Di Pauli, Die Irrisio des Hermias, FChLDG VII,2, Paderborn, 40-52.

Elze (1960): Martin Elze, Tatian und seine Theologie, FKDG 9, Göttingen.

Feldman (1996): Louis H. Feldman, Josephus „Contra Apionem“. Studies in its Character and Context with a Latin Concordance to the Portion Missing in Greek, AGJU 34, Leiden.

Festugière (1949): André-Jean Festugière, La rélévation d'Hermès Trismégiste. II: Le dieu cosmique, Paris.

Fiedrowicz (200I): Michael Fiedrowicz, Apologie im frühen Christentum. Die Kontroverse um den christlichen Wahrheitsanspruch in den ersten Jahrhunderten, Paderborn, 292f.

Frede (1994): Michael Frede, Celsus philosophus Platonicus, in: ANRW 36,7, 51835213.

Gerber (1997): Christine Gerber, Ein Bild des Judentums für Nichtjuden von Flavius Josephus. Untersuchungen zu seiner Schrift „Contra Apionem“, AGJU 40, Leiden.

Haaland (2007): Gunnar Haaland, Beyond Philosophy. Studies in Josephus and his Contra Apionem, Münsteraner Judaistische Studien 7, Münster.

Hanig (1999): Roman Hanig, „Tatian und Justin“, in: VigChr 53, 3I-73.

Hanson/Joussot: Richard Patrick Crossland Hanson u. Denise Joussot, Hermias, Satire des philosophes païens. Introduction, texte critique, notes, appendices et index par R.P.C. Hanson et ses collègues, SC 388, Paris, I6. 66.

Harnack (1905): Adolf von Harnack, Der Vorwurf des Atheismus in den ersten drei Jahrhunderten. Ein Beitrag zur Verfolgungsgeschichte der christlichen Kirche im römischen Staat, TU 28.4, Leipzig. 
Klostergaard Petersen (2009): Anders Klostergaard Petersen, „The Diversity of Apologetics: From Genre to a Mode of Thinking", in: Anders-Christian Jacobsen, Jörg Ulrich, David Brakke (Hgg.), Critique and Apologetics. Jews, Christians and Pagans in Antiquity, ECCA 4, Frankfurt, I5-4I.

Labow (2005): Dagmar Labow, Flavius Josephus, Contra Apionem, Buch I: Einleitung, Text, textkritischer Apparat Übersetzung und Kommentar, BWANT I67, Stuttgart.

Meiser (2000): Martin Meiser, „Frühjüdische und frühchristliche Apologetik“, in: Kalms, Jürgen U. (Hg.), Internationales Josephus-Kolloquium Aarhus I9g9, Münsteraner Judaistische Studien 6, Münster, I55-I84.

Minns u. Parvis (2009): Dennis Minns u. Paul Parvis (Hgg.), Justin, Philosopher and Martyr, Apologies, edited with an Introduction, Translation, and Commentary on the Text, OECT, Oxford.

Möllendorf (2000): Peter von Möllendorf (Hg.), Lukian, Hermotimos oder Lohnt es sich, Philosophie zu studieren?, (TzF 74) Darmstadt.

Möllendorf (2007): Peter von Möllendorf, „Grübler, Schwätzer, Scharlatane - das Bild des Intellektuellen bei Lukian“, in: Pegasus-Onlinezeitschrift 7, 3I-45.

Petersen (1994): William Lawrence Petersen, „Tatian's Diatessaron. Its Creation, Dissemination, Significance and History in Scholarship", in: VigChr.S 25, Leiden.

Pilhofer (1990): Peter Pilhofer, Presbyteron - kreitton. Der Altersbeweis der jüdischen und christlichen Apologeten und seine Vorgeschichte, WUNT II 39, Tübingen.

Riedweg (1993): Christoph Riedweg, Rez. Hermias, Satire des philosophes païens. Par R.P.C. Hanson/D. Joussot (Paris 1993), in: JAC 38, I8I-183.

Riedweg (1994): Einleitung und Kommentar von Pseudo-Justin (Markell von Ankyra?), „Ad Graecos de vera religione“ (bisher „Cohortatio ad Graecos"), Teil I: Einleitung, SBA 25/I, Basel, I09-II5.

Riedweg (2000): Christoph Riedweg, Art. „Hermias“, in: RGG 4 3, 1673.

Skeb (2002): Matthias Skeb, Art. „Hermias", in: LACL" ${ }^{3}, 320 f$.

Steuer (1892): Carl Willibald Steuer, Die Gottes- und Logoslehre des Tatian in ihren Berührungen mit der griechischen Philosophie, Jena.

Ulrich (2005): Jörg Ulrich, „Innovative Apologetik. Beobachtungen zur Originalität Justins am Beispiel seiner Lehre vom Logos spermatikos und anderer Befunde", in: $T h L Z_{130}$, 3-16.

Ulrich (2006): Jörg Ulrich, „Ethik als Ausweis christlicher Identität bei Justin Martyr", in: ZEE 50, 2I-28.

Ulrich (2009a): Jörg Ulrich, „The Reception of Greek Christian Apologetics in Theodoretus' Graecarum affectionum curatio", in: Jörg Ulrich/AndersChristian Jacobsen/Maijastina Kahlos (Hgg.), Continuity and Discontinuity in Early Christian Apologetics, ECCA 5, Frankfurt/M., II3-I3O. 
Ulrich (2009b): Jörg Ulrich, „Apologetics and Orthodoxy“, in: Anders-Christian Jacobsen/Jörg Ulrich/David Brakke (Hgg.), Critique and Apologetics. Jews, Christians and Pagans in Antiquity, ECCA 4, Frankfurt, 209-229.

Waszink (I988): Jan Henrik Waszink, Art. „Hermias”, in: $R A C$ I4, 808-8I5. 



\title{
Einen missglückten Auftritt retten
}

\section{Kor Io,Iof. und die rhetorische Kultur der frühen Kaiserzeit}

\author{
THOMAS JOHANn BAUER
}

\section{Rhetorik und neutestamentliche Exegese}

Mit seinen Arbeiten zum Galaterbrief hat Hans Dieter Betz zu Beginn der 7oer Jahre des letzten Jahrhunderts in der neutestamentlichen Exegese eine erneute intensive Rezeption der antiken rhetorischen Theorie initiiert. ${ }^{\text {I }}$ Der Fokus der von Hans Dieter Betz begründeten rhetorischen Analyse neutestamentlicher Texte lag und liegt auf der Zuweisung eines Textes zu einer der rhetorischen Gattungen und der damit einhergehenden Offenlegung seiner rhetorischen Struktur. Für nahezu jede Schrift des Neuen Testaments - und zum Teil auch für andere Schriften des Frühchristentums - stellte man die Frage, ob sie zur Gänze oder zumindest in Teilen einer der drei Redegattungen (genus iudiciale, deliberativum oder demonstrativum) angehöre, um in ihnen anschließend, ausgehend von den Idealschemata der antiken Rhetorikhandbücher, die Teile einer Rede zu identifizieren und dadurch die „mustergültige“ rhetorische Gestaltung eines Textes zu erweisen. ${ }^{2}$ Jedoch wurde dabei nur für die wenigsten Texte ein dauerhafter Konsens erzielt, weshalb nicht selten der grundsätzliche Wert einer rhetorischen Analyse überhaupt in Frage gestellt wurde. ${ }^{3}$

I Vgl. Betz 1974/75; Betz 1979. Zum Galaterkommentar von Betz und seiner Bedeutung für die rhetorische Analyse der Paulusbriefe (und anderer ntl. Schriften) Klauck 2006, 222f.; Porter 1997, 539-54I. Eine kritische Würdigung des Ansatzes von Betz auch bei Classen 1991, I3-16 u. 29-33; Porter 1993, IO2-IO4. Ein Überblick zur Rezeption des Kommentars von Betz in der ntl. Exegese bei Classen 2009, I46-I53. Zur Geschichte und älteren Ansätzen der rhetorischen Analyse der ntl. Schriften vgl. Betz 1986, I6-21; Anderson 1996, I3-28.

2 Von diesen Versuchen sei exemplarisch Kennedy 1984 genannt; dazu Classen 2009, I47. Für die echten Paulusbriefe vgl. auch Porter 1997, 538-56I; Anderson 1996, III-248; für die übrigen ntl. Schriften Thurén 1997.

3 Classen 1991, 2-5, sieht die Anwendung der antiken Rhetorik in der ntl. Exegese schon allein deshalb gerechtfertigt, weil sie sich grundsätzlich mit Gewinn zur Analyse jedes geschriebenen oder gesprochenen Textes heranziehen lässt. Die Anwendbarkeit auf einen Text erlaubt für ihn aber nicht per se den Umkehrschluss, dass dieser bewusst mit Hilfe der Regeln der Rhetorik gestaltet wurde. Skeptischer zur Frage der Möglichkeit und Berechtigung, ntl. Schriften anhand der antiken rhetorischen Theorie zu analysieren, Porter 1993, I05-I09. 
Die Reserve gegen eine rhetorische Analyse neutestamentlicher Texte ist aber teilweise auch in einem grundlegenden Unbehagen und Misstrauen gegenüber der Rhetorik an sich begründet. Denn Rhetorik sei die Kunst, durch Überredung und Manipulation ohne Rücksicht auf die Wahrheit auch der schwächeren und eventuell sogar moralisch schlechteren Sache zum Sieg zu verhelfen (so das von den antiken Philosophen in ihrer Kritik an der Rhetorik als Beweis vielzitierte

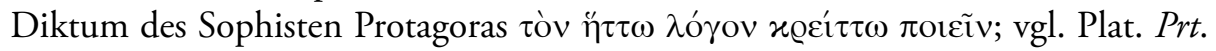
317b). Die christliche Verkündigung dagegen wolle die Menschen nicht durch Wortprunk und raffinierte Argumentation für das Evangelium gewinnen, sondern in schlichten Worten und Sätzen durch die einfache Wahrheit (vgl. I Kor I,26-29). ${ }^{4}$ Aus diesem Grund sehen es manche Exegeten geradezu als zwingend an, dass sich in den neutestamentlichen Schriften keine Anzeichen paganer Beredsamkeit finden.

Aufgrund ihrer Haltung zur Rhetorik stehen sich in der neutestamentlichen Forschung somit zwei Lager gegenüber: Die einen gehen relativ unbefangen davon aus, dass sich in den neutestamentlichen und frühchristlichen Schriften durchaus Elemente der klassischen antiken Rhetorik aufweisen lassen, und nehmen deshalb an, dass ihre Verfasser über eine entsprechende rhetorische Schulung und Übung verfügten. 5 Die anderen lehnen derartige Annahmen weitgehend $\mathrm{ab}$ und verorten die neutestamentlichen Autoren, bis auf wenige Ausnahmen (Hebr, I Petr, Jak), im sozialen Milieu der kaum gebildeten städtischen Unterschicht. ${ }^{6}$ Wo sich dennoch, wie z.B. in den Briefen des Paulus, in der sprach-

4 Dies knüpft an den antiken (philosophischen) Diskurs über den rechten Gebrauch der Rhetorik bzw. wahre und falsche Rhetorik an, der mit dem Stichwort „Sophisten“ bzw. „Sophistik“ verbunden ist und unter anderem bei Platon (Grg.), Demosthenes (I9,246. 250; 29,32 u.ö.) und Aristophanes (Nu.) fassbar wird; dazu Whitmarsh 2005, I5-I9; Andersen 200I, I84-I94 u. 20I208; Ueding/Steinbrink 2005, I5-23. Solche Vorurteile beeinflussten die Bewertung der Rhetorik bis in die Neuzeit, wie die von Andersen 200I, 25f., aufgelisteten modernen Definitionen der Rhetorik zeigen. Auch davon ist die Antwort auf die Frage bestimmt, ob die ntl. Autoren sich rhetorischer Techniken bedienten und ob eine Analyse der ntl. Texte mit dem Instrumentarium der rhetorischen Kunst überhaupt sinnvoll und statthaft sei.

5 Für Paulus glaubt Vegge 2006, 425-486, dies nachweisen zu können. Auch Lohse 2003, Iogf., anerkennt eine grundsätzliche Vertrautheit des Paulus mit rhetorischen Techniken, doch habe er diese nicht in einer hellenistischen Rhetorenschule gelernt, sondern sie seien ihm durch die hellenistische Synagoge vermittelt. Kritisch zur Annahme, dass alles Hellenistische bei Paulus und im (frühen) Christentum sich der Vermittlung des hellenistischen Judentums verdanke, Schnelle 2003, 69-7I. Grundsätzliche methodische Überlegungen zur Identifizierung rhetorischer Elemente in ntl. Texten (insbesondere den Paulusbriefen) und zur Frage, wie die Ergebnisse auszuwerten sind und welche Schlüsse sie erlauben (z.B. für die Frage nach der Bildung des jeweiligen Autors) bei Classen 2009, I53-I56; vgl. auch den Überblick bei Porter 1993, 99I05.

6 In der Nachfolge von Deißmann 1923, 53-56 u. I98-213. Auch Norden 1915, 474-476, stand der Frage, ob Paulus mit hellenistischer Literatur und Bildung vertraut war, skeptisch gegenüber; wo sich Anklänge finden, sieht er sie durch das hellenistische Judentum vermittelt. Die Frage nach der sozialen Herkunft des Paulus stellt er nicht. 
lich-stilistischen Gestaltung oder auch der Argumentation ein gewisser Einfluss der Rhetorik nicht bestreiten lässt ${ }^{7}$, verweist man zur Erklärung auf das natürliche Genie und den religiösen Impetus des Verfassers und gesteht unter Umständen zu, er habe sich entsprechende Formulierungen und Argumentationsfiguren bei einem der in jener Zeit zahlreichen Wanderphilosophen und professionellen „Konzertrednern“ auf den Marktplätzen der Städte Kleinasiens und Griechenlands abgelauscht und sie später eher unbewusst nachgeahmt. ${ }^{8}$

\section{Kor Io,Iof. und der rhetorische Auftritt}

Der vorliegende Beitrag kann und will die von beiden Seiten vorgebrachten Argumente nicht noch einmal aufrollen. Dennoch soll mit 2 Kor Io,Iof. einer der in dieser Diskussion zentralen neutestamentlichen Referenztexte unter einem bisher nicht beachteten Aspekt aufgegriffen und eine neue Interpretation und Einordnung seiner Aussagen vorgeschlagen werden. Darin rekurriert Paulus auf den in der Gemeinde von Korinth vorgebrachten Vorwurf, als Redner bleibe er weit hinter der Qualität seiner Briefe zurück; es bestehe also eine unüberbrückbare Diskrepanz zwischen dem $\lambda$ ó ${ }^{\circ}$ s seiner mündlichen Predigt und dem geschrieben $\lambda$ óyos seiner Briefe. Darin sieht man mehrheitlich den Beweis dafür, dass Paulus tatsächlich über keine rhetorische Ausbildung verfügte oder zumindest der Anwendung der Rhetorik in der Verkündigung des Evangeliums kritisch bis ablehnend gegenüber stand (vgl. I Kor 2,I-7).

Diese Interpretation und Einordnung des Textes greift jedoch genau besehen zu kurz und vermag ein Grundproblem der Rezeption der antiken Rhetorik in der Exegese neutestamentlicher und frühchristlicher Schriften aufzuzeigen. Rhetorik erscheint hier verengt und einseitig als Prinzip und Technik der formalen und inhaltlichen Gestaltung eines schriftlich vorliegenden Textes. ${ }^{9}$ So wichtig die

7 Elemente, die in den echten Paulusbriefen einen möglichen Einfluss der Rhetorik erkennen lassen (z.B. im Arrangement des Stoffs, in der Argumentation, in der Anwendung von "Stilmitteln"), sind aufgelistet bei Porter 1997, 567-584; vgl. auch Norden 1915, 502-510; Lona 2009, Iof. Porter steht allerdings der Annahme, dass Paulus über Grundkenntnisse der rhetorischen Theorie verfügte oder gar eine rhetorische Ausbildung genossen hatte, skeptisch ablehnend gegenüber; vgl. Porter 1993, I05.

8 So Classen 199I, 3If.; ähnlich schon Norden 1915, 493f.; tendenziell auch Kennedy 1984, gf., der jedoch die Möglichkeit einer formalen rhetorischen Ausbildung nicht grundsätzlich ausschließen will; außerdem Anderson 1996, 249-255. Zur Frage, ob sich aus den Briefen des Paulus seine rhetorische Ausbildung erkennen lasse, vgl. Porter 1997, 535-538; dazu auch Norden 1915 , 507; Dihle 1989, 218f.; zu dieser Problem- und Fragestellung ausführlich Vegge 2006, 352-375.

9 Diese Verkürzung ist kein Spezifikum der Rezeption und Anwendung der rhetorischen Theorie in der ntl. Exegese; Ähnliches galt und gilt auch für die Beschäftigung mit der Rhetorik in der klassischen Philologie. Martin 1974, 353-355, verwendet auf den rhetorischen Auftritt (pronuntiatio) lediglich drei Seiten; noch knapper Lausberg 2008, 527. Eine Neuakzentuierung hat erst 
äußere Form und der Inhalt eines Textes sind, Rhetorik erschöpft sich nicht darin. Das Zentrale und Eigentliche der rhetorischen Theorie und Praxis ist nicht die schriftliche „Publikation“, sondern der rhetorische Auftritt. ${ }^{\text {I0 }}$ Rhetorik zielt auf den $\lambda$ ó schriebenen $\lambda$ ó ${ }^{\circ}$ s, sondern erst im mündlichen Vortrag der Rede oder allgemein in der "Performance“ des Redners. ${ }^{\text {II }}$ Die private Lektüre einer schriftlich vorliegenden Rede, mag sie auch stilistisch noch so ausgefeilt sein, entbehrt deshalb wie der jüngere Plinius in einem seiner Briefe nachdrücklich hervorhebt (epist. 2,3,9f.) - wesentlicher Elemente, die integraler und unverzichtbarer Bestandteil der Rede sind. ${ }^{\mathrm{I} 2}$ Es fehlen nicht nur Gestik, Mimik und Artikulation, sondern auch die gesamte äußere Erscheinung des Redners, mit der er seinen Worten Stimme und Gestalt verleiht.

Die rhetorische Kunst will also nicht nur einen perfekten Text formulieren, sondern sie zielt auf die Inszenierung eines gelungenen Auftritts, mit dem der Redner sein Publikum für sich und seine Sache gewinnt (vgl. Cic. de orat. 3,213; Brut. 234; Quint. inst. II,3,2). ${ }^{13}$ Deshalb geben die antiken Handbücher der Rhe-

durch die verstärkte Beschäftigung mit dem kaiserzeitlichen griechischen Literatur- und Rhetorikbetrieb (Zweite Sophistik) eingesetzt.

Io So auch Hall 20IO, 234. Die große Bedeutung bzw. den herausragenden Stellenwert, den man dem rhetorischen Auftritt beimaß, zeigt eine Anekdote über den großen attischen Rhetor Demosthenes, die sich unter anderem bei Cicero findet. Auf die Frage, was für den Redner das Wichtigste sei, soll Demosthenes geantwortet haben: erstens der Vortrag, zweitens der Vortrag, drittens der Vortrag (Cic. de orat. 3,213; Quint. inst. 3,3,4); vgl. Ueding/Steinbrink 2005, 236. Die Bezeichnung „rhetorischer Auftritt" statt des verbreiteten „Vortrag der Rede“ ist hier bewusst gewählt. Es ging nämlich um weit mehr als nur darum, das geschriebene Wort durch die Stimme hörbar zu machen.

II Dazu Gleason 1995, xx-xxvi. Die antike rhetorische Theorie war sich bewusst, dass die persönliche Glaubwürdigkeit eines Redners und damit auch die der von ihm vertretenen Sache nicht allein durch die Wahl der Worte, die Schlagkraft der Argumente und die Anordnung des Stoffes erreicht werden kann; sie hängt weit mehr davon ab, wie der Redner in seinen Gesten und Gebärden, im Minenspiel seines Gesichts und der Haltung seines Körpers, im Klang seiner Stimme und im Ausdruck seiner Augen seinen Charakter darstellt und dadurch sein Publikum für sich gewinnen kann. Dies darf man nicht als bloße Schauspielerei abqualifizieren, wie Cicero als Reaktion auf derartige Kritik schon zu seiner Zeit ausdrücklich betont: Der Redner ist Darsteller des wirklichen Lebens, der Schauspieler dagegen ahmt es nur nach (de orat. 3,214); vgl. dazu auch Olbricht 1997, I62f.; Andersen 200I, IIgf.

I2 Auch wenn die kulturelle Welt der frühen Kaiserzeit zweifelsohne in hohem Maße literarisch, d.h. durch das geschriebene Wort, geprägt war, so bedeutet das nicht, dass dadurch der öffentliche Auftritt und der mündliche Vortrag an Bedeutung verloren. Dies zeigt sich an der Welt und Zeit der Zweiten Sophistik (ca. 50-250 n. Chr.) mit ihren öffentlichen Deklamationen und professionellen „Konzertrednern“. Hier sind auch die Aussagen bei Plin. epist. 2,3 einzuordnen. Näheres bei Whitmarsh 2005, 23-40; Andersen 200I, 95-97 u. 255-268. Zur kaiserzeitlichen Rhetorik im Kontext einer „theatralischen Gesellschaft" vgl. Korenjak 2000, 2I-40.

I3 Dabei wussten bereits die antiken Rhetoren, dass jede rhetorische Inszenierung mit der Gefahr des Scheiterns verbunden war und dass der Redner deshalb damit rechnen musste, statt der erhofften Tränen der Rührung bei seinem Publikum Gelächter zu erregen (vgl. Quint. inst. 6,I,44-49). Ebenso war den antiken Rhetoren klar, dass beim Vortrag auch die natürliche Bega- 


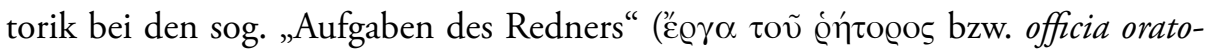
ris), die den Produktionsprozess einer Rede beschreiben, am Ende auch Anweisungen für die Vorbereitung des wirkungsvollen Vortrags der Rede (íróx@ıðı bzw. pronuntiatio oder actio), bei denen es um mehr geht als nur um das Auswendiglernen eines elaborierten Manuskripts ( $\mu v \eta \dot{\eta} \eta$ bzw. memoratio). ${ }^{14}$ Denn der öffentliche Auftritt war eine komplexe Interaktion zwischen dem Redner und seinem Publikum (vgl. Cic. Brut. 290). ${ }^{15}$ Ein versierter Redner musste in der Lage sein, durch nichtsprachliche Mittel seine Worte zu unterstützen sowie die Emotionen seiner Zuhörer zu wecken und zu steuern. Zugleich verhielten sich diese Zuhörer beim Vortrag der Rede nicht ruhig und weitgehend passiv, sondern reagierten auf das Gesagte spontan und lautstark mit Zeichen der Zustimmung und Ablehnung oder griffen mit Zwischenrufen, mitunter sogar handgreiflich in den Vortrag ein. ${ }^{16}$ Ein guter Redner hatte durch Training und Erfahrung gelernt, wie er all das geschickt in seinen eigenen Vortrag integrieren konnte, und war deshalb in der Lage, seine vorbereitete Rede durch Improvisation spontan an die Reaktionen und Erwartungen seiner Zuhörer anzupassen.

In der Welt der frühen römischen Kaiserzeit mit ihrer hohen Wertschätzung der Rhetorik als Befähigung zur öffentlichen Rede bestimmte der erfolgreiche rhetorische Auftritt als gelungene Selbstinszenierung den Status und das Prestige des einzelnen. ${ }^{17}$ Das Scheitern als Redner war deshalb eine Blamage, die mit weit reichenden Folgen für das Ansehen und die Stellung einer Person verbunden war. Auf- und Abstieg im sozialen Gefüge der Gesellschaft des Imperium Romanum entschied sich auch daran, ob sich jemand auf dem Feld der rhetorischen Kunst

bung eine Rolle spielte. Doch galt hier, wie überhaupt in der Rhetorik, dass Übung ohne Begabung, aber auch Begabung ohne Übung nichts nutzte. Der gute Vortrag und der perfekte Auftritt waren also durchaus etwas, was man durch Unterweisung und Übung lernen und immer weiter optimieren konnte (vgl. Quint. inst. II,3,I4-25). Dazu insgesamt Andersen 200I, II9-I23.

I4 Der erste, der den Aspekt des Vortrags ausführlich theoretisch erörterte, war vermutlich Theophrast (ca. 371-287), doch sind seine Ausführungen verloren (vgl. D.L. 5,48; Rh. I4,I77,3-8). Vgl. auch Ueding 2005, 7If.; Hall 20I0, 218.

I5 Dazu Andersen 200I, 30-34 u. I23f.; Hall 20IO, 218-220; Whitmarsh 2005, 24-26.

I6 Vgl. dazu am Beispiel des Aelius Aristides Gleason 1995, I22f. Ausführlich zu den verschiedenen Handlungen und Haltungen, durch die das Publikum das Setting eines rhetorischen Auftritts mitbestimmte und seinen Ablauf beeinflusste, Korenjak 2000, 68-95.

I7 Dies gilt insbesondere für den griechischen Osten des römischen Reiches (Griechenland, Kleinasien, Ägypten etc.). Bildung und Bildungsdemonstration, in deren Kontext die Rhetorik zu verorten ist, wurde hier für die provinzialen Eliten, d.h. die Oberschicht der alten Poleis, zu einem zentralen Feld der Selbstdarstellung und Konkurrenz, weil das traditionelle Feld ihrer politischen Betätigung und Bewährung unter römischer Herrschaft eingeschränkt war. Der öffentliche Vortrag von Reden, die keinem anderen Zweck als der gebildeten Unterhaltung und kulturellen Selbstvergewisserung der Zuhörer dienten (Deklamationen), gehörte deshalb vor allem in den Poleis des östlichen Imperiums zum Alltag. Entsprechend hoch waren in dieser rhetorisch geprägten Kultur (Zweite Sophistik) die Anforderungen an den Redner und die Erwartungen des Publikums. Vgl. dazu Whitmarsh 2005, 3-22 u. 4I; Korenjak 2000, 38-40; Hose 1999, I57f.; auch Whitmarsh 200I, 96-I08; Anderson 1993, 55-68. 
bewährte oder scheiterte. ${ }^{18}$ Aus diesem Grund war es für Paulus, aber auch für andere frühchristliche Missionare und Gemeindeleiter keineswegs nebensächlich, ob sie sich als Redner behaupten konnten, zumal Rede und Reden in Form der Missions- und Gemeindepredigt ihre Identität wesentlich bestimmte. ${ }^{19}$

In diesen Kontext sollte man auchdie Aussage in 2 Kor Io,Iof. einordnen, in der Paulus ausdrücklich die in Korinth laut gewordene Kritik zitiert, dass er Menschen zwar schriftlich mit seinen Briefen, nicht aber im mündlichen Vortrag überzeugen und für sich gewinnen könne. ${ }^{20}$ Diese Kritik entzündete sich offenbar an einem noch nicht lange zurückliegenden rhetorischen Auftritt des Paulus vor den Korinthern, der für ihn zum persönlichen Fiasko geworden war (vgl. 2 Kor 2,5-II; 7,I2). In den Augen der Korinther erschien Paulus durch diesen missglückten Auftritt und sein Scheitern als Redner inkompetent und war deshalb in der Gefahr, sich als maßgebende Autorität in der von ihm gegründeten christlichen Gemeinde disqualifiziert und damit seinen Leitungsanspruch verwirkt zu haben. Für das Verständnis des Textes sind zunächst einige Klärungen zum konkreten Anlass und zum (ursprünglichen) Kontext der Aussagen in 2 Kor Io,Iof. nötig.

\section{Briefsituation und Kontext von 2 Kor Io,Iof.}

Gemäß den - in ihrer historischen Zuverlässigkeit nicht über jeden Zweifel erhabenen - Angaben in Apg I8,I-I4 kam Paulus um das Jahr 50 n. Chr. nach Ko-

I8 Näheres bei Schmitz 1997, 44-63.

I9 Vor diesem Hintergrund ist wohl auch die Aussage von Paulus in I Thess I,5 zu deuten, mit der

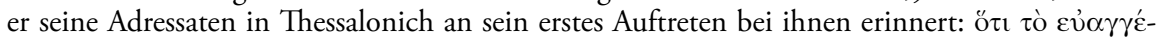

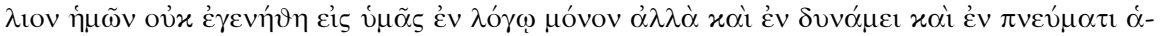

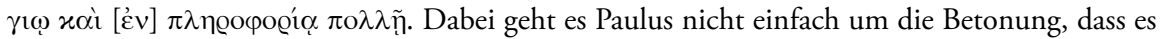
sich bei seiner Predigt nicht nur um leere Worte, sondern um eine wirksame Heilsbotschaft handelte. Paulus erinnert die Thessalonicher vielmehr daran, dass seine Evangeliumsverkündigung nicht nur der schönen Worte wegen überzeugend und gewinnend war, sondern weil sie seinen rhetorischen Auftritt als geglückt, da perfekt „inszeniert" erlebten. Bemerkenswert ist, dass Paulus ein solches Statement in die Corpuseröffnung des I Thess und damit in seine briefliche Selbstdarstellung integriert, die den weiteren lehrhaft-mahnenden Ausführungen seines Briefes zugrunde liegt; dies zeigt, dass es auf Seiten seiner Adressaten offenbar entsprechende Erwartungen und Anforderungen an die Fähigkeiten eines Missionars und Gemeindeleiters gab. Näheres über die Eigenart dieses ersten rhetorischen Auftritts und die Qualitäten der Inszenierung des Paulus lässt sich I Thess 2,I-I2 entnehmen. Zur Stelle vgl. Betz 1986, 2I-23.

20 Dafür, dass der Misserfolg des Paulus und die Kritik der Korinther an ihm auf mehr zielte als nur auf seine mangelnden rhetorischen Fähigkeiten, nämlich darauf, dass ihm die Gabe „freier, pneumatischer Rede" fehle, wie Wendland 1980, 230, oder Lang 1986, 331, meinen, lässt sich dem Text so nicht entnehmen. Eine Tendenz in diese Richtung, doch deutlich abgeschwächt, auch bei Lietzmann 1969, I42; Bultmann 1976, 192 [bei beiden mit ausdrücklichem Hinweis auf Richard Reitzenstein]. 
rinth und wirkte hier etwa eineinhalb Jahre. ${ }^{21}$ Die von ihm gegründete christliche Gemeinde in dieser römischen „Kolonie“ bestand überwiegend aus ehemaligen Heiden (IKor I2,2). Unter ihnen fanden sich neben einfachen Leuten aus der Schicht der Handwerker und Gewerbetreibenden Mitglieder der Oberschicht, die aufgrund von Reichtum und Bildung über soziales Prestige verfügten und deshalb sicher auch in der christlichen Gemeinde tonangebend waren (vgl. I Kor I,26-29; II,22-32; Röm I6,23). ${ }^{22}$ Als Gründer der Gemeinde beanspruchte Paulus für sich eine gewisse Kontroll- und Leitungsfunktion, die er nach dem Ende des Gründungsaufenthalts durch Briefe aus der Ferne (von Ephesus und Makedonien aus) auszuüben versuchte (vgl. I Kor 3, Iof.; 4,I5; II,I7). Dies führte zu einer ausgedehnten brieflichen Korrespondenz zwischen Paulus und seiner Gemeinde, die sich in den beiden Korintherbriefen des neutestamentlichen Kanons nur fragmentarisch erhalten hat. Sie zeigen einen Paulus, der in dieser Gemeinde mit ihren sozialen und religiösen Spannungen Fehlentwicklungen zu korrigieren versucht und zugleich mitten zwischen Streitereien und Spaltungen seine Autorität als Apostel und Gemeindeleiter immer wieder verteidigen muss. ${ }^{23}$

Die Korrespondenz zwischen Paulus und den Korinthern umfasste, soweit sie sich aus den Angaben der beiden kanonischen Korintherbriefe rekonstruieren lässt, ursprünglich mindestens vier Briefe des Paulus und einen Brief der korinthischen Gemeinde. ${ }^{24}$ Bald nach seinem Weggang schickte Paulus aus Ephesus einen Brief nach Korinth, in dem er die Mitglieder der Gemeinde aufforderte, sich von allen „Unzüchtigen“ zu trennen [Kor A oder Trennungsbrief]. Dieser Brief, der durch die Einlassung in I Kor 5,9 bekannt ist, aber offenbar keine Aufnahme

2I Die Gründung der christlichen Gemeinde von Korinth wird in Apg I8,I-8 überliefert. Falls diese Erzählung historisch zuverlässige Informationen bewahrt, kann man daraus den eineinhalbjährigen Gründungsaufenthalt des Paulus ungefähr auf 5o/5I n. Chr. datieren: Priska und Aquila, mit denen Paulus hier zusammentrifft, hatten infolge der Judenausweisung des Kaisers Claudius Rom verlassen (49 n. Chr.); Gallio war um das Jahr 5I/52 n. Chr. Prokonsul von Achaia. Vgl. Lona 2009, 24f. Näheres zur Geschichte der Gemeinde und zu den Hintergründen der Korintherbriefe bei Vielhauer 1978, I28-156.

22 Zur Interpretation von I Kor I,26-29 und zur angemessenen Auswertung der Stelle für die Frage nach der sozialen Zusammensetzung der korinthischen Gemeinde vgl. Theißen 1983, 232234; zur sozialen Schichtung der Gemeinde vgl. ebd. 257-260; Klauck 2000, 6-9; Schnelle 2003, 202f.; Broer 2006, 358-360; Schmeller 2008a, 318-322; allgemein zur sozialen Herkunft und Zusammensetzung der pln. Gemeinden Lohse 2003, I32-I37; Becker 1992, 254-270; Meeks 2003, 5I-73. Die Annahme, dass zur Gemeinde von Korinth Mitglieder der sozialen, politischen und ökonomischen Elite gehörten, sei ausdrücklich auf Goodrich 2010 verwiesen, der durch Auswertung neuer epigraphischer Daten glaubhaft machen kann, dass der Christ Erastos

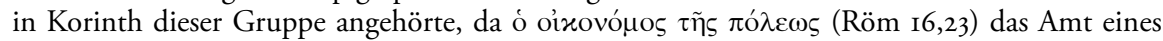
Quästors bezeichnete, das den Mitgliedern der reichen Oberschicht vorbehalten war.

23 Ein Überblick zur Situation in der christlichen Gemeinde von Korinth bei Marxsen 1978, 7If.; Schnelle 2007, 75-78; Schnelle 2003, 205f.; Meeks 2003, II7-I25.

$24 \mathrm{Zu}$ Umfang und Rekonstruktion der Korintherkorrespondenz vgl. Klauck 2000, 9-II; Vielhauer 1978, I26f.; Schnelle 2003, 25I-253; Schmeller 2008b, $337 f$. 
in die Sammlung der Paulusbriefe fand ${ }^{25}$, führte bei den Korinthern zu Missverständnissen und Verunsicherungen, so dass sie sich in einem Brief mit ihren Fragen an Paulus wandten (vgl. I Kor 7,I). Auf diesen ebenfalls verlorenen Fragebrief antwortete Paulus mit dem erhaltenen I Kor [Kor B]. Zugleich sollte der I Kor Missstände im Gemeindeleben unterbinden, von denen Paulus offenbar zur selben Zeit durch die Leute der Chloë in einem Brief und/oder durch eine Gesandtschaft erfahren hatte (I Kor I,II).

Ob Paulus durch den I Kor und die gleichzeitige Entsendung seines Mitarbeiters Timotheus (I Kor 4,I7; I6,Iof.) die Missstände beenden und seine im Parteiengezänk von Korinth erschütterte Autorität wieder festigen konnte, muss offenbleiben. Bald jedenfalls sah Paulus sich zu einer erneuten Intervention genötigt. Auf die Nachricht hin, dass man seine Autorität nach dem Auftreten fremder Missionare in der Gemeinde ernsthaft in Frage stellte, entschloss er sich, die Gemeinde persönlich aufzusuchen (vgl. 2 Kor I2,I4; I3,I, wo ein zweiter Besuch des Paulus nach dem Gründungsaufenthalt vorausgesetzt ist). Vermutlich war Paulus der Meinung, dass ein weiterer Brief nicht genügte, um seine gefährdete Autorität in Korinth zu retten. Der persönliche Auftritt des Paulus vor Ort endete aber mit einer Niederlage, verbunden mit Spott und Beleidigungen, die Paulus sich von einem Mitglied der Gemeinde gefallen lassen musste (2 Kor 2,9; 7,I2) ${ }^{26}{ }^{26}$ kränkt und überstürzt verließ Paulus Korinth. Von Ephesus aus schrieb er „unter Tränen" erneut einen Brief an die Korinther, auf den er in 2 Kor 2,4 Bezug nimmt [Kor C oder Tränenbrief]. Darin stellte er die Gemeinde wegen des Zwischenfalls zur Rede und forderte die Disziplinierung jenes Gemeindemitglieds, das ihn öffentlich brüskiert hatte. ${ }^{27}$ Den Brief ließ er durch seinen Mitarbeiter Titus überbringen, der sich auch persönlich für eine Aussöhnung mit der Gemeinde in Korinth engagieren sollte (2 Kor 7,6f.I5). Wenig später machte sich auch Paulus selbst auf den Weg von Kleinasien nach Griechenland. Als er in Makedo-

25 Teilweise wird erwogen, dass der I Kor in seiner heutigen Gestalt nicht einheitlich ist, sondern ein Kompilat darstellt, d.h. in den Antwortbrief [Kor B], mit dem Paulus die Anfragen der Korinther klären wollte, sind Teile des sog. Vorbriefes [Kor A] eingefügt; vgl. Schenke/Fischer 1978, 92-94; vorsichtiger Vielhauer 1978, I40f.; eher ablehnend Broer 2006, 36I-365; Marxsen I978, 72; Schnelle 2007, 79-82 u. 9of.; Schmeller 2008a, 308-3II; völlig ablehnend Kümmel 1983, 239-24I; Becker 1992, 198-208; Lona 2009, 67. Vgl. auch Wikenhauser/Schmid 428-432; zum Stand der Diskussion Schnelle 2007, 88.

26 Dazu Lietzmann 1969, I40.

27 Klauck 1994, 29, erklärt den Zwischenfall wahrscheinlich zutreffend: „Der Vorfall steht in Zusammenhang mit dem Eindringen von Paulusgegnern in Korinth. Ein ortsansässiges, einflussreiches Gemeindemitglied, möglicherweise schon seit den Parteistreitigkeiten des I Kor dem Paulus nicht sonderlich gut gesonnen, macht sich die Position der neuen Paulusgegner zu eigen und geht beim Zwischenbesuch vor der Gemeinde gegen Paulus vor. Die Gemeinde unternimmt nichts dagegen. Ihr Stillhalten muss Paulus als Zustimmung interpretieren. Ihm bleibt nur die eilige Abreise." Vgl. Marxsen 1978, 76f. u. 80; Schenke/Fischer 1978, 108 u. II3f.; Schnelle 2007, 93f.; Schmeller 2008b, $338 \mathrm{f}$. 
nien die Nachricht erhielt, dass sein Brief und die Mission des Titus zum Ziel geführt hatten, schrieb er versöhnlich an die Korinther und kündigte der Gemeinde seinen baldigen Besuch an [Kor D oder Versöhnungsbrief].

Dieser Versöhnungsbrief müsste an sich im 2 Kor vorliegen. Allerdings überrascht es, dass der versöhnliche Ton der ersten Kapitel (vor allem 2 Kor I,3-2,II und 7,2-16) plötzlich ab 2 Kor IO in einen polemisch-aggressiven Ton umschlägt. ${ }^{28}$ Als Erklärung für diesen abrupten Wechsel im Tonfall hat man neben erneuten schlechten Nachrichten aus Korinth auch eine Diktierpause mit einer schlaflos durchwachten Nacht vorgeschlagen. ${ }^{29}$ Am plausibelsten erscheint die heute oft diskreditierte Annahme, beim kanonischen 2 Kor handle es sich um eine nachträgliche Kompilation aus mindestens zwei selbständigen Briefen des Paulus, nämlich dem Tränenbrief [Kor C $=2$ Kor IO-I3] und dem Versöhnungsbrief $\left[\right.$ Kor $\mathrm{D}=2$ Kor I-9]. ${ }^{30}$ Trifft diese Annahme zu, ist 2 Kor Io, Iof. Teil des Tränenbriefes [Kor D], mit dem Paulus auf seinen gescheiterten Auftritt vor der Gemeinde bei seinem zweiten Besuch („Zwischenbesuch“) reagiert, und muss vor dem Hintergrund dieser konkreten Briefsituation verstanden und ausgelegt werden. $^{3 \mathrm{I}}$

28 Vgl. Klauck 1994, 7.

29 So z.B. Lietzmann 1969, I39. Lediglich durch einen Diktierpause erklärt Kümmel 1980, 252f., den Umschwung im Ton. Kritisch zu solchen Thesen Klauck 1994, 7 f.

30 Nach Vielhauer 1978, 150-155, ist der 2 Kor wahrscheinlich ein Kompilat aus mehreren Briefen: dem Tränenbrief [Kor C], dem Versöhnungsbrief [Kor D] und einem Empfehlungsbrief für Titus [Kor E]; ähnlich, aber mit anderer Abgrenzung und Einordnung der Briefe Schenke/Fischer 1978, I09-II2; Becker 1992, 229-235. Marxsen 1978, 72-77, teilt den kanonischen 2 Kor sogar in fünf Briefe auf; vgl. auch Gräßer 2002, 29-35. Nach Klauck 1994, 9f., besteht der 2 Kor aus nur zwei ehemals selbständigen Briefen, wobei 2 Kor IO-I3 gegenüber 2 Kor I-9 der zeitlich frühere Brief ist; vgl. auch Klauck 2006, 309f.; Wikenhauser/Schmid 1973, 435-448. Martin 1986, xxxviii-lii, teilt den 2 Kor ebenfalls in dieser Weise, sieht die heutige Anordnung aber als Reihenfolge der Entstehung der Briefe. Grundsätzlich zustimmend zu den Teilungshypothesen, wenn auch vorsichtig Lona 2009, 71; eher skeptisch ablehnend dagegen Broer 2006, 409-419; Schmeller 2008b, 332-336. Kümmel 1983, 249-255, hält den 2 Kor in seiner kanonischen Gestalt für literarisch einheitlich und von Paulus geschrieben (einschließlich des in Wortgebrauch und Theologie merkwürdig unpaulinischen Abschnittes 6,I4-7,I); ähnlich auch Wolff 1989, 2ff; Schnelle 2007, 96-IO4 (mit einem Überblick über die traditionellen Teilungshypothesen und ihren Argumenten); Schnelle 2003, 260-262. Zum Stand der Diskussion vgl. Schnelle 2007, I08; Harris 2005, 8-5I.

3I Nach Vielhauer 1978, I53, gehören zum „Tränenbrief“ [Kor C] die Abschnitte 2 Kor 2,I4-7,4 (ohne 6,I4-7,I) u. IO-I3. Marxsen 1978, 73-77, und Gräßer 2002, 3I-33, sehen in 2 Kor 2,I46,13; 7,2-4 einen selbständigen Brief (Apologie); der Tränenbrief umfasst also nur 2 Kor IO-13; so auch Klauck 1994, 9. Ebenso sieht Betz 1972, I-9 u. 13f., 2 Kor IO-I3 als Fragment eines ursprünglich selbständigen Briefes; doch ist für ihn diese „Apologie“ nicht mit dem in 2 Kor 2,4 erwähnten „Tränenbrief“ identisch, da in 2 Kor IO-I3 nirgends von Trauer und Tränen die Rede ist. Der „Tränenbrief“ ist seiner Meinung nach vollständig verloren (ebd. II). Näheres zur Datierung und zum Abfassungsort von 2 Kor IO-13 (bei Akzeptanz der Teilungshypothese) Klauck I994, 5-IO; Klauck 2006, 309-311; Schenke/Fischer 1978, II6; Becker 1992, I72f. 
Ausgehend von dieser Einordnung in die Korintherkorrespondenz stellen sich der Anlass und die Funktion von 2 Kor Io,Iof. wahrscheinlich folgendermaßen dar: Einige Zeit nach dem I Kor kamen fremde christliche Missionare nach Korinth $(2$ Kor II 4 ), die in der Gemeinde durch ihr Auftreten und vor allem durch Berichte über ekstatisch-visionäre Erlebnisse Eindruck machten (2 Kor 5,I2f.; II, 5 f.). ${ }^{32}$ Es handelte sich bei ihnen möglicherweise um judenchristliche Wandermissionare (2 Kor II,22f.). ${ }^{33}$ Die freundliche Aufnahme in Korinth verdankten sie nach 2 Kor 3,I Empfehlungsschreiben; Paulus lässt allerdings offen, wer sie damit ausgestattet hat und woher sie kamen. ${ }^{34} \mathrm{Da}$ sich in der paulinischen Polemik gegen diese Konkurrenten keine spezifisch theologischen Gegensätze erkennen lassen (Gesetz, Beschneidung etc.), kann man kaum von einer gezielten judaistischen Gegenmission ausgehen. ${ }^{35}$ Dennoch wurde durch ihr Auftreten die Stellung des Paulus in der Gemeinde unterminiert, denn ihre Visionen und ihr sonstiges Auftreten ließen sie Paulus überlegen und im Vergleich mit ihm besser qualifiziert erscheinen (2 Kor IO,Iof.; II, 5 f.; I2,I).$^{36}$

In Korinth wuchs deshalb allmählich die Kritik an Paulus, die sich wohl vor allem auf die rhetorische Qualität und den theologischen Tiefsinn seiner Predigt bezog. Beides war für die Christen in Korinth offenbar wichtig (vgl. I Kor I-2).$^{37}$ Von einem Missionar und Gemeindeleiter erwarteten sie einen Überfluss an $\lambda$ ó$-^{2}$ $\gamma \circ \varsigma$ und $\gamma \nu \tilde{\omega} \sigma 15$ (I Kor I,, 5$).{ }^{38}$ Es ging den Korinthern also, nicht anders als Paulus

32 Zur Frage nach der Identität und dem theologischen Profil der Konkurrenten des Paulus in Korinth vgl. Becker 1992, 235-345. Eine zuverlässige Rekonstruktion ist allerdings aufgrund der stark polemischen Darstellung bei Paulus kaum mehr möglich. Zu den verschiedenen Hypothesen in der Forschung vgl. Klauck 1994, IO-I2; Gräßer 2005, I25-I28; Broer 2006, 420-423; Schmeller 2008b, 338-340; Klauck 2006, 309.

33 Dass es sich um christliche (Wander-)Missionare handelte, lässt sich aus 2 Kor I,I5 schließen,

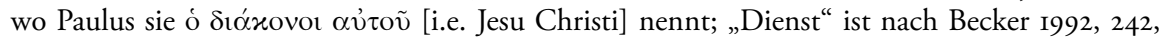
eine gängige christliche Umschreibung für missionarische Tätigkeit (vgl. Röm I2,7; I Kor I2,5).

34 Entgegen einer weit verbreiteten These, ist dem Text nirgends zu entnehmen, dass die Empfehlungsschreiben von der Jerusalemer Gemeinde stammen und dass deshalb die Konkurrenten des Paulus in Korinth in irgendeiner Form mit Jerusalem (Petrus und/oder Jakobus) in Verbindung stünden; vgl. Becker 1992, 236; Taylor 2005, II8 u. I2If.

35 Vgl. dazu auch Lona 2009, 69f.; Taylor 2005, 99 u. IIgf.

36 Vgl. Becker 1992, 253.

37 Dem I Kor ist zu entnehmen, dass bei den Korinthern „Erkenntnis“ ( $\gamma v \tilde{\omega} \sigma ı \varsigma)$ und „Weisheit“ ( $\left.\sigma \operatorname{op}^{\prime} \alpha\right)$ hoch in Kurs standen $(2,6-16 ; 8, \mathrm{I}-6 ; \mathrm{I3}, 2)$. Dies darf nicht vorschnell auf eine besondere Begeisterung für die religiös-philosophische Gnosis reduziert werden, sondern deutet auch auf das Bemühen korinthischer Christen um soziale Distinktion durch Bildung. Vgl. auch Kirner 2003, 39-4I; Schnelle 2003, 210-218.

38 Dazu Betz 1986, 26f.; ferner Meeks 2003, II7f., der in der Wertschätzung von Rhetorik und Bildung zurecht bereits einen Grund für die im I Kor erkennbare Spannungen zwischen der Paulus- und Apollospartei vermutet (I,I2; 3,4.22; 4,6). Dies würde bedeuten, dass Paulus mit den Ausführungen zu бофí $\alpha$ und $\gamma v \tilde{\omega} \sigma ı \varsigma$ im I Kor die Situation nur vorübergehend beruhigt und zu seinen Gunsten entschieden hatte. In diesem Sinn ist wohl auch die bereits zitierte Aussage bei Klauck 1994, 29, zu verstehen, dass der „Übeltäter“ aus 2 Kor 2,9; 7,I2, ein Gemeindemitglied war, das schon seit den im I Kor genannten Parteistreitigkeiten Groll gegen Paulus hegte. 
selbst, auch um den Inhalt und nicht nur um einen leeren rhetorischen Wortprunk. ${ }^{39} \mathrm{Im}$ Unterschied zu Paulus waren jedoch zumindest für die maßgebenden Kreise der korinthischen Gemeinde die äußere Schönheit der Rede und der gelungene rhetorische Auftritt ein unverzichtbarer Bestandteil christlicher Predigt (ı Kor 2,I5)..$^{\circ}$ Die Wertschätzung der Rhetorik verdankte sich der Herkunft dieser Christen aus der Schicht der Gebildeten ( $\pi \varepsilon \pi \alpha \iota \delta \varepsilon v \mu \varepsilon ́ v o \imath)$, die in der Schule durch theoretische Unterweisung und praktische Übungen die Kunst der Rhetorik und der rhetorischen Deklamationen verinnerlicht hatten. Da rhetorische Fertigkeiten in der kaiserzeitlichen Gesellschaft ein Mittel sozialer Distinktion und unabdingbare Voraussetzung für einen (politischen) Führungsanspruch waren, erwarteten die gebildeten Christen in Korinth (und anderswo) auch von einem Mann wie Paulus, dass er sich auf dem Feld der Rhetorik als qualifiziert ausweisen konnte. ${ }^{41}$

Zur rhetorischen Kultur dieser Zeit, unter deren Einfluss die christliche Gemeinde von Korinth stand, gehörte auch das agonistische Prinzip; Autorität und Führungsanspruch mussten im rhetorischen Wettstreit mit anderen stets neu errungen werden..$^{42}$ Dies musste Paulus bereits bald nach dem Ende seines Gründungsaufenthalts erfahren, als der hellenistisch gebildete Judenchrist Apollos aus Alexandria nach Korinth kam (I Kor I,I2; 3,4.22; 4,4; I6,I2; Apg I8,24). ${ }^{43}$ Dieser verstand sich zwar offensichtlich nicht als Gegner des Paulus (I Kor I6,I2), den-

39 Dahinter steht derselbe Anspruch, der sich im Bildungsprogramm des attischen Rhetors und Lehrers Isokrates (436-338 v.Chr.) findet: Gegen die sophistische Konzeption der Rhetorik als Kunst der Überredung bindet Isokrates sie an die Philosophie; als Korrektiv soll sie die Rhetorik davor bewahren, zur Lehre von Wortprunk und Manipulation zu verkommen (vgl. orat. 3; I3; I5). Dieses rhetorisch-philosophische Programm des Isokrates bestimmt auch Cicero in seinem Ideal des philosophus orator und perfectus orator in Abgrenzung zum vulgaris orator; vgl. Betz 1986, 28-32.

40 Die Affinität sozialer Eliten der kaiserzeitlichen Gesellschaft zur Rhetorik zeigt sich in ihrer aktiven und passiven Partizipation an öffentlichen Prunkdeklamationen, die nicht nur der Unterhaltung, sondern auch der Selbstvergewisserung über die Zugehörigkeit zum Kreis der durch Abstammung und Bildung ausgezeichneten sozialen Oberschicht dienten; vgl. dazu Whitmarsh 2005, 19-22; Russell 1983, 3-20 u. 74-86.

4I Nach den Vorstellungen der frühen Kaiserzeit beruhte der Anspruch des einzelnen auf Teilhabe an Macht und Leitung in einer Gemeinschaft auf seiner „natürlichen“ Überlegenheit der Masse gegenüber. Das entscheidende Kriterium dafür wurde zunehmend Bildung ( $\left.\pi \alpha 1 \delta \varepsilon^{\prime} i \alpha\right)$, die nicht zuletzt in Rhetorik bestand und sich im brillanten rhetorischen Auftritt beweisen musste. Vgl. Schmitz 1997, 39-50, und Kirner 2003, 30-32. Auch deshalb gefährdete das in 2 Kor IO,Iof. reflektierte Scheitern des Paulus auf dem Feld der Rhetorik seinen Führungsanspruch in der Gemeinde.

42 Ein Reflex dieses agonistischen Prinzips, das der griechischen Kultur von Anfang an eigen war und das sie der hellenistisch-römischen Welt „vererbte“, ist das von Paulus im I Kor 9,24 zur Motivation gebrauchte Bild vom Wettlauf im Stadion.

43 Näheres zu Apollos bei Bauer 2007, 22I-224. Ob I Kor I,I2 und 3,22, wo Simon Petrus als Identifikationsfigur einer Partei innerhalb der korinthischen Christengemeinde genannt wird, dahingehend zu verstehen ist, dass auch er in Korinth predigte, lässt sich nicht mit Gewissheit sagen. Vgl. Marxsen 1978, 68; Wikenhauser/Schmid 1973, 427. 
noch aber wurde er zum Konkurrenten und damit zur Gefahr für die Autorität des Paulus, weil er viele in der Gemeinde durch sein rhetorisches Talent und seine Bildung beeindrucken konnte. ${ }^{44}$ Einige Zeit später sah Paulus erneut und vielleicht in noch größerem Maße seine Autorität in der Gemeinde durch fremde Missionare in Frage gestellt oder zumindest akut gefährdet, da diese in den Augen der Korinther auf rhetorischem Gebiet mehr zu bieten hatten als ihr Apostel, der ohnehin schon geraume Zeit in weiter Ferne weilte. Dadurch geriet Paulus nicht nur unter den Zwang, sich seiner Gemeinde gegenüber zu rechtfertigen (2 Kor 2,I7; II,5.I2-I5), sondern er empfand offensichtlich auch die Notwendigkeit, sich im direkten Vergleich mit seinen Konkurrenten zu profilieren, um so seine Autorität bei den Korinthern wiederherzustellen. ${ }^{45}$

Dies dürfte der Grund gewesen sein, warum Paulus sich entschloss, die Gemeinde von Korinth erneut persönlich aufzusuchen. Der Besuch aber verlief anders, als von Paulus erhofft. Es kam zu einem Auftritt des Paulus vor der Gemeinde, bei dem er versuchte, die Korinther wieder für sich zu gewinnen. Über den Ort und die Gelegenheit dieses Auftritts macht Paulus keine Angaben. Man muss wohl an eine Versammlung denken, möglicherweise zum Brotbrechen, die im Privathaus eines vermögenden Gemeindemitglieds stattfand (vgl. I Kor II,I734). ${ }^{46}$ Dabei kam es allem Anschein nach zu einer Auseinandersetzung zwischen Paulus und einem Mitglied der Gemeinde, das den Autoritätsanspruch des Paulus missachtete und ihn darüber hinaus auch noch persönlich beleidigte $(2$ Kor 2,5; 7,I2). ${ }^{47}$ Worin genau diese Kränkung bestand, die Paulus über sich ergehen lassen musste und die er nach seinen eigenen Worten als Unrecht empfand, ist den Angaben im 2 Kor nicht zu entnehmen. ${ }^{48}$ Wahrscheinlich konnte der Aggres-

44 Dazu Kirner 2003, 44-47; Wikenhauser/Schmid I973, $426 f$.

$45 \mathrm{Zu} 2$ Kor 2,I7 Klauck 1994, 33f.; Gräßer 2003, II3-II7; zu 2 Kor II,5 Klauck 1994, 83; Gräßer 2005, I28-I30; zu 2 Kor II,I2-I5 Klauck I994, 85f.; Gräßer 2005, I42-I49.

46 Wesentliche Rahmenbedingungen, die Wirkung und Erfolg des Vortrags beeinflussen können, sind auch die Wahl des Ortes, die Zusammensetzung der Zuhörer und der konkrete Ablauf des rhetorischen Auftritts. Wie diese Rahmenbedingungen im Fall des Paulus oder anderer frühchristlicher Missionare aussahen, dazu finden sich in den ntl. und frühchristlichen Schriften keine genauen Einlassungen. Am meisten erfährt man aus der Apg, doch gilt für ihre Aussagen stets der Vorbehalt, dass sie weniger die Verhältnisse am Anfang der christlichen Mission als vielmehr die zu ihrer eignen Zeit und diese zudem idealisierend beschreibt. Interessant ist dennoch der Hinweis, Paulus habe in Ephesus zwei Jahre év $\tau$ ñ $\sigma \chi 0 \lambda \tilde{n}$ Tv@óvvov Lehrgespräche geführt oder doch wohl eher Lehrvorträge gehalten (vgl. Apg 19,9f.). In Troas zeigt die Apg Paulus, wie er einen langen Lehrvortrag vor der zum Brotbrechen versammelten Gemeinde $\dot{\varepsilon} v$

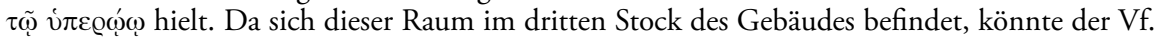
hier an eine Privatwohnung in einem mehrstöckigen Mietshaus denken (Apg 20,7-I2). Daran ist sicher zutreffend, dass nach erfolgter Gemeindegründung die weiterführende Unterweisung gewöhnlich in privaten Räumen stattfand, wo sich die Gemeinden auch sonst zum Gebet und zum Brotbrechen versammelten (vgl. Apg 2,46; I2,I2). Was sich mit einiger Sicherheit über Verlauf und Strukturen der pln. Mission sagen lässt, stellt Schnelle 2003, I52-160, zusammen.

47 So Lohse 2003, I62f. 
sor die Anwesenden auf seine Seite ziehen und gegen Paulus aufbringen (vgl. 2 Kor 7,9-I2). ${ }^{49}$ Paulus musste Korinth und seine Gemeinde gedemütigt verlassen. Die Beziehung zu den Korinthern war nachhaltig gestört, seine Autorität und sein Führungsanspruch in der Gemeinde erschüttert (2 Kor 13,6; IO,I5; vgl. auch I0,8; I3,IO)..$^{\circ}$

Die Tatsache, dass Paulus in Korinth als Redner gescheitert ist, bedeutet nicht zwangsläufig, dass er über keine rhetorische Befähigung und damit über keine entsprechende Ausbildung verfügte. ${ }^{5 \mathrm{I}}$ Die antike Literatur kennt Beispiele für das Scheitern auch anderer, weit begabterer und erfahrenerer Redner vor und nach Paulus. ${ }^{52}$ Der Misserfolg des Paulus könnte auch darin begründet sein, dass er sich in den Erwartungen seines Publikums getäuscht und deshalb für seinen Auftritt eine falsche Strategie gewählt hatte. Möglicherweise glaubte er, durch ein möglichst schlichtes Auftreten den Korinthern glaubhaft und überzeugend zu erscheinen (gemäß der philosophischen Rhetorik-Kritik), während sein „Publikum" in Korinth von ihm das genaue Gegenteil erwartete. ${ }^{53}$ Nicht auszuschließen ist außerdem, dass der von Paulus in seinem Brief direkt angegriffene Störenfried in Korinth seinen Auftritt gezielt sabotierte, um sich dadurch auf Kosten des Paulus in der Gemeinde zu profilieren und zu positionieren. ${ }^{54}$ Als Reaktion auf

48 Man sollte bei der Frage, wie und wodurch Paulus meinte, von diesem Gemeindemitglied Un-

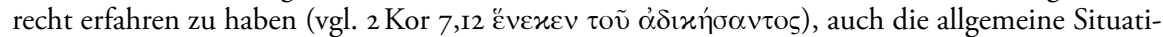
on eines rhetorischen Auftritts einbeziehen. In der Literatur ist öfter von der Nervosität oder gar Angst auch erfahrener Redner vor ihrem Publikum die Rede (vgl. Quint. inst. I2,5,I-4; Plin. epist. 7,I7,8-I3; Philostr. VS 54I). Wenn von den Zuhörern bereits vor dem eigentlichen Beginn des Auftritts mutwillige Störungen und Signale der Ablehnung kamen, konnte dies den emotional ohnehin schon angespannten Redner noch mehr verunsichern. Für einen gelingenden Vortrag war dies auch deshalb eine ungünstige Voraussetzung, weil davon die Konzentration des Redners negativ beeinflusst wurde, der Vortrag in der Antike aber ohne Manuskript aus dem Gedächtnis erfolgen musste und zudem einen klaren Kopf für Improvisation und spontane Anpassungen an Reaktionen des Publikums verlangte. Vgl. dazu Korenjak 2000, IO2-IO4 u. I08-II4. Zur Bedeutung von Gedächtnis und Improvisation beim Auftritt vgl. auch Andersen 200I, I07-II9. Bei der Bedeutung eines gelungenen Auftritts für die soziale Selbstbehauptung des Redners, war bereits die mutwillige Sabotage durch Kleinigkeiten, die seine Konzentration beeinträchtigten, für Paulus sicher etwas, was er als Unrecht und Beleidigung empfinden konnte, zumal die Situation in Korinth beim sog. „Zwischenbesuch“ für ihn ohnehin schwierig war und er deshalb im Vorfeld seines Auftritts in der Gemeindeversammlung sicher unter besonderer psychischer und emotionaler Anspannung stand.

49 Dazu Betz 1972, IIf.; Broer 2006, 4I9f.; Wikenhauser/Schmid I973, 435f.

$50 \mathrm{Vgl}$. Betz 1972, of.

5I So z.B. Marxsen 1978, 80: „... und wenn man daraus auch sicher nicht schließen kann, daß das Ganze wörtlich zutrifft, so dürfte Paulus doch in der Tat kein gewandter Redner gewesen sein, und eine imponierende Erscheinung war er auch kaum."

52 Berühmte antike Beispiele sind der Misserfolg des Demosthenes vor König Philipp II. von Makedonien (Aeschin. 2,34f.; Gell. 8,9 u.ö.) sowie der des Sophisten Herakleides vor Kaiser Septimius Severus (Philostr. VS 6I4); ersterer scheiterte an seiner Nervosität, letzterer an seiner Überheblichkeit und an bewusster Sabotage des Publikums.

53 Diese Annahme hat, wie im folgenden Abschnitt zu zeigen ist, durchaus ihre Berechtigung. 
das Debakel in Korinth schrieb Paulus den Tränenbrief (2 Kor IO-I3; vgl. 2,3f.), in dem er seinen gescheiterten rhetorischen Auftritt in Korinth thematisiert (2 Kor Io,Iof.) und sich bemüht, sein Scheitern nachträglich zu relativieren und zu korrigieren. Sein Vorgehen dabei lässt durchaus rhetorische Ausbildung vermuten.

\section{Die Kritik am rhetorischen Auftritt des Paulus}

Während Paulus in 2 Kor 2,5 und 7,12 nur allgemein von Beleidigung und Unrecht spricht, das er in Korinth erlitten hat, und ein den Adressaten bekanntes, im Brief aber nicht identifiziertes Mitglied der Gemeinde dafür verantwortlich macht, könnte der Inhalt dieses direkten Angriffes auf die Stellung und Autorität des Paulus in Korinth möglicherweise in 2 Kor IO,Iof. angegeben sein. 55

a

b

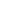

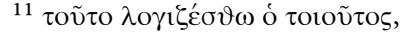

$a^{\prime}$

$b^{\prime}$

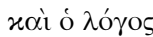

ö $\tau 1$

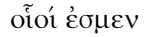

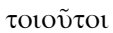

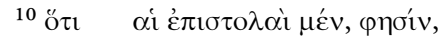

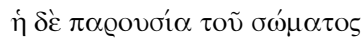

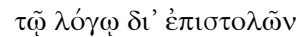

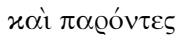

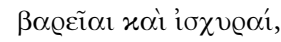

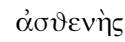

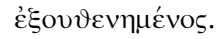

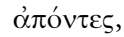

$\tau \tilde{\omega}$ ह้อ $\gamma \omega$.

54 Bei Philostrat findet sich der Fall des Sophisten Philagros aus Kilikien, der sich schon im Vorfeld eines Auftritts in Athen bei seinen dortigen Zuhörern unbeliebt gemacht hatte, die ihm deshalb gezielt eine Falle stellten. Bei seinem Auftritt blamierte er sich so sehr, dass sein Renommee dauerhaft beschädigt war (VS 578-580); vgl. Korenjak 2000, I42-I47. Um eine Vorstellung davon zu gewinnen, wie das Publikum oder einzelne Zuhörer den Vortrag nachhaltig stören oder gar seinen Abbruch erzwingen konnten, ohne sich vieler Worte zu bedienen, geschweige denn sachliche Einwände vorzubringen, genügt ein Blick in Korenjak 2000, 78-83, der anhand von Beispielen aus der antiken Literatur Geschrei, Gemurmel, Stöhnen, Auszischen, Johlen, aber auch Schweigen auflistet. Als intensivste Form einer negativen Publikumsintervention nennt er das Werfen von Steinen. Als Beleidigung galt auch, wenn die Zuhörer teilnahmslos auf ihren Plätzen sitzen blieben und sich so der Interaktion und Kommunikation mit dem Redner verweigerten; vgl. ebd. 9If.

55 Zum Zusammenhang von 2 Kor Io,Iof. und dem gescheiterten Auftreten des Paulus vor der Gemeinde beim sog. Zwischenbesuch vgl. Klauck 1994, 80; Kirner 2003, 49f. Ein unmittelbarer Bezug von 2 Kor Io,Iof. auf die Niederlage des Paulus beim „Zwischenbesuch“ ist jedoch nicht gegeben, wenn man wie Schnelle 2003, 255f., keinen Zusammenhang mit dem „Übeltäter" aus 2 Kor 2,3-8; 7,8.I2 sieht; diese Annahme ist für Schnelle u. a. wegen der postulierten literarischen Integrität des kanonischen 2 Kor nötig. Sonst ließe sich nicht erklären, warum Paulus in 2 Kor IO-I3 nochmals auf die Sache zu sprechen kommen sollte, nachdem die Gemeinde den Übertäter bestraft und er ihm in 2 Kor 2,6-8 ausdrücklich verziehen hat. Etwas anders liegen die Dinge bei Betz 1972, IIf., der ebenfalls einen Konnex zwischen dem Gemeindemitglied aus 2 Kor 2,3-8 und den Gegnern in 2 Kor IO-13 zurückweist; dies ist bei ihm in der Annahme begründet, dass 2 Kor IO-I3 zwar ein ehemals eigenständiger Brief, nicht aber mit dem in 2 Kor 2,4 genannten „Tränenbrief“" identisch ist. Zur Problematik vgl. Gräßer 2005, 72-74. 
Die syntaktische Abhängigkeit von $\varphi$ đóv belegt, dass es sich hier um das mehr oder weniger wörtliche Zitat eines in Korinth gegen Paulus erhobenen Vorwurfes handelt. Die 3. Pers. Sg. Präs. pnớv lässt zudem vermuten, dass der Vorwurf von einer Einzelperson stammt und nach der Meinung des Paulus noch zur Zeit der Abfassung des Tränenbriefes erhoben wird. Da kein Subjekt zu pๆớv genannt wird und der Urheber dieses Vorwurfes deshalb unbestimmt bleibt, plädiert man teilweise dafür, die Verbform im Sinne von „man sagt“ zu verstehen. Paulus würde demnach nicht den konkreten Vorwurf einer Einzelperson zitieren, sondern eine allgemein in Korinth kursierende Meinung. ${ }^{56}$ Die Wiederaufnahme des im-

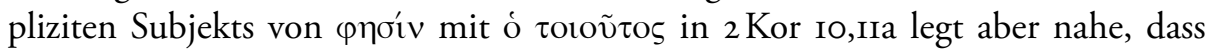
Paulus sehr wohl an eine ganz bestimmte Einzelperson denkt, wenn auch unklar bleibt, ob diese allein oder als Sprecher einer Gruppe agiert. ${ }^{57}$ Sofern die Annahmen zur Korintherkorrespondez, wie sie vorweg skizziert wurden, zutreffen,

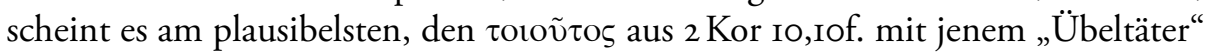
zu identifizieren, der Paulus bei seinem zweiten Besuch durch einen offenen Angriff brüskierte und der als Reaktion auf den Tränenbrief von den Korinthern zur Rechenschaft gezogen und gemaßregelt wurde (2 Kor 2,5; 7,I2).

Die Kritik dieses Mitglieds der korinthischen Gemeinde bestand darin, dass Paulus als Apostel zwar in seinen Briefen aus der Ferne beeindrucken könne, dass sein persönliches Auftreten im Vergleich damit aber enttäuschend sei..$^{8}$ Paulus hatte sich folglich bei seinem Besuch in Korinth in einer Art präsentiert, dass man ihm vorwerfen konnte, er bleibe hinter den Erwartungen zurück, die er

56 Diese Deutung von $\varphi$ ๆóv findet sich z.B. bei Bultmann 1976, 192; Gräßer 2005, 97f.; Martin 1986, 3II; Harris 2005, 698. Der Sing. pnớv bereitete im Kontext des heutigen 2 Kor offensichtlich schon früh den Abschreibern Probleme, wie die abweichende Lesart als Pl. poøvv im Codex B (o3) belegt, die durch die Vetus Latina, die Vulgata und die syrische Überlieferung gestützt wird.

57 Klauck 1994, 79, geht davon aus, dass Paulus sich in 2 Kor I0,7-II primär an eine Einzelgestalt (den „Rädelsführer") wendet, wenn auch nicht auszuschließen ist, dass der Singular hier stellvertretend für die ganze Gruppe der Gegner steht; vgl. auch Kremer 1990, 87, der ebenfalls annimmt, dass Paulus mit $\varphi$ đóv primär auf die in 2 Kor Io,7 genannte Einzelperson ziele.

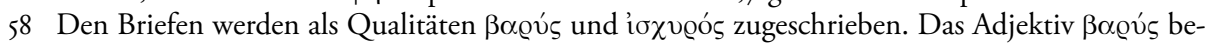
deutet „schwer" im Sinne von „gewichtig“ und „eindrucksvoll“, aber auch „beschwerlich“ und „grausam"; vgl. Bauer/Aland I988, Sp. 269. ioðv@ós steht für das Vorhandensein sowohl physischer Kraft als auch geistiger Stärke; vgl. Bauer/Aland 1988, Sp. 776f. Das Urteil der Korinther über die Briefe des Paulus lautet demnach, dass sie Eindruck machen und sich nicht einfach ignorieren lassen. Nach Betz 1986, 4I, beziehen sich die Termini auf einen Stil, der für Philosophen typisch ist; vgl. Bultmann 1976, 192. Dagegen versteht Gräßer 2005, 98, die zitierte Aussage der Gegner über die Qualitäten der Briefe des Paulus in 2 Kor IO,Io nicht anerkennend, sondern als Vorwurf (offenbar wegen 2 Kor IO,If.): „Die Gegner sehen darin ein bloßes Imponiergehabe.“ Auch Harris 2005, 698f., erkennt in den Adjektiven die Kritik, die Briefe wären „aggressiv" und "gewalttätig", so dass sie Angst einflößten; ähnlich Windisch 1924, 305f. Demgegenüber ist jedoch m.E. der Deutung bei Betz 1972, 44f., der Vorzug zu geben, dass auch die Gegner die Qualität der Briefe anerkennen und die Diskrepanz zwischen brieflicher und leiblicher $\pi \propto$ oovoí $\alpha$ gegen Paulus anführen; so auch Wolff 1989, $202 \mathrm{f}$. 
durch seine Briefe geweckt hatte. ${ }^{59}$ Derselbe Vorwurf steht offensichtlich auch hinter der formal und inhaltlich parallelen Aussage in 2 Kor IO,If. (ö $x \alpha \tau \dot{\alpha} \pi$ đó́-

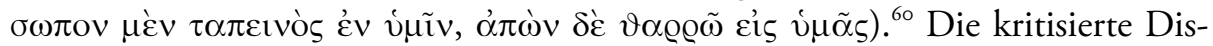
krepanz bestand demnach darin, dass Paulus bei seinen persönlichen Auftritten vor der Gemeinde demütig und sanft wirkte, während seine Briefe den Eindruck von Tatkraft und Stärke erweckten. ${ }^{6}$ An beiden Stellen setzt Paulus voraus, dass die Qualität seiner Briefe in Korinth nicht zur Debatte stand. ${ }^{62}$ Dies ist für das Verständnis der argumentativen Strategie in 2 Kor Io,Iof. nicht unerheblich. Desweiteren darf man nicht übersehen, dass die von Paulus in 2 Kor Io,Iof. zitierte Kritik zwar auf Mängel in seiner rhetorischen Qualifikation zielte, sich dabei

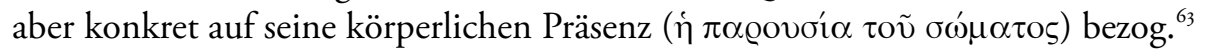

Bei der Frage, worin das Defizit in der körperlichen Erscheinung bestand, das in Korinth gegen Paulus ins Feld geführt wurde, muss man beachten, dass $\dot{\alpha} \sigma-$

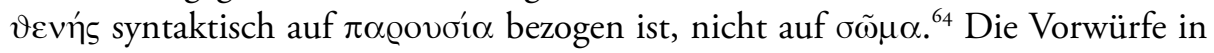
Korinth stehen demnach, entgegen immer wieder vorgeschlagener Deutungen, nicht einfach in Zusammenhang mit Defiziten in der körperlichen Erscheinung des Paulus, d.h. es geht nicht um eine Krankheit, ein hässlich-abstoßendes Äußeres oder um die eventuell ungriechische Erscheinung eines Juden oder Orientalen. ${ }^{65}$ Es geht vielmehr um die "Schwäche“ und damit das Versagen des Redners Paulus bei einer der rhetorischen Kunst gemäßen Inszenierung und Instrumenta-

59 Ebenso Gräßer 2005, 98.

60 Dazu auch Betz 1972, 46-57, der darauf hinweist, dass die in 2 Kor Io,If. verwendeten Begriffe, $\tau \alpha \pi \varepsilon ı v o ́ \varsigma$ und das kontrastierende $\vartheta \alpha \varrho \varrho \varepsilon i v ~(\tau о \lambda \mu \tilde{\alpha} \nu)$, in der Zeit des Paulus4 in Bezug auf das Auftreten von Philosophen und Rhetoren verwendet werden, in ihrer Bedeutung aber durchaus ambivalent sind. Beide Begriffe können je nach Standpunkt sowohl einen Vorzug als auch einen Makel bezeichnen (Textbelege aus Epiktet, Lukian und Diogenes Laertios bei Betz, a.a.O.). Es geht also in 2 Kor Io,If. nicht um die Frage, wann, wo und wie Paulus sich den Korinthern gegenüber mutig oder feige gegeben hat. Das Problem war vielmehr, dass Paulus bei seinem Zwischenbesuch, und sicher auch schon zuvor, in Korinth eine Art des Auftretens und der Selbstdarstellung gewählt und favorisiert hatte, die hinsichtlich ihrer Deutung ambivalent war und Paulus deshalb angreifbar machte. Insgesamt verkörperte Paulus in seinem (leibhaften) Auftreten wohl gezielt mehr den Typos des anspruchslosen (Wander-)Philosophen denn den des glanzvollen Rhetors. Dies war jedoch offenbar, zumindest seit dem Auftreten der auswärti-

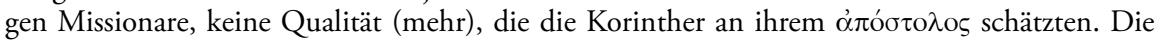
neuen Missionare hatten in ihrer Selbstdarstellung mehr zu bieten bzw. trafen die schon länger vorhandenen Erwartungen der Korinther besser; vgl. dazu Kirner 2003, 28f. u. 5If. Hier sei aber nochmals darauf hingewiesen, dass man das Auftreten des Paulus als $\tau \alpha \pi \varepsilon$ vó́ nicht als einfach gegeben, d.h. als Erkennungszeichen des Ungebildeten auslegen kann; es geht um einen Habitus, der unter dem grundsätzlichen Verdacht der bewusst gewählten Selbstdarstellung und Inszenierung steht. Vgl. auch Klauck 1994, 77.

6I Dazu Klauck 1994, 77f.

$62 \mathrm{Vgl}$. Wolff $1989,2 \mathrm{O}$.

63 In diesem Sinne ist Betz 1986, 4I, zu präzisieren.

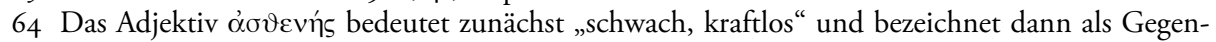
satz zu iơv@ós jedes Vorliegen einer Schwäche; vgl. Bauer/Aland 1988, Sp. 23If.

65 Vgl. auch Betz 1986, 4I; Wolff 1989, 203. 
lisierung seines Körpers vor dem Publikum; Paulus war also nach dem Urteil seines oder seiner Kritiker im Bereich der v́đóx@ı

Wie sehr nämlich die Zuhörer in der frühen Kaiserzeit beim Auftritt eines Redners auf seinen Körper und seine leibliche Erscheinung achteten und welche Formen des Körpereinsatzes man von einem guten Redner erwartete, lässt sich bei Lukian von Samosata nachlesen, obgleich man hier einige Übertreibungen und parodistische Brechungen in Rechnung stellen muss (Rh. Pr. 4I,2O; ähnlich bei Philostr. VS 49If.; 589). ${ }^{67}$ Wichtig waren die äußere Erscheinung und der Gesamteindruck des Redners $(\sigma \chi \tilde{\eta} \mu \alpha)$, die Art und der Einsatz seiner Stimme ( $\varphi \omega-$ v' mit $\mu \varepsilon^{\prime} \lambda \mathrm{o}$ und $\tau$ ò $\left.\tau \alpha \chi v^{\prime}\right)$ sowie sein gesamtes körperliches Agieren und Re-

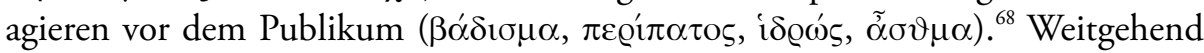
dieselben Aspekte nennt der bereits erwähnte Brief des jüngeren Plinius (epist. 2,3,9: pronuntiatio vultus habitus gestus etiam dicentis). In ihren Aussagen folgen Lukian und Plinius der traditionellen rhetorischen Theorie, wie sie in den antiken Handbüchern dokumentiert ist: Voraussetzung für einen erfolgreichen rhetorischen Auftritt ist, dass der Redner durch theoretische Unterweisungen und praktische Übungen den richtigen Einsatz und die Beherrschung seiner Stimme (vox) und seines Körpers (corporis motus), d.h. seiner Gestik (gestus) und Mimik (vultus), erlernt und verinnerlicht hat. ${ }^{69}$ Deshalb muss es nicht überraschen, dass in Korinth das Auftreten des Paulus an denselben Maßstäben gemessen wurde.

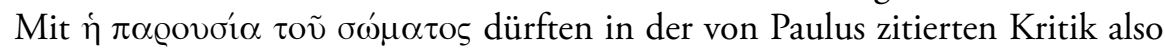
jene Aspekte des rhetorischen Auftritts angesprochen sein, die in den antiken Rhetorikhandbüchern unter dem Stichwort corporis motus verhandelt werden (Cicero spricht auch von sermo corporis oder eloquentia corporis; vgl. de orat. 3,222; orat. 55). ${ }^{70}$ Blickt man auf die traditionellen Anweisungen für den corporis

66 So Lietzmann 1969, I42, und Bultmann 1976, 192. Kirner 2003, 50, hebt zurecht hervor, dass man aus 2 Kor IO,Iof. folgern muss, Paulus habe in den Augen der Korinther auf dem Gebiet der Rhetorik primär in der actiolpronuntiatio, nicht in inventio, dispositio und elocutio versagt, die er sogar nach dem Urteil seiner Kritiker in seinen Briefen unbestreitbar unter Beweis gestellt hatte.

67 Die Bedeutung des „Körpers“ als Voraussetzung und Mittel der rhetorischen performance in der Zweiten Sophistik zeigt sich z.B. in den letzten Worten des Polemon von Laodikeia (ı./2. Jh. n.Chr.), der freiwillig den Hungertod wählte, als ihm eine körperliche Erkrankung weitere

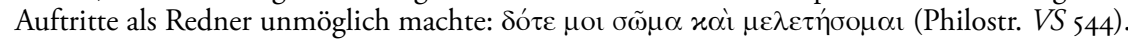

68 So Korenjak 2000, 54-56; insgesamt zu den unterschiedlich gebildeten Zuhörergruppen und ihren Erwartungen an Rede und Redner ebd. 4I-65; vgl. auch Schmitz 1997, I60-168.

69 Anmerkungen zur Stimme beim Vortrag finden sich schon bei Aristoteles $(R h .3, \mathrm{I}, 3-5)$; insgesamt ist er daran aber relativ wenig interessiert. Erst der anonyme Autor der Rhetorica ad Herennium, ein Zeitgenosse Ciceros, differenziert in seinen Anweisungen für den rhetorischen Auftritt ausdrücklich Stimme und Körpersprache des Redners (rhet. Her. 3,20; vgl. Quint. inst. II,3,I). Vgl. Andersen 200I, II9 u. I23-I29; Hall 2010, 220; auch Olbricht 1997, I6of.; Fuhrmann 2003, 79f.; Ueding/Steinbrink 2005, 236f.

70 In dieser Hinsicht ist die Auslegung bei Klauck 1994, 80, zu ergänzen und zu präzisieren, der die Kritik der Korinther am persönlichen Auftreten des Paulus allein in der kunstlosen äußeren 
motus, scheint der Angriff auf Paulus darauf zu zielen, dass es ihm bei seinem Auftritt (bzw. seinen Auftritten) vor der Gemeinde nicht gelang, durch den effektvollen Einsatz von Gebärden und Gesichtsausdrücken den Inhalt seines Vortrags überzeugend zu akzentuieren und zu unterstützen (vgl. rhet. Her. 3,27; Cic. de orat. 3,22I; Quint. inst. II,3,96). ${ }^{71}$ Dies lässt sich weiter präzisieren. Denn nach den Erwartungen der frühen Kaiserzeit sollte ein Redner in seiner äußeren Erscheinung und seinem Auftreten Würde und Autorität ausstrahlen. Das bedeutete, dass er durch sein Agieren vor dem Publikum und seine Körpersprache den Eindruck von Männlichkeit, edler Abstammung und Bildung vermitteln sollte. ${ }^{72}$

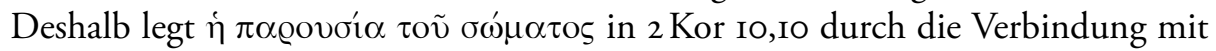

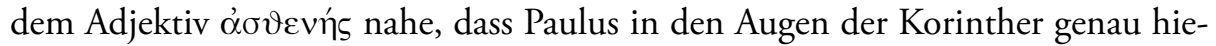
rin versagte. Paulus machte offensichtlich bei seinem Auftritt in Korinth keinen männlich würdevollen Eindruck, jedenfalls nicht in dem Maße, dass er zum autoritären Tonfall seiner Briefe passte. Für diese Deutung spricht, dass sich derselbe Vorwurf auch in 2 Kor Io,If. erkennen lässt, wo Paulus mit dem Gegensatz

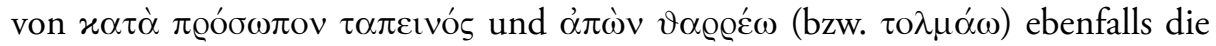
in Korinth artikulierte Kritik an seinem Auftreten aufgreift. Weil in der Welt und Zeit des Paulus Autorität in hohem Maße von der Kompetenz abhing, sich in seinem gesamten Auftreten als männlich, edel und gebildet zu präsentieren, musste er durch den gescheiterten Auftritt in Korinth auch die Wirkung und Rezeption seiner Briefe bedroht sehen.

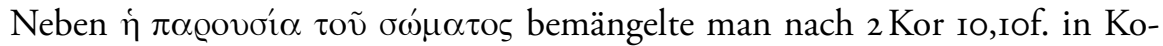

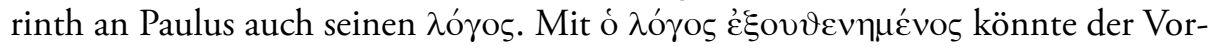
trag des Paulus sowohl im Blick auf den Inhalt, d.h. die Auswahl und das Arrangement der Argumente (dispositio/ $\tau \alpha \dot{\xi} \xi 1 \varsigma$ ), als auch im Blick auf den sprachlichen

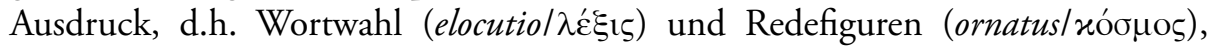
anvisiert sein. ${ }^{73}$ Dagegen spricht jedoch, dass, sofern Paulus in 2 Kor Io,If. und

Form und der mangelnden rhetorischen Brillanz seiner Rede begründet sieht.

71 Ein Überblick zu den Aussagen der rhetorischen Theorie über den richtigen Körpereinsatz findet sich bei Hall 20I0, 224-227; eine schematisierende Darstellung der Ausdifferenzierungen in rhet. Her. 2,26-27 ebd. 225 (Fig. 2). Vgl. auch Olbricht 1997, 163; Fuhrmann 2003, 80.

72 Dazu Hall 20IO, 227-232. Es ging dabei um die Frage der Übereinstimmung der äußerlichen Erscheinung und des Auftretens des Redners mit konventionellen Erwartungen und Normen, wenn sich auch keine allgemein gültigen und festen Regeln benennen lassen, die den Redner zum sicheren Erfolg führten. Am wichtigsten war die glaubwürdige Demonstration von Bildung als distinktives und identitätsstiftendes Kennzeichen, durch das sich Freie von Sklaven, Edle von Gemeinen, Griechen von Barbaren unterschieden; vgl. Whitmarsh 2005, 29-34. Zur Bedeutung von Elementen der äußeren Inszenierung für den gelungenen Auftritt als Redner vgl. auch Whitmarsh 2005, 26-29.

73 Der Begriff $\lambda$ ó ${ }_{0}$ s ist vielgestaltig. Er bezeichnet sowohl den Akt des Sprechens als auch das Gesprochene hinsichtlich seiner äußeren Form und seines Inhalts; vgl. Bauer/Aland 1988, Sp. 968-972; Debrunner 1942, 73f.; Kleinknecht 1942, 76-79. Bultmann 1976, 192, bezieht ó $\lambda$ ó

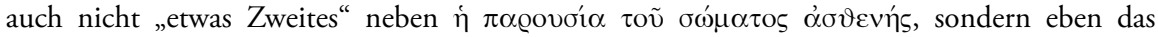


IO,Iof. die gegen ihn vorgebrachte Kritik zuverlässig wiedergibt, er in Korinth mit dem $\lambda$ ó $\gamma$ os seiner Briefe durchaus Eindruck gemacht hatte. Man müsste folglich annehmen, dass der $\lambda$ ó $\gamma$ os seiner mündlichen Rede hinsichtlich Disposition, Wortwahl und Stil deutlich hinter dem $\lambda$ ó $o s$ der Briefe zurückblieb. Der

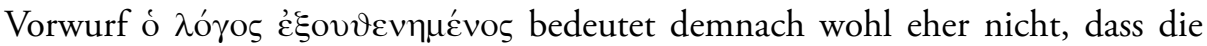
Rede in ihrem Inhalt oder in ihrer formalen Gestaltung zu verachten wäre. ${ }^{74} \mathrm{Da}$

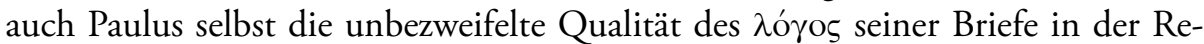
plik auf die Kritik an seinem persönlichen Auftreten voraussetzt und in 2 Kor IO,II den Korinthern entgegenhält, er werde bei ihnen als Redner das nächste Mal genauso beeindruckend und überzeugend auftreten, wie er es jetzt trotz leib-

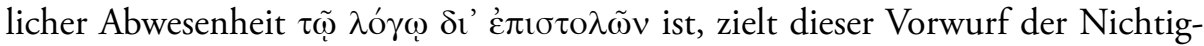

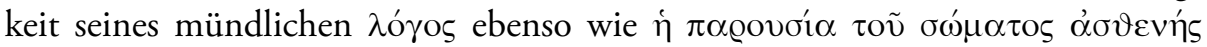
auf die Qualität des rhetorischen Auftritts (ن́ंóx@ıøı), der nicht geeignet ist, den Inhalt der Rede zur Geltung zu bringen (vgl. D.H. Dem. 53; Cic. de orat. 2,I88; Quint. inst. II,3,30ff.). ${ }^{75}$ Die in 2 Kor IO,IO zitierte Kritik am Auftreten des Paulus dürfte demnach lauten: Seine Rede taugt nichts, weil ihr Vortrag aufgrund der Mängel in seiner körperlichen Präsenz und Selbstdarstellung bei den Zuhörern nicht ankommt. ${ }^{76}$

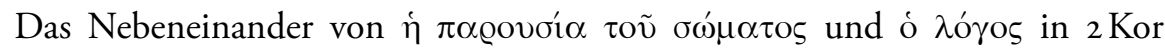
IO,Io könnte zudem auf zwei verschiedene Aspekte oder Qualitäten des rhetori-

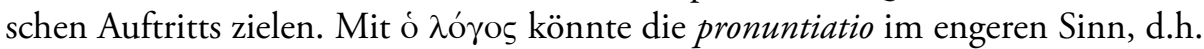
der stimmliche Vortrag ( $v o x)$ des Redetextes, intendiert sein, der auch in den antiken Rhetorikhandbüchern vom corporis motus unterschieden wird. ${ }^{77}$ Die Stim-

Hauptproblem des schwächlichen Auftritts. Betz 1972, 57-60, dagegen versteht ausgehend von 2 Kor II,6 $\lambda$ ó ${ }^{\circ} \varsigma$ als die äußere Form der Rede im Unterschied zu $\gamma v \tilde{\omega} \sigma ı$, , mit der ihr Inhalt bezeichnet werde; vgl. Harris 2005, 699f. Auch Windisch 1924, 306f., sieht ó $\lambda$ ó $\mu$ ćvos als Angriff auf die `Art des Paulus zu reden‘; es ging also um die kunstlose Form der Rede bzw. des Redens.

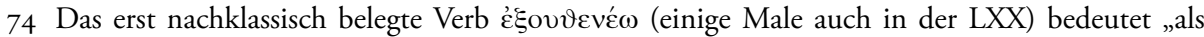
Nichts erachten“, also „geringschätzen, verachten“; vgl. Bauer/Aland 1988, Sp. 562. Das Partizip Aorist Medium in 2 Kor IO,IO ist wohl so zu verstehen, dass der (mündliche) $\lambda$ ó von einer Art ist, die Geringschätzung und Verachtung einbringt bzw. eingebracht hat, also bei den Zuhörern keine Akzeptanz findet und keine Wirkung erzielt.

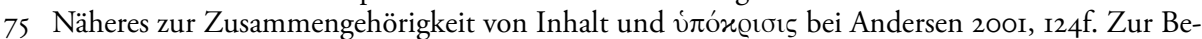
deutung des guten Vortrags merkt Cicero an: neque enim refert videre quid dicendum sit, nisi id queas solute et suaviter dicere; ne id quidem satis est, nisi id quod dicitur fit voce voltu motuque conditius (Brut. IIо).

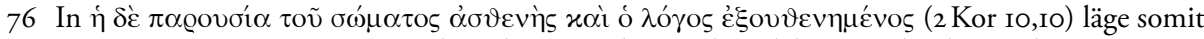
ein xát consecutivum vor („so dass" bzw. „und so" oder „daher"); vgl. Blass/Debrunner 1990, $367[\$ 442,2]$.

77 Ähnlich Harris 2005, 700, der die in 2 Kor IO,IO zitierte Kritik an Paulus auf die beiden zentralen Aspekte des rhetorischen Auftritts bezogen sieht: (I) den Körpereinsatz des Redners und (2) die Wortgestalt und den Inhalt der Rede. Gegen die vorgeschlagene Deutung lässt sich einwenden, dass man statt $\lambda$ ó $\gamma o s$ dann eher $\varphi \omega v \eta ́$ erwarten würde. Trotz der Unterschiede in der Wortbedeutung schließen beide Begriffe einander nicht aus. Denn nach der Definition des Ari- 
me des Redners soll beim Vortrag neben der korrekten und deutlichen Artikulation der Worte Volumen (magnitudo) und Stabilität ( firmitudo), aber auch eine angemessene Modulation (mollitudo) besitzen (rhet. Her. 3,20-24; Cic. de orat. 3,217-219; Quint. inst. II,3,15-65). ${ }^{78}$ Der letzte Punkt ist der entscheidende, aber auch der schwierigste; er verlangt vom Redner, dass er seine Stimme in Tonlage, Rhythmus und Geschwindigkeit den wechselnden Inhalten seiner Rede anpassen kann, um so bei seinem Publikum die jeweils gewünschten Emotionen zu wecken (rhet. Her. 3,24; Cic. de orat. 3,225-227; Quint. inst. I,IO,25). ${ }^{79}$ Vor allem aber galt, ähnlich wie beim corporis motus, dass der Redner stets einen männlich würdevollen Klang seiner Stimme wahren und deshalb das Abgleiten in einen verweichlicht weiblichen Tonfall oder gar ins Kreischen vermeiden musste (vgl.

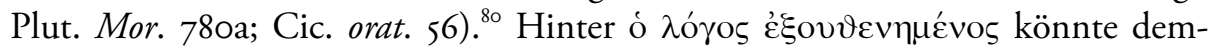
nach der Vorwurf stehen, Stimme und Tonfall des Paulus seien verachtenswert, d.h. sein Vortrag lasse eine angemessene Modulation und einen männlich-kraft-

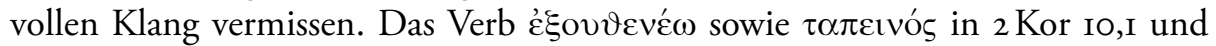

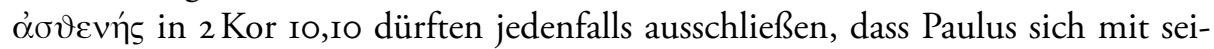
nem rhetorischen Vortrag angreifbar machte, weil er im Tonfall und gleichermaßen in Gestik und Mimik zu theatralischen Übertreibungen neigte, wie sie in dieser Zeit vorkamen und immer wieder beklagt wurden. ${ }^{81}$

\section{Die briefliche Replik des Paulus}

Das Scheitern des Paulus in Korinth war also darin begründet, dass er bei seinem Auftritt vor der Gemeinde in Korinth - wohl in gesuchtem Kontrast zum selbstgewissen und auftrumpfenden Auftreten der konkurrierenden Missionare - in

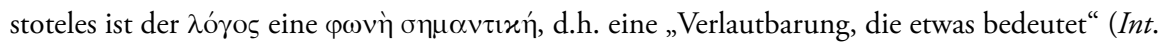
I6b 26); vgl. dazu Kleinknecht 1942, $78 f$.

78 Aristoteles nennt drei Qualitäten, die Stimme beim Vortrag haben soll: Volumen, Harmonie und Rhythmus (Rh. 3,5). Vgl. Olbricht 1997, I60; Andersen 200I, I25f. Zu den Qualitäten der Simme (vocis figura) beim rhetorischen Auftritt vgl. Hall 2010, 220-224, bes. den schematischen Überblick zu ihrer Ausdifferenzierung in rhet. Her. 3,20-24 ebd. 22I (Fig. I); vgl. auch Martin 1974, 353f.

79 Vgl. Fuhrmann 2003, 80.

80 Ergänzend ist anzumerken, dass die kaiserzeitliche Kultur sehr wohl eine klare Vorstellung von der idealen Stimme des Redners hatte, die sich einerseits auf eine möglichst perfekte Annäherung in Rhythmus und Aussprache an das attische Griechisch des 5./4. Jh. v.Chr. bezog, andererseits aber auch auf den vollkommenen männlichen Klang. Die Annäherung daran versuchte man im Rhetorikunterricht durch Stimmübungen zu erreichen. Das Fehlen einer eindeutig männlichen Stimme wurde als ebenso großer Makel empfunden wie weibliche und effeminierte Züge im Auftreten und in der äußeren Erscheinung des Redners. Ausführlich dazu Gleason I995, 82-IO2; zu den Stimmübungen vgl. auch Andersen 200I, I22f.

8I Beispiele für derartige Klagen finden sich bei Seneca, Plinius d.Ä., Tacitus und Plinius d.J.; vgl. dazu Hall 20I0, 223f. 
Körpersprache und Tonfall eine Selbstdarstellung anstrebte, die seine Demut und Niedrigkeit im Dienst als Apostel und Gemeindeleiter hervorheben sollte (vgl. 2 Kor Io,If.). ${ }^{82}$ Dennoch ist zu fragen, ob man wirklich ausschließen kann, dass Paulus deshalb scheiterte, weil er über keine rhetorische Ausbildung verfügte und daher das traditionelle System der Regeln für den Einsatz von Körper und Stimme beim rhetorischen Auftritt nicht kannte, dessen Einhaltung beim Vortrag aber zumindest ein gebildetes Publikum, zu dem auch ein Teil der korinthischen Gemeinde gehörte, erwartete und überwachte. ${ }^{83}$ Dabei sollte man nicht verges-

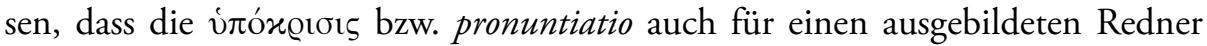
reichlich Gelegenheit zum Scheitern bot und ihr Erfolg nur bedingt planbar war; denn der rhetorische Auftritt durfte dann als perfekt gelten, wenn Gestik, Mimik und Stimme des Redners sowohl dem Publikum als auch dem Anlass, aber auch der Person des Redners angemessen waren (Quint. inst. II,3,I53-I84). ${ }^{84}$ Die Entscheidung, ob dies einem Redner geglückt war, lag allein beim Publikum und war deshalb der Stimmung des Augenblicks unterworfen.

Die Art und Weise, wie Paulus in 2 Kor Io, Iof. sein Scheitern in Korinth gegenüber der Gemeinde thematisiert, zeigt jedenfalls, dass er sich sowohl der Bedeutung seines Fauxpas bewusst war als auch der Notwendigkeit, ihn zu korrigieren oder zumindest zu relativieren, wenn er seine Stellung und Autorität in der Gemeinde weiter behaupten bzw. wiederherstellen wollte. Das Problem, das Pau-

82 Dem 2 Kor lassen sich weitere Hinweise dafür entnehmen, dass Paulus eine Art der Selbstdarstellung als Missionar und Apostel wählte, zu der Aussagen über die eigene Niedrigkeit, Schwäche und Demut gehörten (2 Kor 4,7-I2; 6,3-IO; II,22-29; I2,7-IO; I3,9). Diese Aussagen sollten das Streben des Apostels nach Gleichgestaltigkeit mit dem erniedrigten und gekreuzigten Herrn, aber auch seinen in einer derartigen Christusförmigkeit begründeten Autoritätsanspruch herausstellen (2 Kor I,3-7; 5,20; 6,I). Näheres dazu bei Dautzenberg 1986, I50-I53. Daneben betonte Paulus offenbar in Anknüpfung an philosophische Rhetorikkritik, dass seine Rede einfach, klar und ehrlich sei und nicht auf die Mittel bloßer Überredung setze (2 Kor 4,If.5). Dazu in der Sache durchaus treffend Becker 1992, 253f.; Schnelle 2003, 262-269. Jedoch wird das Auftreten und die Verkündung des Paulus damit noch nicht per se a-rhetorisch oder gar anti-rhetorisch; auch dies kann eine gezielte Strategie und Form der rhetorisch motivierten Selbstdarstellung und Inszenierung des Auftritts sein. Dahinter steht der bereits angesprochene rhetorik-kritische Diskurs der Antike, der die Rhetorik als Kunst der Überredung mit der Philosophie als Wahrheitssuche kontrastiert. Betz 1972, I4f., mag recht haben, wenn er ausgehend von I Kor I-2 für Paulus eine bewusste Anknüpfung an diesen Diskurs und eine darin begründete Zurückweisung der Rhetorik in der Evangeliumsverkündigung reklamiert; doch darf dies nicht als eine vollständige Absage an rhetorische Techniken und Mittel missverstanden werden, wie auch ein Durchgang durch die Briefe des Paulus zeigen kann.

83 Näheres bei Andersen 200I, I24-I29. So sehr auch die Einhaltung der Konventionen für den Erfolg des Auftretens eines Redners wichtig war, erwartete man von ihm dennoch innovative Elemente, d.h. einen kreativen Umgang mit der normativen Tradition. Die Folgen waren für den Redner dabei nicht immer im Voraus abschätzbar, da einerseits der Regelbruch als schwerer Fehler, andererseits eine zu große Regeltreue als Schwäche gewertet werden konnte. Vgl. Whitmarsh 2005, 35-37 u. 4I.

84 Dazu Olbricht 1997, I63. 
lus dabei bewältigen musste, war genau besehen aber nicht nur, dass man in Korinth seine rhetorischen Fähigkeiten bestritt und man sich darin durch den gescheiterten Auftritt in der Gemeindeversammlung bestätigt sah. Das eigentliche Problem, gegen das Paulus ankämpfen musste, war, dass durch das Debakel seines letzten Besuches auch seine Briefe diskreditiert waren, deren Qualität und Überzeugungskraft bisher in der Gemeinde niemand beanstandet hatte. Mit dem Vorwurf, das persönliche Auftreten des Paulus bleibe hinter dem Eindruck seiner Briefe zurück, stand die Rezeption der Briefe in Korinth nämlich unter dem Vorzeichen, sie würden den Adressaten aus der Ferne etwas vorspiegeln, was Paulus, wenn er einmal kommt, nicht einlösen wird und einlösen kann.

Die Brisanz dieses Urteils ist in der antiken Brieftheorie begründet, deren zentrale Stichworte und Topik Paulus in 2 Kor Io,Iof. (und 2 Kor Io,If.) nun seinerseits aufgreift, um die behauptete Diskrepanz zwischen seiner brieflichen Selbstdarstellung und seinem persönlichen Auftreten zurückzuweisen. Der Gegensatz

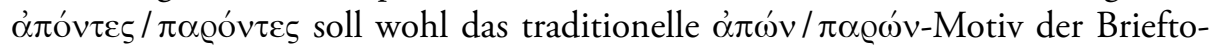

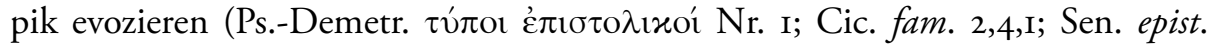
$75, \mathrm{I}){ }^{85}$ Der Brief überbrückt die räumliche Trennung und macht den leiblich abwesenden Absender beim Adressaten gegenwärtig (vgl. Cic. fam. 3,II,2; I2,30,I; 16,I6,2). ${ }^{86}$ Paulus löst in 2 Kor IO,II dieses Paradox der Brieftopik zwar scheinbar

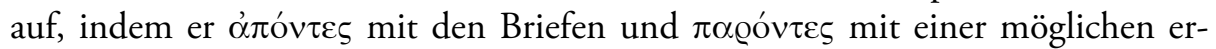

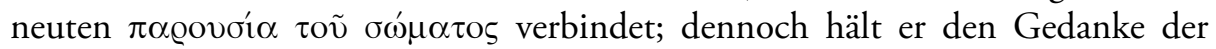
Quasi-Gegenwart im Brief fest. ${ }^{87}$ Denn trotz körperlicher Abwesenheit ist er im Brief $\tau \tilde{\omega} \lambda \hat{\gamma} \gamma \omega$ bei den Adressaten so präsent, wie er es bei körperlicher Anwesenheit $\tau \tilde{\omega}$ " lich das $\delta \imath^{\prime} \dot{\varepsilon} \pi \imath \sigma \tau \Delta \lambda \tilde{n} \varsigma \lambda \alpha \lambda \tilde{\varepsilon} \tilde{v}$ der antiken Brieftheorie an, das die allgemeine Überzeugung ausdrückt, im Brief werde die Stimme des Absenders nicht anders als im Gespräch von Angesicht zu Angesicht vernehmbar (Demtr. Eloc. 232; vgl. Cic. Att. 8,I4,I; Sen. epist. 75,I) ${ }^{89}$ Paulus affirmiert also gegen das anders lautende Urteil der Korinther, dass er in seinen Briefen so vernehmbar und gegenwärtig wird, wie er wirklich ist. Die völlige Identität des brieflich gegenwärtigen mit dem leiblich anwesenden Paulus wird durch die korrelativen Pronomina oíor -

85 Für die Verwendung dieses traditionellen Topos in den pln. Briefen vgl. Thraede 1970, 95-I06; zur Herkunft aus der antiken griech. Brieftheorie ebd. 27.

86 Ausführlich dazu Koskenniemi 1956, 38-42. 172-200; Malherbe 1988, I2. In der antiken Brieftheorie bürgert sich für diesen Aspekt deshalb die Bezeichnung $\pi \propto \varrho 0 v \sigma i ́ \alpha$ ein.

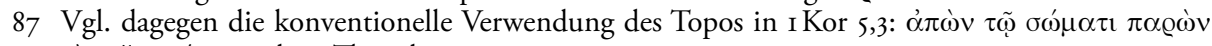
$\delta \dot{\varepsilon} \tau \tilde{\omega} \pi v \varepsilon v ́ \mu \alpha \tau 1$; dazu Thraede 1970, 97-IO2.

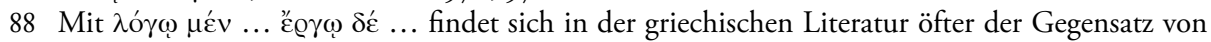
Reden und Tun ausgedrückt, häufig mit der Konnotation angeblich vs. tatsächlich (z.B. Isoc. 8,I34; I2,80; I7,I7; Lys. 2,5; Plut. Per. 9,I; J. BJ I,288). Vgl. dazu Debrunner 1942, 74.

89 Vgl. Thraede 1970, 22f.; Koskenniemi 1956, 42-47 u. 177-179; Malherbe 1988, I2. In der Brieftheorie wird für diesen Aspekt später die Bezeichnung ó $\lambda_{1}$ ía üblich. 


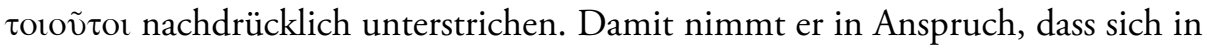
seinen Briefen sein Charakter und seine Person spiegeln, dass sie also, wie es die

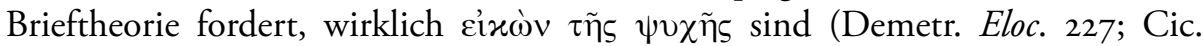
fam. 16,16,2; Sen. epist. 40,1). ${ }^{90}$

An der Art, wie Paulus in 2 Kor Io, Iof. mit der Kritik der Korinther umgeht, zeigt sich die schwierige und problematische Position, in der er sich der Gemeinde gegenüber befindet. Aus der Ferne bleibt ihm letztlich nur die Option zu behaupten, er könne mündlich beim Auftritt als Redner vor der Gemeinde sehr wohl dasselbe leisten, wie schriftlich mit seinen Briefen, wenn er es will - verbunden mit der kaum verhohlenen Drohung, dass es für die Adressaten besser sei, wenn sie ihn nicht dazu zwingen (2 Kor IO,2.II). ${ }^{9 \mathrm{r}}$ Vielleicht setzte Paulus darauf, dass dieses nachdrückliche Insistieren seine Adressaten zumindest darüber nachdenken ließ, ob seine Niederlage nicht doch nur als Missgeschick und nicht als Beweis seiner grundsätzlichen Inkompetenz zu werten sei. Eine solche Deutung war den Korinthern aber wohl auch deshalb kaum oder nur schwer nahezubringen, weil Paulus nach seiner Niederlage offensichtlich überstürzt abgereist war, statt die erneute Konfrontation mit dem Aggressor und Kritiker zu suchen.

Aus diesem Grund setzte Paulus möglicherweise in der formalen und inhaltlichen Gestaltung von 2 Kor Io, Iof. (ähnlich auch in 2 Kor Io,If.) auf Elemente, die den Korinthern subtil seine Bildung $\left(\pi \alpha \imath \delta \varepsilon^{\prime} \alpha\right)$ und damit seine Gleichwertigkeit suggerieren konnten (vgl. den strukturierten Text auf S. 90). Die korinthische Kritik und die Replik des Paulus sind, ganz nach griechischen Stilvorstellungen, bei parallelem Aufbau (a-a' Brief; b-b' rhetorischer Auftritt) inhaltlich als Antithese gestaltet (a-b Diskrepanz; $a$ '-b' keine Diskrepanz)..$^{92}$ In der Kritik sind die Satzglieder parallel geordnet, wobei sie gleichzeitig inhaltliche Gegensätze bilden

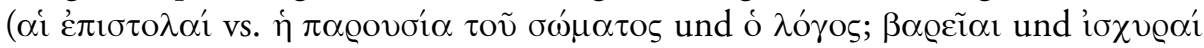

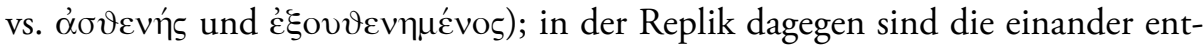

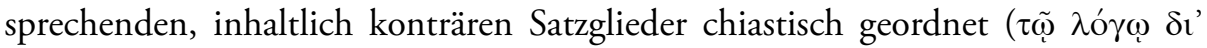

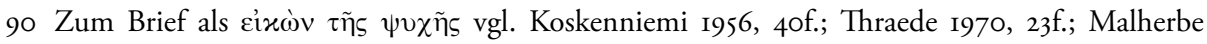
I988, I2.

91 Vgl. Klauck 1994, 79f. („Autorität in Wort und Schrift“); Harris 2005, 702; Windisch 1924, 307. Anders Gräßer 2005, 99, der davon ausgeht, Paulus verweigere sich hier ganz bewusst einem „demonstrativen Imponiergehabe“, wie es seine Gegner pflegen, da er darin ein „Kämpfen mit irdischen Waffen“ sehe (2 Kor Io,3f.), das seinem „Amtsverständnis“ widerspreche; denn er predige nicht „mit überredenden Worten menschlicher Weisheit, sondern in Erweisung des Geistes und der Kraft" (I Kor 2,4). Dagegen lässt sich einwenden, dass die von ihm angeführte Aussage in den Kontext des philosophischen Diskurses über die wahre Rhetorik bzw. über Sinn und Berechtigung der Rhetorik gehört und dass der Rekurs darauf im Rahmen der Auseinandersetzungen mit und in der „bildungsbegeisterten“ Gemeinde von Korinth durchaus als ein Gestus des rhetorischen Auftrumpfens des Paulus gelesen werden soll und muss. Vgl. dazu Betz I986, $36 \mathrm{f}$.

92 Zur Antithese in der griechischen Literatursprache Landfester 1997, I40f.; Blass/Debrunner I990, 420f. [\$ 489]; Lausberg 2008, 392 [\$\$ 794-796]. 


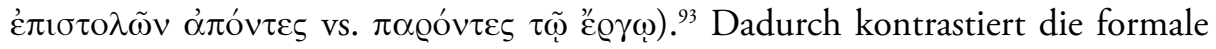
Ordnung der Satzglieder in Kritik und Replik jeweils mit der Aussageintention: Die Behauptung des Widerspruchs zwischen Briefen und rhetorischem Auftritt erfolgt mit parallel geordneten Satzgliedern, die Behauptung der Gleichwertigkeit mit gekreuzten. Geschickt ist auch, dass Paulus ó $\lambda$ ó $\gamma o \varsigma$, den die Kritik unter die beanstandeten Aspekte seines persönlichen Auftretens rechnete, in seiner Replik mit den in ihrer Qualität anerkannten Briefen verbindet. Damit etabliert Paulus den $\lambda$ ó $\gamma$ os als Bindeglied zwischen Briefen und mündlichem Vortrag und provoziert die Frage, wie und warum derselbe $\lambda$ ó $\gamma o \varsigma$ in den Briefen zwar gehaltvoll und überzeugend, im mündlichen Vortrag aber kraftlos und verachtenswert sein soll und kann.

Bei den genannten Aspekten der formalen Gestaltung von 2 Kor Io,Iof. kommt es nicht darauf an, welche Intention und Funktion sich jedem einzelnen Element zuschreiben lassen, es geht darum, dass sie in ihrer Gesamtheit dem Leser den Eindruck vermitteln sollen, dass Paulus hier sehr überlegt und gekonnt formuliert hat. Insofern lässt sich 2 Kor Io,Iof. als eine Form der Demonstration literarischer und rhetorischer Kompetenz verstehen und dient der Selbstinszenierung des Paulus als Gebildetem. Der Abschnitt ist folglich als Kompetenzaufweis zu verstehen, mit dem Paulus seine Autorität in der und über die Gemeinde zurückgewinnen und das Terrain für eine erneute Intervention oder gar einen erneuten persönlichen Auftritt vor der Gemeinde bereiten will (vgl. 2 Kor Io,If.). ${ }^{94}$

Diese Strategie der Selbstdarstellung ist nicht auf 2 Kor Io,Iof. (und Io,If.) beschränkt, sondern bestimmt weite Strecken des Tränenbriefes. Genannt sei hier nur der lange Abschnitt 2 Kor II,I6-I2,I3. Hier präsentiert sich Paulus durchgängig in einer Art und Weise, wie sie für einen Rhetor typisch ist und von ihm erwartet wird. ${ }^{95}$ Dazu gehört vor allem das als Apologie stilisierte Selbstlob verbunden mit der Selbstdarstellung als Leidender in Form der „Narrenrede“.$^{96}$ Auch

93 Parallelismus und Chiasmus sind als Formen, in denen sich das Bemühen um Symmetrie ausdrückt, Elemente der (griechischen) Kunstprosa; vgl. Landfester 1997, I30-I32.

94 Vgl. auch Klauck 1994, 80. Es geht also nicht einfach um den drohenden Hinweis an die Adressaten, dass er seinen Willen in der Gemeinde sehr wohl durchsetzen könne und werde wenn man ihn dazu zwingt; gegen Bultmann 1976, 193; Lang 1986, 33If.; Kremer 1990, 87.

95 Deshalb notiert Klauck 1994, 77, für den 2 Kor zu Recht, dass Paulus immer wieder den Verzicht auf rhetorische Mittel erkläre, nur damit diese „durch die Hintertür" doch wieder in den Brief kommen.

96 Zur Bedeutung dieser Elemente in der Rhetorik der Zweiten Sophistik vgl. besonders Whitmarsh 2005, 79-85: Da autobiographische Aussagen leicht als Selbstlob und deshalb als anstößig empfunden werden konnte, bot die Apologie dem Redner eine gute Möglichkeit, über sich selbst und die eigenen Verdienste zu sprechen, ohne Anstoß zu erregen (vgl. Plutarchs Schrift De se ipsum citra invidiam laudando). Zugleich konnte man damit an die literarisch-philosophische Tradition der Apologie des Sokrates (Plat. u. Xen.) anknüpfen und sich selbst als Philosoph in der Nachfolge jenes Sokrates präsentieren. Auch die Thematisierung der eigenen Leiden gehört in diesen Kontext von Selbstinszenierung durch indirekten Verweis auf die eigenen Leistungen und dient damit der Konstruktion der eigenen moralischen persona ( $\tilde{\eta} \vartheta \mathrm{\vee})$ ). Des- 
hier geht es also um Bildungsdemonstration und den Kompetenzaufweis im Bereich der literarischen und rhetorischen Kunst. Dies ist bei der biographischen Auswertung dieser (und anderer) Aussagen des Paulus in Rechnung zu stellen.

Die Frage, ob Paulus mit dieser Strategie und seiner kurzen, durchaus aggressiv vorgetragenen Stellungnahme in 2 Kor Io,Iof. Erfolg hatte und den Angriff seines Gegners in Korinth relativieren und so seinen missglückten Auftritt doch noch retten konnte, lässt sich, sofern die vorgeschlagene Rekonstruktion der Korintherkorrespondenz zutrifft, wahrscheinlich positiv beantworten. Die Auseinandersetzung endete mit einer Versöhnung zwischen Paulus und den Korinthern (vgl. 2 Kor 7,8-I3a). Zu fragen bleibt allerdings, inwieweit die Versöhnung tatsächlich dem Tränenbrief geschuldet ist oder ob sie nicht auch ein Verdienst des Titus war, jenes treuen Mitarbeiters, den Paulus als seinen Unterhändler mit dem Brief nach Korinth entsandt hatte (2 Kor 7,6f.15). ${ }^{97}$

\section{Weiterführende Überlegungen}

Die traditionelle Sicht zu Bildung und Herkunft des Paulus basiert weitgehend auf dem Selbstzeugnis in den beiden Korintherbriefen: Paulus präsentiert sich hier als einer, der im Vergleich mit anderen Aposteln keine beeindruckende Gestalt war, da er kein großartiger Rhetor (2 Kor IO,Iof.), kein bewundernswerter Enthusiastiker (2 Kor I2,Iff.) und auch kein mächtiger Wundertäter (2 Kor I2,IIf.) war; vielmehr war er ein kranker Mensch, den Gott nicht geheilt hatte (ı Kor I2,7ff.). Dabei werden diese Aussagen der Briefe unhinterfragt als „real“ verstanden. Übersehen wird jedoch, dass derartige Aussagen zum festen Repertoire rhetorischer Selbstinszenierung gehören und dass auch ein Brief keine unmittelbaren und „ungekünstelten“ Einblicke in die physische und psychische Konstitution seines Verfassers gewährt, sondern, nicht anders als eine Rede, auf Mittel der gezielten Selbstdarstellung vor den Adressaten setzt. ${ }^{98}$

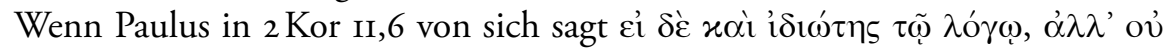
$\tau \tilde{n} \gamma \nu \omega ́ \sigma \varepsilon l$ so darf dies nicht vorschnell als Eingeständnis mangelnder rhetori-

halb sollte man aus dem oberflächlichen Charakter von 2 Kor IO-I3 als Apologie nicht zu schnell eine tatsächlich apologetische Absicht des Paulus ableiten, wie dies auch bei Betz 1972, I9, der Fall ist. Zur „Narrenrede“ und ihren Wurzeln in der paganen Bildungstradition vgl. auch Becker 1992, 245-254; Betz 1972, 73-100 (mit Parallelen in der antiken Literatur).

97 Klauck 1994, 6, urteilt, dass der Einsatz des Titus „als eine Art flankierende Maßnahme gedach"“ war; er „sollte durch persönliches Einwirken die Aufnahme des Briefes günstig beeinflussen und Paulus von den Ergebnissen berichten".

98 Hier sind die Thesen von Deißmann I923, 193-208, zur Unterscheidung von Brief und Epistel und der kunstlosen Ungekünsteltheit echter Briefe, zu denen er auch die Paulusbriefe rechnet, bis heute prägend; Neuansätze in der klassischen Philologie werden nicht gewürdigt und rezipiert (bes. die Arbeiten von J. Radike und M. Ludolf zu den Briefen des jüngeren Plinius). 
scher Qualifikation und damit als Beweis für das Fehlen einer rhetorischen Ausbildung des Paulus gewertet werden. Denn auf dieses Statement folgt sofort eine Demonstration seiner Kenntnisse und Fähigkeiten auf dem Gebiet der Rhetorik. ${ }^{99}$ Mit dieser Aussage versucht Paulus sich im Blick auf seine in Korinth rhetorisch überzeugenden Konkurrenten zu positionieren. Die Kontrastierung von $\lambda$ ó$-^{-}$ $\gamma \circ \varsigma$ und $\gamma v \tilde{\omega} \sigma r \varsigma$ zielt nämlich nicht auf eine grundsätzliche Ablehnung der Rhetorik, sondern auf die Absage an eine falsche Rhetorik, die mehr auf die Überwältigung durch Wortprunk, denn auf das Überzeugen durch die Wahrheit setzt (vgl. dazu auch die der philosophischen Polemik gegen Sophisten entlehnte Kritik in 2 Kor 4,2). ${ }^{100}$ Derselben Strategie der Selbstdarstellung bediente sich Paulus auch schon in I Kor, indem er zwischen einer Rhetorik, die bloße Kunst der Überredung ist, und einer Rhetorik, in der sich Geist und Macht zeigt, differen-

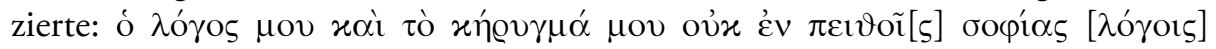

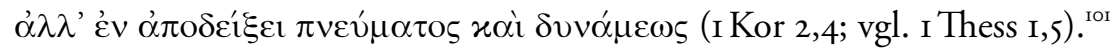

All dies führt unvermeidlich auch zur Frage nach Art und Umfang der Schulbildung des Paulus. Die Überlegungen zur formalen Gestaltung von 2 Kor Io,Iof., die dort zu beobachtende Adaption der epistolographischen Theorie sowie allgemein sein Einsatz rhetorischer Techniken lassen vermuten, dass seine Ausbildung mehr umfasste als nur den grundlegenden Elementarunterricht. ${ }^{\mathrm{IO}}$ Die Annahme, Paulus habe den Unterricht eines Grammatikers und womöglich sogar eines Rhetors besucht, sollte man deshalb nicht vorschnell zurückweisen. ${ }^{103}$ Die Stadt Tarsus, die nach den Angaben der Apostelgeschichte die Heimat des Paulus war (Apg 9,II; 2I,39; 22,3), bot jedenfalls die nötigen Voraussetzungen für eine derartige Ausbildung. ${ }^{\text {.04 }}$

99 Ausführlich Betz 1986, 42-44. Anders Klauck 1994, 83, der die Aussage in 2 Kor II,6 dahingehend versteht, dass Paulus im Blick auf die gegen ihn erhobenen Vorwürfe zwar Unterlegenheit auf dem Gebiet der Rhetorik konzediert, aber auf seiner pneumatisch-charismatischen Begabung und Überlegenheit insistiert. Angesichts der Tatsache, dass Paulus, wie Betz hervorhebt, im engeren und weiteren Kontext der Aussage rhetorische Fähigkeiten demonstriert, sollte man das Eingeständnis rhetorischer Schwäche eher als gezieltes Understatement werten, das die Korinther zur lobenden Anerkennung seiner Kunstfertigkeit motivieren soll.

IOo Vgl. Betz 1986, 40.

IOI Dazu Betz 1986, 36f.; Betz 1972, 59-67. In diesem Passus scheint Paulus zudem technische Begriffe aus der antiken rhetorischen Theorie aufzugreifen (vgl. Arist. Rh. I,2,I).

IO2 Es sei denn, man nimmt an, all diese Elemente seien den Sekretären zuzuschreiben, deren sich Paulus nach allgemeinem Usus bei der Abfassung seiner Brief bediente (vgl. Röm 16,22); dies hieße aber, dass an den pln. Briefen nicht mehr als die Grundintention auf Paulus zurückgeführt werden kann. Zur Diskussion um die Schulbildung des Paulus vgl. Porter 1997, 534-536.

IO3 So auch Hock 2008, I5f. Das „Schulsystem“ im griechischen Osten des römischen Reiches war dreistufig organisiert: Auf die Elementarschule (Lesen, Schreiben und Rechen; Sport und Musik; oft öffentlich unter Aufsicht der Stadt) folgte der Grammatikunterricht (Lektüre der klassischen Schulautoren; Progymnasmata des Rhetorikunterrichts; im Gymnasium der Stadt) und als höchste Stufe der Unterricht beim Rhetor oder Sophisten (privat). Vgl. Hose 1999, I62-167; Pitts 2008, 20-27 (anhand von Papyrustexten aus Ägypten). 
Bei der Frage nach einer möglichen rhetorischen Ausbildung des Paulus und nach rhetorischen Elementen und Einflüssen in den neutestamentlichen und frühchristlichen Schriften ist in höherem Maße als bisher üblich zu beachten, dass Rhetorik in der Welt und Zeit des Frühchristentums mehr war als nur "Stilkunde“. Rhetorik war die Kunst der wirkungsvollen Selbstdarstellung und des perfekten Auftritts im öffentlichen Raum. Aufgrund ihrer Allgegenwärtigkeit und ihres hohen gesellschaftlichen Stellenwerts war die Bewährung auf dem Feld der rhetorischen Performance ein Faktor, der über Erfolg und Scheitern der christlichen Mission entscheiden konnte. Als Reaktion auf einen gescheiterten rhetorischen Auftritt zeigt 2 Kor Io,Iof., dass frühchristliche Missionare und Gemeindeleiter nicht allein auf die Überzeugungskraft der inhaltlichen Komponenten ihrer Predigt setzen konnten. ${ }^{\text {105 }}$ Der Erfolg der christlichen und damit auch der paulinischen Mission hing nicht allein vom Inhalt, sondern auch von der Form der Predigt und dem Auftreten des Predigers ab. Die Analyse und Interpretation der neutestamentlichen und frühchristlichen Schriften kann sich deshalb nicht damit begnügen, die christliche Predigt, d.h. den christlichen $\lambda$ ó ${ }^{\circ} \varsigma \varsigma$ von Gott, im Blick auf seinen Inhalt zu analysieren. Es geht auch um die äußere Ge-

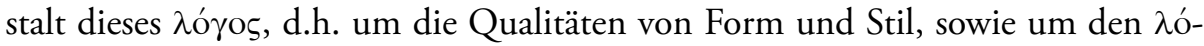
ros in Aktion, d.h. um die christliche Predigt unter den Vorzeichen der Anforderungen an den geglückten und erfolgreichen rhetorischen Auftritt. Sollte die christliche Predigt Gehör finden, so konnte und durfte der $\lambda$ ó $\gamma$ os des Glaubens

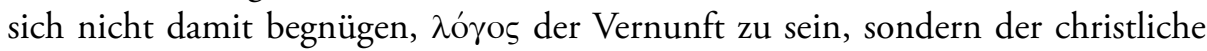
$\lambda$ óyos musste in seiner äußeren Gestalt schön und wohlklingend sein und seine Verkündiger mussten ihn unter vollem Einsatz von Körper und Stimme auf der Bühne der Welt zur Sprache bringen.

I04 Zu Tarsus in Kilikien als Bildungszentrum in der Zeit des Paulus vgl. Porter 1997, 534. In den letzten Jahren wurde, aufgrund der Angaben der Apg über die Erziehung des Paulus in Jerusalem, verstärkt auch die Möglichkeit diskutiert, Paulus habe hier eine literarische und rhetorische Ausbildung nach hellenistischem Modell erhalten (Martin Hengel). Näheres zu einem formal und inhaltlich an der griechischen Bildungstradition orientierten „Schulwesen“ in Jerusalem bei Pitts 2008, 27-50 (mit allerdings nur vorsichtiger Zustimmung).

IOS Nach Quintilian kommt es nicht so sehr darauf an, wie das beschaffen ist, was der Redner in seinem Inneren formuliert hat, sondern darauf, wie es vorgetragen wird (Quint. inst. II,3,2); ähnliche Aussagen finden sich schon bei Cicero (Brut. IIO u. I4If.). 


\section{Literatur}

Andersen (200I): Øivind Andersen, Im Garten der Rhetorik. Die Kunst der Rede in der Antike (aus dem Norwegischen von Brigitte Mannsperger und Ingunn Tveide), Darmstadt.

Anderson (1993): Graham Anderson, The Second Sophistic. A Cultural Phenomenon in the Roman Empire, London / New York.

Anderson (1996): R. Dean Anderson, Ancient Rhetorical Theory and Paul. Contributions to Biblical Exegesis and Theology I8, Kampen.

Bauer u. Aland (1988): Griechisch-deutsches Wörterbuch zu den Schriften des Neuen Testaments und der frühchristlichen Literatur von Walter Bauer, 6. völlig neu bearbeitete Auflage herausgegeben von Kurt Aland und Barbara Aland, Berlin / New York.

Bauer (2007): Thomas Johann Bauer, Who is who in der Welt Jesu?, Freiburg i.Br.

Becker (1992): Jürgen Becker, Paulus. Der Apostel der Völker, Tübingen (2. Aufl.).

Betz (1972): Hans Dieter Betz, Der Apostel Paulus und die sokratische Tradition. Eine exegetische Untersuchung zu seiner "Apologie" 2 Korinther I0-I3. BHTh 45, Tübingen

Betz (1974/75): Hans Dieter Betz, „The Literary Composition and Function of Paul's Letter to the Galatians", in: NTS 2I (1974/75) 353-379.

Betz (1979): Hans Dieter Betz, Galatians. A Commentary on Paul's Letter to the Churches in Galatia. Hermeneia, Philadelphia.

Betz (1986): Hans Dieter Betz, „The Problem of Rhetoric and Theology according to the Apostle Paul“", in: Albert Vanhoye (Hg.), L'Apôtre Paul. Personnalité, style et conception du ministère. BEThL 73, Leuven, I6-48.

Blass u. Debrunner (1990): Friedrich Blass u. Albert Debrunner, Grammatik des neutestamentlichen Griechisch. Bearbeitet von Friedrich Rehkopf, Göttingen (I7. Aufl.).

Broer (2006): Ingo Broer, Einleitung in das Neue Testament (Studienausgabe), Würzburg.

Bultmann (1976): Bultmann, Rudolf, Der zweite Brief an die Korinther. KEK Sdb., Göttingen.

Classen (199I): Carl Joachim Classen, „Paulus und die antike Rhetorik“, $Z N W$ $82, \mathrm{I}-33$.

Classen (2009): Carl Joachim Classen, „Kann die rhetorische Theorie helfen, das Neue Testament, vor allem die Briefe des Paulus besser zu verstehen?“, $Z N W$ IOO, I45-I72.

Dautzenberg (1986): Gerhard Dautzenberg, „Motive der Selbstdarstellung des Paulus in 2 Kor 2,I4-7,4“, in: Albert Vanhoye (Hg.), L'Apôtre Paul. Personnalité, style et conception du ministère. BEThL 73, Leuven, I50-162. 


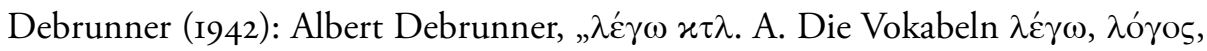
@̃̃ $\mu \alpha, \lambda \alpha \lambda \varepsilon \dot{\varepsilon} \omega$ im Griechentum“, ThWNT 4, 7I-76.

Deißmann (1923): Adolf Deißmann, Licht vom Osten. Das Neue Testament und die neuentdeckten Texte der hellenistisch-römischen Welt, Tübingen (4. Aufl.).

Dihle (1989): Albrecht Dihle, Die griechische und lateinische Literatur der Kaiserzeit. Von Augustus bis Justinian, München.

Fuhrmann (2003): Manfred Fuhrmann, Die antike Rhetorik. Eine Einführung, Düsseldorf (5. Auf.).

Gleason (1995): Maud W. Gleason, Making Men. Sophists and Self-Presentation in Ancient Rome, Princeton.

Goodrich (2010): John K. Goodrich, „Erastus, Quaestor of Corinth: The Ad-

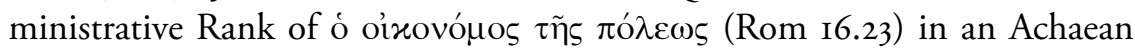
Colony", NTS 56, 90-II5.

Gräßer (2002): Erich Gräßer, Der zweite Brief an die Korinther. Band I: Kapitel I,I-7,I6. ÖTBK 8,I, Gütersloh.

Gräßer (2005): Erich Gräßer, Der zweite Brief an die Korinther. Band 2: Kapitel 8,I-I3,I3. ÖTBK 8,2, Gütersloh.

Hall (20I0): Jon Hall, „Oratorical Delivery and the Emotions: Theory and Practice", in: William Dominik u. Jon Hall (Hg.), A Companion to Roman Rhetoric. Blackwell Companions to the Ancient Word, Oxford, 218-234.

Harris (2005): Murray J. Harris, The Second Epistle to the Corinthians. NIGTC, Grand Rapids.

Hock (2008): Ronald F. Hock, „The Problem of Paul's Social Class: Further Reflexions“, in: Stanley E. Porter (Hg.), Paul's World. Pauline Studies 4, Leiden, 7-I8.

Hose (1999): Martin Hose, Kleine griechische Literaturgeschichte. Von Homer bis zum Ende der Antike (bsr 1326), München.

Kennedy (1984): George A. Kennedy, New Testament Interpretation through Rhetorical Criticism, Chapel Hill / London.

Kirner (2003): Guido O. Kirner, „Apostolat und Patronage (II). Darstellungsteil: Weisheit, Rhetorik und Ruhm im Konflikt um die apostolische Praxis des Paulus in der frühchristlichen Gemeinde Korinth (I Kor I-4 u. 9; 2 Kor IO13)“, $Z A C$ 7, 27-72.

Klauck (1994): Hans-Josef Klauck, Der 2. Korintherbrief. NEB.NT 8, Würzburg (3. Aufl.).

Klauck (2000): Hans-Josef Klauck, Der I. Korintherbrief. NEB.NT 7, Würzburg (4. Aufl.)

Klauck (2006): Hans-Josef Klauck, Ancient Letters and the New Testament. A Guide to Context and Exegesis (with the collaboration of Daniel P. Bailey), Waco.

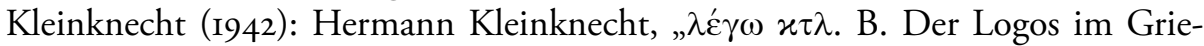
chentum und Hellenismus“, ThWNT 4, 76-89. 
Koskenniemi (1956): Heikki Koskenniemi, Studien zur Idee und Phraseologie des griechischen Briefes bis 400 n. Chr. AASF B IO2,2, Helsinki.

Korenjak (2000): Martin Korenjak, Publikum und Redner. Ihre Interaktion in der sophistischen Rhetorik der Kaiserzeit. Zetemata I04, München.

Kremer (1990): Jacob Kremer, 2. Korintherbrief. SKK.NT 8, Stuttgart.

Kümmel (1983): Werner Georg Kümmel, Einleitung in das Neue Testament, Heidelberg (2I. Aufl.).

Lang (1986): Friedrich Lang, Die Briefe an die Korinther. NTD 7, Göttingen.

Landfester (1997): Manfred Landfester, Einführung in die Stilistik der griechischen und lateinischen Literatursprachen. Mit einem Beitrag von Barbara Kuhn über Formen des Prosarhythmus, Darmstadt.

Lausberg (1990): Heinrich Lausberg, Handbuch der literarischen Rhetorik. Eine Grundlegung der Literaturwissenschaft (3. Aufl. mit einem Vorwort von Arnold Arens), Stuttgart.

Lietzmann (1969): Hans Lietzmann, An die Korinther I, II (erg. von Werner Georg Kümmel). HNT 9, Tübingen (5. Aufl.).

Lohse (2003): Eduard Lohse, Paulus. Eine Biographie, München.

Lona (2009): Horacio E. Lona, Kleine Hinführung zu Paulus. Grundlagen Theologie, Freiburg i.Br. (2. Aufl.).

Malherbe (1988): Abraham J. Malherbe, Ancient Epistolary Theorists. SBL.RBS i9, Atlanta.

Martin (1974): Josef Martin, Antike Rhetorik. Technik und Methode. HAW II/3, München.

Martin (1986): Ralph P. Martin, 2 Corinthians. WBC 40, Waco.

Marxsen (1978): Willi Marxsen, Einleitung in das Neue Testament. Eine Einführung in ihre Probleme, Gütersloh (4. Aufl.).

Meeks (2003), Wayne A. Meeks, The First Urban Christians. The Social World of the Apostle Paul, New Haven / London (2. Aufl.).

Norden (1915): Eduard Norden, Die antike Kunstprosa vom VI. Jahrhundert v. Chr. bis in die Zeit der Renaissance, 2 Bde., Stuttgart/Leipzig (3. Aufl., ND 1995).

Olbricht (1997): Thomas H. Olbricht, „Delivery and Memory“, in: Stanley E. Porter (Hg.), Handbook of Classical Rhetoric in the Hellenistic Period 330 b.c. - a.d. 40o, Leiden, $159-167$.

Pitts (2008): Andrew W. Pitts, „Hellenistic Schools in Jerusalem and Paul's Rhetorical Education“, in: Stanley E. Porter (Hg.), Paul's World. Pauline Studies 4, Leiden, I9-50.

Porter (1993): Stanley E. Porter, „The Theoretical Justification for Application of Rhetorical Categories to Pauline Epistolary Literature", in: ders. u. Thomas H. Olbricht (Hg.), Rhetorik and the New Testament (Essays from the 1992 Heidelberg Conference). JSNT.S 90, Sheffield, IOO-I22. 
Porter (1997): Stanley E. Porter, „Paul of Tarsus and His Letters“, in: ders. (Hg.), Handbook of Classical Rhetoric in the Hellenistic Period 330 B.C. - A.D. 40o, Leiden, 533-585.

Russell (1983): Donald Andrew Russell, Greek Declamation, Cambridge u.a.

Schenke u. Fischer (1978): Hans-Martin Schenke u. Karl Martin Fischer, Einleitung in die Schriften des Neuen Testaments, Bd. I: Die Briefe des Paulus und die Schriften des Paulinismus, Gütersloh.

Schmeller (2008a): Thomas Schmeller, „Der erste Korintherbrief“, in: Martin Ebner u. Stefan Schreiber (Hg.), Einleitung in das Neue Testament. KStTh 6, Stuttgart, 303-325.

Schmeller (2008b): Thomas Schmeller, „Der zweite Korintherbrief“, in: Martin Ebner u. Stefan Schreiber (Hg.), Einleitung in das Neue Testament. KStTh 6, Stuttgart, 326-346.

Schmitz (1997): Thomas Schmitz, Bildung und Macht. Zur sozialen und politischen Funktion der zweiten Sophistik in der griechischen Welt der Kaiserzeit. Zetemata 97, München.

Schnelle (2003): Udo Schnelle, Paulus. Leben und Denken, Berlin.

Schnelle (2007) Udo Schnelle, Einleitung in das Neue Testament, Göttingen (6. Aufl.).

Taylor (2005): Nicholas H. Taylor, „Apostolic Identity and the Conflicts in Corinth and Galatia", in: Stanley E. Porter (Hg.), Paul and His Opponents. Pauline Studies 2, Leiden, 99-I29.

Theißen (1983): Gerd Theißen, Studien zur Soziologie des Urchristentums. WUNT I9, Tübingen (2., erw. Aufl.).

Thraede (1970): Klaus Thraede, Grundzüge griechisch-römischer Brieftopik. Zetemata 48, München.

Thurén (1993): Lauri Thurén, „The General New Testament Writings“, in: Stanley E. Porter (Hg.), Handbook of Classical Rhetoric in the Hellenistic Period 330 b.c. - a.d. 400 , Leiden, 587-632.

Ueding (2005): Gert Ueding, Klassische Rhetorik, München (4. Aufl.).

Ueding u. Steinbrink (2005): Gert Ueding u. Bernd Steinbrink, Grundriß der Rhetorik. Geschichte - Technik-Methode, Stuttgart / Weimar (4. Aufl.).

Vegge (2006): Tor Vegge, Paulus und das antike Schulwesen. Schule und Bildung des Paulus. BZNW I34, Berlin / New York.

Vielhauer (1978): Philipp Vielhauer, Geschichte der urchristlichen Literatur. Einleitung in das Neue Testament, die Apokryphen und die Apostolischen Väter, Berlin / New York (2. Aufl.).

Wendland (1980): Heinz-Dietrich Wendland, Die Briefe an die Korinther. NTD 7, Göttingen (I5. Aufl.).

Whitmarsh (200I): Tim Whitmarsh, Greek Literature and the Roman Empire. The Politics of Imitation, Oxford. 
Whitmarsh (2005): Tim Whitmarsh, The Second Sophistic. Greece \& Rome. New Surveys in the Classics 35, Cambridge.

Wikenhauser u. Schmid (1973), Alfred Wikenhauser u. Josef Schmid, Einleitung in das Neue Testament, Freiburg i.Br. (völlig neu bearbeitete Auflage).

Windisch (1924): Hans Windisch, Der zweite Korintherbrief. KEK 6, Göttingen (9. Aufl.).

Wolff (1989): Christian Wolff, Der zweite Brief des Paulus an die Korinther. ThHK.NT 8, Berlin. 


\title{
Ptolemäische Gnosis bei Hegel?
}

\author{
Anmerkungen zur Interpretation des Johannesprologs \\ durch Amelius
}

ThOMAS M. BÖHM

\author{
I. Einleitung
}

Dass der Johannesprolog einer der zentralen Texte des frühen Christentums ist, ist unumstritten. Welche Rolle er allerdings im johanneischen Corpus bzw. in der johanneischen Schule spielt, wann er entstanden ist, welche redaktionellen Stufen er durchlaufen hat, wie er religionsgeschichtlich zu verorten ist, welche Verhältnisbestimmungen etwa zu gnostischen Kreisen, zur Weisheitsliteratur oder zu Philo von Alexandrien vorzunehmen sind usw., sind Fragestellungen, die in der exegetischen Literatur völlig unterschiedlich beantwortet worden sind. ${ }^{\mathrm{I}}$ Es nimmt nicht Wunder, dass auch die frühchristliche Rezeption des Johannesprologs ganz unterschiedliche Wege genommen hat. Exemplarisch kann hier etwa auf die Auseinandersetzungen zwischen Herakleon und Origenes ${ }^{2}$ verwiesen werden oder auf die unterschiedliche - wenn auch umstrittene - Rezeption des Prologs in gnostischen Gruppierungen ${ }^{3}$. In der Forschung kaum Beachtung gefunden hat jedoch eine Deutung des Johannesprologs durch den Neuplatoniker Amelius, einem Schüler und Weggefährten Plotins. Diese Interpretation ist aber nicht nur deshalb bedeutsam, weil sich ein Nichtchrist um die Auslegung des Johannesprologs verdient gemacht hat, sondern auch insofern, als dessen Ausführungen über Eusebius von Caesarea eine Wirkungsgeschichte entfaltet hat, die nicht allein auf die Antike beschränkt ist (so z.B. bei Theodoret von Cyrus ${ }^{4}$ und Cyrill von Alexandrien'), sondern vielleicht einen Nachhall bei Hegel gefunden hat.

I Auf die uferlose Fülle an unterschiedlichen Deutungsansätzen kann und braucht an dieser Stelle nicht eingegangen zu werden.

2 Vgl. Wucherpfennig 2002, IO4-I79.

3 Vgl. Nagel 2000.

4 Vgl. Theodoret, Gr. Aff. Cur. II 87-88 (I62 Canivet = Théodoret de Cyr, Thérapeutique des malades helléniques, ed. P. Canivet, Paris 1958 [SC 57]).

5 Vgl. Cyrill von Alexandrien, Contra Iul. 8 (PG 76, 936 AB). Eine kritische Edition fehlt bisher. 
Die folgende Untersuchung wird zunächst den Ansatz Hegels während seiner Frankfurter Zeit thematisieren. In einem zweiten Schritt soll die Auslegung des Amelius dargestellt werden, um von hier aus den Kontext dieser Interpretation zu erörtern und einen Vergleich zu Hegel zu ziehen.

\section{Die Interpretation des Johannesprologs durch Hegel}

In seiner Frankfurter Zeit (I797 bis I800) beschäftigte sich Hegel intensiv mit dem Christentum, wie dies u.a. seine aus den Jahren I798 / I800 stammende Schrift „Der Geist des Christentums und sein Schicksal“ belegt. In diesem Werk geht Hegel erstmals nachweislich auf den Johannesprolog ein. ${ }^{6}$ Hier zitiert Hegel zunächst Joh I,I und 4: „Im Anfang war der Logos, der Logos war bei Gott, und Gott war der Logos; in ihm war Leben. "7 Solche Sätze versteht Hegel als thetische Sätze oder die einfachste Reflexionssprache. ${ }^{8}$ Wenn Hegel die Anfangspassage des Johannesprologs, wie er sie zitiert, als thetische Sätze ausweist, schließt er sich vermutlich an J. G. Fichtes Position des Setzens an', wonach es in der intellektuellen Anschauung, wie Fichte bereits in seiner Frühschrift „Recension des Aenesidemus" aus dem Jahre 1792 betont $^{\mathrm{TO}}$, ein absolutes Subjekt geben muss, zu dem eine Tätigkeit gehört, die als solche intuitiv evident ist und folglich auch

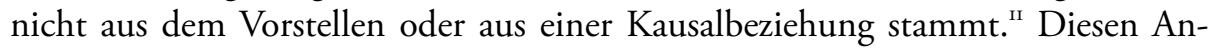
satz führt Fichte konsequent in seinen folgenden Schriften fort, etwa in den Werken „Ueber den Begriff der Wissenschaftslehre“ (I794) ${ }^{12}$ oder „Versuch einer neuen Darstellung der Wissenschaftslehre" (I797) ${ }^{13}$. Wenn ein absolutes Subjekt bzw. ein absolutes Ich oder Prinzip als selbstbegründet gesetzt wird, kann von ihm nicht abstrahiert werden, ohne es zugleich wieder vorauszusetzen. ${ }^{14}$ In der Begründung der Wissenschaft als einer Wissenschaft oder in der Wissenschaft von der Wissenschaft überhaupt ist eine Selbstbegründung nur möglich, wenn im obersten Satz Form und Inhalt übereinstimmen ${ }^{\text {t5 }}$ oder wenn - mit Fichtes „Versuch einer neuen Darstellung der Wissenschaftslehre" formuliert - für das Be-

6 Vgl. Hegel 1986, 373-375; es handelt sich hier um eine verbesserte Ausgabe von Rohl 1966, 306-308; vor allem wurden die griechischen Begriffe korrigiert. Eine kritische Edition dieses Textes in der Hegel-Gesamtausgabe fehlt bisher.

7 Hegel 1986, 373.

8 Vgl. Hegel I986, 373 .

9 Vgl. dazu Halfwassen 1999, 68 sowie Halfwassen I998, I07.

IO Vgl. Fichte 1971, 22f.

iI Vgl. z.B. Rohs I99I, 42f.

I2 Vgl. Fichte i971a, z.B. $69 f$.

I3 Vgl. Fichte i97Ib, z.B. 528-530.

I4 Vgl. Hösle 1988, 22.

I5 Vgl. Hösle 1988, 24. 
wußtsein gilt: „Alles mögliche Bewusstseyn, als Objectives eines Subjects, setzt ein unmittelbares Bewusstseyn, in welchem Subjectives und Objectives schlechthin Eins seyen, voraus; ausserdem ist das Bewusstsein schlechthin unbegreiflich. (...) Dieses unmittelbare Bewusstseyn ist die soeben beschriebene Anschauung des Ich; in ihr setzt das Ich sich selbst nothwendig, und ist sonach das Subjective und Objective in einem. ${ }^{\text {"16 }}$ Wenn Subjektives und Objektives in der Setzung eins sind, hat auch das Prädikat im thetischen Satz keine Bestimmung und ist folglich auch nicht begrenzt, so dass die Prädikate der zitierten Sätze des Johannesprologs für Hegel auch keine Begriffe sind. ${ }^{17}$ Dennoch gehören diese thetischen Sätze für Hegel offensichtlich der Reflexionssprache $\mathrm{an}^{\mathrm{r}}{ }^{8}$, weil im Urteil notwendig das Prädikat vom Subjekt getrennt wird; insofern haben diese Sätze „den täuschenden Schein von Urteilen "19. Indem Gott und Logos unterschieden werden, handelt es sich Hegel zufolge um zwei Rücksichten, das Seiende zu betrachten, nämlich einerseits als das Einige ohne Teilung und Entgegensetzung (Gott), andererseits als die Möglichkeit der Trennung bzw. der unendlichen Teilung des Einigen (Logos): Gott und Logos sind nur insofern verschieden, als jener der Stoff in der Form des Logos ist; der Logos selbst ist bei Gott, sie sind Eins. ${ }^{\text {“20 }}$ Diese Deutung, die Hegel hier vornimmt, ist als prinzipientheoretisch zu bezeichnen, sofern jegliche Form der Entgegensetzung oder Reflexion den Grund der Möglichkeit der Entzweiung wiederum voraussetzt, also die strikte Einheit, so dass zwar die unendliche Entgegensetzung des Logos gegenüber Gott im BeiGott-Sein ausgedrückt ist, dass allerdings die Bedingung der Möglichkeit der Entgegensetzung in der Einheit besteht. Insofern ist die Verschiedenheit von Gott und Logos lediglich als unterschiedliche Hinsicht auf ein und dassselbe zu betrachten: „denn die Reflexion supponiert das, dem sie die Form des Reflektierten gibt, zugleich als nicht reflektiert ${ }^{\text {“2I. }}$. Wenn Hegel Joh I,I mit „im Anfang“ begin-

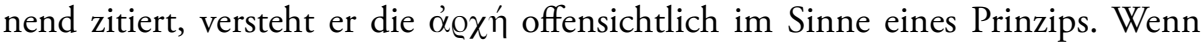
im Einen oder dem Prinzip die Einheit und die Möglichkeit der Entgegensetzung gegeben sind und diese wiederum notwendig „bezogen“ sind auf das Einssein, kann dies im Sinne Hegels als Leben gedeutet werden. ${ }^{22}$ Ein solches Verstehen des Beginns des Johannesprologs ist jedoch - dies sei hier kritisch angemerkt - nur möglich, wenn man mit Hegel Joh I,I folgender Maßen übersetzt: „der Logos war bei Gott, und Gott war der Logos“. Bereits in der Spätantike hat Origenes, den Hegel an dieser Stelle sicherlich nicht kennt, darauf auf-

I6 Fichte 1971b, 528.

17 Vgl. Hegel 1986, 373; dazu Halfwassen 1999, 68.

I8 Vgl. Hegel 1986, 373f.

19 Hegel $1986,373$.

20 Hegel 1986, 374; dazu und zum Folgenden Halfwassen 1999, 68.

2I Hegel 1986, 374.

22 Vgl. Hegel 1986, 373f. 
merksam gemacht, dass man auf die Artikelsetzung achten müsse: „der Logos war bei dem Gott, und ein Gott war der Logos“. Mit Hilfe der antiken Lehre zum Prädikatsnomen ergebe sich hier zwingend eine Differenz zwischen dem einen wahren Gott und dem Logos ${ }^{23}$, so dass Gott und Logos nicht so in der Einheit gedacht werden können, wie dies Hegel insinuiert.

Wenn man nun mit Hegel die Einheit und die Möglichkeit der Entgegensetzung als die Einheit unterschiedlicher Hinsichten auf das Prinzip interpretiert, ist damit im Sinne Hegels auch die Möglichkeit gegeben, die Mannigfaltigkeit bzw. die Unendlichkeit des Wirklichen zu verstehen. Negativ bedeutet dies zunächst, dass die Welt oder das Mannigfaltige nicht als Emanation der Gottheit verstanden werden kann, weil unter Voraussetzung einer Emanation das Emanierte Teil der Gottheit wäre. ${ }^{24}$ Vielmehr ist unter der Hinsicht, dass der Logos die Möglichkeit der Teilung oder Entgegensetzung darstellt, der Logos wiederum der Grund dafür, dass Vielheit möglich ist - oder mit Hegel formuliert: „aber als Wirkliches ist es Emanation, Teil der unendlichen Teilung. " ${ }^{25}$ Dies bedeutet - und hier interpretiert Hegel Joh I,3 -, dass die unendliche Teilung, die als die Möglichkeit der Diversifizierung des Logos verstanden ist, die Bedingung der Möglichkeit dafür darstellt, dass Vielheit oder Teilung ist. Als Vieles ist es Wirkliches. Anders formuliert: Wenn Vieles oder Welt ist, dann kann es im Prinzip nicht als Vieles sein, sondern nur in der Form der Möglichkeit, die im Sinne Hegels der Logos ist. Erst hier im Bereich des Vielen bzw. des Endlichen kann es deshalb nicht nur die Möglichkeit der Entgegensetzung geben, sondern diese „Endlichen haben Entgegensetzungen “26. Dabei betont Hegel textkritisch: „zugleich aber [ist] im Teile (' $\varepsilon v$

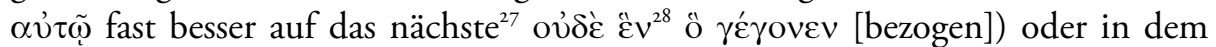

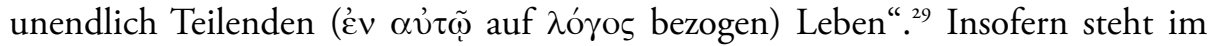
Endlichen oder Geteilten Leben gegen Tod, Leben als ein reflektiertes in Rücksicht auf die Teilung, Licht gegen Finsternis etc. ${ }^{30}$ In diesem Sinne interpretiert Hegel auch die Täuferpassagen des Prologs, die Welt als das Eigenste und doch Fremde etc. ${ }^{3 \mathrm{I}}$ Zentral ist nun für Hegel, dass die Menschen in diesem Kontext in

23 Vgl. Origenes, In Joh 2,2 (54,I2-22 Preuschen [GCS]); dazu Brox (1993), 32-39; für den Zusammenhang zur Lehre vom Prädikatsnomen vgl. Böhm 2004, $698 \mathrm{f}$ (mit weiterer Lit.); für die moderne Exegese vgl. z.B. Theobald 1992, bes. 5I-62.8I. Zur Frage von Differenz und Einheit von Gott und Logos vgl. etwa Böhm 2005, 6I-7I.

24 Vgl. Hegel I986, 374.

25 Hegel 1986, 374; dazu Halfwassen 1999, 69.

26 Hegel 1986, 374.

27 Gemeint ist nicht, dass sich $\dot{\varepsilon} v \alpha$ $\alpha \tilde{\tau} \tilde{a}$ aus Joh I,4 auf das im Text Folgende bezieht, sondern auf das zunächst Stehende, also das, was unmittelbar zuvor in Joh I,3 angeführt ist.

28 Offensichtlich trennt hier Hegel den Satz nach ह̌v nicht ab.

29 Hegel I986, 374.

30 Vgl. Hegel $1986,374$.

3I Vgl. Hegel 1986, 374f. Auf die Einzelheiten braucht an dieser Stelle nicht weiter eingegangen zu werden. 
der Erkenntnis Gottes zwar schwächer als er sind, aber von gleicher Natur sind und ihr Wesen in Gott finden. ${ }^{32}$ Dies ist insofern entscheidend, als er mit der Redeweise von Natur und Wesen darauf abhebt, dass das Menschsein als solches intendiert ist, nicht der Einzelmensch. Dies wird auch dadurch deutlich, dass Hegel unmittelbar im Anschluss daran dazu übergeht, die Inkarnationsaussage aus Joh I,I4 zu interpretieren: „Bisher war nur von der Wahrheit selbst und dem

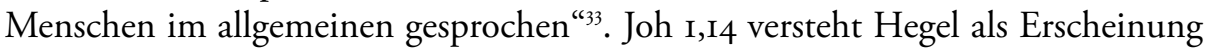
des Logos in der Modifikation als Individuum. ${ }^{34}$ Deutlich unterscheidet er zwischen dem Individuum und dem ö $v \vartheta \varrho \omega \pi \varsigma^{35}$, so dass hier davon auszugehen ist, dass Hegel die Menschwerdung aus Joh I,I4 zwar als real ansieht, dass diese jedoch nicht allein in einem einzigen Menschen erfolgt ist ${ }^{36}$, sondern das allgemeine Wesen des Menschen betrifft. ${ }^{37}$ Dies wird auch in den folgenden Passagen Hegels deutlich, wenn er zwischen Jesus und dem Sohn Gottes unterscheidet: „Jesus nennt sich aber nicht nur Sohn Gottes, er nennt sich auch Sohn des Menschen; wenn Sohn Gottes eine Modifikation des Göttlichen ausdrückt, so wäre ebenso Sohn des Menschen eine Modifikation des Menschen; aber der Mensch ist nicht eine Natur, ein Wesen, wie die Gottheit, sondern ein Begriff, ein Gedachtes; und der Menschensohn heißt hier ein dem Begriffe Mensch Subsumiertes; Jesus ist ein Mensch, ist ein eigentliches Urteil, das Prädikat ist nicht ein Wesen, sondern

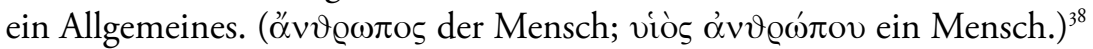

Dies bedeutet zusammenfassend: Selbst wenn Hegel explizit wie implizit auf zahlreiche Verse des Johannesprologs eingeht (Joh I,I.3.4.7.8.IO.II.I2.I4.I5), sind die zentralen Aussagen, die für Hegel entscheidend sind, in den Versen Joh I,I.34 und I4 zu suchen. Diese interpretiert Hegel dahingehend, dass mit Joh I,I die Einheit Gottes und die Möglichkeit der Entzweiung in der Einheit gegeben sind. Durch den Logos im Sinne der Möglichkeit der Entzweiung, die durch den Begriff Leben ausgelegt wird, ist zugleich die Möglichkeit des Wirklichen im Sinne der Vielheit eröffnet. Eine Besonderheit stellt die Inkarnation dar (Joh I,I4), die Hegel zwar als reale Menschwerdung verstehen kann, die für ihn aber nicht das Zentrum darstellt, insofern die Erscheinung des Logos lediglich eine Modifikati-

\footnotetext{
Vgl. Hegel 1986, 375 .

Hegel 1986, 375 .

Vgl. Hegel $1986,375$.

Vgl. Hegel 1986, 375 .

So zurecht Halfwassen 1999, 78.

37 Dieser Gedanke, der für Meister Eckhart charakteristisch ist, konnte Hegel zur Zeit der Studien im Tübinger Stift durch J. L. von Mosheim vermittelt worden sein; vgl. dazu Halfwassen 1998, II4; zum Ansatz Meister Eckharts vgl. z.B. Haas 1979, I57-I6I; Haas 1997, 294f; speziell zum Prozess in Avignon in dieser Hinsicht vgl. Suárez-Nani 1992, 64-67; zur Bedeutung der Kirchengeschichte von Mosheim für die Studien im Tübinger Stift zur Zeit Schellings und Hegels vgl. Franz 1996, 47-63.

38 Hegel 1986 , Werke I, $377 f$.
} 
on als Individuum darstellt, allerdings die Menschwerdung wesentlich so begriffen werden muss, dass der Mensch in den Kosmos gekommen ist. Insofern stellt der Mensch Jesus als Individuum lediglich einen Sonderfall - oder mit Hegel gesprochen - eine Modifikation dar.

Wenn man nun nach den Quellen dieses Ansatzes von Hegel sucht, spielt in der Tat nicht nur Fichte, wie zuvor ausgeführt, eine besondere Rolle, sondern offensichtlich auch die spätantiken Quellen, mit denen Hegel im Laufe seines Studiums vertraut geworden ist. Jens Halfwassen hat eindringlich und überzeugend neben Philo von Alexandrien und Numenius von Apamea ${ }^{39}$ auf den Neuplatoniker Amelius aufmerksam gemacht ${ }^{40}$, der als einziger Neuplatoniker, soweit dies die Überlieferungslage erkennen lässt, einen Kommentar zum Johannespro$\log$ verfasst hat. Im Folgenden sollen zunächst die Aussagen des Amelius in sich interpretiert werden, um dann in einem abschließenden Teil Hegels Deutungen und die des Amelius miteinander zu vergleichen.

\section{Amelius und der Johannesprolog}

Bei dem Vergleich zwischen Hegel und Amelius verweist J. Halfwassen zunächst darauf, dass die Interpretation des Johannesprologs durch Amelius nur bei Eusebius von Caesarea überliefert sei ${ }^{41}$ und dass dieser Text Hegel in der Form der Edition von F. Vigier in der Kölner Ausgabe von 1688 bekannt gewesen sein könnte. ${ }^{42}$ Zum ersten Aspekt ist zu betonen, dass der Amelius-Text nicht allein bei Eusebius von Caesarea in der Praeparatio evangelica überliefert ist ${ }^{43}$, sondern darüber hinaus - wenn auch von Eusebius abhängig ${ }^{44}$ - bei Theodoret ${ }^{45}$ und Cyrill von Alexandrien ${ }^{46}$. Zum anderen ist zu betonen, dass es sich bei dem Herausgeber der Ausgabe, die Hegel zur Verfügung gestanden haben könnte, um François Viger handelt (nicht Vigier oder Viguier $\left.{ }^{47}\right)^{48}$, dessen Text zunächst in Pa-

39 Vgl. Halfwassen 1999, 69-76 sowie Halfwassen 1998, I08-II2. Auf diese beiden Autoren sei an dieser Stelle nicht weiter eingegangen.

40 Vgl. Halfwassen I999, 76-78 sowie Halfwassen 1998, II2-II4; zustimmend - auch im Blick auf J. W. Goethe - Franz 2003, bes. 99.

4I Vgl. Halfwassen 1998, 95 unter Bezug auf des Places 1975, 19-5I, und zwar für Numenius, Atticus und Amelius.

42 Vgl. Halfwassen I998, 96 Anm. 27.

43 Vgl. Eusebius von Caesarea, PE XI I9,I (I46/I48 Favrelle / des Places = Eusèbe de Césarée, La préparation évangélique XI, Paris I982 [SC 292]).

44 Vgl. dazu Ulrich 2009, II3-I30; J. Ulrich betont hier nicht nur die Abhängigkeit des Theodoret von Eusebius (vgl. Ulrich 2009, z.B. I23f) oder des Cyrill von Alexandrien (vgl. knapp Ulrich 2009, II7), sondern darüber hinaus auch das apologetische Anliegen des Theodoret selbst (vgl. Ulrich 2009, bes. I24-130).

45 Vgl. Theodoret, Gr. Aff. Cur. II 87-88 (I62 Canivet).

46 Vgl. Cyrill von Alexandrien, Contra Iul. 8 (PG 76, 936 AB). 
ris im Jahre $1628^{49}$ und schließlich in einer Neuauflage in Leipzig im Jahre I688 erschienen ist. ${ }^{50}$ Der Text ist von F. Viger mit Anmerkungen und einer lateinischen Übersetzung versehen, der dann erneut in der Patrologia graeca von J.-P. Migne abgedruckt ist ${ }^{5 \mathrm{I}}$, und zwar mit den expliziten Verweisen auf Theodoret und Cyrill ${ }^{2}$, selbst wenn der Text des Eusebius, den Viger gegenüber Stephanus entscheidend verbessert hatte, bei Migne nicht sehr sorgfältig abgedruckt worden ist. ${ }^{53}$ Ferner ist zu beachten, dass Viger wie auch Stephanus nur zwei Handschriften zur Verfügung standen. ${ }^{4}$

Diese Überlegungen haben zusammenfassend zur Folge, dass hier zunächst ein Text geboten wird"s, der sowohl die Überlieferung bei Eusebius berücksichtigt als auch diejenige bei Theodoret und Cyrill. Damit auch ein Vergleich zur möglichen Textgrundlage bei Hegel geschaffen ist, werden die Varianten von F. Viger verzeichnet.

\section{I. Text und Übersetzung}

$\mathrm{Da}$ in der kritischen Edition (SC 292) keine Varianten angegeben sind, sei der Text hier in dieser Form übernommen. Eingetragen werden im Apparat die Abweichungen bei Viger (Vig) sowie Theodoret (Thdt) und Cyrill.

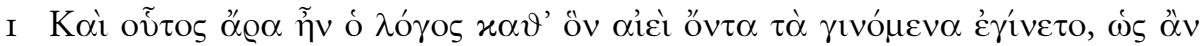

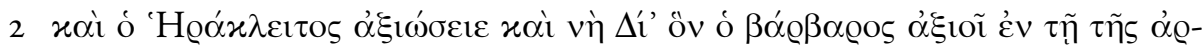

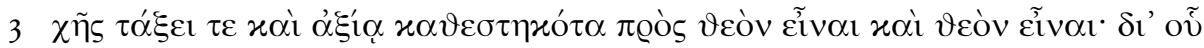

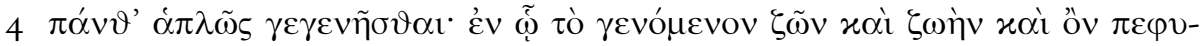

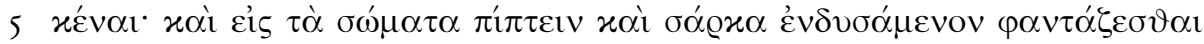

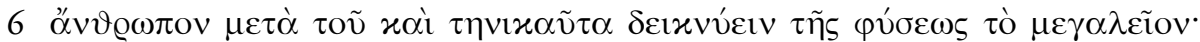

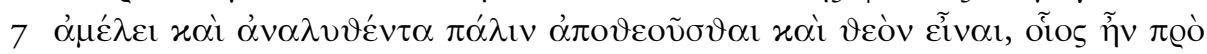

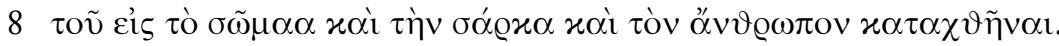

47 So Mras 1954, LII.

48 Vgl. Sommervogel I898, 74I.

49 Vgl. die Angaben bei Mras 1954, LI.

50 Fälschlich ist Köln als Druckort angegeben: vgl. Mras 1954, LI; anders Halfwassen 1998, 96 Anm. 27, der Köln als Herausgabeort angibt. Dies ist insofern - historisch betrachtet - von Bedeutung, als dadurch auch die entsprechenden Kontakte des Tübinger Stifts zu Verlagshäusern sichtbar wird.

5I Vgl. für den Amelius-Text PG 2I (I857) 900B.

52 Vgl. PG 2I, 899 Anm. 27.

53 Vgl. dazu Mras 1954, LI-LII.

54 Vgl. Mras 1954, LII mit den entsprechenden Nachweisen.

55 Vgl. auch Zoubos 1956, If. 


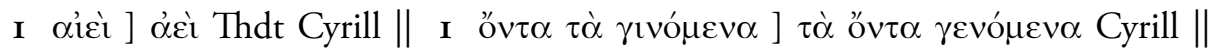

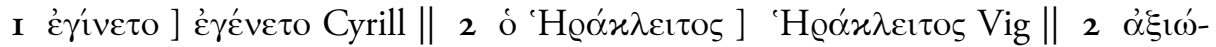

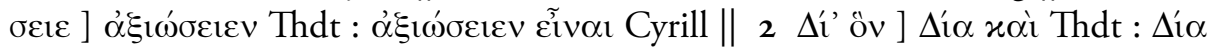

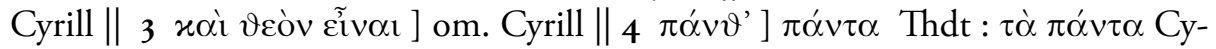

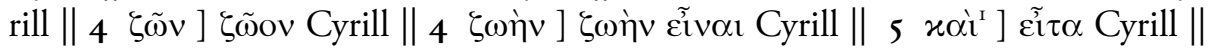

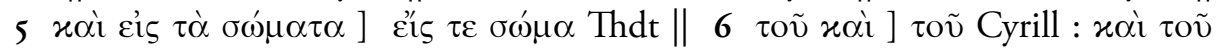
Vig $\| 8 x \alpha \tau \alpha \chi \vartheta \tilde{\eta} v \alpha \iota$ ] $x \alpha \tau \varepsilon v \varepsilon \chi \vartheta \tilde{\eta} v \alpha \iota$ Cyrill

Der Vergleich der Überlieferung zeigt, dass der Grundtext bei Eusebius überliefert ist und die Varianten auf Theodoret bzw. Cyrill zurückzuführen sind, zumal für letzteren eine kritische Edition noch aussteht. Auch die Abweichungen in der Ausgabe von F. Viger sind so minimal, dass obiger Text als Grundlage der Übersetzung gewählt werden kann.

„Und dieser war also der Logos, dem zufolge, da er immer ist, das Gewordene geworden ist, wie auch Heraklit geglaubt haben dürfte, und - bei Zeus - den der Barbar, da er (sc. der Logos) in der Ordnung und Würde des Prinzips angeordnet ist, für würdig erachtet, bei Gott zu sein und Gott zu sein; (er glaubt), dass durch ihn schlechthin alles entstanden ist, dass in ihm das Gewordene lebendig und Leben und Seiendes ist, und dass er in die Körper fällt und, nachdem er Fleisch angezogen hat, als Mensch erscheint, um auch da die Herrlichkeit der Natur zu zeigen; (er glaubt), dass er (sc. der Logos), nachdem er übrigens auch befreit worden ist, wieder vergöttlicht wird und Gott ist, wie er war, bevor er in den Leib und das Fleisch und den Menschen hinabgestiegen ist. ${ }^{\text {"s6 } 6}$

\subsection{Die Deutung des Johannesprologs durch Amelius}

Bereits ein flüchtiger Blick zeigt, dass sich Amelius bei seiner Auslegung des Prologs allein auf Joh I,I.3.4 und I4 konzentriert. ${ }^{57} \mathrm{Zu}$ betonen ist zunächst, dass Amelius, wenn er Johannes bzw. den Autor des Prologs als Barbar bezeichnet, die Ansichten des Johannes nicht zwingend teilt, zumal die gesamte Bezugnahme auf den Prolog als Meinung des Johannes ausgegeben wird..$^{58}$ Zentral ist in einem ersten Schritt, dass der Johannesprolog, wie ihn Amelius versteht, so gedeutet wird,

56 Diese Übersetzung weicht von derjenigen von Halfwassen 1999, 78 ab, da dort manche grammatikalische Beziehungen in der Übersetzung nicht klar herausgearbeitet sind und manche Terminologie - wie unten zu zeigen sein wird - im Kontext gnostischer Entwürfe fest verankert ist, dies aber bei J. Halfwassen nicht weiter thematisiert wird.

57 Zur Johannesprologexegese des Amelius vgl. Dyroff 1939, 88f; Mras 1956, 212; Rist 1969, 230f; Dörrie 1972, 75-87; Brisson 1987, 840-843; Halfwassen 1998, II2-I44; Halfwassen 1999, 76-78.

58 Dies steht sicherlich quer zu dem, was J. M. Rist als Meinung anderer Interpreten angibt, ohne diese zu nennen - Rist 1969, 230: ,he is usually thought to have been more favourably inclined than Porphyry towards orthodox Christianity“. 


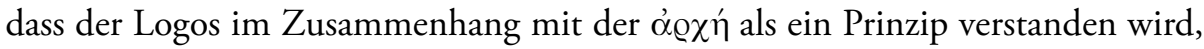
das bei Gott ist und selbst Gott ist. Wie Hegel thematisiert Amelius das Problem der Artikelsetzung bei Gott nicht, wie dies z.B. Origenes in seinem Johanneskommentar getan hatte. ${ }^{9}$ Unklar bleibt an dieser Stelle zunächst, wie das Verhältnis des Prinzips „Logos“ zu Gott selbst bestimmt ist. Jedenfalls assoziiert Amelius mit dem Prolog, dass durch den Logos alles entstanden ist. Im Kontext einer Metaphysik der Präpositionen ${ }^{60}$ hatte bespielsweise Alkinoos zwischen Wirkursache

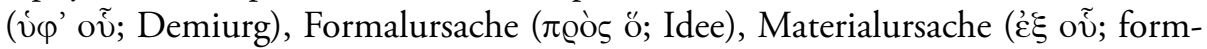
los ungeordnete Materie) und einer Finalursache ( $\delta \imath^{\prime}$ ö; Gutheit des Demiurgen) unterschieden. ${ }^{61}$ Der Logos des Johannesprologs wäre dann für Amelius ein Demiurg, der aufgrund seiner Gutheit alles entstehen lässt. Wenn Amelius ferner darauf abhebt, dass im Logos alles Gewordene lebendig, Leben und Seiendes ist, ist sein Blick nicht zuallererst darauf gerichtet, wie die Vielheit als solche verstanden werden kann, sondern darauf, dass im Logos als Prinzip die Konstituierung von Vielheit ermöglicht ist. ${ }^{62}$ Dies hat jedoch zur Folge, dass das, was entsteht oder entstehen kann, also die Vielheit der Welt, im Logos im Modus des Logos, d.h. im Sinne der möglichen Entfaltung enthalten ist und somit als Lebendiges, Leben und Seiendes im Modus des Logos begriffen werden kann. Ist dann aber mit dem Logos qua Demiurg die Weltseele gemeint? ${ }^{\gamma_{3}}$ Aufschluss könnte hier zunächst eine Referenz bei Proklos geben, der zufolge Amelius Plato, Tim 39 E so interpretiert habe, dass für den voũ $\varsigma$ drei unterschiedliche Formen differenziert werden müssen: das Denken, das ist - das Denken, das hat - das Denken, das sieht. ${ }^{64}$ Aufschluss für diese Passage könnte eine andere Stelle bei Proklos bieten ${ }^{65}$, bei der deutlich wird, dass Amelius die dreifache Gestalt des Denkens mit dem demiurgischen Aspekt verknüpft, wenn er betont, dass die drei Formen des Denkens auch das dreifache Demiurgische sei. Der erste voũ sei tatsächlich das, was er ist (das Denken), der zweite das Gedachte oder Zu-Denkende in ihm (also das voךtóv im voũs), sofern er das, was er denkt, von dem hat, was vor ihm ist dies könnte so verstanden werden, dass das voๆtóv im Modus des Denkens bereits im voṽ sist und der voũs im vontóv in der Form des Gedachten expliziert ist. Indem das $\mathrm{Zu}$-Denkende wiederum im Denken ist, ist der ganze voũ $\mathbf{z u -}$ sammengespannt und sieht das Denken, ist dann also auch eins. ${ }^{66}$ Diese Interpre-

59 Vgl. oben Anm. 23.

60 Vgl. Dörrie 1976, I24-136.

6I Vgl. Alkinoos, Didask. I2 I67,8-I9; dazu Orbe 1955, 192 sowie Wucherpfennig 2002, I4If.

62 Vgl. Halfwassen 1999, 77, der hier zurecht davon spricht, dass es sich beim Logos um ein weltentfaltendes Prinzip der Trennung und Entzweiung handelt.

63 So zumindest die gängige Meinung innerhalb der Forschung: vgl. Dyroff 1939, 88; Brisson 1987, 840; Halfwassen 1999, 76.

64 Vgl. Proklos, in Tim. III I03,I8ff (Diehl).

65 Vgl. Proklos, in Tim. I 306,Iff (Diehl); zu beiden Referenzen vgl. Corrigan 1987, 978.

66 Es handelt sich hier um eine Interpretation des Textes bei Corrigan 1987, 978 Anm. Io. 
tation des Denkens, die sich zumindest mit den Frühschriften Plotins, etwa Enn. $V_{\mathrm{I}}$, in Einklang bringen lassen könnte ${ }^{67}$, wird von Amelius explizit mit dem demiurgischen Akt des Denkens in Verbindung gebracht. Dies wird, wie erneut Proklos referiert ${ }^{68}$, von Amelius jedoch dahingehend verstanden, dass er das Denken in die Seele setzt, die Seele aber wiederum in den Körper - eine Denkfigur, die Plotin zumindest in Enn. III 9,I erörtert. ${ }^{69}$ Der Logos des Johannesprologs könnte demnach von Amelius so aufgefasst worden sein, dass die selbstreflexive Form des Denkens über die (Welt-)Seele die Bedingung der Möglichkeit einer Entfaltung in die Vielheit darstellt, so dass alles, was entstehen kann, notwendig in der Selbstreflexion als Leben und Seiendes ideenhaft konstituiert ist und folglich auch realisierbar ist.

Näheren Aufschluss, wie dies gedacht ist, könnte vor allem die Deutung von Joh I,I4 sein. Amelius versteht diesen Text so, dass der (demiurgische) Logos in die Körper fällt, Fleisch anzieht, als Mensch erscheint und in dieser Erscheinung die Herrlichkeit der Natur zeige; vom Körper befreit, werde er vergöttlicht und sei Gott. Diese Position sei entweder doketisch ${ }^{70}$, als Auslegung eines Mythos ${ }^{71}$ oder jedenfalls so zu verstehen, dass damit kein heilsgeschichtliches einmaliges Ereignis gemeint sei, sondern eine allgemeine Begründung der Welt der Vielheit $^{7^{2}}$. Sicherlich zielt Amelius, wenn er in diesem Kontext von der Herrlichkeit der Natur spricht, die dadurch erscheint, dass der Logos in die Körper fällt und Fleisch anzieht, vorrangig darauf ab, dass das Wesen des Logos darin besteht, jenseits eines konkreten Menschen zu sein. Dies wird auch durch das Motiv der Vergöttlichung nach der Trennung von Körper und Fleisch deutlich. Dennoch bedeutet dies nicht, dass der Logos nicht in einem Menschen erschienen ist, sondern lediglich, dass der Mensch (Jesus), der Körper keinerlei „Erlösungsfunktion" hat. Doketisch ist dies jedenfalls nicht. ${ }^{73}$ Mit dem Fall in die Körperwelt und dem Aufstieg ist jedoch eindeutig auf ein gnostisches Schema angespielt, das auch bereits Plotin in seinen Einwendungen gegen die Gnostiker vorbringt. Plotin betont nämlich bei der Theorie des Falls der Sophia, dass nach Meinung der Gnostiker die übrigen Seelen zusammen mit der Sophia herabgestiegen seien, Glieder der Weisheit seien und sich mit Leibern, z.B. den menschlichen, bekleidet haben. ${ }^{74}$ Unschwer zu erkennen ist, dass es sich um solche Vorstellungen han-

67 Vgl. dazu neuerdings für Plotin Jürgasch 2009, bes. 219-225.

68 Vgl. Proklos, In Tim. I 398, I6-26 (Diehl).

69 Vgl. Plotin, Enn. III 9, I (378f Henry / Schwyzer); vgl. dazu Corrigan 1987, 983; vgl. zur Amelius-Interpretation des Denkens und der Seele ferner Dillon 1969, Massagli 1982, 225-243 und Lautner 1997, bes. 300-303.

70 Vgl. Rist 1969, 230.

7I Vgl. Dörrie 1972, 8I.

72 Vgl. Dörrie 1972, 79f; Brisson 1987, 842f; Halfwassen 1999, 77.

73 Gegen Rist 1969, 230.

74 Vgl. Plotin, Enn. II 9,IO,I9-23 (218 Henry / Schwyzer). 
delt, die in der Schule des Ptolemäus diskutiert wurden. ${ }^{75}$ Dabei ist zu beachten, dass hinsichtlich der Johannesprologauslegung zwischen dem Schulgründer Ptolemäus und seinen Anhängern zunächst Unterschiede bestehen. So versteht etwa Ptolemäus in seiner epistula ad Floram Joh I,3 dahingehend, dass mit dem Begriff $\pi \alpha ́ v \tau \tau \alpha$ die Schöpfung der Welt gemeint sei; folglich ist eine Differenzierung zwischen dem (bösen) Schöpfer der Welt und einem ihm fremden Gott (Christus) nicht sinnvoll, was deutlich die anti-markionitische Stoßrichtung deutlich macht. ${ }^{76}$ Diese Vorstellung ist mit der derjenigen des Amelius insofern nicht konform, als Amelius vor allem darauf abhebt, dass das, was geworden ist, im Logos lebend, Leben und seiend ist. Amelius betont also gerade nicht die Weltvielheit, sondern deren ideenhafte Konzeption im Demiurgen. Dies trifft sich gerade mit dem, was die Schüler des Ptolemäus Irenäus von Lyon zufolge gelehrt haben. Sie verstehen nämlich Joh I,3 in dem Sinne, dass der Begriff $\pi \alpha ́ v \tau \alpha$ auf das Pleroma bezogen werden müsse:

„Als Johannes, der Schüler des Herrn, die Entstehung aller Dinge berichten wollte, wonach der Vater alles emanierte, da nahm er eine Arche (Anfang) an, das Ersterzeugte von Gott, das er auch Sohn und den Gott Monogenes nannte, in dem der Vater alle Dinge in einer Emanation von Samen hervorbrachte. Von ihm, sagen sie, ist der Logos emaniert worden und in ihm das gesamte Sein der Äonen, die der Logos später dann selbst formte. Wo er (sc. Johannes) nun von der ersten Entstehung spricht, da entwickelt er die Lehre richtigerweise von der Arche, das heißt vom Sohn aus, und vom Logos. Das lautet bei ihm so: ,Im Anfang (Arche) war der Logos, und der Logos war bei Gott, und Gott war der Logos; im Anfang (Arche) war er bei Gott. Zunächst hält er die drei auseinander, Gott und Arche und Logos, und dann nimmt er sie zusammen, um die Emanation der beiden, Sohn und Logos, zu zeigen und auch ihre Einheit untereinander wie zugleich die mit dem Vater. (...) ,Alles ist durch den Logos geworden, und ohne ihn wurde nichts'; für alle Äonen nach ihm ist der Logos die Ursache der Formgebung und Entstehung gewesen. Aber es heißt (bei Johannes) weiter: ,Was in ihm geworden ist, ist Zoe (Leben)'. Damit hat er auf die Syzygie hingewiesen; denn er drückt sich so aus, daß das All durch ihn, die Zoe aber in ihm geworden ist. (...) Indem

75 Man braucht deshalb auch nicht, wie dies Rist 1969, 23I tut, Phil 2,7 zur Erklärung heranziehen. Schon eher handelt es sich in der Tat um die Auslegung eines Mythos, wie Dörrie 1972, 8I betont, ohne allerdings den ptolemäischen Diskussionszusammenhang zu erkennen. Wenn Brisson 1987, 842 zwar zurecht den antignostischen Kontext herausstellt, verkennt er mit dem Hinweis auf Zostrianos (vgl. C. Barry, W.-P. Funk, P.-H. Poirier, J. D. Turner, Zostrien [NH VIII, I], Québec - Louvain - Paris 2000) und der Auseinandersetzung in der Schule Plotins (vgl. Porphyrius, Vita Plotini 16 [ı Henry / Schwyzer], wonach Amelius 40 Bücher gegen Zostrianos geschrieben habe; dazu Brisson 1987, 824 mit dem expliziten Hinweis, dass die Deutung des Johannesprologs durch Amelius in diesem Kontext zu verorten sei) den tatsächlichen Diskussionszusammenhang, da in dem Werk Zostrianos gerade das von Amelius für den Johannesprolog angeführte Schema dort fehlt.

76 Vgl. Ptolemaeus, ep. ad Floram 3,6 (48 Quispel = Ptolemée, Lettre a Fora, ed. G. Quispel, Paris ${ }^{2}$ I966 [SC 24 ${ }^{\text {bis }]) ; ~ d a z u ~ W u c h e r p f e n n i g ~ 2002, ~ I 2 o f ~ s o w i e ~ f e r n e r ~ P a g e l s ~ 1973, ~} 29 f$ mit Anm. I7. 
Johannes nämlich dazusagt: ,Und die Zoe war das Licht der Menschen', hat er im Wort ,Menschen' unter ein und demselben Namen zugleich auch die Ekklesia (Kirche) angezeigt (...) aus dem Logos und der Zoe entstehen nämlich Anthropos (Mensch) und Ekklesia."

Der Text ist im Rahmen des zuvor zu Amelius Ausgeführten selbstredend. Die Ptolemäer verstehen den Anfang des Johannesprologs in dem Sinne, wie ihn auch Amelius referiert, und zwar bezogen auf eine vorkosmische Schöpfung, das Pleroma. ${ }^{78}$ Auch die Vorstellung, die Amelius für Joh I,I4 zugrundlegt, ist als ptolemäisch einzustufen. Im Anschluss an das bisherige Referat der Ptolemäer bei Irenäus von Lyon heißt es nämlich: „Und Sohn nennt er (sc. Johannes) ihn, auch Aletheia (Wahrheit) und Zoe und fleischgewordenen Logos." W9 Was unter dem fleischgewordenen Logos in diesem Kontext zu verstehen ist, wird an anderer Stelle deutlich, wenn Irenäus von Lyon die Johannesexegese der Ptolemäer kritisiert: „Nach der Idee dieser Leute war es aber nicht der Logos, der Fleisch wurde; er ist ja niemals aus dem Pleroma herausgekommen; sondern das war der Soter, der aus allen (Äonen) entstanden und später als der Logos ist. " 80 Dies müsste wohl in dem Sinne verstanden werden, dass eine vom Logos verschiedene Größe erschienen ist, so dass der Logos das blieb, was er ist. Ein einmaliges heilgeschichtliches Ereignis als Menschwerdung des Logos hätte im Sinne der ptolemäischen Gnostiker nicht stattgefunden.

Dies hätte nun zusammenfassend folgende Genese zur Folge:

- Was hier nicht ausgeführt wurde, sei zumindest erwähnt: Der Johannesprolog steht selbst unter einer mehrfachen Entwicklung und redaktionellen Überarbeitung, wird an das Evangelium des Johannes angefügt und unterliegt der Diskussion in der johanneischen Schule.

- Innerhalb der gnostischen Systeme erfährt der Prolog eine Deutung durch Ptolemäus, der den Prolog offensichtlich anti-markionitisch dahingehend zuspitzt, dass es keine Entgegensetzung zwischen dem Schöpfergott und dem Logos geben könne, durch den alles, d.h. die Welt, geworden ist.

77 Irenäus von Lyon, Adv. Haer. I 8,5 (I82-I85 Brox [FC 8/I]); die Übersetzung stammt mit einer einzigen Änderung von N. Brox.

78 Es ist deshalb zweifelhaft, ob Amelius tatsächlich eine allgemeine Begründung der Vielheit liefert, wie Halfwassen 1999, 77 vermutet, da zunächst nichts anderes von Amelius referiert wird als diese Meinung der Ptolemäer. Zweitrangig ist hier zunächst, wie Amelius selbst dies verstehen könnte. Darauf wird in der Zusammenfassung einzugehen sein.

79 Irenäus von Lyon, Adv. Haer. I 8,5 (I86 f. Brox; Übersetzung von N. Brox).

80 Irenäus von Lyon, Adv. Haer. I 9,2 (I9of. Brox; Übersetzung von N. Brox). 
- In der Schule des Ptolemäus wird diese Deutung (in Rom) insofern korrigiert, als die Entstehung von allem, also der Vielheit, als ein Akt innerhalb des Pleromas begriffen wird. Die Frage einer Menschwerdung ist zwar präsent, betrifft aber nicht die Natur der Logos.

- Bei Plotin wird gerade dieses Schema in der Auseinandersetzung mit den Gnostikern (Enn. II 9,Io) dahingehend problematisiert, ob denn mit dem Fall der Sophia ein Anziehen von Körpern verbunden ist.

- Amelius wiederum referiert zunächst nur eine Meinung, nämlich die der Ptolemäer, die das, was Plotin kritisiert hatte, als eine Deutung des Johannesprologs darstellen.

- Amelius zitiert diese Meinung der Ptolemäer als die Ansicht eines Barbaren, wodurch klar wird, dass er diese Deutung nicht zwingend teilt.

- Amelius selbst konnte allerdings - hypothetisch angenommen, wie dies im ersten Teil der Interpretation versucht wurde - diese ptolemäische Deutung des Johannesprologs als in gewissem Sinne konform mit seinem eigenen Verstehen der platonischen Philosophie auslegen, zumindest mit Rücksicht auf die Frühschriften Plotins.

- Eusebius von Caesarea, der den Text des Amelius zitiert, sah in der Deutung des Johannesprologs durch Amelius offensichtlich eine Bestätigung dessen, was im vierten Jahrhundert im Sinne einer praeparatio vertreten werden konnte.

- Mit Rekurs auf Eusebius verwendeten Theodoret und Cyrill den AmeliusText bei Eusebius zu apologetischen Zwecken jeweils ohne Kritik. Dies zeigt, dass die Deutung bzw. die Ausführungen des Amelius in den neuen Kontexten bei Eusebius, Theodoret und Cyrill als eine Bestätigung der Überlieferung gewertet wurden und insofern eine positive Einschätzung erfahren hatten.

Davon zu unterscheiden ist nun, ob und wie Hegel inhaltlich auf Amelius Bezug nimmt. Ferner ist zu klären, wenn Hegel tatsächlich diese Deutung gekannt hat, wie ihm diese bekannt geworden ist. 


\section{Ergebnisse: Hegel und Amelius}

J. Halfwassen hat sich dezidiert dafür ausgesprochen, dass Hegel in seiner Frankfurter Zeit, als er den Johannesprolog interpretierte, die Prolog-Deutung des Amelius, wie sie bei Eusebius überliefert ist, herangezogen hat. Neben Philo von Alexandrien und Numenius sei sie eine der entscheidenden Quellen. ${ }^{8 \mathrm{I}} \mathrm{J}$. Halfwassen führt in diesem Zusammenhang zunächst vier inhaltliche Übereinstimmungen an:

I. Das Verhältnis von Gott und Logos werde sowohl von Hegel als auch von Amelius als Prinzipientheorie gedeutet, des ,seinsbegründenden Prinzips der Einheit und des weltentfaltenden Prinzips der Trennung und Entzweiung ${ }^{482}$. Hegel gewinnt die Struktur des Prinzips der Einheit, des Prinzips der Möglichkeit des Entzweiung sowie deren Einheit (von Gott und Logos) jedoch zunächst vorrangig in Auseinandersetzung mit Fichtes Theorie der thetischen Sätze. Ferner ist zu betonen, dass Amelius zwar eine Prinzipientheorie von Einheit und (demiurgischer) Entfaltung kennt, dass die Prologaussagen, wie sie Amelius als Meinung anderer referiert, wohl aus dem ptolemäischen Kontext stammen. Dort wird aber, wie die Irenäusreferate zeigen, gerade nicht die Einheit der Prinzipien postuliert, sondern deren Differenz. Dementsprechend spielt im Prologtext des Amelius die Einheit der Prinzipien auch kaum eine Rolle. Dass der Logos bei Gott sei und Gott sei sowie wieder vergöttlicht werde, kann man als Einheit der beiden Prinzipien verstehen, muss es aber zumindest im Kontext der Ptolemäer nicht. Davon abzuheben ist ein unterstelltes Verständnis des Amelius selbst, der sich mit dem Begriff „Barbar“ von den Ausführungen distanziert, diese aber als konform mit seinen eigenen Positionen sehen konnte, wie die Proklosreferate im Timaioskommentar über Amelius zeigen. Unter der Voraussetzung, dass Hegel den Eusebiustext gekannt hat, könnte Hegel mit der Positionierung gegenüber der Fichteschen Theorie des Setzens den Amelius-Text im obigen Sinne verstanden haben. Eine völlige Konvergenz lässt sich jedenfalls nicht herstellen.

2. Dieselben Überlegungen treffen auch auf das zweite Argument zu: Der Logos werde bei Amelius und bei Hegel als belebendes Prinzip verstanden. ${ }^{8_{3}} \mathrm{Zu}$ nächst ergibt sich dies zwanglos aus dem Johannesprolog selbst (Joh I,4). Von Hegel wird dies jedoch eigentümlich in einer „Alternative“ eingeholt: „zu-

8I Halfwassen 1999, 76-78 sowie Halfwassen 1998, II2-II4. Da sich die beiden Ausführungen zu Hegel und Amelius nahezu decken, sei im Folgenden zunächst jeweils nur auf die erste Publikation, die Hablilitationsschrift von J. Halfwassen, verwiesen.

82 Halfwassen $1999,77$.

83 Vgl. Halfwassen 1999, 77. 
gleich aber [ist] im Teile (...) oder in dem unendlich Teilenden (...) Leben ${ }^{\text {" } 84}$. Vergleicht man dies zunächst mit dem ptolemäischen Ansatz, so wird dort zwar das Leben (die Zoe) als im Logos entstanden gedacht, allerdings als eine eigenständige Größe. Dies wiederum ist in der Prologdeutung, wie sie Amelius übermittelt, dahingehend verändert, dass im Logos „alles“ (Joh I,3) lebendig, Leben und als Seiendes ist - eine Position, die auch mit dem konvergieren könnte, was Amelius über den demiurgischen voũ szw. die Weltseele ausführt. Hier ist m.E. die stärkste Konvergenz zwischen Hegel und Amelius zu sehen.

3. Eine Überstimmung zwischen Amelius und Hegel sei ferner darin zu sehen, dass der Abstieg in die Welt bzw. die Menschwerdung „nicht als einmaliges heilsgeschichtliches Ereignis, sondern als die allgemeine Begründung der Welt der Vielheit" verstanden wird, „deren Zweck für Amelios die ,Herrlichkeit der Natur' ist ${ }^{\text {"85 }}$, was sich auch sonst bei Hegel etwa im Fragment vom göttlichen Dreieck finde. ${ }^{86}$ Was Amelius in seiner Darstellung des Johannesprologs bietet, ist jedoch zunächst wiederum als das gnostische (ptolemäische) Abstiegs- und Aufstiegsschema des Retters (des Soter) zu verstehen, der in die Körperwelt fällt und einen (menschlichen) Leib anzieht. Ob Amelius selbst eine solche Vorstellung geteilt haben könnte, ist zweifelhaft, da er sich nicht nur ausführlich mit Zostrianos abgrenzend auseinandergesetzt hat, wie Porphyrius in der Vita Plotini 16 berichtet (was hier aber näherhin von untergeordneter Bedeutung ist), sondern weil er gerade auch die brüske Ablehnung einer solchen Vorstellung durch Plotin gekannt haben muss (Plotin, Enn. II 9,Io mit derselben Terminologie). Sollte also Hegel den Amelius-Text bei Eusebius gelesen und für seine eigene Deutung rezipiert haben, dann versteht er diesen gegen Amelius als die Position des Amelius oder er überginge die distanzierte Haltung des Amelius, die sich wohl auch aus Plotins Auseinandersetzung mit den Gnostikern ergibt, die in diesem Falle (bei Plotin) ebenfalls als Ptolemäer zu identifizieren wären.

4. Einen weiteren Konvergenzpunkt zwischen Amelius und Hegel sieht J. Halfwassen in dem Dreischritt In-sich-Bleiben, Hervorgang und Rückkehr. ${ }^{87} \mathrm{Da}$ der Amelius-Text diese Begriffe jedoch nicht verwendet, scheint dies zu unspezifisch zu sein, als dass daraus eine Abhängigkeit konstatiert werden könne, zumal dies in den zur Zeit Hegels gängigen Darstellungen neuplatoni-

84 Hegel I986, 374.

85 Halfwassen 1999,77

86 Vgl. Halfwassen 1999, 77 mit Anm. 175; dort die entsprechenden Nachweise und weiterführende Lit.

87 Halfwassen 1999, 77. 
scher Philosophie - etwa bei Brucker, Tiedemann oder später Tennemann durchaus ersichtlich war. ${ }^{88}$

Daraus ergibt sich m.E. folgendes: Die von J. Halfwassen angeführten Parallelen könnten eine Lektüre des Euseb-Textes über Amelius und dessen Deutung des Johannesprologs nahelegen, zwingend ist dies jedoch nicht. Wenn Hegel tatsächlich auf Amelius Bezug genommen und dessen Ansichten konstruktiv für seine eigene Interpretation des Johannesprologs herangezogen haben sollte, dann geschähe dies zum Teil gegen die Intention des Amelius selbst. Vor allem wäre der gesamte ptolemäische Kontext ausgeblendet, der offensichtlich für Amelius von Bedeutung ist. Obwohl Hegel später zumindest in seinen Vorlesungen über die Geschichte der Philosophie über A. Neander ${ }^{89}$ mit den Ansätzen etwa der Valentinianer und Ptomeläer vertraut war ${ }^{9 \circ}$, spielte dies in der Frankfurter Zeit keine Rolle. Die Ptolemäer bleiben deshalb - falls Hegel den Amelius-Text gelesen und verwendet hat - unerkannt.

Unter der Voraussetzung, dass Hegel tatsächlich auf Amelius Bezug genommen hat, stellt sich die Frage, wie Hegel auf diesen Text aufmerksam werden konnte, und zwar bevor er den Johannesprolog in seiner Frankfurter Zeit interpretierte. Der einzige Hinweis bei D. Tiedemann auf Amelius und dessen Auseinandersetzung mit den Gnostikern ${ }^{91}$ oder ein vereinzelter Hinweis in der Philosophiegeschichte von J. Brucker ${ }^{92}$ reichen sicher nicht aus, um die Kenntnis des Amelius bei Hegel anzunehmen. Eher kommt der Repetent C. G. Bardili am Tübinger Stift in Frage, der in seiner Schrift Epochen der vorzüglichsten Philosophischen Begriffe für die Frage der Deutung des Demiurgen und der Weltseele explizit auf Amelius, Plotin, Porphyrius und Numenius in dieser Reihenfolge verweist. ${ }^{93}$ Entscheidend ist nun aber, worauf J. Halfwassen eindringlich hingewiesen hat, dass Hegel selbst in dem Werk, in dem auch seine Johannesprolog-

88 Darauf kann hier nicht näher eingegangen werden.

89 Vgl. Neander I8r8.

90 Vgl. Hegel 1986a, 428-430 unter expliziten Hinweis auf Neander; vgl. den davon abweichenden Text: Hegel 1996, 173-174 (hier handelt es sich um ausgewählte Nachschriften und Manuskripte).

9I Vgl. Tiedemann 1793, 434; dasselbe betrifft Tennemann 1807, 200 Anm. 9, wo auf Griechisch der Name Amelius aus der vita Plotini zitiert ist, zumal dieses Werk Tennemanns in die Zeit nach Hegels Aufenthalt in Frankfurt fällt; zu Tiedemann, Tennemann und darüber hinaus F. Creuzer in ihrer Bedeutung für Schelling und Hegel vgl. vor allem Beierwaltes 1972, z.B. 8385.IO2-I09. I56-I59.

92 Vgl. Franz 1996, 74 mit den dortigen Nachweisen.

93 Vgl. Bardili 1788, I07; vgl. dazu Franz 1996, I42. Eine Beschäftigung mit Theodoret und - was hier von Interesse ist - Eusebius belegen auch Arbeiten am Tübinger Stift, etwa von F. Ph. I. Niethammer, Über die Zulässigkeit der Varianten aus den Anfürungen der alten Schriftsteller sowie G. F. Rau, Variae de Cosmogonia, imprimis Mosaica opiniones; vgl. die Texte bei Jacobs 1989, I54.159. 
deutung zu finden ist, explizit die Praeparatio evangelica des Eusebius anführt ${ }^{94}$ und dass Hegels Zimmergenosse und Freund Schelling in seiner Magister-Dissertation Antiquissimi de prima malorum humanorum origine philosophematis Genes. III. explicandi tentamen criticum et philosophicum aus dem Jahre 1792 mehrfach auf diese Schrift des Eusebius verweist. ${ }^{95}$ Es ist deshalb - historisch gesehen plausibel, dass Hegel bereits seit seiner Tübinger Zeit die Praeparatio evangelica des Eusebius kannte und sie auch in Frankfurt in der Ausgabe von F. Viger verwendet haben konnte. Wieweit die Amelius-Deutung des Johannesprologs Hegel selbst angeregt hat, steht m.E. jedoch unter den oben genannten Vorbehalten bzw. Einschränkungen. Selbst wenn Hegel vor allem in Auseinandersetzung mit Fichte den Amelius-Text konstruktiv für seine eigenen Ansätze einer spekulativen Philosophie genutzt haben mag, ist ihm der ursprüngliche Kontext des ptolemäischen Systems aus den genannten Gründen entgangen.

94 Vgl. Hegel 1986, 276 mit Anm. 3, hier allerdings im Kontext des Turmbaus zu Babel; vgl. Halfwassen 1998,95 .

95 Schelling 1976, 59-99, hier 67f. 73 und 77; dazu Halfwassen 1998, 96. 


\section{Literaturverzeichnis}

Bardili (1788): Christoph Gottfried Bardili, Epochen der vorzüglichsten Philosophischen Begriffe, nebst den nöthigsten Beylagen. Erster Theil. Epochen von einem Geist, von Gott und der menschlichen Seele. System und Aechtheit der beiden Pythagoreer, Ocellus und Timäus, Halle 1788.

Beierwaltes (1972): Werner Beierwaltes, Platonismus und Idealismus, Frankfurt 1972.

Böhm (2004): Thomas Böhm, „The Exegesis of Arius: Biblical Attitude and Systematic Formation", in: Ch. Kannengiesser, Handbook of Patristic Exegesis, Vol. II, Leiden - Boston 2004, 687-705.

Böhm (2005): Thomas Böhm, „Die Theologie des Arius: Zwischen Tradition und Innovation", in: M. Knapp, Th. Kobusch (Hgg.), Querdenker. Visionäre und Außenseiter in Philosophie und Theologie, Darmstadt 2005, 6I-7I.

Brisson (1987): Luc Brisson, „Amélius: Sa vie, son oeuvre, sa doctrine, son style“, in: ANRW II 26,2 (1987) 793-860.

Brox (1993): Norbert Brox, „,Gott' mit und ohne Artikel. Origenes über Joh I,I“, in: BN 66 (1993) 32-39.

Corrigan (1987): Kevin Corrigan, „Amelius, Plotinus and Porphyry on Being, Intellect and the One. A Reappraisal“, in: ANRW II 36,2 (1987) 975-993.

Dillon (1969): John M. Dillon, „Plotinus, Enn. 3.9.I, and Later Views on the Intelligible World“, in: TAPhA Ioo (1969) 63-70.

Dörrie (1972): Heinrich Dörrie, „Une exégèse néoplatonicienne du prologue de l'évangile de saint Jean“, in: J. Fontaine, Ch. Kannengiesser (Hgg.), Epektasis. FS J. Daniélou, Paris 1972, 75-87.

Dörrie (1976): Heinrich Dörrie, „Präpositionen und Metaphysik. Wechselwirkung zweier Prinzipienreihen", in: ders., Platonica Minora, München 1976 (STA VIII), I24-I36.

Dyroff (1939): Adolf Dyroff, „Zum Prolog des Johannes-Evangeliums“, in: Pisculi. Studien zur Religion und Kultur des Altertums. FS Franz Joseph Dölger, Münster 1939, 86-93.

Fichte (197I): Johann Gottlieb Fichte, „Recension des Aenesidemus“, in: ders., Werke Bd. I, ed. I. H. Fichte, Berlin I97I, I-25.

Fichte (197Ia): Johann Gottlieb Fichte, „Ueber den Begriff der Wissenschaftslehre“, in: ders., Werke Bd. I, ed. I. H. Fichte, Berlin 1971, 27-8I.

Fichte (197Ib): Johann Gottlieb Fichte, „Versuch einer neuen Darstellung der Wissenschaftslehre“, in: ders., Werke Bd. I, ed. I. H. Fichte, Berlin I97I, 5I9434.

Franz (1996): Michael Franz, Schellings Tübinger Platon-Studien, Göttingen 1996 (Neue Studien zur Philosophie II).

Franz (2003): Michael Franz, „Die Verfügbarkeit der neuplatonischen Gedanken- 
welt für Goethe“, in: K. Manger (Hg.), Goethe und die Weltkultur, Heidelberg 2003, 89-100.

Haas (1979): Alois M. Haas, Sermo Mysticus. Studien zu Theologie und Sprache der deutschen Mystik, Freiburg i.Ue 1979.

Haas (1997): Alois M. Haas, Mystik als Aussage. Erfahrungs-, Denk- und Redeformen christlicher Mystik, Frankfurt ${ }^{2} 1997$ (stw II96).

Halfwassen (1998): Jens Halfwassen, „Die Bedeutung des spätantiken Platonismus für Hegels Denkentwicklung in Frankfurt und Jena", in: Hegel-Studien 33 (1998) 85-I3I.

Halfwassen (1999): Jens Halfwassen, Hegel und der spätantike Neuplatonismus. Untersuchungen zur Metaphysik des Einen und des Nous in Hegels spekulativer und geschichtlicher Deutung, Bonn 1999 (Hegel-Studien, Beiheft 40).

Hegel (1986): Georg Wilhelm Friedrich Hegel, „Der Geist des Christentums und sein Schicksal“, in: G. W. F. Hegel, Frühe Schriften = Werke I, edd. E. Moldenhauer, K. M. Michel, Frankfurt I986 (stw 6oI), 274-4I8.

Hegel (1986a): Georg Wilhelm Friedrich Hegel, Vorlesungen über die Geschichte der Philosophie $I I=$ Werke Bd. 19, Frankfurt 1986 (stw 619).

Hegel (1996): Georg Wilhelm Friedrich Hegel, Vorlesungen über die Geschichte der Philosophie, Teil 3. Griechische Philosophie. II. Plato bis Proklos, hgg. P. Garniron, W. Jaeschke, Hamburg 1996.

Hösle (1988): Vittorio Hösle, Hegels System. Der Idealismus der Subjektivität und das Problem der Intersubjektivität, Hamburg 1988.

Jacobs (1989): Wilhelm G. Jacobs, Zwischen Revolution und Orthodoxie? Schelling und seine Freunde im Stift und an der Universität Tübingen. Texte und Untersuchungen, Stuttgart - Bad Cannstatt 1989.

Jürgasch (2009): Thomas Jürgasch, Der dreieine Gott als Prinzip praktischen Wissens. Betrachtungen zur Philosophie der Praxis des Augustinus und des Boethius, Diss. masch. Freiburg 2009.

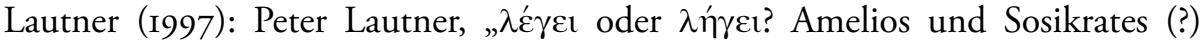
über ,Timaios' $37 \mathrm{A6}-7$ (bei Proklos, in Tim. II 300.23-30I.5 Diehl)“, in: Hermes I25 (1997) 294-308.

Massagli (1982): Massimo Massagli, „Amelio neoplatonico e la metafisica del Nous“, in: RFN 74 (1982) 225-243.

Mras (1954): Karl Mras, Eusebius Werke. Achter Band. Die Praeparatio evangelica, Erster Teil, Berlin 1954.

Mras (1956): Karl Mras, „Die Stellung der Praeparatio Evangelica des Eusebius im antiken Schrifttum", in: AÖAW.PH 93 (1956) 209-217.

Nagel (2000): Titus Nagel, Die Rezeption des Johannesevangeliums im 2. Jahrhundert. Studien zur vorirenäischen Aneignung und Auslegung des vierten Evangeliums in christlicher und christlich-gnostischer Literatur, Leipzig 2000 (Arbeiten zur Bibel und ihrer Geschichte 2). 
Neander (I8I8): August Neander, Genetische Entwickelung der vornehmsten gnostischen Systeme, Berlin I8I8.

Orbe (1955): A. Orbe, En los albores de la exegesis iohannea (Ioh. I, 3). Estudios Valentinianos II, Rom 1955 (AnGr 65).

Pagels 1973: Elaine Pagels, The Johannine Gospel in Gnostic Exegesis: Heracleon's Commentary on John, Nashville - New York 1973 (SBL MS I7).

des Places (1975): Édouard des Places, „Numénius et Eusèbe de Césarée“, in: StP I3 (I975) I9-5I.

Rist (1969): John M. Rist, „St. John and Amelius“, in: JThS 20 (1969) $230 f$.

Rohl (1966): Herman Rohl, Hegels theologische Jugendschriften nach den Handschriften der Kgl. Bibliothek in Berlin, Tübingen 1907 (ND Frankfurt 1966), 24I-342.

Rohs (I99I): Peter Rohs, Johann Gottlieb Fichte, München I99I (BsR Große Denker 52I).

Schelling (1976): Friedrich Wilhelm Joseph Schelling, Antiquissimi de prima malorum humanorum origine philosophematis Genes. III. explicandi tentamen criticum et philosophicum, in: Werke I, hgg. W. G. Jacobs u.a., Stuttgart 1976.

Sommervogel (1898): C. Sommervogel, Bibliothèque de la Compagnie de Jésus, VIII, Bruxelles - Paris I898.

Suárez-Nani (I992): Tiziana Suárez-Nani, „Philosophie- und theologiehistorische Interpretationen der in der Bulle von Avignon zensurierten Sätze“, in: H. Stirnimann, R. Imbach (Hgg.), Eckardus Theutonicus, homo doctus et sanctus. Nachweise und Berichte zum Prozeß gegen Meister Eckhart, Freiburg i.Ue. I992 (dokimion II), 3I-96.

Tennemann (I807): Wilhelm Gottlieb Tennemann, Geschichte der Philosophie, Sechster Band, Leipzig I807.

Theobald (1992): Michael Theobald, „Gott, Logos und Pneuma. ,Trinitarische“ Rede von Gott im Johannesevangelium“, in: H.-J. Klauck (Hg.), Monotheismus und Christologie. Zur Gottesfrage im hellenistischen Judentum und im Urchristentum, Freiburg - Basel - Wien 1992 (QD I38), 4I-87.

Tiedemann (1793): Dieterich Tiedemann, Geist der spekulativen Philosophie. Dritter Band, welcher von der neuern Akademie bis auf die Araber geht, Marburg I793.

Ulrich (2009): Jörg Ulrich, „The Reception of Greek Christian Apologetics in Theodoretus" Graecarum affectionum curatio", in: J. Ulrich, A.-C. Jacobsen, M. Kahlos (Hgg.), Continuity and Discontinuity in Early Christian Apologetics, Frankfurt u.a. 2009 (Early Christianity in the Context of Antiquity 5), II3-I3O.

Wucherpfennig (2002): Ansgar Wucherpfennig, Heracleon Philologus. Gnostische Johannesexegese im zweiten Jahrhundert, Tübingen 2002 (WUNT I42).

Zoubos (1956): A. N. Zoubos, Amelii neoplatonici fragmenta, Athen 1956. 


\title{
Zwischen Christologie und Rhetorik
}

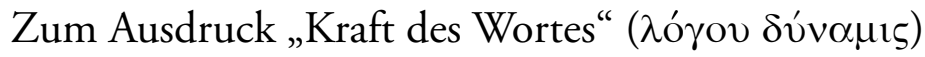 \\ in Tatians „Rede an die Griechen“
}

JOSEF LÖSSL

Die „Rede“ (ò $\lambda$ ó zwar erst in Testimonien, also noch nicht in der handschriftlichen Überlieferung, erstmals ausdrücklich als solche bezeichnet, ${ }^{\mathrm{I}}$ sie wurde aber schon früh als ein Produkt ausgereifter Redekunst wahrgenommen. ${ }^{2}$ In der modernen Forschung gingen die Meinungen über ihre gattungsspezifische Zuordnung sowie über ihre Qualität zwar lange Zeit auseinander, ${ }^{3}$ es überwiegen aber heute eher positive

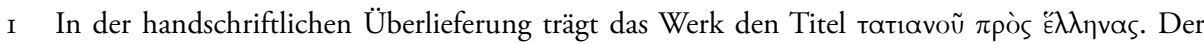

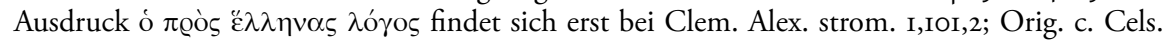
I,I6 und Euseb. hist. eccl. 4,I6,7 sowie 4,29,7. Sämtliche modernen Editionen folgen im Griechischen den Handschriften, übersetzen den Titel aber ins Lateinische mit „oratio“. П@ò

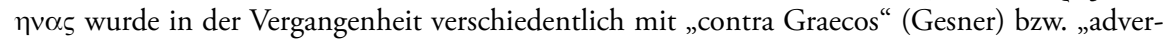
sus Graecos“ (Morel, Maran) wiedergegeben, ehe sich „ad Graecos“ durchsetzte (Worth, Otto, Schwartz, Whittaker, Marcovich); s. C. Gesner, ...Tatiani Assyrii, Iustini martyris discipuli, Oratio contra Graecos, Zürich 1546; F. Morel, ... Tatiani Assyrii Oratio adversus Graecos, Paris I6I5; P. Maran, Tatiani Oratio adversus Graecos, Paris 1742 (= PG 6, 243-276); W. Worth, Tatiani Oratio ad Graecos, Oxford I700; J. K. Th. Otto, Tatiani Oratio ad Graecos, Jena I851; E. Schwartz, Tatiani Oratio ad Graecos, Leipzig 1888; M. Whittaker, Tatian: Oratio ad Graecos and Fragments, Oxford 1982; M. Marcovich, Tatiani Oratio ad Graecos, Berlin 1995. Im Folgenden wird Tatians Text nach der Edition von Marcovich zitiert, wobei der Problematik dieser Edition von Fall zu Fall Rechnung getragen werden soll; s. dazu jetzt auch H.-G. Nesselrath, „Il testo di Taziano, Oratio ad Graecos, e due recenti edizioni," in: Eikasmos is (2005) 243-263.

2 Etwa auch schon in antiken Zeugnissen; s. Euseb. h.e. 4,29,7 (I66 Schwartz): ... $\mu \alpha \dot{\alpha} \lambda \_\tau \alpha \pi \alpha-$

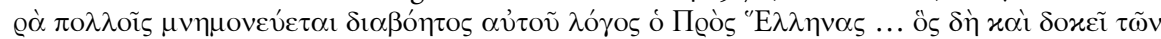

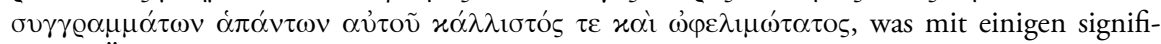
kanten Änderungen, aber ansonsten beinahe wörtlich übernommen wird von Hier. vir. ill. 29,3 (I24 Ceresa-Gastaldo): Tatianus infinita scripsit volumina, e quibus unus contra Gentes florentissimus extat liber, qui inter omnia opera eius fertur insignis. Erst bei Hieronymus wird aus dem $\lambda$ óyos ein „liber“, aus dem „An die Griechen“ ein „Gegen die Heiden“, und aus den ästhetisch-pragmatischen Qualifizierungen xó $\lambda \lambda$ ı $\tau$ ós und $\dot{\omega} \varphi \varepsilon \lambda \mu \omega \dot{\tau} \tau \alpha \tau o s$ ein eher panegyrisches „insignis“. Ausserdem erwähnt Hieronymus den Altersbeweis in Tatians Rede, den Eusebius noch für zentral hielt, überhaupt nicht mehr. Auch das Diatessaron erwähnt er nicht. Er kennt von Tatian, obwohl er von ihm sagt: „infinita scripsit volumina“, nur die „Rede an die Griechen".

3 Typisch und reich an Qualifizierungen ist etwa die zusammenfassende Darstellung von $\mathrm{O}$.

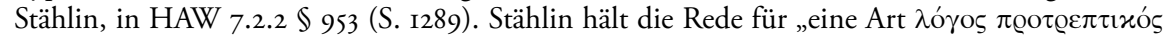
nach dem Muster der Sophistik“ und wendet sich gegen Vorschläge, die in ihr eine „sophisti- 
Würdigungen ${ }^{4}$ und ein gewisser Konsens hat sich entwickelt, nach dem sie ein Logos Protreptikos ist, der die Adressaten zu einer christlich-philosophischen Lebensweise einladen möchte. ${ }^{5}$ Ihre Gliederung wird zwar häufig als lose bzw. offen, aber damit eben einem Protreptikos angemessen charakterisiert. ${ }^{6}$ Dass sie auch

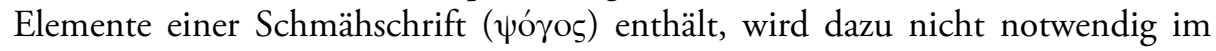
Widerspruch gesehen. ${ }^{7}$

sche Spottrede“ sehen möchten (Anm. 4). „Dazu, “ meint Stählin, „ist es dem Verfasser zu ernst mit seinem Hass.“ Das sprachliche „Können“ Tatians hält Stählin für „recht gering”: Sein Werk sei schlecht gegliedert, sein Stil oft dunkel, seine Gelehrsamkeit dubios. Alles in allem sei Tatian „unsympatisch“. Viel subtiler urteilte demgegenüber schon A. Harnack, Tatians Rede an die Griechen, Gießen I884, 8: „Tatian weiss die Sprache mit einer nicht gewöhnlichen Freiheit und Selbständigkeit im Ausdruck zu handhaben“ und „er sucht als der Apostat des Griechentums auch in gezierter Nachlässigkeit und in berechneten Sonderlichkeiten seinen Bruch mit dem Herkömmlichen und dem Classischen darzuthun." Zur Gattungsfrage vgl. auch C. Andresen, „Antike und Christentum, “ in: TRE 3 (1978) 50-99, 60, der zwar ebenfalls meint, dass Tatian mit seiner Rede „für ein Christentum sittlicher Überlegenheit warb“ (also ganz im Sinne eines Protreptikos), aber hinzufügt, Tatian habe sich zu diesem Zweck jedoch der "Scheltrede“ ( $\psi$ ó-

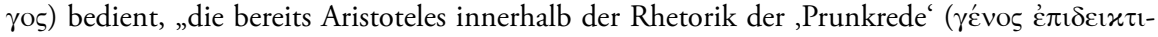
xóv) im Unterschiede zur ,Lobrede' ("Éxıvos) zugewiesen hatte." Demgegenüber weit verbreitet war lange Zeit die Praxis, die Rede von ihrer Überlieferungsgeschichte her einfachhin als „Apologie“" zu bezeichnen; vgl. etwa als Beispiele zeitlich so weit auseinanderliegende Untersuchungen wie A. Puech, Les apologistes grecs du Ile siècle de notre ère, Paris I9I2, I67, M. Edwards u. a. (Hg.), Apologetics in the Roman Empire. Pagans, Jews and Christians, Oxford 1999, I-I3, und M. Fiedrowicz, Apologie im frühen Christentum. Die Kontroverse um den christlichen Wahrheitsanspruch in den ersten Jahrhunderten, Paderborn 2006, 52-54. Allerdings bezeichnete schon Puech Tatians Rede mitunter als „Protreptikos“ (vgl. etwa S. I48-I7I) und Fiedrowicz spricht von ihr als einer „neuen Form der Apologie“ (S. 52), die „einer literarischen Gattung kaum eindeutig zuzuweisen" sei (S. 53), wobei aber auch Fiedrowicz der Protreptikos-Hypothese zuneigt. Eine Lösung ganz anderer Art bot A. E. Osborne, Tatian: A Literary Analysis and Essay in Interpretation, Diss. Cincinnati 1969, 4-28. Osborne hielt dafür, dass der heute erhaltene Text aus zwei zu verschiedenen Zeiten und Zwecken gehaltenen Reden zusammengesetzt sei: Die Kapitel I-30 und 42 seien eher dialektisch struktiert, die dazwischenliegenden Kapitel trügen eher die Merkmale anderer, „typischer“, frühchristlicher Apologien. Insgesamt bahnbrechend war sicher die Arbeit von M. McGehee, „Why Tatian Never ,Apologized" To the Greeks," in: JECS I (1993) I43-158. McGehee setzte sich kritisch mit der Gewohnheit früherer Forscher auseinander, Tatians Rede als Apologie zu bezeichnen, er vermittelte aber auch zwischen scheinbaren Diskrepanzen wie etwa, dass die Rede zugleich Protreptikos und Schmähschrift sei, und er verband diese formalen Überlegungen mit Überlegungen zum inhaltlichen Zweck der Rede, nämlich der Werbung für eine bestimmte Form des christlichen Lebens als Philosophie. Neuere Studien wie etwa die von E. Hunt, Christianity in the Second Century. The Case of Tatian, London 2003, bauen ganz entschieden auf diesen neuen Grundlagen auf.

4 Vgl. zur jüngeren Forschung zusammenfassend D. Karadimas, Tatian's Oratio ad Graecos: Rhetoric and Philosophy/Theology, Stockholm 2003, $7 \mathrm{f}$.

5 Bahnbrechend dazu McGehee, „Why Tatian Never ,Apologized““ (vgl. Anm. 3).

6 McGehee, "Why Tatian Never ,Apologized“ (Anm. 3), I49: „If the speech is understood as a protrepticus, Tatian need not be faulted for digressions since a protrepticus did not have to be systematic." Vgl. aber auch den darüberhinausgehenden Erklärungsversuch von Karadimas, Tatian's Oratio ad Graecos (vgl. Anm. 4), 9-24, dass Tatian einige Versatzstücke parat hatte, die er bei passender Gelegenheit, sei es mündlich oder schriftlich, als Exkurse in die bereits vorstrukturierte Rede einbauen konnte. 
Schon Richard Kukula zog aus einem ähnlichen Gesamtbefund den Schluss, dass wir es wahrscheinlich nicht mit einem Werk exklusiver Schriftlichkeit zu tun haben, sondern dass Tatians Rede auch Züge trägt, die darauf hindeuten könnten, dass sie (in einer entsprechenden, von der schriftlichen Version etwas verschiedenen Form $)^{8}$ einmal (oder vielleicht auch wiederholt) mündlich vorgetragen worden sein könnte. ' Kukulas Vorstellung dass sie eine programmatische Rede zur Eröffnung eines ganzen Schulzyklus gewesen sein könnte, ${ }^{\mathrm{IO}}$ die mit Abwandlungen auch Martin Elze aufgriff," ist zwar wohl etwas zu spekulativ, insbesondere in Verbindung mit einer Spätdatierung des Werkes und der Lokalisierung in einem orientalischen Kontext, ${ }^{12}$ die vehemente Leugnung jeglichen oralen Charakters des Werks, wie sie insbesondere unter Philologen des späten 19. und frühen 20. Jahrhunderts verbreitet war, ${ }^{13}$ kann aber nur durch das Vorherrschen eines bestimmten Vorurteils erklärt werden, nämlich dem Bestreben, die christlichen Lehrer vom allgemeinen Kulturbetrieb der kaiserzeitlichen Philo-

7 So ja bereits Stählin, allerdings in bezug auf den Inhalt nicht ganz korrekt, in HAW 7.2.2 $\$ 953$

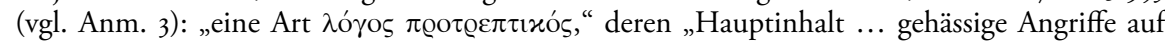
alles Griechische" bilden.

8 Vgl. hierzu die Einteilung bei U. Neymeyr, Die christlichen Lehrer im zweiten Jahrhundert, Leiden 1989, I89, in I. Tatians Rede als direkte Mitschrift eines Vortrags, 2. als Text, dem zwar ein Vortrag zugrunde liegt, der aber für die Veröffentlichung schriftlich ausgearbeitet wurde, 3. als literarisches Produkt, das Erfahrungen und Elemente aus tatsächlich gehaltenen Vorträgen widerspiegelt, 4. als literarisches Produkt, das lediglich den Anschein einer Rede erwecken will. Nach dem oben Gesagten wäre Möglichkeit 2 am wahrscheinlichsten.

9 Vgl. R. Kukula, Tatians sogenannte Apologie. Exegetisch-Chronologische Studie, Leipzig I900, 3-I8, bes. I5-17, sowie 44. Der konkreteste Hinweis im Text wäre orat. 5,5 (I4.I6 Marcovich):

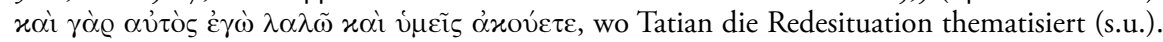
Zwar könnte auch dies erfunden sein, und es ist ja auch in der schriftlichen Version verblieben, aber seinen Ursprung hat das Beispiel in einer oralen Redesituation, ja noch konkreter, in einer Lehrsituation. Tatian möchte in diesem Abschnitt das Wesen und die Funktion gesprochener

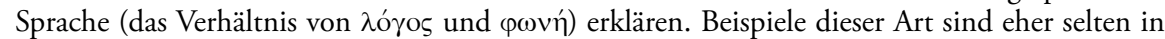
der Literatur. Viel häufiger findet sich die Thematisierung des nicht Funktionierens von Rede

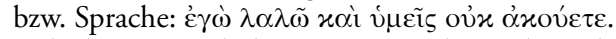

Io Vgl. dazu R. Kukula, „Tatians Rede an die Bekenner des Griechentums“ in: Frühchristliche Apologeten und Märtyrerakten, Bd. I (= BKV I2), München 1913, I77-257, I92.

II M. Elze, Tatian und seine Theologie, Göttingen I960, 44.

I2 Vgl. dazu die Kritik bei U. Neymeyr, Die christlichen Lehrer (vgl. Anm. 8), I93f. Eine eindeutige Datierung des Werks erweist sich nach wie vor als unmöglich. Die Vorschläge reichen von den frühen I5oer bis zu den späten I7oer Jahren. Neuere Diskussionen der einschlägigen Literatur finden sich bei Hunt, Christianity in the Second Century (vgl. Anm. 3), 3, und Karadimas, Tatian's Oratio ad Graecos (vgl. Anm. 4), 7, Anm. 4. Entgegen Hunt sehe ich die Argumente gegen eine Frühdatierung in Rom nach wie vor nicht für völlig entkräftet. Doch kann eine Datierung und Situierung um I60 in Rom tatsächlich die größte Plausibilität für sich beanspruchen.

I3 Typisch etwa, wie bereits erwähnt (vgl. Anm. 3), ist die Einstellung Stählins, der Tatians Rede für lediglich „in die Form einer Rede gekleidet“ hielt. Ähnlich J. Geffcken, Zwei griechische Apologeten, Leipzig/Berlin 1907, 107, der Tatians Rede für ein ausschließlich literarisches Produkt hält, das lediglich den Anschein einer Rede erwecken wolle. 
sophie weitgehend zu isolieren und ihre literarischen Ausdrucksformen als Produkte eines künstlichen, ghettoïsierten Milieus abzutun, das keinen Zugang zu einer breiteren gebildeten Öffentlichkeit fand. ${ }^{14}$

Demgegenüber soll im Folgenden vom Text und der Eigenaussage des Autors selbst her davon ausgegangen werden, dass dieser in erster Linie ein in vielerlei Hinsicht typischer kaiserzeitlicher Rhetor und Philosoph war, ${ }^{15}$ dessen spezifische philosophische Ausrichtung erst von einer neuzeitlich-modernen Perspektive her so gedeutet werden kann, als ob sie von der seiner andersdenkenden Zeitgenossen grundlegend verschieden gewesen wäre. ${ }^{16}$ Damit soll die Christlichkeit des Denkens Tatians nicht in Abrede gestellt werden. Es handelt sich dabei aber nicht um irgendeine, zeitlos-allgemeine Christlichkeit, sondern um die Christlichkeit einer von einem ganz bestimmten Denker aus einem ganz bestimmten gemeindlichen Kontext heraus ${ }^{17}$ vertretenen, in Rhetorik gekleideten kaiserzeitli-

I4 So auch Neymeyr, Die christlichen Lehrer (vgl. Anm. 8), I90: „Die Überlegung J. Geffckens, für die Oratio als tatsächlich gehaltene Rede sei kein Publikum denkbar, ist ein nicht begründetes Vorurteil." Von dem eben beschriebenen Vorurteil beeinflusst, wenngleich anders motiviert, ist W. Kinzig, Überlegungen zum Sitz im Leben der Gattung $\pi \varrho \varsigma^{~}{ }^{~ E} \mathrm{E} \lambda \lambda \eta v \alpha \varsigma$ Ad nationes, in: R. von Haehling (Hg.), Rom und das himmlische Jerusalem, Darmstadt 2000, I52-I83. Kinzig meint, Tatians „Rede“ sei als Rechtfertigungsschreiben eines kürzlich neubekehrten paganen Intellektuellen bei seiner christlichen Gemeinde eingereicht worden und sein Sitz im Leben sei ausschließlich dort zu suchen. Er weist freilich selbst auf den spekulativen Charakter dieser Erklärung hin.

I5 Vgl. angesichts der Qualität der Rede Tatians durchaus glaubwürdige Hinweise, er habe in der

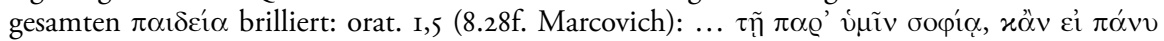

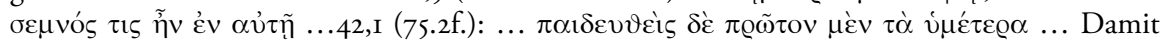
wäre er allgemein als öffentlicher Lehrer und Redner qualifiziert gewesen; vgl. Whittaker, Tatian (vgl. Anm. I), xiiif.; zur sprachlichen Kompetenz bereits K. L. Heiler, De Tatiani Apologetae Dicendi Genere, Marburg 1909. Beachte auch 3,I (IO.If.) die Verächtlichmachung von Heraklits Autodidaktentum, das auf Tatian offenbar nicht zutraf, I5,4 (32.I2) Tatians Hinweis auf ein

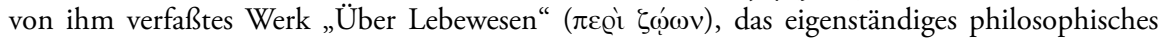
Forschen nahelegt, I9,If. (39.I-II) den Hinweis auf die öffentliche Auseinandersetzung mit dem Philosophen Crescens, 29,I (55.I) auf die Initation in Mysterien und 29,2 (55.9) auf selbständi-

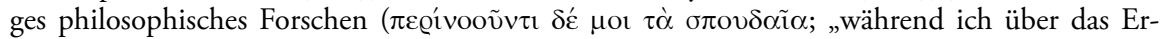
strebenswerte nachsann"; vgl. Elze, Tatian (vgl. Anm. II), 29f., der aus dem Ausdruck (neben einer ganzen Reihe ähnlicher Ausdrücke) eine Tätigkeit Tatians als Philosoph platonischer Prägung, ähnlich wie Justin, ableitet).

I6 So gesehen verhielte sich Tatian zu einem heutigen Christen in einer ähnlichen Weise wie sich ein Bürger Athens im 5. Jahrhundert v. Chr. zum Bürger einer westlichen Demokratie heute verhielte. Die Grundbegriffe (Christentum, Demokratie) scheinen sich zu entsprechen, die kulturellen Kontexte aber sind grundverschieden. Dennoch macht es Sinn, die Phänomene aufeinander zu beziehen; denn sowohl modernes Christentum als auch moderne Demokratie definieren sich unter anderem auch durch einen Rückbezug auf antike Vorbilder.

I7 Insofern ist auch die Aussage von Neymeyr, Die christlichen Lehrer (vgl. Anm. 8), I88, Tatian habe „mit den ,Unsrigen“ (orat. 30,3 [56.IO Marcovich]) die Christen allgemein und nicht eine besondere Gruppe gnostischer Christen“ gemeint, wie R. M. Grant, „Tatian (Or. 30) and the Gnostics," in: JTS i5 (1964) 65-69, gemeint habe, zu differenzieren: Es stimmt, dass Tatian, insofern er mit seinem Werk einen allgemeinen Anspruch erhob und auf einen möglichst weiten Leserkreis abzielte, seine Version des Christentums als allgemeingültig (universal) hinstellte, 
chen Philosophie. Die sich aus dieser Gemengelage ergebenden Spannungen und Vieldeutigkeiten, wie sie sich besonders am Logosbegriff in Tatians Rede festmachen lassen, sind Thema des vorliegenden Beitrags. Eine überaus häufige Thema-

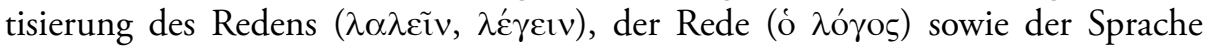

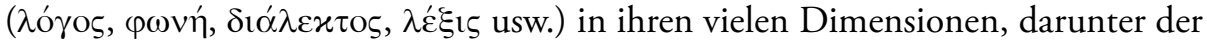
physischen (ihre Lautgestalt), der kulturellen (die verschiedenen Dialekte des Griechischen) sowie der geistig-moralischen Dimension (etwa das Phänomen wahrer gegenüber falscher, lügnerischer Rede) usw. illustriert auf beeindruckende Weise den rhetorischen wie auch (sprach-)philosophischen Charakter von Tatians Rede. $^{18}$ Dieser Aspekt überlappt sich auf eigenartige Weise mit einer philosophischen Logosspekulation, die sowohl in einem weiteren philosophiegeschichtlichen als auch in einem engeren frühchristlichen Kontext gedeutet werden kann.

Als Schlüsselbegriff wurde in dieser Hinsicht in der Forschungsgeschichte bereits mehrmals der Ausdruck von der „Macht“, „Gewalt“ oder „Kraft“ der „Rede“ bzw. des „Wortes“, des „Logos“, ${ }^{\text {, }}$ identifiziert. ${ }^{20}$ Besonders intensiv etwa hat

eben als eine Philosophie, wie Hunt, Christianity in the Second Century (vgl. Anm. 3), herausstrich. Anderseits zeigen sowohl Tatians Lehre als auch seine Hinweise auf gemeindliches Leben (etwa in orat. 32,2 [60.5-Io Marcovich]), dass es sich bei seinem konkret erlebten Christentum um eine ganz bestimmte Form handelt, die gegenüber anderen Formen drastische Unterschiede aufweist. Diese Diskrepanz wird auch in der Rezeption sichtbar. Die Nachwelt behandelt Tatian einerseits als einen Häresiarchen; vgl. dazu A. Pourkier, L'hérésiologie chez Épiphane de Salamine, Paris 1992, 343-361. Anderseits wird er als einer der Apologeten geführt und seine „Rede an die Griechen" allgemein anerkannt und bewundert. Vgl. zu beiden Einstellungen bereits

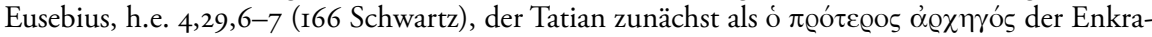

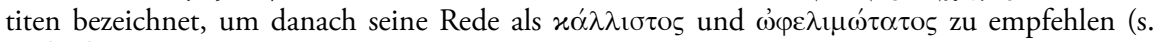
auch oben Anm. 2).

I8 Das Verb $\lambda \dot{\varepsilon} \gamma \varepsilon ı v$ findet sich ca. $35 \mathrm{mal}$ im Text, $\lambda$ óyos in der Bedeutung von „Wort“, „Rede“

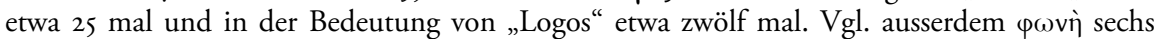

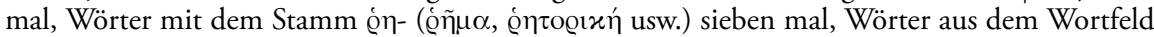

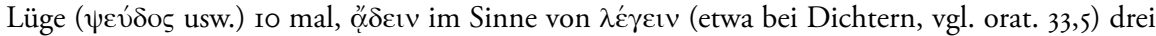

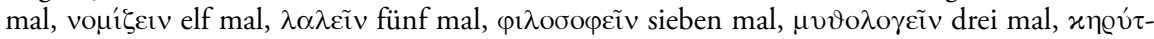
$\tau \varepsilon ı v$ drei mal usw. Zur Diskussion der wichtigsten Stellen s. im Folgenden.

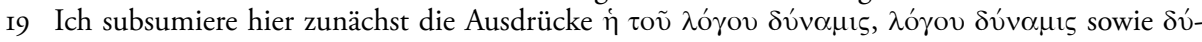

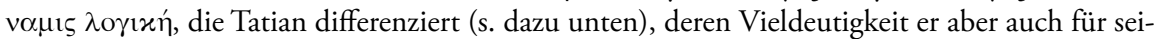
ne rhetorischen Zwecke nutzt. Vgl. Elze, Tatian (vgl. Anm. II), 74f., S. Di Cristina, „Lidea di $\Delta$ v́vouı nel De Mundo e nell'Oratio ad Graecos di Taziano," in: Aug. I7 (I977) 485-504, 496499, Id., Taziano il Siro. Discorso ai Greci, Rom 199I, sowie R. Hanig, „Tatian und Justin. Ein Vergleich," in: VigChr 53 (1999) 3I-73, 39-43, bes. 40. Bei den Stellen handelt es sich um orat.

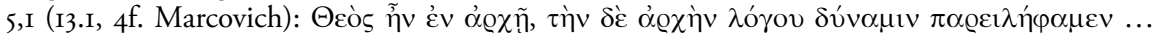
$\tau \dot{\alpha} \pi \alpha ́ v \tau \alpha \ldots \delta i \alpha ̀ ~ \lambda o \gamma ı x \tilde{\eta} \varsigma \delta v v \alpha ́ \mu \varepsilon \omega \varsigma$... Ich folge hier dem Text von Schwartz und Whittaker.

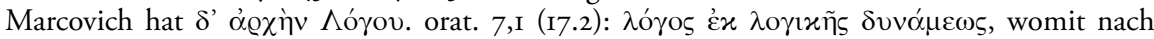

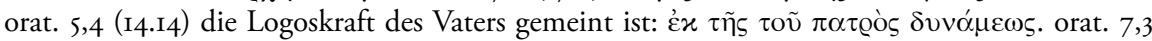

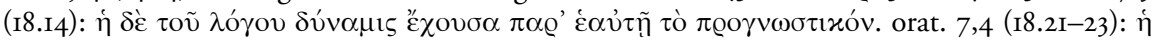

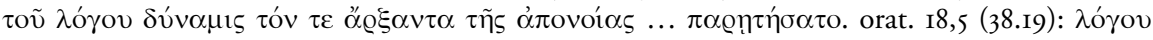

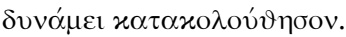

20 Neuerdings von Karadimas, Tatian's Oratio ad Graecos (vgl. Anm. 4), 34-38, und Hunt, Christianity in the Second Century (vgl. Anm. 3), 68-7I.I26-I30; s. aber bereits Kukula, Tatians so- 
kürzlich Roman Hanig die christologische Dimension des Ausdrucks (insbesondere in Abgrenzung von Justin) analysiert. ${ }^{2 \mathrm{I}}$ Justin hatte ja dem Logos als Sohn Gottes bzw. auch als Weisheit, Engel, Herr, Gott (

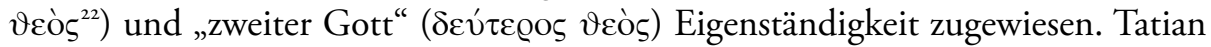
tat dies nicht. Für ihn besaß der Logos keine eigenständige Existenz und demgemäß auch keine eigenständige Kraft. Was ihn betraf, war die „Kraft des Logos“

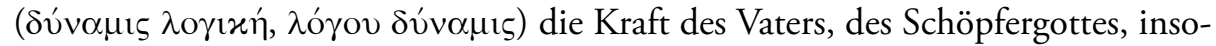
fern sie sich durch das von ihm willentlich geäußerte Wort manifestierte. ${ }^{23}$

Tatian wollte sich aber, wie es scheint, mit dieser Konzeption nicht völlig von Justin distanzieren, ${ }^{24}$ sondern er versuchte offenbar, auf den Grundlagen des Denkens seines Lehrers eine vermittelnde Position zu entwickeln. ${ }^{25}$ Dass er direkt

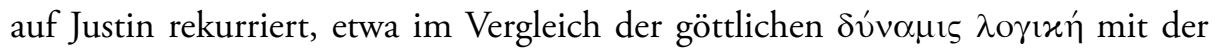
menschlichen Rede und dem Feuer, ${ }^{26}$ steht ausser Zweifel. ${ }^{27}$ Was genau dabei sei-

genannte Apologie (vgl. Anm. 9), 3f., Elze, Tatian (vgl. Anm. II), 70-76, und R. Hanig, „Tatian und Justin" (vgl. Anm. 19), 39-43.

2I Hanig, „Tatian und Justin“ (vgl. Anm. I8), 39-43; vgl. Hunt, Christianity in the Second Century (vgl. Anm. 3), 68-7I, sowie weiterhin Elze, Tatian (vgl. Anm. II), 70-74.

22 Vgl. dazu N. Brox, Terminologisches zur frühchristlichen Rede von Gott, SBAW.PH, München $1996,28-39$.

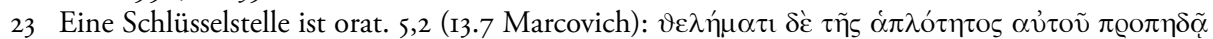
$\lambda$ óyos: Das Wort (Gottes) springt durch den Willen dessen hervor, der seinem Wesen nach einfach ist. Dies ist nach Hanig, „Tatian und Justin“ (vgl. Anm. 19), 44-46 im Vergleich mit Justin, dial. I28,3 (292f. Marcovich) zu lesen. Dort weist Justin die Verwendung des Ausdrucks sei-

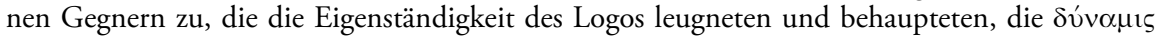
des Vaters (die für Justin synonym mit dem Logos ist) existiere nur von Fall zu Fall, d. h. im-

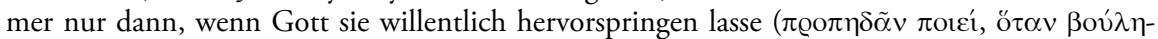

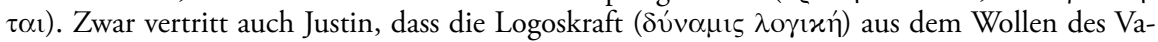

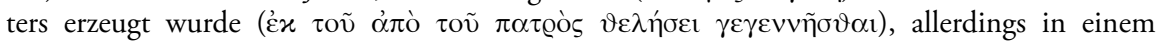
einmaligen Akt und als eigenständiges Wesen. Danach ist sie dem Willen des Vaters gehorsam

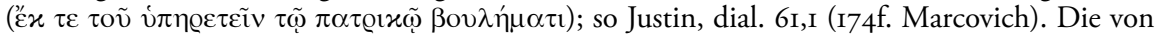
M. Edwards wieder erwähnte These J. R. Harris', dass $\pi \varrho 0 \pi \eta \delta \tilde{\alpha} v$ hier auf die mythische Geburt Athenes aus dem Haupt des Zeus anspielen könnte, trägt zum Verständnis der Stelle speziell bei Tatian nichts Wesentliches bei. J. R. Harris, „Athena, Sophia and the Logos, “ in: BJRL 7 (I923) 55-72; M. Edwards, Catholicity and Heresy in the Early Church, Farnham 2009, 44.

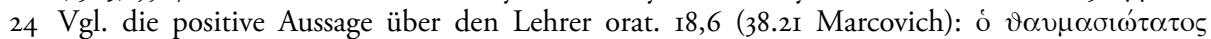
'Iovotívo5, was bereits auf die Verehrung Justins als Märtyrer hindeuten könnte (so Marcovich, Tatiani Oratio [vgl. Anm. I], If.), sowie orat. I9,2 (39.6-II) die Solidarisierung mit Justin in der Auseinandersetzung mit Crescens.

25 Auf der Grundlage einer neueren Studie von P. Parvis, „Justin, Philosopher and Martyr,“ in: S. Parvis \& P. Foster, Hg., Justin Martyr and His Worlds, Minneapolis 2007, 22-37, wurde sogar die Vermutung geäussert, dass Tatian in seiner Rede eine Position entwickelte, die Justin (in Anlehnung an den in 2 apol. erwähnten Ptolemäus) so oder ähnlich selbst einmal vertreten haben könnte, ehe er sie in der ersten Apologie verwarf. Dies könnte auch die von Grant, „Tatian“ (vgl. Anm. I7), gezogenen Verbindungslinien zwischen Tatian und Valentinian in einem neuen Licht erscheinen lassen. Vgl. Edwards, Catholicity (vgl. Anm. 23), 4If.

26 Vgl. Tatianus, orat. 5,3-4 (I3f. Marcovich); Justin, dial. 6I,2 (I75.9-I4 Marcovich).

27 Vgl. etwa Marcovich, Tatiani Oratio (vgl. Anm. I), I, und bereits Elze, Tatian (vgl. Anm. II) 76, sowie die Diskussion bei Hanig, „Tatian und Justin“ (vgl. Anm. 19), 5I, Anm. 85. 
ne Absicht gewesen sein könnte, ist die Frage. Klar ist, dass er die justinischen Motive stark umdeutete und insbesondere viel engere Verbindungslinien zwischen göttlichem und menschlichem Wort zog als Justin. ${ }^{28}$ Ihn interessierte offensichtlich besonders die Schwelle ${ }^{29}$ zwischen geistiger und physischer Welt. Er sah im Begriff des göttlichen Wortes weniger ein eigenständiges Wesen oder einen philosophischen Gegenstand als die Reflexion eines Prozesses, ${ }^{30}$ und er entwickelte im Zusammenhang damit auch einen stärkeren Begriff des Geistes, des Pneumas, den er dann sowohl mit Gott als auch mit dem (göttlichen wie

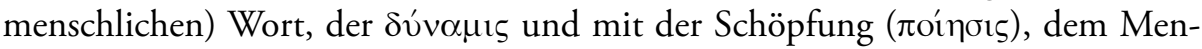
schen wie der materiellen Welt, in einen engen Bezug setzte. ${ }^{31}$ Der Begriff $\delta u ́ v \alpha-$

28 Vgl. etwa orat. 5,5-7 (I4.I4-26 Marcovich), wo er dafürhält, dass das von ihm als einem im Wort Gottes neu geborenen und bekehrten Menschen gesprochene Wort die Unordnung in den Körpern seiner Adressaten auf ähnliche Weise wieder in Ordnung bringen könne ( $\mu \varepsilon \tau \alpha-$

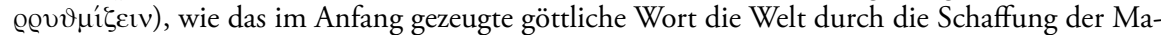
terie überhaupt erst hervorgebracht habe. Zu den Unterschieden zu Justin vgl. die Diskussion bei Hanig, „Tatian und Justin“ (vgl. Anm. 19), 55-57.

29 In philosophischer Terminologie könnte man hier vielleicht auch von der Analogie von Transzendenz und Immanenz sprechen, von göttlichem und hylischem Pneuma sowie von göttlichem und menschlichem Logos.

30 Was er, wie wir gleich sehen werden, in orat. 5,5-7 (I4.I4-26 Marcovich) versuchte, erinnert stark an das, was Justin an seinen Gegnern kritisierte, nämlich dass sie die göttliche Kraft ( $\delta$ v́v $\alpha \mu \iota$ ) nur deshalb als „Logos“ bezeichneten, weil sie die vom Vater ausgehenden Worte zu den

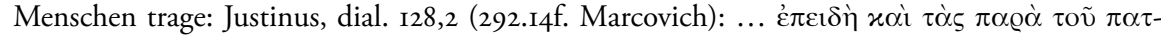

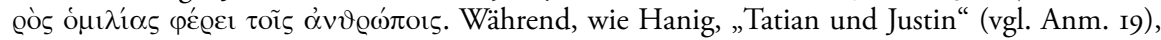
bes. 39, 42, 50 und 59, richtig bemerkt, Justins Absicht relativ klar ist, nämlich der Aufweis der Existenz eines „,zweiten Gottes“, des Logos, bleibt bei Tatian der Logos „eigentümlich wesenlos" (Zitat Elze, Tatian [vgl. Anm. II], 8If.). Hanig nennt als mögliches Motiv für Tatians Vorgehen seine „Nähe zur monarchianischen Lehre“ (73). Dagegen könnte Justins Bemerkung darauf hindeuten, dass es Tatian anders als seinem Lehrer weniger um das Wesen des Logos (und a fortiori auch des Pneumas) gegangen sein könnte als um das Wie der Vermittlung, und zwar sowohl von Gott zu den Menschen, als auch zwischenmenschlich, als auch hinsichtlich der Rückkehr des Menschen zu Gott. Was Tatian demnach beabsichtigt hätte, wäre weniger die Ausarbeitung einer theologischen Metaphysik gewesen als die einer theologischen Rhetorik, Hermeneutik und Ethik. Zum Aspekt der Hermeneutik s. demnächst J. Lössl, „Hermeneutics and Doctrine of God in Tatian's Ad Graecos," in: Studia Patristica (im Druck).

3I Am deutlichsten kommt dies in orat. 7,I (I7.I Marcovich) zum Ausdruck, wo der Logos als „Geist vom Geist“ (Gottes), analog zu seiner Identität als „Logos aus der Logoskraft“ (Gottes),

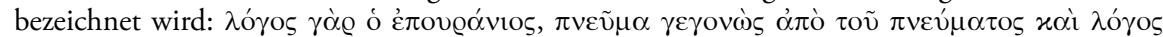

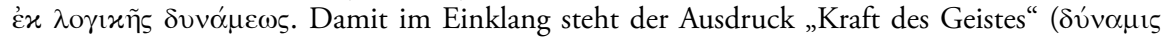

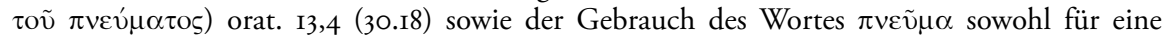
stoffliche Größe, etwa orat. I2,3f. (28.22ff.) $\pi v \varepsilon \tilde{v} \mu \alpha$ vं $\lambda$ เxóv, als auch für den „Geist Gottes“

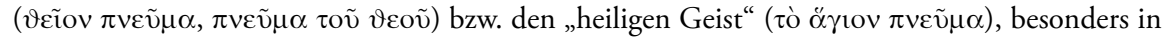
orat. I3 (30), analog zur Verwendung des Ausdrucks $\lambda$ ó $\gamma 0 \varsigma$ in orat. 5. (häufig). Angesichts dieses Befundes trifft auch erneut die Beobachtung von Hanig, „Tatian und Justin“ (vgl. Anm. 19), 63, II8 ins Schwarze, „dass die Aussagen Tatians über den Geist nicht präzis erfassbar sind.“ Vgl. auch F. Dünzl, Pneuma. Funktionen des theologischen Begriffs in frühchristlicher Litera-

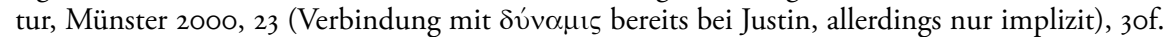
(Unterscheidung von immanentem und transzendentem, göttlichem Pneuma bei Tatian), 60 (Logos als Pneuma), 204, 242f., 264, 289. 
$\mu ı \varsigma$ spielte dabei eine Vermittlerrolle. Mit seiner Hilfe formte Tatian, so könnte man vielleicht sagen, Justins „Logoschristologie“ in eine "Geistchristologie“ um..$^{32}$ Noch entscheidender aber ist, wie schon angedeutet, die Rolle, die rhetorisches Denken bzw. eine richtiggehende Rhetorik- oder Kommunikationstheorie in Tatians Überlegungen spielt, in das hinein Justins Logosdenken geradezu verwoben wird, das aber gleichzeitig über Justins Logosspekulation hinausführt und eine Vielfalt von Lebensbereichen berührt, über die Tatian sich in seiner Rede auslässt. Als locus classicus und Ausgangspunkt für einige weitere Überlegungen hierzu sei zunächst orat. 5 etwas ausführlicher zitiert, wobei in der Übersetzung versucht wird, an entsprechenden Begriffen mögliche rhetorische Bedeutungsnuancen besonders herauszuarbeiten:

(5,I) Gott war im Anfang. ${ }^{33}$ Der Anfang aber ist die Kraft des Wortes. ${ }^{34}$ So ist es uns überliefert. Denn der Herr des Alls ist als Grund des Ganzen auch sein (transzendentes) Prinzip. ${ }^{35}$ Er war, ehe die Schöpfung geworden war, allein. Doch

32 Bisher wurde die Rolle des Geistes eher in Verbindung mit der Anthropologie, nicht aber in Verbindung mit der Logoslehre wahrgenommen; vgl. etwa Hunt, Christianity in the Second Century (vgl. Anm. 3), I36-I39. Auch A. Harnack, Die Mission und Ausbreitung des Christentums in den ersten drei Jahrhunderten, Leipzig 1902, I48-I6I, bes. I56f., greift zu kurz: Tatian ging es nicht nur um den „sittlichen Ernst“ der Christen. Für ihn bestand ein innerer, wesentlicher, geistiger $(\pi v \varepsilon \tilde{v} \mu \alpha)$ wie auch vernunftgemäßer ( $\lambda$ ójos) Zusammenhang zwischen philosophischer Gesamtschau der Welt und konsequent christlicher Lebensweise, den er begrifflich

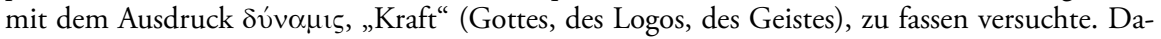
mit thematisierte er, was Harnack (ebd.) entging, die "Geistigkeit“ und „Kraft“ seiner Religion wie sonst kaum ein christlicher Denker des 2. Jahrhunderts. Seine Synthese systematischer und praktisch-spiritueller Elemente erinnert auch an die Denkweise späterer syrischer Theologen; so richtig Hunt, Christianity in the Second Century (vgl. Anm. 3), I7-I9, I44-I75. Dass Hunt, Christianity in the Second Century (vgl. Anm. 3), 22-50, Tatians Rede (gegen Grant, „Tatian“ [vgl. Anm. 17]) deswegen nicht gleich als „gnostisch“ („valentinianisch“) bezeichnet haben will, kann nicht ohne weiteres einer zu ängstlich enggeführten („parsimonious“) Exegese des Textes angelasted werden (gegen Edwards, Catholicity (vgl. Anm. 23), 4I), sondern trägt Tatians sorgfältigem Austarieren seines Denkens mit dem Justins Rechnung, das die Forschung hinsichtlich Tatians genauer Positionen seit jeher im Unsicheren ließ; vgl. dazu Hanig, „Tatian und Justin“ (vgl. Anm. 19), 63, Anm. II8. S. oben Anm. 25.

33 Es fällt auf, dass $\vartheta$ غ̇ò h hier ohne Artikel steht. Vgl. dazu auch oben Anm. 22. Joh I,I betont,

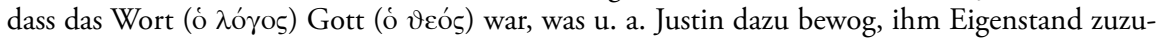
weisen. Für Tatian ist das Wort höchstens insofern ó veós, als es mit Gott einfachhin eins ist. Als geäussertes Wort hat es keinen Eigenstand.

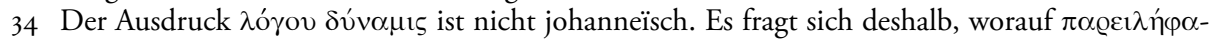
$\mu \varepsilon v$ anspielen soll; vgl. Justin, dial. 6I,I (I74f. Marcovich); I apol. I4,5 (53.24 Marcovich); 23,2 (66.6f.); 32,9 (79.3If.) u.a.; oder eine paulinische oder lukanische Tradition, I Kor I,I8.24; 2,5; 5,4; Röm I,4; Lk I,35; 4,36; 5,17; zur möglichen Herkunft von Tatians Denken vgl. auch oben Anm. 25 .

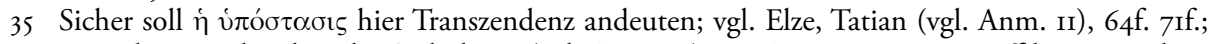
neuerdings auch Edwards, Catholicity (vgl. Anm. 23), 44, Anm. 27. Der Begriff korrespondiert mit $\dot{\pi} \varepsilon \dot{\sigma \tau \eta \sigma \varepsilon v ~ i m ~ f o l g e n d e n ~ S a t z . ~ T a t i a n ~ u n t e r s c h e i d e t ~ h i e r ~ e i n ~ t r a n s z e n d e n t e s ~ P r i n z i p ~(G o t t) ~}$

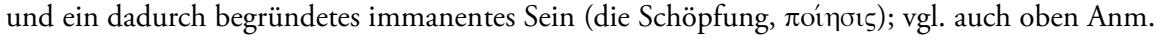


insofern alle Macht über die sichtbaren wie die unsichtbaren Dinge bei ihm lag, hatte er die Existenz aller Dinge durch die Kraft seines Wortes bereits grundgelegt. ${ }^{36}$

$(5,2)$ Aber erst durch einen Willensakt seinerseits springt sein Wort aus seiner Einfachheit hervor. ${ }^{37}$ Dabei ist das Hervortreten des Wortes nicht zweckfrei, sondern es wird zum erstgeborenen Werk des Vaters. ${ }^{38}$ Wir kennen es als den Anfang des Kosmos.

$(5,3)$ Seine Entstehung aber erfolgt gemäß dem Prinzip der Unterteilung, nicht der Abtrennung; denn das Abgeschnittene ist von dem, zu dem es ursprünglich gehörte, getrennt, das Unterteilte hingegen erfüllt noch zusätzlich eine Ordnungsfunktion, und zwar ohne dass das (Ganze), von dem es genommen wurde, (in seiner Ganzheit) von ihm beeinträchtigt würde. ${ }^{39}$

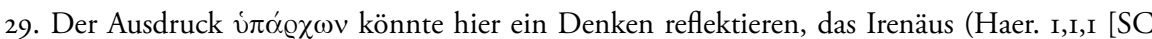

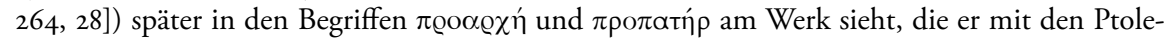

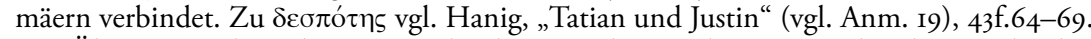

36 Die Übersetzung lässt die im Griechischen in eckigen Klammern stehenden Ausdrücke unbe-

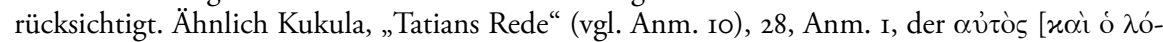

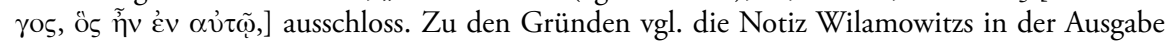
von Schwartz (vgl. Anm. I), S. 5 im Apparat zu den Zeilen 19-2I. Den gesamten Wortbestand übersetzen Harnack, Tatians Rede (vgl. Anm. 3), I5; Elze, Tatian (vgl. Anm. II), 72, und Whittaker, Tatian (vgl. Anm. I), II. Diese Übersetzungen machen zwar als Wiedergabe einer frühchristlichen „Standard-Logoslehre“ Sinn, es stellt sich aber die Frage, ob sie Tatians spezifisches Denken reflektieren oder vielleicht doch nur die bereits im Scholion Arethae (77.13-25 Marcovich) angelegte Tradition von Tatian als einem Proto-Arianer perpetuieren. Vgl. Hanig, „Tatian und Justin" (vgl. Anm. 19), 47, Anm. 72.

37 Vgl. dazu oben Anm. 23.

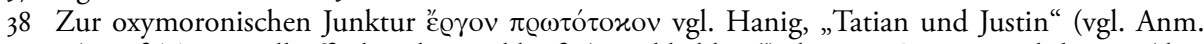
19), 46f. Tatian will offenbar die Wirkkraft („Wirklichkeit“) des von Gott aus sich heraus (des-

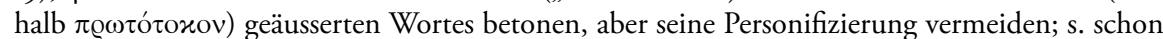
B. Ponschab, Tatians Rede an die Griechen, Metten I894, 20 (Logos bei Tatian „nicht ... leerer Schall, sondern ..., Realität“"). Zurück geht $\pi \varrho \omega \tau$ tó sonifizierte Weisheit bezogen). Doch vgl. Philo, Ebr. 3I (II I76.9f. Wendland): $\pi \varrho \omega \tau i \sigma \tau \eta v \tau \tilde{\omega} v$

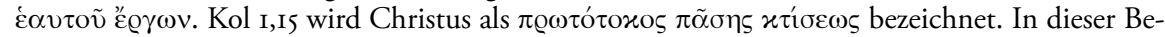
deutung kommt der Ausdruck bei Justin häufig vor; vgl. etwa I apol. 23,2 (66.6 Marcovich): $\lambda$ ó-

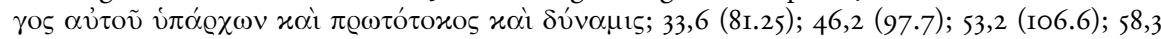
(II4.Iof.); 63,I5 (I23.40); dial. 84,2 (215.8f.); 85,2 (216.I2f.); I00,2 (24I.IIf.); II6,3 (270.22f.) u. ö.

39 Zum Verständnis dieser Passage vgl. R. M. Grant, "Studies in the Apologists, “ in: HTR 5I (I958) I23-I34, I26-I28; Elze, Tatian (vgl. Anm. II), 77-79; Hanig, „Tatian und Justin“ (vgl. Anm. 19), 48, Anm. 75. Nach Grant verwendet Tatian hier ein aus der Grammatik genomme-

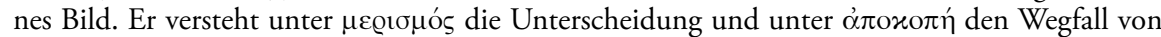

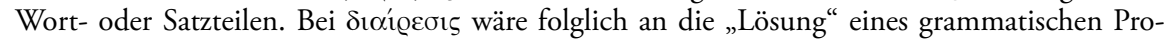
blems zu denken, also an die vollständige Analyse einer Wortform oder eines Satzes, bei oixovouí $\alpha$ an das System (Wort oder Satz), an dem die Analyse vorgenommen wurde. Tatian würde dann also sagen wollen, dass die Analyse trotz ihres „teilenden“ Charakters das Ganze eines Wortes oder Satzes erhält und sogar eine zusätzliche Erkenntnis verspricht, nämlich das Verständnis des Ganzen aus seinen Teilen, während der Wegfall eines Wort- oder Satzteils lediglich eine Lücke hinterlässt. Elze möchte die Passage eher auf dem Hintergrund zeitgenössischer platonischer Lehren und Texte deuten, etwa Plotinus, Enn. 4,9,5 (der Same als ein Beispiel dafür, dass das Ganze in seinen Teilen Eines ist). Angesichts des rhetorischen Charakters seiner Rede 
$(5,4)$ Denn wie von einer einzigen Fackel viele Feuer entzündet werden können, das Licht der ersten Fackel durch das Entzünden der vielen anderen Fackeln aber nicht schwächer wird, so geht auch das Wort aus der Kraft des Vaters hervor, ohne dass es ihn, seinen Erzeuger, dadurch ,wortlos' machen würde. ${ }^{40}$

$(5,5)$ Denn auch ich rede und ihr hört. ${ }^{4 \mathrm{I}}$ Dennoch gehe ich durch die Übermittlung meiner Rede, also dadurch, dass mein Wort auf euch übergeht, keineswegs meines Wortes (meiner Vernunft, meiner Verbundenheit mit dem göttlichen Wort ${ }^{42}$ verlustig. Dadurch dass ich meine Stimme ${ }^{43}$ auf euch projiziere, verfolge ich vielmehr den Zweck, die ungeordnete Materie in euch zu ordnen. ${ }^{44}$

könnte Tatian aber an beides gedacht haben. Die Übersetzung greift diesbezüglich einen Vor-

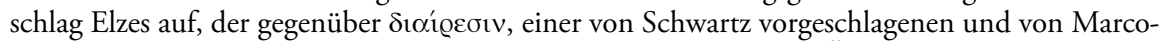

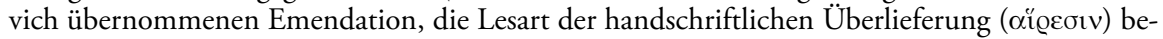

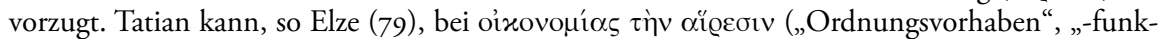
tion") an "die ordnende Verwaltung der Materie“ durch den Logos gedacht haben. Er könnte aber auch, wenn man Grant folgen möchte, an die Ordnungsfunktion gedacht haben, die ein

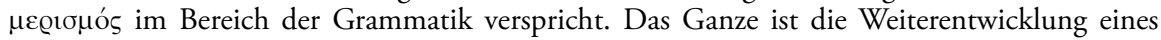
Gedankens Justins, der diese Unterscheidung nicht vorgenommen zu haben scheint; vgl. dial.

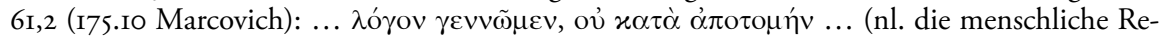

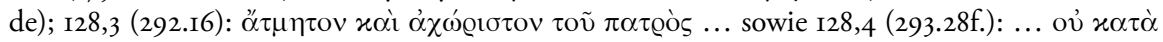

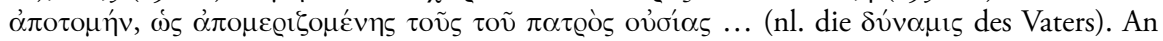
Justin anzuknüpfen scheint (gegen Tatian?) Clemens Alexandrinus, str. 7,2,5,5 (GCS 17, 5.26f.):

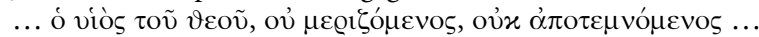

40 Ein detaillierter Vergleich dieses sowie des folgenden Abschnitts mit der wahrscheinlichen Quelle, Justinus, dial. 6I,2 (I75.9-I4 Marcovich), findet sich bei Hanig, „Tatian und Justin“ (vgl. Anm. 19), 49-57.

4I Dazu dass hier eine konkrete, orale Redesituation zugrundeliegen könnte s. oben Anm. 8f.

42 Zur Vielschichtigkeit von Tatians Rede vgl. Hanig, „Tatian und Justin“ (vgl. Anm. I9), 68f.

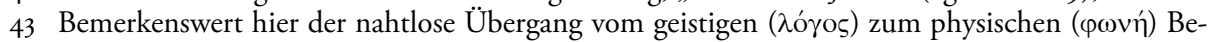
reich. Die Stimme Tatians (als eines christlichen Protreptikers), die nicht einfach nur im rheto-

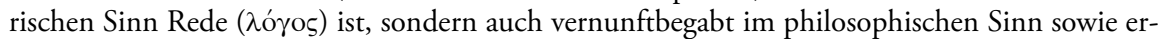
füllt vom göttlichen Wort (all diese Motive schwingen hier rhetorisch mit), kann dadurch, dass sie selbst materiell verfasst ist, bei der Materie ( tümlich als einem kosmischen Prinzip anhängen, ansetzen, um sie im Sinne des göttlichen Wortes umzuformen, ganz ähnlich wie das göttliche $\pi v \varepsilon \tilde{v} \mu \alpha$ dies mit dem hylischen $\pi v \varepsilon \tilde{u} \mu \alpha$ macht. Vgl. dazu auch oben Anm. 3I.

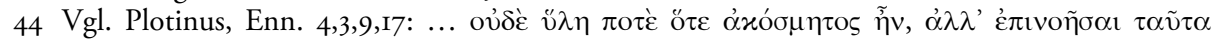
$\chi \omega \varrho i \zeta o v \tau \alpha \varsigma$... Plotins Perspektive ist hier aber eine rein theoretische: „Es gab keine Zeit, in der die Materie ungeformt gewesen wäre, sondern wir treffen diese Unterscheidung nur zum besseren Verständnis." Keine Rede davon, dass der Logos oder seine Kraft die ungeformte Materie formte. Nach Karadimas, Tatian's Oratio (vgl. Anm. 4), 35, Anm. I47, und 36, Anm. I53, könnte die Rhetorik Vorbilder für Tatians Vorstellung einer kosmischen Ordnungsfunktion von menschlicher Rede geliefert haben. Er zitiert dazu u. a. Aelius Aristides, Or. 2,379 (262.7f.

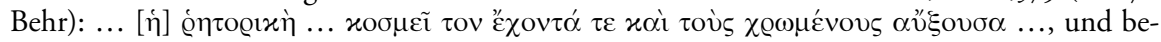
sonders 394-402 (269-272 Behr) den Mythos vom göttlichen Ursprung der Redekunst und ihrer ordnenden Funktion in der menschlichen Gesellschaft; s. etwa 40I (27I.I3-I6 Behr): ... oủ

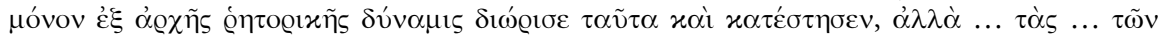

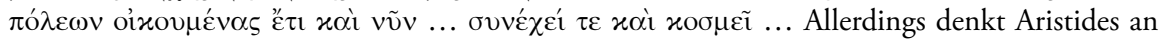
diesen Stellen immer in erster Linie an die menschliche Gesellschaft, während es Tatian um die „innere" (leib-seelische) Struktur jedes einzelnen Menschen geht. 
$(5,6)$ Und wie das im Anfang gezeugte Wort wiederum unsere Welt erzeugt hat, indem es sich zunächst die Materie schuf, so forme auch ich, der ich zur Nachahmung des Wortes neu geboren und zum Erfassen der Wahrheit fähig gemacht worden bin, die Ungeordnetheit der Materie, der ihr noch immer verhaftet seid, ${ }^{45}$ neu.

$(5,7)$ Denn die Materie ist nicht anfangslos wie Gott, noch hat sie eine durch Anfangslosigkeit begründete gottgleiche Macht; sondern sie ist geworden und durch keinen anderen entstanden als allein durch den Schöpfer aller Dinge. ${ }^{46}{ }^{47}$

45 Die Übersetzung folgt hier dem Text der Edition; wörtlich: „... die euch (noch immer) wesensverwandt ist ..."

46 Diese letzte Bemerkung könnte sich gegen eine Position wie die unter Anm. 44 zitierte Plotins wenden. Als (platonisierender) Philosoph verteidigt Tatian zwar die Transzendenz (deswegen

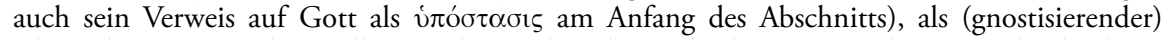
Rhetoriker (Protreptiker) will er sie aber auch nicht verabsolutieren, sondern sie vielmehr dynamisieren, durch etwas, was Aelius Aristides (s. oben Anm. 44) einen „Mythos“ nennen würde,

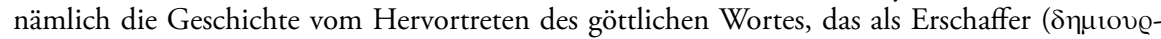

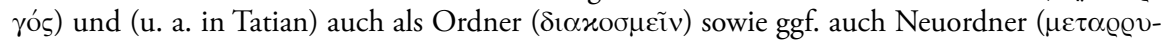
$\left.\vartheta \mu^{\prime} \hat{\prime}_{\varepsilon ı v}\right)$ der Materie in jedem einzelnen Wesen fungiert. Vgl. dazu Elze, Tatian (vgl. Anm. II), 8of., der jedoch die Rolle Tatians selbst als Mittler des Wortes zu äusserlich auffasst (vgl. ibid. S. 32f.). Was Tatianus, orat. 5,5-7 von sich selbst sagt, ist nicht nur ein äusserlicher Vergleich, sondern auf einer gewissen Ebene eine Identifizierung von Christologie und (philosophischer) Rhetorik.

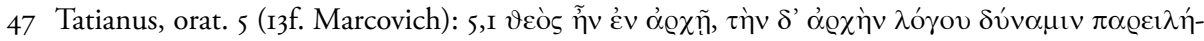

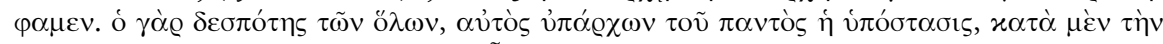

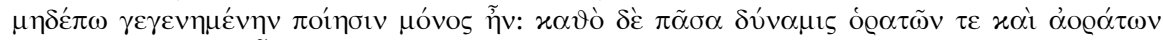

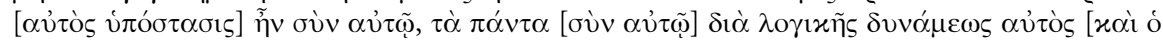

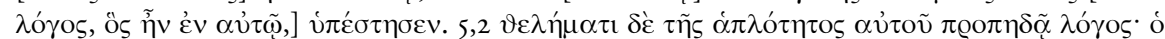

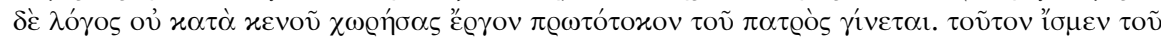

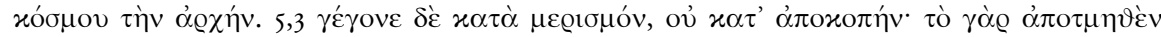

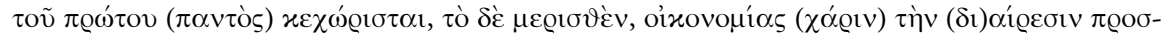

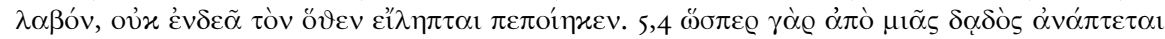

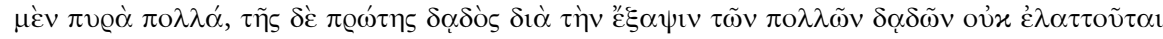

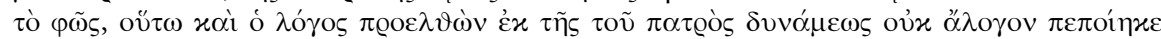

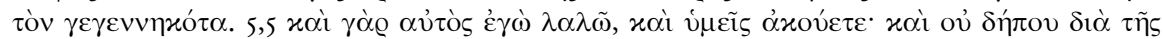

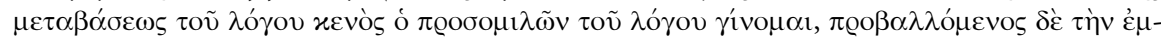

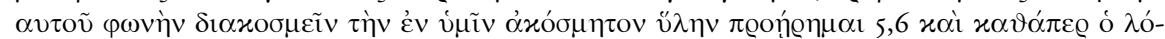

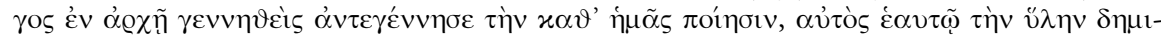

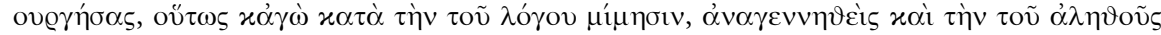

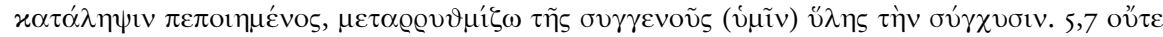

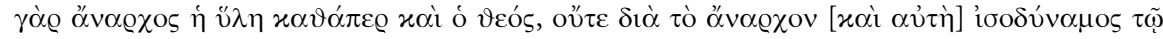

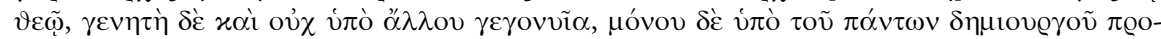
$\beta \varepsilon \beta \lambda \eta \mu \varepsilon ́ v \eta$. Von der Edition abweichend ist der hier zitierte Text durchgängig kleingeschrieben. Ausdrücke in [...] sind (auch für die Übersetzung) ausgeschlossen. Ausdrücke in (...) wurden von Marcovich eingefügt, werden aber in der Übersetzung nicht mit berücksichtigt.

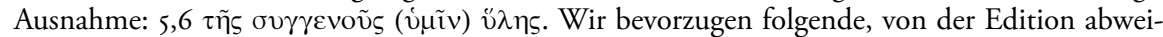

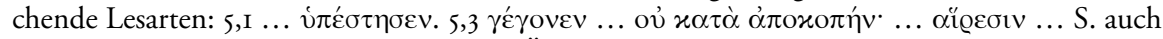
die Anmerkungen zu einzelnen Teilen der Übersetzung. 
Dieser Abschnitt zerfällt in vier Teile: In 5,I-2 wird das Wesen Gottes, in 5,2-3 die Beziehung zwischen Gott und Wort (Logos) bestimmt. In 5,4-5 wird die in 5,3 vorgenommene Definition mit Bildern illustriert. In 5,6-7 wird das Bild von der menschlichen Rede in einen engeren Zusammenhang mit dem ursprünglichen Motiv vom göttlichen Wort gebracht, ja in gewisser Hinsicht sogar mit ihm identifiziert, womit sich der Kreis schließt.

Für das vorliegende Thema besonders interessant ist orat. 5,5f. Hanig hat richtig gesehen, dass sich im Grunde nur 5,5 mit der Vorlage bei Justin vergleichen lässt. ${ }^{48}$ Für diese Passage lässt sich schon bei Justin eine gewisse Vieldeutigkeit feststellen. ${ }^{49}$ Was Hanig nicht berücksichtigt hat, ist, dass Tatian hier nicht dabei stehen bleibt, ein Bild zu gebrauchen. Vielmehr versucht er, mit seiner „Logos-

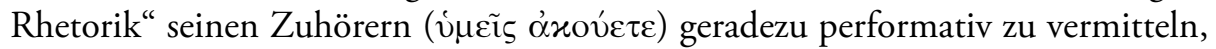
wie gesprochene Rede als körperliche Stimme bis in die Bereiche des Physischen hinein auf den Menschen als Hörer dieser Stimme wirkt. Der Mensch wird nach Tatian sozusagen von seiner materiellen Verfasstheit her, der er im Zuge seines Sündenfalls ja ganz verfallen ist, durch die von einem menschlichen Redner (Protreptiker, Prediger) vermittelte „Kraft des Wortes“ zu einem neuen (dem göttlichen Wort gemäßen) Leben umgeformt. Das in orat. 7 ausgeführte Motiv des Sündenfalls hängt dabei eng mit der in orat. 5 behandelten Thematik zusammen:

$(7, \mathrm{I})$ Denn das himmlische Wort, Geist geworden vom Geist und Wort aus der Kraft des Wortes, schuf den Menschen als ein Abbild der Unsterblichkeit unter Nachahmung des Vaters, der ihn hervorgebracht hatte. Infolgedessen ist der Mensch durch Teilhabe am Wesen Gottes in derselben Weise unsterblich, wie Gott unvergänglich ist.

$(7,2)$ Nun wurde aber das Wort noch vor Erschaffung der Menschen zum Schöpfer von Engeln, wobei beide Arten von Schöpfung (Menschen und Engel) frei geschaffen wurden ...

$(7,3)$... Die Kraft des Wortes schloss auch die Voraussicht der Zukunft mit ein, allerdings nicht als etwas, was sich schicksalhaft ereignen würde, sondern als Resultat von Handlungen sich frei entscheidender Wesen. Sie sagte also die zukünftigen Ereignisse (als mögliche Folgen von Handlungen) voraus und verhinderte durch Abraten, dass Böses getan wurde, während sie diejenigen, die im $\mathrm{Gu}-$ ten verharrten, mit Lob überhäufte.

$(7,4)$ Doch als die Menschen einem Engel folgten, der klüger war als die übrigen, ${ }^{50}$ weil er als erster entstanden war, und ihn, obwohl er sich gegen Gottes Ge-

48 Hanig, „Tatian und Justin“ (vgl. Anm. I9), 55; vgl. Justinus, dial. 6I,2 (I75.9-II Marcovich): $\lambda$ ó-

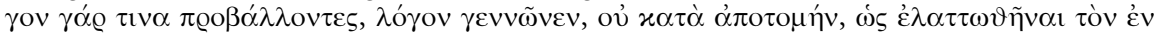

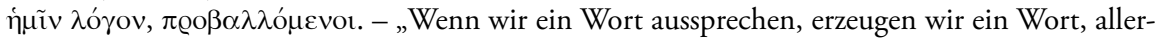
dings nicht wie bei einer Abspaltung; d. h. das Aussprechen schwächt nicht die Kraft des Wortes (des Logos, der Vernunft) in uns."

49 Vgl. den unter Anm. 48 zitierten Text. Anders Osborne, Tatian (vgl. Anm. 3), Io6, Anm. I, zitiert bei Hanig, „Tatian und Justin“ (vgl. Anm. 19), 56, Anm. 94.

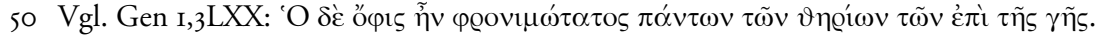


setz aufgelehnt hatte, für einen Gott erklärten, da schloss die Kraft des Wortes sowohl den Urheber des Aufstands als auch diejenigen, die ihm nachgefolgt waren, aus der Gemeinschaft mit dem Wort aus. ${ }^{5 \mathrm{I}}$

Mit dem Wort, so Tatian weiter, habe auch der mächtigere Geist ( $\delta v v \alpha \tau \omega \dot{\tau \varepsilon \varrho o v ~}$ $\pi v \varepsilon \tilde{v} \mu \alpha$ ) Gottes die Menschen verlassen und so seien die Menschen sterblich ge-

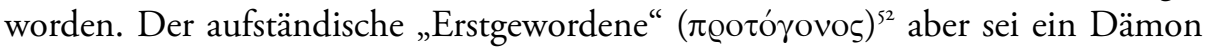
und Anführer eines Heers von Dämonen geworden, dem die Menschen verfielen, indem sie den Kosmos, die Materie, vergötterten und dabei die Freiheit leugneten. ${ }^{53}$ Jener „mächtigere“ oder „größere“ Geist, so erklärt Tatian, sei jene durch die Gemeinschaft mit dem Wort gestiftete Ähnlichkeit mit Gott gewesen, die die ersten Menschen unsterblich und, mit dem göttlichen Wort als Verhinderer des Bösen und Enkomiasten des Guten, fähig gemacht habe, immer das Gute zu tun. ${ }^{54}$ Durch ihn habe der Mensch zugleich ganz in der Materie wie auch souverän über ihr stehen können. Diesen höheren Geist also habe der Mensch durch den Fall verloren und es bliebe ihm jetzt nur noch der geringere Geist, die Seele

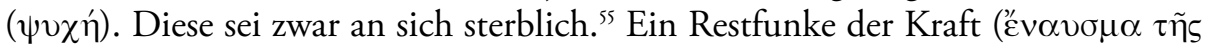
$\delta v v \alpha ́ \mu \varepsilon \omega \varsigma)$ des göttlichen Geistes und Wortes sei jedoch in ihr am Leben geblieben und könne unter bestimmten Umständen wieder entfacht werden. ${ }^{56} \mathrm{Nicht}$

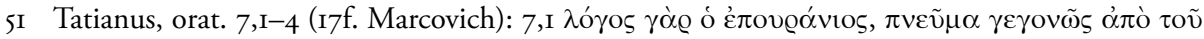

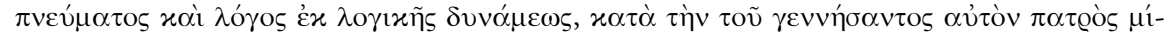

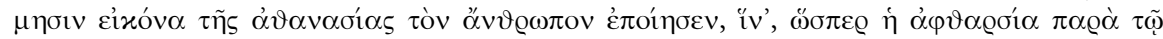

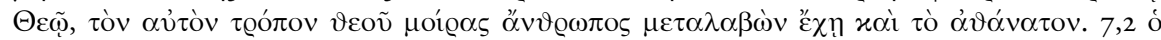

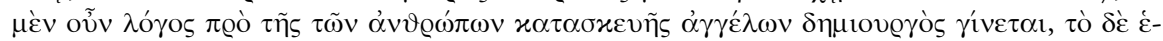

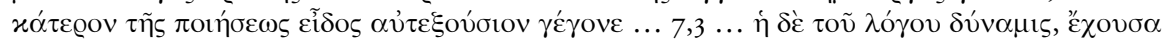

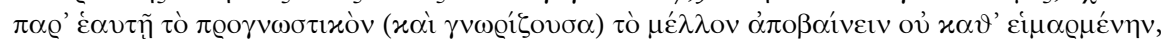

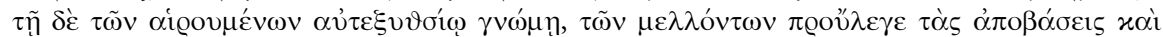

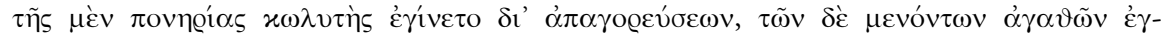

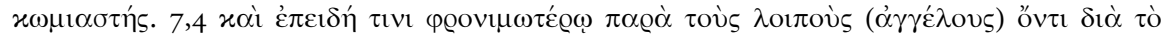

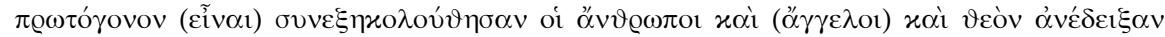

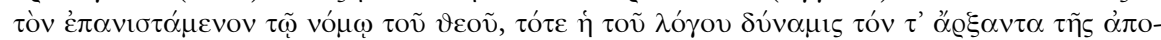

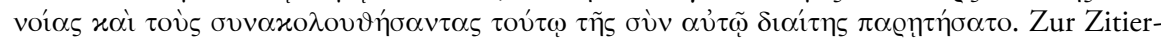
weise vgl. oben Anm. 47. Die in (...) stehenden Ausdrücke wurden für die Übersetzung nicht

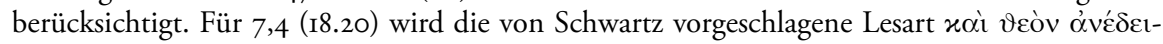

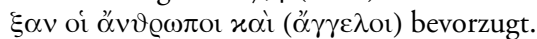

52 Vgl. im Gegensatz dazu das „erstgeborene Werk des Vaters“ orat. 5,2.

53 Tatianus, orat. 8-II (19-26 Marcovich) führt Tatian aus, wie die Vielfalt des Kosmos, etwa der Sternenhimmel, als eine Vielzahl mythologischer Götter gedeutet und dann (durch die Astrologie) in fatalistischer Weise in Bezug zur Bestimmung des Menschen gesetzt werde. orat. II,4 (26.20-22 Marcovich) endet emphatisch: „Nicht zum Sterben wurden wir erschaffen. Wir sterben durch uns selbst. Unsere Freiheit hat uns zugrundegerichtet. Wir, die wir frei waren, wurden zu Sklaven. ,Durch die Sünde wurden wir verkauft' (Röm 7,I4).”

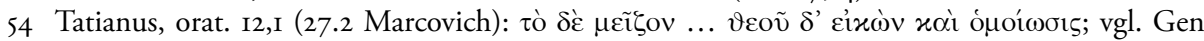
I,26. orat. 7,I.

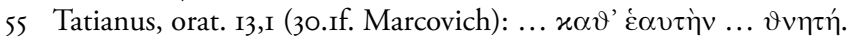

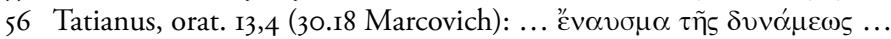


alle Menschen würden dieses Potential verwirklichen, besäßen es aber. ${ }^{57}$ Deshalb kann nach orat. 5,5 davon ausgegangen werden, dass die „Kraft“ einer von einem Bekehrten $^{58}$ (wie eben Tatian) gehaltene und somit im Einklang mit dem göttlichen Wort stehenden Rede zumindest dazu beitragen kann, es zu verwirklichen. Nach orat. 5,5 versteht Tatian seine Rede dezidiert in diesem Sinne.

Dimitrios Karadimas hat kürzlich Tatians Verständnis des Ausdrucks $\lambda$ ó $\gamma o v$

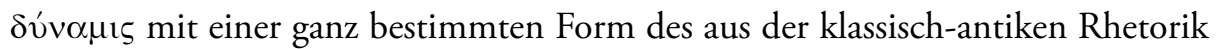
bekannten Begriffs der „Macht der Rede“ in Verbindung gebracht, ${ }^{99}$ nämlich dem „Lob“ auf diese Macht, das zwar, so Karadimas, bereits bei früheren Autoren, etwa Isokrates, ${ }^{60}$ nachweisbar sei, das aber erst Tatians Zeitgenosse Aelius Aristides zum Begriff einer wesenhaft guten, schöpferisch-zivilisatorischen und letztlich göttlich begründeten Macht ausgebaut habe. ${ }^{61}$ Interessant ist, dass Aristides seinen Begriff mit Hilfe eines Mythos einführt, ${ }^{62}$ der seinen Zuhörern aber bereits in mehreren Versionen hinlänglich bekannt zu sein scheint, weshalb Aristides sich gegen mögliche Kritiker (er spricht von einem Witzbold, «ouıxós) verteidigen sowie betonen zu müssen glaubt, ${ }^{63}$ er habe ein höheres, philosophisches Ziel im Auge, nämlich den Aufweis, dass die „Macht der Rede“ nicht nur historisch, sondern auch metaphysisch jegliches zivilisatorische Leben begründe. ${ }^{64}$

57 Vgl. Tatianus, orat. 13,5 (30.2If. Marcovich): Der Geist Gottes wird nicht allen verliehen, son-

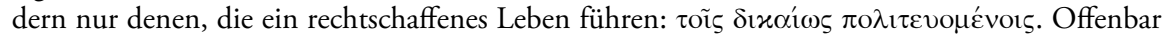
konnte Tatian bei seinen Zuhörern eine entsprechende Disposition voraussetzen, einen $\mathrm{Zu}$ stand irgendwo auf halbem Wege zwischen Desinteresse und Bekehrungsbereitschaft.

58 Vgl. Tatianus, orat. 29,2f. (55.9-19 Marcovich). Elze, Tatian (vgl. Anm. II), 22f. weist zu Recht auf die große Inhaltsähnlichkeit zwischen griechischer und barbarischer Philosophie hin, die in Tatians Bekehrungsbericht zutagetritt. Tatian betont zunächst lediglich das hohe Alter der biblischen Schriften und ihren (rhetorisch!) unprätentiösen Stil, und dann die Lehren von Schöpfung, prophezeitem Weltende, Verehrung des einen Gottes, Absolutheitsanspruch der barbarischen Lehre (also ewiges Heil nur für die, die ihr folgen), sowie Universalität der Möglichkeit zur Bekehrung (d.h. alle Menschen besitzen den Geist, aber wegen ihres Irrtums halten

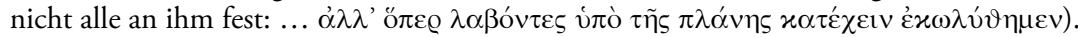

59 Vgl. Karadimas, Tatian's Oratio (vgl. Anm. 4), 34-38; oben Anm. 44. Die folgenden Überle-

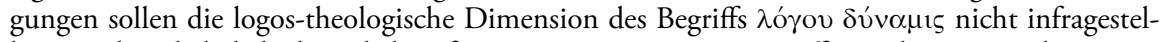
len, sondern lediglich den Blick auf eine weitere Dimension eröffnen, die so etwa bei Justin nicht gegeben ist.

60 Loci classici etwa sind Isoc. Antid. 253-257; vgl. auch Paneg. 49; Antid. 5; I5; I89; 206 u. ö.

6I Vgl. dazu D. Karadimas, Sextus Empiricus Against Aelius Aristides. The Conflict Between Philosophy and Rhetoric in the Second Century A.D., Lund 1996, 218-223. Bei der fraglichen Aristides-Passage handelt es sich um Aristides, Or. 2,394-402 (269-272 Behr).

62 Zur Funktion des Mythos bei Aristides s. jetzt auch S. Saïd, „Aristides’ Uses of Myths,“ in: W. V. Harris \& B. Holmes (Hg.), Aelius Aristides Between Greece, Rome, and the Gods, Leiden \& Boston 2008, 5I-67, bes. 65-67.

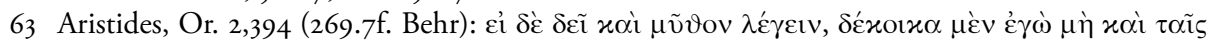

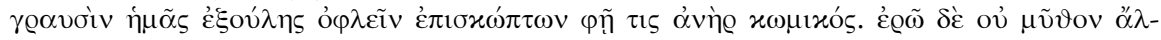

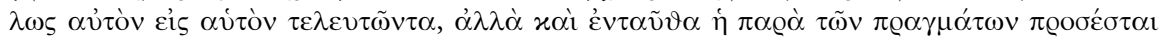

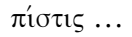

64 Aristides, Or. 2,4OI (27I.I3-I6 Behr), zitiert oben unter Anm. 44. 
Obwohl, so Karadimas weiter, Aristides ausgiebig aus klassischen Quellen, insbesondere Isokrates und Platons Gorgias schöpfe, teile er die kritische Haltung jener Autoren, die eben nicht nur die Stärken der Rhetorik, sondern auch ihre eklatanten Schwächen, einschließlich der Möglichkeit ihres Missbrauchs zu lügnerischen, betrügerischen und zerstörerischen (gewalttätigen) Zwecken herausgestrichen hätten, nicht. ${ }^{65}$ Für Aristides sei die Rhetorik keine ambivalente menschliche Fähigkeit, sondern eine transzendentale, intellektuelle, ja letztlich göttliche Kraft. Ein solches Konzept wäre Tatians „Kraft des Wortes“ in der Tat nicht völlig unähnlich. Dass der Begriff auch schon bei Justin vorkommt und auch auf andere, biblische wie klassische Einflüsse zurückgehen kann, widerspricht dem ebensowenig wie die Tatsache, dass wir es bei Aristides mit einem etwas älteren Zeitgenossen Tatians zu tun haben, in dessen Werk wir zudem noch mögliche Spuren antichristlicher Polemik finden können. ${ }^{66}$

Entscheidend ist, dass Aristides mit seinem Mythos einen hypostasierten Rhetorikbegriff einführt, der durchaus strukturelle Ähnlichkeiten mit Tatians „rhetorischer Logoslehre" aufweist. Vielleicht provozierte Tatian gerade auch ein Phänomen wie dieses zu seiner beissenden Polemik gegen die griechische Rhetorik ${ }^{67}$ und vor allem seine häufigen Verweise auf die Lügenhaftigkeit der paganen rhetorisch-literarischen Tradition, ${ }^{68}$ während gleichzeitig seine eigene Argumentation

65 Karadimas, Sextus Empiricus (vgl. Anm. 59), 223: Für Aristides, so Karadimas, „any power of this kind has nothing to do with rhetoric."

66 Vgl. Aristides, Or. 3,67I (5I4f. Behr), wo Aristides eine Gruppe von Gegnern mit ,jenen gottlo-

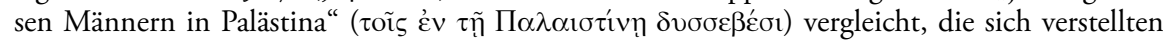

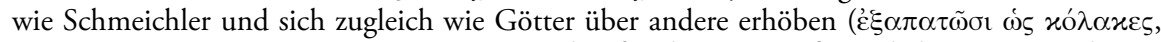
$\pi \varrho \pi \eta \lambda \alpha x^{\prime} \zeta$ lichkeit und Mutwilligkeit ( $\left.\tau \alpha \pi \varepsilon v v o ́ \tau \eta\rceil . . \alpha v^{\vartheta} \alpha \dot{\delta} \delta \varepsilon 1 \alpha\right)$. Sie hätten auch „die Griechen im Stich

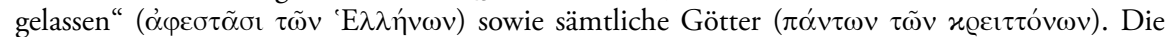
Charakterisierung würde gut zu Tatian passen. Die Entstehung von Or. 3 fällt in die Zeit zwischen I6I und I65, die der in Pergamon entstandenen Or. 2 zwischen 145 und I47. Aristides' Heimatort ist Smyrna, wo Mitte der I6oer Jahre Polykarp sein Martyrium erlitten haben soll. Zur Verbindung von Christen mit Palästina s. Lucian. Peregrin. II; Philopseud. I6. Vgl. Ch. A. Behr, P. Aelius Aristides. The Complete Works. Vol. I, Leiden I986, I4If. 275. 449. 460.477.

67 Vgl. Tatianus, orat. I,5 (8.33 Marcovich): Die Griechen hätten die Rhetorik auf den Grundla-

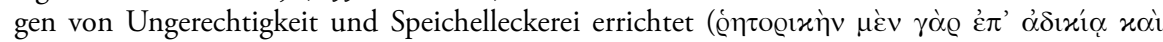

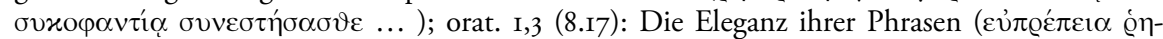
$\mu \alpha \dot{\tau} \omega v)$ diene ihnen lediglich zum Selbstlob; orat. I4,I (3I.I): Ihre Ausdrücke zeichneten sich

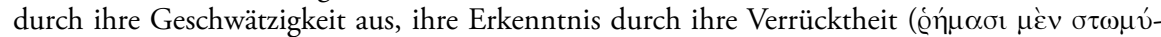

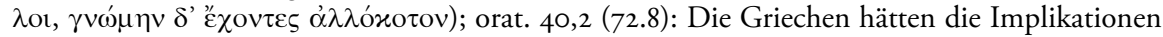
der biblischen Chronologie nicht verstanden und bedeckten sie deshalb mit der Tünche ihres

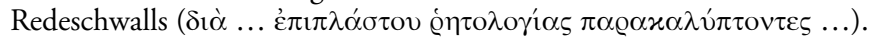

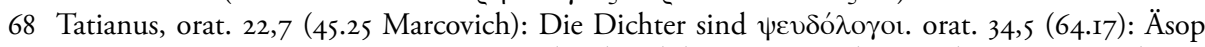

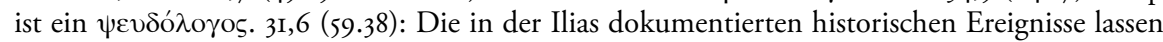
sich leicht als Lügen entlarven: $\psi \varepsilon v \delta \varepsilon \tilde{\varsigma} \varsigma \dot{\alpha} \pi \circ \varphi \eta ́ v \alpha \sigma \vartheta \alpha$. orat. 19,8 (40.27) Apoll belog sich mit seiner Weissagung über Daphnis selbst; vgl. 8,9 (2I.4I-43). orat. 27,6 (53.I4f.): Tatian sieht sich von seinen paganen Gesprächspartnern in Versuchung geführt, seinen eigenen Lebenswandel

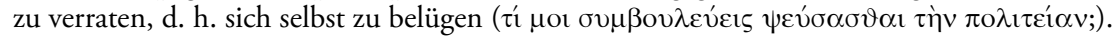


stark auf wesentliche Elemente der rhetorischen Tradition aufbaut. ${ }^{69}$ Tatians Kritik an der griechischen Rhetorik unterscheidet sich damit grundlegend von der philosophischen Rhetorikkritik seiner Zeit, gegen die sich Aristides verteidigte, ${ }^{70}$ und die Art wie Tatian Rhetorik kritisierte und dabei selbst eine Rhetorik entwickelte, weist ihn nicht nur als Philosophen sondern auch dezidiert als Rhetor (und auch als Anti-Rhetor, nämlich gegen die dominierende pagane Kultur) aus. $^{71}$ Der Begriff der „Kraft des Wortes”, der nicht nur logostheologisch sondern, wie Karadimas gezeigt hat, auch rhetorisch fassbar ist, bietet Tatian die Gelegenheit, über einen christlichen Lehrvortrag philosophischer Art, wie sein Lehrer Justin ihn praktiziert hatte, hinaus viele Aspekte des kulturellen Lebens seiner Zeit zu thematisieren, ohne dabei zentrale Themen seiner Rede aus dem Blick zu verlieren. Zumindest auf rhetorischer Ebene blieb das Wortfeld „reden“ ständig auf dem Tablett bzw. konnte Tatian seine ganze Rede hindurch mit ihm ,jonglieren“. Der Preis den er dafür bezahlte, war, wie immer wieder zu lesen ist, ${ }^{72}$ die Eindeutigkeit. Tatians Begriffe, und gerade auch seine zentralen Begriffe wie Logos und Pneuma, sind notorisch vieldeutig. Der Grund dafür liegt jedoch nicht an Tatians Unfähigkeit, eine glatte, scholastisch stimmige Glaubenslehre zu for-

69 Vgl. Tatianus, orat. 32,3 (60.Io Marcovich) sein Insistieren bezüglich der Praxis christlicher Phi-

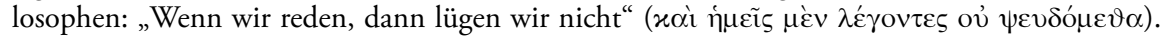
Die Betonung hier liegt auf dem „wir“ (im Gegensatz zu den griechischen, also paganen Rhetoren) und auf dem „reden“ (gemeint ist das rhetorische Reden im Kontext der philosophischen Lehre). Weniger deutlich orat. 4,2 (I2.9), wo Tatian „bekennt“, er wolle lieber sterben als den

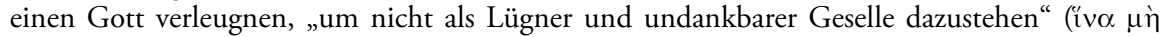

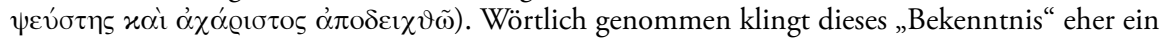
wenig dubios und von kleinbürgerlichen Moralvorstellungen geleitet. Im Kontext von Tatians rhetorischer Gesamtstrategie, etwa auch im Licht of orat. 5,5, entwickelt es eine eigene Sinnhaftigkeit: Tatians rhetorische Glaubwürdigkeit erwächst u. a. auch aus seiner persönlichen Haltung. Umgekehrt ist der Kontext seiner persönlichen Haltung sein Selbstvollzug als Redner: Er trägt seinen Logos an die Griechen vor. Darin erweist er sich als wahrhaftig und glaubwürdig.

70 S. dazu ausführlich Karadimas, Sextus Empiricus (vgl. Anm. 59).

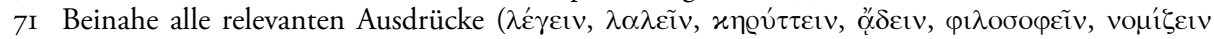
usw.) werden sowohl meliorativ, auf Tatian und die Christen bezogen, als auch pejorativ, auf die Vertreter der Gegenkultur bezogen, verwendet. Vgl. etwa die Selbstbezeichnung orat. 17,2 (35.IO) als „Herold der Wahrheit“ (

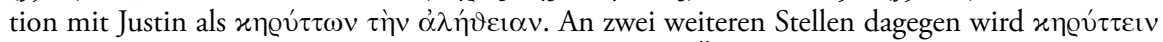

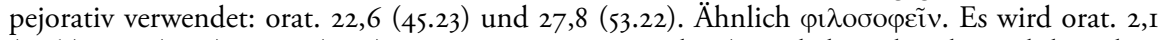
(9.I/5); 2,3 (9.20); 40,2 (72.6) u. ö. pejorativ verwendet (Was haben die alten Philosophen schon Würdiges von sich gegeben usw.?). Dagegen orat. 32,2 (60.5): „Bei uns philosophieren nicht nur die Schwerreichen;“ orat. 32,7 (61.26): „Alle die philosophieren wollen, lassen wir zu. “ Ähnlich $\lambda \alpha \lambda \varepsilon \tilde{\varepsilon} v$ : orat. 5,5 (I4.I6): „Ich rede $(\lambda \alpha \lambda \tilde{\omega})$, ihr hört zu.“ Dagegen ist orat. 22,4-7 (45) von schändlichen Lügen, dichterischen Vorträgen bzw. Gesängen (ớ $\delta \varepsilon เ v)$, anzüglichen Re$\operatorname{den}(\lambda \alpha \lambda \varepsilon \tilde{i} v)$, leeren Sophistereien und weiteren kulturellen Aktivitäten rhetorischer Art seitens der paganen „Griechen“ aufgelistet. Der Eindruck, dass es Tatian hier um die Auseinandersetzung mit einer durch und durch rhetorisierten Kultur geht, und zwar mit den Mitteln der Rhetorik selbst, wird so geradezu überwältigend.

72 Vgl. etwa Elze, Tatian (vgl. Anm. II), 25 zum Barbarenbegriff; Hanig, „Tatian und Justin“ (vgl. Anm. 19), 68f. zum Logosbegriff. 
mulieren, sondern an seinem Versuch, eine Rede zu halten, die die philosophischen Inhalte dieser Lehre mit Hilfe der rhetorisch gekonnt eingesetzten Begriffe möglichst effektiv aus dem Fühlen und Denken des Redners über seinen Mund in die Ohren, das Denken und das Fühlen seiner Hörer übertrug, um deren Leben von innen heraus neu formen zu helfen (vgl. orat. 5,5). Es ist anzunehmen, dass auch Tatian selbst den Wert seines $\lambda$ ó vouı) bemaß und weniger danach, ob er sich treu in den Bahnen der sich gerade entwickelnden frühchristlichen Christologie und Trinitätslehre bewegte. ${ }^{73}$

73 Interessant übrigens dass noch ein Rezipient wie Eusebius ähnlich dachte; s. oben Anm. 2. 


\section{Literaturverzeichnis}

Andresen (1978): C. Andresen, „Antike und Christentum, “ in: TRE 3, 50-99. Behr (1986): Ch. A. Behr, P. Aelius Aristides. The Complete Works. Vol. I, Leiden.

Brox (I996): N. Brox, Terminologisches zur frühchristlichen Rede von Gott, SBAW.PH, München.

Di Cristina (1977): S. Di Cristina, „L'idea di $\Delta$ v́vouıৎ nel De Mundo e nell'Oratio ad Graecos di Taziano," in: Aug. 17, 485-504.

Di Cristina (199I): S. Di Cristina, Taziano il Siro. Discorso ai Greci, Rom.

Dünzl (200o): F. Dünzl, Pneuma. Funktionen des theologischen Begriffs in frühchristlicher Literatur, Münster.

Edwards (1999): M. Edwards u.a. (Hgg.), Apologetics in the Roman Empire. Pagans, Jews and Christians, Oxford.

Edwards (2009): M. Edwards, Catholicity and Heresy in the Early Church, Farnham.

Elze (1960): M. Elze, Tatian und seine Theologie, Göttingen.

Fiedrowicz (2006): M. Fiedrowicz, Apologie im frühen Christentum. Die Kontroverse um den christlichen Wahrheitsanspruch in den ersten Jahrhunderten, Paderborn.

Geffcken (1907): J. Geffcken, Zwei griechische Apologeten, Leipzig / Berlin.

Gesner (I546): C. Gesner, ... Tatiani Assyrii, Iustini martyris discipuli, Oratio contra Graecos, Zürich.

Grant (1958): R. M. Grant, „Studies in the Apologists“, in: HTR 5I, I23-I34.

Grant (1964): R. M. Grant, „Tatian (Or. 30) and the Gnostics,“ in: JTS 15, 65-69.

Harris (1923): J. R. Harris, „Athena, Sophia and the Logos," in: BJRL 7, 55-72.

Hanig (1999): R. Hanig, „Tatian und Justin. Ein Vergleich, “ in: VigChr 53, 3I-73.

Harnack (1884): A. Harnack, Tatians Rede an die Griechen, Giessen.

Harnack (1902): A. Harnack, Die Mission und Ausbreitung des Christentums in den ersten drei Jahrhunderten, Leipzig.

Heiler (1909): K. L. Heiler, De Tatiani Apologetae Dicendi Genere, Marburg.

Hunt (2003): E. Hunt, Christianity in the Second Century. The Case of Tatian, London.

Karadimas (1996): D. Karadimas, Sextus Empiricus Against Aelius Aristides. The Conflict Between Philosophy and Rhetoric in the Second Century A. D., Lund.

Karadimas (2003): D. Karadimas, Tatian's Oratio ad Graecos: Rhetoric and Philosophy/Theology, Stockholm.

Kukula (1900): R. Kukula, Tatians sogenannte Apologie. Exegetisch-Chronologische Studie, Leipzig.

Kukula (1913): R. Kukula, „Tatians Rede an die Bekenner des Griechentums,“ in: Frühchristliche Apologeten und Märtyrerakten, Bd. I (= BKV I2), München, I77-257. 
Lössl (20Iо): J. Lössl, „Hermeneutics and Doctrine of God in Tatian’s Ad Graecos, " in: Studia Patristica (im Druck).

Maran (1742): P. Maran, Tatiani Oratio adversus Graecos, Paris.

Marcovich (1995) M. Marcovich, Tatiani Oratio ad Graecos, Berlin.

McGehee (1993): M. McGehee, "Why Tatian Never ,Apologized' To the Greeks,“ in: JECS $\mathrm{I}, \mathrm{I} 43-\mathrm{I} 58$.

Morel (I6I5): F. Morel, ... Tatiani Assyrii Oratio adversus Graecos, Paris.

Nesselrath (2005): H.-G. Nesselrath, „Il testo di Taziano, Oratio ad Graecos, e due recenti edizioni," in: Eikasmos 15, 243-263.

Neymeyr (1989): U. Neymeyr, Die christlichen Lehrer im zweiten Jahrhundert, Leiden.

Osborne (1969): A.E. Osborne, Tatian: A Literary Analysis and Essay in Interpretation, Diss., Cincinnati.

Otto (1851): J. K. Th. Otto, Tatiani Oratio ad Graecos, Jena.

Parvis (2007): P. Parvis, „Justin, Philosopher and Martyr, “in: S. Parvis u. P. Foster (Hgg.), Justin Martyr and His Worlds, Minneapolis, 22-37.

Ponschab (1894): B. Ponschab, Tatians Rede an die Griechen, Metten.

Pourkier (1992): A. Pourkier, L'hérésiologie chez Épiphane de Salamine, Paris.

Puech (19I2): A. Puech, Les apologistes grecs du IIe siècle de notre ère, Paris.

Saïd (2008): S. Said, „Aristides' Uses of Myths,“ in: W.V. Harris u. B. Holmes (Hgg.), Aelius Aristides Between Greece, Rome, and the Gods, Leiden / Boston, $5 \mathrm{I}-67$.

Schwartz (1888): E. Schwartz, Tatiani Oratio ad Graecos, Leipzig.

Stählin, in HAW 7.2.2 $\$ 953$.

Whittaker (1982): M. Whittaker, Tatian: Oratio ad Graecos and Fragments, Oxford.

Worth (I700): W. Worth, Tatiani Oratio ad Graecos, Oxford. 



\section{Süße Lust des Logos}

\section{Die Vorrede zum Protreptikos des Clemens von Alexandrien und die prolaliai der Zweiten Sophistik}

\section{ThOMAS LeCHNER}

Der Protreptikos des Clemens von Alexandrien wurde im Vergleich zu seinen literarischen Brüdern, dem Paidagogos und den Stromateis, als eigenständiges Werk in der Forschungsgeschichte weitgehend vernachlässigt. Dies hat sich in den letzten Jahren geändert. Seit der Edition von Marcovic (1995) sind immerhin eine kommentierte Übersetzung ins Italienische (2004), eine Edition mit kommentierter Übersetzung ins Spanische (2008) und ein umfangreicher Kommentar in englischer Sprache (2008) erschienen. ${ }^{\mathrm{I}}$ Zur rhetorischen und philosophischen Struktur des Protreptikos liegt seit 2007 eine ausführliche Analyse vor. ${ }^{2}$ Außerdem wird zur Zeit ein weiterer Kommentar für die Reihe KfA vorbereitet. Was bislang fehlt, ist eine präzise Einordnung des Protreptikos in den kulturgeschichtlichen Kontext der Zweiten Sophistik. Da die Zweite Sophistik als kulturelles Phänomen die entscheidende Konstante christlicher Mission in den ersten drei Jahrhunderten darstellt, sollte eine Werbeschrift, die sich an gebildete Griechen richtet, gerade unter diesem Aspekt gelesen und interpretiert werden. Die vorliegende Studie versucht, mit einer exemplarischen Analyse der Vorrede zum Protreptikos christliche Werbung kulturgeschichtlich einzuordnen und die Position des Clemens in der Welt der Zweiten Sophistik näher zu bestimmen. ${ }^{3}$

Die Forschungsbedingungen sind in diesem Fall äußerst günstig, da Clemens in seiner Vorrede zum Protreptikos auf ein rhetorisches Modell zurückgreift, das für die Zweite Sophistik geradezu charakteristisch ist: die sophistische Vorrede oder prolalia. ${ }^{4}$ Solche prolaliai zählen zu den rhetorischen Innovationen der

\footnotetext{
Migliore 2004; Merino Rodríguez 2008; Herrero de Jáuregui 2008.

2 Lechner 2007. Insgesamt kann der rhetorische Aufbau des Protreptikos folgendermaßen beschrieben werden: prolalia $(\mathrm{I}, \mathrm{I}-2,4)$ - exordium $(3, \mathrm{I}-5,4)$ - narratio $(6, \mathrm{I}-\mathrm{IO}, \mathrm{I})$ - propositio (IO,2-3) - argumentatio (II,I-II7,5) - peroratio (II8,I-I23,2); vgl. dazu Lechner 2007, I96-22I. Zur philosophischen Struktur vgl. unten den Abschnitt 4.7. Intertextuelle Steuerzeichen.

$3 \mathrm{Zu}$ den Einleitungsparagraphen des Protreptikos gibt es bereits einige Studien, in denen aber dieser Aspekt nicht behandelt wird; vgl. Brigham 1962, 9-13; Irwin 1982, 51-62; Halton 1983, 177-199, Cosgrove 2006, 255-282.

4 Zur prolalia bzw. lalia vgl. Amato 2009; Anderson 1977 und 1993, 53-55; Billault 2006; Betz 2004, 222-225; Bompaire 1958, 286-289; Bost Pouderon 2006, 229-263; Branham 1989, 38-46;
} 
Zweiten Sophistik und sind für die öffentlichen Auftritte der Sophisten durch Philostrat gut belegt. ${ }^{5}$ Die Identifizierung der Vorrede des Clemens als prolalia ist Marco Rizzi zu verdanken, der die einleitenden Paragraphen des Protreptikos mit dem Kapitel über die lalia im rhetorischen Handbuch des Menander verglichen hat und zu einem eindeutigen Ergebnis kam. ${ }^{6}$ Der Vergleich mit dem Lehrbuchwissen späterer Zeit kann allerdings nur belegen, dass Clemens sein rhetorisches Handwerk beherrschte, nicht aber, ob seine prolalia tatsächlich den Zeitgeschmack der pepaideumenoi getroffen hat. Da aber zahlreiche Vorreden von Dion, Lukian und Apuleius überliefert sind, besteht die Möglichkeit, die prolalia des Clemens tatsächlich mit authentischen Texten zu vergleichen und in der realen Vortragskultur der Zweiten Sophistik zu verorten. Im Gegenzug könnten sich auch für die Erforschung der sophistischen Prolalien ${ }^{7}$ neue Erkenntnisse ergeben, weil der Text des Clemens noch nie in entsprechende Untersuchungen einbezogen wurde und als christliche Variante für die Gattungsanalyse höchst aufschlussreich sein dürfte.

Aus diesen skizzenhaften Bemerkungen ergibt sich folgende Vorgehensweise: Zunächst wird die prolalia als Gattung definiert und in ihrer rhetorischen Funktion beschrieben. Mit der anschließenden Charakterisierung der prolalia als süßer Lust des Logos wird der Titel der Studie aufgegriffen und erläutert. Es folgt der griechische Text der prolalia (Protr. I,I-2,4) mit einer deutscher Übersetzung, die sich weitgehend an Stählin orientiert. Anschließend wird die Analyse von Marco Rizzi in einer tabellarischen Übersicht zusammengefasst und teilweise ergänzt. Nach diesen Vorarbeiten kann schließlich die Vorrede des Clemens mit den erhaltenen Prolalien der Zweiten Sophistik verglichen werden.

\section{Definition, Funktion und Charakter der $\pi \varrho \circ \lambda \alpha \lambda \iota \alpha ́$}

\section{I.I. Begriff und Definition der Prolalia}

Die $\pi \varrho \circ \lambda \alpha \lambda \iota \alpha$, eine informelle Vorrede vor dem eigentlichen Hauptvortrag, die

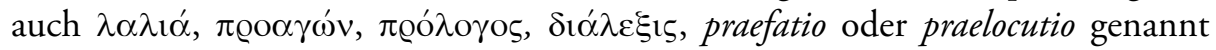
werden $\mathrm{kann}^{8}$, ist eine typische Form sophistischer Redepraxis und zugleich eine

Georgiadou / Larmour 1995; Harrison 2000, I33; Hunink 200I, I4-I5; Klauck 2000, I63-165; La Rocca 2005, 25-34; Mras I949a und 1949b; Nesselrath 1990; Pernot 1993, 546-568; Pernot I994, II4; Pohl/Schirren 200I; Reardon 1971, 165-I67; Russell 1983, 77-79; Sandy 1997, 156-I7I; Steinmetz 1982, I92-202; Stock I9II; Volkmann 1963, 360-36I; Zweimüller 2008, 67-78.

5 Vgl. Pernot 1993, 553-554.

6 Rizzi 1993, I7I-I88.

7 Diese deutsche Version für prolaliai benutze ich in Anlehnung an die französische Pluralform, die Pernot verwendet hat (les prolalies; vgl. z. B. Pernot 1993, 550).

$8 \mathrm{Zu}$ den einzelnen Begriffen vgl. Pernot 1993, 558-559, und Pohl/Schirren 200I, 23-24. 
rhetorische Innovation ${ }^{9}$, da solche Prolalien vor der Zeit der Zweiten Sophistik nicht nachzuweisen sind. Die ersten Texte, die man als Prolalien bezeichnen kann, findet man bei Dion von Prusa, die erste theoretische Darstellung in dem rhetorischen Handbuch des Menander. ${ }^{10}$ Menander verwendet allerdings nur den Begriff $\lambda \alpha \lambda ı \alpha$ und charakterisiert damit sowohl eigenständige Vorträge als auch typische Vorreden. ${ }^{\text {II }} \mathrm{Ob}$ der Begriff der $\pi \varrho 0 \lambda \alpha \lambda$ เó tatsächlich schon im 2. Jahrhundert als terminus technicus existierte, ist umstritten. ${ }^{\text {I2}}$ Philostrat verwendet in seinen Sophistenbiographien den Begriff $\delta \iota^{\prime} \alpha \varepsilon \xi 1 \varsigma$, um die Prolalien sophistischer Starredner wie Polemon, Alexander Pelopaton, Herodes Atticus oder Philagros zu beschreiben. ${ }^{13}$ Dieser Begriff dürfte im 2. Jahrhundert für Prolalien durchaus verwendet worden sein, er ist aber keineswegs eindeutig, da beispielsweise auch philosophische Texte wie die Vorträge des Maximus von Tyrus als dialexeis bezeichnet werden. ${ }^{\mathrm{I}}{ }^{\mathrm{U}} \mathrm{Um}$ Verwechslungen auszuschließen, verwendet man gewöhnlich den Begriff prolalia, zumal Menander den Begriff $\lambda \alpha \lambda \iota \alpha$ und nicht $\delta \iota^{\alpha} \lambda \varepsilon \xi \xi_{1 \zeta}$ verwendet, um sophistische Vorreden terminologisch einzuordnen. ${ }^{15}$ Für weitere Überlegungen erscheint es hilfreich, von einer Definition auszugehen, die Laurent Pernot vorgelegt hat:

Une prolalia est un petit discours qui sert de préambule à la lecture ou à la récitation, improvisée ou non, d'un discours ou d'une oeuvre quelconque; une lalia est un discours autonome, qui peut porter sur quelque sujet que ce soit. La première ressemble à un exorde, la seconde à différentes formes oratoires. Leur caractéristique commune, qui les distingue en principe de tous les autres discours, est d'être brèves, plaisantes, informelles. ${ }^{16}$

9 Zur Herkunft der Gattung vgl. Pernot 1993, 557-558.

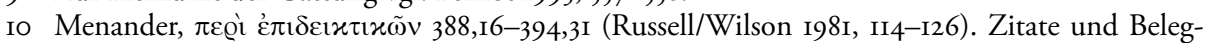
stellen aus diesem Handbuch werden z. B. wie folgt abgekürzt: Menander II, 388,I6-I8.

II Vgl. Menander II, 393,24-26, der an dieser Stelle davon spricht, dass eine lalia nicht zu lang sein sollte, außer der Redner habe vor, sie ist als autonomen Vortrag ( $\dot{\varepsilon} \pi \hat{\imath} \delta \varepsilon 1 \xi 1 \varsigma)$ zu konzipieren; vgl. Pohl/Schirren 200I, 26.

I2 Vgl. Stock I9II, Io (mit Anm. 2). I8, und Nesselrath I990, III-II2, die darauf verweisen, dass der Begriff erst in den byzantinischen Handschriften von Lukians Hercules und Bacchus als

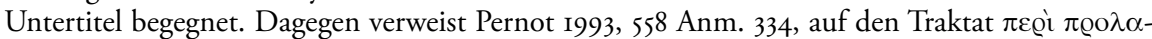
$\lambda 1 \tilde{\omega} v$ des Tiberios (3./4. Jh.) und stellt fest: „En réalité, le témoignage de la Souda sur Tibérios et celui des manuscrits de Lucien convergent pour laisser penser que le mot prolalia remonte à l'Antiquité." Hinzukommt, dass die lateinischen Übersetzungen praefatio und praelocutio den Begriff prolalia eigentlich voraussetzen; vgl. Pohl/Schirren 200I, 26. Praefatio findet sich sinngemäß als Übersetzung von prolalia bei Apuleius, Flor. I; vgl. Pernot 1993, 55I.

I3 Vgl. Pernot 1993, 553-554, der eine vollständige Liste aller Sophisten bietet, die nach Philostrat Prolalien gehalten haben.

I4 Ein Zusammenhang zwischen diesen philosophischen Essays und den laliai der Sophisten ist freilich nicht auszuschließen. Trapp 1997, XL-XLI, sieht sogar einen direkten Zusammenhang; vgl. dazu auch Russell 1983,78 . Zu weiteren als dialexeis charakterisierten Texten vgl. Pernot I993, 559 mit Anm. 335.

I5 Vgl. Nesselrath 1990, II2-II3.

I6 Pernot 1993, 546. 
Demnach erinnert die prolalia an ein exordium, wobei die Gemeinsamkeit mit der autonomen lalia darin besteht, dass beide Varianten eine gemeinsame Charakteristik aufweisen, die nicht durch inhaltliche Vorgaben bestimmt ist, sondern durch strukturelle und funktionale Kriterien: Die (pro)lalia muss vergleichsweise kurz, unterhaltsam und informell sein. Diese Beobachtungen führen zu der Frage, weshalb in der Zweiten Sophistik das exordium durch eine unterhaltsame Vorrede funktional ersetzt bzw. erweitert wurde.

\section{I.2. Zur Funktion der Prolalia in der Zweiten Sophistik}

Prolalien konnten, wie schon die Definition von Pernot verdeutlichte, den unterschiedlichsten Vorträgen vorangehen. Die von Philostrat beschriebene Praxis der Sophisten, eine prolalia der folgenden - mehr oder weniger improvisierten - Deklamation $(\mu \varepsilon \lambda \varepsilon \dot{\tau} \tau)$ voranzustellen ${ }^{17}$, ist für die funktionale Bestimmung der Vorrede aber von besonderem Interesse. Der Themenkatalog der Deklamationen war relativ genau festgelegt ${ }^{18}$, weshalb sich die Konzertredner der Zweiten Sophistik innerhalb des Hauptvortrags vor allem darauf konzentrieren mußten, in perfektem attizistischem Griechisch, die konventionellen Themen geistreich und geistesgegenwärtig zu präsentieren. Die Beurteilung der Sprachkompetenz eines Redners war wiederum vom linguistischen Diskurs der Zweiten Sophistik abhängig und nicht immer eindeutig geregelt. Insofern konnte man während des Hauptvortrags eigentlich nur Fehler machen. ${ }^{19}$ Hinzu kam, dass prinzipiell jeder Sophist mit jedem anderen Sophisten verglichen werden konnte, da alle über dieselben Themen sprachen und in denselben Städten auftraten. ${ }^{20}$ Der Auftritt der Konzertredner war also immer mit der Gefahr verbunden, grandios zu scheitern:

Es dürfte evident sein, ein wie schwieriges, ja geradezu unmögliches Unterfangen es war, aus dem Stegreif eine Rede in der attizistischen Kunstsprache zu improvisieren, dabei die historische Situation im Auge zu behalten, das Ethos des Spre-

I7 Zum Improvisieren der Reden vgl. Schmitz 1997, I56-I59.

I8 Vgl. dazu Bowie 2004, 70-72. 82-83. Die Begrenztheit der Themen wird auch durch den Vortrag des Redelehrers in Lukians Rhetorum praeceptor parodiert: „Füge zu jedem Thema Marathon und Kynegeiros hinzu, ohne die überhaupt nichts geht. Auch soll jedes Mal der Athos durchsegelt, der Hellespont zu Fuß überschritten werden, die Sonne sich wegen der Medergeschoße verfinstern, Xerxes fliehen und Leonidas bewundert werden, die Inschrift von Othryadas vorgelesen werden, und auf Salamis, Artemision, Plataiai musst du oft und in dichter Abfolge anspielen“. (Rh.pr. I8, Übers. Zweimüller 2008, I63); vgl. dazu den Kommentar von Zweimüller 2008, 345-359.

I9 Vgl. Schmitz 1997, II5-I27.

20 Zum Wettbewerbscharakter der Vorträge und den anschließenden Debatten vgl. Schmitz 1997, IIO-I27. 
chers zu beachten, und dies alles vor den aufmerksamen Ohren eines großen

Publikums, in dem oft missgünstige und sehr sachkundige Konkurrenten saßen. ${ }^{21}$

Um sein persönliches Risiko zu minimieren, musste der Redner von Anfang an alles daran setzten, das Publikum zu kontrollieren. ${ }^{22}$ Diesem Ziel diente in besonderer Weise die Vorrede, die im Gegensatz zum klassischen exordium mehr Möglichkeiten bot, den Redner mit dem Publikum in Kontakt zu bringen, und zwar auch deshalb, weil die prolalia keine inhaltliche Verbindung zum nachfolgenden Hauptvortrag aufweisen musste. ${ }^{23}$ Die freie, themenunabhängige Gestaltung der Vorrede war für die meisten Auftritte der Sophisten allein schon deshalb geboten, weil erst nach der prolalia das Publikum dem Redner Themenvorschläge für die Deklamation unterbreitete, also eine thematische Hinführung sinnlos gewesen wäre. ${ }^{24}$ Damit ist aber der Hauptzweck der Vorrede darin zu sehen, dass sich der Redner - wie dies Nesselrath formulierte - so gut wie möglich verkaufte ${ }^{25}$, weshalb die in den Prolalien vorgetragenen Erzählungen, Beschreibungen, Vergleiche, Sprichwörter, Witze, literarischen und kunstgeschichtlichen Anspielungen, Fabeln oder Anekdoten in der Regel keine andere Bedeutung hatten als den Redner möglichst eloquent und gebildet erscheinen zu lassen. ${ }^{26}$ Eine gelungene Vorrede erzielte aber auch den synergetischen Effekt, dass die Kritikfähigkeit des Publikums reduziert wurde: soziale Kontrolle durch entertainment - eine wohl zu allen Zeiten funktionierende Strategie. Um den zwanglosen und informellen Charakter der prolalia zu betonen, blieb der Redner während der Vorrede zunächst sitzen und erhob sich erst für den Hauptvortrag. ${ }^{27}$ Manche Sophisten hat-

2I Schmitz 1997, II5-II6.

$22 \mathrm{Vgl}$. Anderson 1989, 92: „Having assembled his audience, the speaker had to control them. The preamble or prolalia was a matter for special skill calling for a concentration of nerve, often in unfamiliar circumstances before an untried audience; for wit, to put the audience at their ease; and for self-confidence, if not actual arrogance." Zur Zusammensetzung und Bildung des Publikums vgl. Korenjak 2000, 4I-65.

23 Die Vorreden des Dion von Prusa lassen erkennen, dass sich die prolalia aus dem exordium enwickelt hat, da beispielsweise die prolalia des Olympikos (Or. I2) noch in inhaltlichem Zusammenhang mit der nachfolgenden Rede steht; vgl. Klauck 2000, I65.

24 Zum Ablauf solcher Auftritte vgl. Anderson I989, 89-99, und 1993, 53-68; Korenjak 2000, 3338; Russell I983, 74-86; Schmitz I997, I97-209, der auch die inschriftlich belegten diplomatischen Missionen der Sophisten schildert, und Whitmarsh 2005, 23-40.

25 Nesselrath I990, II2: „For such performers it mattered less what they would say than how they would say it; hitherto, the aim of an orator was to sell people a certain political course or a certain judgement in law case - now, one would simply want to sell oneself."

26 Vgl. Nesselrath I990, II2: „Therefore it was paramount to come across as being intelligent, educated, and eloquent from the very first moment; and it was under these circumstances that introductory chapters tended to gain importance and take on a life of their own."

27 Sehr anschaulich beschreibt Aelius Aristides in den Heiligen Berichten einen seiner Vorträge in Smyrna: „Obwohl nun mein Auftreten so kurzerhand zustandekam und die große Menge nichts davon wußte, füllte sich trotzdem der Rathaussaal dermaßen an, dass man nur Köpfe von Menschen sehen konnte und nicht einmal die Hand hätte irgendwo dazwischenstecken können. Und wahrhaftig, die Äußerungen des Beifalls und des Wohlwollens, oder vielmehr, 
ten aber schon nach ihrer Vorrede beim Publikum verspielt ${ }^{28}$, andere überzeugten nur durch ihre Prolalien. ${ }^{29}$ Im Idealfall hatte der Redner durch eine gelungene Vorrede das Publikum für sich gewonnen ${ }^{30}$ und seine Nervosität beruhigt - immerhin verglich Polemon den Zustand eines Sophisten vor der Deklamation mit der angsterfüllten Anspannung eines Gladiators vor dem Kampf in der Arena. ${ }^{3 \mathrm{I}}$ Eindeutiges Ziel der prolalia war es also, die Zuhörer intelligent zu unterhalten, um eine ungezwungene und unbelastete Atmosphäre für den sich anschließenden Hauptvortrag zu erzeugen. Es wurde bereits weiter oben darauf hingewiesen, dass die Redner der Zweiten Sophistik indirekt auch immer miteinander konkurrierten. Als Symbolfiguren einer Kultur, die den Wettkampf als einziges Prinzip gesellschaftlicher Distinktion akzeptierte, mussten sie zwangsläufig den agonalen Charakter griechischer Identität verkörpern. ${ }^{32}$ Thomas Schmitz hat überzeugend nachgewiesen, dass das Phänomen der Zweiten Sophistik ohne den Wettbewerbsgedanken und das elitäre Bildungskonzept, das der Machtreproduktion der Oberschicht diente, nur unzureichend verstanden werden kann. ${ }^{33}$ Insofern lassen sich dem Verhalten der Starredner auf der Bühne, die ja in paradigmatischer Weise als pepaideumenoi und damit als Repräsentanten der städtischen Eliten galten, alle relevanten Strategien ablesen, die bewusst oder unbewusst Mitglieder der Oberschicht verfolgten, um ihr Bedürfnis nach philotimia und philonikia zu befriedigen. ${ }^{34}$ Die in diesem Zusammenhang von Schmitz äußerst gewinnbringend

wenn ich die Wahrheit sagen soll, der Begeisterung wurden von allen Seiten so stürmisch, dass man keinen sitzenbleiben sah, weder bei der Einleitung, noch als ich mich zum eigentlichen

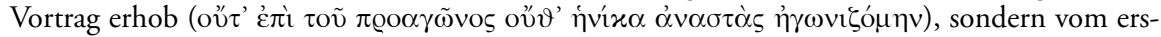
ten Wort an standen sie, ängstigten sich, freuten sich, schraken zusammen, nickten meinen Worten zu und ließen Zurufe ertönen, die zuvor noch nie gehört worden waren" (HL, V,32-33, Übers. Schröder 1986, I32); vgl. dazu Russell 1983, 76-77, dem ich den Hinweis auf diesen Text verdanke. Vgl. auch VS 572, wo Philostrat eine Rede des Alexander in Athen schildert und bemerkt, Alexander sei nach dem Themenvorschlag und einer kurzen Bedenkzeit mit strahlendem Gesicht vom Sitz aufgesprungen, so als ob er seinen Zuhörern nun erfreuliche Nachrichten mitzuteilen hätte; außerdem Philostrat, VS 519, zu Skopelian, der seine Vorreden $\alpha \dot{\pi} \mathrm{ò} \mu \grave{\varepsilon} v$

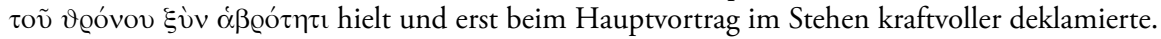

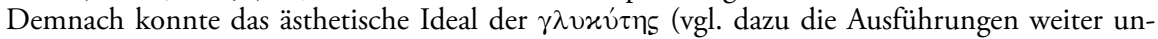
ten) nicht nur die Textgestaltung der Vorrede, sondern auch die Modulation der Stimme während der prolalia prägen.

28 Bekannt ist das Beispiel des Philagros von Kilikien, der in seiner Vorrede ein Enkomion auf die Athener durch eine Klagerede auf seine in Ionien verstorbene Frau unterbrach, weshalb seine prolalia von den Athenern als kindisch ( $\mu \varepsilon 1 \varrho \alpha x \iota \omega \delta \eta \varsigma)$ beurteilt wurde; vgl. Philostrat, VS 579.

29 Vgl. Pernot 1993, 562.

30 Die Ausdrucksmöglichkeiten des Publikums waren durchaus vielfältig, wenn es darum ging, Zustimmung oder Ablehnung zu signalisieren; vgl. dazu das kleine Lexikon zur Sprache des Publikums bei Korenjak 2000, 68-95.

3I Vgl. Philostrat, VS 54I. Zur emotionalen Aufgeladenheit sophistischer Auftritte vgl. Korenjak 2000, 96-II4.

32 Vgl. Whitmarsh 2005, 37-40.

33 Vgl. Schmitz 1997 und Whitmarsh 2005, 38-39.

34 Vgl. dazu Schmitz 1997, 97-I35. 
eingesetzte Terminologie des französischen Soziologen Bourdieu verdeutlicht, worum es geht: einerseits um gesellschaftliche Distinktion und die Vorrangstellung innerhalb der städtischen Eliten, andererseits um die Sicherung von Macht durch den Zugewinn von symbolischem Kapital, das durch Bildung erworben und durch die Inszenierung von Bildung konsolidiert und vermehrt wird. ${ }^{35}$ Ein wesentlicher Zweck der prolalia bestand deshalb darin, den allgemeinen gesellschaftlichen Diskurs über Bildung zu inszenieren und die individuelle Rolle des Redners innerhalb der Bildungskultur der Zweiten Sophistik zu thematisieren. Dies gelang vor allem durch die Technik der Selbstreferenz, d. h. durch die Übertragung der in der prolalia entwickelten Themen und Motive auf die eigene Person, wodurch der Redner wiederum seine persona fingierte und gewissermaßen als der wahre Held seiner Geschichten erschien. ${ }^{36}$ Öffentliche Kritik an Kollegen gehörte in diesem Zusammenhang ebenso dazu ${ }^{37}$ wie die bewusste Stilisierung der äußeren Erscheinung. In der performance culture der Zweiten Sophistik musste ein Redner nicht nur rhetorisch brilliant sein, sondern auch durch seine äußere Aufmachung beeindrucken, dem zeitgenössischen Männlichkeitsideal entsprechen $^{38}$ und physiognomisch überzeugen ${ }^{39}$. Dass sich die Sophisten tatsächlich mit derartigen Strategien beschäftigt haben, wird durch die neue Edition eines physiognomischen Handbuches belegt, das der Sophist Polemon verfasst hat. ${ }^{40}$ Die Stilisierung der physischen Erscheinung bildete demnach zusammen mit der selbstre-

35 Vgl. Schmitz 1997, 26-31. 193-234.

36 Billault 2006, 59, hat die selbstreferentiellen Bildbeschreibungen in Lukians Prolalien als „fragments of an autobiographical novel" charakterisiert, die Lukian als Romanhelden zeigen. Man muss dieser Einschätzung nicht uneingeschränkt zustimmen, richtig ist jedoch, dass in der Gestaltung der persona autobiographische und fiktionale Elemente zusammenfließen. So auch Hunink 2004, I75-I87, der die Selbstdarstellung des Apuleius in den Florida folgendermaßen zusammenfasst: „Finally, and perhaps most importantly, apart from presenting himself as a religious, widely-travelled and well-educated author of first class Greek and Latin poetry and prose in many genres, the ,I' also pictures himself as a V.I.P. who remains loyal to his African cultural background and even brings home some cultural prestige to his native land" (S. I82).

37 Vgl. z. B. die Kritik des Athenodorus an Pollux (VS 594-595) und des Apollonius von Naukratis an Herakleides (VS 6I5), sowie die wohl kürzeste prolalia der Zweiten Sophistik, die als Kritik des Antiochus am aufgeblasenen Stil des Alexander, aber auch generell an den thematisch stereotypen Prolalien anderer Sophisten aufzufassen ist: „Immer wieder Ionien, immer wieder Lydien, immer wieder Marsyas, immer wieder Torheiten, gebt mir Themenvorschläge!" (VS

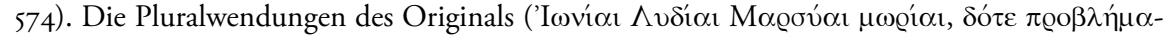
$\tau \alpha)$ sind im Deutschen nicht exakt wiederzugeben.

$38 \mathrm{Zu}$ diesem speziellen Aspekt vgl. Gleason 1995. Die Tatsache, dass ein Mann wie Favorinus in diesem System Karriere machen konnte, wird von Gleason als eine Ausnahme bewertet, die letztlich die Regel bestätigt (vgl. hierzu S. 162).

39 Vgl. Whitmarsh 2005, 26-32.

40 Vgl. dazu Swain 2007, I25-20I, und die neue Edition des arabischen Textes mit englischer Übersetzung von Hoyland (Swain 2007, 329-463). Auf die Bedeutung physiognomischer Kenntnisse für die antike Welt hatte schon Gleason (1995) hingewiesen und die Fähigkeit zur Analyse von Gesichtern als „essential survival skill“ (S. 55) bezeichnet. 
ferentiellen Technik der prolalia eine wirksame Möglichkeit die persona des Redners eindrucksvoll zu gestalten. ${ }^{41}$ Dies um so mehr als der Redner in der Vorrede keine historische Rolle spielen mußte wie in der $\mu \varepsilon \lambda \varepsilon \dot{\tau} \tau$, sondern sich durch autobiographische Erzählungen, Danksagungen für Ehreninschriften oder Reflexionen über die eigene künstlerische Arbeit ganz auf sich selbst konzentrieren konnte. Die Prolalien von Lukian, Dion und Apuleius sind, wie wir noch sehen werden, Paradebeispiele für die selbstreferentielle Technik der Sophisten. Bekannt ist auch das Beispiel des Marcus von Byzanz, der in seiner prolalia mit der Beschreibung eines Regenbogens das rhetorische Ideal der $\pi$ oux $\lambda \lambda_{i \alpha} \alpha$ visualisierte und damit nichts anderes als seine eigene Rhetorik zum Thema machte. ${ }^{42} \mathrm{Da}$ die Möglichkeiten nahezu unerschöpflich waren, im freien Vortrag der prolalia Bildungswissen unter Beweis zu stellen und gewissermaßen mit symbolischem Kapital zu prunken, war die Vorrede vorzüglich geeignet, die Sophisten als Mitglieder der städtischen Eliten machtvoll zu positionieren, und dies gewissermaßen mit einem Augenzwinkern, da Bildung als entertainment präsentiert wurde, wodurch die spielerische Überlegenheit der pepaideumenoi noch deutlicher hervortrat.

\section{I.3. Der Charakter der Prolalia - stilistische und inhaltliche Anforderungen}

Obwohl die formalen, stilistischen und inhaltlichen Vorgaben nicht strikt geregelt waren, gab es dennoch gewisse Kriterien, die den Charakter der Prolalien bestimmten. Die Forderung nach $\alpha \dot{\alpha} \varphi \hat{\imath} \lambda \varepsilon \imath \alpha$ beschreibt die Stilanforderung der prolalia, d.h. der Stil sollte einfach, schlicht und ungekünstelt sein. ${ }^{43}$ Dem entspricht die Charakterisierung der prolalia als ein „in lockerem Plauderton“ gehaltener Vortrag, der „keinem strengen Aufbauschema“ folgt bzw. diesen Eindruck erwecken will. ${ }^{44}$ Denn in Wirklichkeit sind die uns erhaltenen Prolalien sorgfältig komponiert und bis ins Detail ausgearbeitet, um den hohen Ansprüchen des Publikums zu genügen. Inhaltlich erwarteten die Zuhörer in einer sophistischen Vorrede exotische und paradoxe Geschichten, mythologische Erzählungen, ethnographische Exkurse, literarische und philosophische Referenzen, Beschreibungen von Skulpturen, Bildern, Räumen, Menschen und Landschaften, Vergleiche mit Göttern, Tieren, Barbaren und anderen Sophisten, Reiseerlebnisse und An-

4I Dion verwendet z. B. in seinen Prolalien viel Zeit darauf, sein äußeres Erscheinungsbild zu interpretieren, wobei er häufig seine langen Haare zum Thema macht, um sich beim Publikum als Philosoph einzuführen (vgl. Or. I2,I5; Or. 35,2-3. II-I2; Or. 72,2); vgl. dazu Hahn 2009, 244-252.

42 Vgl. Philostrat, VS 528, und dazu die Interpretation von Pernot 1993, 565-566.

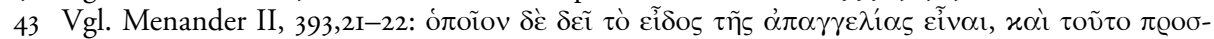

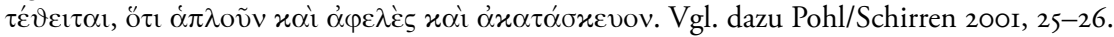

Beide Zitate aus Klauck 2000, I64. 
ekdoten, Schilderungen von musikalischen und sportlichen Wettkämpfen und dergleichen mehr, also eine bunte Sammlung unterhaltsamer Kurzbeiträge. ${ }^{45}$ Nach Menander zeichnen sich (Pro)lalien durch diese narrativen Elemente aus, denn gerade durch sie wird das Kriterium der $\gamma \lambda$ wesentliche Qualitätskriterium neben der $\alpha_{\varphi} \varphi \dot{c} \lambda \varepsilon 1 \alpha .{ }^{46}$ Die Gattungsmerkmale werden deshalb von Pernot kurz und präzise durch folgende Definitionen beschrieben: „Apheleia et glukutês restent les vertus essentielles du genre“ und „l' hêdonê est l'esthétique du genre“ ${ }^{47}$ Wollte man also das ästhetische Ideal der sophistischen prolalia auf eine griffige Formel bringen, so könnte man von der süßen Lust des Logos sprechen, also von der süßen Lust, die durch den Logos der Vorrede erzeugt wird. ${ }^{4}$

\section{Die Prolalia des Protreptikos - Text und Übersetzung}

(Clem. Alex., Protr. I,I-2,4)

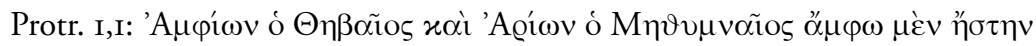

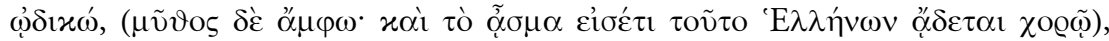

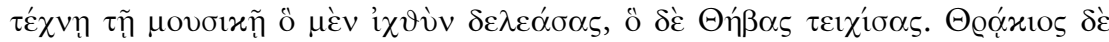

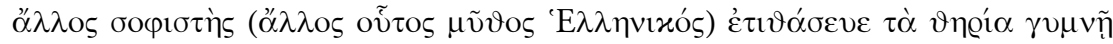

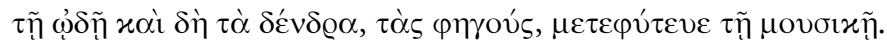

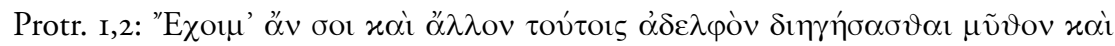

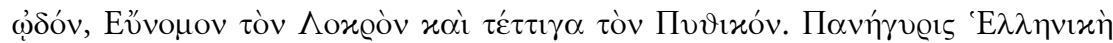

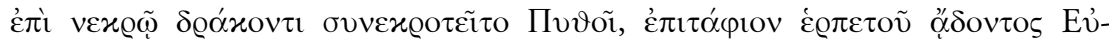

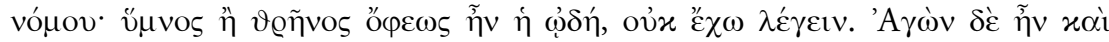

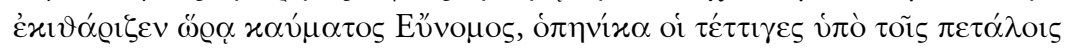

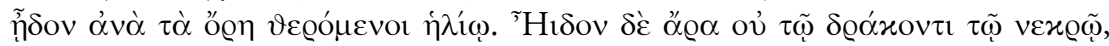

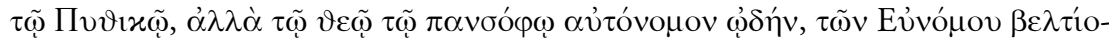

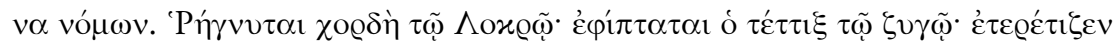

45 Vgl. schon die Definition von Volkmann 1963 (Nachdruck der 2. Aufl. von I885), 360: „Die $\lambda \alpha \lambda ı \alpha$ will ganz besonders ergötzen, sie liebt daher anmuthige Erzählungen und Schilderungen, geschickte Einkleidungen, geistreiche Wendungen, Sentenzen, Sprichwörter, Chrien, Dichtercitate. Die Form will frei und ungezwungen erscheinen, der Redner bindet sich daher an keine bestimmte, schulmässige Reihenfolge der Gesichtspunkte."

46 Vgl. Menander II, 389,9-393,I6. Der Begriff ist im Deutschen schwer wiederzugeben. Die Übersetzungen anderer Sprachen vermitteln einen besseren Eindruck von dem, was $\gamma \lambda u x v i \tau \eta\rceil$ meint, wie etwa sweetness, dolcessa, douceur.

47 Pernot $1993,564-565$.

48 Der Charakter der prolalia erinnert in dieser Hinsicht an das ästhetische Ideal der $\chi \alpha$ óøı wie es von Möllendorff (2006a) für einzelne Texte der Zweiten Sophistik (speziell Lukian) beschrieben hat. 


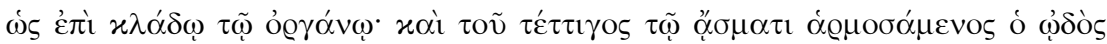

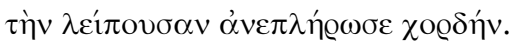

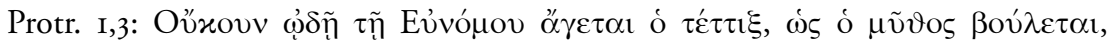

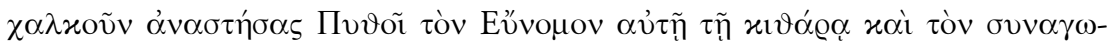

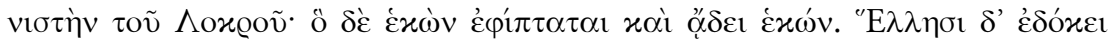

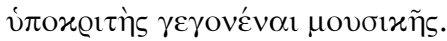

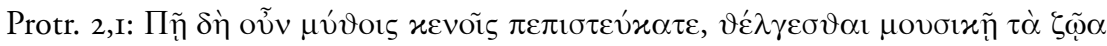

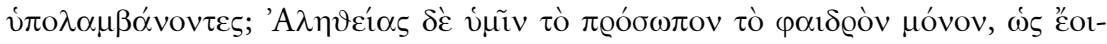

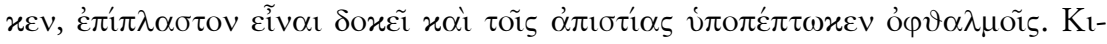

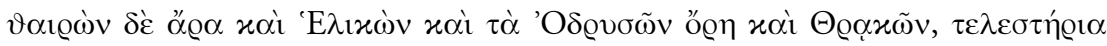

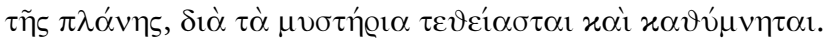

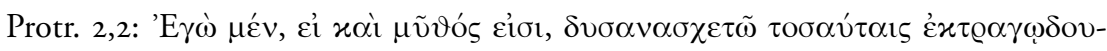

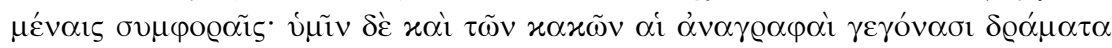

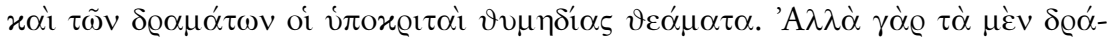

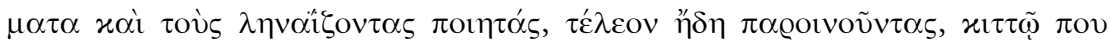

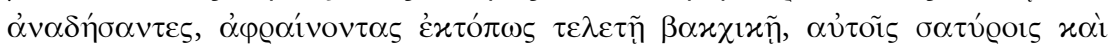

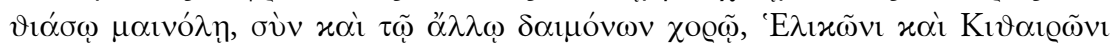

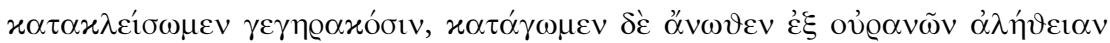

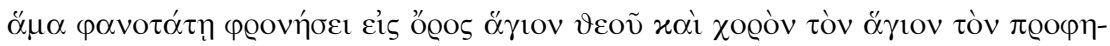

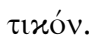

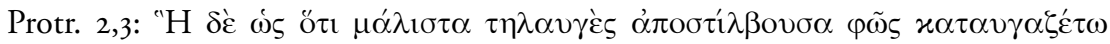

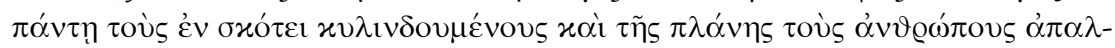

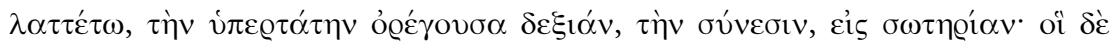

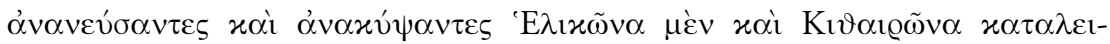

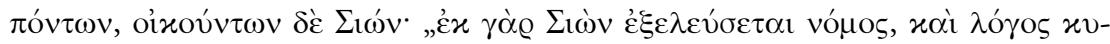

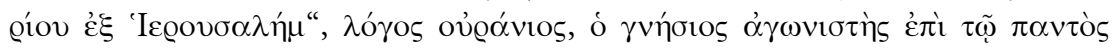

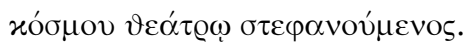

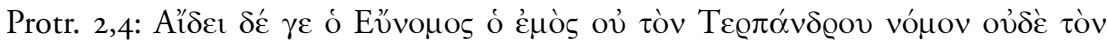

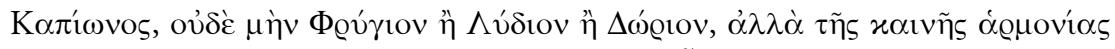

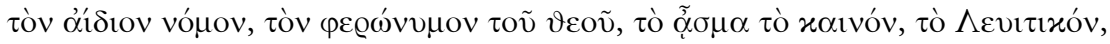

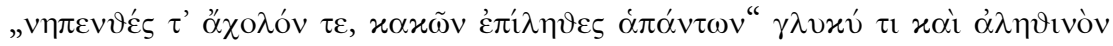

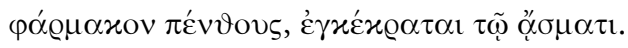

Protr. I,I: Amphion aus Theben und Arion aus Methymna waren beide Sänger, beide freilich nur in der Sagenwelt - aber noch jetzt wird das Lied von ihnen im Chor der Griechen gesungen; der eine lockte mit Musik einen Fisch herbei, der 
andere erbaute mit Musik die Mauern von Theben. Und ein anderer Freund der Künste, ein Thraker - das ist wiederum eine griechische Sage -, zähmte durch bloßen Gesang die wilden Tiere; ja sogar die Bäume, und zwar Eichen, verpflanzte er durch die Musik.

Protr. I,2: Ich kann dir auch noch eine weitere fabelhafte Geschichte erzählen, die den zuvor erwähnten verwandt ist, und von einem anderen Sänger berichten, dem Lokrer Eunomos und der pythischen Zikade. Ein griechisches Fest wurde zu Ehren des toten Drachen in Pytho gefeiert, und Eunomos sang das Grablied des Reptils; ob der Gesang ein Hymnus oder eine Totenklage auf die Schlange war, vermag ich nicht zu sagen; es war jedenfalls ein Wettkampf, und es spielte Eunomos die Kithara zur Zeit der größten Sommerhitze, als sich die Zikaden in den Bergen an der Sonne wärmten und unter den Blättern zirpten. Sie sangen aber gewiss nicht für den toten Drachen von Pytho, sondern für den allweisen Gott ihr eigenes Lied, das besser als die Melodien des Eunomos klang. Da reißt dem Lokrer eine Saite und die Zikade fliegt auf den Steg der Kithara: dann zirpte sie auf dem Musikinstrument wie auf einem Zweige; und indem sich der Sänger dem Gesang der Zikade harmonisch anpasste, ergänzte er die fehlende Saite.

Protr. I,3: Also nicht durch den Gesang des Eunomos wird die Zikade angelockt, wie es der Mythos will, der dafür sorgte, dass man in Pytho den Eunomos mit seiner Kithara und auch die Mitstreiterin des Lokrers in Bronze aufstellte. Vielmehr fliegt sie freiwillig herbei und singt freiwillig; den Griechen aber erscheint es so, als ob sie eine Konzert-Sängerin geworden sei.

Protr. 2,I: Warum habt ihr eigentlich an so hohle Märchen geglaubt, davon überzeugt, dass die Tiere durch Musik bezaubert werden? Allein das strahlend schöne Gesicht der Wahrheit haltet ihr, wie es scheint, für geschminkt, und so ist es ungläubigen Augen ausgesetzt. Der Kithairon, der Helikon, die odrysischen und thrakischen Berge, Weihestätten des Irrtums, werden aber wegen ihrer Mysterien vergöttert und in Hymnen besungen.

Protr. 2,2: Ich finde es unerträglich, auch wenn es nur Geschichten sind, dass so viele Unglücksfälle den Stoff für eure Tragödien liefern; euch sind die Aufzeichnungen furchtbarer Ereignisse zu Dramen geworden, und die Interpreten dieser Dramen bieten euch ein herzerfreuendes Schauspiel. Lasst uns doch die Dramen und die tobenden und taumelnden Dichter, die schon vollkommen vom Wein berauscht, mit Efeu bekränzt und durch die bakchischen Weiheriten außerordentlich unvernünftig geworden sind, mitsamt den Satyrn und dem rasenden Thiasos, und zusammen mit dem übrigen Chor der Dämonen auf dem Helikon und Kithairon einsperren, die selbst altersschwach geworden sind; lasst uns dagegen von oben aus dem Himmel die Wahrheit zusammen mit der überaus leuchtenden 
Weisheit auf den heiligen Berg Gottes herabführen und dazu den heiligen Chor der Propheten.

Protr. 2,3: Möge aber die Wahrheit, die wie ein ganz besonders leuchtendes Licht aufstrahlt, überall diejenigen erleuchten, welche sich in der Finsternis herumtreiben, und die Menschen vom Irrtum erlösen, indem sie ihnen ihre kraftvolle Rechte, nämlich die Einsicht, zur Rettung hinstrecke! Sie aber mögen aufblicken und in die Höhe schauen, den Helikon und Kithairon verlassen und den Zion bewohnen; denn vom Zion wird ausgehen das Gesetz, und das Wort des Herrn von Jerusalem, das himmlische Wort, der wahre Wettkämpfer, der auf der Bühne des Welttheaters den Siegeskranz erhält.

Protr. 2,4: Mein Eunomos singt freilich nicht im Stil des Terpandros und nicht in der Weise des Kapion, auch keine phrygische oder lydische oder dorische Melodie, sondern der neuen Tonart ewige Melodie, die von Gott ihren Namen hat, das neue Lied, das Lied der Leviten; ein süßes und wirksames Heilmittel gegen Leid, das Kummer und Zorn lindert und alle Übel vergessen lässt, ist diesem Liede beigemischt.

\section{Clemens Alexandrinus, Protr. I,I-2,4 und das rhetorische Modell des Menander}

\section{I. Die Analyse von Marco Rizzi}

Wie in der Einleitung schon erwähnt wurde, war Rizzi der erste Forscher, der den Anfang des Protreptikos als prolalia identifizierte, indem er den Abschnitt über die lalia aus dem rhetorischen Handbuch des Menander zum Vergleich heranzog. Da Rizzis Arbeit, die bislang unverständlicherweise kaum rezipiert wur$\mathrm{de}^{49}$, einen wichtigen Ausgangspunkt für die nachfolgenden Überlegungen darstellt, werden die Ergebnisse seiner Analyse nun in Form einer Tabelle wiedergegeben. In der linken Spalte sind die wichtigsten Vergleichspunkte angegeben, in der mittleren Spalte die Anweisungen Menanders in Paraphrase, in der rechten Spalte stichwortartig die Parallelen im Protreptikos, bzw. Kurzkommentare, falls es sich um strukturelle Fragen handelt.

49 Selbst Migliore (2004) ignoriert in seiner italienischen Ausgabe Rizzi. Bei Herrero de Jáuregui findet man die Arbeit zwar in der Bibliographie vermerkt, aber ohne Konsequenzen für die rhetorische Analyse des Protreptikos (vgl. Herrero de Jaúregui 2008, I4-I5). 
Vergleichspunkte

I. Themen \& Motive

I.I. Künstler ${ }^{50}$

I.2. Berge $^{53}$

I.3. Mysterien 55
Menander II, 388,I6-394,3I
Clem. Alex., Protr. I,I-2,4

$\begin{array}{ll}\text { I.I. Künstler }^{50} & \text { Der Redner soll Kitharaspieler } \\ \text { wie Orpheus, Arion und Am- } \\ \text { phion oder berühmte Flöten- } \\ \text { spieler und Propheten oder } \\ \begin{array}{l}\text { Erfolge berühmter Künstler } \\ \text { erwähnen. }\end{array}\end{array}$

I.3. Mysteriens
Die Erwähnung berühmter Berge wie des Olymp, Pieria, Ida, Helikon und Parnass verleihen der Lalia hedone. ${ }^{54}$

Falls der Redner von Athen herkommend in der Heimatstadt eintrifft oder in Athen eine Abschiedsrede hält ${ }^{56}$, soll er der Mysterien, Hierophanten, Fackelträger, Dionysien, Panathenäen, eleusinischen Prozessionen, Wettbewerbe, usw. gedenken. Dies erzeuge viel glukutes. ${ }^{57}$
Amphion, Arion und der Thraker Orpheus (I,I), sowie der Kitharaspieler Eunomos $(\mathrm{I}, 2-3)$, dessen Erfolg bei den pythischen Spielen beschrieben wird. ${ }^{52}$

Kithairon, Helikon, die odrysischen und thrakischen Berge (2,I-3), sowie der Zion $(2,3)$.

Die erwähnten Berge mit ihren Mysterien (2,I), der dionysische Thiasos der Dichter $(2,2)$.

50 Vgl. Rizzi 1993, I75-I76.

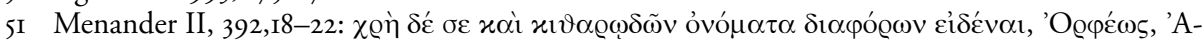

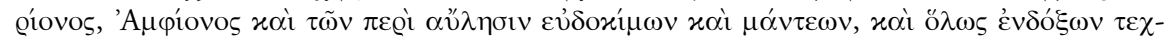

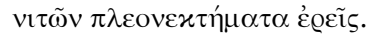

52 Diese Erfolgsgeschichte hat Rizzi als Parallele übersehen.

53 Vgl. Rizzi 1993, 176.

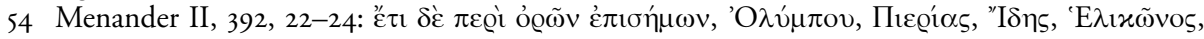

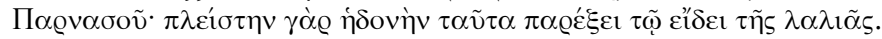

55 Vgl. Rizzi 1993, 176.

56 Die Bezugnahme auf Athen wird von Rizzi vollkommen ignoriert; dies scheint aber auch kein echtes Problem zu sein, da in den Prolalien der Zweiten Sophistik die Mysterien und vor allem dionysische Themen auch ohne Bezug zu Athen vorkommen können; vgl. auch Menander II, 392,24-26, wo Dionysos mit seinem Gefolge in einer Auflistung typischer Themen, die hedone erzeugen (Musiker, Berge, dionysischer Thiasos, Flüsse), als selbstständiges Motiv erwähnt wird. Zum dionysischen Thiasos der Dichter im Protreptikos vgl. unten zur ekphrasis.

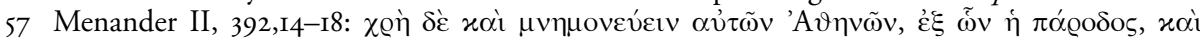

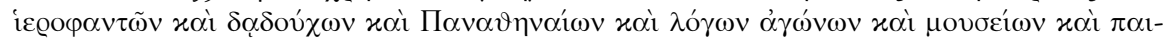

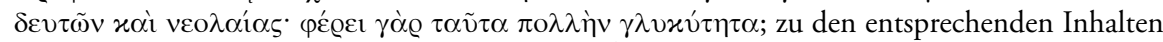

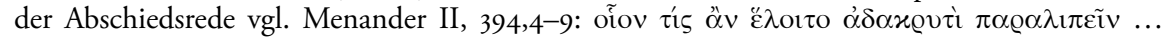

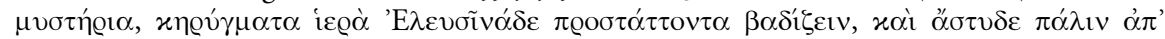

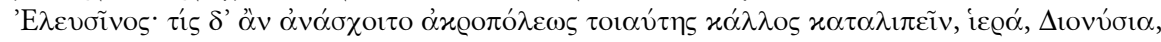

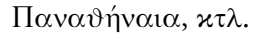


2. Erzählungen $\&$ Geschichten $^{58}$

3. Charakter der Lalia:

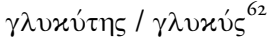

4. Protreptische Funktion ${ }^{64}$
Die lalia erfreut sich an süßen Die Geschichte von EunoZauber $(\dot{\alpha} \beta \varrho o ́ \tau \eta \varsigma))^{59}$ von Er- mos und der Zikade $(\mathrm{I}, 2-3)$, zählungen. Durch Beispiele, die Clemens durch seine Indie die Intentionen des Red- terpretation umdeutet und ners verdeutlichen, und reiz- mit pädagogischer Intention volle Geschichten, aus denen als Mythenkritik vorträgt. der Zuhörer (auch über das Gott erscheint in Gestalt des fürsorgende Wesen der Göt- neuen Liedes und bietet sich ter) etwas lernen kann, wird den Menschen als Heilmit-

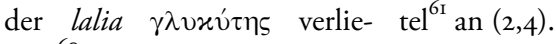
hen. ${ }^{60}$

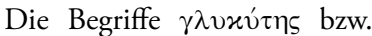
$\gamma \lambda$ uxús werden von Menander mehrfach verwendet, um die Gattung der lalia, gattungsspezifische exempla oder die von ihm favorisierten Modellautoren $\mathrm{zu}$ charakterisieren. $^{63}$

Das gattungstypologisch zentrale Stichwort $\gamma \lambda u x u ́ s$ wird von Clemens benutzt, um das neue Lied als süßes und wahrhaftiges Heilmittel zu charakterisieren: $\gamma \lambda u x v ́$ $\tau$

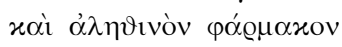
$(2,4)$.

Nach Menander ist die für den Sophisten äußerst nützliche lalia sowohl der epideiktischen als auch der symbouleutischen Rhetorik zuzuordnen und erfüllt die Ansprüche beider Gattungen. Menander erwähnt auch die Funktionen beider Gattungen, d.h. in Bezug auf die beratende Rede das Zuraten und das Abraten

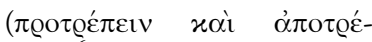
$\pi \varepsilon i v)^{65}$
Die protreptische bzw. apotreptische Funktion der Prolalia entspricht vollkommen den Intentionen des Clemens, seine Zuhörer zur Wahrheit hinzuwenden und von der Gewohnheit abzuwenden, und zwar nicht nur in der Prolalia, sondern im gesamten Protreptikos. ${ }^{66}$

58 Vgl. Rizzi 1993, I77.

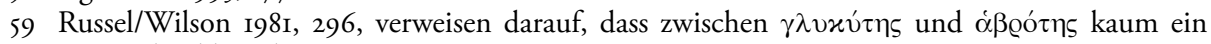
Unterschied besteht.

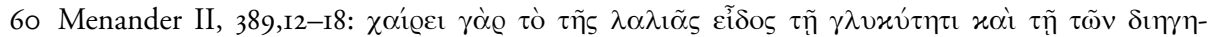

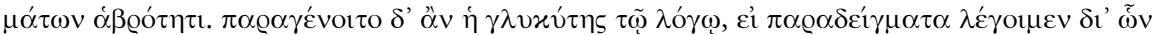

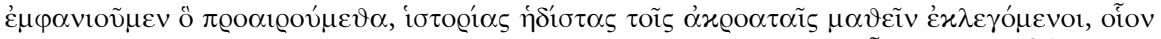

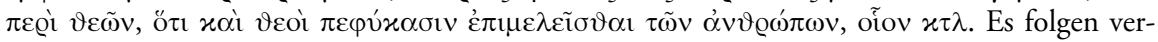
schiedene Beispiele und der Hinweis, man solle sich inhaltlich und stilistisch an den Geschichten Herodots orientieren; aber auch Xenophon, Nikostrat, Dion und Philostrat werden als Vorbilder genannt (vgl. Menander II, 389,I8-390,4).

6I Diese Parallele wurde von Rizzi übersehen.

62 Vgl. Rizzi 1993, I78.

63 Vgl. Menander II, 389,I4. 27; 392,8. 18; 393,15. 
5. Emotionen $^{67}$

6. Struktur und Disposition ${ }^{69}$
In einer lalia ist es durchaus erlaubt, persönliche Gefühle wie Zorn, Trauer und Freude zu artikulieren und seine $\mathrm{Zu}$ hörer direkt zu kritisieren. ${ }^{68}$

Nach Menander zeichnet sich eine Lalia dadurch aus, dass sie keine bestimmte Ordnung einhält und die Reihenfolge der zu behandelnden Gegenstände frei wählbar ist. Das paradoxe Prinzip der $\tau \alpha \dot{\xi} \xi \varsigma$ besteht demnach in der Vorgabe, fortwährend einen unordentlichen Eindruck zu

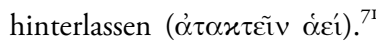
Dennoch sollte der Redner eine gewisse Ordnung einhalten und überlegen, ob er die einzelnen Punkte jeweils zum richtigen Zeitpunkt und in einer vorteilhaften Reihenfolge arrangiert hat. ${ }^{72}$
Mit der ersten Apostrophe der Zuhörer verbindet Clemens eine Mythenkritik, die sehr emotional vorgetragen wird (2,I-2).

Nach Rizzi trifft dies für die ersten Paragraphen des Protreptikos $\mathrm{zu}$, in denen Clemens seine Gedanken frei zu entwickeln scheint und damit den Eindruck von Unordnung erweckt (una apparenza di disorganicità). ${ }^{70} \mathrm{Ei}$ ne logische Struktur ist nach Rizzi aber dennoch zu erken-

nen, da Clemens seinem Text eine chiastische Struktur zugrunde legt: Die pagane Kultur wird durch Elemente des christlichen Glaubens modifiziert und der christliche Glaube durch Elemente der paganen Kultur interpretiert. $^{73}$

64 Vgl. Rizzi 1993, I78-I79.

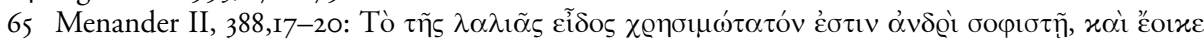

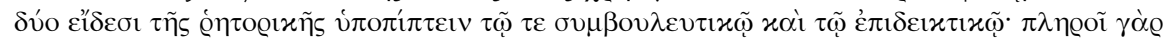

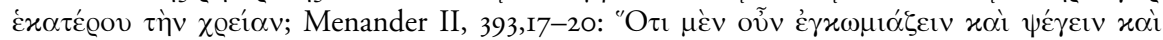

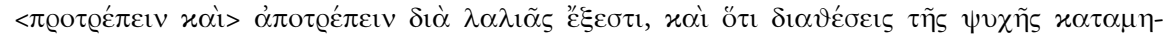

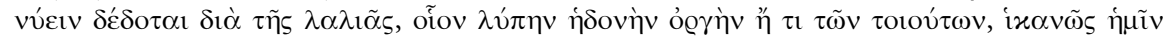

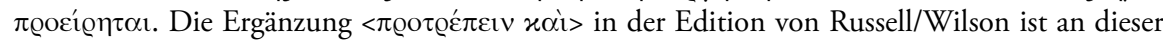
Stelle sinnvoll und notwendig: "The sense is incomplete without a mention of exhortation“" (Russell/Wilson 198I, 302).

66 Zur Grundstruktur protreptischer Texte und deren Einordnung in das System der antiken Rhetorik vgl. Lechner 2007, I87-196.

67 Vgl. Rizzi 1993, I79-I8I.

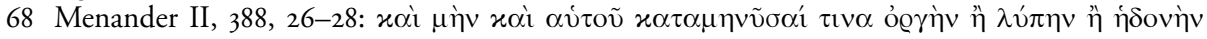

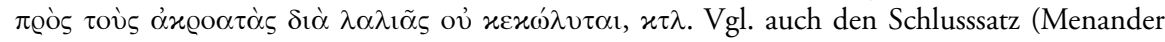
II, 393,17-20) in Anm. 65.

69 Vgl. Rizzi 1993, I8I. I83-I88.

70 Vgl. Rizzi 1993, I8I.

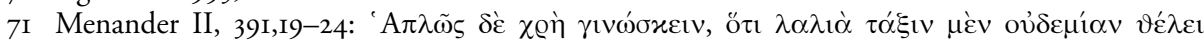

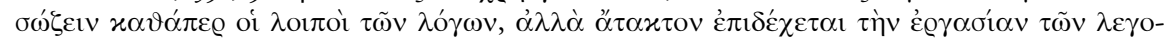

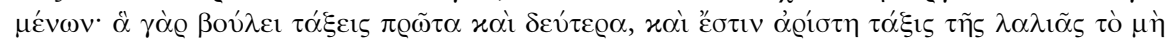

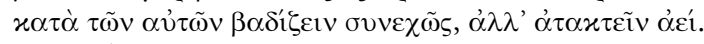

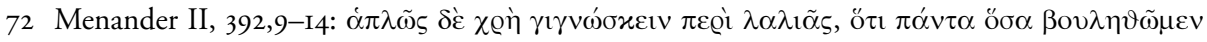


Es ist in der Tat überraschend, wie exakt die Beschreibung der lalia durch Menander inhaltlich und strukturell mit dem Text des Protreptikos übereinstimmt. Dieser Eindruck wird durch die nachfolgende Besprechung der Studie von Rizzi noch verstärkt werden, wobei nun auch dessen Analyse zur elocutio des Protreptikos, die aus Platzgründen nicht in die Tabelle integriert wurde, einzubeziehen ist.

\subsection{Kritischer Kommentar und Ergänzungen zur Analyse von Rizzi}

Die von Rizzi verwendete Methode, die Einleitung zum Protreptikos mit den Anweisungen in einem rhetorischen Handbuch zu vergleichen, hat selbstverständlich viel für sich. Andererseits werden auf diese Weise auch Fragen ausgeklammert, die für die Beurteilung des Textes wichtig sind. Dazu zählt beispielsweise die Frage, in welchem Verhältnis die lalia zum exordium steht, falls die lalia als prolalia einer Rede vorangeht. Da Menander auf dieses Problem nicht eingeht, wird es von Rizzi auch nicht behandelt. Rizzi bezeichnet deshalb die gesamte prolalia als exordium. Dieses exordium umfasst nach Rizzi die ersten drei Paragraphen des ersten Kapitels (Protr. I,I-3,2) und endet mit der Beschreibung des himmlischen Logos als Sänger, den Clemens wiederum als seinen Sänger bezeichnet. $^{74}$ Rizzi entgeht, dass Protr. 3,I-2 mit der Synkrisis zwischen diesem Sänger und den in der prolalia genannten Musikern nun aber das eigentliche exordium beginnt, das erst Protr. 5,4 endet. ${ }^{75}$ Interessanterweise zieht Rizzi den Textabschnitt Protr. 3,I-2 auch nur ein einziges Mal für seine vergleichende Analyse heran, übersieht hierbei aber, dass die Formulierung mein Sänger, die er als gattungstypisches Merkmal einstuft, weil persönliche Gefühle artikuliert werden, schon durch die Formulierung mein Eunomos Protr. 2,4 am Ende der prolalia vorbereitet wurde. Die Stelle selbst kennt Rizzi selbstverständlich, behandelt sie aber ausschließlich unter dem Aspekt, dass Clemens hier mit dem Namen des Eúvouos ein Wortspiel treibt. ${ }^{76}$ Dieses Wortspiel leitet aber zum ersten Homerzitat über, durch das die prolalia der Empfehlung Menanders folgend, berühmte

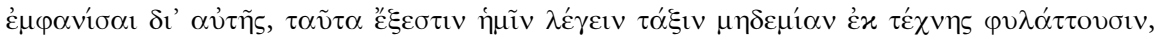

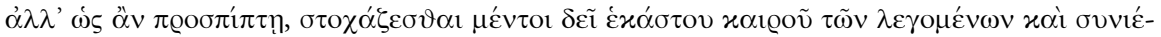

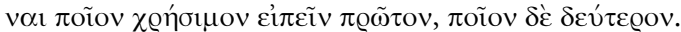

73 Vgl. Rizzi I993, I85: „E evidente la struttura chiastica di questa sezione proemiale, in cui i vari elementi della cultura e del mito ellenico sono progressivamente accostati e sostituiti da contenuti propri del Cristianesimo. Questi vengono di volta in volta caratterizzati in modo più mar-

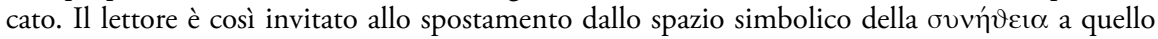
dell' $\dot{\alpha} \lambda \dot{\eta} \vartheta \varepsilon 1 \alpha$, secondo la funzione propria e caratteristica del protrettico in quanto genere." Vgl. S. I87 Anm.7I: „il chiasmo è così lo strumento di organizzazione testuale dell' exordium.“

74 Vgl. Rizzi 1993, 175. I80.

75 Vgl. Lechner 2007, 200-203.

76 Vgl. Rizzi 1993, I77; vgl. dazu die Ausführungen unter 4.7. weiter unten. 
Dichter wie Homer und Hesiod zu zitieren ${ }^{77}$, elegant oder - wie Menander formuliert hätte - charmant und süß beendet wird..$^{7}$ Der Vergleich mit anderen Prolalien wird noch zeigen, dass es durchaus dem Stil der Zweiten Sophistik entspricht, eine Vorrede mit einem Homerzitat zu beenden. Aus den genannten Gründen ist deshalb die prolalia auf den Textabschnitt Protr. I,I-2,4 zu begrenzen, wobei festzuhalten ist, dass das eigentliche exordium noch folgt. Dies ist keineswegs ungewöhnlich. Als Vergleichstext zum Protreptikos kann man die Olympische Rede des Dion von Prusa heranziehen, die den gleichen rhetorischen Aufbau hat (prolalia - exordium - narratio - argumentatio - peroratio).$^{79} \mathrm{Zu}$ den von Rizzi beigebrachten Parallelen selbst sind noch einige Anmerkungen hinzuzufügen. Diese beziehen sich vor allem auf die gattungstypischen Funktionen der prolalia und die elocutio.

\subsection{Gattungstypische Funktionen der Prolalia}

Clemens findet in seiner Vorrede teilweise äußerst kritische Worte, um die pagane Kultur seiner Zielgruppe zu beschreiben. Lässt sich dies mit den gattungstypischen Funktionen der prolalia vereinbaren? Wie schon erwähnt, wird die lalia von Menander gleichermaßen der epideiktischen und der symbouleutischen Gattung zugeordnet. ${ }^{80}$ Bislang zu wenig berücksichtigt wurde die Tatsache, dass er den einzelnen Gattungen, der rhetorischen Tradition folgend, unterschiedliche Funktionen zuordnet, nämlich der Festrede das Loben und Kritisieren, der Beratungsrede das $\mathrm{Zu}$ - und Abraten, und dass er an mehreren Stellen die Möglichkeit hervorhebt, in der lalia tatsächlich Kritik zu formulieren. ${ }^{8 \mathrm{I}}$ Dies bedeutet, dass die vor allem in der epideiktischen Gattung selten vorkommende Kritik, den antiken Zuhörern häufig in der rhetorischen Gestalt der lalia begegnet sein dürfte,

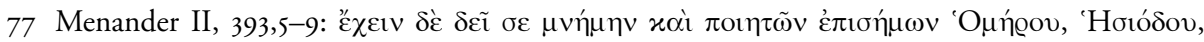

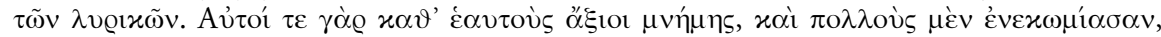

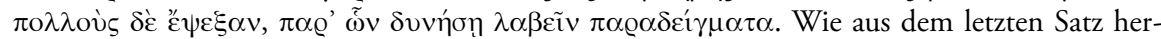
vorgeht, kann der Redner bei diesen Dichtern Beispiele finden, um andere zu loben oder zu kritisieren - eine Funktion, die das Homerzitat im Protreptikos durchaus erfüllt, da hier das neue Lied gefeiert wird. Wie man Homerzitate in den Kontext einer Rede einbinden kann, zeigt Menander am Beispiel einer lalia, die man bei einer Rückkehr in die Heimat halten könnte (vgl. Menander II, 39I,29-392,9). Das zweite Homerzitat des Textes (Od. 9,34) enthält

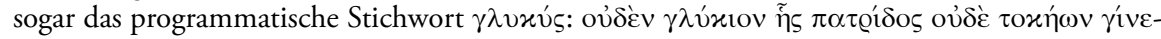
$\tau \alpha_{1}(392,8-9)$.

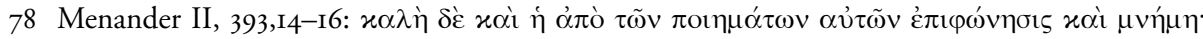

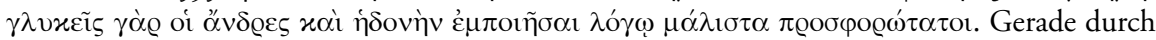
die Dichterzitate werden also auch die gattungstypischen Effekte glukutes und hedone erzielt.

79 Vgl. Klauck 2000, 27-30, und Betz 2004.

80 Vgl. weiter oben die Tabelle zur protreptischen Funktion der lalia.

8I Vgl. Menander II, 388,26-3I; 39I,6-IO; 393,7-I2. I7-20. 
denn Menander betont, wie wir oben schon sehen konnten, dass der Redner in der lalia durchaus seinem Ärger (ỏorí) Luft machen darf ${ }^{\beta_{2}}$, wie er auch dazu ermuntert, sich über andere Personen und deren Lebensstil satirisch, polemisch

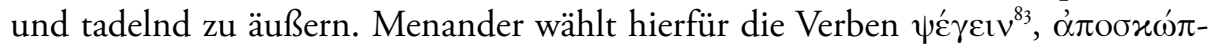
$\tau \varepsilon v^{84}, x \omega \mu \omega \delta \varepsilon \tilde{\varepsilon} v^{85}$ und $\delta 1 \alpha \beta \alpha \dot{\alpha} \lambda \lambda \varepsilon v^{86}$. Besonders aussagekräftig ist der folgende Textabschnitt, der bis auf $\varkappa \omega \mu \omega \delta \tilde{\varepsilon i v}$ alle Verben enthält:

Du solltest häufig spotten oder tadeln, aber ohne Namen zu nennen, wenn du die äußere Erscheinung skizzierst, sofern du das willst, oder den Charakter kritisierst. So wie es beim Loben möglich war, aus jeder Tugend Enkomien zu entwickeln, so ist es hier möglich, von jedem Fehler auszugehen, um zu spotten und zu tadeln, ganz wie du willst. ${ }^{87}$

Dieser Grundzug der lalia findet sich nun aber überdeutlich in der Vorrede des Clemens, der die Narrenfreiheit der prolalia geradezu provokativ ausnutzt. Oder wie sollte man sonst die durch die Interpretation der Eunomoserzählung vorbereitete Mythenkritik an den Griechen beurteilen (Protr. I,2-2,I), von dem Dichter-Thiasos ganz zu schweigen, den Clemens Protr. 2,2 satyrisch ausgestaltet hat, und zwar als eine Prozession von betrunkenen, verrückten und efeubekränzten Poeten, die zusammen mit den Satyrn und Dämonen in die Bergwelt der Mythen verbannt werden? Dass im Anschluss der Chor der Dämonen durch den heiligen Chor der Propheten ersetzt wird (vgl. Protr. 2,2), ist aus christlicher Sicht durchaus verständlich, entspricht aber wiederum der Vorgabe des Menander, neben berühmten Kithara- und Flötenspielern auch Wahrsager ( $\mu \alpha \dot{v} v \tau \mathrm{or}) \mathrm{zu}$ erwähnen. ${ }^{88}$ Religionswissenschaftliche Genauigkeit war in diesem Zusammenhang ohnehin nicht gefragt, da der Text einer lalia nach Menander vor allem durch phantasievolle Ausschmückungen Charme gewinnt, während die Behand-

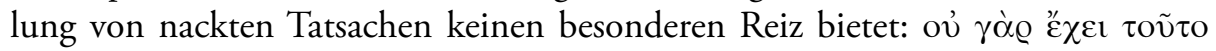

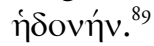

In diesen durchwegs epideiktischen Passagen wird das protreptische Anliegen des Clemens immer deutlicher formuliert (vgl. Protr. 2,3) und schließlich durch

82 Menander II, 388,$27 ; 393,20$.

83 Menander II, 388,30; 391,6. I0; 393,8. II. 17.

84 Menander II, 388,29; 391,6.

85 Menander II, 388,29.

86 Menander II, 39I,7-8. Io.

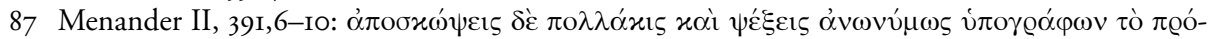

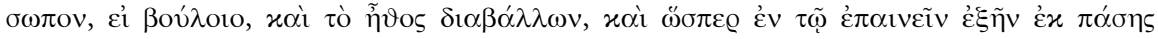

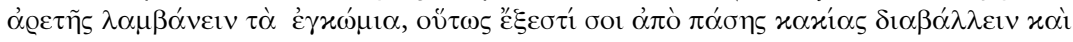

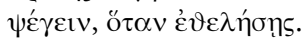

88 Vgl. den Text in Anm. 5I (Menander II, 392,I8-22): Diese Parallele mit Protr. 2,2 ist Rizzi entgangen.

89 Menander II, 389,II-I2. Auch an anderen Stellen empfiehlt Menander das Erfinden von Geschichten; vgl. Menander II, 390,4-I3 (Träume und Berichte) und 390,2I-32 (Mythen mit dem Beispiel Apollon und die Musen). 
das Homerzitat selbstbewusst propagiert: Die Werbung für das neue Lied verheißt die Therapie aller Leiden. Mehr kann man nicht versprechen. Damit findet die Vorrede, die in ihrem leidenschaftlichen, teilweise aggressiven, aber in jeder Hinsicht mit dem Gattungsschema harmonierenden ethos, ein sanftes und süßes Ende.

Dass Clemens überhaupt so offen und unmittelbar von der christlichen Wahrheit und dem himmlischen Logos sprechen konnte, ohne einen apologetischen Vorspann oder andere einführende Worte vorauszuschicken, ist wiederum als gattungstypische Besonderheit der lalia einzuordnen, denn Menander verweist am Ende seiner Ausführungen darauf, dass in der lalia - offensichtlich im Gegensatz zu anderen epideiktischen Redeformen - jedes Thema ( $\pi \tilde{\alpha} \sigma \alpha \nu$ vं $\pi$ ó $\varepsilon-$ $\sigma \iota v)$ behandelt werden kann. ${ }^{90}$ Dies dürfte wohl auch der Grund gewesen sein, warum diese neue Gattung, die geradezu modellhaft den esprit sophistique ${ }^{91}$ verkörperte, auch für pepaideumenoi mit philosophischen Interessen attraktiv war. Jedenfalls findet man entsprechende Beispiele bei Lukian, Dion und Apuleius, also den unmittelbaren Vergleichsgrößen zu Clemens. ${ }^{92}$

\subsubsection{Elocutio}

Wie bereits weiter oben angemerkt wurde, soll die prolalia der Stilebene der $\alpha \dot{\alpha} \varphi \varepsilon^{-}$ $\lambda \varepsilon\llcorner\alpha$ entsprechen. Menander empfiehlt deshalb die Erzählungen von Herodot für die stilistische Ausarbeitung der lalia:

Die Geschichte Herodots ist voll reizvoller Erzählungen. In diesen wird jegliche Art von Charme dem Text hinzugefügt, nicht nur durch die neuartige Exotik der Erzählungen, sondern auch durch eine bestimmte Art der Komposition, falls der verwendete Stil weder rauh, noch periodisch, noch argumentativ, sondern einfacher und unkomplizierter ist, usw. ${ }^{93}$

Als weitere Modellautoren werden noch Xenophon, Nikostrat, Dion und Philostrat genannt. ${ }^{94}$ Allerdings findet man bei Menander an einer anderer Stelle den Hinweis, die elocutio sollte sorgfältig ausgearbeitet und ausgeschmückt ( $\lambda \varepsilon^{\prime} \xi 1 \varsigma$

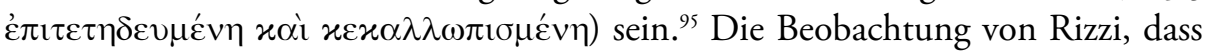

90 Menander II, 394,29-3I.

9I Pernot 1993, 546.

92 Vgl. dazu Pernot 1993, 567-568, und weiter unten 4.6 und 4.7.

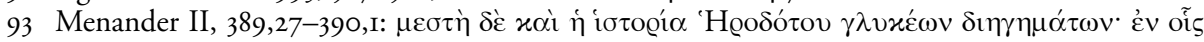

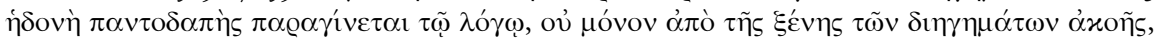

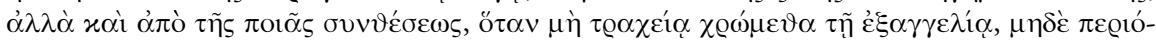

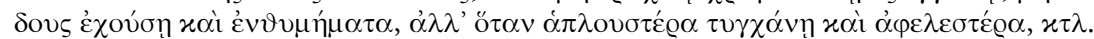

94 Menander II, 390,I-4.

95 Vgl. Menander II, 4II,23-4I2,2. Hier wiederholt er zunächst die Stilkriterien der lalia, um schließlich die ausgearbeitete und ausgeschmückte elocutio von Platon, Xenophon, Dion und 
die von Menander geforderte Schlichtheit der lalia weder mit den angegebenen Modellautoren $\mathrm{zu}$ verbinden ist, noch mit dieser rhetorischen Anweisung übereinstimmt, ist grundsätzlich richtig. ${ }^{96}$ Jedoch findet sich der entsprechende Text (Menander II, 4II) nicht in dem Abschnitt über die Verabschiedungsrede ( $\pi$ @o $\pi$ -

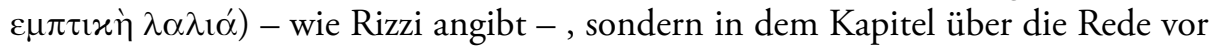

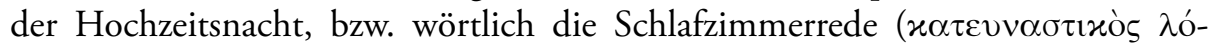

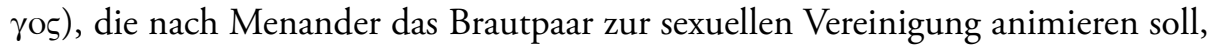

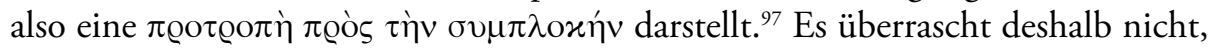
dass Menander einen unkomplizierten Redevortrag fordert, der sich an der lalia orientieren sollte. Dennoch darf hier die $\lambda \hat{\varepsilon}^{\prime} \xi 1 \zeta$ sorgfältig ausgearbeitet und ausgeschmückt sein, eigentlich ein Widerspruch, den Russell und Wilson dadurch zu beseitigen versuchen, dass sie das Kriterium der $\alpha \dot{\alpha} \varphi \dot{\lambda} \lambda \varepsilon \mathbf{\alpha} \alpha$ lediglich auf das ethos des Redners beziehen..$^{98}$ Andererseits stimmen die an dieser Stelle genannten Verfasser mit den weiter oben zitierten Autoren im Wesentlichen überein, so dass man wohl auch für die gewöhnliche lalia gehobene Stilansprüche erwarten darf9, solange insgesamt der Eindruck eines unkomplizierten Vortragsstils erhalten bleibt und der Text sich durch charis auszeichnet. ${ }^{100}$ Für die Vorrede des Clemens hatte schon Steneker ${ }^{\text {ror }}$, auf den sich Rizzi in seiner Untersuchung bezieht, eine kunstvoll gestaltete elocutio nachgewiesen und von einem ,prooemium d'un raffinement consommé" gesprochen. ${ }^{102}$ Clemens unterscheidet sich darin wohl kaum von den Modellautoren der Zweiten Sophistik und deren Kompositionen. Jedenfalls zeigt schon das klassische Urteil Eduard Nordens wie sehr Clemens dem Stil der Zweiten Sophistik verpflichtet ist:

Der Anfang des clementinischen Protrepticus gehört mit seinen zerhackten, rhythmisch fallenden, figurengeschmückten Sätzen zu dem Raffiniertesten, was es aus der sophistischen Prosa gibt, stark erinnernd an das etwa gleichzeitige Proömium des Hirtenromans des Longos. ${ }^{\mathrm{IO}}$

Philostrat zu empfehlen.

96 Rizzi 1993, I8I-I82.

97 Menander II, 405,23-24.

$98 \mathrm{Vgl}$. Russel/Wilson 198I, 323.

99 Vgl. dazu (mit Beispielen aus der Zweiten Sophistik) Pernot 1993, 564-565.

IOO Charis ist in diesem Zusammenhang für Menander das Kriterium schlechthin (vgl. 4II,30; $4 \mathrm{I} 2,2)$.

IOI Vgl. Steneker $1967,38-42$.

IO2 Steneker 1967, 42.

I03 Norden 1915, 549. 


\section{Clemens Alexandrinus, Protr. I,I-2,3 und die $\pi \varrho \circ \lambda \alpha \lambda \iota \alpha^{\prime}$ der Zweiten Sophistik}

\section{I. Übersicht zu den prolaliai der Zweiten Sophistik}

Die zuerst von Stock ${ }^{104}$ zusammengestellten Prolalien der Zweiten Sophistik sind in späteren Forschungsbeiträgen nicht immer als Prolalien eingestuft worden, weshalb zunächst eine auf der Auswahl von Pernot ${ }^{\text {Ios }}$ basierende Übersicht über die noch erhaltenen Prolalien gegeben wird:

Dion $^{\text {ro6 }}$ : Eine Ansprache in der Vaterstadt (Or. 42) und Nestor (Or. 57). Als Prolalien können nach Pernot ${ }^{\text {107 }}$ mit einer gewissen Wahrscheinlichkeit auch folgende Texte gelten: Dions Freude am Zuhören (Or. 19), Sokrates (Or. 54) ${ }^{\text {108 }}$, Von der äußeren Erscheinung (Or. 72) ${ }^{109}$. Klauck ${ }^{\text {IIO }}$ fügt den oben genannten Prolalien (Or. 42 und Or. 57) noch die Einleitungen der Olympischen Rede (Or. I2,I-I5), der Alexandrinischen Rede (Or. 32,I-24) und der Ersten Tarsischen Rede (Or. 33,I-I6) hinzu, weiterhin die von Pernot genannte Or. 72 und die Einleitung zur Rede in Kelainai in Phrygien (Or. 35,I-I2) ${ }^{\mathrm{III}}$. Die zuletzt genannte Rede (Or. 35) hält Pernot insgesamt für eine Lalia ${ }^{\text {II2 }}$, die Einleitungen zu den großen Reden wie der Olympischen Rede (Or. I2) dagegen für Exordien, die eine sehr große Ähnlichkeit mit Prolalien haben, weshalb er sie als Schein-Prolalien („quasi-prolalies“) einstuft. ${ }^{\mathrm{II}}$

Lukian $^{\mathrm{II}}$ : Herodot oder Aëtion (Herod.), Harmonides (Harm.), Der Skythe (Scyth.), Die Dipsaden (Dips.), Der Bernstein oder die Schwäne des Eridanus (Electr.), Zeuxis oder Antiochus (Zeux.), Der Gallische Herakles (Herc.) und Di-

IO4 Vgl. Stock 19II, II-95.

I05 Vgl. Pernot 1993, 547-557.

I06 Zu den Prolalien Dions vgl. Stock 19II, 4I-66, und vor allem Pernot 1993, 548-550, sowie Klauck 2000, I63-165, mit der ebd. angegebenen und diskutierten älteren Literatur.

I07 Vgl. Pernot I993, 548-550. Die Auswahl von Amato 2009, 23-32, erscheint insgesamt zu großzügig. Er bezieht auch die Einleitungen zu den Reden 3, I3, 34 und 43 als Prolalien in seine Untersuchung mit ein.

I08 So zuletzt auch Amato 2009, 23-28.

I09 So zuletzt auch Amato 2009, 28-32.

IIO Vgl. Klauck 2000, I65.

III Diese Einleitungen hat schon von Arnim 1898, 438, als Prolalien qualifiziert. Zur Ersten Tarsischen Rede (Or. 33) und zur Rede in Kelainai (Or. 35) vgl. jetzt auch Bost Pouderon (2006).

II2 Vgl. Pernot 1993, 555 .

II3 Vgl. Pernot 1993, 559-560.

II4 Vgl. Anderson 1977, 313-315; Billault 2006, 47-59; Bompaire 1958, 286-288; Branham 1989, 3846; Mras 1949a, 7I-74; Nesselrath I990, III-I40; Pernot 1993, 550, und 1994, II4; Reardon I97I, I65-I66; Stock 19II, II-36; Zweimüller 2008, 67-78. Die Reihenfolge der Prolalien folgt der Untersuchung von Nesselrath 1990, II7-139, der die Prolalien chronologisch geordnet hat. 
onysos (Bacch.). Ausgeschlossen werden Prometheus es in verbis ${ }^{\mathrm{II}}$ und Somnium sive Vita Luciani ${ }^{\text {II }}$, da diese Texte nicht sicher zuzuordnen sind.

Apuleius ${ }^{\mathrm{II}}$ : Flor. I8, sowie Flor. I und Flor. $3 .{ }^{\mathrm{II}}$ Nach Pernot sind Flor. 9 und Flor. I6 eigenständige laliai. Flor. I5 ist (nach Stock, Mras, Nesselrath und La Rocca) ${ }^{\mathrm{II}}$ ebenso als prolalia zu betrachten wie Flor. 17 (nach Stock, Mras und La Rocca). Pernot stuft dieses Fragment als ein gewöhnliches exordium ein. ${ }^{\text {I2O }}$

Die von Pernot vollkommen zu Recht als laliai bezeichneten Texte (Dion, Or. 35; Apuleius, Flor. 9 und Flor. 16) werden in die folgende Untersuchung insofern mit einbezogen, als diese Texte wiederum Prolalien enthalten, die den eigentlichen Reden vorangehen, weshalb beispielsweise Or. 35,I-I2 auch schon als eigenständige prolalia identifiziert wurde. ${ }^{\mathrm{I} 2 \mathrm{I}}$ Dies gilt aber auch für die übrigen Texte, denn sowohl Flor. 9,I-29 als auch Flor. I6,I-24 sind als Prolalien zu den jeweiligen Reden aufzufassen. ${ }^{\mathrm{I} 2}$ Weiterhin werden die oben genannten Einleitungen zu den großen Reden Dions (Or. I2, Or. 32 und Or. 33) der Auswahl von Pernot hinzugefügt. Speziell für die Einleitung zur Olympischen Rede (Or. I2) haben Klauck und zuletzt Betz ${ }^{\mathrm{I} 23}$ überzeugende Argumente vorgebracht. Die Einleitungen der beiden anderen Reden lassen sich dieser Gattung aber ebenso problemlos zuordnen. ${ }^{124}$ Schließlich werden mit Bezug auf die oben genannten Forscher (gegen Pernot) auch Flor. I5 und Flor. I7 des Apuleius als Prolalien betrachtet. Diese

II5 Diese Schrift wird von Zweimüller 2008, 68, als prolalia eingestuft; vgl. dagegen Nesselrath 1990, II5 Anm. 9.

II6 Für die Beurteilung des Textes als lalia spricht sich Pernot 1993, 555, aus. Anderson 1977, 314 Anm. 5, hält den Text für eine prolalia; vgl. dagegen Bompaire 1958, 288-289 Anm.5, und Nesselrath 1990, IIs Anm. 9.

II7 $\mathrm{Zu}$ den in unterschiedlichem Umfang als Prolalien eingestuften Florida des Apuleius vgl. Harrisson 2000, 89-I35; Hilton 200I, I27-I28; Hunink 200I, II-I9; La Rocca 2005, I3-77; Lee 2005, I-30; Mras 1949b, 218-223; Pernot 1993, 550-55I; Sandy 1997, I48-I75; Steinmetz 1982, 192-202; Stock 191I, 69-74. Insgesamt besteht die Textsammlung der Florida aus 23 Stücken (vgl. die Editionen von Helm 1977 und Valette 197I), die allerdings unterschiedlich unterteilt werden. Da alle neuen Editionen und Kommentare (mit Ausnahme von La Rocca) der Textgliederung von Valette gefolgt sind, werden die einzelnen Paragraphen der Florida auch hier nach Valette und nicht nach der Edition von Helm angegeben.

II8 Pernot betrachtet noch die Fragmente I-IV, die zusammen mit dem Fragment V die falsche Einleitung zu De deo Socratis bilden, als mögliche Prolalien. Da weder die Zuordnung zu den Florida noch zu De deo Socratis gesichert ist und die Charakterisierung der kurzen Texte als Vorreden schwierig erscheint, werden diese Fragmente nicht herangezogen. Vgl. dazu Harrison 200I, I77-I80.

II9 Stock I9II, 76-78; Mras 1949b, 207. 2I0; Nesselrath 1990, II4 Anm. 8; La Rocca 2005, 29 Anm. 58; Flor. I5 wird von Pernot merkwürdigerweise vollkommen übergangen.

I20 Vgl. Pernot 1993, 55I Anm. 303, wo er Flor. I7 und Flor. 20 erwähnt, „qui sont en fait des exordres plutôt que des prolalies."

I2I Vgl. Klauck 2000, I65.

I22 Alle drei Texte zeichnen sich dadurch aus, dass den kurzen Reden relativ lange Prolalien vorangehen.

I23 Vgl. Betz 2004, 222-225.

I24 Vgl. Klauck 2000, I65. 
Auswahl genügt, um die Prolalien der Zweiten Sophistik als Gattung beschreiben zu können, selbst wenn man mit La Rocca noch weitere Texte aus den Florida des Apuleius hinzufügen könnte. ${ }^{125}$ Insgesamt ergibt sich also folgende Textsammlung als Grundlage der Untersuchung:

Dion (Or. I2,I-15, Or. 19, Or. 32,I-24, Or. 33,I-I6, Or. 35,I-I2, Or. 42, Or. 54, Or. 57 , Or. 72$)$,

Lukian (Herodotus sive Aëtion, Harmonides, Scytha, Dipsades, Electrum, Zeuxis sive Antiochus, Hercules, Bacchus),

Apuleius (Flor. I, Flor. 3, Flor. 9,I-29, Flor. 15, Flor. 16,I-24, Flor. 17, Flor. 18).

\subsection{Zur Struktur und Komposition der Prolalien}

Die Gattungscharakteristik der prolalia lässt sicherlich kein festes Kompositionsschema erwarten. Dennoch hat man in der Forschungsgeschichte versucht, in den Prolalien der Zweiten Sophistik feste Strukturen oder sogenannte patterns zu bestimmen. Die von Mras für Lukian und Apuleius vorgelegte Klassifizierung in zwei- oder dreiteilige Kompositionen, denen jeweils eine captatio benevolentiae folgt ${ }^{126}$, wurde von Anderson zu Recht kritisiert, der für die Prolalien Lukians ein flexibleres Schema vorschlug, das aus zwei frei kombinierbaren rhetorischen Elementen und einer captatio benevolentiae besteht. ${ }^{127}$ Lukian kombiniert vor allem

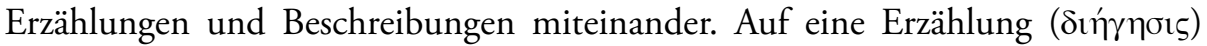

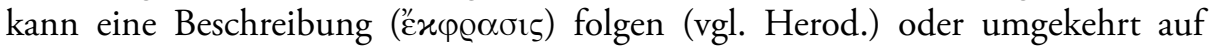
eine Beschreibung eine Erzählung (vgl. Zeux.); es können aber auch zwei Erzählungen (vgl. Electr. und Bacch.) oder zwei Beschreibungen (vgl. Dips.) vorkommen. Solche Erzählungen und Beschreibungen finden sich auch bei Apuleius ${ }^{128}$, ohne dass man aber durchwegs ein Schema mit zwei rhetorischen Einheiten erkennen könnte. Dion nimmt eine Sonderstellung ein, da er auf Erzählungen weitgehend verzichtet, dafür aber kurze Beschreibungen, Fabeln, Alltags- und Naturbeobachtungen, Anekdoten, Dichterzitate und Sprichwörter bunt aneinan-

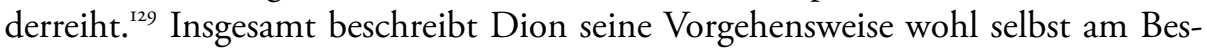

I25 La Rocca 2005, 30 Anm. 63.

I26 Vgl. Mras 1949a, 70-74. 8I.

I27 Vgl. Anderson 1977, 313-315, der auch von Diptychen spricht: „In fact these diptychs are highly formal miniatures" (S. 315); ebenso Nesselrath I990, II3-II5.

I28 Vgl. Flor. 3 (die Erzählung von Apollon und Marsyas), Flor. 9 (die Erzählung vom Auftritt des Hippias in Pisa, die eigentlich eine ekphrasis seiner äußeren Erscheinung ist), Flor. Is (die Beschreibung der Statue des Bathyllos und die Biographie des Pythagoras), Flor. I6 (die anekdotische Erzählung vom Lebensende des Dichters Philemon), Flor. I8 (die anekdotischen Erzählungen von Protagoras und Thales).

I29 Vgl. z. B. die ornithologischen ekphraseis Or. I2,I-4 oder die Fabeln Or. I2,7-8 und Or. 33,I6. 


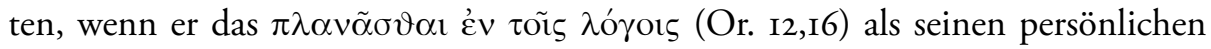
Stil definiert. ${ }^{130}$ Dies entspricht vollkommen dem "Gebot der Zwanglosigkeit"131, das für Prolalien typisch ist und von Menander variantenreich beschrieben wurde.

Letztlich spielt es auch keine Rolle, welche rhetorischen Elemente aus dem Kanon der klassischen progymnasmata ausgearbeitet und miteinander kombiniert wurden, weil es nur darum ging, die persona des Redners situationsgerecht zu inszenieren. Ob der Redner dafür eine Anekdote oder Bildbeschreibung benutzte, war gleichgültig, solange er damit sein Publikum unterhielt und sich durch die Technik der Selbstreferenz eindrucksvoll präsentierte. Mit solchen Periauto$\operatorname{logien}^{132}$ ist bei Dion auch häufig eine Kritik an Sophisten ${ }^{133}$ und falschen Philosophen ${ }^{134}$ verbunden. ${ }^{135}$ Lukian kritisiert in den erhaltenene Prolalien mehrfach den Zeitgeschmack seines Publikums, das nur durch neue, paradoxe und skurile Geschichten zu begeistern ist. Damit setzt er sich von der Showrhetorik der Sophisten positiv ab, und zwar, wie Zweimüller nachgewiesen hat ${ }^{136}$, durch einen eindeutigen Rekurs auf die Tradition, wodurch er sich wiederum als Mitglied einer traditionsbewussten Elite präsentiert. ${ }^{137}$ Seine Innovationen respektieren die Spielregeln der klassischen Rhetorik, erschöpfen sich aber nicht in der mimesis traditioneller Formen, sondern verbinden intelligent und phantasievoll Neues mit Traditionellem. ${ }^{138}$

Auch bei Apuleius stehen Person und Werk im Mittelpunkt der Prolalien: Apuleius beschreibt beispielsweise in einer bezaubernden ekphrasis den Auftritt des Sophisten Hippias während der Olympischen Spiele zu Pisa, um sich schließlich mit ihm zu vergleichen, wobei er alle Gattungen seiner Schriftstellerei von

I30 Vgl. schon von Arnim I898, 438-443.

I3I Mras 1949a, 2IO.

I32 Vgl. Pernot 1994, II4: „Ces périautologies déguisées ne sont pas des coquetteries de sophistes qui se regardent écrire. Leur portée est plus profonde. Dion et Lucien utilisent la prolalie à titre de manifeste intellectuel et littéraire, pour camper leur propre persona en tant qu' auteurs."

I33 Vgl. Or. 19,3-5; Or. 35,8; Or. 54; vgl. auch Lukian, Electr. 6.

I34 Vgl. Or. 32,9 und Or. 35,2-3.

I35 Vgl. von Arnim I898, 444: „Allen vier Prooemien (Or. I2, Or. 32, Or. 33, Or. 35 TL) gemeinsam ist die Bezugnahme auf Dios Verhältnis zu den Sophisten einerseits, zu den übrigen Philosophen andererseits. Nur durch diese doppelte Vergleichung glaubt er den Hörern seine eigene Berufsauffassung verdeutlichen zu können."

I36 Vgl. Zweimüller 2008, 72-78.

I37 Zweimüller 2008, 78: „Somit ist er zwar ein Sophist unter Sophisten, gleichzeitig aber ein kritischer Beobachter dieses Phänomens der Kaiserzeit, der durch vielfältige, innovative Umsetzung des gemeinsamen griechischen Erbes seinen Teil zur Selbstwahrnehmung der zeitgenössischen Elite beiträgt."

I38 Vgl. Zweimüller 2008, 75; vgl. außerdem von Möllendorff (2006a) zu Lukians ästhetischem Konzept, in dem hybride Gattungen und Motive eine neuartige Ästhetik kreieren. Damit entsprechen sie dem rhetorischen Ideal der charis, das nicht nur durch reine mimesis verwirklicht werden kann. 
der leichten Komödie bis zur ernsten Philosophie angibt und zusätzlich auf seine griechischen Werke verweist. ${ }^{139}$

Will man also eine Struktur herausarbeiten, die allen Prolalien zugrunde liegt, dann kann man letztlich nur auf diese selbstreferentielle Struktur verweisen: Jede Prolalia enthält eine selbstreferentielle Äußerung, die sich auf die jeweilige rheto-

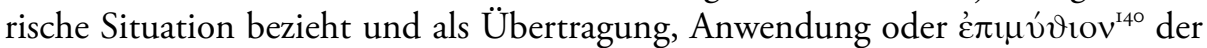
vorangegangenen Darstellung erscheint. Die Darstellung selbst umfasst in der Regel autobiographische, literarische, mythologische und anekdotische Erzählungen, sowie Beschreibungen aller Art. Sie kann aber auch wie in Dions Nestor (Or. 57) aus dem Zitat und der Interpretation einer längeren Homerstelle bestehen, wie überhaupt Zitate aus Ilias und Odyssee mehrfach begegnen. ${ }^{141}$ Diese $\mathrm{Zi}$ tate dienen zumeist der distinguierten Unterhaltung der Zuhörer, haben also keine gliedernde Funktion. Homerzitate können aber auch als strukturierende Elemente eingesetzt werden, um den Übergang von der Prolalia zur eigentlichen Rede zu markieren. ${ }^{\mathrm{I} 2}$

Geht man von den Prolalien des Apuleius und des Lukian aus, die bereits eine gewisse Entwicklung der Gattungsgeschichte voraussetzen und überdies dem Werk des Clemens zeitlich näherstehen als die Prolalien Dions, dann könnte man für die Zeit des Clemens folgende Kompositionselemente als relativ stereotype Merkmale von Prolalien benennen: (I) Die Erzählung, (2) die Beschreibung, (3) die Selbstreferenz. Hinzu kommt noch ein viertes Element, das nicht ganz so leicht zu identifizieren ist, denn es befindet sich unter der Oberflächenstruktur der prolalia. Es handelt sich hierbei um eine Art Spiel mit dem Zuhörer, der durch versteckte Hinweise und geistreiche Anspielungen dazu aufgefordert wird, sein Bildungswissen einzusetzen und interaktiv mitzuwirken. ${ }^{143}$ Pernot hat in seiner Auslegung der bereits erwähnten Regenbogenprolalia des Marcus von By$\mathrm{zanz}^{\mathrm{I44}}$ darauf hingewiesen, dass der zunächst nicht gerade originell wirkende Re-

I39 Flor. 9,15-29. Zu den selbstreferentiellen Aussagen bei Apuleius, die auch religiöse und lokalpolitische Themen aufgreifen können, vgl. Hunink 2004, I75-I87.

I40 Diesen Begriff verwendet Lukian (Bacch. 8), um seinen Zuhörern zu verdeutlichen, dass die soeben vorgetragene Geschichte von den drei Quellen keiner weiteren Erläuterung bedarf, weil

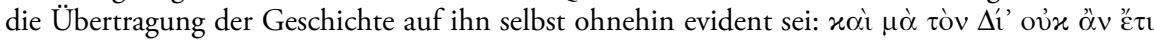

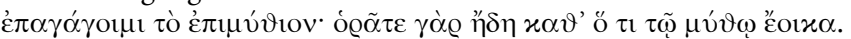

I4I Homerzitate und -reminiszenzen findet man z. B. bei Lukian, Zeux. 2 (Od. I,35I-352), Zeux. IO (Il. I6,379), Scyth. 9 (Homer-Reminiszenz an den Besuch des Telemach bei Menelaos Od. 4,43); Herc. 4 (vgl. Il. 3,IO8, Il. I,249 und Il. 3,I5O-I52); Herc. 7 (Il. 8,IO3-IO4); Herc. 8 (Od. II,I7 und I8,74); Bacch. 7 ( Il. 3,222); Dion, Or. I2,I5 (Od. I,376), Or. 35,6 (Il. 19,386), sowie zahlreiche Zitate und Anspielungen in den Reden 32 und 33; bei Apuleius findet man außer einer fraglichen Homer-Reminiszenz Flor. I8,28 (Od. 5,328; vgl. Valette 197I, I64 Anm.I) nur noch Flor. 15,23 einzelne, aber durchaus witzig eingesetzte homerische topoi (geflügelte Wortel im Gehege der schimmernden Zähne), wobei Homer namentlich Flor. 15,21 erwähnt wird.

I42 Vgl. Lukian (Herc. 8) und Dion (Or. I2,I5). Zu diesen Texten vgl. unten den Abschnitt 4.6.

I43 Vgl. dazu Pernot 1993, 565-568.

I44 Philostrat, VS 528. 
genbogenvergleich auch eine Anspielung auf Platons Theaitetos enthält, da das

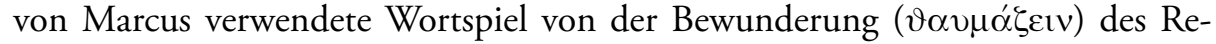
genbogens (ĩoı) auf eine mythologische Genealogie verweist (Iris als Tochter des Thaumas), die schon von Platon herangezogen wurde, um sein berühmtes Wort zu illustrieren, das Staunen sei der Anfang der Philosophie (Theaitetos I5sd). Welche konkrete Funktion dieser Subtext hatte, ist schwer zu beantworten, er verlieh jedenfalls dem Text eine zusätzliche Qualität und eröffnete dem Zuhörer ein neues Textverständnis. Das gebildete Publikum erwartete geradezu solche literarischen Spielformen. Durch die Entschlüsselung der intertextuellen Rätsel wurde die Lust am Zuhören gesteigert und das Elitebewusstsein der pepaideumenoi gestärkt, da sie mit den entsprechenden Bildungscodes zu einem tieferen, der ungebildeten Masse verborgenen Textverständnis vordringen konnten. Insofern sollte man derartige Anspielungen auf Subtexte als intertextuelle Steuerzeichen lesen, die letztlich der Interpretation der Texte dienten. ${ }^{\mathrm{I}}{ }^{5} \mathrm{Im}$ spezifischen Kontext der Prolalien profitierte vor allem der Redner selbst von der Decodierung der Anspielungen, da den Subtexten selbstreferentielle Aussagen abzulesen waren. Die soeben erwähnten vier Kompositionselemente werden nun in einer vergleichenden Analyse untersucht und für die prolalia des Clemens ausgewertet.

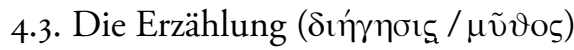

Die von Clemens als $\mu$ ṽ $\vartheta$ os eingeführte Erzählung von dem Kitharaspieler Eunomos und der Zikade (Protr. I,2-3) schließt sich an eine thematische Einleitung an, in der in kurzen Paraphrasen die Mythen der drei Sänger Amphion, Arion und Orpheus wiedergegeben werden. Clemens skizziert hier eigentlich nur die highlights der Mythenerzählungen und überlässt es dem Leser bzw. Zuhörer diese Skizzen auszugestalten: Amphion und die Mauern von Theben, Arion und der Delphin, Orpheus mit den wilden Tieren und den wandelnden Bäumen. Mit diesen starken, geradezu ikonographisch verkürzten Szenen, die auch in den antiken Kunstwerken immer wieder reproduziert wurden - man denke nur an die zahlreichen Mosaikdarstellungen mit dem Orpheusmotiv ${ }^{146}$ - führt Clemens den Zuhörer in eine musikalische Zauberwelt ein, die als Kulisse für die weiteren Ausführungen dient. Durch die Eunomosgeschichte wird das bereits in den ersten Zeilen anklingende Thema Musik und Mythenkritik weiter entfaltet, wobei

I45 Zum Begriff der Steuerzeichen vgl. von Möllendorff 2000, I2, der intertextuelle Anspielungen bzw. Reminiszenzen seinem hermeneutischen Ansatz entsprechend, „als absichtlich vom Autorsubjekt für ein Lesersubjekt hinterlassene, teils klare, teils chiffrierte Steuerzeichen der Interpretation" versteht.

I46 Vgl. exemplarisch das wohl aus dem 2. Jh. n. Chr. stammende Schwarz-Weiß-Mosaik aus den Termen von Perugia bei Binder 2009 (Abb. 6). 
die Mythenkorrektur der Eunomoserzählung die nachfolgende und wesentlich polemischere Dichter- und Mythenkritik didaktisch vorbereitet.

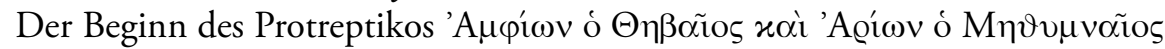

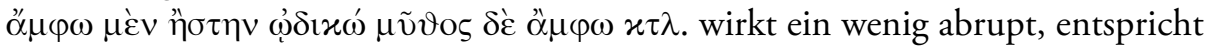
aber vollkommen dem Anfang anderer Prolalien. Man vergleiche nur Lukians

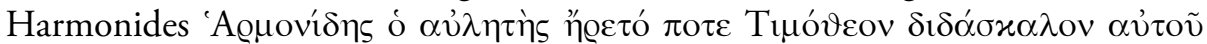
öv $\tau \alpha, x \tau \lambda .{ }^{147}$ oder Apuleius' Flor. 3 Hyagnis fuit, ut fando accepimus, Marsyae tibicinis pater et magister ${ }^{\mathrm{T}{ }^{8}}$. Wie im Protreptikos des Clemens wird in diesen beiden Prolalien der Name eines Musikers programmatisch vorangestellt und der Vortrag paukenschlagartig eröffnet.

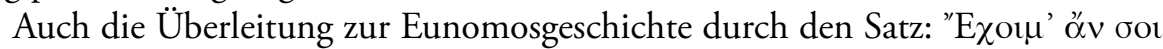

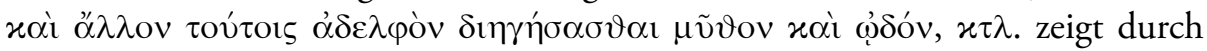
seine gekünstelte Spontanität eine enge Verwandschaft mit anderen Prolalien wie

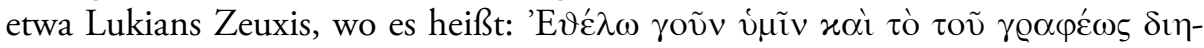

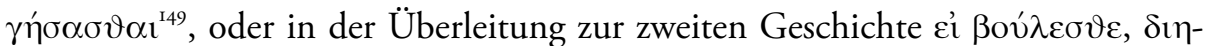

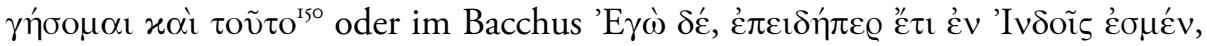

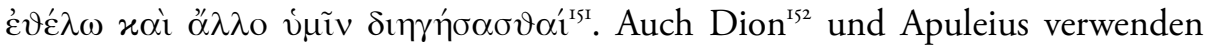
solche Überleitungen. Apuleius führt seine Erzählung über den tragischen Tod des Philemon mit folgenden Worten ein:

Ich will euch dafür ein recht ähnliches Beispiel erzählen, wie unvorhergesehene Gefahren plötzlich den Menschen begegnen, nämlich vom Komödiendichter Philemon. Von seinem Talent wisst ihr ja genug, von seinem Ende hört, was ich in Kürze berichte. Oder wünscht ihr auch ein weniges über sein Talent? ${ }^{\text {IS3 }}$

I47 Harm. I: „Harmonides, der Flötenspieler, fragte einmal Timotheus, seinen Lehrer, usw.“ Ähnlich unvermittelt beginnen auch alle weiteren Prolalien Lukians. Vgl. auch Dion Or. 57 (Nestor) und Or. 72 (Von der äußeren Erscheinung). Beide Prolalien werden geradezu überfallartig durch eine Frage eröffnet. Vgl. auch die Namensliste am Anfang von Dions Prolalia Or. 54,r: „Die Sophisten Hippias von Elis, Gorgias von Leontinoi, Polos und Prodikos ..."

I48 Flor. 3: „Hyagnis war, wie wir durch die Sage erfahren haben, der Vater des Flötenspielers Marsyas und sein Lehrer." Unter den Prolalien des Apuleius findet sich nur noch eine weitere, die ebenso abrupt beginnt wie die oben zitierte, nämlich Flor. I5, die mit ihrer unmittelbar einsetzenden geographischen ekphrasis an den Beginn von Lukians Dipsades erinnert.

I49 Zeux. 3: „Ich will euch dazu wenigstens auch eine Geschichte von einem Maler erzählen“; vgl. auch Scyth. I.

I50 Zeux. 8: „Wenn ihr wollt, werde ich euch auch das noch erzählen.“

I5I Bacch. 6: „Aber weil wir nun einmal in Indien sind, so will ich euch doch noch eine andere Geschichte erzählen"; vgl. auch Bacch. I.

I52 Vgl. die Überleitung zur Geschichte vom Vogelfang in d. prolalia der Olymp. Rede (Or. I2,I2).

I53 Übers. Helm 1977, 191; Flor. 16,5: „Exemplum eius rei paulo secus simillimum memorabo, quam improvisa pericula hominibus subito oboriantur, de Philemone comico. de ingenio eius qui satis nostis, de interitu paucis cognoscite. an etiam de ingenio pauca vultis?" Vgl. auch Flor. I8,I8. Apuleius verweist hier implizit auf die Möglichkeit, zwei Geschichten zu erzählen, stellt aber sofort fest: „video, quid postuletis: utramque narrabo. “Hilton 2000, I25, interpretiert sowohl Flor. 16,5 als auch Flor. I8,I8 als Belege für echte Themenvorschläge: „If these were merely rhetorical and not actual exchanges between speaker and audience they would lose their impact 
Auf diese Weise gelingt es dem Redner, mit dem Publikum in einen - freilich nur rhetorisch inszenierten - Dialog zu treten. Die Rede wirkt dadurch freier und spontaner und entspricht damit den Kompositionsregeln der prolalia. Es lohnt sich auch den Überleitungssatz selbst genauer zu betrachten, denn mit der For-

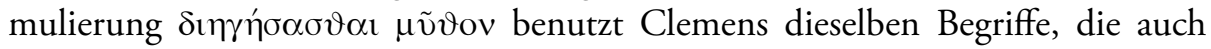

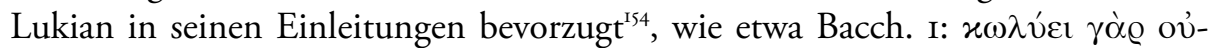

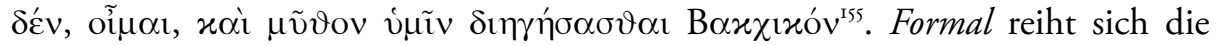
Einleitung des Clemens mit der anschließenden Erzählung also problemlos in den Kanon der Prolalien der Zweiten Sophistik ein. Inhaltlich gewinnt die Eunomosgeschichte ihren Reiz aus der christlich inspirierten Mythenkorrektur, sollte aber nicht ausschließlich als gegenkulturelle Provokation gelesen werden, sondern vielmehr als eine geistreiche und unterhaltsame Variante, die vollkommen mit den Konventionen der Zeit übereinstimmt. Denn seit der Dichter- und Mythenkritik des Xenophanes von Kolophon im späteren 6. Jahrhundert v. Chr. und der didaktischen Verwendung und Neuschöpfung von Mythen in der (ersten) Sophistik war ein kritischer und kreativer Umgang mit Mythen nicht nur erlaubt, sondern philosophisch gefordert. ${ }^{156}$ In der Zeit der Zweiten Sophistik findet man vor allem bei Aelius Aristides zahlreiche Beispiele für eine religionsphilosophisch und politisch motivierte Bearbeitung und Neuschöpfung von Mythen. ${ }^{157}$ Die von Clemens vorgetragene Mythenkorrektur der Eunomosgeschichte und die sogleich in der prolalia nachfolgende Mythen- und Dichterkritik gewinnen in diesem Kontext ein erstaunlich aktuelles Profil. ${ }^{158}$ Beispiele für Mythenkritik und Mythenexegese finden sich selbstverständlich auch in anderen Prolalien. ${ }^{159}$ Lukian thematisiert beispielsweise die Unglaubwürdigkeit des Phaëthon-

as demonstrations of oratorical versatility and skill." Dies erscheint allerdings höchst unwahrscheinlich, da die Selbstreferenz in der Prolalia (Flor. 18,36) gerade den Kontrast der beiden Geschichten voraussetzt.

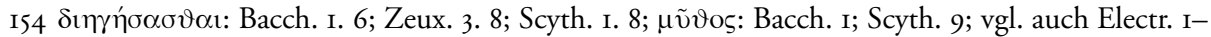
2, $\mu \tilde{v} \vartheta \circ \varsigma$ hier aber nicht in der Überleitung zu einer Geschichte, sondern allgemein als terminus für mythologische Erzählungen; vgl. dazu auch Pernot 1993, 563 Anm. 359.

I55 "denn es ist nicht verboten, hoffe ich, euch auch eine dionysische Geschichte zu erzählen."

I56 Vgl. dazu das Kapitel „Philosophen, Allegoristen und Mythologen“" bei Graf 1999, I68-189.

I57 Vgl. dazu Pernot 1993, 762-772, Saïd 2008, 5I-67 und Gangloff 2002, 25-56.

I58 Vgl. Pernot 1993, 772: „Il s'agit, pour Aristide et pour ses confrères, de compléter les leçons religieuses tirées des mythes anciens, en appliquant leur réflexion aux événements contemporains. Devant les décès et les catastrophes naturelles, ils posent les questions cruciales, celles qui hantent l'esprit du public: l'interprétation de la tukhê, la responsabilité des dieux." In diesem Zusammenhang gewinnt auch der von Clemens in der narratio (Protr. 6,I-IO,I9) vorgetragene Christusmythos, in dem die gesamte Heilsgeschichte kurz rekapituliert wird, eine interessante kulturkritische Dimension.

I59 Vgl. nochmals Pernot 1993, 763: „Enfin, la mythologie est un parti esthétique. Elle procure le charme et la douceur nécessaires au style ,détendu'. D'où la multiplication des allusions et des récits mythologiques dans la lalia, dans l'éloge paradoxal et dans les autres discours de style anetos, comme certains épithalames." 
Mythos in der prolalia über den Bernstein, um seinen eigenen Mythos als Redner - hier durchaus im Sinne einer captatio benevolentiae - selbstironisch zu hinterfragen. Man solle sich von seiner Rede nicht zuviel erwarten, er selbst sei,

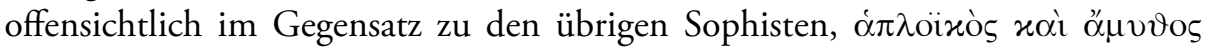
(Electr. 6). Die prolalia beginnt folgendermaßen:

Bezüglich des Bernsteins hat auch uns der Mythos unzweifelhaft davon überzeugt, dass ihn am Fluss Eridanus die Pappeln weinen, die den Phaëthon beklagen, dass jene Pappeln die Schwestern des Phaëthon waren, bevor sie in ihrer Trauer um den Knaben in Bäume verwandelt wurden, und dass sie weiterhin ihre Tränen vergießen, die seitdem zu Bernstein werden. ${ }^{160}$

Lukian berichtet daraufhin von seiner Reise zum Eridanos. Seine Hoffnung, durch diese Expedition ins Mythische reich zu werden, wird schließlich durch die ungebildeten, zugleich aber über einen gesunden Menschenverstand verfügenden Schiffsleute zerstört. Lukian erzählt ihnen den Mythos und erhält folgende Antwort:

Wir haben weder einen Wagenlenker abstürzen sehen, noch gibt es solche Pappeln bei uns, von denen du sprichst. Wenn es so etwas gäbe, meinst du wir würden für zwei Obolen rudern oder Lastschiffe den Fluss hinaufziehen, wenn wir bloß Pappeltränen sammeln müssten, um reich zu werden $?^{161}$

Im Anschluss (Electr. 4-5) wird noch der Mythos von den singenden Schwänen Apollons als Lügengeschichte entlarvt, worauf schließlich (Electr. 6) die Übertragung beider Geschichten auf Lukian als Redner, also der selbstreferentielle Teil mit der oben schon zitierten Selbsteinschätzung, folgt. ${ }^{162}$

Das von Lukian angewandte Prinzip rationaler Mythenkritik, das letztlich nur auf der Logik von Alltagserfahrungen beruht, findet sich auch bei Clemens. So wie Lukian in der Prolalia vom Bernstein die Geschichte von den in Schwäne verwandelten Musikern aus dem Gefolge Apollons entmythologisiert, indem er die Schiffsleute als objektive Zeugen zitiert, die freilich nur das jämmerliche, unmusikalische Krächzen der Schwäne kennen und sich wundern, „woher solche

I60 Electr. I: 'H

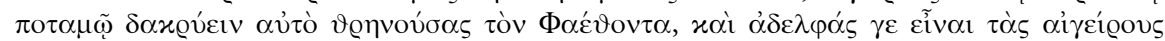

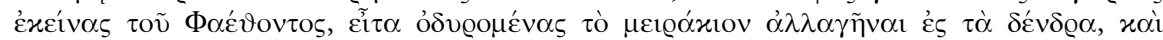

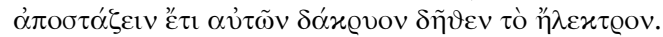

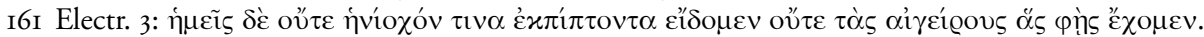

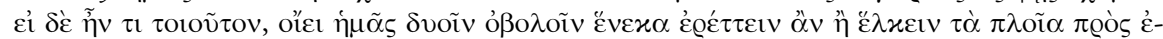

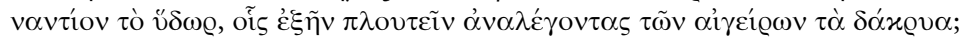

I62 Als weiteres Beispiel könnte man Lukians prolalia Hercules heranziehen, in der ein Gallier als Exeget dem staunenden Lukian das Bild des Herakles-Ogmios erklärt. Barbara Borg hat darauf hingewiesen, dass in beiden Prolalien „die Strategie der Etablierung einer ironischen Komplizenschaft zwischen Rhetor und Publikum" vorliegt, da die vorgespielte Naivität Lukians dem ohnehin skeptischen Zuhörer „einen intellektuellen Erfolg und das momentane Gefühl geistiger Überlegenheit" suggeriert (Borg 2004b, 47). 
Lügen ... kommen können “163, so beschreibt Clemens die Zikaden als Geschöpfe

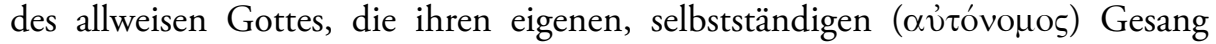
pflegen und keineswegs ein Kultlied auf den Drachen Pytho anstimmen. Mit diesem autonomen Gesang können Clemens zufolge die Melodien (vónou) des Eunomos nicht konkurrieren. Insofern ist von Anfang an ausgeschlossen, dass die Zikade durch die Musik des Eunomos angelockt wird (wie im Mythos die Steine durch Amphion, der Delphin durch Arion, die Tiere und Bäume durch Orpheus). Nach Clemens verhält es sich umgekehrt: Eunomos passt sich in seiner Not dem Gesang der Zikade an und ergänzt damit die fehlende Seite. Wie die Schwäne im Sumpfgebiet des Eridanos natürlicherweise krächzen, so zirpt die Zikade auf dem Steg der Kithara wie auf einem Zweig. Es gibt nichts Übernatürli-

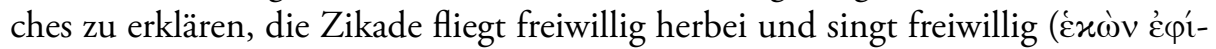

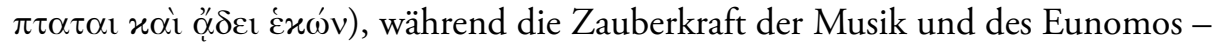
und natürlich auch der übrigen mythologischen Sänger - versagt. Diese Mythen-

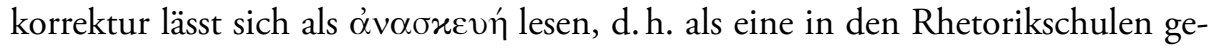
übte Form der progymnasmata, bei der es darum ging, möglichst plausibel Mythen, Erzählungen, ja selbst historische Ereignisse zu negieren oder einfach anders darzustellen. ${ }^{164}$

Auf weitere Aspekte der Erzählung kann an dieser Stelle nicht eingegangen werden. Dies ist auch nicht zwingend notwendig, da im Anschluss an den nächsten Abschnitt ein Überblick über alle Themen und Motive gegeben wird, die Clemens in seiner prolalia verarbeitet hat, wobei auch die entsprechenden Parallelen aus den Prolalien der Zweiten Sophistik aufgelistet und ausgewertet werden. Die in der Erzählung vorkommenden Anspielungen auf platonische Subtexte werden wiederum im Abschnitt über die intertextuellen Steuerzeichen besprochen. Dass mit dem Gesang der Zikaden Platons Phaidros die Szene betreten hat, sollte aber bereits an dieser Stelle nicht unerwähnt bleiben.

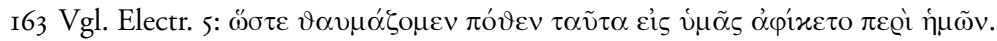

I64 Vgl. Webb 200I, 300-302, und Schmitz 1997, 194-195, der das rhetorische Spiel mit mythologischen und geschichtlichen Themen in der Zeit der Zweiten Sophistik als den Versuch der Bildungselite interpretiert, die Deutungshoheit über die in die Gegenwart hineinreichende Vergangenheit zu gewinnen: „Angesichts der Wichtigkeit, die Tradition und Geschichte für die Gruppenidentität haben, kann man somit wiederum konstatieren, dass die Bildungselite die interpretatorischen Mittel der Sinndeutung und damit einen großen Teil der symbolischen Macht monopolisiert hat" (S. I95). Dagegen betont Webb 200I, 302: „These stories are elements of a common cultural property, to be manipulated and exploited as a demonstration of the art of argumentation. Their utility for the purpose lies precisely in the fact that they are well known." 


\subsection{Die Beschreibung ('̌x}

Nach Aelius Theon versteht man unter einer $e k p h r a s i s^{165}$ „eine beschreibende Rede, die den Gegenstand klar vor Augen führt:

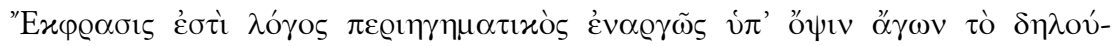

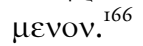

Wie zuletzt Ruth Webb gezeigt hat, unterscheidet die Qualität der enargeia eine Beschreibung von einer Erzählung. ${ }^{167}$ Eine gute Beschreibung muss demnach durch Anschaulichkeit überzeugen, wobei die Kunst darin besteht, dem Zuhörer etwas vor Augen zu führen, was er aktuell nicht sehen kann. ${ }^{168}$ Dies gelingt einerseits durch eine detailliertere Ausgestaltung der Rede und andererseits durch die Verwendung konventioneller Motive, die den Zuhörer dazu animieren, die dargestellte Szene selbstständig zu imaginieren. ${ }^{169}$ Dies hat wiederum den Effekt einer größeren Emotionalisierung des Zuhörers, der gewissermaßen als Augenzeuge in das Geschehen involviert wird. Die Strategie der ekphrasis besteht also darin, den Zuhörer zu einem emotionalisierten Zuschauer zu machen ${ }^{\mathrm{I70}}$, und zwar häufig mit der Absicht, ihn durch die Illusion einer Autopsie zu manipulieren. ${ }^{171}$

Dies harmoniert ausgezeichnet mit dem Hedone-Konzept der Prolalia, wobei die Ekphraseis auch dazu benutzt werden, die persona des Redners zu etablieren, da sich die selbstreferentiellen Aussagen der Prolalien sehr oft auf Beschreibungen beziehen. ${ }^{172}$ Beschreibungen von Ereignissen, Bildern, Statuen, Personen und Tieren gehören deshalb zum Grundrepertoire der Prolalien. ${ }^{173}$ Lukians Kunstfertig-

165 Zur Technik der ekphrasis, die zu den Ausbildungsinhalten der progymnasmata zählte, vgl. jetzt die umfassende Darstellung von Webb 2009 mit der S. 217-222 genannten Literatur.

I66 Progymn. II8,6. Diese Definition aus dem Kapitel über die ekphrasis (Progymn. II8,6-I20,II) findet sich nahezu wörtlich auch in den progymnasmata von Ps.-Hermogenes, Aphthonios und Nikolaos. Die entspechenden Abschnitte zur ekphrasis sind jetzt bei Webb 2009, 197-205, zusammengestellt. Die vollständigen Texte dieser rhetorischen exercises kann man nun in einer englischen Übersetzung bei Kennedy (2003) bequem einsehen und vergleichen.

I67 Vgl. Webb 2009, 70-7I, bezieht sich auf eine Definition aus den progymnasmata des Nikolaos.

I68 Vgl. hierzu das Kapitel „Enargeia: Making Absent Things Present" bei Webb 2009, 87-Io6.

I69 Vgl. hierzu das Kapitel „Phantasia: Memory, Imagination and the Gallery of Mind“ bei Webb 2009, 107-130.

I70 Vgl. die Erklärung von Nikolaos (Progymn. 68,II,9-IO), weshalb die Beschreibung im Gegen-

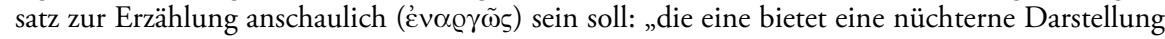

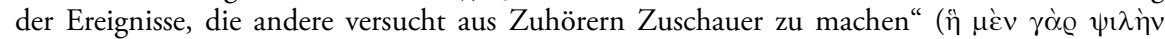

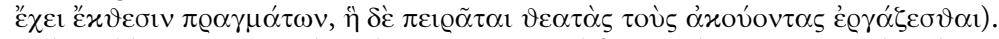

171 Vgl. Webb 2009, 193: „Though enargeia is used frequently in genres such as historiography and poetry, its effects can also be thoroughly rhetorical, helping the orator to involve his audience (and himself) emotionally and imaginatively in the subject of the speech and thus to promote their acceptance of the ideas he is putting forward."

I72 Vgl. dazu den Abschnitt zur Technik der Selbstreferenz weiter unten.

173 Dies korrespondiert weitgehend mit den in den progymnasmata vorgeschlagenen Themen; vgl. die Übersicht bei Webb 2009, 64. 
keit in der Darstellung von Gemälden verführte bekanntlich Renaissancekünstler - wie Raffael, Dürer und Botticelli - zur Rekonstruktion antiker Bilder nach den lukianischen Beschreibungen. ${ }^{174}$ Aber schon die antiken Zuhörer dürften die von den Sophisten beschriebenen Bilder und Motive unmittelbar vor Augen gehabt haben, zumal häufig erotische, exotische und paradoxe Sujets vorkamen, wie etwa Aëtions Bild, das Alexander und Roxane im Schlafgemach darstellt (Herod.), das Pferdemenschenfamilienbild des Malers Zeuxis mit der schönen Zentaurin (Zeux.), das Bild vom gallischen, zungendurchbohrten Herkules und seinem Anhang (Herc.), die Beschreibung der Libyschen Wüste mit ihren DipsasSchlangen (Dips.), Dions ekphrasis des Pfaus (Or. I2,2-3. 5), die ein parodistisches Portrait sophistischer Starredner darstellt ${ }^{175}$, oder die boshafte Beschreibung des Sophisten Hippias durch Apuleius (Flor. 9) ${ }^{176}$. Exemplarisch soll hier Apuleius' ekphrasis der Statue des Kitharaspielers Bathyllos wiedergegeben werden (Flor. I5,6-IO):

So steht etwa gleich vor dem Altar eine Statue des Bathyllos, vom Tyrannen Polykrates geweiht, wohl das Vollkommenste, was ich gesehen habe; manche halten es fälschlich für ein Standbild des Pythagoras. Es ist ein Jüngling von auffallender Schönheit, die Haare vorn, gleichmäßig geteilt, über die Wangen zurückgestrichen, hinten aber beschatten die reichlichen Locken den durchschimmernden Nacken bis zu den Schulterblättern; der Nacken ist voller Kraft, die Wangen voll, das Kinn rund, aber in der Mitte des Kinnes ein Grübchen, und seine Haltung ist ganz die eines Kitharaspielers: den Blick auf die Göttin (Hera TL) gerichtet, einem Singenden ähnlich, das mit Stickereien buntverzierte Gewand bis ganz auf die Füße herabgelassen, mit griechischem Gürtel, verhüllt er beide Arme mit dem Mantel bis zum Handgelenk, das übrige hängt in anmutigen Falten herab. Die Kithara, an einem verzierten Gurt befestigt, wird eng an den Körper gehalten; seine Hände sind zart, ziemlich schlank, die linke setzt mit gespreizten Fingern die Saiten in Bewegung, die rechte bewegt in der Haltung eines Spielenden das Schlagstäbchen auf die Kithara zu, gerade als wäre sie bereit zu schlagen, sobald die Stimme mit dem Gesang aussetzt. Diesen Gesang scheint er inzwischen aus

I74 Vgl. Borg 2004b, 5I, die feststellt, „dass die Rekonstruktion antiker Kunstwerke aus literarischen Ekphraseis - übrigens nicht nur des Lukian - eine mehr als heikle Angelegenheit ist. Es ließe sich ausführlicher zeigen - und wurde auch bereits vielfach gezeigt -, dass diese Ekphraseis zwar gelegentlich real existierende Kunstwerke zum Anlass nehmen, ihren Ehrgeiz aber nicht in eine möglichst exakte Beschreibung derselben legen, sondern in ein oftmals äußerst raffiniertes Spiel mit Sehen und Gesehenwerden, mit Sehen und Hören und nicht zuletzt mit der Realität bildlicher Darstellung und der Kunst rhetorischer enargeia, der Macht der Sprache, visuelle Bilder zu schaffen, den Zuhörer zum Zuschauer zu machen." Zu Lukians Bildbeschreibungen in den Prolalien Herkules, Herodot und Zeuxis vgl. zuletzt Billault 2006, 47-59.

I75 Vgl. Klauck 2000, I09 Anm. II und III Anm. 29.

I76 Vgl. auch die Narren-Ekphrasis Flor. 3,8-II, in der der Flötenspieler Marsyas die Vorzüge Apollons tadelt. 
dem feingeschnittenen Mund den beim Ansatz halbgeöffneten Lippen entströmen $\mathrm{zu}$ lassen. ${ }^{\mathrm{I} 77}$

Auch Clemens erwähnt in seiner prolalia die Statue eines berühmten Kitharaspielers. Er notiert zwar, dass Eunomos mit der Zikade und seiner Kithara zu sehen war und dass es sich um eine Bronzestatue handelte, eine ekphrasis ist dies aber keineswegs. Immerhin zeigt Clemens, dass er die rhetorische Strategie kennt, in der prolalia auf Kunstwerke zu verweisen. ${ }^{178}$ Der Verzicht auf eine ekphrasis im Stil des Apuleius kann aber auch erklärt werden. Einmal ist durch die Erzählung bereits alles Wesentliche über die Geschichte des Eunomos gesagt, Clemens hätte also die Statue lediglich unter ästhetischen Gesichtspunkten beschreiben können. Dies hätte die prolalia unnötig in die Länge gezogen und keinen weiteren Gewinn gebracht. Selbst Apuleius verzichtet auf eine Auslegung seiner schönen Beschreibung und geht unmittelbar zur nächsten Geschichte über, indem er nochmals betont, dass die Statue nicht Pythagoras darstelle, woraufhin er dann den Studienweg des Pythagoras nacherzählt und schließlich - das pythagoreische Schweigen thematisierend - zur Übertragung auf die eigene Person fortschreitet (Flor. I5,II-26). Die ekphrasis der Statue ist an sich völlig überflüssig und dient nur der hedone des Publikums. ${ }^{179}$ Auf solche rhetorischen Prunkstücke kann Clemens verzichten, zumindest im Zusammenhang mit der Eunomosgeschichte, denn tatsächlich folgt noch eine kunstvolle ekphrasis, nämlich die visionäre Beschreibung des dionysischen Dichter-Thiasos und der Epiphanie des himmlischen Logos (Protr. 2,2-3). Die in den ersten Zeilen des Protreptikos vorgetragene Mythenkritik, die Clemens nochmals Protr. 2,I als Frage zusammenfasst, wird nun fortgesetzt und verschärft. Es geht um die Mythen, die auf den heiligen Bergen als Mysterien gefeiert werden und von den Dichtern zu Tragödien ausgestaltet wurden. Clemens erscheint es befremdlich, dass „das strahlend schöne Gesicht der Wahrheit" von den Griechen ungläubig betrachtet wird, während sie selbst die „Weihestätten des Irrtums“ in Mysterienkulten verehren. Geradezu unerträglich findet Clemens die Darstellung tragischer Stoffe im Theater und die Begeisterung der Griechen für solche Dramen. Da die Dichter als Mythenerzäh-

I77 Übers. Helm 1977, I87 (nach der Zählung von Helm I5,4-7).

$178 \mathrm{Vgl}$. die prolalia der Olympischen Rede, in der Dion nur ganz kurz auf das von Pheidias geschaffene Standbild der Athena Parthenos mit der Eule verweist, das auf der Akropolis aufgestellt war (Or. 12,6); vgl. dazu Klauck 2000, II2 Anm. 35-36. Vgl. auch Harrison 2000, II4: „sOphistic orations could often begin with material drawn from the speaker's journeys, thereby presenting the speaker as an impressively well-travelled and cosmopolitan figure." Diesen Eindruck hinterlässt Clemens mit seiner kurzen kunstgeschichtlichen Notiz durchaus.

I79 Möglich ist allerdings, worauf zuletzt La Rocca 2005, 213, hingewiesen hat, dass Apuleius gegenüber dem anwesenden Prokonsul den Standpunkt philosophischer Freiheit reklamierte: „,ome Pitagora, Apuleio non può essere confuso con il giovinetto della statua. Se gli altri panegiristi, come Batillo con Policrate, lusingano il proconsole, egli non si piegherà a un discorso adulatorio ma dimostrerà, come Pitagora, l'incoercibile libertà del filosofo." 
ler im Kampf gegen die Wahrheit eine Schlüsselrolle spielen, werden sie von Clemens in die Bergwelt der alten Mythen verbannt (Protr. 2,2):

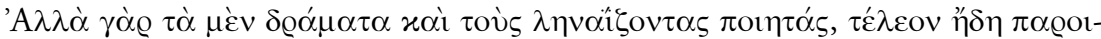

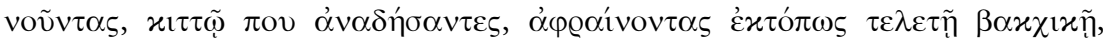

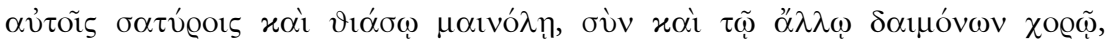

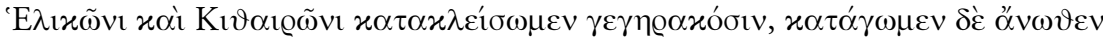

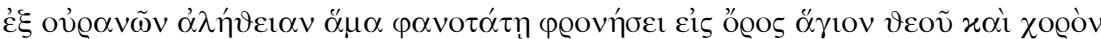

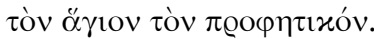

Dieser Text gewinnt seinen Reiz vor allem durch drei Motive: Die Beschreibung der Dichter als Teilnehmer am dionysischen Thiasos, die Verbannung der Dichter in die Bergwelt und die Ankunft des neuen Kultpersonals.

Als Bildmotiv war der Thiasos in der Antike omnipräsent (vgl. Abb. I). Auf Vasen, Gemmen, Mosaiken, Wandmalereien und Sarkophagen wurde der Auftritt des Dionysos mit seinem Gefolge geradezu massenmedial vermittelt. ${ }^{180} \mathrm{Cle-}$ mens kann also mit wenigen Strichen das ganze Szenario eines bacchanalischen Umzugs dem Leser vor Augen führen. Die detaillierte Kenntnis dieses Bildmotivs setzt im 2. Jahrhundert auch Lukian voraus, der im Bacchus den dionysischen Thiasos auf seinem Weg nach Indien beschreibt (Bacch. I-5), wobei er zunächst das Gefolge des Dionysos aus indischer Perspektive schildert, um den Zuhörer selbst erraten zu lassen, welche Figur des Thiasos jeweils gemeint sein könnte. Während der lukianische Text seinen Witz aus der Unwissenheit der Inder und der Komplizenschaft des Lesers bezieht, erzielt der Text des Clemens allein durch die Beteiligung der Dichter am Thiasos seine komische Wirkung, zumal er die Rolle der Dichter satyrisch überzeichnet. Das $\lambda \eta v \alpha^{\prime} i \zeta \varepsilon v^{181}$ der betrunkenen Dichter ist an polemischer Schärfe kaum zu überbieten, da die rasenden Poeten die Rolle der Mänaden zu übernehmen scheinen. ${ }^{182}$ Als literarische Vorlage dieser oreibasia ist selbstverständlich an die Bakchen des Euripides zu denken. Wie schon Riedweg nachweisen konnte, existieren engste inhaltliche und strukturelle Parallelen zwischen Protr. 2 und Protr. II8,5-II9,2, die „auf dieses Drama als gemeinsame Inspirationsquelle“ verweisen. ${ }^{183}$ Tatsächlich ist in den Bakchen auch

I80 Aus der umfangreichen Literatur zum Thiasos bzw. dessen Ikonographie vgl. Zanker/Ewald 2004, 135-167. 304-316, und Schöne-Denkinger 2008, 42-53.

I8I So reizvoll es wäre, das Verb $\lambda \eta v \alpha i ́ \zeta \xi \varepsilon v$ mit Rizzi 1993, I76, auf das Dionysosfest der Lenäen zu beziehen, das im Wintermonat Gamelion in Athen gefeiert wurde, so unsicher ist dieser Bezug auch. Denn Clemens dürfte den Begriff einem Heraklit-Text (Frg. 15) entnommen haben, den

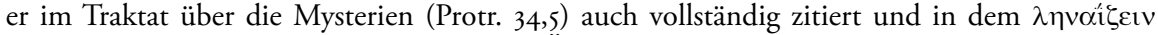

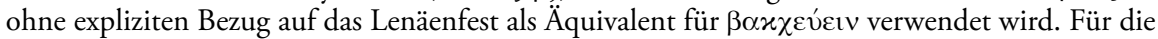
ausschließliche Herkunft aus dem Heraklit-Text spricht auch, dass der Begriff nach dem TLG nur noch ein einziges Mal vorkommt, und zwar bei Plutarch, De Iside et Osiride 362, wiederum innerhalb desselben Heraklit-Zitats. Vgl. dazu Pickard-Cambridge 1988, 30, mit Bezug auf die zuvor S. 27-29 zusammengestellten Texte zum Lenäenfest (darunter auch die Texte des Clemens und des Heraklit mit den jeweiligen Scholien).

I82 Zu den einzelnen Formen und Begriffen bacchischer Raserei vgl. Schlesier 2008, 28-4I. 
der Kithairon der Ort der orgiastischen Feiern ${ }^{184}$ und der Schauplatz der von Clemens kritisierten Tragödien. Mehrfach werden die Bakchen in die Berge gerufen

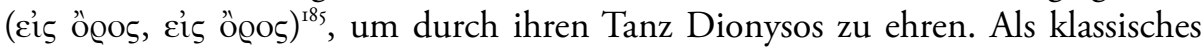
Offenbarungsmedium bewirkt der Tanz der Mänaden die Epiphanie des Dionysos in den Bergen ${ }^{186}$ An diese Vorstellung kann Clemens kulturgeschichtlich anknüpfen. Die im folgenden Textabschnitt (Protr. 2,3) als Vision geschilderte Herabkunft des himmlischen Logos ist durch den intertextuellen Verweis auf die Bakchen des Euripides ideal vorbereitet. Als Metropole des neuen Welttheaters wird nun der Zion mit Jerusalem präsentiert:

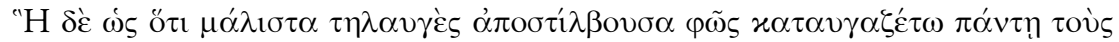

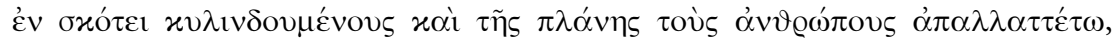

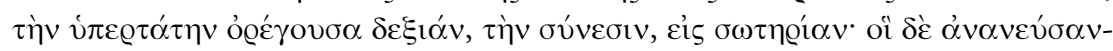

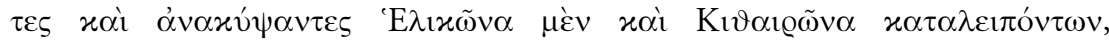

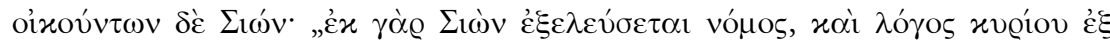

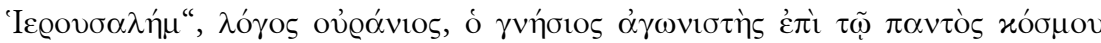

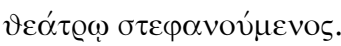

Mit der direkten Aufforderung an die Zuhörer, zum Himmel zu schauen, verweist Clemens bereits hier in der prolalia auf das Thema der Gottesschau, das den gesamten Protreptikos als philosophische Leitidee bestimmt. ${ }^{187}$ Den gebilde-

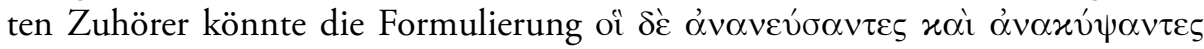
an Phaidros 249c erinnert haben, d.h. an die zum wahrhaft Seienden emporblickende Seele des Philosophen - eine Stelle, an der Platon ebenfalls àvaxúr $\tau \varepsilon v v$ verwendet hat. Der nach oben gerichtete Blick dürfte aber auch, vor allem in der Kombination mit der Theatermetaphorik des Textes ${ }^{188}$ und dem deutlich akzentuierten Rettungsmotiv, als szenischer Hinweis zu interpretieren sein, dass nun der christliche Erlösergott als deus ex machina in das große Weltendrama eingreift. ${ }^{189}$

Insgesamt hat Clemens mit seiner Beschreibung des dionysischen Thiasos, der oreibasia der Dichter und der anschließenden Epiphanie des Logos eine ekphrasis geschaffen, die dem Zeitgeschmack wohl voll entsprochen haben dürfte. Das religiöse Motiv der ekphrasis wird den Zuhörern keineswegs ungewöhnlich vorgekommen sein, da die ekphraseis der Zweiten Sophistik, wie Pernot gezeigt hat, häufig religiöse Themen entfalteten:

I83 Vgl. dazu Riedweg 1987, I50-I54.

I84 Vgl. Euripides, Bacchae 62; 661; 751; 797; 945; I045; II42; II77; I219; I292.

I85 Vgl. Euripides, Bacchae 76; II6; 135; 165; 726; 977; 986.

I86 Zu den Epiphanien des Dionysos vgl. Seaford 2006, 39-48.

I87 Vgl. dazu Riedweg 1987, I50-158, und Lechner 2007, I83-22I.

I88 Vgl. Lugaresi 2003, IO-29.

189 Das deus ex machina Motiv findet man außerhalb der Theaterliteratur auch bei Aelius Aristides, der freilich mit dem Auftreten von Rettergestalten eine Theodizee der paganen Religion entwickelt; vgl. dazu Pernot 1993, 768-772. 
La description possède de surcroît une dimension religieuse, parce que les images de l'art antique représentent souvent des dieux et des scènes mythologiques. L'ekphrasis met en jeu la présence sensible du divin et le discours sur cette présence. ${ }^{190}$

Dies zeigt wiederum, wie geschickt Clemens die rhetorischen Elemente der prolalia einsetzte, um für seinen himmlischen Logos zu werben. Da Polemik und Kritik in einer prolalia durchaus erwünscht waren, konnte sich Clemens zudem die Freiheit sophistischer $\pi \alpha \varrho \varrho \eta \sigma^{\prime} \alpha$ herausnehmen, ohne sein Publikum schon in der Einleitung seiner Rede zu brüskieren: Menander formulierte die entsprechende Theorie, Dion, Lukian und Apuleius die praktischen Vorlagen. Lukians prolalia über den Bernstein enthält beispielsweise neben der bereits erwähnten Mythenkritik auch eine an Clemens erinnernde Dichterkritik, die Lukian in der Rolle des Betrogenen selbstironisch vorträgt:

Ich schwieg beschämt, dass es mir tatsächlich wie einem Kind ergangen ist, da ich den verlogenen Dichtern, die so gut wie nichts Vernünftiges vorzubringen haben, etwas derart Unglaubliches geglaubt habe. ${ }^{\text {I91 }}$

In der lukianischen Auslegung der Mythen erscheinen freilich als direkte Nachfolger dieser Dichter die Sophisten mit ihrer Showrhetorik, „denen nicht nur Bernstein, sondern lauter Gold aus den Reden, die noch heller als alle Schwäne der Dichter klingen, herabträufelt “ ${ }^{192}$ Lukians Polemik veranschaulicht nochmals einen wichtigen Grundzug der Prolalia, nämlich die Möglichkeit, in der Rolle des Entlarvers kulturkritisch zu argumentieren. In dieser Rolle können wir unschwer auch Clemens erkennen, der die Narrenfreiheit der Vorrede ausnutzt, um die Mythologie der Griechen zu bekämpfen. Dies gelingt ihm vor allem deshalb so überzeugend, weil er sowohl in der Erzählung als auch in der ekphrasis Themen und Motive verwendet, die in den Prolalien der Zweiten Sophistik wiederholt vorgekommen sind und deshalb die süße Lust der Zuhörer animiert haben dürften.

\section{5. Überblick zu den Themen und Motiven der Prolalien}

Die folgende Übersicht umfasst in Kategorien zusammengestellt und alphabetisch geordnet alle Themen und Motive, die in der prolalia des Clemens vorkommen. Die entsprechenden Parallelen aus den Prolalien der Zweiten Sophistik

\footnotetext{
I90 Pernot 2002, 36.

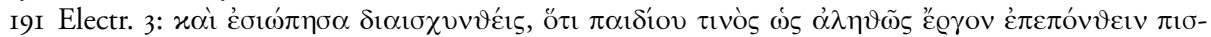

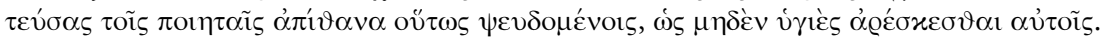

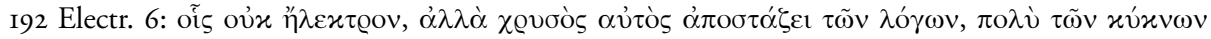

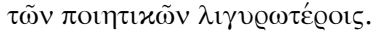


werden jeweils stichwortartig angefügt, so dass eine Synopse entsteht, die im Anschluss an die Darstellung ausgewertet wird.

Berge

Clemens, Protr. I,2: Die Zikaden in den Bergen; Protr. 2,I: Kithairon und Helikon, die odrysischen und thrakischen Berge; Protr. 2,2: Helikon und Kithairon, der heilige Berg Gottes; Protr. 2,3: Helikon und Kithairon, Zion; Dion, Or. 33,2: Das tarsische Land mit seinen Bergen; Apuleius, Flor. I8,6: Kithairon.

Dichter, Dramen und Komödien ${ }^{193}$

Clemens, Protr. 2,2: Kritik an Dichtern ( $\pi \circ \eta \eta \tau \alpha i)$, Dramen $(\delta \varrho \alpha ́ \mu \alpha \tau \alpha)$ und

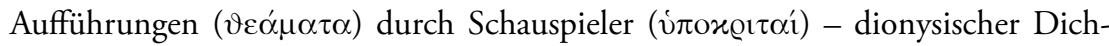
ter-Thiasos mit Anspielungen auf die Bakchen des Euripides; Dion, Or. 19,4-5: Vergleich der Schauspieler, Sänger und Dichter mit den Sophisten und Vergleich der Komödien mit Tragödien; Or. 32,6: Kritik der alten Dichter an den Athenern mit Zitaten von Aristophanes und Eupolis; Or. 32,16: Menanderzitat; Or. 32,23: Anonymes Dichterzitat; Or. 33,2: Die Verse der Dichter, die die Stadt Tarsos rühmen; Or. 33,4: Pindarzitat; Or. 33,9-IO: Die Komödiendichter (Aristophanes, Kratinos, Platon) als ängstliche Kritiker der Athener; Or. 33,II-I2: Synkrisis zwischen Homer und Archilochos; Or. 33,I6: Fabel des Äsop vom Honig und den Augen; Or. 57,II: Dion wiederholt eine Rede, die er schon vor dem Kaiser gehalten hat, und vergleicht dies mit den Tragödien und Komödien, die auch immer wieder aufgeführt werden; Or. 72,I3-I5: Erwähnung der Fabeln des Äsop mit der Nacherzählung der äsopischen Fabel von der Eule und den Vögeln; Lukian, Dips. 9: Vergleich mit dem Dichter Nikander; Electr. I-6: Die Mythendichter, die Lügengeschichten erzählen; Herc. 4-5: Zitate von Homer (Ilias 3,IO8), Euripides (Phoenissen 530) und einem anonymen Komödiendichter; Apuleius, Flor. 9,8: Vergleich mit Tragödien; Flor. 9,27: Komödientracht und Kothurn; Flor. 16,5-18: Werkbeschreibung und dramatisches Ende des Komödiendichters Philemon; Flor. 17,8: Tägliches Stimmtraining der Schauspieler; Flor. I8,6-7: Anonymes Tragikerzitat und Plautuszitat (Truculentus prol. I-3).

Exotische Menschen, Orte, Länder, Götter

Clemens, Protr. 2,3: Der Berg Zion als neuer Wohnort der Menschen; Dion, Or. I2,IO: Babylon, die Stadt von Ninos und Semiramis, Baktra, Susa, Palibothra; Or. 35,3: Die Tracht der Meder und Araber; Or. 72,3: Die exotischen Kopfbedeckungen fremder Völker; Or. 72,5: Die Götterbilder der Ägypter, Phönizier und anderer Völker; Lukian, Scyth. I-Io: Die Skythen Anarcharsis und Toxaris und der skythische Gott Zamolxis (Scyth. I.4); Dips. I-8: Die Beschreibung der Libyschen Wüste; Electr. I-5: Reise auf dem mythischen Strom Eridanus; Herc. I-6: Die

$193 \mathrm{Zu}$ den Homerstellen vgl. Anm. I4I. 
Gallier und ihr Gott Herkules-Ogmios; Bacch. I-5: Dionysos mit seinem Gefolge in Indien; Bacch. 6-7: Die drei Quellen bei dem indischen Hirtenvolk der Machleer; Apuleius, Flor. 15,I4-I8: Studienreisen des Pythagoras nach Ägypten und Indien.

\section{Götter und Heiligtümer}

Clemens, Protr. I,2-3: Musischer Agon am Heiligtum des Apollon in Delphi; Protr. 2,I-3: Die Weihestätten auf den Bergen; Dion, Or. I2: Die Zeusstatue des Pheidias als Thema; Or. I2,6: Athena und die Eule; Or. 32,3: Apollons pädagogischer Rat, das Schönste in die Ohren der Kinder zu legen; Or. 32,2I-23: Dion vergleicht sich mit dem von Zeus gesandten Hermes; Or. 33,I: Perseus, Herakles und Apollon als mythische Gründer der Stadt Tarsos; Or. 33,I2: Apollon und der Dichter Archilochos; Or. 72,5: Statuen und Bilder von Zeus, Poseidon und anderen Göttern, die an die äußere Erscheinung von Philosophen erinnern; Lukian, Herod. 5: Der Hochzeitsgott Hymenaios; Scyth. II: Aphrodite als Personifikation rhetorischer Verführungskunst; Electr. 2: Helios und Phaëthon; Electr. 4: Apollon; Herc. 4: Hermes und Herakles; Bacch. I-5: Dionysos und sein Gefolge; Bacch. 6-7: Der Dionysos-Hain mit den drei Quellen; Apuleius, Flor. I: Beschreibung verschiedener Weihestätten; Flor. 3: Die Geschichte von Apollon und Marsyas; Flor. 15,4-6: Heiligtum der Hera auf Samos; Flor. I8,6: Dionysos und sein Heiligtum im anonymen Dichterzitat (Liber, qui augusta haec loca Cithaeronis colis); Flor. 18,3739: Äskulap, dem der folgende zweisprachige Hymnus geweiht ist.

\section{Kunstwerke}

Clemens, Protr. I,3: Die Bronzestatue des Eunomos in Delphi; Dion, Or. I2: Die ganze Rede bezieht sich letztlich auf die Zeusstatue des Pheidias; Or. I2,6: Das Standbild der Athena Parthenos des Pheidias; Or. 72,5: Statuen und Bilder von Göttern, Bürgern, Feldherren und Königen; Lukian, Herod. 5-6: Das Hochzeitsbild des Malers Aëtion mit der Darstellung von Alexander und Roxane; Scyth. 2: Das Grabmal des Skythen Toxaris; Dips. 6: Das Grabmal eines Mannes, der von einer Dipsasschlange getötet wurde; Zeux. 3-7: Das Zentaurenbild des Zeuxis; Zeux. II: Siegesdenkmal mit der Darstellung eines Elephanten; Herc. I-6: Das Bild vom gallischen Herkules; Apuleius, Flor. 15,6-I2: Statue des Bathyllos.

\section{Lieder}

Clemens, Protr. I,I-2: Mehrfache Erwähnung von Liedern mit unterschiedlichen

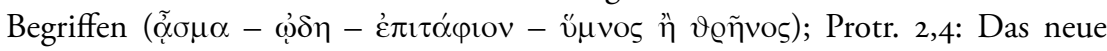

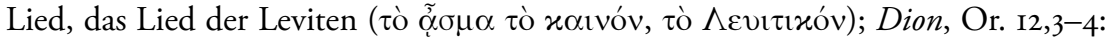
Der Gesang der Nachtigall und das letzte Lied des Schwans; Or. 19,2: Das Lied eines öffentlich auftretenden Sängers; Or. 32,20-2I: Gesang und Kithara als Schutzmittel gegen das Volk von Alexandria - Dion bedauert, keine Melodie oder ein Lied vortragen zu können; Or. 42,4: Dions Reden werden wie leichte Lieder, die 
Kinder in den Städten singen, wenn es Abend wird, in der ganzen Welt verbreitet; Lukian, Zeux. 2: Das neue Lied (nach Od. I,35I-352); Apuleius, Flor. I5,II: Anakreonteisches Lied; Flor. I7,I8: Ein nützliches Lied - mein Lied.

\section{Medizin/ Krankheit/ Leiden/ ärztliche Heilkunst}

Clemens, Protr. 2,4: Das Lied der Leviten, ein süßes und wirksames Heilmittel ( $\propto \alpha ́ \varrho \alpha \varkappa o v)$ gegen Leid - implizite Selbststilisierung als Arzt, der dieses Heilmittel verabreicht; Dion, Or. 32,IO: Vergleich der Sophisten mit schlechten Ärzten; Or. 32,I4: Vergleich mit dem von Gott geschickten Arzt; Or. 32,I7-I9: Das kranke Volk und die Heilmethoden der Ärzte, Philosophen und Herrscher; Or. 32,20: Musik als $\alpha \lambda \lambda \varepsilon \xi 1 \varphi \alpha ́ \varrho \mu \alpha x o v$ gegen das alexandrinische Publikum; Or. 33,6-7: Vergleich der sophistischen Redner mit falschen Ärzten und das Ideal des wahren Arztes; Or. 42,3: Dion vergleicht sich als Redner mit Tieren, die wegen ihrer heilkräftigen Mittel gejagt werden; Or. 57,5-9: Dion vergleicht Nestors Rede an Agamemnon und Achilles mit ärztlicher Heilkunst ( $\propto \alpha \varrho \alpha x o v / ~ \vartheta \varepsilon \varrho \alpha \pi \varepsilon i \alpha) ; ~ L u k i a n$, Scyth. I-2: Toxaris, der fremde Arzt, und die große Pest; Dips. 4-5: Der giftige Biss der Dipsasschlange, seine gesundheitlichen Folgen und die Meinung der Ärzte; Apuleius, Flor. 15,17: Die Heilmittel (medendi remedia) der Chaldäer; Flor. 15,19: Die Krankheit des Pherekydes; Flor. 16,19-24: Krankheitsgeschichte des Apuleius; Flor. 17,6: Vergleich der Stimme, die zum Schweigen gezwungen ist, mit einem kranken Körper.

\section{Musik/ Melodien}

Clemens, Protr. I,I: Amphion, Arion, Orpheus und der Zauber der Musik; Protr. I,2: Das nach der eigenen Melodie gesungene Lied der Zikaden ( und die Melodien (vómoı) des Eunomos; Protr. I,3: Die Zikade als Konzertsänge-

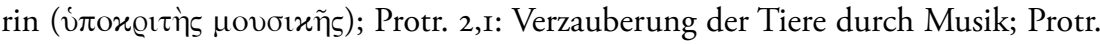
2,4: Der himmlische Logos wird von Clemens als sein Eunomos bezeichnet, der nicht nach den Melodien (vó $\mu \mathrm{or}$ ) des Terpandros oder Kapion oder nach phrygischen, lydischen oder dorischen Melodien singt, sondern nach der ewigen Melo-

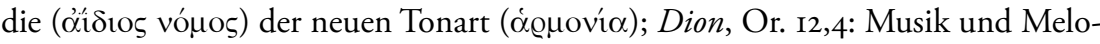
die des Schwanengesangs; Or. 19,2-3: Dion hört dem Konzert eines berühmten Sängers zu und erklärt seine Leidenschaft für die Musik; Or. 33,I: Vergleich öffentlicher Reden mit Melodien; Or. 33,I4: Kritik an Sophisten, die wie flötenspielende, singende und betrunkene Männer zu einem Gelage ziehen; Lukian, Harm. I: Harmonides charakterisiert die lydische, phrygische, dorische und ionische Tonart

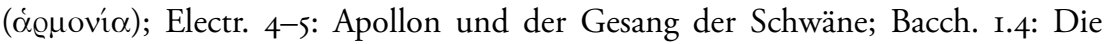
Musikinstrumente des Thiasos; Apuleius, Flor. 3: Musikhistorische Erklärungen (3,I-5) und musikalischer Wettbewerb zwischen Marsyas und Apollon (3,6-I4); Flor. 17,IO: Der Klang verschiedener Musikinstrumente. 
Musiker und Sänger

Clemens, Protr. I,I: Amphion, Arion und Orpheus; Protr. I,2-3: Der Sänger Eunomos mit seiner Kithara; Protr. 2,4: Der himmlische Logos als Sänger; Dion, Or. 19,2-4: Vergleich eines berühmten Sängers, dem Dion zugehört hat, mit Arion Erwähnung des Orpheus und Vergleich mit den Sophisten; Or. 35,9: Dummköpfe, die einem Sophisten folgen wie die Eichen, Felsen und Steine dem Orpheus; Lukian, Harm. I-3: Der Flötenspieler Harmonides und dessen Lehrer Timotheos von Theben, sowie die mythologischen Flötenspieler Marsyas und Olympos; Apuleius, Flor. 3: Vater und Sohn - die Flötenspieler Hyagnis und Marsyas; Flor. 15,6I2: Ekphrasis der Statue des Kitharaspielers Bathyllos; Flor. I7,I5: Die Sänger Orpheus und Arion.

\section{Mysterien}

Clemens, Protr. 2,I: Die Berge, die wegen ihrer Mysterien vergöttert und besungen werden; Protr. 2,2: Der dionysische Thiasos mit Dichtern, Satyrn und Dämonen; Dion, Or. 35,8: Vergleich der Jugendlichen, die Sophisten bewundern, mit Bacchantinnen, die um Dionysos herumtanzen; Lukian, Scyth. 8: Einweihung des Skythen Anacharsis in die Mysterien; Bacch. 5: Mysterienvergleich - Lukian vergleicht das Erlebnis des folgenden Vortrags mit der Teilnahme an einem dionysischen Thiasos; Apuleius, Flor. I5,I4: Zarathustra als Hohepriester aller göttlichen Mysterien.

\section{Mythologische Geschichten}

Clemens, Protr. I,I: Die Mythen von den Sängern, die durch ihren Gesang bezaubern (vgl. Protr. 2,I); Protr. I,2-3: Der Eunomos-Mythos; Dion, Or. 19,2-4: Rettung des Arion aus dem Meer -- Orpheus und die wilden Tiere; Or. 35,9: Die Zauberkraft des orphischen Gesangs; Lukian, Dips. 6: Anspielung auf den Tantalus-Mythos; Electr. I-3: Der Phaëthon-Mythos; Electr. 4-5: Apollon und die Schwäne des Eridanus; Bacch. I-4: Der Zug des Dionysos nach Indien; Apuleius, Flor. 17,15: Arion und Orpheus.

\section{Propheten und Orakel}

Clemens, Protr. 2,2: Der heilige Chor der Propheten; Protr. 2,3: Das Prophetenorakel Jes 2,3; Dion, Or. I2,I5: Dion beherrscht weder die Seherkunst noch die sophistische Technik; Or. 32, I2-I3: Die Orakelsprüche des Serapis und Apis - Kinder als Propheten; Or. 33,r: Orakelsprüche, die sich auf die Stadt Tarsos beziehen; Or. 33,I2: Das Orakel über den Dichter Archilochos; Or. 35,2: Die Wahrheiten der Sibylle und des Bakis; Or. 72,I2: Die Sprüche der Sieben Weisen und das Orakel der Pythia; Lukian, Scyth. 2: Das Pestorakel des Toxaris; Apuleius, Flor. 15,20: Der Prophet Epimenides. 


\section{Theater}

Clemens, Protr. 2,3: Das Welttheater, in dem der himmlische Logos den Siegeskranz erhält; Dion, Or. I2,2: Vergleich des Pfauenrades mit einem Theater; Or. 19,5: Aufführungen von Tragödien im Theater; Or. 32,4-5: Kritik am Theaterprogramm der Alexandriner; Or. 33,9-IO: Das attische Theater und die Pädagogik der Komödiendichter; Lukian, Harm. 2: Das Theater als Ort musikalischer Aufführungen; Apuleius, Flor. I6,I3. I7: Das Theater, in dem der Dichter Philemon den zweiten Teil seiner Komödie vorlesen sollte; Flor. I8,3-4: Beschreibung eines Theaters.

Tiere und Fabelwesen

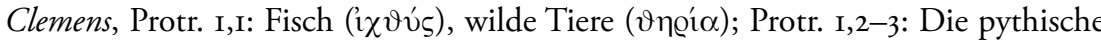

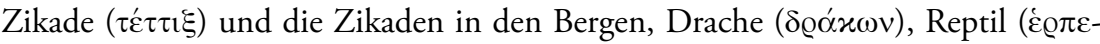

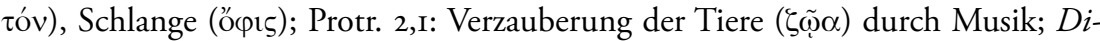
on, Or. I2,I-5: Vergleich der Beziehung zwischen Redner und Publikum mit dem Verhältnis der Vögel zur Eule, zum Pfau, zur Nachtigall und zum Schwan (vgl. auch Or. I2,I3); Or. I2,7-8: Die drei weisen Ratschläge der Eule aus einer Fabel Äsops; Or. 19,3: Hirschkälber und andere junge Tiere, die dem Orpheus nachfolgen; Or. 33,I: Singende Vögel; Or. 33,5: Vergleich der temporeichen Reden der Sophisten mit Rennpferden; Or. 33,II: Homers Lobgesang auf Tiere, Pflanzen, ..., Pferde; Or. 33,I5: Vergleich der Zuhörer mit verwöhntem Vieh, das immer auf weichem Boden steht; Or. 35,3: Aus Eseln können keine Pferde werden (so wie aus Kynikern keine wahren Philosophen werden können); Or. 35,I2: Beispiele aus dem Tierreich, um die Bedeutung von langem Haar zu illustrieren (Hasen, Vögel, Stuten, Esel, Hähne); Or. 42,3: Tiere, die Mittel zur Heilung von Krankheiten in sich tragen; Or. 57,I: Wilde Tiere der Berge, die von Helden getötet wurden (im Homerzitat Ilias I,267-268); Or. 72,I4-I6: Die Fabel des Äsop von der Eule und den Vögeln; Lukian, Harm. I: Die Vögel, die sich um die Eule scharen; Scyth. 2: Ein weißes Pferd als Opfertier; Dips. 2: Tiere, die von den Garamanten gejagt

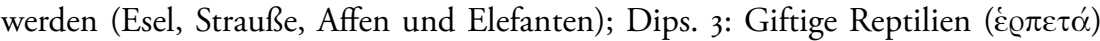
wie Kröten, Ottern, Vipern, Hornschlangen, Bupresten, Schießschlangen, Am-

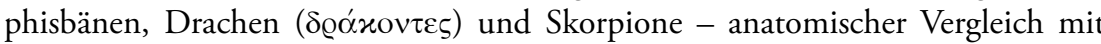
Heuschrecken, Grillen und Fledermäusen; Dips. 4: Die Dipsade als gefährlichste Schlange ("öpis); Electr. 4-6: Die Schwäne des Eridanus; Electr. 5: Raben und Dohlen; Zeux. 3-6. I2: Die Pferdemenschen und ein junger Löwe (Zeux. 4) auf dem Bild des Zeuxis; Zeux. 9-I2: Die Elefanten und Pferde in der Schlacht des Antiochus gegen die Galater; Herc. 2: Die Herden des Geryonos; Bacch. I. 3-5: Indische Elefanten; Bacch. I-4: Beschreibung des dionysischen Thiasos (Leoparden, der Esel Silens, die Schlangen der Mänaden; vgl. auch das animalische Aussehen der einzelnen Gestalten: Silen mit dem Affengesicht, Pan - halb Mensch, halb Ziegenbock -, die Satyrn mit Hörnern und Schwänzen); Bacch. 7: Vergleich der durch die Silenquelle geschenkten Redegabe mit Schwänen und Zikaden; Apuleius, Flor. 3,I3: Bär; Flor. I7,II-I2: Verschiedene Tierstimmen (Stiere, Wölfe, 
Elefanten, Pferde, Vögel, Löwen); Flor. 17,I5: Arion und die Delphine, Orpheus und die wilden Bestien; Flor. 17,I6-I7: Tiere, die in der Einsamkeit singen - Amsel, Nachtigall und Schwan.

Wettbewerbe

Clemens, Protr. I,2-3: Der musikalische Wettbewerb ( $\alpha \gamma \omega \dot{v})$ während der pythischen Spiele, an dem Eunomos teilnimmt; Protr. 2,3: Der himmlische Logos, der als Wettkämpfer ( $\alpha \gamma \omega v ı \sigma \tau$ $)$ ) auftritt und im Welttheater den Siegeskranz erhält; Dion, Or.33,9: Dichterwettbewerb in Athen; Lukian, Herod. I-4: Der Vortrag des Herodot während der Olympischen Spiele (vgl. auch Herod. 7) und die Ausstellung eines Bildes von Aëtion in Olympia (vgl. auch die Wettkampfmetaphern Herod. 8); Harm. I: Auftritt des Timotheus in Athen; Harm. 3: Der Tod des Harmonides während seines Auftritts bei den Dionysien; Harm. 4: Der olympische Wettkampf als Metapher für den folgenden Auftritt; Apuleius, Flor. 3,6-I4: Wettkampf zwischen Marsyas und Apollon.

Diese Übersicht zu den Themen und Motiven der Prolalia des Clemens und den übrigen Prolalien der Zweiten Sophistik lässt sich kurz zusammenfassen und bewerten:

I. Zu allen Themen und Motiven in der Vorrede des Clemens gibt es zahlreiche Parallelen in den Prolalien des Dion, Lukian und Apuleius. Damit wirkt die Einleitung zum Protreptikos wie ein literarisches Mosaik, das die bunte Welt der Zweiten Sophistik en miniature abbildet. Allerdings überschattet die Kulturkritik des Clemens nachhaltig die dargestellten Szenen. Dennoch könnte gerade diese kulturkritische Werbung für das Christentum überzeugt haben, weil eben auch Lukian, Dion und Apuleius mit den vorgegebenen Themen und Motiven spielerisch umgehen und den Kulturbetrieb ihrer Zeit als herausragende pepaideumeno $i$ kritisch kommentieren.

2. Die aus der jüdisch-christlichen Tradition stammenden Elemente (der Chor der Propheten, das Prophetenzitat, die Erwähnung des Zion, das neue bzw. levitische Lied) werden so geschickt integriert, dass sie als religiöses Sondergut kaum auffallen. Dies gelingt vor allem durch die Ausnutzung gattungstypischer Vorgaben, da Clemens der Forderung nach exotischen Schauplätzen mit der Erwähnung des Zion mühelos nachkommen kann, wodurch es ihm gelingt, einen in der griechisch-römischen Religionsgeschichte fast unbekannten heiligen Berg neben den alten Kultbergen der Griechen zu plazieren. Ebenso entspricht die Erwähnung der Propheten und das Prophetenzitat der Erwartungshaltung des Publikums, da die Bezugnahme auf Propheten, Seher und Orakel, wie vor allem die Prolalien Dions zeigen, keine Seltenheit war. Auch 
das Hauptmotiv der Prolalia, das neue Lied - mit allen weiteren semantischen Konnotationen wie Sänger, Melodie, Musik -, entspricht vollkommen den Konventionen. Dies betrifft nicht nur das musikalische Thema, sondern auch die Vorstellung des Liedes als neues Lied, denn das Neue und Neueste ist gerade das, was die Zuhörer vom Redner erwarten. Lukian widmet diesem Thema sogar eine eigene prolalia (Zeux.), in der er die Sensationsgier seiner Zuhörer kritisiert, weil nur noch das Neue bewusst wahrgenommen wird und nicht mehr die künstlerische Qualität der Rede (vgl. Zeux. I-2). Lukian versäumt es auch nicht, dieses Verhalten mit Homer zu kommentieren: „denn, wie Homer sehr richtig sagt, der neueste Gesang ist den Zuhörern immer der angenehmste ". ${ }^{194}$ Das Motiv vom neuen Lied entspricht also ideal der Disposition eines Publikums, das sich gerne durch Neues überraschen lässt und vermutlich vom neuen Lied keine apokalyptische Botschaft, sondern eine homerische Darstellung heroischer Taten erwartet hat. ${ }^{195}$

3. Auffällig ist schließlich, wie souverän sich Clemens durch den Zoo der Sophisten bewegt. Die größte Überraschung besteht nämlich in der Erkenntnis, dass in den Prolalien der Zweiten Sophistik Tiere eine zentrale Rolle spielen. ${ }^{196}$ Demnach muss das Publikum Tiergeschichten und Tiervergleiche äußerst amüsant gefunden haben. Dieser rezeptionsästhetischen Vorgabe stellt sich Clemens bravourös, da er sein musikalisches Hauptmotiv fortwährend mit Tiergeschichten verknüpft: Arion und der Delphin, Orpheus und die wilden Tiere, Apollon und der Python (Schlange, Reptil und Drache - alle Begriffe bei Lukian, Dips. 3-4), Eunomos und die Zikade. ${ }^{197}$ Clemens wußte also sehr gut, wie man auf unterhaltsame Weise süße Lust erzeugt und sein Publikum manipuliert.

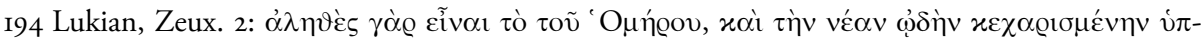

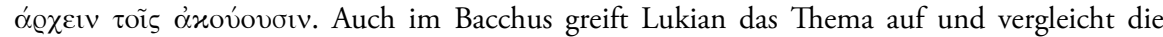
Neuartigkeit seiner Kompositionen mit dem neuen, fremdartigen und geradezu lächerlichen Erscheinen des dionysischen Thiasos in Indien (vgl. Bacch. 5). Dass hinter dem oberflächlichen Witz mehr steckt, zeigt der Sieg des Dionysos über die Inder, die in der Geschichte vom Indienfeldzug Lukians Zuhörer repräsentieren. Vgl. zum Thema des Neuen in Lukians Prolalien Zweimüller 2008, 72-78, die leider nicht näher auf den Bacchus eingeht; speziell zu Lukians Zeuxis vgl. von Möllendorff 2006a, 75-79.

195 Zum apokalyptischen Rahmen des Protreptikos vgl. Lechner 2007, 219-220.

196 Apuleius zeigt sowohl in weiteren Texten der Florida als auch in seinen anderen Schriften man denke nur an den Goldenen Esel der Metamorphosen - ein großes Interesse an der Welt der Tiere; vgl. dazu Hunink 2000, 7I-79. Eine intensive Beschäftigung mit zoologischen Fragen verrät zudem die bereits erwähnte Studie des Sophisten Polemon, der im 2. Kapitel seines physiognomischen Handbuches erklärt, wie man über Tiervergleiche den Charakter eines Menschen bestimmen kann; vgl. den arab. Text mit engl. Übers. in der Edition von Hoyland (Swain 2007, 384-395).

197 Dass Clemens nicht der Erste war, der Tiere in den Dienst christlicher Werbung nahm, zeigen schon die Apokryphen Apostelakten; vgl. dazu Klauck 2008, 95-138. 


\subsection{Die Technik der Selbstreferenz}

Die prolalia des Clemens führt über die Darstellung der Sängermythen und die Kritik an den Dichtern zur Frage nach der Wahrheit und des Heils, wobei das soteriologische Thema von Clemens fortlaufend durch kontrastierende Motive ausgestaltet wird: Mythen, Mysterien, Unglücksfälle, Dramen, Dichter, Wahnsinn, Dämonen, Dunkelheit und Irrtum auf der einen Seite, Wahrheit, Weisheit, Propheten, Licht, Erkenntnis, Rettung und Heilung auf der anderen Seite. Diese kontrastierenden Bilder sind um zwei Zentren gruppiert: Die Eunomosgeschichte und das Bergmotiv. In der Vision des Clemens erscheint neben den Gipfeln der alten Kultberge der Zion als Ort des Heils. Hier können die Griechen mit eigenen Augen die Epiphanie des Logos bestaunen, der von Clemens enthusiastisch als sein persönlicher Eunomos gefeiert wird: ò Eưvouos ò żuós. Die Selbstreferenz des Clemens bezieht sich demnach auf die Synkrisis zwischen dem mythischen Sänger Eunomos und seinem Eunomos, also dem Sänger des neuen Liedes, mit dem sich Clemens identifiziert. Durch diese indirekte Selbstreferenz tritt er als Redner hinter den Gegenstand seiner Rede zurück und handelt letztlich wie ein Arzt, der eben nicht sich selbst, sondern sein Heilmittel den Patienten anbietet. Dies entspricht vollkommen dem therapeutischen Charakter protreptischer Reden und passt deshalb vorzüglich zur prolalia einer Werberede. ${ }^{198}$ Damit die Griechen nun auch an diese neue Pharmazie glauben, kleidet Clemens den Text des Beipackzettels in homerische Verse (Od. 4,22I):

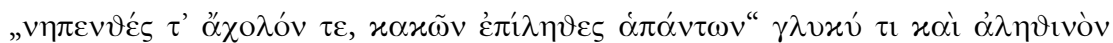

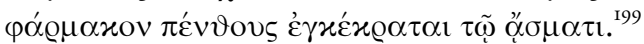

Perfekter kann man seine Werbebotschaft nicht verpacken. Als Elemente der selbstreferentiellen Technik des Clemens lassen sich demnach die Synkrisis, die Selbststilisierung als Arzt und die Verwendung eines Homerzitats benennen. Diese Elemente findet man auch in den übrigen Prolalien der Zweiten Sophistik. Dion und Lukian zitieren ebenfalls Homer, um ihre Texte zu strukturieren. ${ }^{200}$ Wäh-

I98 Vgl. Lechner 2007, I88-I89. 202 mit Anm. 98.

I99 Ich lese mit Stählin/Treu (GCS Clemens Alexandrinus I [4,2I]) und zuletzt auch Migliore

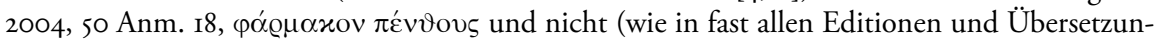
gen) $\varphi \alpha ́ \varrho \mu \alpha \varkappa o v ~ \pi \varepsilon เ \vartheta$ oṽ . Diese Lesart hat zuletzt Herrero de Jáuregui 2008, II4, nochmals verteidigt. Zwar ist der Hinweis durchaus bedenkenswert, dass durch die Formulierung $\varphi \alpha ́ \varrho \mu \alpha-$ xov $\pi \varepsilon \vartheta \vartheta_{0} \tilde{5}$, die durch P (Parisinus graecus 45I) belegt ist, Übereinstimmungen mit Platons Phaidros (23od und 275a) deutlich werden, dennoch gibt es gute Gründe, an der Konjektur von Stählin festzuhalten. Berücksichtigt man nämlich, dass in der zitierten Homerstelle das фó $\mu_{\alpha \varkappa o v}$ mit Wein vermischt wird und dass in der Prolalia mehrfach auf die Bakchen des Euripides Bezug genommen wird, dann dürfte Bacchae 278-283 die bessere Parallele darstellen. Denn hier wird Dionysos als Heilsbringer gefeiert, der den Sterblichen den Wein gebracht hat, um sie von den Leiden der Welt zu befreien: ov̉ ' '

200 Durch ein Zitat beschließt Lukian sonst nur noch seine prolalia über die Dipsasschlangen (Dips. 9), hier allerdings mit Platon. 
rend Lukian seine prolalia über den gallischen Herkules mit einem Homerzitat beendet (Herc. 8), verknüpft Dion in seiner Olympischen Rede die prolalia mit dem exordium, indem er das exordium mit einem Homerzitat einleitet (Or. I2,15). Lukian verbindet wie Clemens mit dem Homerzitat selbstreferentielle Aussagen, da sich der Vergleich mit dem heimkehrenden Odysseus selbstironisch auf sein fortgeschrittenes Alter bezieht:

Gerade jetzt brauche ich dringend einen segelfüllenden, kräftigen, freundlichen Fahrtwind (Od. II,7), damit auch mir, hält man mich für würdig, jemand den homerischen Vers nachruft: Seht, was für Schenkel enthüllt unter seinen Lumpen der Alte! (Od. 18,73). ${ }^{201}$

Da Dion in der Olympischen Rede mit der Formel „Wenn euch dies vorzüglicher und besser zu sein scheint (vgl. Od. I,376; Od. 2,I42)“ seine vorangegangene komödiantische Selbstvorstellung ${ }^{202}$ nochmals ironisch kommentiert, indem er wie Telemach vor den Freiern auftritt ${ }^{203}$, darf man auch dieses Homerzitat als Selbstreferenz auffassen.

Inhaltlich verweist das Homerzitat des Clemens auf die therapeutische Wirkung seiner Rede. Auch hierzu gibt es Parallelen. Die Selbststilisierung des Redners als Arzt, der Heilmittel verabreicht, findet man außer bei Clemens vor allem bei Dion ${ }^{204}$, dessen Prolalien auch zeigen, dass die Arztmetapher das Ideal des wahren Philosophen umschreibt, und dies durchaus in kritischer Auseinandersetzung mit anderen Rednern (vgl. z. B. Or. 33,6-7). Von Dion wird deshalb auch die Notwendigkeit verteidigt, seinen Zuhörern Unangenehmes mitteilen zu müssen, da er sie nur so bessern könne:

Glaubst du also, Homer habe diese Worte Nestor umsonst in den Mund gelegt, jenem Mann, von dem er sagt, er sei der gewaltigste Redner unter den Menschen, und dessen Redegabe er der Süße des Honigs vergleicht? Den Gesunden ist Honig das Liebste und Süßeste von allem, den Kranken und Fiebrigen aber, wie es heißt, das Unangenehmste, und doch reinigt und ätzt er mit seiner natürlichen Kraft eiternde und kranke Stellen. So kommt auch Nestors Rede den anderen süß, Archilleus und Agamemnon aber bitter vor, da sie krank und durch ihren Zornesmut verdorben sind, so dass sie in ihrem Unverstand nicht auf ihn hören. ${ }^{205}$

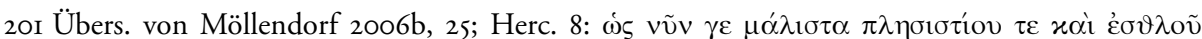

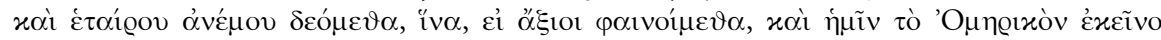

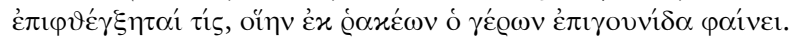

202 Vgl. Klauck 2000, 117 Anm. 79.

203 Vgl. Klauck 2000, iI8 Anm. 8I.

204 Vgl. dazu die Textstellen, die weiter oben in der Tabelle s.v. Medizin angegeben sind.

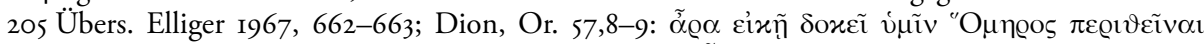

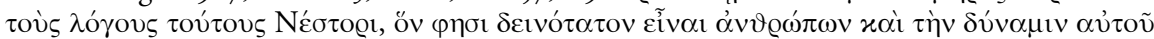

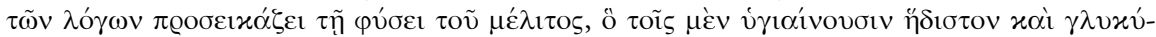

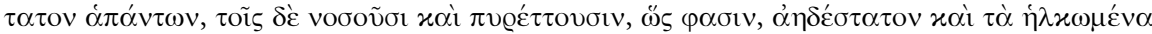

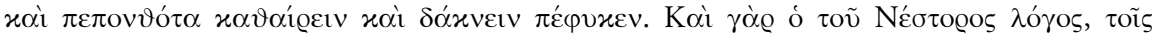


Neben dem Stichwort $\gamma \lambda u x v$ s erinnert der ganze Stil der Passage an die prolalia des Clemens, der seine ärztliche Rolle ebenfalls mit aufklärerischer Kritik verbindet und damit den Anspruch philosophischer Ernsthaftigkeit verteidigt. Das therapeutische Konzept, das inhaltlich auf dem neuen Lied basiert, ist aber unmittelbar mit dem Erscheinen des christlichen Eunomos verbunden, mit dem sich Clemens identifiziert. Dies setzt logischerweise die Synkrisis zwischen dem $m y$ thischen Eunomos und dem christlichen Eunomos voraus. Solche Vergleiche sind auch in anderen Prolalien zu finden und für die selbstreferentielle Technik geradezu charakteristisch. Beliebt sind vor allem Vergleiche mit historischen, literarischen und mythologischen Figuren: So vergleicht sich beispielsweise Apuleius mit dem berühmten Sophisten Hippias (Flor. 9), Pythagoras bzw. Platon (Flor. I5), dem Komödiendichter Philemon (Flor. 16), Orpheus und Arion (Flor. 17), dem Sophisten Protagoras bzw. Thales von Milet (Flor. I8), Dion mit Nestor (Or. 57,IO-II), Sokrates (Or. I2; Or. 54; Or. 57,II; Or. 72), Archilochos (Or. 33,II-I2), Odysseus (Or. 33,15) und Diogenes (Or. 72), Lukian mit dem gallischen Herkules und Odysseus (Herc.), dem Skythen Anacharsis (Skyth.), dem Maler Zeuxis und dem Feldherrn Antiochus (Zeux.), dem Historiker Herodot (Herod.) und dem Flötenspieler Harmonides (Harm.). Die jeweiligen Vergleichspersonen können hierbei als positive Vorbilder für die Übertragung auf die eigene Person fungieren (Pythagoras, Platon, Thales, Nestor, Sokrates, Diogenes, Herkules, Odysseus, Anacharsis, Herodot), aber auch als Negativfiguren erscheinen, von denen sich der Redner kritisch oder ironisch distanziert (Hippias, Orpheus, Arion, Philemon, Protagoras, Zeuxis, Antiochus, Harmonides $\left.{ }^{206}\right)$. Die Synkrisis zwischen dem Redner und einer Vergleichsperson zählt damit zum Grundrepertoire der selbstreferentiellen Technik in der prolalia. ${ }^{207}$ Clemens macht sich die potentielle Doppelrolle der Vergleichsperson zunutze, indem er den historischen Eunomos zur Gegenfigur aufbaut, während er den himmlischen Sänger zu seinem Eunomos, also zur eigentlichen Identifikationsfigur erwählt. Die Übertragung auf die eigene Person wird nicht ausdrücklich thematisiert, da Clemens im Gegensatz zu Dion, Lukian und Apuleius nicht sich selbst in den Vordergrund stellt, sondern die Werbung für das neue Lied und den wahren Wettkämpfer. Es genügt ihm, seinen Sänger im großen Welttheater mit dem Siegeskranz bekränzt zu sehen und das

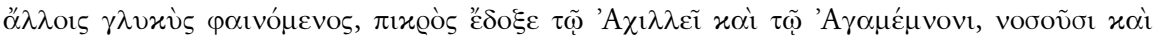

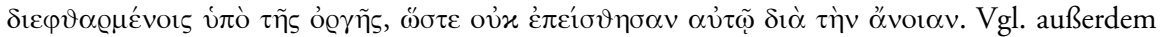
die Prolalien zur Alexandrinischen Rede, Or. 32,I-24, und zur Ersten Tarsischen Rede, Or. 33,I-I6, die insgesamt dem Thema der philosophischen Aufklärung gewidmet sind und zahlreiche medizinische Vergleiche enthalten (vgl. Tabelle s.v. Medizin weiter oben).

206 Man könnte noch die Synkrisis zwischen Apollon und Marsyas (Apul. Flor. 3) hinzufügen. Leider fehlt hier die Übertragung auf die Person des Redners.

207 Freilich kann sich der Redner auch mit Tieren vergleichen wie etwa Dion in der prolalia des Olympikos (Or. I2) mit einer Eule (vgl. auch Or. 72,I4-I6). 
süße und wirksame Heilmittel der neuen Lehre anbieten zu können. Mit dieser Selbstreferenz konnte er eigentlich nur gewinnen.

\subsection{Intertextuelle Steuerzeichen}

Wie schon der Vergleich mit den Prolalien Dions zeigte, ist das Bild vom Arzt, der ein rettendes pharmakon verabreicht, eine Metapher für den wahren Philosophen. Die von Clemens gesetzten intertextuellen Steuerzeichen lassen erkennen, welche philosophische Rolle er für sich beanspruchte. Es sind vor allem die Anspielungen auf Phaidros und Politeia, die hierfür aufschlussreich sind. Während die Subtexte des Phaidros den Leser auf das große Thema der Gottesschau hinführen und damit als intertextuelle Steuerzeichen auf die Struktur des Protreptikos verweisen, führen die Subtexte der Politeia zu Platons Dichterkritik. ${ }^{208}$ Butterworth hatte bereits darauf hingewiesen, dass die Eunomoserzählung zwar die Erwähnung der Zikaden zwangsläufig voraussetzt, dass aber die Beschreibung der ganzen Szene an den platonischen Phaidros erinnert, d.h. an jene Szene, in der

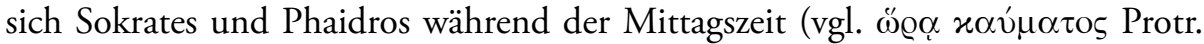
I,2) an einen schattigen Platz vor der Stadt begeben, um zu philosophieren. ${ }^{209}$ Die Szenerie des Phaidros wird eindeutig durch die Zikaden bestimmt (vgl. 230c, 258e-259a), deren Mythos von Sokrates auch erzählt wird (259 b-d). Sicherlich sind dies nur sehr zarte Übereinstimmungen, deren Beweiskraft für sich genommen gering ist, betrachtet man aber den gesamten Protreptikos, so kann man wiederum mit Butterworth feststellen, dass Clemens ein intimer Kenner des Phaidros war, weshalb eine bewusste Anspielung auf die szenische Rahmenhandlung des Phaidros durchaus wahrscheinlich ist. ${ }^{210}$ Dies um so mehr als Clemens das didaktische Modell der platonischen Mysterienanalogien verwendet hat, um seinen Protreptikos zu strukturieren. ${ }^{211}$ Den einzelnen Stufen der Mysterieninitia-

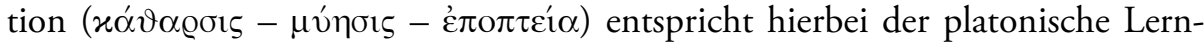
und Erkenntnisprozess, der über die Widerlegung falscher Ansichten (" $2 \lambda \varepsilon \gamma \chi 0 \varsigma$ )

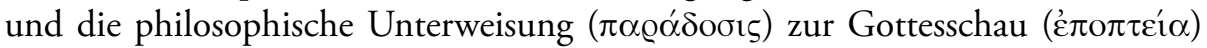
führt. ${ }^{212}$ Das Motiv der Gottesschau hat Clemens wiederum im Schlussteil seiner Werberede als Phaidrosexegese ausgestaltet (Protr. 120,2-I23,2). ${ }^{213}$ Insofern dürfte bereits in der prolalia die Aufforderung des Clemens, emporzublicken ( $\alpha$ vaxv́ $\pi$ -

208 Zu Platons Dichterkritik in den Büchern II-III (376c-398b) und X (595a-608b) vgl. Figal 2002, 30I-315, und Halliwell 2005, 313-332.

209 Butterworth 1916, I98-199.

210 Butterworth 1916, 205.

2II Vgl. Lechner 2007, I83-22I.

212 Zur Mysterienterminologie im Protreptikos vgl. Riedweg 1987, II6-I6I.

213 Vgl. Lechner 2007, 214-218. 


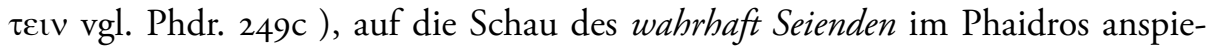
len, wenngleich auch diese Anspielung erst durch die nachfolgende Rede an Deutlichkeit gewinnt.

Mit dieser szenischen, am Phaidros orientierten Einstimmung verbindet Clemens zusätzlich die in der Politeia vorgetragene Dichterkritik. Der Verbannung der Dichter in die Berge entspricht hier die Ausweisung der Dichter aus der Stadt (III,398a):

Einem Mann also, wie es scheint, der sich infolge seiner Kunstfertigkeit vielgestaltig zeigen und alle Dinge nachahmen kann, wenn uns derselbe in die Stadt käme und auch seine Dichtungen uns darstellen wollte, würden wir als einen heiligen und wunderbaren und anmutigen Mann verehren, würden ihm aber sagen, dass es einen solchen Mann in unserer Stadt nicht gebe und nicht geben dürfe. Wir würden Salböl auf sein Haupt gießen und es mit Wolle bekränzen und ihn dann in eine andere Stadt fortschicken, usw. ${ }^{214}$

Auf diesen Text wird in der Regel auch in den Kommentaren zum Protreptikos verwiesen, um die Ironie der Stelle zu verdeutlichen. ${ }^{215}$ Damit ist aber der platonische Subtext noch nicht hinreichend in die Textanalyse einbezogen. Denn gerade die Abschlussszene der prolalia bietet mit der Epiphanie des himmlischen Logos weitere Parallelen zur Dichterkritik in der Politeia. Dieser Abschnitt ist vor allem durch das Wortspiel mit der doppelten Bedeutung des Begriffs vónos geprägt. Nach der Einführung des Begriffs durch das Jesajazitat, in dem vó $\mu$ os eindeutig Gesetz bedeutet, wird vómoऽ ambivalent verwendet, da mit dem Erscheinen des Logos als Wettkämpfer wiederum an Eunomos und die mythologischen Sänger erinnert wird. Durch die Charakterisierung des Logos als Eüvouos der Christen und den Vergleich des neuen Liedes mit den antiken vónor wird deutlich, dass nun die Übersetzung mit Melodie oder Tonart vorzuziehen ist. Die folgende Identifizierung des ewigen vóno licht aber abschließend, dass die ewige Melodie ein ewiges Gesetz erklingen lässt und dass der Logos als Eűvouos die heilende Wirkung des Gesetzes personifiziert.

Die Frage nach den richtigen Gesetzen bestimmt auch die beiden Abschnitte der Politeia, in denen der Diskurs über die erzieherische Bedeutung der Dichtung geführt wird. Besonders eindringlich wird der Zusammenhang zwischen

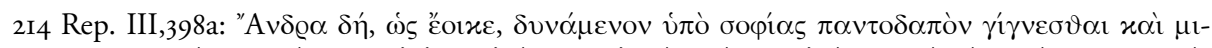

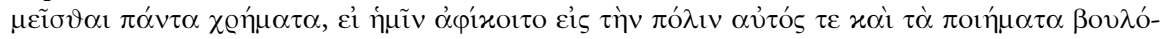

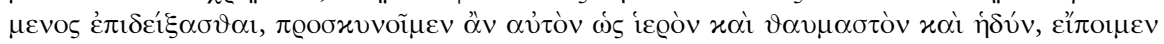

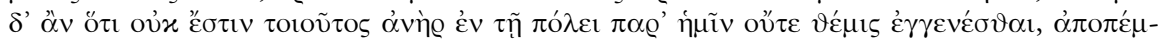

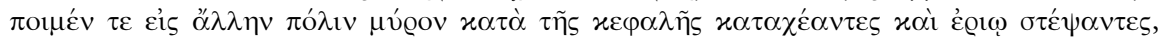
$x \tau \lambda$.

2I5 Vgl. Migliore 2004, 48-49. 
Dichtung und Gesetzgebung in der an Glaukon gerichteten Prophezeiung des Sokrates formuliert:

Nimmst du aber die süße Muse auf, sei es in lyrischer oder epischer Gestalt, dann werden in deiner Stadt Lust und Schmerz königlich herrschen statt des Gesetzes und der Vernunft, die sich noch immer und überall als das Beste erwiesen hat. ${ }^{216}$

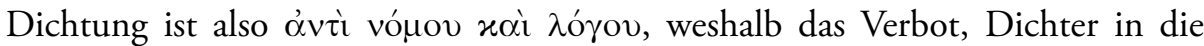

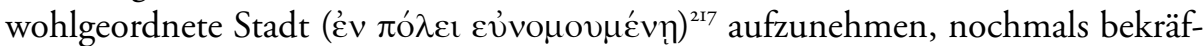

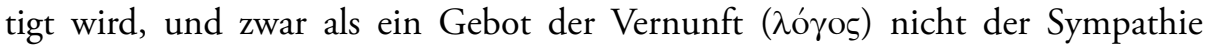
(X,607b). Denn von der Anziehungskraft der Dichtung sind auch Philosophen nicht verschont und selbst Sokrates gesteht ein: „Nicht wahr, Freund, auch du wirst doch von ihr bezaubert, und am meisten, wenn du sie bei Homer betrachtest?"218 Dennoch sind die Dichter auszuschließen, da sie, wie Sokrates zuvor schon feststellte, alle "nur Nachahmer von Schattenbildern“ sind, „die Wahrheit aber gar nicht berühren “. ${ }^{219}$ Geradezu frech klingt in diesem Zusammenhang auch die Apostrophe Homers: „Welche Stadt erkennt an, dass du ein guter Gesetzgeber gewesen bist und ihr Wohl begründet hast? ${ }^{\text {'220 }}$ Muss man im Hinblick auf diese Texte das Ende der Prolalia mit dem Homerzitat nicht als ein besonders gelungenes Beispiel intertextueller Ironie auffassen, zumal unmittelbar zuvor vom

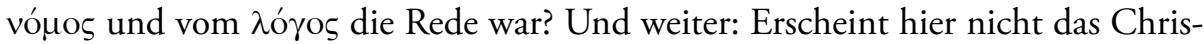
tentum als neue Philosophie, ja geradezu als neue Utopie? Denn Clemens wirbt in der Rolle des Sokrates für eine christliche politeia, die auf dem ewigen vó $\mu$ os des himmlischen $\lambda$ ó $\gamma$ os gründet ${ }^{221}$ und die Dichter als Staatsfeinde ausschließt. ${ }^{222}$

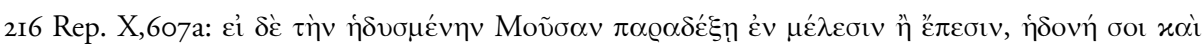

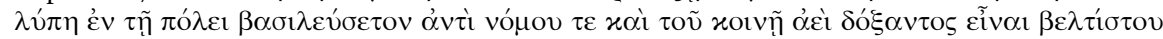
$\lambda$ ó

217 Rep. X,607c (wörtlich: in die mit guten Gesetzen versehene Stadt; vgl. auch X,605b). Diese Stelle könnte Clemens durchaus zur Kombination der Eunomos-Geschichte mit der Dichterkritik angeregt haben.

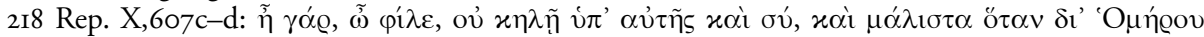
$\vartheta \varepsilon \omega \varrho$ ñ $\alpha$ vinnv; Platons Kritik an Homer wird in der Zweiten Sophistik auch von Dion, Maximos und Aelius Aristides diskutiert; vgl. dazu Kindstrand I973, I39-I4O. I87-I89. 213-2I4.

219 Rep. X,6ooe. Zur philosophischen Begründung der Dichterkritik vgl. nochmals Figal 2002, 30I-315, und Halliwell 2005, 313-332.

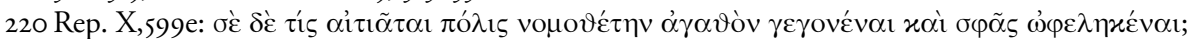

22I Möglicherweise darf man darin auch eine Reaktion auf die Kritik des Kelsos sehen, der „die beiden großen Wertbegriffe griechischen Denkens, Logos und Nomos" durch das Christentum gefährdet sah (Andresen 1955, 209). Eine geschichtstheologische und beide Begriffe einschließende Konzeption, wie sie hier bei Clemens im neuen Lied anklingt, hat zuerst Justin entwickelt; vgl. Andresen 1955, 312-344. Vgl. nun auch den Kommentar von Lona zur wahren Lehre des Kelsos (2005), in dem völlig zu Recht der zweite Teil des Alethes Logos (3,I-5,65) unter dem Titel „Die Welt ohne Logos und ohne Nomos der Juden und Christen“ und der dritte Teil $(6, I-8,75)$ unter dem Titel „Der Logos und der Nomos der griechischen Überlieferung“ zusammengefasst werden. Zur Begründung dieser Aufteilung vgl. Lona 2005, 23-27.

222 Die ganze Szene erinnert an Dions I3. Rede, in der Sokrates als deus ex machina erscheint (Or. 13,I4-15). Vgl. Döring 1979, 86, sowie Fornaro 2009, 172-176. 
Clemens legt damit wie Dion die Maske des Sokrates an, um als anspruchsvoller Philosoph zu erscheinen. ${ }^{223}$ Insofern wäre die Prolalia des Clemens vor allem mit den Vorreden Dions zu vergleichen, zumal die protreptische Pädagogik Dions, die nicht selten politisch motiviert ist, an die visionäre Werbung des Clemens erinnert. Insgesamt darf man also festhalten, dass Clemens auch dieses Kompositionselement perfekt ausgearbeitet hat. Durch die Dichterkritik werden zunächst auf einer relativ oberflächlichen Ebene die entsprechenden Subtexte der Politeia aktiviert und dann durch die heilsgeschichtliche Interpretation der Begriffe vó-

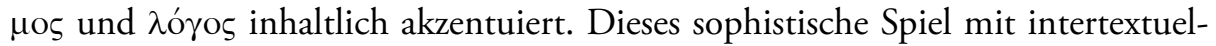
len Steuerzeichen, das letztlich Clemens als platonischen Sokrates präsentierte, dürfte seine Wirkung auf die Zielgruppe der pepaideumenoi nicht verfehlt haben.

\section{Zusammenfassung}

Der Vergleich mit den Prolalien der Zweiten Sophistik hat eindeutig das Ergebnis der Analyse von Rizzi bestätigt, der die Vorrede des Protreptikos zutreffend als prolalia charakterisiert hatte. Dieses Ergebnis konnte man durchaus erwarten, da die von Rizzi notierten Parallelen zwischen dem Protreptikos und dem rhetorischen Handbuch Menanders bereits evident waren. Darüber hinaus hat der Vergleich gezeigt, wie perfekt Clemens die Kulturtechniken seiner Zeit beherrscht. Seine prolalia erscheint formal und inhaltlich als ein typisches Produkt der Zweiten Sophistik und verrät eine enge Vertrautheit mit der rhetorischen Praxis der Starredner. Die Adaption dieser innovativen rhetorischen Gattung für den Prolog einer christlichen Missionsschrift darf man durchaus als werbepsychologische Meisterleistung einstufen. Denn einerseits nutzt Clemens die Narrenfreiheit der prolalia geschickt aus, um die pagane Kultur aus christlicher Perspektive zu kritisieren, andererseits verwendet er die typischen Motive und Themen paganer Prolalien und verleiht dadurch seiner Einleitung viel Charme. Damit erinnert er an die kulturkritischen Prolalien eines Dion oder Lukian, reiht sich also in die Gruppe philosophisch orientierter Sophisten ein, der man auch Apuleius zurechnen darf. Sophist oder Philosoph? Diese Alternative wirkt für die Epoche der Zweiten Sophistik anachronistisch, da beide Rollen zwar unterschiedlich strukturiert, aber durch das normierende Paideiakonzept zugleich aufeinander verwiesen waren. ${ }^{24}$ Mit der Maske des Sophisten war der Anspruch des

223 Vgl. Or. I2, I-I5, Or. 33,I-I6, Or. 54 und Or. 72. Zu Dion und Sokrates vgl. Döring 1979, 80II3, und zuletzt Fornaro 2009, 3-40. I63-I82; zur Or.I2 vgl. zusätzlich Betz 2004, 222-225; zu den philosophischen Masken des Apuleius in den Florida vgl. La Rocca 2005, 35-49, der auch einen Vergleich mit Dion bietet (S. 38-39 Anm. 98). Zur Rolle des Sokrates in Lukians Werk und speziell in den Wahren Geschichten vgl. von Möllendorff 2000, 553-562.

224 Vgl. dazu Puech 2002, IO-I5, und zuletzt Hahn 2009, 24I-258, der dies für Dion zeigt, wobei 
Redners auf gesellschaftlichen Erfolg und kulturelle Überlegenheit verbunden. Da die sophistischen Kulturtechniken fortwährend Macht reproduzierten und dadurch die gesellschaftlichen Strukturen insgesamt legitimierten, war die Rolle des Sophisten nicht nur kulturell, sondern vor allem auch sozial und politisch definiert. Was bedeutet dies aber für Clemens? Hat er realisiert, dass das machtlose und politisch diffamierte Christentum nur dann überleben konnte, wenn es sich an den Machtspielen der Oberschicht beteiligte, und sei es nur durch den Erwerb von symbolischer Macht? Jedenfalls hat Clemens mit der bewussten Ausgestaltung seiner Vorrede als prolalia Zeichen gesetzt, die man nicht übersehen konnte.

Hinter der Maske des Sophisten verbirgt sich aber auch die Maske des Sokrates. In der Rolle des Philosophen verteidigt Clemens mit seiner platonisch inspirierten Dichter- und Mythenkritik schon in der Vorrede des Protreptikos das Christentum gegen Kritiker wie Kelsos oder Lukian. Als neuer Sokrates vermittelt er die Vision einer auf das Christentum gegründeten politeia, in der die Einheit

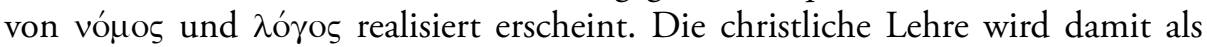
politisch relevante und philosophisch attraktive Lebensform vorgestellt, und zwar als kulturkritische, aber keineswegs kulturfeindliche Alternative. Dies erreicht Clemens mit subtilem Maskenspiel und sophistischer Verführungskunst, wobei er die von der süßen Lust des Logos verzauberten Griechen am Ende seiner Vorrede mit geflügelten Worten umwirbt, das pharmakon des neuen Liedes anzunehmen und seinem Eunomos bzw. seinem Logos protreptikos zu folgen, denn dies war erst der Anfang.

er vielleicht zu schematisch die beiden Rollen auf die einzelnen Reden verteilt. Wichtig ist in diesem Zusammenhang auch die Studie von Borg (2009) zu den Selbstdarstellungen römischer Eliten in den ersten drei Jahrhunderten (Portraitstatuen, Büsten, Sarkophage), die belegt, dass in der Selbstdarstellung die ikonographischen Verweise auf Bildung und sozialen Status dominieren, also insgesamt der Bildtyp des "glamorous intellectual“ (vgl. dazu auch Borg 2004a, 157-178). Die Masken des Sophisten bzw. des Philosophen sind demnach nur Erscheinungsweisen der einen, umfassenden und auch normierenden paideia, die die Hauptrolle spielt. 


\section{Literaturverzeichnis}

Amato (2009): Eugenio Amato, „Literarische Gattung und praktische Zwecke“, in: Heinz-Günther Nesselrath (Hg.), Dion von Prusa. Der Philosoph und sein Bild, SAPERE XIII, Tübingen, 2I-40.

Anderson (1977): Graham Anderson, „Patterns in Lucian's Prolaliae“, Philologus I2I, 313-315.

Anderson (1989): Graham Anderson, „The pepaideumenos in Action: Sophists and their Outlook in the Early Empire“, $A N R W$ II,33,I, Berlin / New York, 79-208.

Anderson (1993): Graham Anderson, The Second Sophistic: A Cultural Phenomenon in the Roman Empire, London / New York.

Betz (2004): Hans Dieter Betz, „Paraenesis and the Concept of God according to Oratio XII (Olympikos) of Dion of Prusa“, in: James Starr u. Troels Engbert-Pedersen (Hgg.), Early Christian Paraenesis in Context, BZNW I25, Berlin / New York, 217-234.

Billault (2006): Alain Billault, „Very Short Stories: Lucian's close Encounters with some Paintings“, in: Shannon N. Byrne, Edmund P. Cueva u. Jean Alvares (Hgg.), Authors, Authority, and Interpreters in the Ancient Novel (FS Gareth L. Schmeling), Ancient Narrative Suppl. 5, Groningen, 47-59.

Binder (2009): Gerhard Binder, „Tuoro sul Trasimeno und Perugia“, $A W W_{40}, 67-$ 72.

Bompaire (1958): Jacques Bompaire, Lucien écrivain. Imitation et création, Paris.

Borg (2004a): Barbara Borg, „Glamorous intellectuals: Portraits of pepaideumenoi in the second and third centuries AD“, in: Barbara Borg (Hg.), Paideia: The World of the Second Sophistic, MSt 2, Berlin / New York, I57-I78.

Borg (2004b): Barbara Borg, „Bilder zum Hören - Bilder zum Sehen: Lukians Ekphraseis und die Rekonstruktion antiker Kunstwerke“, Millenium Jahrbuch I, $25-57$.

Borg (2009): Barbara Borg, „Das Bild des Philosophen und die römischen Eliten“, in: Heinz-Günther Nesselrath (Hg.), Dion von Prusa. Der Philosoph und sein Bild, SAPERE XIII, Tübingen, 2II-240.

Bost Pouderon (2006): Cécile Bost Pouderon, Dion Chrysostome. Trois discours aux villes (Orr. 33-35). Tome II: Commentaires, bibliographie et index, Cardo 5 , Salerno.

Bowie (2004): Ewen Bowie, „The Geography of the Second Sophistic. Cultural Variations", in: Barbara Borg (Hg.), Paideia: The World of the Second Sophistic, MSt 2, Berlin / New York, 65-83.

Branham (1989): Robert Bracht Branham, Unruly Eloquence. Lucian and the Comedy of Traditions, Cambridge Mass. / Los Angeles. 
Brigham (1962): Frederick H. Brigham, „The Concept of New Song in Clement of Alexandria's Exhortation to the Greeks", Classical Folia 16, 9-13.

Cosgrove (2006): Charles H. Cosgrove, „Clement of Alexandria and early Christian Music“, JEChSt I4, 255-282.

Elliger (1967): Dion Chrysostomos. Sämtliche Reden. Eingeleitet, übersetzt und erläutert von Winfried Elliger, Zürich / Stuttgart.

Figal (2002): Günter Figal, „Die Wahrheit und die schöne Täuschung. Zum Verhältnis von Dichtung und Philosophie im platonischen Denken“, PhJ IO7, 3OI-315.

Fornaro (2009): Sotera Fornaro, „Wahre und falsche Philosophen in Dions Werk und Zeit", in: Heinz-Günther Nesselrath (Hg.), Dion von Prusa. Der Philosoph und sein Bild, SAPERE XIII, Tübingen, I63-I82.

Gangloff (2002): Anne Gangloff, „Mythes, fables et rhétorique à l'époche impériale", Rhetorica 20, 25-56.

Georgiadou u. Larmour (1995): Aristoula Georgiadou u. David H. Larmour, "The prolaliae to Lucian's Verae Historiae“, Eranos 93, IOO-II2.

Gleason (1995): Maud W. Gleason, Making Men. Sophists and Self-Presentation in Ancient Rome, Princeton.

Graf (1999): Fritz Graf, Griechische Mythologie. Eine Einführung, 5. Aufl. Düsseldorf.

Hahn (2009): Johannes Hahn, „Das Auftreten und Wirken von Philosophen im gesellschaftlichen und politischen Leben des Prinzipats", in: Heinz-Günther Nesselrath (Hg.), Dion von Prusa. Der Philosoph und sein Bild, SAPERE XIII, Tübingen, 24I-258.

Halliwell (2005): Stephen Halliwell, „The Republic's Two Critiques of Poetry (Book II 376c-398b, Book X 595a-608b)“, in: Otfried Höffe (Hg.), Platon. Politeia, KA 7, 2. bearb. Aufl. Berlin, 313-332.

Halton (1983): Thomas Halton, „Clement's Lyre. A broken String, a New Song“, SecCen 3, 177-199.

Harrison (2000): Stephen J. Harrison, Apuleius. A Latin Sophist, Oxford / New York.

Helm (1977): Apuleius. Verteidigungsrede. Blütenlese. Lateinisch und Deutsch von Rudolf Helm, Schriften und Quellen der Alten Welt 36, Berlin.

Herrero de Jáuregui (2008): Miguel Herrero de Jáuregui, The Protrepticus of Clement of Alexandria: A Commentary, http://amsdottorato.cib.unibo.it/III//I/ Tesi_Herrero_de_Jauregui_Miguel.pdf (Stand I.I.20Io).

Hilton (200I): John Hilton, „Florida, Introduction, Translation“, in: Stephen Harrison (Hg.), Apuleius. Rhetorical Works, Oxford, I23-175.

Hunink (2000): Vincent Hunink, „An Apuleian Parrot (on Apul. Fl.12)“, Acta Classica 43, 7I-79. 
Hunink (200I): Apuleius of Madauros. Florida, edited with a Commentary by Vincent Hunink, Amsterdam.

Hunink (2004): Vincent Hunink, „The Persona in Apuleius' Florida“, in: Maaike Zimmermann u. Rudi van der Paardt (Hgg.), Metamorphic Reflections (FS Ben Hijmans), Leuven, I75-187.

Irwin (1982): Eleanor Irwin, „The Songs of Orpheus and the New Song of Christ", in: John Warden (Hg.), Orpheus. The Metamorphosis of a Myth, Toronto, 5I-62.

Kennedy (2003): Progymnasmata. Greek Textbooks of Prose Composition and Rhetoric. Translated with Introductions and Notes by George A. Kennedy, Writings from the Greco-Roman World Io, Leiden / Boston.

Kindstrand (1973): Jan Fredrik Kindstrand, Homer in der Zweiten Sophistik. Studien zu der Homerlektüre und dem Homerbild bei Dion von Prusa, Maximos vonTyros und Ailios Aristeides, Uppsala.

Klauck (2000): Dion von Prusa. Olympische Rede oder Über die erste Erkenntnis Gottes. Eingeleitet, übersetzt und interpretiert von Hans-Josef Klauck. Mit einem archäologischen Beitr. von Balbina Bäbler, SAPERE II, Darmstadt.

Klauck (2008): Hans-Josef Klauck, „Die apokryphe Bibel. Ein anderer Zugang zum frühen Christentum", Tria Corda 4, Tübingen.

Korenjak (2000): Martin Korenjak, Publikum und Redner: ihre Interaktion in der sophistischen Rhetorik der Kaiserzeit, Zetemata I04, München.

La Rocca (2005): Adolfo La Rocca, „Il filosofo e la città. Commento storico ai Florida di Apuleio", Saggi di Storia Antica 24, Rom.

Lechner (2007): Thomas Lechner, „Rhetorik und Ritual. Platonische Mysterienanalogien im Protreptikos des Clemens von Alexandrien", in: Ferdinand R. Prostmeier (Hg.), Frühchristentum und Kultur, KfA.E 2, Freiburg, I83-221.

Lee (2005): Benjamin Todd Lee, Apuleius' Florida. A Commentary, Texte und Kommentare 25, Berlin / New York.

Lugaresi (2003): Leonardo Lugaresi, „Fuggiamo la consuetudine: pratiche sociali cristiane, rappresentazione e spettacoli in Clemente Alessandrino", Adamantius 9, I0-29.

Marcovic (1995): Clementis Alexandrini Protrepticus, edidit Miroslav Marcovich, SVC 34, Leiden.

Merino Rodríguez (2008): Clemente de Alejandría. El protréptico. Introducción, traducción y notas de Marcelo Merino Rodríguez, Fuentes Patrísticas 2I, Madrid.

Migliore (2004): Clemente Alessandrino. Protrettico ai Greci. Introduzione,traduzione e note a cura di Franzo Migliore, CTePA 179, Rom.

Mras (1949a): Karl Mras, „Die $\pi \varrho 0 \lambda \alpha \lambda$ tó bei den griechischen Schriftstellern“, WSt 64, 7I-8I. 
Mras (1949b): Karl Mras, „Apuleius' Florida im Rahmen ähnlicher Literatur“, AÖAW.PH 86, 205-223.

Nesselrath (1990): Hans-Günther Nesselrath, „Lucian’s Introductions“, in: Donald Andrew Russell (Hg.), Antonine Literature, Oxford, III-I40.

Norden (1915): Eduard Norden, Die antike Kunstprosa vom VI. Jahrhundert v.Chr. bis in die Zeit der Renaissance, 2. Bd., 3. Aufl. Leipzig / Berlin.

Pernot (1993): Laurent Pernot, La Rhétorique de l'éloge dans le monde gréco-romain. Tome II. Les valeurs, Collection des Études Augustiniennes SA I38, Paris.

Pernot (1994): Laurent Pernot, „Lucien et Dion de Pruse“, in: Alain Billault (Hg.), Lucien de Samosate (Actes du colloque internationale de Lyon), Centre d'études romaines et gallo-romaines N.S.I3, Paris, IO9-II6.

Pernot (2002): Laurent Pernot, „Les sophistiques réhabilitées“, in: Laurent Pernot (Hg.), Actualité de la rhétorique (Colloque de Paris), Paris, 27-48.

Pickard-Cambridge (1988): Arthur Pickard-Cambridge, The Dramatic Festivals of Athens. Second Edition, revised by John Gould and D. M. Lewis, Oxford.

Pohl u. Schirren (200I): Rainer Pohl u. Thomas Schirren, Art. „Lalia, Prolalia“, in: $H W B R$, Tübingen / Darmstadt, 23-28.

Puech (2002): Bernadette Puech, Orateurs et sophistes grecs dans les inscriptions d'époche impériale, Textes et traditions 4, Paris.

Reardon (197I): Bryan P. Reardon, Courantes littéraires grecs des $I I^{e}$ et $I I I^{e}$ siècles après J.-C., Annales littéraires de l'Université de Nantes 3, Paris.

Riedweg (1987): Christoph Riedweg, Mysterienterminologie bei Platon, Philon und Klemens von Alexandrien, UALG 26, Berlin / New York.

Rizzi (1993): Marco Rizzi, Ideologia e retorica negli exordia apologetici. Il problema dell' altro (II-III secolo), Mailand.

Russell (1983): Donald R. Russell, Greek Declamation, Cambridge.

Russell u. Wilson (198I): Menander Rhetor. Edited with Translation and Commentary by Donald A. Russell and Nigel G. Wilson, Oxford.

Saïd (2008): Suzanne Saïd, „Aristides' Uses of Myths“, in: William Harris u. Brooke Holmes (Hgg.), Aelius Aristides between Greece, Rome, and the Gods, CSCT 33, Leiden / Boston, 5I-67.

Sandy (1997): Gerald N. Sandy, The Greek World of Apuleius, Mn.S 174, Leiden.

Schlesier (2008): Renate Schlesier, „Dionysos als Ekstasegott“, in: Renate Schlesier u. Agnes Schwarzmaier (Hgg.), Dionysos. Verwandlung und Ekstase (Kata$\log$ zur Ausstellung in der Antikensammlung im Pergamonmuseum auf der Berliner Museumsinsel 5.II.2008 - 2I.6.2009), Regensburg, 28-4I.

Schmitz (1997): Thomas Schmitz, Bildung und Macht. Zur sozialen und politischen Funktion der zweiten Sophistik in der griechischen Welt der Kaiserzeit, Zetemata 97, München.

Schöne-Denkinger (2008): Angelika Schöne-Denkinger, „Dionysos und sein Ge- 
folge in der attischen Vasenmalerei“, in: Renate Schlesier u. Agnes Schwarzmaier (Hgg.), Dionysos. Verwandlung und Ekstase (Katalog zur Ausstellung in der Antikensammlung im Pergamonmuseum auf der Berliner Museumsinsel 5.II. 2008 - 2I.6. 2009), Regensburg, 42-53.

Schröder (1986): Publius Aelius Aristides. Heilige Berichte. Einleitung, deutsche Übersetzung und Kommentar von Heinrich O. Schröder, Heidelberg.

Seaford (2006): Richard Seaford, Dionysos, London / New York.

Steinmetz (1982): Peter Steinmetz, Untersuchungen zur Römischen Literatur des Zweiten Jahrhunderts nach Christi Geburt, Palingenesia I6, Wiesbaden.

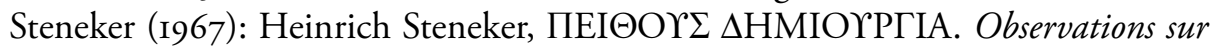
la fonction du style dans le Protreptique de Clément d'Alexandrie, Nijmegen.

Stock (I9II), Alois Stock, De prolaliarum usu rhetorico, Königsberg.

Swain (2007): Simon Swain (Hg.), Seeing the Face, Seeing the Soul. Polemon's Physiognomy from Classical Antiquity to Medieval Islam, Oxford.

Trapp (1997): Maximus of Tyre. The philosophical Orations. Translated, with an Introduction and Notes by Michael B. Trapp, Oxford.

Vallette (1971): Apulée. Apologie. Florides. Texte établi et traduit par Paul Vallette, 3. Aufl. Paris.

Volkmann (1963), Richard Volkmann, Die Rhetorik der Griechen und Römer in systematischer Übersicht (Nachdruck der 2. Aufl. Leipzig I885), Hildesheim.

Von Arnim (1898): Hans von Arnim, Leben und Werke des Dio von Prusa. Mit einer Einleitung: Sophistik, Rhetorik, Philosophie in ihrem Kampf um die Jugendbildung, Berlin.

Von Möllendorff (2000): Peter von Möllendorff, Auf der Suche nach der verlogenen Wabrheit. Lukians Wahre Geschichten, Classica Monacensia 2I, Tübingen.

Von Möllendorff (2006a): Peter von Möllendorff, „Camels, Celts and Centaurs. Lucian's aesthetic concept - The charis of the hybrid“, in: Ruurd R. Nauta (Hg.), Desultoria Scientia. Genre in Apuleius' Metamorphoses and related Texts, Caeculus 5, Leuven, 63-86.

Von Möllendorff (2006b), Lukian. Gegen den ungebildeten Büchernarren. Ausgewählte Werke. Übersetzt von Peter von Möllendorff, Düsseldorf / Zürich.

Webb (200I): Ruth Webb, „The Progymnasmata as Practise“, in: Yun Lee Too (Hg.), Education in Greek and Roman Antiquity, Leiden / Boston, 289-316.

Webb (2009): Ruth Webb, Ekphrasis, Imagination and Persuasion in Ancient Rhetorical Theory and Practise, Farnham / Burlington.

Whitmarsh (2005): Tim Whitmarsh, The Second Sophistic, Greece \& Rome 35, Cambridge.

Zanker u. Ewald (2004): Paul Zanker u. Björn Chr. Ewald, Mit Mythen leben. Die Bilderwelt der römischen Sarkophage, München.

Zweimüller (2008): Serena Zweimüller, Lukian „Rhetorum praeceptor“. Einleitung, Text und Kommentar, Hypomnemata 176, Göttingen. 


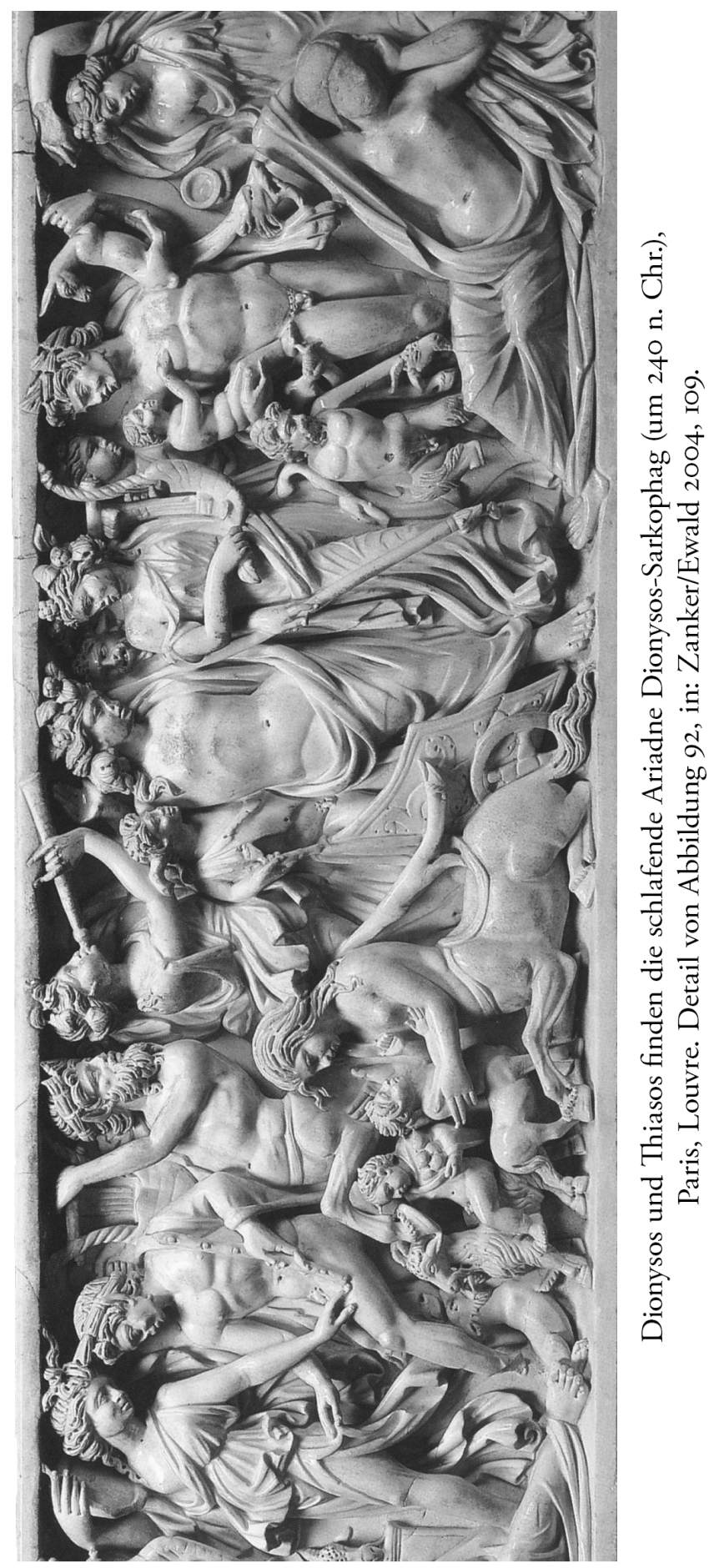





\title{
Der Logos im Paradies
}

\author{
Theophilos von Antiochia \\ und der Diskurs über eine zutreffende theologische Sprache
}

\author{
FERdinand R. Prostmeier
}

\section{Hinführung - Wer ist Gott wirklich?}

Das Ringen um eine zutreffenden Rede von Gott ist zwar nicht nur jüdisches Erbe im Christentum, aber es wird in der christlichen Literatur zuerst durch einen Verfasser bezeugt, der aus dem hellenistischen Judentum stammt und den wir als einzigen mit seinem echten Namen kennen: Paulus. Der Apostel war von der Frage umgetrieben: „Wer ist Gott wirklich?““. Indem er als Antwort darauf Jesus Christus als den präexistenten, gekreuzigten und auferstandenen Sohn Gottes predigte, sah sich christliche Theologie einer doppelten Front gegenüber. Juden empfanden sie als ein unerträgliches und jede Form der Gemeinschaft torpedierendes Ärgernis und aus der Sicht gebildeter Heiden war diese Theologie nicht nur irrig, sondern eine Torheit. Das Lexem $\mu \omega$ oí $\alpha$ findet sich in der neutestamentlichen Literatur nur im I Kor. ${ }^{1}$ Aus den vier Belegen (I Kor I,2I.23; 2,I4; 3,19) ergibt sich, dass Paulus die $\mu \omega \varrho$ í $\alpha$ wie schon Platon und auch Philon ${ }^{2}$ als den im negativsten Sinn vom, rechten Maß` der Einsicht getrennten Zustand

I In den griechischen Bibelübersetzungen sind der Spruch Sir 20,3I [33] = Sir 4I,I5 [18] („Besser ein Mensch, der seine Torheit verbirgt, als ein Mensch, der seine Weisheit verbirgt.") zusammen mit Ijob 24,I2 [ $\left.\sigma^{\prime}\right]$ die einzigen Belege für das Nomen. Die Nachweise bei Philon, all 2,70; imm I64; sobr II und Josephus, ant. I,224; 17,209; 19,107 sind nicht signifikant. $\mu \omega \varrho i \alpha$ fehlt bei den Apostolischen Vätern und den griechischen Apologeten, abgesehen von der Polemik in Di-

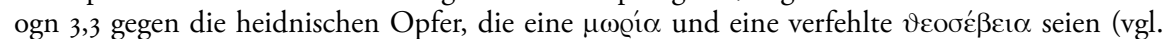

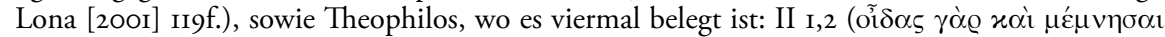

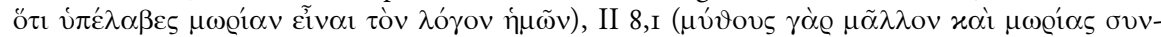

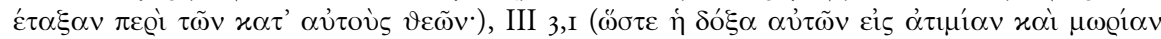

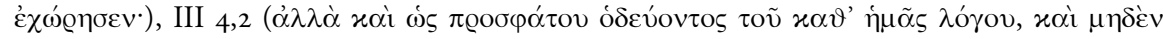

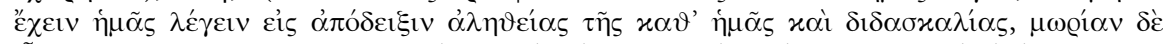

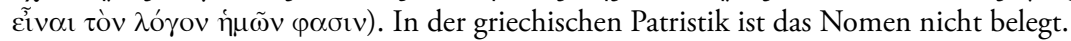

2 Philon, imm 164b: „In der Mitte zwischen Kühnheit und Feigheit aber liegt die Tapferkeit, zwischen überschäumendem Leichtsinn und schmutzigem Geiz die Mäßigkeit, zwischen Frevelmut und Torheit die Einsicht, zwischen Aberglauben und Gottlosigkeit die Frömmigkeit ( $\pi \alpha v$ vove-

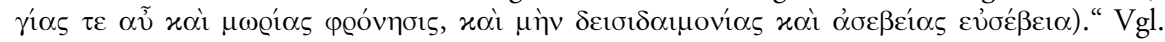
Platon, leg. 818d. 
versteht. Paulus verwendet den Begriff dazu, das theologische Erkenntnisvermögen zweier Menschheitsgruppen entsprechend ihrer Haltung gegenüber dem Evangelium zu unterscheiden. Vor dem Forum der, Weisheit dieser Welt' ist die christliche Gottesrede eine Torheit. Vor Gott gilt umgekehrt gerade diese, Weisheit der Welt' als Torheit (ıKor 3,19a). Die Weisheit der Welt - worunter die jüdische Schriftgelehrsamkeit ebenso fällt wie die $\pi \alpha \imath \delta \varepsilon i ́ \alpha$ der hellenistisch-römischen Kulturtradition (I Kor I,20a) - ist untauglich, um Gott zu erkennen (I Kor I,20b). Hierfür bedarf es vielmehr der Zurüstung durch den Geist Gottes (ı Kor 2,I4). ${ }^{3}$ Wer die christliche Gottesrede als Torheit hinstellt, macht seine eigene $\mu \omega Q^{\prime} \alpha$ und damit seinen Unglauben evident, wodurch er letztlich seine Rettung

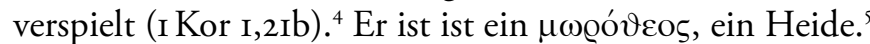

Paulus zufolge ist also einerseits das Evangelium weder aus der kulturellen Tradition herzuleiten ${ }^{6}$ noch mit deren hermeneutischen Instrumentarien sachgemäß zu erschließen. Andererseits wird im Echo auf die christliche Verkündigung neben der Eigenständigkeit der christlichen Botschaft zugleich evident, dass die Kultur der Ort für die Verkündigung der Botschaft ist, denn in Kultur und Geschichte geschehen sowohl die Annahme des Evangeliums als auch dessen signifikante Ablehnung und Zurückweisung. Wenn nun aber „Gott durch die Torheit der Verkündigung" - wie Paulus in I Kor I,2Ib schreibt - ,alle gerettet hat, die glauben“, dann ist die, Weisheit der Welt' der Weg, auf dem das Kerygma zur Rettung werden kann, weil das Evangelium nicht anders als in Kultur und Geschichte den Glauben hervorruft. Muss die Weisheit Gottes also auf dem Weg der Weisheit der Welt erkannt werden, dann bedarf es der intellektuellen Plausibilisierung des Evangeliums sowie der Überzeugung, dass diese Redeweise die theologische Wahrheit zutreffend zur Sprache bringt.

Gegen Ende des 2. Jahrhunderts war das Ringen um eine zutreffende christliche Rede von Gott zu einem vielstimmigen Diskurs angewachsen, in dem gebildete Christen versuchten, unter Wahrung des biblischen Monotheismus den Glauben

3 Die Vorstellung, der Mensch sei aus sich zu theologischer Erkenntnis nicht fähig, sondern bedürfe einer spezifischen Befähigung von Gott her, ist zwar nicht spezifisch christlich (vgl. Früchtel 2006, 268-27I), prägt aber von den christlichen Anfängen her die binnenchristlichen Wortmeldung zur Sache (vgl. I Klem I3,I; 23,4; 38,2; Barn 2,2f; 6,IO; 2I,5f.; IgnSmyrn I,I). Bei Theophilos kehrt diese Auffassung in Autol. I 2.5-7 wieder; vgl. Prostmeier 2007, I58-168.

4 Zu I Kor vgl. Zeller 20IO, I07-II2. I42-I5O.

5 Vgl. Passow I84I, 2/308 unter Verweis auf Orac. Sib. I4,32I.

6 Das dürfte Gültigkeit haben, auch wenn Röm 2,I4-I6 als „Anweg“ zu begreifen sein mag, die Möglichkeit einer sog. natürlichen Gotteserkenntnis zu durchdenken. Justin, I apol 23,2 weist auf den Logos Gottes, den Sohn Gottes, durch den die Erkenntnis der Wahrheit ermöglicht ist, wobei er in 2 apol IO,I und I3 mittels der stoischen Lehre vom $\lambda$ ó liche Erkenntnisdisposition erläutert. 
an die Göttlichkeit Jesu Christi im Rahmen der kaiserzeitlichen Theosophie plausibel und überzeugend auszusagen. ${ }^{7}$

Bevor nun eine dieser Wortmeldungen aus dem 2. Jahrhundert besprochen wird, nämlich jene des Theophilos von Antiochia, scheinen mir zwei Anmerkungen für das Verständnis der theologischen Sprachgeschichte im Frühchristentum wichtig.

I. Mit dem Erfolg der Heidenmission war das Christentum vor die Aufgabe gestellt, den Glauben unter den Konditionen der hellenistisch-römischen Tradition auszusagen. In den christlichen Anfängen bleiben Regelungen, die dem Spannungsverhältnis von Evangelium und Kultur geschuldet sind, noch auf den Binnenraum der Gemeinden fokussiert - man denke an die Götzenopferfleischfrage in I Kor Io oder an die Empfehlungen für christliche Ehefrauen von Heiden in I Petr 3,I-6. Paulus spricht zwar davon, dass die Christen vor allem wegen ihrer Theologie einer prinzipiellen Kritik ausgesetzt sind. Doch auch hierbei ist zuerst an Auseinandersetzungen innerhalb der Gemeinden zu denken. Weil aber die Konversion zum Christentum die persönliche kulturelle Verwurzelung nicht eliminiert, muss davon ausgegangen werden, dass gebildete Christen bald bestrebt waren, die Wahrheit ihres neuen Glaubens auch im Rahmen ihrer ererbten Tradition aufzuzeigen. In diesen innergemeindlichen theologischen Diskursen besaß spätestens mit dem Johannesprolog „die Bezeichnung Christi als Logos Gottes eine herausragende Rolle ${ }^{\text {(8 }}$. Entsprechend musste die christliche Bedeutung dieses Epitheton in seiner Relation zu logostheoretischen Reflexionen innerhalb der kaiserzeitlichen Philosophie geklärt werden, wodurch selbstverständlich die Frage des Monotheismus in den Blick rückte. ${ }^{9}$

2. Als ab Mitte des 2. Jahrhunderts christliche Theologie direkt im akademischen Diskurs mit der hellenistisch-römischen Bildungswelt abgefragt wurde, ${ }^{\text {10 }}$ musste sie die Wahrheit ihrer Aussagen, die in der Gemeinde durch die Schrift, die Paradosis und das Zeugnis als christliche Glaubenstradition patentiert war,

7 Gegen Theologien, wie sie von frühchristlichen Apologeten erarbeitet wurden, regte sich Widerstand nicht nur von Gebildeten wie Kelsos, die im Namen der hellenistisch-römischen Tradition Protest einlegten und ihre Einwände auf die Gottesfrage fokussierten, sondern auch in den Gemeinden hagelte es Kritik. Am Ende des zweiten Jahrhunderts klagt z. B. ein zum Christentum übergetretener Intellektueller über die Lage in den Gemeinden seiner nordafrikanischen Heimat: „So verbreiten diese Leute immer wieder, wir würden zwei oder drei Götter verkünden." Tertullian, praxean 3,I; vgl. ebd. I2,I (FC 34,IO8f. I48f.); ähnlich Origenes, Jo. II 2,I6; Näheres vgl. Brox 1996, I-46; ders. 2000, 432-429. - Wie der Glaube an das Evangelium in einem von griechischen Denktraditionen nur peripher berührten Kulturraum festgehalten und entfaltet werden konnte, hat Brox 1984, I-26 skizziert.

8 Löhr 2009, Sp. 328; vgl. Krämer 1967, 282-292; Dörrie 1979, I36-152; Brox 1996, I-46; ders. 2000, 32-39.

9 Nähers vgl. Dörrie (1975).

Io Vgl. Gigon 1959, 34-74. I04-I26. I42-I8I; Brox 1996, I-46; Zeegers 1998, I35-I75; Rosen 2000, I52-I83; Prostmeier 2007, I55-182. 
vor der, Weisheit der Welt ${ }^{`}$ - wie Paulus geschrieben hatte - und mit deren Mitteln erweisen. In einer Gesellschaft, die sich in Gestalt der ,Zweiten Sophistik ${ }^{\text {II }}$ an einem Konzept der Klassik orientierte und sich elitär durch die literarische Tradition und rhetorische Meisterschaft sowie durch einen verfeinerten Lebensstil definierte, besaß auch in akademischen Diskursen neben der Stringenz der Argumentation die Form ihrer Durchführung und Darbietung eminente Bedeutung. ${ }^{12}$ Daher konnten sich die frühchristlichen Apologeten, die in der Blütezeit der Zweiten Sophistik schrieben, nicht mehr damit begnügen, einen bündigen Beweis für die Richtigkeit und Zulässigkeit der christlichen Gottesrede abzuliefern. Schon die Wichtigkeit des Themas erforderte es, entsprechend dem Zeitgeist durch literarische und rhetorische Brillianz von der Wahrheit der Aussagen zu überzeugen und die Hörer und Leser für das Christentum zu gewinnen oder zum Bleiben zu bewegen. ${ }^{13}$

2. Theophilos von Antiochia und der ,Logos im Paradies‘

Ein Beispiel dafür, wie ein gebildeter Christ versucht, die Wahrheit des Evangeliums in einer Diskurskultur darzulegen, die unter dem Eindruck der Zweiten Sophistik floriert, findet sich in den drei Büchern, die Theophilos von Antiochia um I80 „An Autolykos " ${ }^{\text {"I4 }}$ - einen gebildeten Heiden - schreibt. Von den facettenreichen, dissonanten frühchristlichen Versuchen einer gleichermaßen exegetisch wie philosophisch plausiblen und literarisch überzeugenden Gottesrede hebt sich diese Trilogie in dreifacher Hinsicht ab:

I. Theophilos entwirft eine christliche Theologie, ohne Jesus Christus expressis verbis zu erwähnen. Er knüpft die christliche Lehre über Gott, Menschen und Welt an die biblische Urgeschichte. In ihr findet er nicht nur alle inhaltlichen Haftpunkte sowie die Begründung für die Zulässigkeit der christlichen Lehre, sondern in der biblischen Sprache auch die Maßgabe für eine zutreffende christliche Rede von Gott.

Selbstverständlich kommen in den drei Büchern christliche Traditionen zum Tragen, wie schon Adolf Harnack gezeigt hat. ${ }^{\text {Is }}$ Diese erlangen aber nirgends jene argumentative Funktion, die Theophilos der biblischen Urgeschichte einräumt. Das gilt auch für die Stellen, an denen er Joh I,I zitiert (II 22) und summarisch

II Vgl. Norden 1915, I/35I-354; Aderson 1993; Nesselrath 1997, 270-287; Schmitz 1997.

I2 Entsprechend heben sich die Werke der frühchristlichen Apologeten durch ihre Disposition, die Sujets und das literarische Niveau von dem vorausgehenden christlichen Schrifttum ab. Vgl. Grant 1959, 33-45; Nesselrath 1997, 269-293; Korenjak 2000.

I3 Vgl. Diehle 1989, 310-314; Näheres bezüglich Theophilos vgl. Prostmeier 2007, I6of.

I4 Griechischer Text vgl. Otto I86I; Marcovich I995; Martín 2004.

I5 Vgl. Harnack I890, I-2I.; ferner Grant 1947, I8I-I89; ders. 1959, 33-45; Zeegers 1970, 37I-382. 
auf die Evangelien verweist (III I2). ${ }^{16}$ Wenn er christliche Traditionen aufruft, dienen sie zur Illustration und Bekräftigung dessen, was Gott in seiner Schöpfung festgelegt hat, in der Genesis geschrieben steht und durch Propheten für das Christentum avisiert wurde. Dass alle Offenbarung immer schon auf das Christentum geeicht war, hat seinen Grund darin, dass die Verfasser der Schrift und der christlichen Literatur - z.B. Mose, die Propheten und Johannes - von demselben Geist Gottes erfüllt waren (II 22). Theophilos ruft hierdurch eine Argumentationsstrategie auf, die sich von der Stephanusrede über die Petrusrede beim Apostelkonzil, sodann I Petr I,23-25, dem wohl schönsten Text im I Petr, und selbstverständlich dem Barnabasbrief sowie frühchristlichen Apologeten wie Theophilos bis zu den Kirchenvätern verfolgen ließe. ${ }^{17}$

2. Theophilos entfaltet seine Theologie gegenüber dem Heiden Autolykos, den er als $\pi \varepsilon \pi \alpha 1 \delta \varepsilon v \mu \varepsilon ́ v o \varsigma$ - als Gebildeten - profiliert. ${ }^{18}$ Autolykos repräsentiert die kaiserzeitliche Bildungskultur und ein geistig-soziales Milieu, in dem Interesse am Christentum und Skepsis gegenüber seinen Lehren keine Gegensätze sein müssen, vielmehr dicht nebeneinander liegen (III 4). Das Adressatenprofil ist aber genauso, vielleicht noch mehr dazu geeignet, dass sich gebildete Christen in ihrem Zustand vor ihrer Konversion wiedererkennen.

3. Die Welt der Zweiten Sophistik ist Theophilos ebenso vertraut wie denjenigen, die sich mit seiner Gestalt des Autolykos zumindest im Rückblick auf die eigene Vergangenheit identifizieren können. Die vielen Zitate aus der paganen Tradition und die noch größere Anzahl der Anspielungen auf pagane Literatur und Diskurs konstruieren einen idealen Erinnerungsraum. Daher sind die Darlegungen darauf angelegt, Eindruck zu machen und die Überzeugung zu festigen, dass in der christlichen Theologie die von Heiden wie Christen erstrebte $\alpha^{\lambda} \lambda \eta \dot{\vartheta \varepsilon \varepsilon \alpha} \alpha$, die Wahrheit, zur Sprache gelangt.

Am Ende des 2. Jahrhunderts war es hierfür unverzichtbar aufzuzeigen, dass christliche Theologie sowohl mit logostheoretischen Reflexionen der kaiserzeitlichen Philosophie ${ }^{\mathrm{rg}}$ verbunden werden kann, als auch davon zu überzeugen, dass die in biblischer Tradition verankerte Rede vom Logos Gottes alle paganen Stimmen hinsichtlich der $\dot{\alpha} \lambda \eta \dot{\vartheta \varepsilon l \alpha}$ übertrifft. Es geht Theophilos also auch darum, die Sprachgestalt der Schrift, speziell die Bilder und Metaphern der Urgeschichte, nicht nur als zulässige, sondern als die im eigentlichen Sinne einzige zutreffende theologische Sprache zu erweisen und zugleich durch geeignete Stilmittel vorzuführen, dass die pagane Tradition exakt an die christliche Tradition und ihre biblische Fundierung anschlussfähig ist. Zur Erklärung verweist Theophilos auf die

I6 Vgl. Autol. III I3,I, wo er offenkundig die Evangelienüberlieferung „Hl. Schrift“ nennt und III I4,2, wo Mt 5,44.46; 6,3 als „das Evangelium“ zitiert; vgl. Aguado Bleye I932, I76-I9I.

17 Vgl. Prostmeier 2005, I-29.

I8 Vgl. Prostmeier 2007, I55-I82.

I9 Dazu Früchtel 1970. 
zeitliche Priorität der Schrift vor der gesamten von ihr deszendenten paganen Literatur. In Anwendung des antiken Altersbeweises sieht Theophilos in der Anciennität der biblischen Überlieferung nicht nur deren unüberbietbaren Wert zur Auffindung der theologischen Wahrheit verbürgt, sondern erkennt in ihr zugleich das vorzügliche sprachliche Vorbild, um diese Wahrheit zur Sprache zu bringen. Diese Vorzüglichkeit untermauert er im III. Buch mit der ersten christlichen Weltchronik.

Vor diesem Hintergrund ist bei Theophilos die Verwendung des Begriffs Logos zu profilieren. Theophilos verwendet den Terminus in voller semantischer Breite. ${ }^{20}$ Dominant sind indes die Bedeutung „Lehre“ und die philosophisch-theologischen Bedeutungen, nämlich zum einen als Gottes Geist und vernünftiges Prinzip und zum anderen als Gottes Wort oder Rede. Sowohl für das Bedeutungsspektrum des Begriffs Logos in der Trilogie als auch speziell hinsichtlich seiner theologischen Verwendung liegen einige Studien vor. ${ }^{21} \mathrm{Im}$ Unterschied zu diesen theologie- und dogmengeschichtlichen Untersuchungen geht es im Folgenden darum, Strategien aufzuzeigen, die Theophilos einsetzt, um Autolykos davon zu überzeugen, dass biblisch-christliche Rede vom Logos Gottes die Wahrheit über Gott zur Sprache bringt.

Theophilos geht nicht planlos und auch nicht ohne eine gewisse Raffinesse ans Werk. Sowohl die thematische als auch die rhetorisch-stilistische Disposition werden in den beiden ersten Kapiteln der Trilogie genannt. ${ }^{22}$ Auch für die vorliegende Fragestellung ist es entscheidend, sich immer wieder die Eröffnungsaufforderung des Autolykos zu vergegenwärtigen: „Zeige mir deinen Gott!“浮 Die unmittelbare Antwort und die folgenden Erläuterungen lassen erkennen, wie Theophilos in seinen drei Büchern vorgehen wird. Er schreibt: „Zeige mir den Menschen in dir, und ich will dir meinen Gott zeigen!" Die darauf folgende Liste mit gegensätzlichen Kategorien der sinnlichen Wahrnehmung fungiert insgesamt als Bild für die Möglichkeit der Gottesschau. Aus der weiteren Argumentation

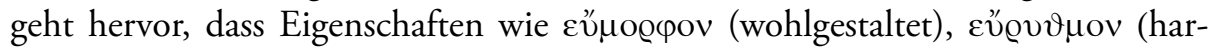

20 Vgl. Löhr 2008, Sp. 374-376.

2I Vgl. Gross 1896, 22-34; Claussen 1903, 8I-213; Pommrich 1904; Dörrie 1979, I45-I52.

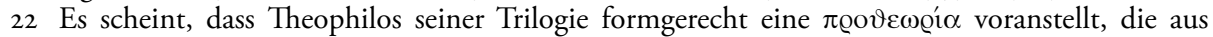
zwei Teilen besteht, nämlich einem Loblied auf die $\dot{\alpha} \lambda \eta \dot{\eta \varepsilon} \boldsymbol{\alpha} \alpha$ und die Wahrheitsliebe sowie aus der Disposition, die sich aus der Fragestellung und den hermeneutischen Überlegungen zu de-

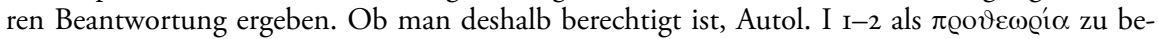
zeichnen, vergleichbar mit Theodoret, affect. proœm. 3, wäre eigens zu untersuchen, auch wenn das vernichtende Urteil von Norden 1915, 2/513 Anm. 2, in das Geffcken 1902, 250, genussvoll eingestimmt hat (,Theophilos, in seinen Büchern an Autolykos der rechte Typus eines ganz oberflächlichen Schwätzers, dessen Stilistik und Sprache mit seiner Gedankenarmut wetteifert."), einer solchen Studie keine günstige Prognose zu stellen scheint.

23 Autol. I 2,I. - Zum popularphilosophischen Hintergrund der Diskussion über den angemessenen Gottesbegriff vgl. Seneca, Ep. 95,47-50. 


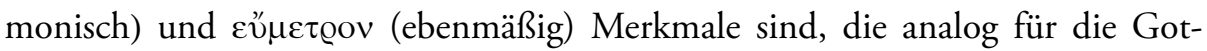
tesschau gelten (Autol. I 2,2). Für die Theologie ist demnach die عúź $\varepsilon \varepsilon 1 \alpha$, also die schöne, angenehme, wohlgestimmte Rede, die angemessene Sprachgestalt für eine zutreffende Rede von Gott. Dabei gilt, dass das literarische Niveau sowohl der Sache als auch der Gelegenheit angemessen sein muss. Theophilos bekundet hierdurch seine klassische Bildung und seinen Konsens mit den literarisch-rhetorischen Erwartungen der zeitgenössischen Bildungswelt. Ausgewogenheit und Wohlklang in der Sprachgestaltung gelten zusammen mit der gekonnten Variation stilistischer Usancen als Indikatoren für den Wahrheitswert.

Dem auf Konsens zwischen christlicher Rede von Gott und antiker Kultur geeichten hermeneutischen Exkurs im 2. Kapitel folgt eine Texteinheit, die schon durch ihre Struktur aus den drei Büchern herausgehoben ist. In einem fast hymnischen Text ${ }^{24}$ bespricht Theophilos Möglichkeiten und Grenzen theologischer Sprache. Der Begriff Logos wird darin theologisch begriffen und als das Prinzip

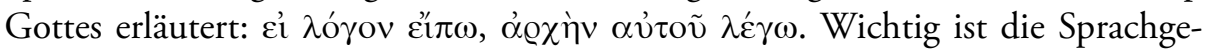
stalt der gesamten Darlegung.

\section{I Der Logos Gottes ,ist sein Prinzip‘ (Autol. I 3 )}

Unter den Erläuterungen in dieser langen Trilogie fällt Autol. I 3 durch seine rhythmische Gestaltung aus dem Rahmen. Auf den ersten Blick handelt sich um eine Art negative Theologie, die mit $\alpha$-privativum-Bildungen Autolykos darüber aufklärt, was über Gott nicht gesagt werden kann. Im Mittelteil folgen 26 theologische Epitheta, die paarweise aufeinander bezogen sind, so dass der Eindruck einer Entsprechungstabelle entsteht, in der theologische Bezeichnungen aus biblischer Tradition auf scheinbar signifikante Begriffe der kaiserzeitlichen Philosophie bezogen sind, die in der linken Spalte aufeinander folgen.

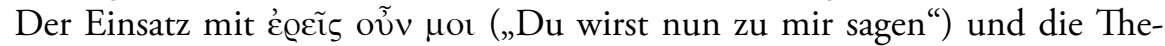

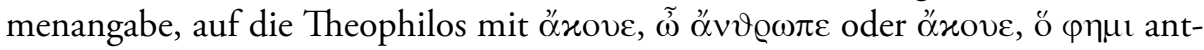
wortet, ist für die ersten beiden Bücher ,An Autolykos' typisch. Der Zweck besteht selbstverständlich darin, den gebildeten Leser, für den Autolykos als Projektionsschild konstruiert ist, in den Diskurs einzubeziehen. Die Aufforderung „Beschreibe du, der du siehst, mir die Gestalt Gottes!“ knüpft inhaltlich die folgenden Ausführungen an die Leitfrage von I 2,I an. Hierbei ist Theophilos durch die Anrede als $\beta \lambda \dot{\varepsilon} \pi \omega v$, als Sehender, die Kompetenz zuerkannt, entsprechend der theologischen Hermeneutik über Gott zutreffend und überzeugend Auskunft zu geben. Seine Antwort muss also den Ansprüchen der عủéreıı genügen.

24 Zum Hymnus in der antiken Literatur vgl. Lattke 199I; Furley u. Bremer 200I; speziell zu Theophilos vgl. Grant 1959, 33-45; zur Wirkungsgeschichte vgl. Bragato 1942 
' $\mathrm{E} \varrho \tilde{\varepsilon} \mathrm{s} \varsigma$ oũv $\mu \mathrm{ol}$ '

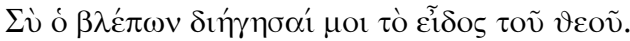

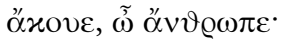

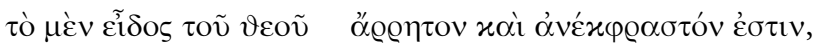

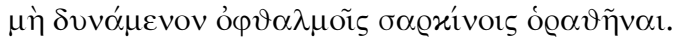

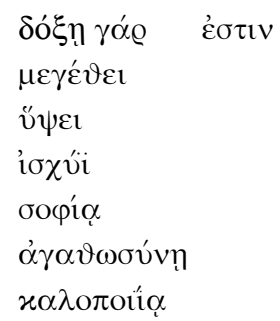

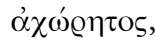
$\dot{\alpha} x \alpha \tau \alpha \dot{\alpha} \lambda \eta \pi \tau \sigma$,

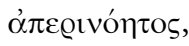

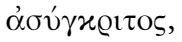

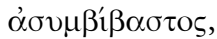
$\dot{\alpha} \mu \dot{\prime} \mu \eta \tau$ то

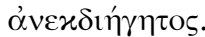

2

\begin{tabular}{|c|c|c|c|c|c|c|}
\hline 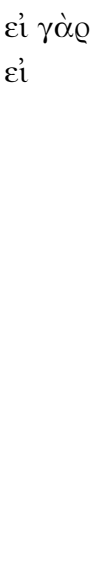 & 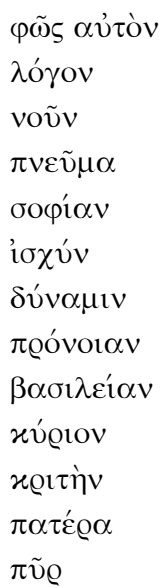 & 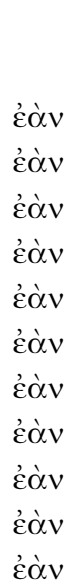 & $\begin{array}{l}\text { हैi } \pi \omega, \\
\varepsilon^{\prime} \pi \omega, \\
\varepsilon^{\prime \prime} \pi \omega, \\
\varepsilon^{\prime \prime} \pi \omega, \\
\varepsilon^{\prime \prime} \pi \omega, \\
\varepsilon^{\prime \prime} \pi \omega, \\
\varepsilon^{\prime \prime} \pi \omega, \\
\varepsilon^{\prime \prime} \pi \omega, \\
\varepsilon^{\prime \prime} \pi \omega, \\
\varepsilon^{\prime \prime} \pi \omega, \\
\varepsilon^{\prime \prime} \pi \omega, \\
\varepsilon^{\prime} \pi \omega, \\
\varepsilon^{\prime \prime} \pi \omega,\end{array}$ & 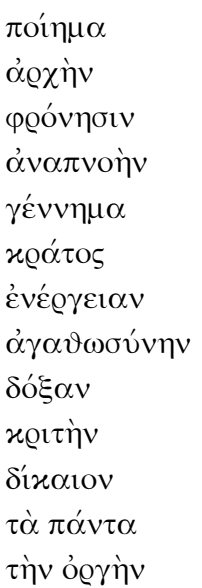 & 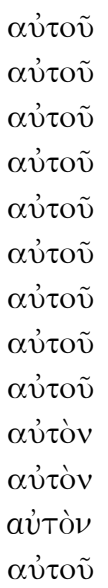 & 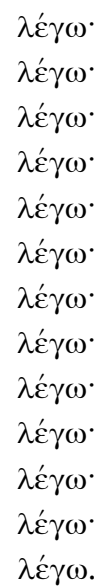 \\
\hline
\end{tabular}

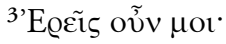

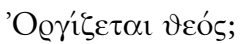

$\mu \alpha{ }^{\prime} \lambda 1 \sigma \tau \alpha$

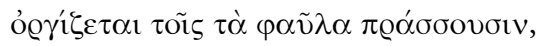

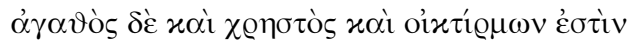

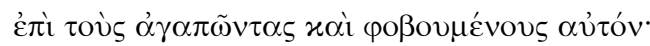

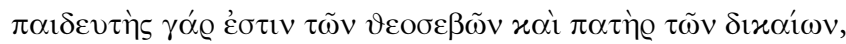

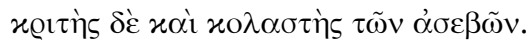


${ }^{1} \mathrm{Du}$ wirst nun zu mir sagen:

Beschreibe mir du, der du siehst, die Gestalt Gottes!

Höre, o Mensch:

die Gestalt Gottes ist unaussprechbar und unerklärbar, unmöglich für leibliche Augen zu sehen.

$\begin{array}{cll}\text { Denn } & \text { Herrlichkeit nach ist er } & \text { unfassbar, } \\ \text { der } & \text { Größe nach } & \text { unbegreifbar, } \\ \text { der } & \text { Erhabenheit nach } & \text { unerreichbar, } \\ \text { der } & \text { Stärke nach } & \text { unermesslich, } \\ \text { der } & \text { Weisheit nach } & \text { unvergleichlich, } \\ \text { der } & \text { Güte nach } & \text { unnachahmlich, } \\ \text { dem } & \text { Rechthandeln nach } & \text { unbeschreiblich. }\end{array}$

2 Denn wenn ich zu ihm Licht wenn ich

Logos
Vernunft

Geist

Weisheit

Stärke

Kraft

Vorsehung

Herrschaft

Herr

Richter

Vater

Feuer sage, nenne ich

sage, nenne ich

sage, nenne ich

sage, nenne ich

sage, nenne ich

sage, nenne ich

sage, nenne ich

sage, nenne ich

sage, nenne ich

sage, nenne ich sage, nenne ich wenn ich sage, nenne ich ihn den Allumfassenden; wenn ich sage, nenne ich

sein Geschöpf;

sein Prinzip;

sein Denken;

seinen Odem;

sein Erzeugnis;

seine Gewalt;

seine Wirksamkeit; seine Güte;

seine Herrlichkeit; ihn Richter; ihn gerecht; seinen Zorn.

${ }^{3}$ Du wirst nun zu mir sagen:

Wird Gott zornig?

\section{Allerdings!}

Er zürnt denen, die Übles tun,

gütig aber, gnädig und erbarmungsvoll ist er

gegen die, die ihn lieben und fürchten;

denn er ist der Lehrmeister der Frommen und der Vater der Gerechten, aber der Richter und Bestrafer der Gottlosen. 
Zunächst scheint Theophilos aus dem vorausgehenden Kapitel nur drei Einsichten in Erinnerung zu bringen. Weil die beiden folgenden Listen jeweils mit einem $\gamma \alpha \dot{\varrho}$ an dieses Diktum angeschlossen sind, könnte der Eindruck entstehen, die Unaussprechbarkeit der Gestalt Gottes werde in der Siebenerliste mit den $\alpha$ privativum-Bildungen entfaltet ${ }^{25}$ sowie seine Unerklärbarkeit in der darauffolgenden Tabelle der 26 theologischen Epitheta. Tatsächlich ist nur mittels des $\alpha \dot{v} \varepsilon x \delta$ -

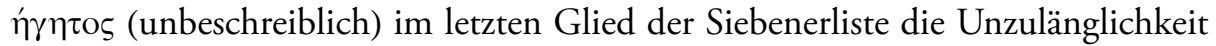
des Sprechens von Gott aufgegriffen.

Die darauf folgende Tafel mit korrespondierenden theologischen Epitheta unterläuft den ersten Eindruck ebenfalls. Zwar sind aus der Siebenerliste vier Epitheta aufgenommen, nämlich Weisheit und Stärke sowie Herrlichkeit und Güte. Allerdings werden die Bezeichnugen $\delta$ ó $\xi \alpha$ und $\alpha \gamma \alpha \vartheta \omega \sigma u ́ v \eta$ nicht erklärt, sondern sie dienen ihrerseits als Übersetzungen für Begriffe, die in die pagane Tradition zu gehören scheinen, nämlich $\pi$ @óvoı $\alpha$ und $\beta \alpha \sigma \imath \lambda \varepsilon^{\prime} \alpha$. Sodann begegnet an

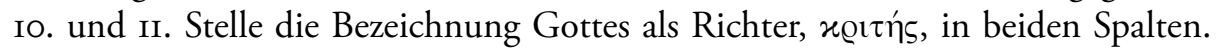
Wegen der gleichförmigen Struktur dieser Entsprechungstafel ist nicht auszuschließen, dass diese Uneindeutigkeit und Rochierbarkeit für alle Epitheta gilt, auch für vermeintlich eindeutige Begriffe wie Logos, Nus, Pneuma und Sophia. Aus der Sicht des Theophilos ist also auch diese hochkarätige Terminologie unzureichend für die Rede von Gott.

Wie eklatant der Irrtum ist zu meinen, diese Terminologie für sich garantiere schon Wahrheit, macht er mit V 3 deutlich. Die Pointe dieser vom abschließenden Epitheton der Vergleichstabelle inspirierten Charakterisierung ist weniger darin zu sehen, dass Gottes Zorn und seine Güte von der Haltung der Menschen gegenüber Gott abhängig gemacht sind, sondern dass eine metonyme Diktion, die kein spezifisch christliches Profil hat, als zulässige Rede von Gott behauptet wird. Von $\mathrm{V}_{3}$ her gesehen, bestätigen die scheinbar elaborierten Listen zum einen exakt das, was Theophilos aus dem 2. Kapitel in Erinnerung gebracht hat, nämlich die Unzulänglichkeit menschlichen Redens von Gott. Zum anderen wird Autolykos daran erinnert, dass die hellenistische Frömmigkeit und Ethik nicht nur mit philosophischer Terminologie operiert, sondern durchaus von Gott im metonymen Sinn als Lehrmeister, Vater und Richter sprechen kann. Aus seiner eigenen Tradition müsste Autolykos somit klar sein, dass die theologische Wahrheit nicht an philosophische Terminologie gebunden ist und diese darum auch nicht garantiert. Theophilos verknüpft hierin seinen Aufweis der mangelnden Verlässlichkeit theologischer Begriffe mit einer bekannten und akzeptierten Sprachgestaltung und wendet beides gegen die Vorbehalte, die Autolykos im Na-

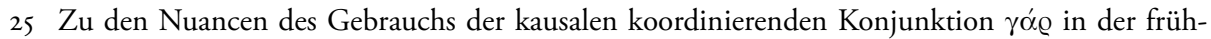
christlichen Literatur (begründend, erklärend, folgernd, fortführend) vgl. Bauer u. Aland I988, Sp. 304f.; Blass 1984, $\$ 452^{1}$. 
men der Tradition gegen die christliche Theologie hat. Geschickt - man kann auch sagen: raffiniert - hält Theophilos dem Autolykos seine pagane Tradition als Spiegel vor, um sie zu paralysieren.

Allerdings ist hiermit nur die inhaltlich-argumentative Seite dieses Kapitels besprochen. Theophilos weiß, dass der Erfolg seiner Argumentation, die er seit dem I. Kapitel entwickelt hat, nicht zuerst von ihrer Plausibilität abhängt. Um die Leser von der Sache zu überzeugen, muss die Darstellung sprachlich einen exzellenten Eindruck machen. Genau das erstrebt Theophilos mittels der beiden Listen im 3. Kapitel; durch das Frage-Antwort-Spiel werden sie mit dem gesamten Argumentationsgang vernetzt.

In der Siebenerliste (Autol. I 3,rb) ist nicht nur die Wortwahl auffällig. Das erste Adjektiv ist eine christliche Wortbildung. Vor Theophilos findet sich das Le-

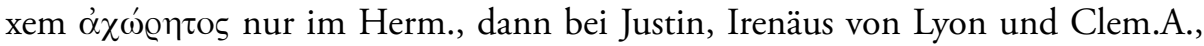
str. VI 39,I-3. Die folgenden sechs Adjektive kommen nur in diesem Vers der Tri-

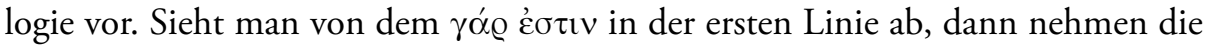
Silben gegen Ende der Liste zu. Offensichtlich sind die sieben $\alpha$-privativum-Bildungen nicht nur gesucht, sondern auch mit Absicht in diese Reihung gestellt.

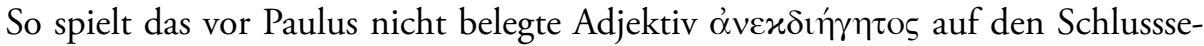
gen in 2 Kor 9,15 an. Der Aufbau ist insgesamt darauf angelegt durch wachsende Silbenzahl, den Wechsel zu langen Vokalen im Wortausgang der drei letzten Epitheta sowie durch den gravitätischen Rhythmus Erhabenheit hervorzurufen. Damit folgt Theophilos den Usancen der antiken Kunstprosa. Diese Absicht wird in der zweiten Liste (Autol. I 3,2) offenkundig. Besonders auffällig ist der regelmäßige Schluss der Perioden. Jeder Satz schließt mit einem Kretikus. ${ }^{26}$ Diese Klausel, bei der eine kurze Silbe von zwei langen Silben eingeschlossen wird - $\alpha v \tau o \tilde{v}$ $\lambda \varepsilon ́ \gamma \omega-$, gilt als besonders schöner, gefälliger Abschluss des Satzgefüges. In den drei Perioden, die mit $\alpha$ ṽ òv $\lambda \hat{\varepsilon} \gamma \omega$ schließen, ist das kretische Versmaß ebenfalls gewahrt, weil die außenstehende kurze Silbe von aủ tóv durch die Doppelkonsonanz positionslang ${ }^{27}$ wird. Hinzu kommt, dass Theophilos gerade auch durch diese feine rhythmische variatio seine rhetorische Meisterschaft unter Beweis

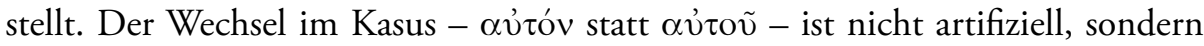
der Aussage geschuldet. Die Intention, durch die sprachliche Gestaltung zu beeindrucken, um in der Sache zu überzeugen, ist auch darin zu erkennen, dass Theophilos die Liste mit einem einsilbigen Epitheton sowohl beginnt - $\varphi \tilde{\omega} \varsigma$ - als auch schließt $-\pi \tilde{v} \varrho$. Hierdurch wird die Zusammengehörigkeit der dreizehn Perioden unterstrichen. Von daher erklärt sich wohl auch, dass er am Schluss wieder auf den Genitiv $\alpha$ ¿่oṽ $\lambda \dot{\varepsilon} \gamma \omega$ zurückkehrt. ${ }^{28}$

26 Landfester 1997, I69f.; Norden 1995, 2/909-923.

27 Bornemann u. Risch $1978, \$ 7$,Ic*.

28 Theophilos zeigt seine rhetorische Kompetenz auf verschiedenste Weise und mit unterschied-

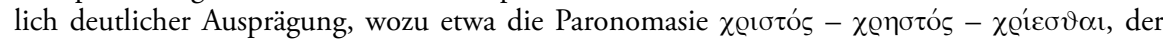


Die Bedeutung des Rhythmus in der Prosa, der rhythmischen variatio sowie des Klauselsystems ist aus einer Reihe von frühchristlichen Schriften durchaus bekannt, etwa durch den Schlussgruß $(65,2)$ im I Klemensbrief ${ }^{29}$ sowie dem berühmten Teilvers 5,5c in der Schrift ,An Diognet, ${ }^{6}{ }^{30}$ ein Protreptikos, über den immerhin Eduard Norden geurteilt hat, er zähle „zu dem Glänzendsten ..., was von Christen in griechischer Sprache geschrieben ist ${ }^{\text {"3i1 }}$. Wie diese Texte so sind auch die beiden Listen in Autol. I 3 auf ihre Wirkung bei Gebildeten hin komponiert.

Im Fokus der Tabelle steht offenkundig die Anschlussfähigkeit der christlichen Rede von Gott. Sie wird hier aber nicht auf dem Weg des stringenten Nachweises versucht, sondern mit den Mitteln, die in dem geistig-sozialen Milieu, in dem sich Theophilos bewegt, Indikatoren für die Wahrheit und somit geeignet sind, auch von der Zuverlässigkeit der christlichen Rede von Gott zu überzeugen. Die verwendeten Bilder sind vertraut und laden ein, sich der Argumentation zuzuwenden und ihr zu folgen. Selbstverständlich werden durch die Terminologie und die sprachliche Gestaltung gängige philosophische Diskurse aufgerufen, deren Signifikanz für das Thema bekannt und deren Bedeutung anerkannt ist. Die Sprachgestalt fügt sich also zur Argumentationslinie, die Theophilos von Beginn an entwickelt hat. Ihr Ziel ist allerdings mitnichten die Demonstration literarischer Virtuosität. Denn das wäre nicht Suche nach der Wahrheit, sondern Ruhmsucht, wogegen er sich im ersten Kapitel seiner Trilogie nachdrücklich wendet. Theophilos will durch sprachliche Eleganz und Finesse Autolykos davon überzeugen, dass die christliche Rede von Gott die theologische Wahrheit zutreffend zur Sprache bringt.

In der zeitgenössischen Diskussion hat hierbei die logostheoretische Reflexion einen eminenten Rang. Die christliche Theologie muss also auch darauf im Kontext der Monotheismusdebatte eine plausible und überzeugende Antwort geben. Die Kapitel I bis 3 des I. Buches an Autolykos, speziell die beiden Listen, bereiten diese Antwort vor, die Theophilos aus der normativen, weil ältesten Quelle entwickeln wird: der Urgeschichte. Diese Anbindung gilt selbstverständlich auch für

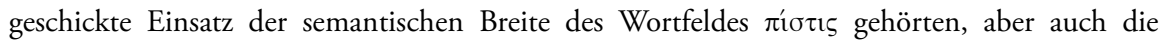

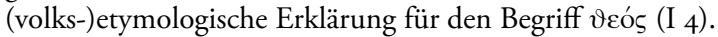

$29 \mathrm{Vgl}$. Lona 1998, 640.

$30 \mathrm{Vgl}$. Lona 200I, I62f.

3I Norden 2/513 Anm. 2. Unmittelbar vor diesem Lob schreibt Norden über die Trilogie des Theophilos: „Von den an einzelne Personen gerichteten apologetischen Schriften ist die des Theophilos an Autolykos nach Inhalt, Disposition, Stilistik und Sprache die schlechteste." Geffcken I902, 250 hat dieses Verdikt verstärkt (vgl. Anm. 2I). Womöglich haben die beiden ,Titanen der Philologie' die drei Bücher doch nicht so eingehend studiert, vielleicht nur nicht mit jenem Wohlwollen, das sie anderen Autoren dieser Epoche entgegenzubringen bereit sind. Die Diskrepanz zwischen heidnischer und christlicher Literatur, die Norden und Geffcken registrieren, wird in der neueren Forschung deutlich geringer veranschlagt; vgl. Hose 1999, 212-225. 
die theologische Rede vom Logos Gottes, worauf er in Autol. II 22 zu sprechen kommt.

Weil bereits aus den Anfangskapiteln des Werks erkennbar ist, dass Theophilos seine Antwort auf die Frage des Autolykos nach der Gestalt Gottes planvoll und mit literarischem Geschick entwickelt, ist anzunehmen, dass er auch auf die Verknüpfung achtet zwischen seinen grundsätzlichen Reflexionen über die Möglichkeit einer zutreffenden Rede von Gott und deren Anwendung auf Einzelthemen. Bezüglich der theologischen Rede vom Logos Gottes beruht die Verbindung zwischen I 3 und II 22 auch auf Stichwortassoziationen. Diese sind das

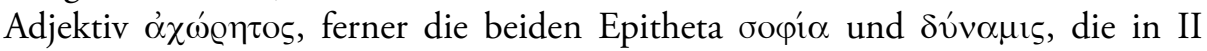
22,2 mit dem Logos gleichsetzt werden, sowie die auffällige Benennung des $\lambda \mathrm{ó}^{-}$

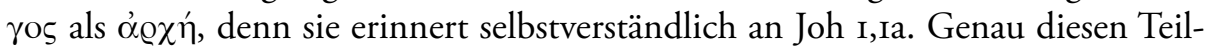
vers zitiert Theophilos in Autol. II 22,5.32 Ferner kehrt in II 22 das in I 3 beobachtete didaktisch-apologetische Schema aus vorweggenommenen Einwand, der mit

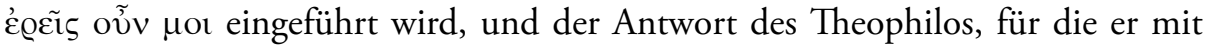
öxove Aufmerksamkeit verlangt, wieder.

\subsection{Der ,Logos im Paradies‘ (Autol. II 22)}

Theophilos zitiert in Autol. II 2I,I-5 die biblische Sündenfallgeschichte (Gen 3,I19) in der Version der älteren griechischen Bibelübersetzung. Im Anschluss an

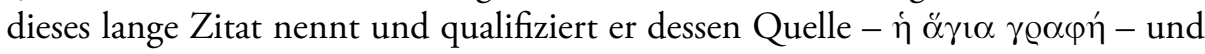
er definiert, worüber das Schriftzitat Auskunft gibt: die Geschichte des Menschen und das Paradies. ${ }^{33}$ Im Folgenden gilt sein Interesse dem Bericht in Gen 3,8a, dass Gott im Paradies umhergewandelt ist. ${ }^{34}$

32 Zur Übersetzung von Joh I,I vgl. Bultmann 1953, I-I7; Schnackenburg 1972, I/208-2I2; Barrett I990, I77-I84. Die Übersetzung von ovvovoí in II 22,3b berücksichtigt den durch das Lexem aufgerufenen Sachbezug zu Autol. II 9 (Zeus’ „übrigen Taten, seine blutschänderische Ehe mit der Schwester, seine Ehebrüche und Knabenschänderei lasse ich besser von Homer und den übrigen Dichtern erzählen."); vgl. Aristides, Apol 9,2a; Näheres vgl. Roscher 1965, s.v. Zeus.

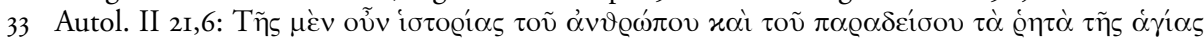

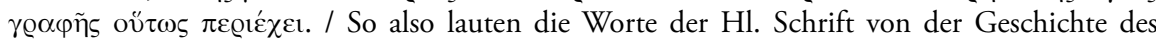

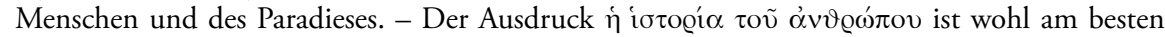
als Kollektivbegriff aufzufassen. Er meint das Geschichtlichsein des Menschen, wie es zum einen durch seine Selbstsetzung gegenüber dem Gebot Gottes und der vom Menschen ergriffenen Verantwortlichkeit profiliert ist und zum anderen durch die in den beiden Gottesreden vollzogene Trennung von der Sphäre Gottes, dem Paradies.

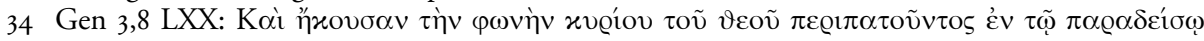

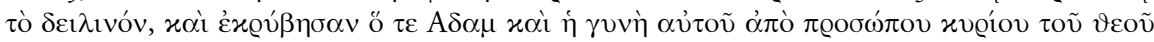

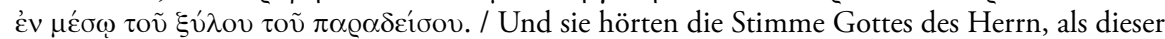
im Gartenpark zur Abendzeit umherging, und sowohl Adam als auch seine Frau verbargen sich vor dem Angesicht Gottes des Herrn inmitten der Bäume des Gartenparks. - Autol. II 2I,3:

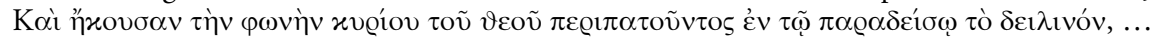




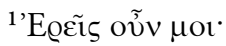

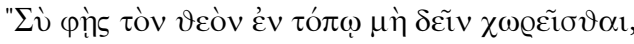

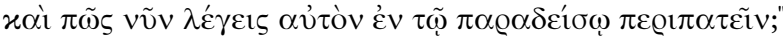

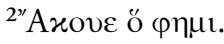

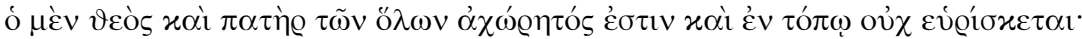

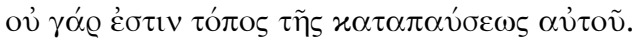

ó $\delta \dot{\varepsilon} \lambda o ́ \gamma 0 \varsigma \alpha v ่ \tau o \tilde{v}$

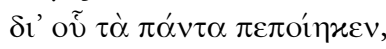

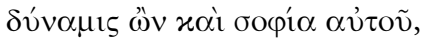

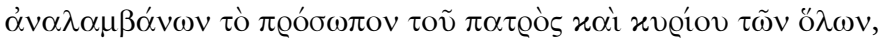

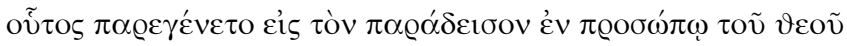

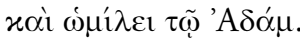

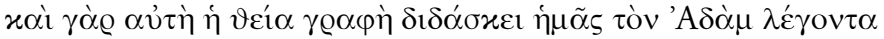

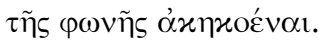

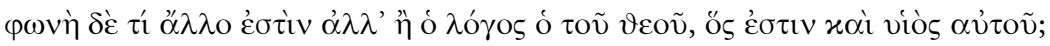

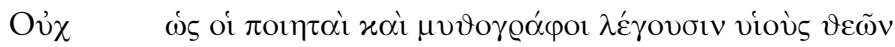

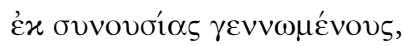

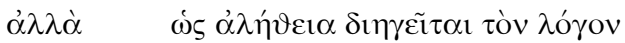

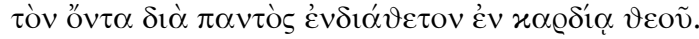

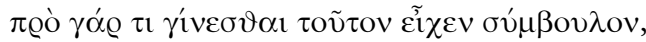

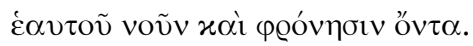

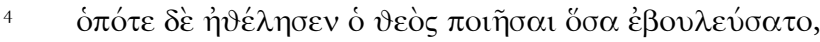

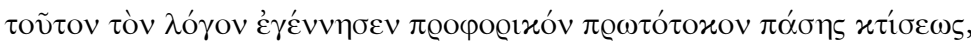

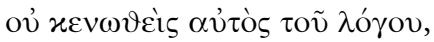

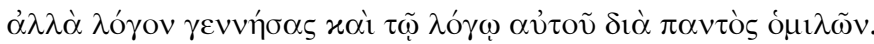

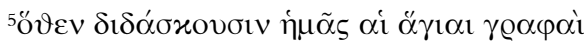

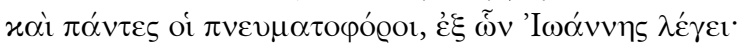

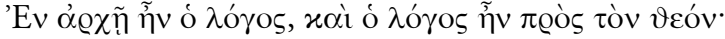

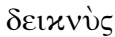

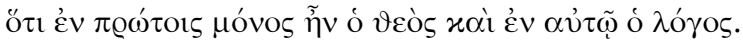

$\sigma_{\varepsilon \prime \pi \varepsilon 1 \tau \alpha} \lambda \varepsilon^{\prime} \gamma \varepsilon{ }^{\prime}$

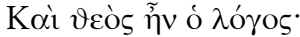

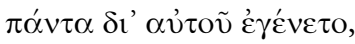

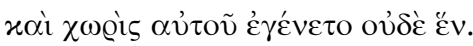

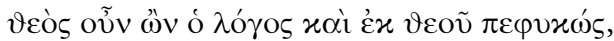

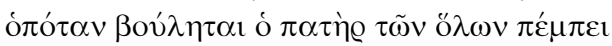

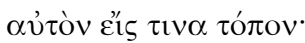

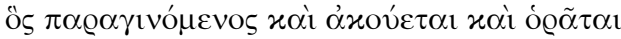

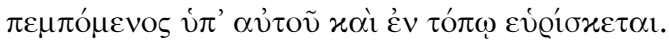


${ }^{1} \mathrm{Du}$ wirst mir nun sagen:

Du behauptest, Gott im Raume einzuschließen ist unzulässig,

und wie kannst du jetzt von ihm sagen, im Paradies umherzuwandeln?

${ }^{2}$ Höre, was ich sage!

Gott, der Vater des Weltalls, ist zwar unfassbar und befindet sich nicht im Raum

- denn es gibt keine „Stätte seiner Ruhe“ (Jes 66,Ic LXX; Apg 7,49c) -,

sein Logos aber,

durch welchen er das All gemacht hat,

der seine Kraft ist und seine Weisheit,

übernahm die Stelle des Vaters und Herrn des Weltalls,

dieser erschien an Stelle Gottes im Paradies

und redete mit Adam.

3 Denn auch die, göttliche' Schrift selbst belehrt uns, dass Adam sagt,

die Stimme gehört zu haben.

Was ist aber die Stimme anderes als der Logos Gottes, welcher auch sein Sohn ist?

Nicht, wie die Dichter und Mythographen die Söhne der Götter durch Verkehr miteinander erzeugt werden lassen,

sondern so, wie Wahrheit den Logos darstellt, als ewig im Herzen Gottes beschlossen.

Denn bevor irgend etwas erschaffen wurde, hatte er diesen zum Ratgeber, da es sein eigener Gedanke und seine Weisheit ist.

4 Als aber Gott alles erschaffen wollte, was er beschlossen hatte,

erzeugte er diesen Logos, den vorangehenden Erstgeborenen aller Schöpfung,

nicht, dass er dieses Logos verlustig wurde,

sondern, dass er ihn zeugte und mit seinem Logos in Allem beisammen blieb.

${ }^{5}$ Von daher lehren uns die Heiligen Schriften

und alle Geistträger, von denen einer, Johannes, sagt:

„Im Anfang war der Logos, und der Logos war bei dem Gott;“" (Joh I,Ia. $\alpha$ ),

womit er anzeigt,

dass zuerst allein Gott war und in ihm der Logos.

${ }^{6}$ Hierauf sagt er:

„Und Gott war der Logos" (Joh I,Ia.ß).

"Alles ist durch ihn geworden“" (Joh $\mathrm{I}, 3 \mathrm{a})$

und ohne ihn wurde, nicht einmal eines" "(Joh $\mathrm{I}, 3 \mathrm{~b})$.

Da also der Logos Gott ist und aus Gott entstanden ist,

deshalb entsendet der Vater des Weltalls ihn - wann immer er will -

an irgendeinen Ort im Raum;

derjenige, der als Anwesender gehört und gesehen wird,

befindet sich, weil er durch ihn entstanden ist, im Raum. 
Die beiden denkbaren Einwände gegen diese Vorstellung nimmt Theophilos selbst vorweg. Zum einen scheint die Vorstellung in Gen 3,8a mit der philosophischen Ansicht von der Unendlichkeit Gottes zu kollidieren und zum anderen wird das anthropomorphe Gottesbild als inadäquat signiert. Der erste Einwand greift auf Autol. II 3,7 zurück, wo Theophilos mit Bezug auf Zeus anmerkt, dass unter den Attributen, die Gott zu eigen sind, die Vorstellung, er könne im Raum eingeschlossen gedacht werden, die abwegigste ist. ${ }^{35}$ Der in Autol. II 22,I vorweggenommene Einwand rekurriert somit auf den Konsens zwischen der paganen und der christlichen Gottesvorstellung darüber, dass die Unendlichkeit Gottes ein zutreffendes theologisches Attribut ist. Damit scheint aber die Aussage in Gen 3,8 unvereinbar. Dennoch hält Theophilos an ihr fest. In II I8, I hat er nämlich das über drei Kapitel reichende Genesiszitat, das mit der Erschaffung des Menschen einsetzt und mit der Sündenfallgeschichte schließt (Gen I,26-3,19), mit der Bemerkung eingeführt, dass „die Erschaffung des Menschen ihre Schilderung seitens der Menschen zwar übersteigt, die Hl. Schrift aber eine kurze Erzählung derselben darbietet" (II I8,I).

Dasselbe Attribut, das in Autol. I 3,Ib hinsichtlich der Gestalt Gottes verwendet worden ist, wird hier für die Erschaffung des Menschen verwendet: sie ist $\alpha$ -

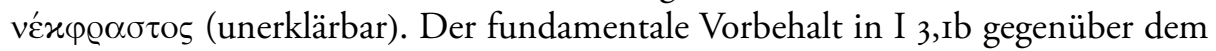
Wahrheitswert theologischer Rede gilt auch für die christliche Rede von Logos Gottes in II 22, denn auf sie strebt die Zitatenkette aus Gen I,26-3,19 hin. Dass die Möglichkeiten für eine zutreffende Rede von Gott, die Theophilos in I 3 demonstriert hat, hinsichtlich der christlichen Logostheologie Geltung behalten, zeigt Theophilos in dem raffiniert konstruierten Satzgefüge von II 22,6b.

Somit ist Autol. II 22,2 ein Exempel, wie Theophilos nicht die Anschlussfähigkeit der christlichen Gottesrede zur paganen Tradition demonstriert, sondern umgekehrt: Theophilos zeigt, dass monotheistische Vorstellungen der kaiserzeitlichen Philosophie an die biblisch-christliche Rede von Gott Anschluss finden können. Genau das leistet das mittels ró@ angeschlossene Jesajazitat. Durch diesen Texteinschub wird die Lehre von der Unendlichkeit Gottes weder erläutert noch fortgeführt, sondern mit einer überraschenden Begründung ausgestattet. Weil sich für dieses Gottesattribut ein Haftpunkt in der Schrift benennen lässt, ist auch der diesbezügliche Konsens nicht erstaunlich, sondern selbstverständlich.

Der eigentlich Zielpunkt des Konsenses ist jedoch die Aussage über den Logos. Dafür bürgt die adversative Konstruktion $\mu \grave{\varepsilon v} \ldots$... $\delta \dot{\varepsilon}$ und die Korrespondenz

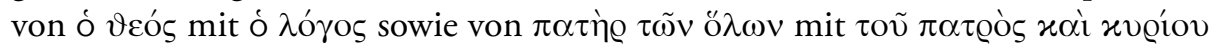

35 Autol. II 3,7: Dem höchsten, wahren Gott, dem Allherrscher aber ist es eigen, nicht bloß überall zu sein, sondern auch alles zu sehen und alles zu hören; davon gar nicht zu reden, dass er von einem Raum eingeschlossen würde. Würde er dies, so wäre der ihn umschließende Raum größer als er; denn das Umschließende ist größer als das Umschlossene; Gott aber wird nicht umschlossen, sondern er ist selbst der Raum für das All. 
$\tau \tilde{\omega} v$ ö $\lambda \omega v$. Theophilos gelingt auf diese Weise eine theologische Deutung von Gen 3,8, in der erstens die Rede von der Unendlichkeit Gottes ihr Recht behält und zweitens der Logos - für den Theophilos alternative Bezeichnungen kennt als die Weise der Gegenwart Gottes eingeführt wird, von der Gen 3,8 berichtet. Wiederum ist der Bezug auf die Schrift entscheidend. Der Vorstellung vom Umherwandeln Gottes im Paradies soll durch die Erklärung, der Logos sei an Stelle Gottes erschienen, alle Anstößigkeit und Widersprüchlichkeit genommen werden. Wie schon für die Unendlichkeit Gottes wird auch in Bezug auf die Deutung, dass der Logos anstelle Gottes im Paradies erschien, ein Schriftbeleg nachgetragen, der das Begleitmotiv fokussiert, nämlich dass Adam die Stimme gehört hat. Das Kalkül dieser Argumentation ist evident. Wenn die Lehre von der Unendlichkeit Gottes aus der Schrift zu begründen oder doch durch sie zu bestätigen ist, dann gilt das auch für die christliche Rede vom Logos Gottes. Im Logos wird Gott gegenwärtig; zugleich ist aber die Unterschiedenheit zwischen Gott, dem Schöpfer und Vater, sowie dem Logos Gottes aufrecht zu erhalten.

Zugunsten der Frage nach einer zutreffenden Rede von Gott sehe ich davon ab, den logostheologischen Aussagen in II 22,3-5 im einzelnen nachzugehen. Vielleicht lässt sich das zu theologischer Phantasie verlockende Potential der Bezeich-

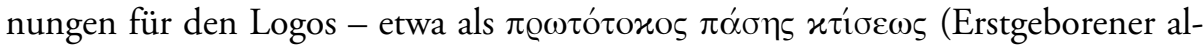
ler Schöpfung) - oder die Auslegung von Joh I,Ia, „dass zuerst allein Gott war und in ihm der Logos" - auf dieselbe Weise mildern, in der Theophilos dies im abschließenden Vers versucht.

Der Schlussvers II 22,6b rekurriert auf den Einsatz der Antwort des Theophi-

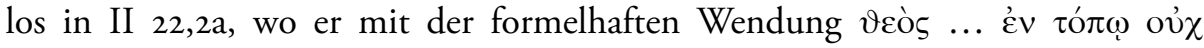

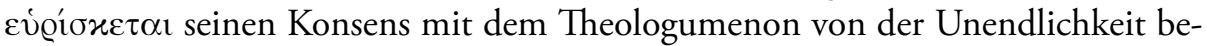
kundet. In 22,6b kehrt dieser Satz ohne die Negation wieder. Diese Änderung korrigiert allerdings nicht das Theologumenon, sondern macht dem Leser mittels der modifizierten Wiederaufnahme der Formel klar, dass christliche Theologie über Gott mehr und zutreffender sagen kann als der theologische Konsens es zulässt, wenn sie über den Logos Gottes spricht.

Die theologische Wahrheit, die in dem Widerspruch zwischen V 2 und 6 zum Vorschein kommt, und die zu dem Resümee von V 6 berechtigt, besteht darin, dass im Logos, der von Gott gezeugt ist und mit ihm „in Allem beisammen blieb", Gott präsent ist, wobei der Logos durch sein Gezeugtsein sowie seine Entsendung durch Gott, von Gott, dem Vater des Weltalls unterschieden werden kann. Folglich ist in Gen 3,8 nichts anderes ausgesagt als die christliche Theologie vom Logos Gottes sagt. Im Logos erscheint Gott im Paradies. Folglich ist die christliche Theologie in der Urgeschichte bereits enthalten.

Dem Inhalt nach ist der Schlussvers also das Resümee aus II 22,2-22,6a. Allerdings leistet der Vers mehr als nur das. Er fokussiert nämlich die Möglichkeit ei- 
ner zutreffenden Rede von Gott und damit auch die Möglichkeiten und Grenzen, die theologische Wahrheit bezüglich des Logos Gottes zutreffend zur Sprache zu bringen.

Schon der erste Satzteil birgt eine Schwierigkeit. Die beiden Partizipien öv und $\pi \varepsilon \varphi v x \omega ́ s$ sind als Nominativus absolutus zu begreifen. Das fehlende Prädi-

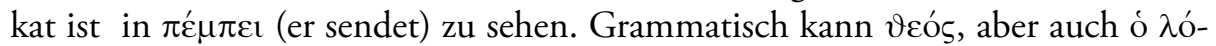

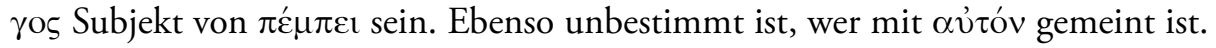
Sendet Gott den Logos oder sendet der Logos Gott an irgend einen Ort? Selbstverständlich wird jeder, der in christlicher Tradition sozialisiert ist, sich dafür entscheiden, dass nur Gott als Sender in Frage kommt.

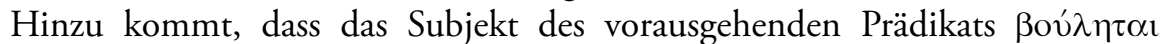

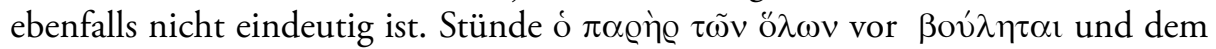
Adverb ó $\pi$ ó $\tau \alpha v$, wie es die Regel fordert, wären die syntaktischen Bezüge klar. Durch die Stellung zwischen den beiden Prädikaten wird die Aussage interpretationsbedürftig.

Folgt man den Angaben bei Schwyzer ${ }^{36}$ zur griechischen Syntax und Stilistik, dann ist diese anakolutische Satzkonstruktion des ersten Teilvers deswegen gewählt, weil sie der Aussage einen gravitätischen Charakter verleiht. Theophilos schwebt wohl folgende passivische Konstruktion vor: „Da also der Logos Gott ist und aus Gott entstanden ist, wurde er also als einer der Gott ist, entsandt." Das ist zwar gemeint, denn in der passivischen Konstruktion ist ó $\lambda$ ó $\gamma o \varsigma$ das gramma-

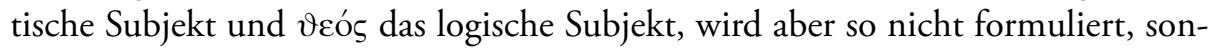
dern muss erschlossen werden. Durch die Transformation in eine aktivische Kon-

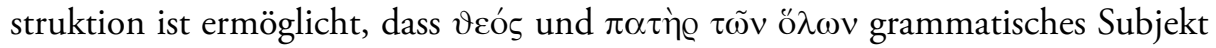
werden und im Nominativ stehen. Mittels der Konstruktion mit dem Nominativus absolutus war zu vermeiden, dass ó $\lambda$ ó $\gamma$ o zum grammatischen Objekt wird. Stattdessen konnte dieser hochkarätige Begriff nun die prominente Anfangsposition im Satzgefüge einnehmen und somit die Aufmerksamkeit auf sich ziehen. Entsprechend ist dann im zweiten Teilvers der Vater des Weltalls das Subjekt und der Logos das Objekt.

Der dritte Teilvers ist nicht minder absichtsvoll konstruiert. Die Argumentation lautet, dass derjenige, der gehört und gesehen wird, anwesend sein muss, also sich an einem Ort im Raum befindet, weil er gesandt ist. Worauf bezieht sich das Relativpronomen? Ist der Logos oder Gott der Anwesende, der gehört und gesehen wird? Befindet sich Gott oder der Logos im Raum?

Im Rückblick auf Autol. I 3 ist ausgeschlossen, dass die Syntax in II 22,6b ein Versehen ist. Der doppelte Nominativus absolutus, ferner die Stellung des Subjekts zwischen den beiden Prädikaten im zweiten Teilvers und die Unbestimmtheit, ob der Logos oder Gott sich im Raum befindet, zeugen von literarischem

36 Vgl. Schwyzer 1959, 2,403f. 
Gespür und Könnerschaft. Die komplexe Satzfügung des Schlussverses provoziert Aufmerksamkeit und ist darum eine Erinnerungsmarke, die alles bisher Gesagte Revue passieren und die Aussage selbst in Erinnerung behalten lässt.

Im Grunde wird in diesem Schlussvers gezeigt, dass sich die Unaussprechbarkeit und Unerklärbarkeit, die Theophilos dem gesamten Abschnitt und jeder Rede von Gott vorausgestellt hat (Autol. I 3,I), literarisch abbilden lässt, sodass diese notwendig exzellente Sprachgestaltung eine Ahnung vermittelt von dem, was unaussprechlich und unerklärbar bleibt. Theophilos operiert - ohne das auszuführen - mit der griechischen Vorstellung, dass im wahrlich Schönen - wofür $\varkappa \alpha \lambda o ́ s$ das gültige Attribut ist - zugleich immer das Gute und das Wahre zum Vorschein kommt. Weil die Erhabenheit der Darstellung transparent ist für die Wahrheit in ihrer Erhabenheit, ist für Theophilos die Ästhetik ein Weg für die zutreffende Rede von Gott. Im geistig-sozialen Milieu, in dem sich Theophilos und Autolykos bewegen und in dem dieser Diskurs über die zutreffende Rede von Gott geführt

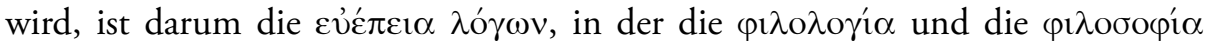
einanderen finden, die angemessene Weise, um die Wahrheit des Evangeliums über den Logos Gottes überzeugend zur Sprache zu bringen. 


\section{Literaturverzeichnis}

Aguado Bleye (1932): Pedro Aguado Bleye, „San Teófilo de Antioquía y el canon del Nuevo Testamento", in: Estudiuos bíblicos 4, I76-I9I.

Anderson (1993): Graham Anderson, The Second Sophistic. A Cultural Phenomenon in the Roman Empire, London/New York.

Barrett (1990): Charles Kingsley Barrett, Das Evangelium nach Johannes (KEK Sonderband), Göttingen.

Bauer u. Aland (1988): Griechisch-deutsches Wörterbuch zu den Schriften des Neuen Testaments und der frühchristlichen Literatur, 6. Aufl. Berlin/New York.

Blass (1984): Friedrich Blass u. Albert Debrunner u. Friedrich Rehkopf, Grammatik des neutestamentlichen Griechisch, I6. Aufl. Göttingen.

Bornemann u. Risch (1978): Eduard Bornemann/Ernst Risch, Griechische Grammatik, 2. Aufl. Frankfurt am Main.

Bragato (1942): José Bragato (Hg.), Himnos y odas al país elogiado, Buenos Aires.

Brox (1984): Norbert Brox, „Jüdische Wege des altkirchlichen Dogmas“, in: Kai$\operatorname{ros} 26, \mathrm{I}-26$.

Brox (1996): Norbert Brox, „Terminologisches zur frühchristlichen Rede von Gott", in: $S B A W \cdot P H \mathrm{I}, \mathrm{I}-46$.

Brox (2000): „,Gott « - mit und ohne Artikel. Origenes über Joh I,I“, in: Franz Dünzl u. a. (Hgg.), Norbert Brox. Das Frühchristentum. Schriften zur Historischen Theologie, Freiburg u. a., 423-429.

Bultmann (1953): Rudolf Bultmann, Das Evangelium des Johannes (KEK), Göttingen.

Clausen (1903): Otto Clausen, „Die Theologie des Theophilus von Antiochien“, in: $Z W T h 46,8 \mathrm{I}-2 \mathrm{I} 3$.

Dihle (1989): Albrecht Dihle, Die griechische und lateinische Literatur der Kaiserzeit. Von Augustus bis Justinian, München.

Dörrie (1975): Heinrich Dörrie, Logos-Religion? oder Nous-Theologie? Die hauptsächlichen Aspekte des kaiserzeitlichen Platonismus, in: Kephalaion. Studies in Greek philosophy and its continuation (FS C. J. de Vogel), Assen, II5-I36.

Dörrie (1979): Heinrich Dörrie, „Der Prolog zum Evangelium nach Johannes im Verständnis der älteren Apologeten“, in: Kerygma und Logos. Beiträge zu den geistesgeschichtlichen Beziehungen zwischen Antike und Christentum (FS für Carl Andresen), Göttingen, I36-I52.

Früchtel (1970): Edgar Früchtel, Weltentwurf und Logos. Zur Metaphysik Plotins (Philosophische Abhandlungen 33), Frankfurt am Main.

Früchtel (2006), Edgar Früchtel, „Inneres Auge und göttliche Schau. Reflexionen zum antiken Horizont des Begriffs "Vision" ", in: Perspektiven der Philosophie. Neues Jahrbuch 32, 259-279. 
Furley u. Bremer (200I): William D. Furley u. Jan Maarten Bremer (Hgg.), Greek hymns. Selected cult songs from the Archaic to the Hellenistic period, 2 Bde. (Studien und Texte zu Antike und Christentum $9 \&$ Io), Tübingen. Gigon (1966): Olof Gigon, Die antike Kultur und das Christentum, Gütersloh. Geffcken (1902): Johannes Geffcken, Zwei griechische Apologeten, Leipzig/Berlin. Grant (1947): Robert Grant, The Bible of Theophilus, in: JBL 2, I8I-I89.

Grant (1959): Robert Grant, Scripture, rhetoric and theology in Theophilus, in: VigChr $13,33-45$.

Gross (1896): Otto Gross, Die Gotteslehre des Theophilos von Antiochia. Abhandlung zum Jahresbericht des städtischen Realgymnasiums zu Chemnitz für Ostern I896, Chemnitz.

Harnack (I890): Adolf Harnack, Theophilus von Antiochien und das Neue Testament, in: $Z K G$ II, I-2I.

Hose (1999): Martin Hose, Kleine griechische Literaturgeschichte. Von Homer bis zum Ende der Antike (bsr 1326), München.

Korenjak (2000): Martin Korenjak, Publikum und Redner. Ihre Interaktion in der sophistischen Rhetorik der Kaiserzeit. Zetemata IO4, München.

Krämer (1967): Hans Joachim Krämer, Der Ursprung der Geistmetaphysik. Untersuchungen zur Geschichte des Platonismus zwischen Platon und Plotin, Amsterdam (2. Aufl.).

Landfester (1997): Manfred Landfester, Einführung in die Stilistik der griechischen und lateinischen Literatursprachen. Darmstadt.

Lattke (1991): Michael Lattke, Hymnus. Materialien zu einer Geschichte der antiken Hymnologie (NTOA 19), Fribourg/Göttingen.

Löhr (2009): Winrich Löhr, Art. „Logos“, RAC 23, 327-435.

Lona (1998): Horacio E. Lona, Der erste Clemensbrief (KAV 2), Göttingen.

Lona (200I): Horacio E. Lona, An Diognet (Kommentar zu frühchristlichen Apologeten 8 [KfA 8]), Freiburg im Breisgau.

Lona (2005): Horacio E. Lona, Die, Wahre Lehre' des Kelsos (Kommentar zu frühchristlichen Apologeten. Ergänzungsband i [KfA.E r]), Freiburg im Breisgau.

Marcovich (1995): Miroslav Marcovich (Hg.), Theophili Antiocheni. Ad Autolycum (PTS 44), Berlin/New York.

Martín (2004): José Pablo Martín, Teófilos de Antioquía. A Autólico. Introducción, texto griego, traducción y notas (Fuentes Patrísticas I6), Madrid u. a.

Nesselrath (1997): Heinz-Günther Nesselrath, „Kaiserzeit“, in: ders. (Hg.), Einleitung in die griechische Philologie (Einleitung in die Altertumswissenschaft), Stuttgart/Leipzig, 269-293.

Norden (1915): Eduard Norden, Die antike Kunstprosa vom VI. Jahrhundert v. Chr. bis in die Zeit der Renaissance, 2 Bde., Stuttgart/Leipzig (3. Aufl., ND Stuttgart/Leipzig 1995). 
Otto (186I): Johann Carl Theodor von Otto (Hg.), Theophili Episcopi Antiocheni Ad Autolycum libri tres (CorpAp 8), Ienae (ND Wiesbaden 1969).

Passow (I84I): Franz Passow, Handwörterbuch der griechischen Sprache, 2 Bde., Leipzig (5. Aufl., ND Darmstadt 1993).

Perendy (2010): László Perendy, The Outlines of Systematic Theology in the Ad Autolycum of Theophilus of Antioch, in: StPatr 45, 413-4I8.

Pommrich (1904): Arno Pommrich, Des Apologeten Theophilus von Antiochia Gottes- und Logoslehre dargestellt unter Berücksichtigung der gleichen Lehre des Athenagoras von Athen, Leipzig.

Prostmeier (2005): Ferdinand R. Prostmeier, „Christliche Paideia. Die Perspektive Theodorets von Kyrrhos", in: $R Q$ I00, I-29.

Prostmeier (2007): Ferdinand R. Prostmeier, „Zeige mir deinen Gott.“ Einführung in das Christentum für Eliten, in: ders. (Hg.), Frühchristentum und Kultur (Kommentar zu frühchristlichen Apologeten. Ergänzungsband 2 [KfA.E 2]), Freiburg im Breisgau, I55-I82.

Prostmeier (2009): Ferdinand R. Prostmeier, „ $\Delta$ ó $\xi \alpha$ bei Theophilos von Antiochien“, in: Rainer Kampling (Hg.), Herrlichkeit. Zur Deutung einer theologischen Kategorie, Paderborn, I25-I56.

Roscher (1965): W. H. Roscher (Hg.): Ausführliches Lexikon der griechischen und römischen Mythologie, 6 Bde. (I893-1937), Leipzig (ND und Supplemente I4 Hildesheim 1965).

Rosen (2000): Klaus Rosen, von der Torheit für die Heiden zur wahren Philosophie. Soziale und geistige Voraussetzungen der christlichen Apologetik des 2. Jahrhunderts, in: R. von Haehling (Hg.), Rom und das himmlische Jerusalem, Darmstadt 2000, I24-I5I.

Schmitz (1997): Thomas Schmitz, Bildung und Macht. Zur sozialen und politischen Funktion der zweiten Sophistik in der griechischen Welt der Kaiserzeit. Zetemata 97, München.

Schnackenburg (1992): Rudolf Schnackenburg, Das Johannesevangelium. Einleitung und Kommentar zu Kap. I-4 (HThK IV/I), Freiburg u. a.

Schwyzer (1959), Eduard Schwyzer, Griechische Grammatik, Band 2, Syntax und syntaktische Stilistik (HAW), München (2. unveränd. Aufl.).

Ueding (2005): Gert Ueding, Klassische Rhetorik, München (4. Aufl.).

Ueding/Steinbrink (2005): Gert Ueding/Bernd Steinbrink, Grundriß der Rhetorik. Geschichte - Technik - Methode, 4. Aufl. Stuttgart/Weimar.

Zeegers (1970): Nicolle Zeegers, Les citations du Nouveau Testament dans les livres à Autolycus de Théophile d'Antioche, in: SP I2, 37I-382.

Zeegers (1998): Nicolle Zeegers, Les trois cultures de Théophile d'Antioche, in: Bernard Pouderon/Joseph Doré (Hgg.), Les apologistes chrétiens et la culture grecque, Paris, I35-I75.

Zeller (20IO): Dieter Zeller, Der erste Brief an die Korinther (KEK 5), Göttingen. 


\title{
Menschenliebe im Superlativ
}

\section{Zur Rezeption der christlichen Lehre von der Feindesliebe bei Athenagoras}

\author{
UTA HEIL
}

\section{Fragestellung}

Den Feind zu lieben und für die Verfolger zu beten, wie es in der sechsten Antithese der Bergpredigt gefordert wird (Mt 5,43-48), dafür hatten die Christen während der ersten drei Jahrhunderte ausreichend Gelegenheit. Die Gefahr, wegen des eigenen christlichen Glaubens angeklagt und verurteilt zu werden, gehörte zum damaligen Alltag, auch wenn die Verfolgungen je nach Region und Zeit unterschiedlich ausfielen. Aber es reichte, als Christ angezeigt zu werden, um mit dem Todesurteil rechnen zu müssen. Als Anhänger eines verbotenen neuen Kults aus dem Osten und Verweigerer des römischen Kultbetriebes waren Christen offiziell nicht erwünscht', und aufgrund ihres „seltsamen“ Lebenswandels und ihrer „obskuren“ Riten waren Christen bei der übrigen Bevölkerung oft verhasst oder zumindest anstößig und erregten Misstrauen². Die Umwelt war also für die Christen von Beginn an mehrheitlich feindlich; das muss man wohl für die Frühzeit feststellen trotz der durchaus auch erfolgreichen Missionstätigkeit.

Vor diesem Hintergrund stellt sich erstens die Frage, ob frühchristliche Autoren das Gebot der Feindesliebe überhaupt thematisieren. Anlässe gab es sicher genug und besonders die sogenannten Apologeten haben immer wieder auf die ho-

I Die Rechtsgrundlage bildete die Antwort des Kaisers Trajan auf die Anfrage des Statthalters von Bithynien und Pontus, Plinius (Plinius, Briefe X 97-97; abgedruckt in: Guyot / Klein, I997, 38-43): Todesstrafe droht denen, die sich als Christ bekennen, auch wenn weder anonymen Anzeigen entgegengenommen noch nach ihnen gefahndet werden soll. Über die Anzahl der Verfolgten und Hingerichteten lässt sich nur spekulieren, zudem schon über die Größe der christlichen Gemeinden nur Vermutungen geäußert werden können; vgl. die geschätzte Wachstumskurve bei Rodney Stark 1996. Immerhin scheint es örtlich zu einer größeren Anzahl von Angeklagten gekommen zu sein, da der Statthalter in seiner Anfrage formuliert: „Die Angelegenheit scheint mir nämlich der Beratung zu bedürfen, vor allem wegen der großen Zahl der Angeklagten; denn vielen jeden Alters, jeden Standes, auch beider Geschlechter wird der Prozess gemacht und vielen wird er in Zukunft noch gemacht werden."

2 Vgl. die Übersicht über die antichristlichen Vorwürfe bei Schäfke 1979. Vgl. ferner Walsh / Gottlieb 1982; Pouderon 2003; Levieils 2007; Engberg 2007. 
he Moral und den untadeligen Lebenswandel der Christen hinwiesen². Auch könnten die Märtyrerakten zum Beispiel ein Ort sein, an dem man einen Bezug auf das Feindesliebegebot erwarten könnte.

Zweitens ist zu betrachten: Wenn die Feindesliebe angesprochen wird, wie wird dieses Gebot präsentiert? Ist es ein zentraler Punkt der christlichen Ethik? Oder steht das Gebot eher am Rande? Ulrich Luz formuliert in seiner Auslegung des Matthäusevangeliums: „Die Feindesliebe ist der Inbegriff und die Spitze der von Gott geforderten ,Gerechtigkeit' und des Lebens in der ihm entsprechenden ,Vollkommenheit'."4 Sahen das auch frühchristliche Autoren so?

Drittens ist die Frage interessant, ob die Autoren das Gebot der Feindesliebe als etwas Neues, etwas spezifisch Christliches ansehen. In der antithetischen Formulierung bei Matthäus wird das Gebot der Feindesliebe ja sowohl in Abgrenzung zum Judentum als auch zum Heidentum als etwas Neues präsentiert. Ist die Feindesliebe etwas, was Christentum und Heidentum unterscheidet oder gar trennt? Oder ist das Gegenteil der Fall? Betonten frühchristliche Autoren mehr die Gemeinsamkeiten zwischen der christlichen und paganen Ethik und galt ihnen die Feindesliebe sozusagen als Gemeingut der Christen und Heiden?5

Eine Betrachtung des Themas „Feindesliebe“ könnte viertens die Aspekte erweitern, unter denen die sogenannte "Hellenisierung des Christentums“ diskutiert wird. Diese Fragestellung der „Hellenisierung“ geht auf Adolf von Harnack zurück, der diesen Prozess immer wieder kritisierte ${ }^{6}$. Gemeint ist die Übernahme Begriffe und Denkweisen aus der griechischen Philosophie in das Christentum ${ }^{7}$, was zu einem Abfall vom ursprünglichen biblischen Zeugnis geführt habe ${ }^{8}$. Die

3 In der Tat haben gerade die hohe Moral, das soziale Engagement in vielen Bereichen von der Krankenpflege bis zur Witwenversorgung und die Bereitschaft zum Gewaltverzicht bis hin zum Martyrium großen Eindruck gemacht und dem Christentum auch zu Ansehen und Erfolg verholfen. Das hat die Forschung seit dem grundlegenden Werk von Adolf von Harnack, Die Mission und Ausbreitung des Christentums in den ersten drei Jahrhunderten (4. Aufl. Leipzig 1924) gezeigt. Vgl. ferner MacMullen I984; Stark 1996; Drake 2005; Löhr 2005; Reinbold 2000.

4 Luz, 2002, 543.

5 Dabei geht es mir vornehmlich darum zu betrachten, wie die frühchristlichen Autoren selbst das Gebot der Feindesliebe anführen und verstehen. Ob das Gebot tatsächlich eine Innovation des historischen Jesus ist, gehört eher zu den Fragen der neutestamentlichen Wissenschaft und ist bekanntlich ein umstrittenes Thema. Vgl. dazu Ebner 2000; Piper 1979; Hoffmann 1984; Reiser, 200I und auch Schrage, 1989, 73-93; Hays, 1996, 317-346.

6 In seinen sechzehn Vorlesungen „Über das Wesen des Christentums“ I899 (viele Nachdrucke) und in seinem „Lehrbuch der Dogmengeschichte“ (Drei Bände, 4. Aufl. Tübingen 1909; Nachdrucke).

7 So schreib Harnack in seinem Lehrbuch, $346:, \ldots$ denn die Logoslehre, mögen in sie auch nachträglich ursprüngliche Interessen eingefügt sein, ist doch die griechische Philosophie in nuce. Ihre Einführung in das Bekenntnis der Gemeinde ... bedeutet für die Zukunft die Verwandlung der Glaubensregel in ein philosophisches System."

8 Aus einer Religion sei eine Lehre geworden und ein Lehrsystem habe den Glauben abgelöst. Harnack, Lehrbuch, I9: „Demgemäß wurde die Religion sehr schnell zu einer Lehre, welche an dem Evangelium zwar ihre Gewißheit, aber nur zum Teil ihren Inhalt hatte, und demgemäß 
Frage der „Hellenisierung des Christentums“ wird aber fast ausschließlich auf dem Gebiet der Dogmatik diskutiert, insbesondere der Gotteslehre und der Christologie. Ethische Fragen spielen kaum eine Rolle, obwohl sich hier dasselbe Problem stellt. Dies ist besonders deswegen erstaunlich, weil Harnack in seiner Beschreibung des Wesens des Christentums als dritten Punkt auch Ethisches aufführt. Er nennt als für das Christentum wesentlich:

I. Das Reich Gottes und sein Kommen (daher gehört „nur Gott“ in das Evangelium, nicht auch der Sohn oder eine Christologie);

2. Gott, der Vater, und der unendliche Wert der Menschenseele;

3. die bessere Gerechtigkeit oder das Gebot der Liebe?.

Deswegen scheint es interessant und lohnend zu sein, gerade das Liebesgebot in der Zuspitzung auf das Gebot der Feindesliebe anzuschauen und hier der Frage nach einer Hellenisierung im frühen Christentum nachzugehen. Ist also auch die Rezeption und Interpretation des Feindesliebegebots im Kontext der „Hellenisierung des Christentums" zu verstehen?

Diese Fragen lassen sich nicht pauschal beantworten, da verschiedene Autoren auf dieses Gebot in jeweils anderen Kontexten unterschiedlich zurückgreifen. Daher sei ein Autor ausgewählt, nämlich Athenagoras, um diese vier Fragen mit einem Blick auf eine Passage aus der Apologie des Athenagoras für diesen Autor zu beantworten. Da er als der griechischste und philosophischste unter den Apologeten gilt, lohnt eine genauere Analyse seines Werks, um einmal die Frage nach der „Hellenisierung“ der biblischen Ethik im Detail anzuschauen. Überdies gibt es bisher kaum Studien, die die Rezeption des Gebots der Feindesliebe im frühen

auch von solchen ergriffen werden konnte, welche mehr nach Erkenntnis als nach Religion suchten.“ Als Folge kommt es zur Ausbildung von Dogmen (Lehrbuch, 20): „Das Dogma ist in seiner Conception und in seinem Ausbau ein Werk des griechischen Geistes auf dem Boden des Evangeliums.“ Zu den Apologeten des zweiten Jh.s schreibt er (Lehrbuch, 523): „In den Apologeten hat mithin das Christentum die Antike, d.h. den rationalen Ertrag der monotheistischen Erkenntnis und Ethik der Griechen mit Beschlag belegt (Justin, 2 apol. I3)." Lehrbuch, 542: „... demgemäß scheint weder eine Erlösung durch Christus im präzisen Sinne des Wortes ins Auge gefaßt, noch die Einzigartigkeit der Erscheinung des Logos in Jesus Christus vorausgesetzt zu sein. ... Die einzelnen Stücke der Geschichte Jesu (des Taufbekenntnisses) haben folgerecht keine direkte Heilsbedeutung, und somit scheinen die Lehrer der Christen in zwei innerlich nicht miteinander verbundene Gruppen zu zerfallen, in die Sätze der vernünftigen Gotteserkenntnis und in die geweissagten und erfüllten historischen Fakten, welche jene Lehrsätze und die Glaubenshoffnungen, die sie einschließen, beweisen."

9 Harnack, Wesen des Christentums, 33. Vgl. Kinzig 200I; Rieske-Braun 2000. Die Forschungen zum Problem der „Hellenisierung" sind an dieser Stelle nicht aufzählbar. Genannt seien als Auswahl: Scheffczyk 1982; Wyrwa 199I; ders. 2000; Meijering 1985; Markschies 2009; LutzBachmann 1992. 
Christentum behandeln. Einen ersten Überblick bietet der Aufsatz von Walter Bauer von 1917, der in zwei Sätzen auch Athenagoras erwähnt ${ }^{\text {10 }}$. Ferner gibt es eine Diskussion zwischen W.C. van Unnik (1966) und John Whittaker (1979), die mit Hilfe der frühchristlichen Rezeption belegen bzw. widerlegen wollen, dass das Gebot der Feindesliebe etwas Einzigartiges und Neues ist ${ }^{\mathrm{II}}$. Erst 2006 gibt es eine kleinere Studie zur Konzeption der Ethik bei Justin und Tertullian von Nils Willert, der Justins Ethik vor dem Hintergrund der imitatio dei darstellt und dabei auch auf das Gebot der Feindesliebe als besonderes Merkmal der christlichen Ethik eingeht ${ }^{\text {12 }}$. Angesichts dieser Forschungslage scheint eine Beschäftigung mit der Präsentation des Gebots der Feindesliebe u. a. bei Athenagoras ein Desiderat zu sein.

\section{Athenagoras}

Athenagoras verfasste seine Apologie Legatio sive supplicatio pro Christianis ${ }^{13}$ wahrscheinlich im Jahr 177, adressiert an den von I6I bis I80 herrschenden Philosophenkaiser Marc Aurel und dessen Sohn Commodus. Das Werk gehört damit in die Hochzeit der sogenannten frühchristlichen Apologien ${ }^{\text {I4 }}$. Während der Herrschaft von Marc Aurel scheint sich die Lage vielerorts für die Christen verschlechtert zu haben ${ }^{15}$, was wohl der Hintergrund für die wachsende Zahl der Apologien der Zeit sein dürfte. Die Christen hatten unter der angespannten Lage

IO Bauer I9I7/I967, 242 und 249.

II van Unnik I966: Er plädiert dafür, das Feindesliebegebot als spezifisch christlich anzusehen. Whittaker 1979: Er referiert verschiedenste christliche und nichtchristliche Autoren des zweiten bis vierten Jahrhunderts, um das Konzept der Feindesliebe in den allgemeinen Gedanken der Philanthropie einzureihen. Der Aufsatz von Karlmann Beyschlag (I977) streift das Gebot der Feindesliebe auf den S. 3I4-3I7 in einem Überblick. Auch Franz Schnider (I993) referiert nur auf einer Seite Stellen frühchristlicher Autoren.

I2 Willert, 2006, 99f. Vgl. auch Ulrich 2006.

I3 Nach der kritischen Edition von Eduard Schwartz (TU 4,2, Leipzig I89I) gibt es heute mehrere kritische Ausgaben: Schoedel 1972; Pouderon 1992; Marcovich 1990. Vgl. zur Überlieferung und den Editionen Heil 2007. Alle überlieferten Handschriften sind abhängig von einem Codex A (Cod. Parisinus Graecus 45I), dem sogenannten Arethas-Codex aus dem Jahr 9I4, der von einem Schreiber namens Baanes für Arethas, Bischof von Cäsarea in Kappadokien, angefertigt wurde. Er enthält auch Text-Korrekturen von Arethas selbst.

I4 Zur Datierung vgl. die Einleitungen der angegeben Editionen. Zu Athenagoras vgl. ferner Barnard 1972; Peglau 1999; Pouderon 1989; ders. 1997; Rankin 2009. Nur das Werk des Athenagoras und das von Theophilus von Antiochien sind vollständig überliefert. Von Melito vor Sardes haben wir nur noch Fragmente (vgl. Pouderon 2005; Hall 1979), und die Apologien von Miltiades (Kleinasien) und Apollinaris von Hierapolis sind gar nicht erhalten.

I5 Umstritten ist, ob Marc Aurel die seit Trajan geltende Regelung, daß nach Christen nicht zu fahnden und suchen ist, geändert und ein Aufspüren von Christen zugelassen hat. In einem Fragment aus der Apologie des Melito von Sardes werden massive Verfolgungen aufgrund von

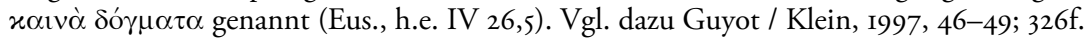


im Reich zu leiden, die durch Pestepidemie, Tiberüberschwemmung, Partherund Markomannenkriege geprägt war ${ }^{16}$. Kaiser Marc Aurel war Anhänger der Stoa, wie man aus seinem zwölfbändigen Werk „Wege zu sich selbst“ ersehen $\operatorname{kann}^{17}$, und hatte nichts für das Christentum übrig, wie auch einer seiner Erzieher, Fronto von Cirta, der als Kritiker des Christentums bekannt wurde ${ }^{18}$. Die generelle Kritik der Gebildeten am Christentum kann man auch bei Celsus in seinem Werk „Die wahre Lehre“ nachlesen, das ungefähr zur selben Zeit entstand wie die Apologie des Athenagoras ${ }^{19}$. Damit ist grob der Hintergrund skizziert, vor dem die Apologie des Athenagoras zu lesen und zu interpretieren ist.

Im Grunde geht Athenagoras nur auf einen Vorwurf ausführlich ein, nämlich den des Atheismus, und zwar in 30 Kapiteln. Hierbei spielt dann auch das Gebot der Feindesliebe eine wichtige Rolle. Es folgen dann noch sechs kleinere Kapitel zum Vorwurf der Inzucht und des Kannibalismus (Kap. 3I-36). Dem Hauptvorwurf der Gottlosigkeit begegnet Athenagoras in einem ersten Schritt, in dem er den Glauben der Christen an den einen Gott als Schöpfer der Welt vorstellt (Kap. 4). Zu ähnlichen Schlussfolgerungen über Gott seien auch schon einige Philosophen gekommen (Kap. 5f.), die ihre Ansichten aber nur auf Vermutungen aufbauen im Unterschied zu den Christen, die ihr Verständnis von Gott auf Offenbarungen der Propheten zurückführen können (Kap. 7). Es folgt ein Gottesbeweis aus der Vernunft heraus (Kap. 8), dann entsprechende biblische Belege (aus Exodus und Jesaja; Kap. 9). Dies wird mit Hinweis auf den Sohn und den heiligen Geist trinitarisch erweitert - Athenagoras bietet hier eine für das 2. Jh. außergewöhnliche Trinitätslehre. Nun folgen die relevanten Kapitel IIf. und noch immer geht es um den Vorwurf des Atheismus, wie man in II,I erkennen kann: Athenagoras beginnt mit einer Entschuldigung, dass er so ausführlich die christliche Lehre vorstellt, aber er möchte Gerüchte und Unterstellungen ausräumen und zur Wahrheit vordringen, damit der Adressat erkennt, dass Christen keine Atheisten sind.

I6 Der lange Brief über die Martyrien von Vienne und Lyon zum Beispiel gibt einen schon fast voyeuristischen Einblick in die Folterungen und Zurschaustellungen der Christen im Theater als Volksvergnügen.

I7 Marc Aurel, Wege zu sich selbst, Griechisch-deutsch, hg. u. übers. v. R. Nickel, München / Zürich 1990, ${ }^{2}$ I998. Vgl. zu Marc Aurel Klein 1979; Noyen 1979; Keresztes 1979; Birley 1987; Fündling 2008.

I8 Briefe von Fronto in BSGRT (Leipzig 1988, hg.v. E. Hauler). Zu Fronto vgl. Rosen 1994; Kasulke 2005 . Vgl. ferner Krafft 2002.

I9 Vgl. Lona 2005 . 


\section{Analyse von Legatio sive supplicatio pro Christianis IIf.}

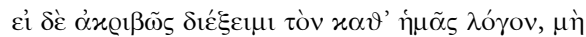

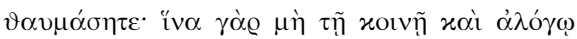

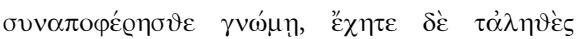

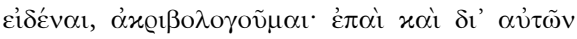

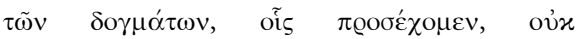

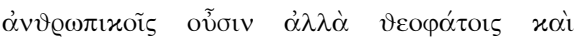

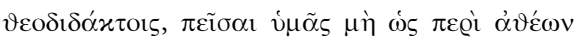

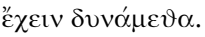

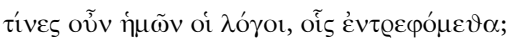

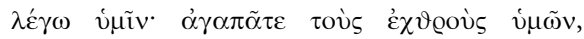

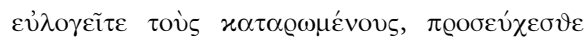

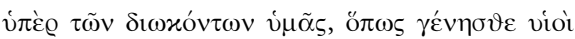

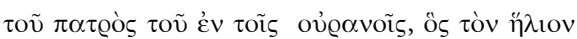

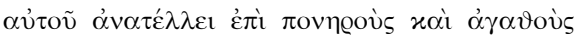

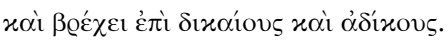

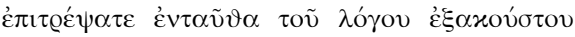

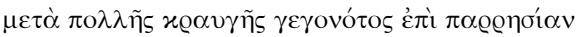

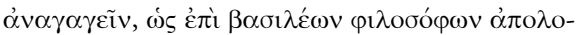

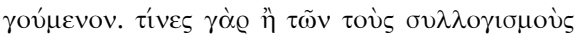

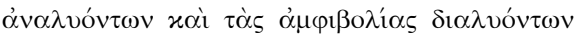

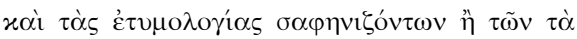

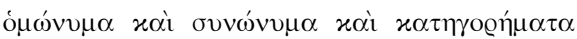

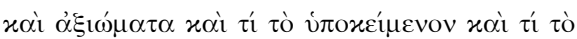

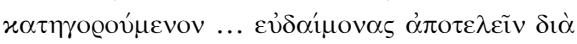

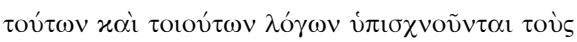

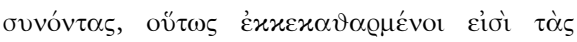

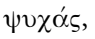

II,I Dass ich unsere Lehre ausführlich behandle, möge Euch nicht befremden. Denn ich tue dies deswegen, damit Ihr Euch nicht von der unvernünftigen Tagesmeinung mit fortreißen lasst, sondern Einblick in die Wahrheit (über die Christen) bekommt. Schon durch die bloßen Lehrsätze, an denen wir festhalten - diese sind eben nicht von Menschen, sondern göttliche Aussprüche und Offenbarungen -, können wir Euch überzeugen, dass wir keine Atheisten sind.

II,2 Welches sind also unsere Lehren, in denen wir erzogen werden?

„Ich sage euch: Liebet eure Feinde, segnet, die (euch) fluchen, betet für die, die euch verfolgen, damit ihr Kinder werdet des Vaters in den Himmeln, der seine Sonne aufgehen lässt über Böse und Gute und regnen lässt über Gerechte und Ungerechte." (Mt 5,44f.; Lk 6,27f.)

II,3 Gestattet hier, da diese Lehre weithin hörbar mit lautem Schall ergangen ist ${ }^{20}$, von der Redefreiheit Gebrauch zu machen, wie dies einer tun darf, der vor Herrschern steht, die Philosophen sind! Welche unter denen, die syllogistische Schlussfolgerungen ziehen ${ }^{2 \mathrm{I}}$ und die doppeldeutigen Aussprüche lösen und die Wortbedeutungen feststellen, oder unter denen, die ... das Homonyme und das Synonyme ${ }^{22}$, die Aussageweisen $^{23}$ und die Axiome, das Subjekt und das Prädikat $^{24} \ldots$ - dabei versprechen sie, ihre Schüler durch diese und ähnliche Lehren glücklich zu machen, haben eine solche Reinheit der Seele,

20 Athenagoras bezieht sich auf die inzwischen weite Verbreitung des Christentums.

2I Syllogismus ist ein Argumentationsgang: Alle Menschen sind sterblich; Sokrates ist ein Mensch; also ist Sokrates sterblich.

22 Homonym oder äquivok sind Wörter, die Verschiedenes bedeuten können (z. B. „Bank“). Synonym sind verschiedene Wörter, die Gleiches bedeuten (z. B. „genau, präzise“).

23 Hier nicht als „Anklage“, sondern im Sinne der Io aristotelischen Kategorien = Grundformen der Aussage: Substanz, Quantität, Qualität, Relation, Ort, Zeit, Lage, Haben, Tun, Erleiden.

24 Text ist verderbt. 


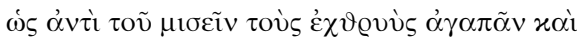

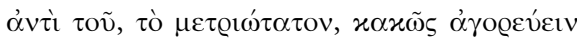

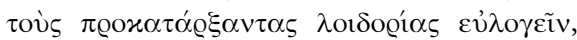

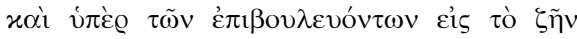
$\pi \varrho \circ \sigma \varepsilon v ́ \chi \varepsilon \sigma \vartheta \alpha$;

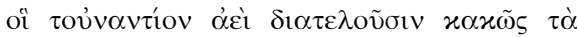

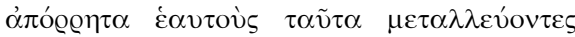

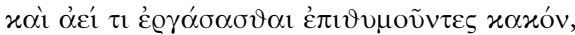

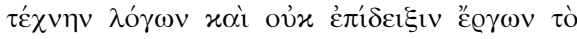

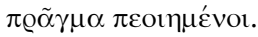

$\pi \alpha \varrho \grave{~} \delta$ '

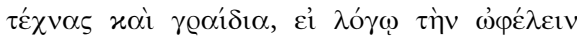

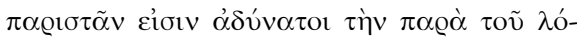

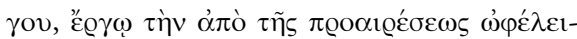

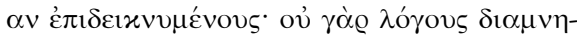

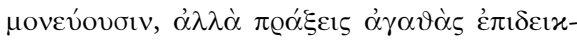
vúovøuv,

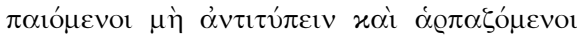

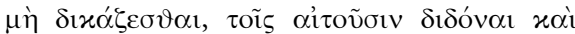

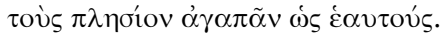

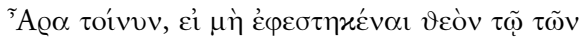

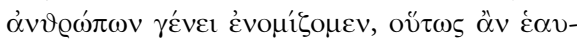

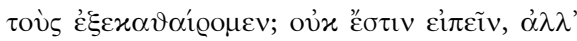

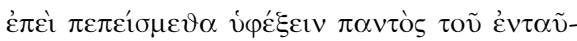

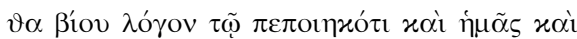

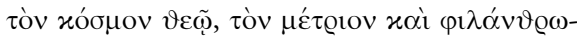

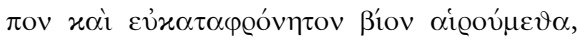

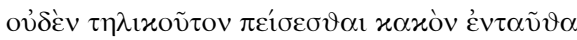

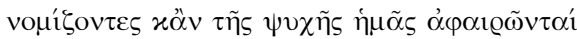

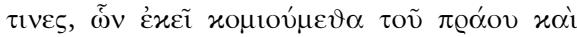

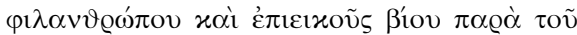
$\mu \varepsilon \gamma \alpha \dot{\lambda} \sigma \mathrm{v} \delta \iota \alpha \alpha \sigma \tau \mathrm{ov}$. dass sie anstatt zu hassen ihre Feinde lieben und dass sie anstatt denen, die ihnen zuerst Schmach zugefügt haben, Übles nachzureden, sie segnen, was überaus angemessen ist, und für die, welche ihnen nach dem Leben trachteten, beten?

Im Gegenteil, sie fragen einander immer in böser Absicht nach den obengenannten Geheimnissen aus und wollen immer etwas Böses ins Werk setzen, da sie sich kunstvolles Spiel mit Worten, aber nicht Aufzeigung von Werken zur Aufgabe gemacht haben.

II,4 Bei uns dagegen könnt Ihr ungebildete Leute, Handwerker und alte Frauen finden, die, wenn sie auch nicht imstande sind, mit Worten die Nützlichkeit ihrer Lehre darzutun, so doch durch Werke die Nützlichkeit ihrer Entscheidung aufzeigen. Denn nicht auswendig gelernte Worte sagen sie her, sondern gute Taten zeigen sie auf:

geschlagen nicht wieder zu schlagen, ausgeraubt nicht zu prozessieren, den Bittenden zu geben, die Nächsten wie sich selbst zu lieben (vgl. Mt 5,39f.42f.; Lk 6,29f.; 10,27; Mt 22,39; 26,67).

I2,I Würden wir uns nun solcher Reinheit befleißen, wenn wir nicht glaubten, dass Gott über der Menschheit walte? Gewiss nicht; sondern weil wir überzeugt sind, dass wir Gott, der uns und die Welt erschaffen hat, über unser ganzes Erdenleben einst Rechenschaft geben müssen, deshalb entscheiden wir uns für das maßvolle, menschenfreundliche und unscheinbare Leben, im Glauben, dass uns hier auf Erden, selbst wenn man uns das Leben nimmt, kein Übel zustoßen wird, das so groß ist wie die Güter, die wir im Jenseits aus der Hand des erhabenen Richters für unser sanftmütiges, menschenfreundliches und anständiges Leben erhalten werden. 


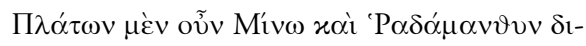

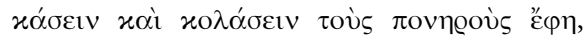

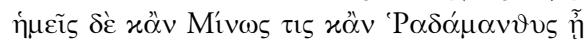

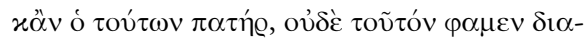

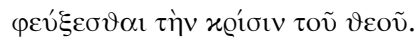

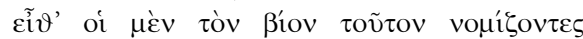

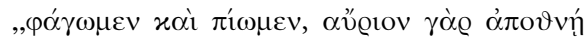

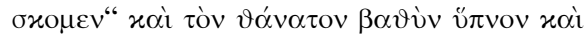
$\lambda \eta \dot{\vartheta \eta \nu} \tau \imath \vartheta \varepsilon \dot{\varepsilon} \mu \varepsilon v o l$, ,

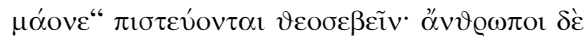

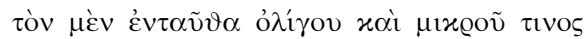

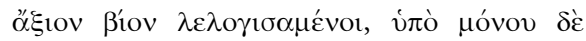

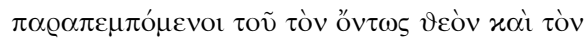

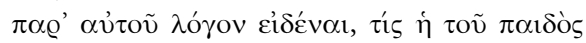

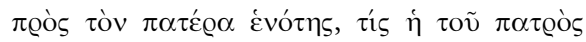

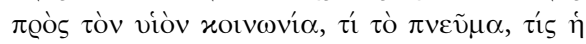

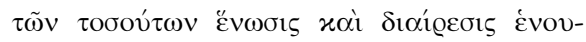

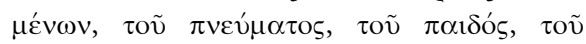

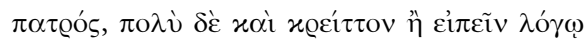

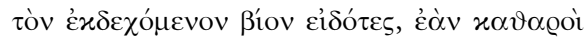

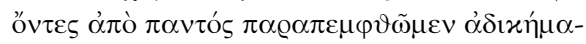
$\tau \mathrm{\tau o}$,

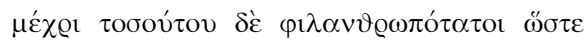

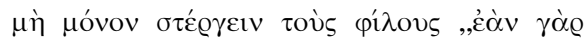

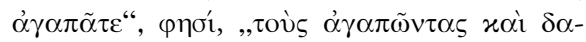

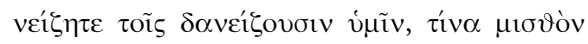

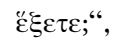

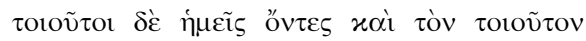

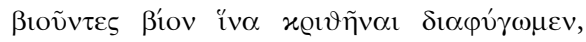

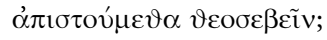

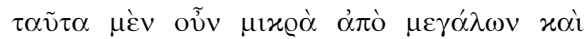

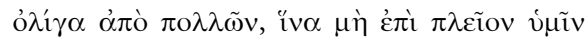

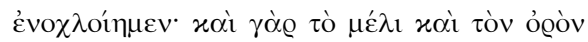

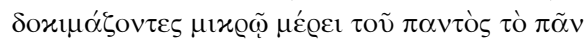

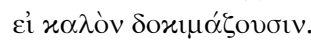

I2,2 Plato sagte, Minos und Rhadamanthys ${ }^{25}$ werden die Bösen richten und strafen, wir dagegen sagen, dass selbst ein Minos und Rhadamanthys und deren Vater dem Gericht Gottes nicht entgehen werden.

I2,3 Und da gelten dann Leute, die vom gegenwärtigen Leben denken: „Lasset uns essen und trinken; denn morgen müssen wir sterben" (Jes 22,I3; IKor 15,32) und den Tod als einen tiefen Schlaf und als ein vollständiges Vergessen auffassen („Schlaf und Tod sind Zwillingsbrüder“ [Homer, Ilias I6,672]), für Gottesverehrer! Wir hingegen, die wir uns darüber klar geworden sind, dass das Erdenleben nur weniges und geringes wert ist, die wir uns einzig von der Erkenntnis des wahren Gottes und seines Wortes leiten lassen (nämlich von der Erkenntnis, welches die Einheit des Sohnes mit dem Vater, welches die Gemeinschaft des Vaters mit dem Sohne ist, was der Geist ist, was die Einigung solcher Größen und der Unterschied der Geeinigten ist, nämlich des Geistes, des Sohnes und des Vaters), die wir ferner wissen, dass das künftige Leben noch viel besser ist, als es sich mit Worten ausdrücken lässt, vorausgesetzt, dass wir von aller Ungerechtigkeit rein (vor Gott) erscheinen,

die wir endlich bis zu dem höchsten Grade voll Menschenliebe sind, so dass wir nicht nur die Freunde lieben -,,wenn ihr nur die liebt", heißt es, „die euch lieben, und nur denen leiht, die euch leihen, welchen Lohn werdet ihr dann bekommen?" (Mt 5,46; Lk 6,32.34) -,

wir sollten, nachdem wir so sind und um dem Gerichte zu entgehen so leben, nicht als Gottesverehrer gelten?

I2,4 Dieses Kleine aus dem Großen, dieses Wenige aus dem Vielen möge genügen, damit wir Euch nicht zu lange aufhalten; auch wer Honig oder Molke versucht, schließt von einem kleinen Teile des Ganzen auf die Güte des Ganzen.

25 Die Brüder Minos (König von Kreta) und Radamanthys, Söhne von Zeus und Europe, waren als Richter in der Unterwelt vorgestellt. Plato, Gorg. 523c-524a. Vgl. Justinus, I apol. 8. 
Welches sind nun die christlichen Morallehren, nach denen Christen erzogen werden? Athenagoras präsentiert in II,2 ein Zitat aus Mt 5,44f., also aus der 6. Antithese zur Feindesliebe, wobei er die zweifache Aufforderung aus Matthäus „Liebt eure Feinde! Bittet für die, die euch verfolgen!“ um eine Aussage aus der Lukasfassung erweitert: „Segnet, die euch verfluchen!“ (Lk 6,28) Wie wichtig Athenagoras das Gebot der Feindesliebe ist, erkennt man daran, dass er es noch dreimal in II,3; II,4 und I2,3 paraphrasierend wiederholt. Außerdem, um erhöhte Aufmerksamkeit zu erregen, unterbricht er den Fluss der Argumentation in II,3 mit einer direkten Anrede an den Kaiser, in der er an dessen philosophische Einstellung appelliert sowie um Gewährung der Redefreiheit bittet. Von einer Redefreiheit für Philosophen sprach Marc Aurel in seinem Werk „Wege zu sich selbst“ (I 6); genau diese will Athenagoras also in Anspruch nehmen.

Athenagoras fährt fort, indem er auf eine wohl auch von Marc Aurel verachtete Gruppe hinweist, um Konsens mit seinem Adressaten herzustellen. Er beschreibt nämlich die von einem "wahren“ Philosophen verachteten sophistischen Redner, die sich nur in rhetorischen Spielereien verlieren, anstatt wirklich gute Taten vorweisen zu können (II,3 Ende ${ }^{26}$. Athenagoras betont, dass die Sophisten eben nicht die Feinde lieben und weder die Schmäher segnen noch für die Verfolger beten wie die Christen ${ }^{27}$. Hier wiederholt er zum ersten Mal das Gebot der Feindesliebe und verbindet dieses mit Begriffen aus der griechischen Ethik, wenn er erwähnt, dass das Ziel des richtigen Handelns darin liege, glücklich zu sein und die Reinheit der Seele zu erlangen.

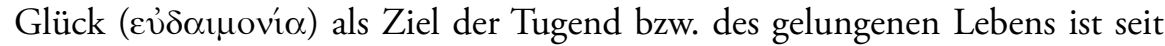
der Nikomachischen Ethik des Aristoteles ein fester Begriff in der Ethik ${ }^{28}$, auch wenn in den verschiedenen philosophischen Richtungen unterschiedlich beschrieben wird, wie genau wahre Glückseligkeit erreicht werden kann. Nach der Ansicht des Adressaten von Athenagoras, Marc Aurel, ist „Glück ein guter göttli-

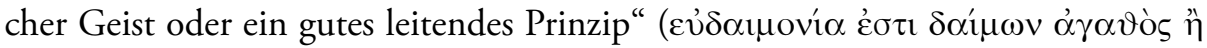

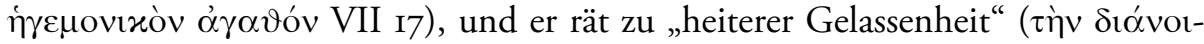
$\alpha \nu$... Év $\gamma \alpha \lambda \eta ̣ v n$ VII 68), da „das glückliche Leben ganz wenige Voraussetzun-

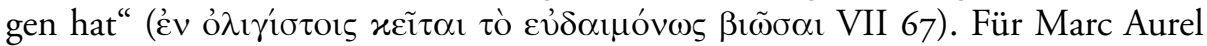
resultiert Glück gut stoisch aus Bedürfnislosigkeit und Leidenschaftslosigkeit $\left(\right.$ VII $\left.16^{29}\right)$. Athenagoras übernimmt hier also den in der griechischen Ethik gut

26 Auch Marc Aurel übt in seinem Werk mehrmals solche Kritik an den Sophisten (II,I7; 8,I).

27 "Verfolgen“ wird hier umschrieben mit „nach dem Leben trachten“, also zugespitzt auf die konkrete Verfolgungssituation der Christen im Römischen Reich zur Zeit des Athenagoras.

28 Das Glück des Menschen besteht darin, dass er das ihn von anderen Wesen unterscheidende Werk, die Vernunfttätigkeit, vollkommen verbringt, was nur möglich ist, wenn seine Seelen-

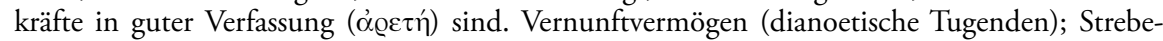
vermögen (ethische Tugenden, bes. Gerechtigkeit). - Vgl. allg. Heller 2004.

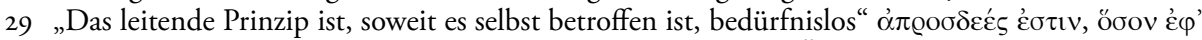

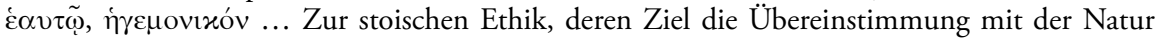


bekannten, im NT nicht verwendeten Begriff der Eudaimonia und verbindet diesen indirekt mit dem Gebot der Feindesliebe. Er setzt natürlich voraus, dass entgegen der falschen Versprechungen der Sophisten - die Befolgung des Gebots der Feindesliebe zur wahren Eudaimonia führt.

Die Sophisten jedoch haben keine guten Taten vorzuweisen, im Gegenteil, sie schaden eher der Gesellschaft und verfolgen hinterlistige, böse Absichten (II,3 Ende). Dies kontrastiert Athenagoras mit dem Verhalten der Christen, bei denen durch die Bank alle - sogar auch die Ungebildeten, Handwerker und alte Frauen - gute Taten vorzuweisen hätten ( $\pi \varrho \alpha ́ \xi \varepsilon 1 \varsigma \alpha ่ \gamma \alpha \vartheta \alpha \dot{\varsigma})$, obwohl sie nicht über solche intellektuellen Fähigkeiten wie die Sophisten verfügen. Athenagoras stellt also den falschen Versprechungen der Sophisten das wohltätige Verhalten aller, auch der ungebildeten Christen gegenüber, die damit ihre Entscheidung, Christ zu werden, als richtig erweisen. Sie schädigen andere nicht, sondern erweisen sich

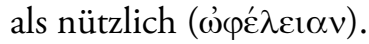

Wieder greift Athenagoras auf einen besonders in der Stoa verwendeten ethi-

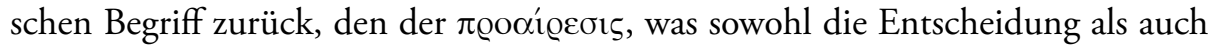

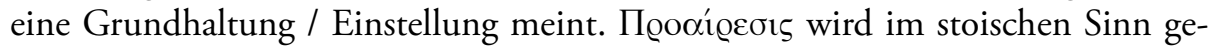
wonnen aus einem Urteil der Vernunft über die Sinneseindrücke und Lebensum-

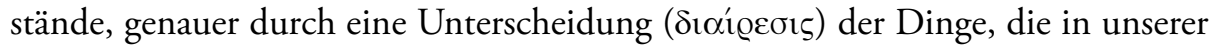

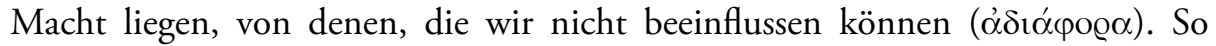

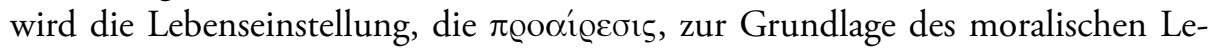
bens und zur Quelle der wahren Glückseligkeit (Eudaimonia). Diese Lebenseinstellung ist, philosophisch verstanden, jedoch keine plötzliche Wandlung, sondern das Ergebnis einer langen Erziehung und Bildung durch philosophische Belehrung. Athenagoras überträgt diesen Begriff in den christlichen Kontext der Bekehrung (auch I8,2) und meint damit die Entscheidung, sein Leben nach der christlichen Lehre wie dem Gebot der Feindesliebe auszurichten ${ }^{30}$.

ist, vgl. Cicero, De finibus bonorum et malorum 3,31: „... so bleibt nur übrig, daß das höchste Gut darin besteht, zu leben gemäß er der Erfahrung in jenen Dingen, die sich von Natur ereignen, und zwar in der Weise, daß man vorzieht, was naturgemäß ist, und zurückweist, was naturwidrig ist, was schließlich bedeutet: der Natur entsprechend und mit ihr in Übereinstimmung zu leben." ... relinquitur ut summum bonum sit vivere scientiam adhibentem earum rerum, quae natura eveniant, seligentem quae secundum naturam et quae contra naturam sint reicientem, id est convenienter congruenterque naturae vivere (Marcus Tullius Cicero, De finibus bonorum et malorum. Über die Ziele des menschlichen Handelns, lateinisch / deutsch, übersetzt und herausgegeben von Olof Gigon / Laila Straume-Zimmermann, München ${ }^{2}$ 2002, 202f.) Vgl. außerdem allg. Seneca, De beata vita und auch beispielsweise Epiktet, Encheiridion I (Wenn wir

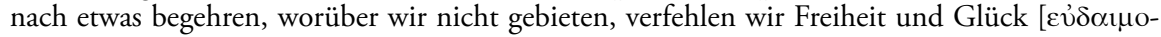
vía]); 8: „Verlange nicht, daß das, was geschieht, so geschieht, wie du es wünschst, sondern wünsche, daß es so geschieht, wie es geschieht, und dein Leben wird heiter dahinströmen ( $x$ ¿i

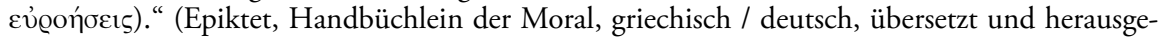
geben von Kurt Steinmann, Stuttgart 1992, 6f.; I4f.).

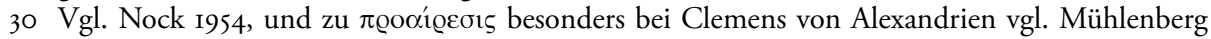
2008. 
Jetzt wiederholt Athenagoras zum zweiten Mal das Gebot der Feindesliebe und liefert entsprechende Beispiele, inwiefern Christen den Feind lieben (II,4): „geschlagen nicht zurückzuschlagen“ (das erinnert an die Passion Jesu Christi: Lk 22,63; Mt 26,67), ,ausgeraubt nicht zu prozessieren“ (entlehnt aus dem Gleichnis vom barmherzigen Samariter), „den Bittenden zu geben“ (das entstammt der lukanischen Feldrede und der matthäischen fünften Antithese vom Vergelten Lk 6,30; Mt 5,42) und „den Nächsten wie sich selbst zu lieben“ (auch dies erinnert an das Gleichnis vom barmherzigen Samariter Lk Io,27). Vornehmlich also in Anlehnung an das Gleichnis vom barmherzigen Samariter und an die Passionserzählungen beschreibt Athenagoras das Verhalten der Christen in einer ihnen feindlich gesonnen Umgebung, wie sie, im Unterschied zu den Sophisten, trotz dieses Leidensdrucks den Feinden nicht schaden, sondern auch hier noch gute Taten vorweisen können.

Dann, in I2,I, kommt Athenagoras auf das übergeordnete Thema, den Atheismusvorwurf, zurück: „Weil wir überzeugt sind, dass wir Gott, der uns und die Welt erschaffen hat, über unser ganzes Erdenleben Rechenschaft werden ablegen müssen, deshalb wählen wir das maßvolle, menschenfreundliche und unscheinbare Leben, im Glauben, dass uns hier auf Erden, selbst wenn man uns das Leben nimmt, kein Übel zustoßen wird, das so groß ist wie die Güter, die wir im Jenseits aus der Hand des erhabenen Richters für unser sanftmütiges, menschenfreundliches und anständiges Leben erhalten werden." Die Christen befolgen diese Gebote aufgrund ihres Glaubens an Gott, vor dem sie als Richter Rechenschaft ablegen müssen. Die Erwartung des Gerichts führt also zu der Ernsthaftigkeit, mit der die Christen ihre Lehren auch in die Tat umsetzen. Die Hoffnung auf Ausgleich und Erquickung im Jenseits ermöglicht überhaupt erst, auf Vergeltung zu verzichten und den lebensbedrohlichen Feind zu lieben. Die Ausführungen zum Ethos der Christen dienen Athenagoras also als Beweis dafür, dass die Christen keine Atheisten sind ${ }^{31}$.

Athenagoras beschreibt hier den Lebenswandel der Christen mit fünf Attributen, die zunächst überraschen: maßvoll, menschenfreundlich, unscheinbar, sanftmütig und anständig. Im Zentrum steht hier die doppelt erwähnte Menschenliebe, $\varphi \imath \lambda \alpha v \vartheta \varrho \omega \pi i \alpha$, die er in I2,3 am Ende noch ein drittes Mal aufgreift, in der doppelt gesteigerten Form der Superlativs: Die Christen sind so übervoll von Menschenliebe, dass sie eben nicht nur die Freunde einbeziehen. Denn was würden sie damit vor Gott gewinnen? Nichts natürlich. Die Philanthropie, ursprünglich ein Attribut für die Götter (vgl. auch Tit 3,4: „erschienen ist die Menschenfreundlichkeit Gottes") und auch eine Herrschertugend gegenüber den Un-

3I Die Ethik folgt aus der Gotteslehre bzw. die Theologie beeinflusst die Ethik. Die Vorstellung vom endzeitlichen Gericht trug den Christen den Vorwurf ein, ihre Anhänger nur mit Drohungen und durch Angstschüren gewinnen zu können. Vgl. zum Vorwurf der „Angstmacherei“ Ulrich 2007. 
tergebenen, ist ein besonders in der jüngeren Stoa ausgebauter ethischer Leitgedanke $e^{32}$, auf den Athenagoras hier zurückgreift. In dem ersten Kapitel seiner Apologie und im Schlusskapitel spricht er den Kaiser Marc Aurel auch direkt auf dessen Menschenliebe an (I,2; 2,I; 37,I), ebenso auf seine Sanftmut und maßvolle Gesinnung als Tugenden eines guten Herrschers. Hier nun beschreibt Athenagoras die Christen mit den Eigenschaften, mit denen Marc Aurel sich gerne als Philosophenkaiser sieht ${ }^{33}$. Zugleich nimmt Athenagoras für sich und die Christen in Anspruch, das durchschnittliche Maß an Menschenliebe zu übertreffen, so dass sie die Allermenschenfreundlichsten seien in ihrer Feindesliebe. Einfache Christen praktizieren Menschenliebe im Superlativ - was sonst nur als Ehrbezeichnung eines Herrschers verwendet wird.

Hier in I2,2 ergänzt Athenagoras die Reihe der Attribute noch um die Unscheinbarkeit. Warum betont Athenagoras hier die Unscheinbarkeit? Der Hintergrund dürfte darin liegen, dass Kritiker wie Marc Aurel den Christen Aufsehen erhaschendes, marktschreierisches Verhalten mit ihrer Martyriumsbereitschaft vorwirft: Christen seien nur bereit, ihr Leben hinzugeben, aufgrund ihrer Ver-

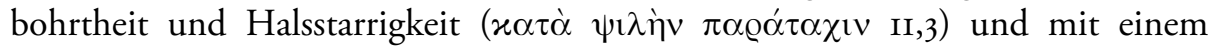
Hang zum Theatralischen ( $\varrho_{0} \alpha \omega \delta \omega \varsigma$ ), quasi als Reklamemittel, was ihre Moral in ein schlechtes Licht rücke - so Marc Aurel in seiner einzigen Erwähnung der Christen in seinem Werk.

Athenagoras versucht also den Kaiser unter Rückgriff auf dessen ethische Maßstäbe vom hohen Ethos der Christen zu überzeugen. Dabei verbindet Athenagoras die Vorstellung von der Menschenliebe mit dem christlichen Gebot der Feindesliebe und beschreibt, dass die Christen mit ihrer entgrenzten Liebe, die jenseits der Kategorie „Freund - Feind“ alle Menschen einbezieht, eigentlich diejenigen sind, die wahre Menschenliebe äußern. Zudem nicht nur die philoso-

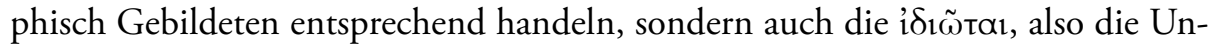
gebildeten vom einfachen Handwerker bis zu den alten Frauen.

Die christliche Vorstellung von der Auferstehung und eines Gerichts vor Gott ist aber nichts, was Marc Aurel akzeptieren könnte. Deswegen ergänzt Athenagoras in I2,3 seine Argumentation noch mit einer Anspielung auf eine sowohl von den Christen als auch Stoikern wie Marc Aurel abgelehnte Ansicht, nämlich die quasi atheistische und hedonistische Haltung der Epikureer ${ }^{34}$. Er will auf den Widerspruch hinweisen, dass die Epikureer, die offen ihre "Gottlosigkeit“ bekennen und ihre Furchtlosigkeit vor dem Tod und den Göttern betonen, als gottesfürchtig gelten können, während man die Christen, die genau der gegenteiligen Ansicht sind, für gottlos hält.

32 Vgl. Hügli / Kipfer 1989; Luck 1973.

33 Vgl. Marc Aurel, Wege zu sich selbst 7,63; 9,42; II,9; II,I8 (sanftmütig); 2,I2; I2,3I (unscheinbar).

34 Er stellt hier das in IKor I5,32 aus Jes 22,13 zitierte Motto einer Aussage Homers an die Seite. 


\section{Das Gebot der Feindesliebe}

Nun zu den zu Beginn angesprochenen Fragen:

Thematisieren frühchristliche Autoren das Gebot der Feindesliebe? Bei den Apologeten wird die Feindesliebe nicht nur erwähnt, sondern dieses Gebot steht durchaus im Vordergrund, zusammen mit der Ermahnung zum Gewaltverzicht. Bei Athenagoras ist das besonders deutlich, da diese Passage das einzige längere Schriftzitat in seiner Apologie überhaupt enthält. Er wählt die Feindesliebe als ethisches Beispiel, um den Vorwurf des Atheismus abzuwehren. Indirekt will Athenagoras damit natürlich auch darauf hinweisen, dass Christen zu Unrecht angeklagt werden: Wer auf Gewalt verzichtet und seine Feinde liebt, kann niemandem schaden. Er zeigt damit die Harmlosigkeit und Ungefährlichkeit des Christentums für das Römische Reich.

Wird die Feindesliebe als etwas Neues präsentiert? Athenagoras weist in II,I eigens darauf hin, dass die christlichen Lehren wie die Feindesliebe nicht menschlicher Weisheit entstammen, sondern göttlichen Ursprungs sind. Athenagoras knüpft zwar mit dem Rückgriff auf die Philanthropia / Menschenliebe an philosophisches Gedankengut besonders aus der Stoa an, aber überbietet dies sogleich, da alle Christen allen mit Liebe begegnen aufgrund ihres Glaubens und ihrer eschatologischen Erwartung. Athenagoras sieht offenbar das Gebot der Feindesliebe als etwas Neues und spezifisch Christliches an.

Ähnlich stellt es auch Justin in seiner Apologie dar ${ }^{35}$. Er reagiert hierin auf Vorwürfe wie Inzest und Kannibalismus; ferner kritisiert er die ungerechtfertigte staatliche Verfolgung, obwohl doch die merkwürdigsten Religionen und auch skurilsten Philosophen unbehelligt bleiben; außerdem will er die Einschätzung des Christentums als minderwertige und irrationale Bewegung korrigieren. So listet er in seiner ersten Apologie auch moralische Standards auf, die Christen einhalten würden, da eine Bekehrung zum Christentum auch eine Änderung des Lebenswandels zur Folge habe. Er orientiert sich hierbei im Grunde an der Bergpredigt, wenn er die Ehemoral, den Umgang mit Geld und Armut und die Nächsten- und Feindesliebe erwähnt (I apol. I4). Das untermauert Justin mit biblischen Zitaten, u. a. auch mit einem Auszug aus der matthäischen Antithese zur Feindesliebe, kombiniert mit der lukanischen Fassung. Justin will darauf hinaus, dass die Christen zu Unrecht angeklagt und verfolgt werden, da sie doch kein Unrecht tun (Kap. I-3). Im Gegenzug gesteht er zu und fordert sogar vom Kaiser, dass solche, die nicht diesen christlichen Lehren entsprechend leben und sich

$35 \mathrm{Zu}$ Justin vgl. allg. Parvis / Foster 2007 und Parvis 2008. Vgl. zu Justins Ethik auch Willert 2006. 
also nur Christen nennen, ohne in Wirklichkeit welche zu sein, bestraft werden $(\text { Kap. I6) })^{36}$.

Justin präsentiert seine christlichen moralischen Standards allein mit Schriftbelegen ohne Hinweis auf pagane Parallelen. Er zitiert das Gebot der Feindesliebe sogar mit einer interessanten Abweichung: „Wenn ihr die liebt, welche euch lieben, was tut ihr da Neues?" - wohl nach Johannes 13,34 („ein neues Gebot gebe ich euch, dass ihr euch untereinander liebt") abgeändert. In seinem Verständnis ist es also etwas Neues, dass Christen auch den Feind lieben ${ }^{37}$. Es ist natürlich deswegen neu, weil jetzt durch die Menschwerdung des Sohnes Gottes, der Gottes Wort ist, die wahre Lehre offenbar und die Verkehrung dessen durch die Dämonen durchschaubar wurde. ${ }^{38}$

Nichtchristliche Autoren sehen das ganz anders. Celsus, der berühmte Kritiker des Christentums und Zeitgenosse des Athenagoras, schrieb um 178 n. Chr.

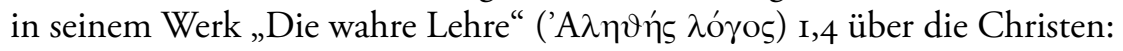

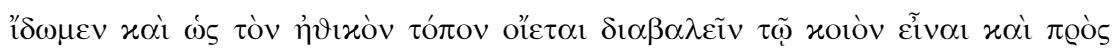

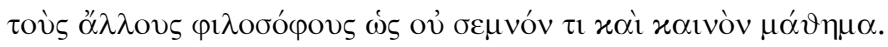

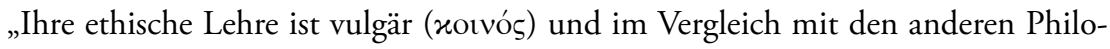

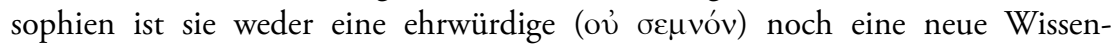
schaft. ${ }^{\text {(39 }}$

Die Ethik der Christen insgesamt sei von niederem Rang, genüge keinen philosophischen Ansprüchen und sei zudem auch nichts Neues ${ }^{40}$. Damit fällt sein Ur-

36 In einem vergleichbaren Zusammenhang bietet auch Theophil von Antiochien das Gebot der Feindesliebe in seiner Apologie Ad Autolycum (III I4). Er stellt die hohe christliche Moral, u.a. auch die Feindesliebe, den Schandtaten gegenüber, die Christen angeblich begangen haben wie Inzest und Kannibalismus. Das zeige doch, wie haltlos diese maßlosen Unterstellungen seien (Kap. I5). Clemens von Alexandrien, Stromateis VII I4,84-88 über Feindesliebe als Ziel der Leidenschaftslosigkeit (stoisch!) im Zusammenhang einer Auslegung von I Kor 6.

37 Auch wenn manche schon vorher, dank des Wirkens des göttlichen Logos, christlichen Lebenswandel zeigten - Justin nennt hier zum Beispiel Sokrates und auch Abraham (I apol. 46).

38 Und was bedeutet es für Justin, den Feind zu lieben? Drei Aspekte spricht er konkret an: Erstens leben in den christlichen Gemeinden Leute aus unterschiedlichen Völkern und Stämmen zusammen, die sich früher hassten und ermordeten; zweitens beten die Christen für die Feinde, drittens versuchen Christen diejenigen, die sie zu Unrecht hassen, von einem Besseren zu belehren und für das Christentum zu gewinnen (I apol. I4). Es sei aber darauf hingewiesen, daß Justin in seinem Dialog mit dem Juden Tryphon (Kap. 85) durchaus die Herkunft dieses Gebots aus dem Alten Testament betonen kann und in diesem Zusammenhang eher die Kontinuität als die Diskontinuität betont.

39 GCS Origenes 2 (Leipzig I899), 207 Koetschau. Übersetzung Lona, 2005, 76.

40 Vgl. das Urteil von Galen nach Walzer, 1949, I5 (Reference 6): „Most people are unable to follow any demonstrative argument consecutively; hence they need parables, and benefit from them - and he (Galen) understands by parables tales of rewards and punishments in a future life - just as now we see the people called Christians drawing their faith from parables [and miracles], and yet sometimes acting in the same wax [as those who philosophize]. For their contempt of death [and of its sequel] is patent to us every day, and likewise their restraint in cohabitation. For they include not only men but also women who refrain from cohabiting all 
teil über die Christen noch vernichtender aus das seines Zeitgenossen Galen, des großen und berühmten Arztes aus dem zweiten Jahrhundert, der in einem arabisch überlieferten Fragment bei aller Kritik am Christentum doch wenigstens die hohe Moral der Christen loben kann, die hierin das Niveau der wahren Philosophen erreichen würden ${ }^{41}$. Für Celsus dagegen kann christliche Ethik bestenfalls als ein Missverständnis von Gedanken Platons interpretiert werden. Dieses Urteil führt Celsus an drei Beispielen aus: der christlichen Demut $\left(6,15^{42}\right)$, der Armut $\left(6,16^{43}\right)$ und dem Gewaltverzicht $(7,58)$. Als Erläuterung zum Thema Gewaltverzicht zitiert Celsus eine berühmt gewordene Stelle aus dem platonischen Dialog Kriton (49b-c; 49d-e $\left.{ }^{44}\right)$, um zu zeigen, dass diese ethische Forderung nicht auf die Christen zurückgeht:

Denn Platon lässt Sokrates mit Kriton folgendermaßen sprechen:

Auf keine Weise darf man also Unrecht tun.

Gewiss nicht.

Also auch nicht der, dem Unrecht geschehen ist, darf wieder Unrecht tun, wie die meisten glauben, wenn man doch auf keine Weise Unrecht tun darf.

Es scheint so.

Wie denn? Darf man Böses tun oder nicht, o Kriton?

Man darf es wohl nicht, o Sokrates.

Wie aber? Böses anzutun dem, von dem man Böses erlitten hat, ist das, wie die meisten sagen, gerecht oder ungerecht?

Auf keine Weise. Den Menschen mit Bösem zu vergelten unterscheidet sich gar nicht von Unrecht tun.

Richtig hast du gesprochen.

Also darf man weder Unrecht zufügen noch Böses den Menschen antun, auch nicht, wenn man unter ihnen leidet. ${ }^{45}$

through their lives, and they also number individuals who, in self-discipline and self-control in matters of food and drink, and in their keen pursuit of justice, have attained a pitch not inferior to that of genuin philosophers."

4I Walzer, 1949, 9I (auch is [vorige Anm.]).

42 Die christliche Buße in Sack und Asche sei eine unselige Erniedrigung, die nichts mehr mit der

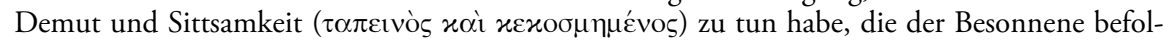
ge, der die Ordnung der Welt anerkenne und sich in ihr einfüge. Vgl. Lona, 2005, $329 f$.

43 Nur unmäßiger, mit Unrecht erworbener Reichtum sei zu kritisieren, nicht der Reichtum an sich wie in Mt 19,24 .

$44 \mathrm{Vgl}$. Apologie 29b!

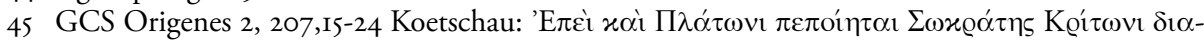

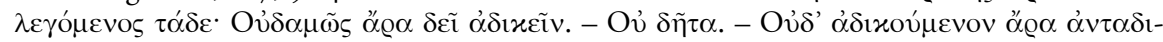

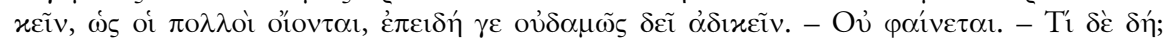

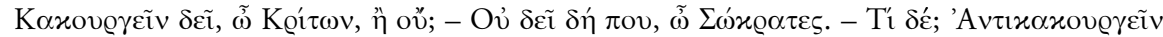

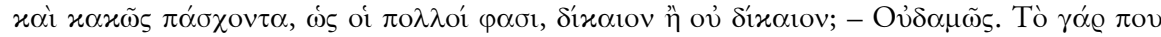

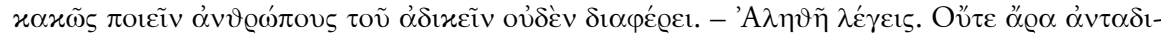


Gewaltverzicht sei also nichts Neues und auch nichts spezifisch Christliches. Die Christen hätten nur ein schlechtes Plagiat vorzuweisen ${ }^{46}$ !

Celsus verfasste sein Werk „Die wahre Lehre“ zeitgleich mit der Apologie des Athenagoras. Indirekt bezeugt er hier die zentrale Stellung dieses Themas bei den Christen, da er sich genötigt sah, den christlichen Anspruch einer besseren und neuen Ethik zu widerlegen. Athenagoras seinerseits sagt nicht direkt, dass ein Philosoph das Gebot der Feindesliebe nicht befolgt, u.a. da er sich ja an einen Philosophenkaiser wendet. Aber er betont, dass man bei den Christen die allgemeine Menschenliebe im Übermaß, im Superlativ, findet, da sie erstens auch die Feinde mit einbezieht und zweitens von allen Christen, nicht nur den philosophisch Gebildeten, praktiziert wird. Aus seiner Sicht wird allgemeine Menschenliebe bei den Heiden also nur im Ausnahmefall praktiziert; Celsus dagegen betont eben gerade diese Ausnahme, um den Anspruch der Christen auf Originalität zu relativieren. Man kann hier also erkennen, dass die frühchristliche Auseinandersetzung um die wahre Lehre auch eine Auseinandersetzung um die beste Ethik gewesen ist.

Es ist natürlich nicht möglich, anhand der Texte eine sozialgeschichtliche Beschreibung des Verhaltens der frühen Christen vorzulegen, ob und wie konsequent das Gebot der Feindesliebe damals befolgt wurde. Die Darstellung des Athenagoras dürfte ohne Zweifel eine Übertreibung sein zu apologetischen Zwecken. Wie sehr dies ein literarischer Diskurs ist, zeigt ein kurzer Blick auf die sogenannten Märtyrerakten: Gerade diese Texte lassen die Feindesliebe missen ${ }^{47}$. Dabei wäre hier ein literarischer Ort, an dem praktische Feindesliebe demonstriert werden könnte, zudem in den Berichten in der Regel ein Gebet des Märtyrers vor seinem Tod wiedergegeben wird. Aber man findet teilweise sogar Verwünschungen der Kläger oder der Heiden allgemein wie im Martyrium Polycarps (Kap. 9): „Hinweg mit den Gottlosen!“48 Oder im Martyrium der Perpetua und Felicitas wird gedroht: „Du richtest uns; Gott wird dich richten!“49 Und der Märtyrer Conon droht seinem Richter ewige Qualen im Hades an. ${ }^{\circ}$ Noch nicht einmal eine Fürbitte für den feindlichen Gegner lässt sich finden. Das ist insofern doch bemerkenswert, als in der lukanischen Passion Jesu Fürbitte am Kreuz „Vater, vergib ihnen, denn sie wissen nicht, was sie tun!“ (Lk 23,34)

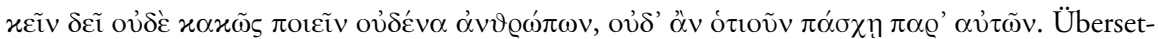
zung Lona, 2005, 422.

46 Für Celsus ergibt sich daraus, dass nicht einmal der Lebenswandel der Christen als deren Existenzberechtigung gelten kann und dass die Gesellschaft das Christentum nicht benötigt.

47 Dies beobachtete auch schon Bauer (1917, 243f.). Vgl. die Ausgaben der Märtyrerakten: R. Knopf/G. Krüger/G. Ruhbach (Hg.), Ausgewählte Märtyrerakten, Tübingen I965; H. Musorillo (Hg.), The Acts of the Christian Martyrs (OECT), Oxford 1972, ${ }^{2}$ I979.

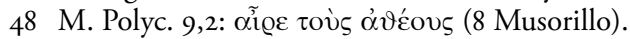

49 P. Perp. I8,8: tu nos, inquiunt, te autem Deus (I26 Musorillo).

50 M. Con. 5 (190 Musorillo). 
und in dem letzten Wort des ersten christlichen Märtyrers Stephanus „Herr, rechne ihnen diese Sünde nicht an!“ (Apg 7,60) Vorbilder zur Verfügung gestanden hätten ${ }^{\text {sI }}$. Die von den Makkabäerbüchern beeinflusste Gattung der Märtyrerberichte sah im Rahmen ihrer Beschreibung der unglaublichen Stärke, dem Durchhaltevermögen und dem Gottvertrauen eine milde Betrachtung der Urheber nicht vor. Auch kommt hier stärker ein anderer Traditionsstrang zum Tragen, nämlich die Dämonisierung der Gegner der Christen als Feinde Gottes, denen man nicht mit Milde zu begegnen hat. Im Vordergrund steht also der Kampf gegen und der Sieg über den Widersacher Gottes, der hinter der Verfolgung der Christen stecke. Dennoch würde man es durchaus begrüßen, wenn die Gattung z.B. nach dem Bericht des Märtyrers Stephanus verändert worden wäre, was schon Walter Bauer in seinem Aufsatz bemerkte.

Ist die Rezeption und Interpretation des Feindesliebegebots im Kontext der „Hellenisierung des Christentums“ zu verstehen? In seinen Ausführungen greift Athenagoras mehrmals auf Begriffe besonders der stoischen Ethik zurück wie die Glückseligkeit / Eudaimonia; die Entscheidung / Prohairesis, die allgemeine Menschenliebe / Philanthropia, um dem griechischen Leser/Hörer Anknüpfungspunkte zum Thema zu bieten. Da er wohl selbst über eine entsprechende Bildung verfügte, war ihm diese Terminologie gewiss geläufig. Insofern ist natürlich in diesen zwei Kapiteln eine „Hellenisierung“ erkennbar. Dennoch werden diese Vorstellungen durchbrochen, erstens mit der Jenseitsvorstellung und der eschatologischen Erwartung. Diese sind für Athenagoras Grund und Ziel moralischen Handelns, nicht die stoische Glückseligkeit. Zweitens werden die ethischen Begriffe wie die Philanthropie übernommen, aber zugleich überboten. Die Verwendung des Attributs „menschenfreundlich“ im Superlativ ist ein sehr subtiler Umgang mit diesem ethischen Begriff. Drittens werden Begriffe in einen anderen Kontext gestellt wie „Entscheidung" / prohairesis und verändern dabei ihre Bedeutung. Athenagoras verbindet auf interessante Weise ethische Begriffe mit dem Gebot der Feindesliebe ${ }^{52}$.

5I Vgl. auch die Verwünschungen bei Ignatius (Röm 5,I z. B.).

52 Ferner bietet er mit seiner mehrmaligen Wiederholung und Paraphrasierung der Feindesliebe das Gebot in einer außerordentlichen Klarheit und Konkretisierung. Den Feind zu lieben bedeutet sowohl, im öffentlichen Prozess gegen die Christen für den zu beten, der einem nach dem Leben trachtet, als auch im kleineren Rahmen z. B. nicht zurückzuschlagen. 


\section{Ein Ausblick}

Athenagoras verteidigte die Christen gegen den Vorwurf des Atheismus. Er erläuterte nicht nur das christliche Verständnis von Gott (Theologie), sondern führte als Argument auch die christliche Ethik an: Leid zu ertragen und den Feind zu lieben ist nur möglich in Erwartung jenseitiger Wiedergutmachung - umgekehrt beweist dieses Verhalten einen Gottesglauben. Athenagoras stand in einem Diskurs über die „Wahre Lehre“, der auch einen Wettstreit um die bessere Ethik einschloss. Ohne Zweifel übertrieb Athenagoras in seiner Darstellung aus apologetischen Motiven. Man sollte sich hüten, diese als Beschreibung der frühchristlichen Sozialethik zu übernehmen. Die Märtyrerakten liefern z.B. mit ihrer Dämonisierung der Feinde ein vollkommen anderes Bild ${ }^{\text {s3. }}$.

Frühchristliche Apologeten wie Athenagoras überlieferten das Gebot der Feindesliebe ohne Abstriche. Zu dem grundsätzlichen Problem der Erfüllbarkeit findet man bei ihnen keine Reflexionen, ebenso spielen die Fragen nach der Sündhaftigkeit des Menschen und nach der Bedeutung der "guten Werke" für die Erlösung noch keine Rolle. Den Autoren deswegen theologische Defizite zu unterstellen wäre ein anachronistisches Fehlurteil, das zudem die besondere Gattung der Apologie nicht berücksichtigt ${ }^{54}$. Erst im Mittelalter unter dem Einfluss einer monastischen Theologie entwickelte sich eine "Zwei-Stufen-Ethik“, die letztendlich zu einer Unterscheidung zwischen Geboten (praecepta) für „Normalchristen" und Räten (consilia) für eine kleine Gruppe von Vollkommenen führ$\mathrm{te}^{55}$. Noch im vierten und fünften Jahrhundert machen Theologen wie Augustinus, Hieronymus oder Johannes Chrysostomus keine Abstriche daran, dass die Bergpredigt an alle Christen gerichtet ist, auch wenn zum Beispiel Hieronymus betont, dass, den Feind zu lieben, natürlich nicht in dem Maße gelte wie den Freunden (Pelag. I 3I): „Geht nun etwa das Gebot soweit, dass ich sie so lieben muss wie die Nächststehenden, die Blutsverwandten und Freunde, so dass jeder Unterschied zwischen Feinden und Angehörigen aufgehoben wird?" ${ }^{36}$ Dennoch betont auch er, dass das Feindesliebegebot erfüllt werden kann mit Hinweis auf die biblischen Vorbilder David, Stephanus und Paulus ${ }^{57}$ (Matthäuskommentar V 44). Augustinus wie Johannes Chrysostomus beschreiben zwar, dass die Christen

53 Vgl. oben S. 244. Eine Dämonisierung des Gegners als widergöttliche Macht, als teuflisch, als Feind Gottes steht einer Regung der Feindesliebe entgegen.

54 Genau darauf läuft jedoch die (altertumswissenschaftliche!) Dissertation von Peglau (1999) hinaus.

55 Vgl. Stoll 1988.

56 Praeceptum est mihi ut diligam inimicos et orem pro persecutoribus: numquid iussum est ut ita diligam quasi proximos et consanguineos et animicos, ut inter aemulum et necessarium nulla distantia est? (CChr.SL 80, Turnholt 1990, 39,6-9 Morschini).

57 In seinem Matthäuskommentar Band I zu Mt 5,44 (Saint Jérôme, Commentaire sur S. Matthieu tom I [livres I-II] (SChr 242), hg.v. E. Bonnard, Paris I977, I24-I27). 
im Glauben und in der Vollkommenheit wachsen und höhere Stufen der Tugend mit der Zeit erreichen können und sollen, machen aber dennoch keine Abstriche daran, dass alle Christen die vollkommene Gerechtigkeit der Bergpredigt erstreben sollen ${ }^{58}$. Insofern ist die Kommentierung von Ulrich Luz in seinem Abschnitt über die Wirkungsgeschichte von der Bergpredigt, eine "Zwei-StufenEthik" schon bei altkirchlichen Autoren wie Ambrosius und Augustinus zu erkennen, zu differenzieren ${ }^{59}$.

Zur Zeit des Athenagoras unter Marc Aurel war die Lage für die Christen bekanntlich vielerorts brenzlig. Viele Christen wurden verfolgt und getötet und mehrere Martyrien sind aus dieser Zeit bekannt. Athenagoras versuchte, den Kaiser zu beschämen und erinnerte ihn indirekt an seine eigenen Moralvorstellungen einschließlich der Menschenliebe. Hinter dem Text stand bitterer Ernst, der heute allzu leicht übersehen wird. Athenagoras fand klare Worte, in denen sich auch sein Mut ausdrückt. Eigentlich war das Verfassen dieser Apologie selbst ein Akt der Feindesliebe.

58 Augustinus, Enchiridion ad Laurentium I9; De sermone in Domini monte (sieben Stufen der Vollkommenheit in Anlehnung an die siebenfachen Gaben des Heiligen Geistes aus Jes II,2f.). Vgl. auch Johannes Chrysostomus, der in den Homilien zu Matthäus in hom. I8 zu Mt 5,38-48

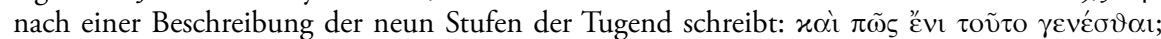

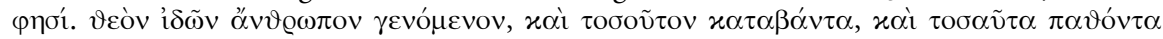

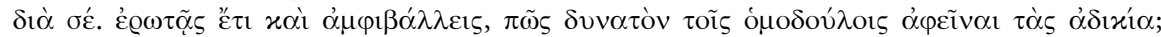

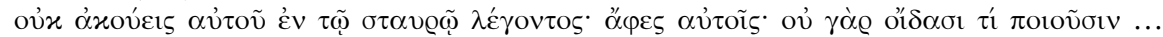
(PG 57, 267f.) „Aber, fragst du, wie soll ich das zustande bringen? Nun, wenn du siehst, wie Gott Mensch geworden ist, so tief herabgestiegen ist und so viel für dich gelitten hat, da fragst du noch und zweifelst, wie es möglich sein sollte, unseren Mitsklaven ihr Unrecht zu verzeihen? Hörst du nicht, wie Christus am Kreuze spricht: Verzeihe ihnen, denn sie wissen nicht, was sie tun ..." Auch Ambrosius unterscheidet zwar zwischen mittleren (wie Dekalog) und vollkommenen Pflichten (wie Feindesliebe und Besitzverzicht), bezieht diese Unterscheidung aber nicht auf verschiedene Personengruppen: De officiis ministerii I $36 f$.

59 Luz, 2002, 4II. 


\section{Literaturverzeichnis}

Athenagoras (1990): Athenagoras, Legatio pro Christianis, hg. v. M. Marcovich (PTS 31), Berlin / New York.

Athenagoras (1972): Athenagoras, Legatio and De Resurrectione, edited an translated by W. R. Schoedel (OECT), Oxford.

Athenagoras (1992): Athénagore. Supplique au sujet des chrétiens et sur la résurrection des morts, Introduction, TExt et Traduction par B. Pouderon (SChr 379), Paris.

Barnard (1972): L. W. Barnard, Athenagoras. A Study in Second Century Christian Apologetic (Théologie historique I8), Paris.

Bauer (1917): W. Bauer, „Das Gebot der Feindesliebe und die alten Christen“, in: W. Bauer, Aufsätze und kleine Schriften, hg. von G. Strecker, Tübingen 1967, 235-252.

Beyschlag (1977): K. Beyschlag, „Zur Geschichte der Bergpredigt in der Alten Kirche", $Z T h K$ 74, 29I-322.

Birley (1987): A. R. Birley, Marcus Aurelius. A Biography, London, 2. Auflage.

Drake (2005): H.A. Drake, „Models of Christian Expansion“, in: W. V. Harris (Hg.), The Spread of Christianity in the First Four Centuries. Essays in Explanation (Columbia Studies in the Classical Tradition 27), Leiden / Boston, II3.

Ebner (2000): M. Ebner, „Feindesliebe - ein Ratschlag zum Überleben? Sozialund religionsgeschichtliche Überlegungen zu Mt 5,38-47/Lk 6,27-35", in: J.M. Asgeirsson u.a. (Hg.), From Quest to Q. Festschrift J.M. Robinson (BEThL I46), Leuven, II9-I42.

Engberg (2007): J. Engberg, Impulsore Chresto. Opposition to Christianity in the Roman Empire c. 50-250 (ECCA 2), Frankfurt.

Fündling (2008): J. Fündling, Marc Aurel (Gestalten der Antike), Darmstadt.

Guyot u. Klein (1997): P. Guyot u. R. Klein (Hgg.), Das frühe Christentum bis zum Ende der Verfolgungen. Eine Dokumentation, Band I: „Die Christen im heidnischen Staat", Darmstadt.

Hall (1979): S. Hall (Hg.), Melito of Sardes. On the pscha and Fragments (OECT), Oxford.

Harnack (I899): A. v. Harnack, Das Wesen des Christentums, hg. und kommentiert von T. Rendtorff, Gütersloh 1999.

Harnack (1909): A. v. Harnack, Lehrbuch der Dogmengeschichte, Drei Bände, 4. Auflage Tübingen, Nachdruck Darmstadt 1964.

Harnack (1924): A. v. Harnack, Die Mission und Ausbreitung des Christentums in den ersten drei Jahrhunderten, 4. Auflage Leipzig. 
Hays (1996): R. B. Hays, The Moral Vision of the New Testament. Community, Cross, New Creation. A Contemporary Introduction to New Testaments Ethics, New York.

Heil (2007): U. Heil, „Athenagoras“, in: M. Landfester u. B. Egger (Hgg.), Geschichte der antiken Texte. Autoren- und Werklexikon (Der Neue Pauly. Supplemente 2), Stuttgart / Weimar, 85-87.

Heller (2004): B. Heller, Glück. Ein philosophischer Streifzug, Darmstadt.

Hoffmann (1984): P. Hoffmann, „Tradition und Reaktion. Zur, Verbindlichkeit des Gebots der Feindesliebe in der synoptischen Überlieferung und in der gegenwärtigen Friedensdiskussion“, in: K. Kertelge (Hg.), Ethik im Neuen Testament (QD IO2), Freiburg, 50-II8; Nachdruck in: P. Hoffmann, Tradition und Situation. Studien zur Jesusüberlieferung in der Logienquelle und den synoptischen Evangelien (NTA.NF 28), Münster 1995, 3-6I.

Hügli u. Kipfer (1989): A. Hügli u. D. Kipfer, „Philanthropie“, in: Historisches Wörterbuch der Philosophie 7, 543-552.

Kasulke (2005): C. T. Kasulke, Fronto, Marc Aurel und kein Koflikt zwischen Rhetorik und Philosophie im 2. Jahrhundert n. Chr. (Beiträge zur Altertumskunde 2I8), München.

Keresztes (1979): P. Keresztes, „War Marc Aurel ein Christenverfolger?“, in: R. Klein (Hg.), Marc Aurel (WdF 550), Darmstadt, 179-303.

Kinzig (200I): W. Kinzig, „Harnack heute. Neuere Forschungen zu seiner Biographie und dem ,Wesen des Christentums'. Zu Harnacks 150. Geburtstag am 7. Mai 200I", ThLZ I26, 473-500.

Klein (1979): R. Klein (Hg.), Marc Aurel (WdF 550), Darmstadt.

Knopf u.a. (1965): R. Knopf, G. Krüger u. G. Ruhbach (Hgg.), Ausgewählte Märtyrerakten, Tübingen.

Krafft (2002): P. Krafft, „Fronto und Minucius Felix“, in: W. Blümer (Hg.), Alvarium, Festschrift für C. Gnilka (JAC.E 33), Münster, 219-225.

Levieils (2007): X. Levieils, Contra Christianos. La critique sociale et religieuse du christianisme des origins au concile de Nicée (45-325) (BZNW I46), Berlin / New York.

Löhr (2005): W.A. Löhr, „Die Ausbreitung des antiken Christentums als historiographisches Projekt - Vorschläge, Probleme, Perspektiven“, Zeitschrift für Neues Testament 15/8, 22-34.

Lona (2005): H.E. Lona, Die ,wahre Lehre' des Kelsos, übersetzt und erklärt (Kommentar zu frühchristlichen Apologeten. Ergänzungsband I), Freiburg.

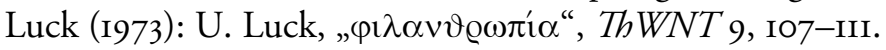

Luz (2002): U. Luz, Das Evangelium nach Matthäus (Mt I-7) (EKK I/I), 5. völlig neu bearbeitete Auflage, Düsseldorf.

Lutz-Bachmann (1992): M. Lutz-Bachmann, „Hellenisierung des Christentums?“, in: C. Colpe, L. Honnefelder u. M. Lutz-Bachmann (Hgg.), Spä- 
tantike und Christentum. Beiträge zur Religions- und Geistesgeschichte der griechisch-römischen Kultur und Zivilisation der Kaiserzeit, Berlin, 77-98.

MacMullen (1984): R. MacMullen, Christianizing the Roman Empire (A.D. I00-400), New Haven / London.

Markschies (2009): C. Markschies, „Hellenisierung des Christentums?‘ - die ersten Konzilien “, in: F. W. Graf u. K. Wiegandt (Hgg.), Die Anfänge des Christentums (Forum für Verantwortung, Fischer Taschenbuch 18277), Frankfurt a. M., 397-436.

Meijering (1985): E. P. Meijering, Die Hellenisierung des Christentums im Urteil Adolf von Harnacks, Amsterdam.

Mühlenberg (2008): E. Mühlenberg, „Bekehrung und Ethik im frühen Christentum", in: E. Mühlenberg, Gott in der Geschichte. Ausgewählte Aufä̈tze zur Kirchengeschichte, hg. v. U. Mennecke u. S. Frost (AKG IIo), Berlin / New York, 294-302.

Musorillo (1972): H. Musorillo (Hg.), The Acts of the Christian Martyrs (OECT), Oxford, ${ }^{2}$ I979.

Nock (1954): A. D. Nock, „Bekehrung“, $R A C$ 2, I05-II8.

Noyen (1979): P. Noyen, „Marc Aurel. Der größte Praktiker der Stoa“, in: R. Klein (Hg.), Marc Aurel (WdF 550), Darmstadt, I05-II8.

Parvis u. Foster (2007): S Parvis u. P. Foster (Hgg.), Justin Martyr and His World, Minneapolis.

Parvis (2008): P. Parvis, „Justin Martyr“, Expository Times I20, 53-6I.

Peglau (1999): M. Peglau, Die ,Presbeia' des Athenagoras im Spannungsfeld zwischen archaia philosophia und kaine didache. Eine Untersuchung zum apologetischen Spektrum im späten zweiten Jahrbundert, Dresden.

Piper (1979): J. Piper, Love Your Enemies. Jesus' love command in the synoptic gospels and in the early Christian paraenesis. A history of the tradition and interpretation of its uses, Cambridge.

Pouderon (1989): B. Pouderon, Athénagore d'Athènes. Philosophe chrétien (Théologie historique 82), Paris.

Pouderon (1997): B. Pouderon, D’Athènes à Alexandrie. Études sur Athénagore et les origines de la philosophie chrétienne (Bibliothèque Copte de Nag Hammadi. Section ,Études' 4), Quebec / Louvain / Paris.

Pouderon (2003): B. Pouderon, „Die Christen und die Antike Kultur“ (dt. Fassung bearb. von M. Durst), in: L. Pietri (Hg.), Die Geschichte des Christentums Band I: Die Zeit des Anfangs (bis 250), Freiburg, 863-942.

Pouderon (2005): B. Pouderon, Les apologistes grecs du II siècle, Paris.

Rankin (2009): D. Rankin, Athenagoras. Philosopher and Theologian, Aldershot.

Reinbold (2000): W. Reinbold, Propaganda und Mission im ältesten Christentum. Eine Untersuchung zu den Modalitäten der Ausbreitung der frühen Kirche (FRLANT I88), Göttingen. 
Reiser (200I): M. Reiser, „Love of Enemies in the Context of Antiquity“, NTS $47,4 \mathrm{II}-427$.

Rieske-Braun (2000): U. Rieske-Braun, „Vom Wesen des Christentums und seiner Geschichte. Eine Erinnerung an Adolf Harnacks Vorlesung

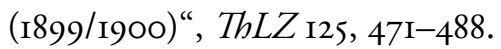

Rosen (1994): K. Rosen, „Marc Aurel und Fronte. Eine Freundschaft zwischen Macht und Kultur“, in: ders. (Hg.), Macht und Kultur im Rom der Kaiserzeit, Bonn, I22-I35.

Schäfke (I979): W. Schäfke, „Frühchristlicher Widerstand“, in: $A N R W$ II 23.I, Berlin / New York, 460-723.

Scheffczyk (1982): Scheffczyk, Tendenzen und Brennpunkte der neueren Problematik um die Hellenisierung des Christentums (SBAW.PH), München.

Schnider (I993): F. Schnider, „Die Behandlung der Feinde im frühen Juden- und Christentum“, in: H. Bürkle (Hg.), Grundwerte menschlichen Verhaltens in den Religionen (Religionswissenschaft 6), Frankfurt a. M., IOI-IIO.

Schrage (I989): W. Schrage, Ethik des Neuen Testaments (Grundrisse zum Neuen Testament 4), 5. erw. Auflage, Göttingen.

Stark (1996): R. Stark, The Rise of Christianity. A Sociologists Reconsiders History, Princeton / New Jersey.

Stoll (1988): B. Stoll, De Virtute in Virtutem. Zur Auslegungs- und Wirkungsgeschichte der Bergpredigt in Kommentaren, Predigten und hagiographischer Literatur von der Merowingerzeit bis um I200 (Beiträge zur Geschichte der biblischen Exegese 30), Tübingen.

Ulrich (2006): J. Ulrich, „Ethik als Auweis christlicher Identität bie Justin Martyr", $Z E E$ I, 2I-28.

Ulrich (2007): J. Ulrich, „Angstmacherei. Beobachtungen zu einem polemischen Einwand gegen das frühe Christentum und zur Auseinandersetzung mit ihm in der apologetischen Literatur“, in: F. R. Prostmeier u.a. (Hgg.), Frühchristentum und Kultur, Freiburg, III-I26.

Unnik (I966): W.C. van Unnik, „Die Motivierung der Feindesliebe in Lukas VI32-35“, Novum Testamentum 8, 284-300.

Walsh u. Gottlieb (I982): J. Walsh u. G. Gottlieb, „Zur Christenfrage im zweiten Jahrhundert“, in: G. Gottlieb u. P. Barceló (Hgg.), Christen und Heiden in Staat und Gesellschaft des zweiten Jahrhunderts. Gedanken und Thesen zu einem schwierigen Verhältnis (Schriften der Philosophischen Fakultäten der Universität Augsburg. Historisch-sozialwissenschaftliche Reihe 44), München, 3-86.

Walzer (1949): R. Walzer, Galen on Jews and Christians, Oxford.

Whittaker (1979): J. Whittaker, „Christianity and Morality in the Roman Empire", VigChr 33, 209-205. 
Willert (2006): N. Willert, „Reception of Biblical and Greco-Roman Ethics in the Apologetics of the Early Church“, in: D. Brakke, A.-C. Jcobsen u. J. Ulrich (Hgg.), Beyond Reception, Mutual Influences between Antique Religion, Judaism, and Early Christianity (ECCA I), Frankfurt, 89-II6.

Wyrwa (199I): D. Wyrwa, „Über die Begegnung des biblischen Glaubens mit dem griechischen Geist", $Z$ ThK 88, 29-67.

Wyrwa (2000): D. Wyrwa, „Hellenisierung des Christentums“, ${ }^{4} R G G$ 3, I608f. 


\title{
Ein stummer Gott?
}

\author{
Beobachtungen zur Verteilung von Reden und Schweigen \\ im Octavius des Minucius Felix
}

\author{
CHRISTOPH SCHUbERT
}

I.

Das Christentum ist von allem Anfang an eine Religion des Wortes. Gott spricht zur Erschaffung der Welt und des Menschen, er spricht zu Abraham, Mose und den Propheten und er spricht vor allem in seinem Sohn Jesus Christus. Entsprechend besitzt die Bibel, gleich ob sie selbst als Wort Gottes oder als Aufbewahrungsort der Worte Gottes angesehen wird, für die Christen höchste Bedeutung. Wer von seinem Christentum erzählen, dafür werben, es verteidigen möchte, wird ganz selbstverständlich von Gottes Worten, seinen Verheißungen und vor allem von dem lebendig gewordenen Wort reden.

Minucius Felix, der mit dem Octavius sein Christentum verteidigen und dafür werben will, tut das nicht. In seiner Apologie wird weder der Name Jesu Christi genannt, noch ein einziges Mal das Alte oder Neue Testament wörtlich zitiert. Eine Fülle verschiedener Vorschläge, dieses Phänomen zu erklären, wurden im Verlauf der Forschungsgeschichte gemacht. Ihre Spannweite reicht von der Annahme, der Verfasser des Octavius habe eine unzureichende und unzutreffende Vorstellung vom Christentum besessen oder er habe eine oberflächliche und laue Form des Glaubens gepflegt, über die Vermutung, häretische Überzeugungen gnostischer Art seien ursächlich, bis hin zu der These, die Scheu, Gegenstände der Arkandisziplin vor unberufenen Ohren auszubreiten, habe Minucius davon abgehalten, sich deutlicher zu äußern. Der größten Zustimmung dürfte sich derzeit eine gewissermaßen funktionale Deutung erfreuen, wonach die Rücksicht auf das heidnische Publikum und die Konzentration auf das Argumentationsziel, das Christentum als monotheistische Religion vor philosophisch gebildeten Hörern zu verteidigen, dazu führten, alle klareren Bezüge auf die Schrift und die Christologie beiseite zu lassen, ohne daß daraus irgendwelche Rückschlüsse auf das Christentum des Minucius möglich wären. ${ }^{1}$

I Zu den älteren Erklärungsansätzen vgl. Mühl (1968), 69-7I, der selbst die Arkandisziplin, den 
Die folgenden Betrachtungen versuchen, sich dem Phänomen und seiner Erklärung von einer anderen Seite aus zu nähern. Sie gehen von der Frage aus wenn schon das Wort Gottes im Octavius nicht präsent zu sein scheint -, wer dann redet, wer schweigt, wie Reden und Schweigen bewertet werden und ob sich nicht von da aus ein neuer Zugang zu dem, was Minucius wollte, finden läßt.

\section{II.}

Schon die Statistik verrät, daß sich Minucius der Bedeutung von Wort und Rede sehr wohl bewußt war. Das üblichste lateinische Wort für 'sagen, sprechen', dicere, kommt in den rahmenden Abschnitten (cap. I-4; I4-I5; 39-40) genau 2 mal vor, ebenfalls 2 mal verwendet es der Heide Caecilius in seiner Rede (cap. 5-13), der Christ Octavius in seiner Antwort (cap. 16-38) hingegen $25 \mathrm{mal}^{2}$

Ein anders geartetes Indiz für die Bewußtheit, mit der das Thema Wort und Rede im Dialog behandelt wird, findet sich in einer Leerstelle innerhalb der Schilderung der guten Schöpfung Gottes, im Zuge derer Octavius nach unbelebter und belebter Natur den Menschen selbst als lebenden Hinweis auf das Wirken eines Schöpfers vorstellt:

„Besonders aber bekennt doch die Schönheit unserer eigenen Gestalt Gott als ihren Bildner: die aufrechte Haltung, das erhobene Antlitz, die Augen, ganz oben wie in einer Warte eingesetzt und alle übrigen Sinne wie in einer Feste aufgestellt. Es würde zu weit führen, alles im einzelnen durchzugehen: keinen Teil des menschlichen Körpers gibt es ja, der nicht deswegen vorhanden wäre, weil er nötig und zugleich schön ist. Und, was noch wunderbarer ist: alle haben die gleiche Gestalt, aber jeder für sich bestimmte abweichende Züge; so kommt es, daß wir uns alle insgesamt ähnlich sehen und zugleich doch untereinander individuell verschieden erscheinen. Wie? Ist nicht die Art und Weise, wie menschliches Leben entsteht, ist nicht der Drang zur Fortpflanzung von Gott gegeben, und daß sich die Brüste mit Milch füllen, wenn die Frucht des Leibes zur Geburt reif ist, und daß das zarte Kleine durch den Reichtum der flüssigen Milch erstarkt? ${ }^{\text {“3 }}$

zeitgenössischen Stand der christologischen Diskussion und das Argumentationsziel des Octavius in Anschlag bringt. Neuere Stimmen bei Heck (1997), 517f. In die Nähe der Gnosis rückt Minucius in Erneuerung der These von Kühn (1872) neuerdings wieder Stölting (2006). Ob und inwieweit Minucius über die vorgeschlagenen Erklärungsmodelle hinaus vielleicht auch innerchristlichem Streit aus dem Weg gehen wollte, wird kaum zu klären sein. Einen Überblick über die neuere Minucius-Forschung geben Ferrarino (1986), Heck (1997) und Chapot (1998).

2 Diese und die folgenden Angaben zur Statistik nach der Konkordanz von Kytzler / Najock (I99I).

3 Oct. I7,II-I8,2: Ipsa praecipue formae nostrae pulchritudo deum fatetur artificem: status rigidus, vultus erectus, oculi in summo velut in specula constituti et omnes ceteri sensus velut in arce composi- 
Das Argument hat eine lange Tradition in der Philosophie und Theologie vor und nach Minucius. ${ }^{4}$ Üblicherweise und oft an prominenter Stelle wird zu den besonderen Gaben, die den Menschen auszeichnen und deren sinnreiche Einrichtung für eine providenzielle Macht sprechen, die menschliche Stimme und Sprache gezählt. So hebt schon Xenophon nach der Erwähnung von aufrechter Stellung und der besonderen Qualität einzelner Körperteile wie der menschlichen Hand die Sprachfähigkeit hervor, bevor er auf die Fortpflanzung zu sprechen kommt: „Und während alle Tiere wohl eine Zunge haben, schufen sie (scil. die Götter) allein die des Menschen derart, daß sie mal da, mal dort den Mund anschlagend die Stimme gliedert und wir einander alles mitteilen können, was wir wollen." Auch Minucius' wichtigste Quelle und Vorbild, Ciceros Schrift De natura deorum, die hier sogar anzitiert wird, ${ }^{6}$ wendet sich, nachdem sie ausführlich die sinnreiche Anlage der Sinnesorgane (nat. deor. II 56,I40-58,I46) entwickelt hat und bevor sie dies für die Hand tut (nat. deor. II 60,I50), der Sprache zu (nat. deor. II 59,I47-I49): „Indes die Herrin aller Dinge, wie ihr zu sagen pflegt, die Macht der Rede, wie herrlich ist sie und wie göttlich. "7 Ganz selbstverständlich verwendet auch Lactanz in De opificio Dei einen großen Abschnitt (cap. I5) auf die menschliche Stimme, nachdem er aufrechten Gang, Körperbau, Sinne, Fortpflanzung und einiges mehr erörtert hat. Wie fest die Sprachfähigkeit zum Topos gehört, läßt sich daran ablesen, daß sie sogar bei der allegorischen Deutung des Baus der Arche auf den menschlichen Körper, die Ambrosius am Ausgang des 4. Jahrhunderts n. Chr. in De Noe vornimmt, nicht fehlen darf. Nach Augen, Ohren und Nase heißt es dort über den Mund: „Eine vierte, vergleichsweise größte Höhlung ist die Öffnung des Mundes; in ihr wird der Geschmack, bis er herangereift ist, genährt, aus ihr fliegt die Stimme hervor, in ihr verbirgt

ti. longum est ire per singula. nihil in homine membrorum est, quod non et necessitatis causa sit et decoris, et, quod magis mirum est, eadem figura omnibus, sed quaedam unicuique lineamenta deflexa; sic et similes universi videmur et inter se singuli dissimiles invenimur. quid? nascendi ratio, quid? cupido generandi nonne a deo data est, et ut ubera partu maturescente lactescant et ut tener fetus ubertate lactei roris adolescat? Dieses und die folgenden Zitate aus dem Octavius nach der Ausgabe von Kytzler (1992).

4 Literatur und weitere Belegstellen zu diesem Topos verzeichnen Beaujeu (1974), I03 f. und Pellegrino (2000), 298-308, besonders $300 f$.

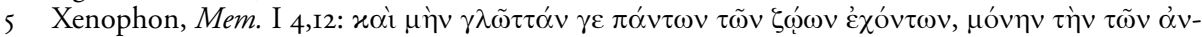

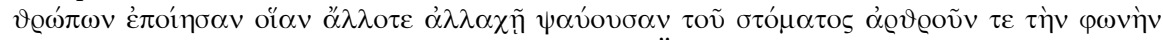

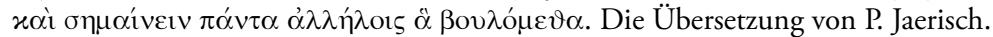

6 Vgl. Cicero, nat. deor. II 56,I40: Ad hanc providentiam naturae tam diligenter tamque sollertem adiungi multa possunt, e quibus intellegatur quantae res hominibus a dis quamque eximiae tributae sint. Qui primum eos humo excitatos celsos et erectos constituit ... Sensus autem interpretes ac nuntii rerum in capite tamquam in arce mirifice ad usus necessarios et facti et conlocati sunt. nam oculi tamquam speculatores altissimum locum optinent ... Vgl. auch nat. deor. I 18,47 zur Schönheit der menschlichen Gestalt.

7 Cicero, nat. deor. II 59, I48: Iam vero domina rerum, ut vos soletis dicere, eloquendi vis quam est praeclara quamque divina. 
sich die Zunge, die wie ein Instrument der Stimme deren Laute kunstvoll und lieblich moduliert und, mag sie auch selbst unverständig sein, die verständige Stimme erzeugt. ${ }^{\text {"8 }}$ Obwohl es der Topos nahelegen mußte, vermeidet es Minucius also offensichtlich ganz bewußt, die menschliche Sprache zu erwähnen. Freilich fällt zu Beginn des Passus ein Wort für reden, fateri, doch meint es gerade keine menschliche Lautäußerung, sondern ein metaphorisches Sprechen: der Mensch bezeugt und bekennt durch sein bloßes Dasein, durch eine Art stummen Lobpreis die Existenz des Schöpfers.?

Auffälligkeiten wie diese berechtigen dazu, hinter der Verteilung von Rede und Schweigen im Octavius tiefere Gründe zu vermuten. Im Folgenden soll dies zunächst für die rahmenden Partien untersucht werden, sodann für die beiden Vorträge des Heiden und Christen, wobei das Wort- und Themenfeld nach den verschiedenen Kategorien von Sprechern bzw. Schweigern, die genannt werden, aufgeschlüsselt wird.

\section{III.}

Proömium und Dialogszenerie, in die das Proömium hinübergleitet, warten zunächst mit lauter positiven, wenn auch ganz unterschiedlichen Beispielen für menschliche Rede auf.

Im Verweis auf den Vortrag, mit dem Octavius den Heiden Caecilius bekehrt, sermone ... quo Caecilium ... disputatione gravissima ad veram religionem reformavit $(\mathrm{I}, 5)$, erscheint sie als wirkungsvolles und sachgemäßes (disputatione gravissima) Instrument, dessen sich ein Christ mit guter Absicht und Erfolg bedienen kann. Dazu paßt es, daß gerade eine Wortäußerung, die Kritik an der Verehrungsgeste des Caecilius vor dem Bildnis des Serapis (3,I), zugleich die erste wörtliche Rede des ganzen Dialogs, das Geschehen überhaupt erst in Gang setzt, das am Ende zur Bekehrung führen wird. Auf den Verbalcharakter der Kritik macht Minucius nicht nur einleitend aufmerksam (tunc Octavius ait), sondern greift ihn nach dem Referat nochmals explizit auf (cum hoc sermone).

8 Ambrosius, Noe 6,I4: quartus maior ceteris hiatus oris, in quo nutritur, donec adolescat, sapor et unde vox evolat, in quo latet lingua, quae velut organum vocis sonos eius artifici suavitate modulatur et, cum sit ipsa inrationabilis, rationabilem vocem exprimit. Vgl. auch Noe I2,40, wo zwischen den fünf Sinnen und dem Fortpflanzungstrieb die menschliche Stimme eingereiht ist: de moralibus autem ut dicamus, non est dubium, quod inrationabile animae nostrae in quinque sensus dividatur et vocem et generatorium, quae natura videntur esse feminea, quia sensus nostri in materialia et saecularia cito repunt, unde claret eos mollioris naturae habere substantiam.

9 Vergleichbarer übertragener Gebrauch begegnet im Octavius an einigen weiteren Stellen, an denen eine Sache für sich spricht, so 17,7 auctorem suum parentemque testatur ver ... cum suis floribus; 22,5 formae ipsae et habitus nonne arguunt ludibria et dedecora deorum vestrorum?; 23,13 adhuc antrum Iovis visitur et sepulcrum eius ostenditur, et ipsis sacris suis humanitatis arguitur. 
Menschliche Rede dient aber nicht nur der Belehrung und Bekehrung, sie sorgt auch für Kurzweil, so wenn Octavius den langen Spaziergang am Meeresufer mit der anmutigen Erzählung über seine Reiseerlebnisse, mit fabulae, narratio, sermo verkürzt. ${ }^{\text {Io }}$ Und sie ist unverzichtbares Mittel zwischenmenschlichen Austauschs, wenn sich Minucius und Octavius nach langer Zeit wiedersehen und über ihr Ergehen seit dem letzten Treffen in wechselseitigem Bericht (relatione alterna) informieren. ${ }^{\text {II }}$

Der positive Aspekt und zugleich das zutiefst Menschliche der Sprache tritt aber vielleicht am deutlichsten in der liebevollen Beobachtung zutage, die Minucius der kindlichen Sprechweise widmet. Denn das Opfer des Octavius, der Frau und Kinder verläßt, um den Freund zu besuchen, wiegt umso schwerer, als seine Kinder noch klein und süß sind. Eben das wird aber nicht etwa am Aussehen oder an der drolligen Gestik, sondern an der Sprache festgemacht: „... er hatte Haus, Gattin, Kinder verlassen und, was bei Kindern besonders reizend ist, die noch jung und unschuldig waren und sich noch an halben Worten versuchten, eine Redeweise, die eben durch das Bruchstückhafte der stockenden Zunge besonders süß ist. “" Indem die Unschuld der Kleinen und ihre noch suchende, unfertige, ganz natürliche Redeweise - zärtlich steht dafür der Deminutiv loquella nebeneinander gestellt werden, wird der Eindruck zumindest nicht vermieden, daß das Sprachvermögen ursprünglich eine gute und an sich unschuldige Gabe des Menschen ist.

Freilich ist ihre Leistungsfähigkeit begrenzt. Darauf macht en passant der unmittelbar folgende Satz aufmerksam. Denn Minucius kann seine Freude über den Besuch mit Worten nicht angemessen ausdrücken: non possum exprimere sermonibus, quanto ... gaudio exultaverim $(2,2)$, gewiß eine Redesart, ${ }^{13}$ aber doch mit Bedacht um das Leitwort sermo erweitert, das im Laufe des Dialogs - nicht aber innerhalb der Rede des Caecilius - noch weitere I2 mal vorkommen wird.

Den versammelten positiven Aspekten der Rede steht das verdrossene Schweigen des Caecilius gegenüber, den die Kritik des Octavius hatte verstummen lassen. Sein Ärger isoliert ihn, am Spiel der Kinder, die Steine über die Wasseroberfläche schlittern lassen, kann er sich nicht mit den anderen freuen: „Caecilius

IO 3,4 sensim itaque tranquilleque progressi oram curvi molliter litoris iter fabulis fallentibus legebamus. haec fabulae erant Octavi disserentis de navigatione narratio. sed ubi eundi spatium satis iustum cum sermone consumpsimus ...

II 2,3 Igitur post unum et alterum diem, cum iam ..., quae per absentiam mutuam de nobis nesciebamus, relatione alterna comperissemus...

I2 2,If. relicta domo coniuge liberis et - quod est in liberis amabilius - adhuc annis innocentibus et adhuc dimidiata verba temptantibus, loquellam ipso offensantis linguae fragmine dulciorem. Zur Herkunft und Rezeption des Motivs und zur Bedeutung der innocentia vgl. Fausch (1966), 33-35 zur Stelle.

I3 Fausch (1966), 35f. weist auf die juristische Differenzierung von verbum 'Einzelwort' und sermo 'mehrere Worte umfassender Ausdruck' hin, die Minucius hier und sonst beachte. 
verriet mit seiner Miene, daß er nicht bei der Sache war und nicht über den Wettstreit lachen konnte, sondern daß ihn, der schweigend, beklommen und verloren dastand, irgendetwas schmerzte. ${ }^{\text {"It }}$ Drei Worte, tacens anxius segregatus, umschreiben seine Einsamkeit mit ihrer physischen (segregatus), psychischen (anxius) und sozialen (tacens) Komponente. Durch sein Schweigen nimmt Caecilius nicht an der fröhlichen Gemeinschaft der anderen teil.

Scheinen die positiven und negativen Aspekte so zunächst klar verteilt, zeigt die Schlußszene, daß auch andere, positive Formen des Schweigens möglich sind. Nach der Gegenrede des Octavius bringen Caecilius und Minucius zunächst kein Wort heraus: „Wir waren so starr vor Staunen, daß wir kein Wort sagen konnten und unsere Gesichter noch eine ganze Weile den Ausdruck gespannter Aufmerksamkeit behielten. Und was mich betrifft, so verging ich vor lauter Bewunderung, weil er das, was leichter zu empfinden als zu sagen ist, mit Beweisgängen, Beispielen und eindrucksvollen Belegen aus der Literatur ausgestaltet hatte. " ${ }^{\text {"Is }} \mathrm{Im}$ Gegensatz zum einsamen Schweigen des Caecilius zu Beginn wirkt das gemeinsame Schweigen nun, wie die Pluralformen zeigen, verbindend. ${ }^{16}$ Auslöser der Bewunderung, die zur Sprachlosigkeit führt, ist dabei gerade die Tatsache, daß es Octavius gelungen ist, eine inhärente Beschränkung der menschlichen Sprache, nämlich Gedanken adäquat und das heißt, intersubjektiv verständlich zu verbalisieren (ea quae facilius est sentire quam dicere), zu überwinden.

Caecilius bricht dann das Schweigen (erupit), will den Spruch des Schiedsrichters (sententia) nicht abwarten und stimmt, frisch bekehrt, Octavius vollumfänglich zu, wobei er sich des technischen Vokabulars wissenschaftlicher Diskussion (fateor, cedo, consentio, requiro 40,2) bedient. Die Wortwahl zeigt an, daß er die Rede des Christen als vollwertigen Beitrag zum philosophischen Diskurs wahrgenommen hat. Diese Einschätzung ist in den Augen des Autors zutreffend, denn auch er verwendet mit perorare $(39, \mathrm{I})$ und orare $(40,3)$ technische Begriffe, die die Ausführungen des Octavius als förmliche, regelgerechte Rede charakterisieren.

Es ist bemerkenswert, daß Minucius, obwohl die Kommunikation mit Gottes Hilfe $^{17}$ geglückt ist, noch einmal leise auf die Grenzen menschlicher Sprache hin-

I4 4,I Caecilius nibil intendere neque de contentione ridere, sed tacens anxius segregatus dolere nescio quid vultu fatebatur.

I5 39, I aliquamdiu nos ad silentium stupefacti intentos vultus tenebamus, et quod ad me est, magnitudine admirationis evanui, quod ea quae facilius est sentire quam dicere, et argumentis et exemplis et lectionum auctoritatibus adornasset.

I6 Eine Zwischenstufe zwischen dem negativen Schweigen des Anfangs und dem positiven am Ende stellt das neutrale aufmerksame Schweigen dar, zu dem Minucius vor der Rede des Octavius im Zwischengespräch auffordert: ... toto silentio liceat responsionem Ianuari nostri iam gestientis audire $(15,2)$.

I7 40,3 ... dei munus eximium a quo ... inspiratus oravit ... 
weist. Er könne Octavius für seine Rede nicht angemessen loben: nec tamen possum meritum eius verborum laudibus repensare $(40,3)$. Der scheinbar überflüssige Zusatz von verborum zu laudibus - Lob wird üblicherweise verbal ausgedrückt bezeichnet gerade den springenden Punkt: die sprachlichen Ausdrucksmöglichkeiten des Menschen sind grundsätzlich beschränkt.

Das bis hier skizzierte, insgesamt helle Bild wird im Anfangsteil mit dem ersten Ausbruch des Caecilius (4,3-5), der seinem aufgestauten Ärger Luft macht, um eine dunkle Seite ergänzt: „die ganze Zeit schnürt mir diese Rede unseres Octavius die Luft ab und wurmt mich sehr, als er dich anfuhr und deine Nachlässigkeit rügte, nur um unter der Hand um so härter meine Unwissenheit anzuprangern. ${ }^{(18}$ Menschliche Rede kann als persönlicher Angriff und als Kränkung empfunden werden (angit et remordet), als heimtückisch (dissimulanter) und ungerecht. Welchen Grad an Aggressivität, Unwahrheit und Ungerechtigkeit sie tatsächlich erreichen kann, demonstriert Minucius geradezu mit der folgenden langen Rede des Caecilius gegen das Christentum, der alle Register der Rhetorik zieht, um zu kränken, zu verunglimpfen und zu verzerren. Das Instrument Sprache läßt sich auch verkehrt und böse benutzen.

Am ersten kurzen Ausbruch des Heiden läßt sich indes noch ein anderer Aspekt menschlichen Redens beobachten: es ist mißverständlich. Caecilius faßt die Worte des Octavius anläßlich seiner Serapis-Verehrung zu Unrecht als persönliche Kränkung auf, als die sie gar nicht gemeint war. Nichts zeigt sein Mißverständnis deutlicher, als daß er die kurze Bemerkung des Octavius in 3,I hier als oratio bezeichnet, als förmliche Rede und damit förmlichen Angriff gegen sich (in te invectus obiurgavit). Dabei hatte es sich eigentlich, wie auktorial festgestellt worden war, um einen sermo $(3,2)$, einen freundlichen Gesprächsbeitrag, gehandelt. $^{19}$ Ein folgenreiches Mißverständnis, denn Caecilius beharrt nun auf einer förmlichen Auseinandersetzung, einer disputatio, worauf ein kurz hintereinander doppelt gesetztes disputare (3,4 f.; aufgegriffen zu Beginn seiner Rede in disputationibus 5,I) deutlich hinweist.

IV.

Die klare begriffliche Unterscheidung von sermo und oratio hat Minucius im ganzen Dialog durchgehalten. Das Wort oratio, das insgesamt 9 mal gebraucht ist, begegnet überwiegend in technischer Verwendung als wohlgesetzte und wohl-

I8 4,3 Iam dudum me Octavi nostri acriter angit et remordet oratio, qua in te invectus obiurgavit neglegentiae, ut me dissimulanter gravius argueret inscientiae.

I9 Fausch (1966), 67 konstatiert zumindest den seltenen Gebrauch von oratio für die kurze Äußerung des Octavius, die übrigen Kommentare gehen darüber hinweg. 
überlegte, mit den Mitteln der Rhetorik gestaltete und auf Überwindung des Gegenübers, nicht auf Dialog oder Wahrheitsfindung hin angelegte Rede, der oft etwas Aggressives anhaftet. Als eine solche Rede hatte Caecilius die Einlassung des Octavius verstanden und eine solche oratio hält er nun selbst, wie Minucius einleitend durch die Wahl des technischen Begriffs für das exordium (tum sic Caecilius exorsus est 5,I) anzeigt und abschließend nochmals ausdrücklich auktorial festhält. ${ }^{20}$ Aber auch Caecilius selbst sieht in seinem Generalangriff gegen das Christentum explizit eine oratio. ${ }^{21}$ Als oratio bezeichnet wird die Rede Frontos gegen die Christen (Cirtensis nostri ... oratio 9,6), der aus der Sicht des Octavius als typischer Vertreter aggressiver Rhetorik erscheint: „In dieser Weise hat auch dein Fronto dazu nicht wie ein Belastungszeuge ausgesagt, sondern wie ein Redner sein Gift verspritzt. ${ }^{122}$ Schließlich wird auch der Lehrvortrag der Astrologen ${ }^{23}$ und der philosophisch-dogmatische Vortrag Platons oratio genannt: „Noch klarer ist die Rede (oratio) Platons von Gott sowohl der Sache selbst als auch der Terminologie nach, und sie wäre ganz himmlisch, wenn sie nicht gelegentlich durch die Beimischung politischer Überzeugungen (persuasionis civilis admixtione) getrübt würde. ${ }^{\text {"24 }}$ Es ist bezeichnend, daß gerade die Grundfunktion der Rhetorik, der

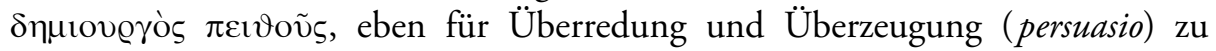
sorgen, an Platon kritisiert wird.

Getrennt von dieser technischen Bedeutung des Begriffs setzt Minucius oratio einige Male auch für das christliche Gebet. Die semantische Schnittmenge beider Verwendungsweisen dürfte wohl darin liegen, daß stets ein förmliches Sprechen gemeint ist, im Falle des Gebets durchaus ein formelhaftes, wie es beim Exorzismus angewandt wird - „das bekennen ... die Dämonen von sich selbst, sooft sie von uns mit dem Marterwerkzeug des Wortes und den Brandfackeln des Gebets (oratio) aus den Körpern ausgetrieben werden ${ }^{\text {“25 }}$ - oder beim bekenntnishaften

20 I4,I nam indignationis eius tumorem effusae orationis impetus relaxaverat. Zum technischen Vokabular der Rhetorik gehört der impetus der Rede, die indignatio als Spielart des Ethos, der tumor als Ausdruck hohen Pathos. Auch I4,3 - et quamquam magnum in modum me subtili varietate tua delectarit oratio - wird oratio von redetheoretischen Termini flankiert: subtilitas und varietas sind Stilqualitäten, das delectare eine der Funktionen der Rede.

2 I II, 5 multa ad haec subpetunt, ni festinet oratio.

22 3I,2 sic de isto et tuus Fronto non ut adfirmator testimonium fecit, sed convivium ut orator adspersit. Zur umstrittenen Frage, in welchem Umfang die antichristliche Argumentation des Caecilius auf Fronto zurückzuführen ist, vgl. Hasenhütl (2008), 74-83. Die Annahme umfänglicher Benützung hatte zuletzt Bammel (1993) zu stützen versucht, dagegen mit guten Gründen Krafft (2002).

23 17,6 relinquenda vero astrologis prolixior de sideribus oratio.

24 I9,I4 Platoni apertior de deo et rebus ipsis et nominibus oratio est et quae tota esset caelestis, nisi persuasionis civilis nonnumquam admixtione sordesceret.

2527,5 haec omnia ... ipsos daemonas de semet ipsis confiteri, quotiens a nobis tormentis verborum et orationis incendiis de corporibus exiguntur. 
Sprechen: „Ist das die natürliche Ausdrucksweise (sermo) der Leute oder die Rede (oratio) eines bekennenden Christen? “26

An der letzten Stelle lassen sich in nuce die drei wichtigsten Konstituenten des Begriffs sermo, wie Minucius ihn gebraucht, beobachten: Er meint ein nichtförmliches, ungeschütztes und unverstelltes Reden „wie einem der Schnabel gewachsen ist" (naturalis); er bezieht sich in der Regel auf Situationen alltäglicher (vulgi) und insbesondere dialogischer Kommunikation; er zielt, redetechnisch gebraucht, auf den Aspekt der Ausdrucksweise und Formulierung.

Der zweite Aspekt der Dialogizität herrscht bei der Bezeichnung von Platons Politeia als sermo, als Dialog, vor $(23,2)$; daß sich auch die Plaudereien während des Spaziergangs am Strand von Ostia $(3,5)$ und die kritische Bemerkung des Octavius gegenüber Minucius $(3,2)$ als auf Dialog angelegte Gesprächsbeiträge verstehen lassen, wurde bereits erwähnt.

Der dritte Aspekt tritt neben der schon zitierten Stelle 2,2, als Minucius zum Ausdruck seiner Freude nicht die rechten Worte findet, auch 19,3 deutlich hervor, wenn es heißt: „Gehen wir, wenn's genehm ist, die Lehre der Philosophen durch: du wirst sie dabei überraschen, wie sie sich, wenn auch in bunt schillernder Ausdrucksweise (sermones varii), der Sache selbst nach in dieser einen Ansicht treffen

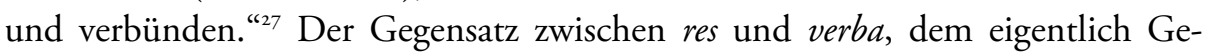
meinten und seiner sprachlichen Formulierung, ist klar benannt. Auf die Ausdrucksseite zielt sermo auch 21,2, wo ein Terenz-Zitat mit den Worten ut comicus sermo est, „wie es die Komödie formuliert", eingeleitet wird; dasselbe gilt für das Vorkommen des Worts 31,5, wo die geselligen Runden der Christen casto sermone, corpore castiore ausgezeichnet sind. Erneut stehen einander res, hier als Taten bzw. die Vermeidung von Untaten, und verba, die Art der Christen, sich auszudrücken, gegenüber. Festzuhalten ist freilich, daß mit der Gegenüberstellung keine grundsätzliche Abwertung des sermo einhergeht, der positiv (castus) qualifiziert werden kann.

26 I8,II vulgi iste naturalis sermo est an Christiani confitentis oratio? Deutlich weniger profiliert als oratio wird das zugehörige Verb orare (drei Belege) verwendet. Für heidnisches Gebet erscheint es wertneutral 24,5 und 24,8, für die Rede des Octavius 40,3. Es ist bemerkenswert, daß Minucius das Wort adorare (acht Belege) ausschließlich in paganen Kontexten, nie aber für echte christliche Anbetung verwendet. Die Junkturen zeigen, daß dabei eine mit Gebeten einhergehende Verehrung gemeint sein kann, aber auch andere Formen kultischer Verehrung eingeschlossen sind. Angebliche christliche Verehrung als Vorwurf der Heiden findet sich an zwei Stellen: 9,4 sacerdotis colere genitalia et quasi parentis sui adorare naturam (aufgenommen in der Replik 29,IO adoratis sacerdotis virilibus) und I2,4 iam non adorandae sed subeundae cruces (aufgenommen 29,6 in retorsio: vos ... cruces ligneas ... adoratis). Für heidnische Verehrung begegnet das Wort 6,I deos ... adorare; 25,6 captivas (scil. religiones) ... adorare; 25,6 adorare, quae (scil. numina) manu ceperis; 28,8 Apim bovem ... adoratis.

27 Recenseamus, si placet, disciplinam philosophorum: deprehendes eos, etsi sermonibus variis, ipsis tamen rebus in hanc unam coire et conspirare sententiam. 
Eine noch präzisere Bestimmung erlaubt die Verwendung des Begriffs innerhalb der theoretischen Diskussion über die Rhetorik im Zwischengespräch. Minucius billigt der Rede des Heiden concinnitas sermonis (I4,2) zu. Damit ist sicherlich primär die Formulierungskunst des Caecilius gemeint, gehört concinnitas doch zu den Qualitäten guten Stils. Doch deutet die ungewöhnliche Relevanz, die der concinnitas zugewiesen wird - Caecilius solle sich über sie nicht zu früh freuen und warten, bis auch der Gegner gesprochen habe -, darauf hin, daß eine inhaltliche Komponente hinzutritt: Glatt und gelungen war die Rede des Heiden auch von der Präsentation der Argumente, ihrer harmonischen Abfolge her, allerdings nur auf der Ebene der sprachlichen Oberfläche, nicht auf der tieferen Ebene echter Logik. ${ }^{28}$ In diesem Sinne greift der Christ Octavius zu Beginn seiner Rede die Kritik des Zwischengesprächs an der Rhetorik verschärfend auf: „Und daher leuchtet die Argumentation (ratio) sogar um so heller, je unbeholfener die Redeweise (sermo) ist, weil sie nicht durch den Prunk anmutiger Eloquenz geschminkt wird, sondern so, wie sie ist, ihre Kraft aus der Ausrichtung am Richtigen erhält. " ${ }^{\text {"29 }}$ Wie zuvor bezeichnet sermo die Ebene der sprachlichen Oberfläche, die der tieferen Ebene der inhaltlichen Logik (ratio) gegenübersteht. An allen genannten Stellen erscheint sermo dabei als eine zunächst neutrale Größe, die positiv oder negativ qualifiziert werden kann. Daß sermones schlecht, aber auch gut sein können, sagt Minucius selbst, als er im Zwischengespräch davor warnt, daß die wiederholte Irreführung durch die Rhetorik in religiösen und philosophischen Fragen zum Agnostizismus und in der Folge zum Mißtrauen gegenüber allen Menschen führen kann. „Also müssen wir uns vorsehen, daß wir es nicht durch die unterschiedslose Ablehnung aller Aussagen (odio identidem sermonum omnium) “ - also der richtigen ebenso wie der falschen sermones - „mit unserer Arbeit dahin bringen, daß sich viele schlichtere Gemüter auch zur Ablehnung und Verabscheuung der Menschen veranlaßt fühlen. " ${ }^{30}$

$\mathrm{Da}$ sermo und ratio indes keinen Gegensatz bilden müssen, sondern an sich beides als gute Gabe Gottes eine Einheit darstellt, sagt Octavius kurz danach: „Wir unterscheiden uns ja von den wilden Tieren darin, daß sie, gebeugt und der Erde zugewandt, dazu geboren sind, nach nichts als nach Futter Ausschau zu halten, wir hingegen, denen ein aufrechtes Antlitz, denen der Blick hinauf zum Himmel, denen Sprache (sermo) und Vernunft (ratio) gegeben sind, mit denen wir Gott erkennen, ihn wahrnehmen und nachahmen können, wir haben nicht

28 Vielleicht soll in der überraschenden Junktur concinnitas sermonis statt des zu erwartenden concinnitas orationis auch leise Ironie gehört werden, wird doch die fulminante Rede des Caecilius so bloß als ein Gesprächsbeitrag, der ergänzt und berichtigt werden kann, klassifiziert.

29 I6,6 atque etiam, quo inperitior sermo, hoc inlustrior ratio est, quoniam non fucatur pompa facundiae et gratiae, sed, ut est, recti regula sustinetur.

30 I4,6 Igitur nobis providendum est, ne odio identidem sermonum omnium laboremus ita, ut in exsecrationem et odium hominum plerique simpliciores efferantur. 
das Recht dazu und es steht uns nicht frei, von der himmlischen Herrlichkeit, die auf unsere Augen und Sinne eindringt, keine Notiz zu nehmen. ${ }^{\text {" }}{ }^{11}$ Das Hendiadyoin sermo et ratio, mit dem Minucius hier die zwei Seiten des griechischen Logos wiedergibt, steht für die ursprüngliche Einheit von Reden und Denken, von Sprachvermögen und intellektuellem Vermögen, deren Zusammenspiel (per quae, nicht per quam!) Erkenntnis und Nachahmung Gottes ermöglichen. So konvergiert die Betrachtung des Gebrauchs von sermo mit den bisherigen Beobachtungen zur Behandlung von Reden und Schweigen in der Dialoghandlung: Grundsätzlich ist das Sprachvermögen (sermo) eine gute Gabe Gottes, die der Mensch gut und richtig, aber auch falsch und schlecht verwenden kann. Hauptkennzeichen des Sprachvermögens ist es, Sachverhalten verschiedenen Ausdruck $($ sermo) geben zu können, adäquaten wie inadäquaten; angelegt ist das Sprachvermögen auf zwischenmenschlichen Austausch jeglicher Art durch das Gespräch (sermo); im Gegensatz zur förmlichen Rede (oratio) bewahrt das Gespräch als natürliche Form der Kommunikation die ursprüngliche Offenheit und Aufrichtigkeit des sermo und ist daher die den Christen angemessene Form. Nichts zeigt dies deutlicher, als daß die wohlgesetzte Rede, mit der Octavius den Caecilius bekehrte, von Minucius selbst gleich zu Beginn sermo $(\mathrm{I}, 5)$ genannt wird.

\section{V.}

Der Seite der oratio und damit der Problematik förmlichen rhetorischen Sprechens wendet sich im Detail der Gesprächsbeitrag des Schiedsrichters Minucius zu, der zwischen die großen Reden des Heiden und Christen eingefügt ist (cap. I4). In der Forschung hat das Kapitel mit seiner theoretischen Diskussion der Probleme und der Gefährlichkeit der Rhetorik die gebührende Beachtung gefunden und konnte in die Tradition christlicher Kritik an der Rhetorik eingeordnet werden. ${ }^{32}$ Verhandelt wird darin - primär bezogen auf Caecilius - ein Problem, das nicht nur die Rede des Heiden innerhalb des Dialogs, sondern den Octavius im ganzen und damit die Tätigkeit des Minucius als Autor betrifft: Ist die Anwendung rhetorischer Mittel mit der Suche oder Darlegung ungeschminkter Wahrheit kompatibel? Der literarische Kunstgriff des Octavius dabei ist, daß eben das, was durch den Verlauf der berichteten Ereignisse und Worte konkret und ge-

3I 17,2 praecipue cum a feris beluis hoc differamus, quod illa prona in terramque vergentia nibil nata sint prospicere nisi pabulum, nos, quibus vultus erectus, quibus suspectus in caelum datus est, sermo et ratio, per quae deum adgnoscimus sentimus imitamur, ignorare nec fas nec licet ingerentem sese oculis et sensibus nostris caelestem claritatem.

32 Vgl. zum sogenannten interloquium und der Bewertung der Rhetorik durch Minucius van der Nat (1977), besonders 20I-2I2, und anders akzentuierend Buchheit (1993). Generell zur Haltung der Christen gegenüber der Rhetorik Piepenbrink (2005), 372-385. 
wissermaßen exemplarisch auf die Bühne gebracht wird, die Gefährlichkeit eines rhetorisch operierenden Gegners, innerhalb der Erzählung von den beteiligten Personen selbst thematisiert wird und daß die abstrakte Erörterung der Gefahren der Rhetorik ihrerseits notwendiger Teil der erzählerischen Umsetzung ist. Zugleich erlaubt das Verfahren Minucius, die kritische Frage der Zeitgenossen, ob man so stark auf den paganen rhetorisch-philosophischen Diskurs einschwenken dürfe, wie er es tut, sehr dezent zu beantworten: Eine verhalten negative Antwort gibt die literarische Figur ,Minucius' in cap. I4, indem sie die christlichen Vorbehalte artikuliert, positive Antworten geben hingegen die Rede des Octavius durch ihre Rhetorisierung, die Dialoghandlung, die zum Bekehrungserfolg führt, und die Anlage der Schrift als solche. Minucius entkoppelt so die prekäre Verteidigung der Rhetorik geschickt von seiner Person.

Ohne das gehaltvolle Kapitel im einzelnen zu untersuchen, soll der Blick hier nur auf das Wortfeld ,Rede' gerichtet werden. Die Rede des Caecilius und die zu erwartende des Octavius werden auktorial und von den Gesprächsteilnehmern als oratio $(\mathrm{I} 4, \mathrm{I} .3)$ und sogar als actio $(\mathrm{I} 4,3 ; \mathrm{I} 5, \mathrm{I})$, als deklamierte Rede, eingeordnet, als Teil des rhetorisch-philosophischen Diskurses (I4,3 de toto genere disputandi) klassifiziert und mit Fachtermini aus dem Bereich der Redetheorie charakterisiert, die keinen Zweifel daran lassen, daß der Leser im Falle des Heiden wie des Christen Erzeugnisse der Rhetorik vor sich hat: Beide Redner sollten bis zum Ende regelgerecht sprechen (I4,2 peroratum); die Rede des Caecilius besäße eine Reihe von rednerischen Tugenden, wobei ihr Minucius selbst nur solche der sprachlichen Gestaltung zubilligt (I4,2 concinnitas; I4,3 varietas und subtilis), während Caecilius in ihr auch Überzeugungskraft sieht (I5,I vires); Octavius habe die Möglichkeit der förmlichen Widerrede (I5,I refutare).

Die Einlassungen zur Gefährlichkeit der Rhetorik im allgemeinen, von denen Minucius (als Dialogfigur) Caecilius ausdrücklich ausnimmt, ${ }^{33}$ weisen ebenfalls etliche technische Begriffe aus der Redetheorie auf. Es ist nun gewiß kein Zufall, daß einige von ihnen kurz zuvor oder danach mit Bezug auf die Rede des Caecilius gebraucht sind. Hingewiesen sei nur auf vires (I4,3), subtilitas (I4,7), ubertas dicendi $(\mathrm{I} 4,7)$, das sich zur caecilianischen varietas stellen läßt, und besonders auf eloquentiae tumore $(\mathrm{I5}, 2)$, das die markanteste, auktorial festgestellte Eigenschaft der Rede des Heiden wiederholt (I4,I indignationis eius tumorem). Was der Gesprächspartner Minucius mit urbaner Höflichkeit von sich weist, legt er dem Leser subtil nahe, die Grundsatzkritik eben doch ganz konkret auf die Rede des jungen Heißsporns zu beziehen.

Überträgt man die allgemeine Problemanalyse auf Caecilius, dann liegt eine wichtige Schwäche seiner Position und seines Vortrags darin, daß bei ihm verba

33 I4,3 ... altius moveor, non de praesenti actione, sed de toto genere disputandi. 
und res auseinanderfallen. Trügerische und verführerische Worte (I4,4 verborum lenocinio) verschleiern das sachlich eigentlich Gegebene (I4,4 a rerum intentionibus avocantur), blendender Scheinlogik (I4,7 argutias, die sich immerhin als rhetorisch gelungen loben lassen) steht die Wahrheit, die oft dunkel ist (I4,7 obscura ... veritas), gegenüber. Was Caecilius nötig hat, ist, aus der Welt der oratio in die Welt des sermo zu gelangen, zurück zur Einheit von Wort und Sinn. Diesen Weg zeigt ihm Octavius, dem Leser der ganze Octavius nicht zuletzt dadurch, daß immer wieder die Bedeutung von Worten korrigiert wird. Das prominenteste Beispiel hierfür ist gewiß das Begriffspaar religio / superstitio, das der Heide für den traditionellen römischen Polytheismus bzw. den vermeintlichen christlichen Aberglauben setzt, bis er belehrt wird und am Ende den Christen beipflichtet, wahre religio sei das Christentum, der alte Götterglaube hingegen in Wahrheit ein Aberglaube. ${ }^{34}$ Man dürfte Minucius unterschätzen, wenn man darin nur eine konziliante Form der Diskussion sieht, bei der der Gesprächspartner seine Begriffe behalten darf und nur neu definieren muß. Das Anliegen ist tiefer. Zumindest geht es um eine neue Kultur des Redens im Sinne von Mt 5,37, um Wahrheit durch Klarheit. Wenn Octavius seine Rede nach der Diskussion über die Rhetorik mit dem schlichtesten Wort für sprechen, dicere, und dem Satz beginnt: „Reden will ich für meinen Teil, soweit ich dazu fähig bin, nach besten Kräften, und du sollst dich zusammen mit mir darum bemühen, daß wir diesen bitteren Schandfleck lästerlicher Vorwürfe mit einem Strom an Worten der Wahrheit abwaschen", 35 so bestimmt er seine Tätigkeit als Redner explizit und programmatisch als Reinigung und Heiligung - die Assoziation zum Abwaschen der Sünden im Wasser der Taufe ist sicherlich gewollt ${ }^{36}-$, die sich der Rede als Mittel bedient, aber auch auf die Rede selbst erstreckt. Wahre Worte, verba veracia, ein

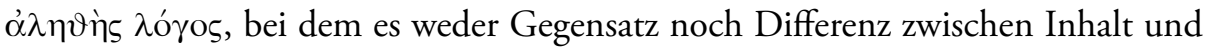
sprachlichem Ausdruck gibt, sind sein Konzept.

34 Zum römischen Religionsbegriff vgl. Muth (1978), zu seiner Ausprägung bei Minucius Lieberg (1963) und Wlosok (1990).

35 I6, I Dicam equidem, ut potero, pro viribus, et adnitendum tibi mecum est, ut conviciorum amarissimam labem verborum veracium flumine diluamus.

36 Pellegrino (2000), 295 zur Stelle weist nur auf die - evidenten - Parallelen in der paganen Literatur, namentlich bei Cicero hin, Bodelón (1994/1995), 8I zur Stelle sieht zudem eine Anspielung auf das Wahre Wort des Kelsos. Anklänge an die Begrifflichkeit der Taufe finden sich im Octavius auch sonst, etwa wenn die Theorie des Thales vom Urspung der Dinge aus dem Wasser gewürdigt wird: Thales rerum initium aquam dixit, deum autem eam mentem, quae ex aqua cuncta formaverit. eo altior et sublimior aquae et spiritus ratio, quam ut ab homine potuerit inveniri, a deo traditum $(19,4)$. 


\section{VI.}

Richtet man den Blick auf die so heftig getadelte Rede des Caecilius, lassen sich bei den menschlichen Sprechern, die in ihr vorkommen, fünf Gruppen unterscheiden. Zum ersten thematisiert Caecilius selbst seine Rolle als Redner. Seinen Vortrag nennt er 8,3 eine actio und schreibt ihm impetus zu, für den er höflich um Nachsicht bittet, ${ }^{37}$ II, 5 nennt er ihn innerhalb einer rhetorischen praeteritioFormel eine oratio und stellt fest, daß er das docere, eines der officia des Redners, für den aktuellen Diskussionspunkt bereits erfüllt habe. ${ }^{38}$ Das Selbstbild, das sich hieraus wie aus der faktischen Rhetorisierung seiner Ausführungen ergibt, stimmt mit dem, das Minucius entwirft, überein: Caecilius agiert als ein den Gesetzen der Rhetorik gehorchender orator und ist sich dessen auch bewußt.

Als zweite, für Caecilius positive Gruppe von Sprechern werden skeptische Philosophen mit Ausdrücken des Redens belegt und mit Wortäußerungen zitiert, Sokrates und der Dichter Simonides, und dies mit Bedacht erst am End- und Höhepunkt der Rede (13,I-4). Verwendet sind neutrale Begriffe, die nicht oder nur wenig affektisch aufgeladen sind: responsio, confiteri, quaerere, inquirere, petere, respondere, und in denen sich die nüchterne Haltung der Skepsis spiegelt. Im Fall von Sokrates wird das Diktum Quod supra nos, nibil ad nos wörtlich (I3,I), sein Ausspruch, er wisse, daß er nichts wisse, und das sei es, was ihn dem Orakel nach zum klügsten Menschen mache, in indirekter Form $(\mathrm{I3}, 2)$ zitiert. Von Simonides erzählt Caecilius die Anekdote, wie dieser dem Tyrannen Hieron auf die Frage nach dem Wesen der Götter nach wiederholter Vertagung antwortete, je länger er nachdenke, desto dunkler werde es ihm. Die Wahl der Sprecher ist Programm. Sokrates ist der unerschrockene Bekenner (confessae inperitiae 13,2) und bekannte Märtyrer seiner Überzeugung, auch Simonides bekennt im Angesicht des auf Antwort drängenden Tyrannen seinen Agnostizismus. Caecilius unterstreicht so sein abschließendes Credo, daß die angemessene Form philosophischer Rede über das Göttliche das Eingeständnis des Nichtwissens ist (13,5). Der Christ Octavius wird darauf nicht nur mit Thales, Zenon und Platon antworten, sondern, um auch den emotionalen Aspekt der Exempla auszustechen, mit den Männern, Frauen und Kindern kontern, die freudig für ihr Christsein in den Tod gehen (37,I-6), ohne Schmerzenslaut und ohne den Mund zur Widerrufung zu öffnen. ${ }^{39}$

378,3 sustinebitis enim me impetum susceptae actionis liberius exserentem.

38 II,5 Multa ad haec subpetunt, ni festinet oratio. iniustos ipsos (scil. Christianos) magis nec laboro, iam docui.

3937,4 et quot ex nostris non dextram solum, sed totum corpus uri cremari sine ullis eiulatibus pertulerunt, cum dimitti praesertim haberent in sua potestate? 
Bei der dritten Gruppe von Sprechern, den Christen, fällt zunächst der Unterschied zwischen den drei Stellen, an denen Caecilius die Du-Form gebraucht und so die christlichen Gesprächspartner ausdrücklich einbezieht, und der Masse der anderen Stellen, an denen er sich über die Christen in der Er-Form äußert, auf. Die zweite Person wird ausschließlich mit dem Wort dicere verbunden (II,6 und I2,2 dicitis, dazu I2,4 praedicitis), das Caecilius nur hier verwendet und offenbar als Kennzeichen christlichen Redens bei früheren Gelegenheiten wahrgenommen hat; sie wird außerdem nur für das zutreffende Referat christlicher Aussagen und nur für gewichtige Themen philosophischer Natur, die Frage der Prädestination, der irdischen und der jenseitigen Gerechtigkeit, verwendet. ${ }^{40}$ Die anwesenden Christen Octavius und Minucius sind als Gesprächspartner ernst genommen.

Die übrigen Stellen, an denen Reden und Schweigen der Christen behandelt werden, lassen sich nach zwei Hauptvorwürfen ordnen. I. Die Christen, eine verschworene Gemeinschaft, sprechen nur miteinander, dies oft und intensiv, nicht aber mit anderen. ${ }^{4 \mathrm{r}} 2$. Wenn sie mit anderen sprechen, herrschen Lüge und Polemik: Sie behaupten in scharfer Form Unwahres, so die Nichtexistenz der heidnischen Götter ${ }^{42}$ und die Auferstehung der Toten ${ }^{43}$, verurteilen zu Unrecht die traditionellen Bräuche ${ }^{44}$ und drohen den Heiden mit Weltuntergang und Fegefeuer ${ }^{45}$; ihre Äußerungen zu philosophischen Themen sind falsch, da ihnen die Grundlagen fehlen, und sollten besser unterbleiben. ${ }^{46}$ Auffällig sind die expressiven Verben, die Caecilius für die Wortäußerungen der Christen wählt (despicere, despuere, ridere, misereri, adstruere, exsecrare, damnare, denuntiare, repromittere, polliceri, dazu auch garrulus und aniles fabulae, mendacia). Das Bild einer

40 II,6 nam quicquid agimus, ut alii fato ita vos deo dicitis: sic sectae vestrae non spontaneos cupere sed electos; 12,2 ecce pars vestrum, et maior melior, ut dicitis, egetis algetis, opere fame laboratis, et deus patitur dissimulat, non vult aut non potest opitulari suis; 12,4 ecce vobis ... ignes etiam quos et praedicitis et timetis: ubi deus ille, qui subvenire revivescentibus potest, viventibus non potest? Die einzigen weiteren Du-Formen bei Ausdrücken des Redens in I2,3 (invitus miser infirmitatis argueris nec fateris), bei denen eher an unpersönliches „man“ $\mathrm{zu}$ denken ist, gehören ebenfalls in die Diskussion über die Prädestination.

4I 8,4 ... latebrosa et lucifugax natio, in publicum muta, in angulis garrula; 9,2 se promisce appellant fratres et sorores; 9,5 conscientia sceleris ad silentium mutuum pignerantur; I0,2 numquam palam loqui.

428,4 templa ut busta despiciunt, deos despuunt, rident sacra, miserentur miseri ... sacerdotum, honores et purpuras despiciunt.

43 II, 2 ... aniles fabulas adstruunt .... renasci se ferunt post mortem et cineres et favillas et nescio qua fiducia mendaciis suis invicem credunt.

44 II, 4 ... et exsecrantur rogos et damnant ignium sepulturas.

45 II,3 ... gemina dementia, caelo et astris ... interitum denuntiare, sibi mortuis ... aeternitatem repromittere; II, 5 hoc errore decepti beatam sibi, ut bonis, et perpetem vitam mortui pollicentur, ceteris, ut iniustis, poenam sempiternam.

46 6,I ... quanto venerabilius ac melius antistites veritatis ... deos ... adorare nec de numinibus ferre sententiam; I2,7 quibus non est datum intellegere civilia, multo magis denegatum est disserere divina; 13,5 ... quae sunt dubia, ut sunt, relinquenda sunt, nec ... temere et audaciter in alteram partem ferenda sententia est. 
Gruppe entsteht, die nur untereinander, nicht aber mit der Gesellschaft kommunizieren kann, immer gleich polemisch wird, sich auf pseudophilosophische Ansichten versteift und zur Drohgebärde neigt, kurz alle Kennzeichen einer religiösen Sekte besitzt. Der Widerspruch zum insgesamt respektvollen Umgang des Caecilius mit den Christen, die er näher kennt, dem Mentor Minucius und dessen Freund Octavius, ist eklatant. ${ }^{47}$

Die vierte Gruppe von Sprechern bilden ,die Leute', die nur im 9. Kapitel vorkommen und denen die besonders häßlichen Vorwürfe gegen die Christen in den Mund gelegt werden, so die Verehrung eines Esels, der Genitalien des Priesters, der Kindsmord, das thyesteische Mahl usw. Schon die Wortwahl zeigt, daß auch Caecilius dies für Gerede hält (9,3 fama loqueretur; 9,4 alii ... ferunt; 9,4 fabulatur; 9,5 fabula; 9,6 omnes loquuntur) und eine gewisse Distanz wahrt. Mit dem Geschwätz der Leute verbunden wird die antichristliche Rede Frontos (9,6), die Caecilius zu einem unverdächtigen Zeugnis erklärt (testatur oratio), die von Minucius als Autor aber schon durch die Koppelung mit der fama auf deren Stufe herabgedrückt wird.

Nur kurz erwähnt wird schließlich die Gruppe der „Alten“. Mythologische Erzählungen in der Dichtung alter Zeit und die Anekdoten über das überraschende Eintreffen von Orakeln wie bei Krösus streift Caecilius nur im Vorübergehen, um sich den Vorwurf, die Altvorderen hätten gerne Märchen erzählt (antiquitas nimium fabulosa), zu ersparen..$^{48}$

Neben die verschiedenen Gruppen von Menschen treten die Götter als eigene Klasse von Sprechern, die von sich aus Kontakt mit den Menschen aufnehmen und sich nicht nur durch Zeichen, etwa den Vogelflug, mitteilen, sondern vor allem durch verbale Äußerungen. Privilegierte Empfänger göttlicher Rede sind die Seher (vates), die „voll und vereint mit dem Gott die Zukunft vorwegnehmen, Achtsamkeit bei Gefahren, bei Krankheiten Heilung, Hoffnung den Niedergeschlagenen, Hilfe den Elenden, Trost im Unglück, in Mühsal Erleichterung geben“" ${ }^{49}$ Doch kommunizieren die Götter auch mit gewöhnlichen Menschen im Traum, was Caecilius als allgemeine und alltägliche Erfahrung hinstellt: „Auch in

47 Eine Erklärung wird man wohl in der Anlage des Charakters und dem Seelenzustand des Caecilius suchen dürfen, der - von seinem Mentor Minucius zur Bekehrung bereits vorbereitet vor dem letzten Schritt noch einmal alle Vorbehalte und Argumente gegen den Christenglauben sammelt, mag er auch innerlich nicht mehr von ihnen überzeugt sein, um sich endgültig von ihnen befreien zu lassen.

48 7,5 omitto vetera, quae multa sunt, et de deorum natalibus donis muneribus neglego carmina poetarum; praedicta etiam de oraculis fata transilio, ne vobis antiquitas nimium fabulosa videatur.

49 7,6 inde adeo pleni et mixti deo vates futura praecerpunt, dant cautelam periculis, morbis medellam, spem adflictis, opem miseris, solacium calamitatibus, laboribus levamentum. 
der Ruhe der Nacht sehen, hören, erkennen wir die Götter, die wir am Tage gottlos leugnen, nicht haben wollen, durch Meineid verletzen. "so Auf die Anrede durch die Götter ist im übrigen eine Antwort des Menschen möglich und nötig. Er kann sich zu seinem Schaden verweigern oder zum Wohle aller gehorchen. ${ }^{\text {SI }}$ Als wichtigste, mit den Sehern verbundene Form der Mitteilung fungieren die Orakel. Die Bedeutung, die ihnen Caecilius zumißt, zeigt sich daran, daß er seine Rede mit zwei Orakelsprüchen rahmt. Im einleitenden Methodenkapitel wird

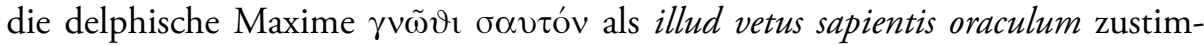
mend zitiert $(5,5)$, im theoretischen Schlußteil das Sokrates erteilte Orakel und dessen zutreffende Deutung referiert (I3,If.). Die Formulierung sapientis oraculum kombiniert dabei im ersten Fall geschickt die divergierenden Überlieferungen des Spruchs, der neben Apollo bzw. der Pythia auch Thales von Milet und Chilon von Sparta zugeschrieben wurde, und erlaubt es, für die eigene Position, die Götterglaube und Skeptizismus verbindet, gleich zu Beginn göttliche und philosophische Legitimation zu beanspruchen.

\section{VII.}

Wie reagiert Octavius? Er scheint die Rolle als postremus philosophorum, die ihm Caecilius zuweist, zunächst anzunehmen und bedient mit dem ersten Wort seiner Rede dicam geradezu Caecilius' Klischee vermeintlich typisch christlicher Ausdrucksweise, des (stilistisch wie gedanklich) schlichten dicere. Zurückgenommen wird dies auch im Verlauf der Rede nicht, wie wiederholtes dicere und loqui für die eigenen Äußerungen zeigen (I7,6 dicam; I7,Io loquar (zweimal); I8,9 eloquar; 18,10 dixerim; 23,7 loquar; 36,5 dicam; hinzu kommt die Bezeichnung seiner Rede als responsio 16,2). Doch ergänzt Octavius die Selbstcharakteristik um Floskeln, die gerade für den professionellen Redner typisch sind, wenn dieser von einem Punkt zum nächsten übergeht (I7,6 transeo; 19,4 omitto; 20,I exposui; 26,I venio ad; 26,5 prosequar) oder seine rednerische Tätigkeit als solche beschreibt ( 16,4 convincam et redarguam; 24,I otiosum est ire per singulos et ... explicare; 26,7 adgrediar ... altius eruere et aperire manifestius; 36,2 de fato satis vel ... disputaturi alias). So zeigt die Wahl des Vokabulars im Kleinen, was Octavius im Großen praktiziert und wofür Minucius wirbt, eine christliche Rhetorik.

Bemerkenswert ist die Wahl der Worte, mit denen Octavius das Referat von Äußerungen des Caecilius einführt, dem gleich zu Beginn die versutia des Rhetors, die bedenkliche Kunst trickreichen Formulierens und Argumentierens, ge-

50 7,6 etiam per quietem deos videmus audimus adgnoscimus, quos inpie per diem negamus nolumus peieramus. Auch kurz davor ist von der Mitteilung Iuppiters an einen gewöhnlichen Menschen in einem Traum (7,3 somnio plebei hominis) die Rede. 
wiß nicht zu dessen reiner Freude abgesprochen wird..$^{52}$ Denn auch hier kommen in gleicher Häufigkeit dicere und loqui ( 16,4 dicta sunt; 27,4 tibi dicta sunt; 28,7 dicis; 33,5 loqueris) neben stärker rhetorisch geprägten Termini ( 16,5 erupit, I7,I adserere ... conisus est; I8,5 inquirendum putas; 26, I testatus es) vor. Vielleicht wird man dies so deuten dürfen, daß Octavius eine Art Angebot unterbreitet, die Einlassungen des Caecilius als grundsätzlich ebenso diskussionswürdig wie die eigene Entgegnung zu betrachten, ${ }^{53}$ und daß er zugleich leicht ironisch andeutet, daß sich unter dem Gehörten stilistisch wie geistig Schlichtes befand.

Den von Caecilius bereits konzedierten Vorwurf, den man gegen die Märchenseligkeit der Altvorderen, die antiquitas fabulosa, erheben könne, baut Octavius breit aus. Die alten Mythen werden fast stereotyp mit dem Ausdruck fabulae belegt (I8,6 fabula für die thebanische Heldensage; 20,4 fabulae für Verwandlungssagen; 22,4 fabula für den Kybele-Attis-Mythos; 23,I fabulae pauschal für Götterund Heldensagen; 23,8 und 24,3 fabulae für Göttermythen) und die Leichtgläubigkeit der Alten, die sich gerne mit Lügenmärchen unterhalten ließen, eingehend beschrieben. ${ }^{54}$ Die wiederholte Verbindung mit Lügen (20,2 mendaciis und 23,8 figmentis et mendaciis) und eine Qualifikation wie aniles fabulae $(20,4)$ lassen keinen Zweifel daran, daß Octavius den heidnischen Mythos für haltloses Gerede hält. Seine primären Träger, die mythologischen Dichter mit Homer an der Spitze, werden scharf verurteilt (23,I-8) und ihre Geschichten über Götter und Orakel als unterhaltsame Erzählungen ohne sittlichen Ernst (23,3 [Homerus] ludos facit), als bloßes Fabulieren (23,4 [Homerus] narrat), als Erfindungen (26,6 Ennius Apollinis Pythi responsa confinxit) charakterisiert. Für ihre Rezipienten ist der Schritt vom Glauben an die Göttermythen mit ihren menschlich - allzu menschlichen Gestalten zur Verehrung von Menschen als Götter gering, wobei dies zu deutlicher Sprachverwirrung führt: „Auch Fürsten und Königen schmeichelt man nicht, wie es recht ist, als großen und auserwählten Männern, sondern auf schändliche Weise wie Göttern in falscher Kriecherei ... Und so rufen sie ihre göttliche Macht an, bringen Bittgebete vor ihren Bildern dar und flehen den Genius, also den Dämon des Herrschers, an, und es ist in ihren Augen gefahrloser, beim Genius Jupiters als bei dem des Königs falsch zu schwören." "ss Bemerkens-

$52 \quad 16,2$ sed in Natali meo versutiam nolo, non credo.

53 Hierfür spricht auch die einzige Pluralform der 2. Person, die einer heidnischen Aussage grundsätzlich zustimmt, 36,8: omnes adeo vestri viri fortes, quos in exemplum praedicatis, aerumnis suis inclyti floruerunt. Um unpersönliches man handelt es sich 37,Io fascibus et purpuris gloriaris? ... nobilitate generosus es, parentes tuos laudas?

$5420,2 \mathrm{f}$. non nos debet antiquitas inperitorum fabellis suis delectata vel capta ad errorem mutui rapere consensus ... maioribus enim nostris tam facilis in mendaciis fides fuit, ut temere crediderint etiam alia monstruosa, mira miracula ... quicquid famae licet fingere, illis erat libenter audire.

55 29,5 etiam principibus et regibus, non ut magnis et electis viris, sicut fas est, sed ut deis turpiter adulatio falsa blanditur ... sic eorum numen vocant, ad imagines supplicant, Genium, id est daemoni- 
wert ist, daß Octavius die Alten maiores nostri $(20,3)$ nennt. Er nimmt damit für sich und die Christen die römische Geschichte als die eigene an. Während Caecilius allerdings einem historischen Dekadenzmodell anhängt (9,I), erkennt Octavius eine aufsteigende Linie, die erst in der Gegenwart mit dem Christentum das volle Licht der Erkenntnis gebracht hat $(38,7)$, und kann von dieser - ebenfalls gut römischen - Position aus kritisch über die eigene Vergangenheit urteilen ${ }^{56}$.

Neben die Kritik tritt als zweite Strategie der Widerlegung die Binnendifferenzierung. Innerhalb der Gruppe der Alten werden die frühen Philosophen, die schon damals Mythenkritik übten, der Masse der Leichtgläubigen gegenübergestellt. ${ }^{57}$ Auch die Dichtung wird aufgespalten in negative polytheistische Aussagen wie in den Epen Homers und positive Zeugnisse für den Monotheismus, allen voran das Vergils: „Ich höre auch die Dichter, wie sie einen Vater der Götter und Menschen verkünden ... Wie? Sagte nicht Maro von Mantua noch deutlicher, treffender, wahrer: ,es nährt' ,am Anfang Himmel und Erde‘ und alle übrigen Weltenglieder ,im Innern ein Geist ' und ,es bewegt sie eingegossener Sinn'; ,von da her kommt der Menschen und ländlichen Tiere Geschlecht' und jede andere Art der Tiere? Derselbe Dichter nennt an einer anderen Stelle diesen Sinn und Geist Gott. So lauten nämlich seine Worte: ,und daß wahrlich ein Gott durch alle Lande und des Meeres Striche und den tiefen Himmel gehe, woher die Menschen und das Vieh, woher der Regen und die Feuer'. Wird nicht auch von uns Gott als nichts anderes denn Sinn, Vernunft und Geist verkündet? ${ }^{\text {«s8 }}$

Augenfällig ist die Binnendifferenzierung auch bei der Gruppe der ,Leute', auf deren Gerede sich Caecilius berufen hatte. Die Schauergeschichten über abstoßende christliche Kultbräuche werden wie der heidnische Mythos konsequent mit dem Begriff fabulae als Märchen bezeichnet ${ }^{59}$, wobei als Sprecher nicht etwa

um inplorant, et est eis tutius per Iovis Genium peierare quam regis. Trotz der Formulierung im Präsens wird man die Passage nicht auf die Gegenwart des Sprechers und den Kaiserkult einengen können, ist doch die göttliche Verehrung des ägyptischen Pharao, die längst obsolet war, unmittelbar zuvor ebenfalls im Präsens geschildert und der römische Kaiser gerade kein rex.

56 Die Deutung der Stelle im Sinne eines spezifisch christlichen Geschichtsbewußtseins bei Buchheit (1985) scheint mir mit dem Aufgreifen römischer Aszendenzvorstellungen kompatibel zu sein.

57 20,3 cum (scil. antiquitas inperitorum) philosophorum suorum sententiis refellatur, quibus et rationis et vetustatis adsistit auctoritas.

58 I9,If. audio poetas quoque unum patrem divum atque hominum praedicantes ... quid? Mantuanus Maro nonne apertius proximius verius, principio' ait, caelum ac terras' et cetera mundi membra, spiritus intus alit et infusa mens agitat, inde hominum pecudumque genus' et quicquid aliud animalium? idem alio loco mentem istam et spiritum deum nominat. haec enim verba sunt: ,deum namque ire per omnes terrasque tractusque maris caelumque profundum, unde homines et pecudes, unde imber et ignes. quid aliud et a nobis deus quam mens et ratio et spiritus praedicatur? $\mathrm{Zu}$ dieser und den übrigen Aufnahmen Vergils vgl. Courcelle (1964), Heck (1990), Buchheit (1996) und zuletzt mit ausführlichem Forschungsbericht und methodischer Klärung Freund (2003), IOI-I9I. 
Volkes Stimme, sondern nur vereinzelte Personen, ${ }^{60}$ vor allem aber die Dämonen fungieren: „Denn mit diesen und ähnlichen Märchen haben besagte Dämonen die Ohren der Ahnungslosen gegen uns vollgestopft, bis ihnen grauste und sie uns verfluchten. Doch verwunderlich ist das nicht, da das allgemeine Gerede, das sich immer aus der Garnierung mit Lügen speist und erlischt, wenn sich die Wahrheit offen zeigt, in eben dieser Weise das Tätigkeitsfeld der Dämonen ist. Von ihnen selbst werden nämlich falsche Gerüchte ausgestreut und dann warm gehalten. "' ${ }^{\text {"I }}$ Obwohl Octavius das Bestehen der Gerüchte über die Christen also nicht bestreitet, vermeidet er es geschickt, auf die vorhandene Menge menschlicher Sprecher hinzuweisen. Vielmehr wird die vox populi, wo sie auftritt, positiv vereinnahmt. Offen geschieht dies, wo Redewendungen als natürliches Zeugnis für den consensus omnium in Sachen Monotheismus gewertet werden: „Ich höre doch die Leute (vulgus): wenn sie die Hände zum Himmel strecken, sagen sie nichts weiter als ,oh Gott' und ,Gott ist groß' und ,wahr ist Gott' und ,wenn's Gott gibt'. Ist das die natürliche Ausdrucksweise der Leute (vulgi sermo) oder die Rede eines bekennenden Christen?"“62 oder Äußerungen der Masse über die Christen zustimmend referiert werden. ${ }^{63}$ Subtiler erfolgt die Vereinnahmung, wenn zwischen der Ausdrucksweise der Christen und der übrigen Menschen gar nicht unterschieden wird, sondern beide im Wir zusammengeschlossen sind, so bei der Rede von Gott - „Unser Herz“ - nämlich das aller Menschen, Christen wie Heiden, - ,aber ist klein und kann Gott nicht erkennen, und deshalb schät-

59 Vgl. Oct. 28,2; 28,6; 3I,2; 3I,4.

60 Singularisch formuliert ist 28, Io etiam ille, qui de adoratis sacerdotis virilibus adversum nos fabulatur und ebenso 30,I illum iam velim convenire, qui initiari nos dicit aut credit de caede infantis et sanguine. Ebenfalls als vereinzelte Äußerung erscheint die Rede Frontos 31,2; die Existenz einer gerichtsfesten Anzeige von Christen wegen irgendwelcher Schandtaten wird - ebenfalls singularisch - überhaupt bestritten: 28,2 nec tanto tempore aliquem exsistere qui proderet, non tantum facti veniam, verum etiam indicii gratiam consecuturum. Daß die giftigste Kritik an den Christen nicht aus dem Volk, sondern aus den Reihen der Gebildeten kommt, zeigt deutlich 28,Io, wo Octavius den Vorwurf der Libertinage und sexuellen Abartigkeit zurückgibt an die, apud quos tota inpudicitia vocatur urbanitas. Denn das Streben nach Urbanität ist ein hervorstechendes Kennzeichen der Oberschicht, der hier bescheinigt wird, an Sprachverwirrung zu leiden. Die despektierliche Fortsetzung - qui medios viros lambunt, libidinoso ore inguinibus inhaerescunt, homines malae linguae etiam si tacerent - bietet nicht nur eine etwas frostige Pointe, sondern zeigt auch, daß diese Gruppe die natürliche Bestimmung des Sprachorgans und der menschlichen Rede pervertiert.

6I 28,6 his enim et huiusmodi fabulis idem daemones ad exsecrationis horrorem inperitorum aures adversus nos referserunt. nec tamen mirum: cum omnium fama, quae semper insparsis mendaciis alitur, ostensa veritate consumitur, sic est negotium daemonum; ab ipsis enim rumor falsus et seritur et fovetur. Ebenso schon 28,2 ab his fabulas istas semper ventilari und erneut 3I, I et de incesto convivio fabulam grandem adversum nos daemonum contio mentita est.

62 I8,II audio vulgus: cum ad caelum manus tendunt, nibil aliud quam, deum 'dicunt et, deus magnus est' et, deus verus est' et, si deus dederit'. vulgi iste naturalis sermo est an Christiani confitentis oratio?

63 So 36,3 Ceterum quod plerique pauperes dicimur, non est infamia nostra, sed gloria. 
zen wir ihn in angemessener Weise ein, wenn wir ihn unschätzbar nennen (dicimus) “64 - oder bei einer Nebensächlichkeit wie der Erläuterung des Ausdrucks ,Sohn der Erde‘: „Denn Sohn der Erde oder auch des Himmels heißt Ianus in der Überlieferung, was bei den Italern, von unbekannten Eltern stammend' bedeutete, wie wir“ - nämlich Heiden und Christen - „bis zum heutigen Tage Leute, die unvermutet erscheinen, ,vom Himmel geschickt' nennen (nominamus), solche von niedriger und unbekannter Herkunft ,Söhne der Erde'."65 Der Isolierung der Christen als sektiererischer Gruppe stellt Octavius ihre Integration, die sich in der Sprechweise ausdrückt, entgegen.

Die Grundlage dafür, ein positives Bild der breiten Menge zu entwickeln, legt Octavius gleich zu Beginn seiner Replik, indem er sich im Anschluß an das Zwischengespräch ganz auf die Seite der schlichten Wahrheit statt des glänzenden rhetorischen Trugs schlägt und in einem zweiten Schritt die Fähigkeit zur Wahrheitserkenntnis und zur schlichten Rede ausdrücklich zur Gabe aller Menschen erklärt: „Einen Anlaß für Empörung oder Schmerz gibt es daher nicht, wenn gleich wer es auch sei hinsichtlich des Göttlichen Fragen aufwirft, Ansichten formt und sich äußert, da es nicht auf die Autorität des Denkers, sondern die Wahrheit der Gedanken ankommt. Und daher leuchtet die Argumentation sogar um so heller, je unbeholfener die Redeweise (sermo) ist, weil sie nicht durch den Prunk anmutiger Eloquenz (pompa facundiae et gratiae) geschminkt wird, sondern so, wie sie ist, ihre Kraft aus der Ausrichtung am Richtigen erhält" ${ }^{66}$. Eine Glorifizierung des vulgus ist damit freilich nicht verbunden - die Masse läßt sich durch Rhetorik wie bildende Kunst täuschen und betet darum die Götzen $\mathrm{an}^{67}$-, wohl aber die Möglichkeit, dem kleinen Mann ohne Dünkel zu begegnen.

Die Strategie der Differenzierung wird schließlich auch bei der Gruppe der Philosophen eingesetzt. Indem Minucius Caecilius nur die Atheisten aussondern und mit den Christen verbinden $(8, \mathrm{I}-5)$ und die mit der Skepsis konkurrierenden Schulen wie Peripatos, Stoa und Epikureismus lediglich mit ihren Weltentstehungslehren erwähnen hatte lassen $(5,7-13)$, eröffnet er sich in der Rede des Oc-

64 I8,8 nobis vero ad intellectum pectus angustum est, et ideo eum digne aestimamus, dum inaestimabilem dicimus.

65 23,I2 [Ianus] Terrae enim vel Caeli filius, quod apud Italos esset ignotis parentibus, proditus, ut in hodiernum inopinato visos caelo missos, ignobiles et ignotos terrae filios nominamus.

66 16,6 nibil itaque indignandum vel dolendum, si quicumque de divinis quaerat sentiat proferat, cum non disputantis auctoritas, sed disputationis ipsius veritas requiratur. atque etiam, quo inperitior sermo, hoc inlustrior ratio est, quoniam non fucatur pompa facundiae et gratiae, sed, ut est, recti regula sustinetur.

6724,5 Quis ergo dubitat horum imagines consecratas vulgus orare et publice colere, dum opinio et mens inperitorum artis concinnitate (!) decipitur, auri fulgore praestringitur, argenti nitore et candore eboris hebetatur? 
tavius die Gelegenheit, diese nun zum philosophischen Gegenpol zu entwickeln. Die doxographische Übersicht, die die Konvergenz aller namhaften Philosophen von Thales bis Platon in Sachen Monotheismus nachweisen will (19,3-20,I), leitet Minucius mit dem schon bekannten Gegensatz von verba und res ein: „Gehen wir, wenn's genehm ist, die Lehre der Philosophen durch: du wirst sie dabei überraschen, wie sie sich, wenn auch in bunt schillernder Ausdrucksweise (sermonibus variis), der Sache selbst nach (ipsis rebus) in dieser einen Ansicht treffen und verbünden. ${ }^{668}$ Es scheint der Philosophie also in diesem Punkt mehr an Klarheit als an Wahrheit zu fehlen. Innerhalb des folgenden philosophischen Parforceritts werden für das Referat der Meinungen immer wieder auch Ausdrücke des Redens verwendet: disputare, dicere (Thales), statuere (Anaximenes, Diogenes von Apollonia), dicere (Anaximenes), tradere (Xenophanes), loqui (Demokrit), variare, adsignare, dicere (Aristoteles), variare, tribuere (Theophrast), adscribere (Heraklides), disserere (Kleanthes) arguere, revincere (Zenon), exponere, disserere (Diogenes von Babylon), negare (Xenophon), oratio, praefari (Platon). Die Mischung spezifisch philosophischen Jargons (disserere, disputare) mit alltäglichem dicere und loqui mag als leiser Hinweis gedacht sein, daß die geschilderten Ansichten mit dem christlichen sermo grundsätzlich kompatibel sind. Daß Minucius ein Thales dixit nicht als austauschbare Floskel benutzt, sondern die Worte mit Bedacht gewählt hat, zeigt sich daran, daß er für seinen Lieblingsphilosophen Platon an den beiden weiteren Stellen, die Lehrinhalte zustimmend referieren (der Eros des Symposion als Dämon 26,12 mit narrare, exprimere, monere, dicere bzw. die grundsätzliche Vergänglichkeit der Welt im Timaios 34,4 mit loqui, zweifach dicere, addere) das Wort dicere benutzt, während es beim Bericht über die von Minucius kritisch beurteilte pythagoreische und platonische Seelenwanderungslehre $(34,6 f$. mit tradere, addere) nicht fällt. Ebenso vorenthalten bleibt es der Gruppe der Skeptiker mit Sokrates an ihrer Spitze.

Diese werden als negativer Gegenpol erst am Ende der Rede des Octavius und dort nur kurz $(38,5)$ erwähnt. Sokrates muß nolens volens zugeben, daß er nichts weiß (nibil se scire confessus), Karneades und die übrigen Skeptiker bleiben im Hin- und Herüberlegen stecken (deliberet), Simonides kommt zu keinem Schluß (in perpetuum comperendinet). Bei ihnen allen, und hierin liegt ein Kern von Minucius' Philosophenkritik, fallen Worte und Leben, verba und res gestae, auseinander, denn sie alle „schwangen stets gegen die eigenen Laster Reden“ ${ }^{69}$

Ergänzt wird die Strategie der Differenzierung durch die Nennung weiterer Gruppen paganer Autoren, deren Ansichten wie bei den philosophischen Vertretern des Monotheismus mit christlichen Anschauungen konvergieren, so daß der

68 19,3 Recenseamus, si placet, disciplinam philosophorum: deprehendes eos, etsi sermonibus variis, ipsis rebus in hanc unam coire et conspirare sententiam.

6938,5 semper adversus sua vitia facundos. 
Eindruck entsteht, die Skeptiker seien auch innerhalb des heidnischen Meinungsspektrums isoliert. In dieser Weise werden die magi für die Dämonologie in Anspruch genommen ${ }^{70}$ und noch deutlicher die euhemeristischen Göttererklärer. Wo sie mit Ausdrücken des Redens belegt sind (2I,2 Prodikos: loqui; Terenz: sermo; 23,9 Thallos und Diodoros: loqui) fällt die Wahl schlichter Worte auf, die als solche die Nähe zur christlichen Position suggeriert.

Hatte Caecilius innerhalb der Gruppe der Christen nur die Gesprächspartner Minucius und Octavius als denkerisch ernst zu nehmendes Gegenüber aus der vermeintlich ungebildeten Masse der übrigen ausgenommen, spricht Octavius den Christen insgesamt philosophische Qualitäten zu. Sie alle besitzen die Wahrheit, die die Philosophen suchten, ohne auf glänzende Formulierung großen Wert zu legen, dafür um so mehr auf den Einklang von Reden und Tun: non eloquimur magna, sed vivimus, gloriamur nos consecutos, quod illi (scil. philosophi) summa intentione quaesiverunt $(38,6)$. Die philosophische Haltung der Christen zeigt sich im Detail, wenn ihre Entscheidung gegen den Genuß von Opferfleisch mithilfe der besonders stoisch besetzten Schlagworte timor und libertas nicht als Eingeständnis von Angst, sondern als Proklamation wahrer Freiheit (38, I non confessio timoris est, sed verae libertatis adsertio) eingeordnet wird oder wenn die Aussagen der Stoa, Epikurs und Platons über die Endlichkeit der Welt als schattenhafte Wiedergabe biblischer Lehre erscheinen: „Du merkst, daß die Philosophen dasselbe diskutieren (disputare), was wir sagen (dicimus), doch nicht, weil wir brav in ihre Fußstapfen getreten wären, sondern weil sie auf Grundlage der göttlichen Verkündigung der Propheten (de divinis praedicationibus prophetarum) einen Schemen verfälschter Wahrheit nachgebildet haben. ${ }^{\text {"7I }}$ Der von Octavius zu Beginn seiner Rede referierte Vorwurf der Anmaßung, ohne hinlängliche Bildung in philosophicis mitreden zu wollen ( 16,5 inliteratos pauperes inperitos de rebus caelestibus disputare), wird so nachdrücklich zurückgewiesen.

Grundlage der christlichen ,Philosophie ist die allgemeinmenschliche Teilhabe am Logos. Denn obwohl Minucius auf die Entwicklung einer Logos-Theologie verzichtet und damit verbunden auch den Begriff der Seele nicht thematisiert, zeigen vereinzelte Wendungen, daß die philosophische Distinktion der Seelenfunktionen und ein entwickeltes Logos-Konzept im Hintergrund stehen. Die Bemerkung „willst du mit fleischlichen Augen sehen, wo du doch deine eigene Seele (animam), durch die du mit Leben erfüllt wirst (vivicaris) und sprichst (lo-

70 Vgl. 26,II über den Erzmagier Hostanes: eorum magorum et eloquio et negotio primus Hostanes et verum deum merita maiestate prosequitur et angelos, id est ministros et nuntios, dei sedem tueri eiusque venerationi novit adsistere ... idem etiam daemonas prodidit terrenos ...

7I 34,5 animadvertis philosophos eadem disputare quae dicimus, non quod nos simus eorum vestigia subsecuti, sed quod illi de divinis praedicationibus prophetarum umbram interpolatae veritatis imitati sint. 
queris), weder ansehen noch festhalten kannst? ${ }^{\text {“72 }}$ deutet eine doppelte, vegetative und rationale, Funktion der Seele an, wobei letztere ihren Ausdruck in der Fähigkeit zu vernünftigem Sprechen findet. Entsprechend wird der menschliche Logos wie bereits erwähnt mit dem Hendiadyoin sermo et ratio $(\mathrm{I} 7,2)$ beschrieben, während für den göttlichen Logos das Wort ratio allein gebraucht ist (I7,6 perfecta ratio). Zwischen beiden besteht eine innere Verbindung, die die Grenze zwischen menschlichem und göttlichem Bereich überwindet: „All diese Dinge [gemeint ist die sinnreiche Einrichtung des Kosmos] haben nun aber ein jedes für sich zu ihrer Hervorbringung, Verfertigung und Anordnung einen vollkommenen Künstler und vollendete Rationalität (perfectae rationis) nötig gehabt, ja nicht nur dies, sondern sie lassen sich gar nicht ohne höchste Kunstfertigkeit und Rationalität (summa ratione) wahrnehmen, erkennen und verstehen. ${ }^{\text {“73 }}$

Caecilius' Vorwurf, die Christen scheuten davor zurück, offen und öffentlich zu sprechen, widerlegt Octavius, indem er ihn aufspaltet. Unter normalen Umständen vermieden die Christen tatsächlich öffentliche Äußerungen, unter besonderen hingegen nicht. Die gewöhnliche Zurückhaltung wird dabei nicht als Zeichen einer verschworenen Gemeinschaft, sondern mit Berufung auf Platon als Kennzeichen einer philosophischen Haltung neu interpretiert: „Für Platon ist also im Timaios Gott ... der Hersteller der himmlischen und irdischen Dinge, den zu finden ... schwierig sei ..., wie es auch unmöglich sei ... von ihm öffentlich zu sprechen. Etwa dasselbe vertritt damit auch er, was unsere Ansicht ist. Denn wir kennen einen Gott und nennen (dicimus) ihn den Schöpfer aller Dinge und verkünden (praedicamus) ihn niemals öffentlich, es sei denn, wir werden verhört. ${ }^{\text {"74 }}$ Als weiterer Grund für das gewöhnliche Schweigen der Christen wird die Angst der Heiden vor offenen Worten genannt, wodurch diese selbst für das Verstummen der Christen verantwortlich werden und jenen als den Vertretern der Sittlichkeit eine weitere philosophische Qualität, nun im Bereich der Ethik, zugesprochen wird: „Denn wir sind nicht deshalb ,in den Winkeln geschwätzig“, wenn ihr euch davor schämt oder ängstigt, uns öffentlich anzuhören. " 75 Moralische Maßstäbe prägen insgesamt das Reden der Christen, die casto sermone, corpore castiore $(3 \mathrm{I}, 5)$ leben, sich scheuen, Abartiges etwa im Kybelekult allzu deut-

72 32,6 deum oculis carnalibus vis videre, cum ipsam animam tuam, qua vivificaris et loqueris, nec aspicere possis nec tenere?

73 17,6 quae singula, non modo ut crearentur fierent disponerentur, summi opificis et perfectae rationis eguerunt, verum etiam sentiri perspici intellegi sine summa sollertia et ratione non possunt.

74 I9,I4f. Platoni itaque in Timaeo deus est ... caelestium terrenorumque fabricator, quem et invenire difficile ...et ... in publicum dicere inpossibile praefatur. eadem fere et ista, quae nostra sunt; nam et deum novimus et parentem omnium dicimus et numquam publice nisi interrogati praedicamus.

75 31,6 nec in angulis garruli si audire nos publice aut erubescitis aut timetis. 
lich zu benennen (pudet dicere 22,4) und deren Umgangston untereinander von herzlicher Freundlichkeit geprägt ist: sic nos, quod invidetis, fratres vocamus $(3 \mathrm{I}, 8)$.

In zwei Fällen geben die Christen laut Octavius ihre Zurückhaltung auf: beim Exorzismus und als Verfolgte vor Gericht. Beiden Situationen gemeinsam ist, daß es um die Aufdeckung der Wahrheit gegenüber Verleumdungen geht, die direkt oder indirekt auf die Dämonen zurückzuführen sind. Der genaue Wortlaut der Gebetsformel, die zur Austreibung der unreinen Geister dient, läßt sich dem Octavius nicht entnehmen. Immerhin wird deutlich, daß sich der Exorzist nicht irgendwelcher Gegenstände oder Gesten bedient, sondern der Kraft von Worten: „All das bekennen (confiteri), wie die meisten und auch ein Teil von euch wissen, die Dämonen selbst von sich selbst, sooft sie von uns mit dem Marterwerkzeug des Wortes (verborum tormentis) und den Brandfackeln des Gebets (orationis incendiis) aus den Körpern ausgetrieben werden “ ${ }^{76}$ und daß der Name Gottes hierbei größte Wirkung entfaltet: „Glaubt doch ihrem eigenen Zeugnis, daß sie Dämonen sind, wenn sie von sich die Wahrheit bekennen (confitentibus). Denn werden sie im Namen des wahren und einzigen Gottes beschworen (adiurati), erbeben sie gegen ihren Willen kläglich in den Körpern und fahren entweder sofort heraus oder verflüchtigen sich allmählich, je nachdem wie der Glaube des Leidenden mithilft oder die Gnade des Heilenden mitwirkt" "77

Als weitere neue Gruppe christlicher Sprecher werden verfolgte Christen eingeführt. Der Kontrast des Märtyrers, der angesichts der drohenden Staatsmacht die christliche Wahrheit bekennt, könnte gegenüber dem Zerrbild des Caecilius, die Christen würden öffentlich nur drohen oder lügen, nicht größer sein. Indem die peinliche Befragung der staatlichen Organe ihr eigentliches Ziel, die Ermittlung der Wahrheit, verfehlt und zum Leugnen zwingt, ${ }^{78}$ ist sie mitverantwortlich dafür, daß einige Christen schwach werden. ${ }^{79}$ In der Regel freilich bekennen sie im Verhör ihre Überzeugung $(28,3$ confitentes $)$ und triumphieren im Tod: „Welch schönes Schauspiel für Gott, wenn ein Christ zum Kampf mit dem Schmerz antritt, wenn er sich gegen Drohungen, flehentliche Bitten und Foltern wappnet, wenn er das Lärmen des Todes und den Schauder vor dem Henker lachend (inridens) in den Staub tritt, wenn er seine Freiheit gegen Könige und Kaiser hochhält

76 27,5 Haec omnia sciunt plerique pars vestrum ipsos daemonas de semetipsis confiteri, quotiens a nobis tormentis verborum et orationis incendiis de corporibus exiguntur.

7727,7 ipsis testibus de se verum confitentibus esse eos daemonas credite! adiurati enim per deum verum et solum inviti miseri corporibus inhorrescunt et vel exsiliunt statim vel evanescunt gradatim, prout fides patientis adiuvat aut gratia curantis adspirat.

7828,3 ... exercentes in his perversam quaestionem, non quae verum erueret, sed quae mendacium cogeret. Ebenso 28,5 eine richtige Untersuchung müßte darauf abzielen, non ut diffiterentur se Christianos, sed ut de incestis stupris ... faterentur.

79 Die Existenz von lapsi, die abgeschworen haben, räumt Minucius offen ein, so 28,4 et si qui infirmior malo pressus et victus Christianum se negasset, favebamus ei, quasi eierato nomine iam omnia facta sua illa negatione purgaret. 
und allein Gott, dessen Eigentum er ist, nachgibt, und wenn er als Triumphator und Sieger dessen spottet (insultat), der gegen ihn das Urteil sprach (sententiam dixit). ${ }^{\text {"80 }}$ Ohne daß Minucius die kaiserliche Gerichtsbarkeit und ihre Vertreter mit abschätzigen Worten angriffe, wie er dies gegenüber allen staatlichen Einrichtungen vermeidet, ${ }^{8 \mathrm{r}}$ liefert der paradoxe Rollentausch zwischen Richter und Verurteiltem einen schlagenden Beweis für die von Caecilius bezweifelte Parrhesie der Christen.

Ebenfalls als Gruppe menschlicher Sprecher figurieren an einigen Stellen die paganen Götter, die entsprechend der euhemeristischen Erklärung, die Octavius breit entwickelt, ursprünglich Menschen waren: Sie trauerten und klagten, ${ }^{82}$ wie am Beispiel der Isis und ihres passionsspielartigen Festes demonstriert wird, ${ }^{8_{3}}$ oder sie hielten den primitiven Altvorderen Lehrvorträge, so Saturn (23,10 docuit), und legten die Bezeichnung von Gegenden und Orten fest. ${ }^{{ }^{4}}$ Die Fülle der Götternamen selbst, die in schärfstem Gegensatz zur Namenlosigkeit des christlichen Gottes steht, erscheint als negatives Attribut: tot sunt Iovis monstra quot nomina $(22,6)$.

Das Orakelwesen, dessen göttlichen Ursprung Caecilius vertreten hatte, unterzieht der Christ einer doppelten Kritik. Einerseits könnten Menschen, wie es die Götter ja einst waren, nach ihrem Tod nicht zu Orakelgottheiten mutieren, ${ }^{85}$ sondern hinter den Verlautbarungen steckten in Wahrheit Menschen aus Fleisch und Blut mit ganz konkreten Interessen, Herrscher wie Philipp II. von Makedonien, Dichter wie Ennius oder die delphische Priesterschaft, die von der Leichtgläubigkeit der Leute profitierte. ${ }^{86}$

Andererseits seien gelegentlich auch die Dämonen am Werk: „Diese unreinen Geister also, die Dämonen, ... verkriechen sich hinter Statuen und Bildern, nachdem diese geweiht wurden, und erzielen durch ihren Anhauch die Autorität

80 37,I Quam pulchrum spectaculum deo, cum Christianus cum dolore congreditur, cum adversum minas et supplicia et tormenta componitur, cum strepitum mortis et horrorem carnificis inridens inculcat, cum libertatem suam adversus reges et principes erigit, soli deo, cuius est, cedit, cum triumphator et victor ipsi, qui adversum se sententiam dixit, insultat.

8I Daraus ist freilich kein ungetrübtes Verhältnis zur römischen Staatlichkeit abzuleiten, vgl. zur insgesamt distanzierten Haltung des Minucius Heck (1984).

82 22,I invenies... luctus atque planctus miserorum deorum.

83 22,I Isis perditum filium cum Cynocephalo suo et calvis sacerdotibus luget plangit inquirit ...; mox invento parvulo gaudet Isis, exsultant sacerdotes, Cynocephalus inventor gloriatur, nec desinunt annis omnibus vel perdere quod inveniunt vel invenire quod perdunt.

84 23,II [Saturnus] itaque latebram suam, quod tuto latuisset, vocari maluit Latium, et urbem Saturniam idem de suo nomine et Ianiculum Ianus ad memoriam uterque posteritatis reliquerunt.

$85 \mathrm{Vgl} .26,5$ post mortem Amphiaraus ventura respondit, qui proditum iri se ob monile ab uxore nescivit.

86 Vgl. 26,6 de Pyrrho Ennius Apollinis Pythi responsa confinxit, cum iam Apollo versus facere desisset; cuius tunc cautum illud et ambiguum defecit oraculum, cum et politiores homines et minus creduli esse coeperunt. et Demosthenes, quod sciret responsa simulata, $\varphi \imath \lambda \iota \pi \pi_{i} \zeta \varepsilon 1 v$ Pythiam querebatur. 
einer gleichsam gegenwärtigen göttlichen Macht, indem sie sich bisweilen von Sehern einatmen lassen, indem sie sich in Heiligtümern aufhalten, indem sie manchmal die Lappen der Eingeweide beleben, den Flug der Vögel steuern, Lose lenken, Orakel hervorbringen, die in mehrheitlich Falsches gehüllt sind. " ${ }^{\circ 7} \mathrm{Wie}$ hier hebt Octavius immer wieder auf Falschheit und Lüge in den Äußerungen der Dämonen ab, die insgesamt als geradezu redselig erscheinen. Sie bringen nicht nur vates und oracula zum Sprechen - daß sie für die Gerüchte, mendacia und fabulae, über die Christen verantwortlich sind, wurde bereits erwähnt ${ }^{88}-$, sondern stecken auch hinter den Traumerscheinungen (27,2 somnos inquietant; Beispiele dazu 27,4) und den wirren Äußerungen der Geistesgestörten, die Octavius auf eine Stufe mit den Prophezeiungen der heidnischen Priester stellt, aus denen die Dämonen sprechen: „Sie sind in Wirklichkeit auch die Rasenden, die ihr auf die Straßen hinausrennen seht, und es sind auch das Seher, nur ohne Tempel: so wahnsinnig gebärden sie sich jedenfalls, so bacchantisch rasen sie, so wild drehen sie sich im Kreis. Gleich groß wie bei jenen ist der Antrieb des Dämons, ungleich nur der Inhalt der Raserei “" ${ }^{\circ 9}$ Ziel der Dämonen ist es, alle zu bereden, sich von Gott ab und dem rein Stofflichen zuzuwenden (27,2 a deo vero ad materias avocant). Nur die Wahrheit sagen sie nicht freiwillig, sondern müssen dazu von den Christen beim Exorzismus gezwungen werden. ${ }^{90}$

In kategorialem Gegensatz dazu trifft man Gott, den der Christ in seiner Rede als Sprecherinstanz neu einführt, nie in Situationen gleichberechtigter Kommunikation mit Menschen an. Stumm ist der Gott des Octavius deswegen nicht, aber er spricht nicht mit, sondern nur über oder zu den Menschen, und in beiden Fällen ist sein Wort unumstößliches Gesetz. So heißt es in der kurzen Replik des Octavius zum Theodizee-Problem: „Denn was ist das Schicksal (fatum) an-

87 27,I Isti igitur inpuri spiritus, daemones ... sub statuis et imaginibus consecratis delitescunt et adflatu suo auctoritatem quasi praesentis numinis consequuntur, dum inspirantur interim vatibus, dum fanis inmorantur, dum nonnumquam extorum fibras animant, avium volatus gubernant, sortes regunt, oracula efficiunt falsos pluribus involuta.

88 Vgl. die oben Anm. 6r zitierten Stellen Oct. 28,2; 28,6 und 3I,I.

8927,3 hi sunt et furentes, quos in publicum videtis excurrere, vates et ipsi absque templo, sic insaniunt, sic bacchantur, sic rotantur: par et illis instigatio daemonis, sed argumentum dispar furoris.

$90 \mathrm{Vgl} .27,2$ veritatem ..., quam sciunt, in perditionem sui non confitentes; $27,5-7$ haec omnia sciunt plerique pars vestrum ipsos daemonas de semetipsis confiteri, quotiens a nobis ... de corporibus exiguntur. ipse Saturnus et Serapis et Iuppiter et quicquid daemonum colitis victi dolore quod sunt eloquuntur nec ... mentiuntur. ipsis testibus de se verum confitentibus esse eos daemonas credite! Ein unüberbrückbarer Widerspruch zwischen der euhemeristischen Göttererklärung und dieser Aussage, wonach die Götter Dämonen sind, der Minucius gelegentlich vorgeworfen wurde, besteht nicht: Historisch betrachtet sind die paganen Götter bedeutende Menschen, die nach ihrem Tod irrig göttliche Verehrung erhielten; für die aktuelle Wirkkraft ihrer toten Statuen und Bilder, für Traumerscheinungen etc. sind die Dämonen verantwortlich, die sich in die Statuen und Bilder begeben und im Schlaf erscheinen, und daher zu Recht ,Saturn' und ,Serapis' genannt werden können. Zur Dämonologie des Minucius vgl. Berge (1929), 32-67, ergänzend von Geisau (1968), I37I-I373, Briquel (I999) und die Kommentare zu cap. $26 f$. 
deres, als was Gott über einen jeden von uns gesagt hat (fatus est)? "बir Der Mensch mit seinem Geschick stellt das Objekt dar, das von Gottes Wort bestimmt wird. Er ist nicht der Adressat des Wortes - einen solchen nennt Minucius nicht - , sondern Gott spricht offenbar bei sich. In gleicher Weise spricht er auch über die Welt und schafft mit seinem gebieterischen Wort den Kosmos (I8,7 universa, quaecumque sunt, verbo iubet). Erneut findet sich kein Adressat, sondern das Wort an sich, das Gott spricht, wirkt. Wo er seinem Volk helfen will, erteilt er Gebote (praecepta) und Befehle, wie den, daß sich das Schilfmeer teilen soll. ${ }^{92}$ Obwohl Minucius die alttestamentliche Prophetie an zwei Stellen erwähnt, ${ }^{93}$ läßt er völlig offen, auf welche Weise die Propheten zu ihrer Erkenntnis und ihrem Auftrag kamen. Das Bemühen, jeden Gedanken an dialogische Situationen zwischen Mensch und Gott zu vermeiden, ist deutlich. Wenn sich Gott mitteilen möchte, tut er dies bevorzugt durch seine Werke: „Wir glauben gerade deshalb, daß er Gott ist, weil wir uns seiner bewußt werden können und ihn doch nicht sehen können. Denn in seinen Werken (in operibus eius) und in allen Bewegungen des Kosmos erblicken wir seine stets gegenwärtige Kraft (virtutem semper praesentem). ${ }^{\text {"94 }}$ Bezeichnenderweise lebt der Mensch daher bei Minucius nicht von einem jeden Wort, das aus Gottes Mund kommt, sondern der Glaube richtet sich auf eben diese unsichtbare, aber spürbare Kraft Gottes: „Vom Glauben an seine allgegenwärtige Größe werden wir mit Leben erfüllt (fide praesentis eius maiestatis animamur)" $(38,4)$.

Trotz der Unsichtbarkeit und unvergleichlichen Überlegenheit Gottes ist dem Christen freilich auch bei Minucius nicht jede Möglichkeit der Kontaktaufnahme mit seinem Gott abgeschnitten. Vielleicht in Anlehnung an Mt 7,7 (petite et dabitur vobis) kann Minucius für das Bittgebet ein starkes Wort einsetzen: „Und dennoch könnten wir von Gott Geldmittel fordern (posceremus), wenn wir sie für nützlich hielten; er, dem alles gehört, wäre gewiß in der Lage, uns ein wenig zu bewilligen. "955 Doch bleibt auch hier der himmelweite Unterschied zwischen menschlichem Bittsteller und Allherrscher, der sich gütig herabläßt (indulgere), gewahrt.

Nirgends tritt die totale Andersartigkeit Gottes so klar hervor wie dort, wo Octavius vom menschlichen Reden über Gott bzw. von der Unmöglichkeit, Gott mit Worten zu umschreiben, handelt: „Und du brauchst auch keinen Namen für

9I 36,2 quid enim aliud est fatum quam quod de unoquoque nostrum deus fatus est?

92 33,3 dum fugiunt insequentes dei iussu et elementis adnitentibus obruerunt. Vgl. auch 33,3 quamdiu praeceptis salubribus obtemperaverunt, de paucis innumeri facti.

93 So 33,4, nichts sei den Juden geschehen, quod non sit his, si in contumacia perseverarent, ante praedictum, und 34,5, vgl. oben Anm. 7 I.

94 32,4 ex hoc deum credimus quod eum sentire possumus, videre non possumus. in operibus enim eius et in mundi omnibus motibus virtutem eius semper praesentem aspicimus.

95 36,7 et tamen facultates, si utiles putaremus, a deo posceremus; utique indulgere posset aliquantum cuius est totum. 
Gott zu suchen. ,Gott' ist sein Name. Dort sind Benennungen nötig, wo man eine Menge mit Hilfe der Kennzeichnung durch spezifische Rufnamen nach Einzelpersonen aufteilen muß. Gott, der nur einer ist, gehört der Name ,Gott' in Gänze. Denn wenn ich ihn ,Vater' nenne, könntest du vermuten, er sei ein Erdbewohner; wenn ,König', könntest du argwöhnen, er sei aus Fleisch und Blut; wenn ,Herr', wirst du es auf alle Fälle so verstehen, als sei er ein Sterblicher. Lasse nur die Zusatzbenennungen beiseite und du wirst die herrliche Klarheit seines Namens erkennen“"966 Einzelne Namen besitzen Pflanzen, Tiere, Menschen, Dämonen, eine eigene Kategorie, deren Begriff mit ihrem Namen zusammenfällt, stellt nur Gott dar ${ }^{77}$.

\section{VIII.}

Minucius Felix hat nicht nur über die Gefährlichkeit der klassischen Rhetorik und über die Möglichkeiten, eine neue christliche Rhetorik zu entwickeln, sondern auch über das Phänomen menschlicher Rede als solches und deren Verhältnis zum Wort Gottes gründlich nachgedacht, wie die Sorgfalt zeigt, mit der er auf diesem Feld die Worte wählt. Überblickt man die Verteilung und Bewertung von Reden und Schweigen im Octavius, zeichnet sich ein Stufenmodell ab, das dem augustinischen Modell der Bildung ähnelt. So wie Augustin den Elementarbereich, lesen und schreiben zu lernen, positiv beurteilt, da er die Kenntnis der Heiligen Schrift erst ermöglicht, und die größten Schwierigkeiten in den höchsten Stufen der rhetorischen Schulung verortet, sieht Minucius in der Fähigkeit zu sprechen, die schon den kleinen Kindern geschenkt wird und auch den schlichtesten Gemütern eignet, eine gute Gabe Gottes, die zwischenmenschlichen Austausch erst ermöglicht, selbst wenn sie ihr Ziel bisweilen verfehlt. Wenn sie als sermo dieser Grundfunktion treu bleibt, sind Mißverständnisse und unvollkommener Ausdruck der res durch die verba zwar nicht ausgeschlossen, aber die dialogische Klärung des eigentlich Gemeinten bleibt möglich. Problematisch wird menschliche Rede dort, wo sie durch die Technik der Rhetorik zu einem Instrument der Macht- und Herrschaftsausübung umgewandelt wird und beginnt, die Wahrheit und in der Folge das Gegenüber zu unterdrücken. Dieser Gefahr sind die Dichter und Philosophen (und Redner) als Gruppen, deren Metier die Sprache ist, besonders ausgesetzt, müssen ihr aber nicht erliegen, wie die Differenzie-

96 I8,Io Nec nomen deo quaeras: Deus nomen est. illic vocabulis opus est, cum per singulos propriis appellationum insignibus multitudo dirimenda est; deo, qui solus est, dei vocabulum totum est. quem si patrem dixero, terrenum opineris; si regem, carnalem suspiceris; si dominum, intelleges utique mortalem. aufer additamenta nominum et perspicies eius claritatem.

97 Zum Gottesbegriff und den einzelnen Prädikaten Gottes im I8. Kapitel des Octavius und ihrem Verhältnis zu Tertullian vgl. ausführlich Paratore (I975). 
rung dieser Gruppen zeigt. Der Christ und damit auch der christliche Philosoph und Redner wird am sermo festhalten und diesen der Rhetorik nur soweit öffnen, als dies nötig ist, um seinen Gesprächspartner zu erreichen. Minucius hat versucht, dieses Konzept im Octavius exemplarisch umzusetzen. Der christlichen Rhetorik, die der Christ Octavius in seiner Gegenrede praktiziert, entspricht die rhetorisch-literarische Gestaltung des Dialogs insgesamt, die darauf berechnet ist, die heidnischen Adressaten dort abzuholen, wo sie aufgrund ihrer Vorbildung stehen, ohne den christlichen Standpunkt irgendwie aufzuweichen..$^{98}$ Mag auch der Begriff des style cryptochrétien nicht ganz glücklich sein, hat Jacques Fontaine das Konzept der Sache nach völlig zutreffend beschrieben. ${ }^{99}$

Konsequent eingeordnet in den Bereich menschlicher Rede und seine Ambivalenz werden alle Äußerungen, die sich den paganen Göttern zuweisen lassen, sei es daß sie als Menschen- oder Dämonenwort gedeutet sind. Hier potenzieren sich die negativen Aspekte, die der Rhetorik zugeschrieben wurden, es dominieren Verunglimpfung, Lüge und Halbwahrheiten.

Zwischen dem unvollkommenen sermo der Menschen und Dämonen und Gottes Logos besteht hingegen ein fundamentaler Unterschied, den Minucius zumindest andeutet. Sein gebieterisches Wort ist ganz wahr und immer gültig, nicht Teil eines Diskurses, sondern von außen kommende, unverfügbare Macht. Schon deshalb muß es innerhalb eines Dialogs, der der Octavius ja ist und in dessen Zentrum der Austausch von Menschen über ihnen zugängliche Gegenstände steht, ein Fremdkörper bleiben. Jede breitere Entwicklung der Andersartigkeit von Gottes Wort hätte Minucius' literarisches Konzept einer dialogischen Apologie erheblich beeinträchtigen müssen: Wozu diskutieren, wenn die Wahrheit ohnehin von Gott dekretiert wird und nachzulesen ist?

Hinzu kommt, daß die apologetische Grundentscheidung, sich an die Gebildeten, nicht aber die zünftigen Philosophen zu wenden, detailliertere philosophische bzw. theologische Erörterungen grundsätzlich nicht erlaubte: Die potenziellen Adressaten hätten von zu viel Tiefe nur abgeschreckt werden können. Daher

98 Vgl. zum Profil des Zielpublikums Aland (1985). Die Nähe des Minucius zur paganen Bildung betont nach anderen von Albrecht (1987), die innere Distanz Buchheit (1993). Tatsächlich ist beides gegeben. Beispielhaft zeigt Rizzi (1990) für den Prolog, wie Minucius die Anschlußfähigkeit an die heidnischen Leser durch die breite Aufnahme ciceronischer Sprache und Gedanken herstellt, ohne sich dem paganen Diskurs unterzuordnen. In gleicher Weise lassen sich die Aufnahme der ciceronischen Dialogtechnik und ihre 'Zweckentfremdung' zu christlichen Zwecken, die Powell (2007) sieht, und die christliche Umformung der literarischen Gattung Dialog, die Heyden (2009) herausarbeitet, als Teil eines Konzepts verstehen, das den Adressatenkreis möglichst wirkungsvoll ansprechen will, ohne daß der Octavius deshalb Gebrauchsliteratur im technischen Sinn wäre.

99 Vgl. Fontaine (I968), II9. Zur stilistischen Differenzierung der einzelnen Teile des Octavius vgl. auch O'Connor (1976), der einen schärferen Gegensatz zwischen der religiös unwahren ciceronischen Rhetorik des Heiden und der christlichen elocutio des Octavius, die in sich den Beweis ihrer Wahrhaftigkeit trägt, sieht. 
bewegt sich Minucius stets auf allgemein vertrautem philosophischem Terrain. Dazu gehört die Orakelkritik und die Kritik am Polytheismus, nicht aber die Diskussion darüber, nach welchen Kriterien zwischen richtiger und falscher Prophetie, zwischen Gesichten Gottes und falschen Träumen, zwischen inspirierten Schriften und solchen, die es nur behaupten, zu unterscheiden ist. Indem Minucius die trügerische (menschlich-dämonische) Götterrede ganz der paganen Religion zuschiebt und Gott nicht in Dialogsituationen mit Menschen zeigt, umgeht er die seinen Adressaten neue Schwierigkeit, solche Kriterien benennen und begründen zu müssen. Daß dies erheblichen Aufwand erfordert, zeigt etwa das Apologeticum Tertullians, der zur Begründung des Offenbarungscharakters der Bibel in Kapitel I8 bis 2I mit Altersbeweis und Christologie weit ausholen muß, ehe er auf die falschen Orakel der Dämonen eingehen kann. Anscheinend hat Minucius gesehen, daß dieser Argumentationskomplex mit dem Zuschnitt seiner Apologie nicht vereinbar war.

Über weitere Gründe läßt sich nur spekulieren. Vielleicht veranlaßte ihn zusätzlich die Skepsis gegenüber der Zungenrede, die sich an der Beschreibung der rasenden Priester $(27,3)$ ablesen läßt, sei es grundsätzlich, sei es aus aktuellem montanistischem Anlaß dazu, das Phänomen der Prophetie und damit inspirierten Sprechens und Schreibens überhaupt möglichst auszublenden. Vielleicht war er sich der Unvollkommenheit auch des eigenen Wortes so bewußt, daß er sich scheute, breiter über das so andere Wort Gottes zu reden, und zog es vor, lieber gar nichts, als etwas Falsches zu sagen. In jedem Fall zeigt die Behandlung des Themenfeldes, daß er gewiß keine oberflächliche Ansicht des Christentums besaß und sich über Besonderheit und Unverfügbarkeit des göttlichen Logos völlig im Klaren war. 


\section{Literaturverzeichnis}

Aland (1985): Barbara Aland, „Christentum, Bildung und römische Oberschicht. Zum Octavius des Minucius Felix“, in: H.-D. Blume / F. Mann (Hgg.), Platonismus und Christentum. Festschrift für Heinrich Dörrie, Münster, 2. Aufl., II-3O.

von Albrecht (1987): Michael von Albrecht, „M. Minucius Felix as a Christian Humanist", Illinois Classical Studies I2, 157-168.

Bammel (1993): Caroline Bammel, „Die erste lateinische Rede gegen die Christen", $Z K G$ 104,295-3II.

Beaujeu (1974): Jean Beaujeu (Hg.), Minucius Felix Octavius, Paris, 2. Aufl.

Berge (1929): Reinhold Berge, Exegetische Bemerkungen zur Dämonenauffassung des M. Minucius Felix, Diss. Freiburg.

Bodelón (1992-1993): Serafín Bodelón, „El discurso anticristiano de Cecilio en el Octavio de Minucio Felix", Memorias de historia antigua (Oviedo) I3-I4, 247-294.

Bodelón (1994-1995): Serafín Bodelón, „El discurso antipagano de Octavio en la obra de Minucio Félix“, Memorias de historia antigua (Oviedo) I5-I6, 5I-I42.

Briquel (1999): Dominique Briquel, „Minucius Felix“, in: dies. u. Charles Guittard (Hgg.), Etrusca disciplina 8. Actes de la table ronde tenue à l'ENS les 24 et 25 octobre 1997, Tours, I25-I30.

Buchheit (1985): Vinzenz Buchheit, „Die Wahrheit im Heilsplan Gottes bei Minucius Felix (Oct. 38,7)“, VigChr 39, I05-I09.

Buchheit (1993): Vinzenz Buchheit, „Bildung im Dienst der Wahrheit (Min. Fel. Oct. I4)“, SO 68, II6-I28.

Buchheit (1996): Vinzenz Buchheit, „Vergil als Zeuge der natürlichen Gotteserkenntnis bei Minucius Felix und Laktanz", RMP 139, 254-259.

Chapot (1998): Frédéric Chapot, „Les grandes orientations des travaux sur l'Octavius de Minucius Felix. Remarques sur trente ans de bibliographie“, Vita Latina $150,18-28$.

Courcelle (1964): Pierre Courcelle, „Virgile et l'immanence divine chez Minucius Felix“, in: Alfred Stuiber / Alfred Hermann (Hgg.), Mullus. Festschrift Theodor Klauser, Münster, 34-42.

Fausch (1966): Walter Fausch, Die Einleitungskapitel zum Octavius des Minucius Felix, Diss. Zürich.

Ferrarino (1986): Pietro Ferrarino, „Il problema artistico e cronologico dell' Octavius", in: ders., Scritti scelti, Firenze, 222-273.

Fontaine (1968): Jacques Fontaine, „Minucius Félix et les valeurs ambiguës d'un style cryptochrétien“, in: ders., Aspects et problèmes de la prose d'art Latine au III siècle, Torino, 98-I2I. 
Freund (2003): Stefan Freund, Vergil im frühen Christentum, Paderborn u.a., 2. Aufl.

Hasenhütl (2008): Franz Hasenhütl, Die Heidenrede im Octavius des Minucius Felix als Brennpunkt antichristlicher Apologetik, Wien u. Berlin.

von Geisau (1968): Hans von Geisau, „M. Minucius Felix“, PRE Suppl. II, 952I0O2 u. I365-I378.

Heck (1984): Eberhard Heck, „Minucius Felix und der römische Staat“, VigChr $38, \mathrm{I} 54-\mathrm{I} 64$.

Heck (1990): Eberhard Heck, „Vestrum est - poeta noster. Von der Geringschätzung Vergils zu seiner Aneignung in der frühchristlichen lateinischen Apologetik", $M H_{47}$, IO2-I2O.

Heck (1997): Eberhard Heck, „M. Minucius Felix“, in: $H A W 8$ 8, München, 512519.

Heyden (2009): Katharina Heyden, „Christliche Transformation des antiken Dialogs bei Justin und Minucius Felix“, Zeitschrift für Antikes Christentum I3, 204-232.

Krafft (2002): Peter Krafft, „Fronto und Minucius Felix“, in: Wilhelm Blümer, Rainer Henke und Markus Mülke (Hgg.), Alvarium: Festschrift für Christian Gnilka, Münster, 219-225.

Kühn (I872): Richard Kühn, Der Octavius des Minucius Felix, eine heidnisch-philosophische Auffassung vom Christenthum, Diss. Leipzig.

Kytzler (1992): Bernhard Kytzler (Hg.), M. Minuci Felicis Octavius, Stuttgart u. Leipzig, 2. Aufl.

Kytzler / Najock (1991): Bernhard Kytzler / Dietmar Najock, Concordantia in Minuci Felicis Octavium, Hildesheim u. a.

Lieberg (1963): Godo Lieberg, „Die römische Religion bei Minucius Felix“, RMP I06, 62-79.

Mühl (I968): Max Mühl, „Zum Problem der Christologie im Octavius des Minucius Felix“, $R M P$ III, 69-78.

Muth (1978): Robert Muth, „Vom Wesen römischer religio“, $A N R W$ 2,I6,I, 290354.

O'Connor (1976): Joseph F. O'Connor, „The conflict of rhetoric in the Octavius of Minucius Felix“, CIF 30, I65-173.

Paratore (1975): Ettore Paratore, „Il c. I7 dell' Apologeticum e il c. I8 dell' Octavius", in: Forma Futuri. Studi in Onore del Cardinale Michele Pellegrino, Torino, 36I-394.

Pellegrino (2000): Michele Pellegrino, Paolo Siniscalco u. Marco Rizzi (Hgg.), Marco Minucio Felice, Ottavio, Torino.

Piepenbrink (2005): Karen Piepenbrink, Christliche Identität und Assimilation in der Spätantike, Frankfurt. 
Powell (2007): Jonathan Powell, „Unfair to Caecilius? Ciceronian dialogue techniques in Minucius Felix “, in: Simon Swain, Stephen Harrison u. Jas Elsner (Hgg.), Severan Culture, Cambridge, 177-189.

Rizzi (1990): Marco Rizzi, „Amicitia e veritas. Il prologo dell'Octavius di Minucio Felice“, Aevum Antiquum 3, 245-268.

Stölting (2006): Gisela Stölting, Probleme der Interpretation des Octavius von Minucius Felix, Diss. Franfurt/Main.

Van der Nat (1977): Pieter G. Van der Nat, „Zu den Voraussetzungen der christlichen lateinischen Literatur: die Zeugnisse von Minucius Felix und Laktanz", in: Manfred Fuhrmann (Hg.), Christianisme et formes littéraires de l'antiquité tardive en occident (EnAC 23), Genèves, 19I-234.

Wlosok (1990): Antonie Wlosok, „Römischer Religions- und Gottesbegriff in heidnischer und christlicher Zeit", in: Eberhard Heck (Hg.): Antonie Wlosok, Res humanae - res divinae, Kleine Schriften, Heidelberg, I5-34. 


\title{
Die Philosophen in Tertullians Apologeticum
}

\author{
Ihre Bedeutung für den Epilog und das gesamte Werk
}

\author{
Tobias GeORgES
}

Das Thema „Tertullian und die Philosophie“ ist häufig traktiert worden. ${ }^{.}$Eine besondere und bislang nicht näher beleuchtete Facette dieses Themas bildet die Art und Weise, in welcher Tertullian in seinem Apologeticum (apol.) auf die Philosophie und vor allem auf die Philosophen Bezug nimmt. Eine Untersuchung zur Bedeutung der Philosophen im apol. und speziell in dessen Epilog bzw. Peroratio (apol. 46-50) ${ }^{2}$ verspricht nicht nur eine Konkretisierung der übergeordneten Thematik anhand eines - herausragenden - Werkes des Nordafrikaners. Sie erweist sich auch als aufschlussreich für die Gesamtanlage des apol., insbesondere für die Frage nach der Funktion der Peroratio innerhalb dieser Anlage.

Im Epilog des apol., speziell in dessen erster Hälfte $(46, \mathrm{I}-49,3)$ macht Tertullian die Philosophie und die Philosophen eigens zum Thema. Er vergleicht die Philosophen und die Christen und grenzt sie voneinander ab. Bis einschließlich apol. 45 werden die Philosophen zwar mehrfach erwähnt, aber nur jeweils im Zusammenhang übergeordneter Themen. Daher stellt sich die Frage: Warum richtet Tertullian am Ende seines Werkes den Fokus speziell auf die Philosophen? Bei der Beschäftigung mit dieser Frage wird sich zeigen, dass sich von ihrer Beant-

I Vgl. z. B. R. Braun, Tertullien et la philosophie païenne. Essai de mise au point, in: ders., Approches de Tertullien, Paris 1992, 2I-4I; E. Osborn, Was Tertullian a Philosopher?, StPatr 3I (1997) 322-334; ders., Tertullian as Philosopher and Roman, in: D. Wyrwa (Hg.), Die Weltlichkeit des Glaubens in der Alten Kirche (FS für Ulrich Wickert zum 70. Geburtstag), Berlin 1997, 23I-247; G. D. Dunn, Tertullian, London / New York 2004, 3I-34.

2 Die Termini „Peroratio“ und „Epilog“" werden hier synonym gebraucht. Vgl. zur Angemessenheit dieses Vorgehens G. Eckert, Orator Christianus. Untersuchungen zur Argumentationskunst in Tertullians Apologeticum, Stuttgart 1993, 178.182. - Die Kapitel 46-50 werden in ihrer Gesamtheit von der Mehrheit der Kommentatoren als Peroratio oder Epilog angesehen; vgl. z. B. C. Becker, Tertullians Apologeticum. Werden und Leistung, München 1954, 269-306; ders. (Hg.), Tertullian - Apologeticum. Lateinisch und deutsch, München ${ }^{4}$ 1992, 24; R. D. Sider, Christian and Pagan in the Roman Empire. The Witness of Tertullian, Washington 200I, 6; Eckert (ebd.), I78-I93. Hingegen hat z. B. J. P. Waltzing, Tertullien - Apologétique. Commentaire analytique, grammatical et historique, Paris I93I, 283-326 nur den Abschnitt 49,450,16 als „Péroraison“ eingestuft und die vorherigen Ausführungen noch der Argumentatio zugerechnet. Eckert (ebd.), I78-245 hat jedoch eingehend dargelegt, warum die fünf Schlusskapitel zusammen als Epilog zu beurteilen sind. 
wortung her die Lösungen für zwei weitere grundlegende Fragen erschließen, die der Epilog aufwirft: die Fragen nach dem zentralen Bindeglied der beiden Epilogteile $(46, \mathrm{I}-49,3 ; 49,4-50,16)^{3}$ sowie nach der Aufgabe, die der Epilog im Gesamtentwurf des apol. wahrnimmt. Die Frage nach dem Bindeglied drängt sich auf. Denn die beiden Teile der Peroratio hängen zwar durch übergreifende Motive, so die Philosophenthematik und die eschatologische Perspektive, offensichtlich miteinander zusammen; angesichts der unterschiedlichen Schwerpunktthemen, mit denen die beiden Teile sich befassen - in 46,I-49,3 die Abgrenzung zwischen Philosophen und Christen, in 49,4-50,16 die Standhaftigkeit der Christen vor dem irdischen Gericht und ihr Triumphieren im Jüngsten Gericht - liegt das Einheit schaffende Moment aber nicht auf der Hand. Die Frage nach der Funktion des Epilogs verlangt gerade insofern eine nähere Betrachtung, als sie bislang sehr unterschiedliche Antworten gefunden hat: So hat z. B. Heinze den Epilog deutlich vom restlichen Werk abgesetzt, ${ }^{4}$ Becker ihn hingegen als integrativen Bestandteil des Werks interpretiert. ${ }^{5} \mathrm{Da}$ die Frage, warum Tertullian sich ab apol. 46 mit den Philosophen auseinandersetzt, den Lösungsweg für die anderen beiden Fragen weist, soll zunächst der ersteren nachgegangen werden.

Bevor der Fokus auf die Peroratio gerichtet wird, ist ein Überblick zu Tertullians Bezugnahme auf die Philosophen in apol. I-45 angezeigt. ${ }^{6}$ Er soll zum einen illustrieren, dass die Philosophen bis zum Epilog nicht selbst im Zentrum des Interesses stehen und dass ihre Thematisierung ab apol. 46 somit auffällig ist; zum anderen soll er anzeigen, auf welche Gedanken zu den Philosophen aus seinem eigenen Werk Tertullian in der Peroratio zurückgreifen kann. Grundsätzlich ist zu konstatieren, dass die "philosophi“ (apol. 3,6; 14,7; 22,I) oder einzelne namentlich genannte Philosophen (II,5; I8,7; 39,I2) auch im vorderen Teil des apol. wiederholt Erwähnung finden, wie es in einem an die pagane Umwelt der Christen gerichteten Werk nicht verwundert. Diese Hinweise auf die Philosophen stehen aber jeweils im Dienste eines anderen, übergeordneten Themas und sind punktuell. Gut veranschaulichen lässt sich die punktuelle Bezugnahme an der Person des Sokrates (II,I5; I4,7f.; 22,I; 39,I2), der neben Plato (II,5; 22,2; 23,I3; 24,3; 40,4) im apol. meistgenannten Philosophengestalt.? Sokrates begegnet ein-

3 Vgl. zur Diskussion über die Frage, ob der Epilog in 46,I und nicht erst in 49,4 beginnt, die vorangehende Anmerkung. Die folgenden Ausführungen werden die Zusammengehörigkeit der Kapitel 46-50 als Epilog belegen.

4 Vgl. R. Heinze, Tertullians Apologeticum, Leipzig I9IO, 462-488.

5 Vgl. Becker, Tertullians Apologeticum. Werden und Leistung (Anm. 2), 269-305.

6 Die folgende Analyse legt die Corpus Christianorum-Edition des apol. durch E. Dekkers (Q. S. Fl. Tertulliani Apologeticum, hg. von E. Dekkers, in: Quinti Septimi Florentis Tertulliani Opera, Bd. I, Turnhout 1954 [CChr.SL i], 85-17I) zugrunde. Die Übersetzung der angeführten Passagen ist meine eigene und lehnt sich an die Übertragung C. Beckers (Tertullian - Apologeticum. Lateinisch und deutsch, hg. und übers. von C. Becker, München ${ }^{4}$ I992) an. 
mal in I4,7f. im Zusammenhang des Vorwurfs, die Ankläger selbst verhielten sich frevelhaft gegenüber ihren Göttern; dort dient er als Zeuge des Götterspotts im paganen Schrifttum. Ein anderes Mal wird er am Beginn der Entlarvung der Dämonen in 22,I erwähnt, wo er als Beispiel dafür fungiert, dass die Philosophen mit dem Wirken der Dämonen rechnen. Ein weiteres Mal verweist Tertullian in 39,I2f. auf ihn, innerhalb der scharfen Abgrenzung des christlichen Gemeinschaftslebens von nichtchristlichen Gemeinschaftsvorstellungen: Er zeichnet ihn als Vorbild paganer Promiskuität. So unterschiedlich die Kontexte sind, in denen Sokrates begegnet, so vielschichtig sind auch die Wertungen der Philosophen, die Tertullian mit diesen Bezugnahmen transportiert. In I4,7f. wendet Tertullian sich kritisch gegen Sokrates, weil dieser gegen die Götter frevelte. Diese Kritik ist freilich nur vordergründig und dient der Retorsio des Vorwurfs der laesa religio. Indem Tertullian zur Verurteilung des Sokrates durch die Athener anmerkt: „Gewiss, seit jeher, das heißt immer, ist die Wahrheit verhasst“ ${ }^{8}$ lässt er erkennen: Mit seinem Götterspott hat Sokrates der Wahrheit einen Dienst geleistet (vgl. 46,6). Sofern der Philosoph Sokrates sich in seinen Ansichten mit den Überzeugungen Tertullians berührt, zollt dieser ihm also durchaus Respekt. Von daher ist es nicht außergewöhnlich, dass Tertullian sich zur Untermauerung seiner eigenen Darlegungen auch auf einzelne Philosophen beruft, so in I8,7 auf den Philosophen Menedemus. Die Anerkennung dieser Philosophen ist aber nie grundsätzlich, sie beschränkt sich jeweils auf den Punkt, in dem die Philosophen mit Tertullian übereinstimmen. Dieser Sachverhalt wird in 22,I deutlich. Tertullian geht dort in seiner Argumentation von der Existenz der Dämonen aus. Zum Beleg dieser Existenz greift er auf die Kenntnis der Philosophen von den Dämonen zurück und veranschaulicht sie an der Person des Sokrates. Jenseits dieser Indienstnahme der Philosophen wird aber Tertullians Kritik an Sokrates unschwer deutlich: Sokrates rechnet nicht nur mit der Existenz der Dämonen, sondern verlässt sich auch auf die Dämonen, die doch in Tertullians Augen den Menschen nur vom Guten abbringen können (vgl. 46,5). ${ }^{9}$ Noch ausgeprägter ist Tertullians Kritik an Sokrates in 39,I2f. Die Ansichten des Philosophen dienen von vornherein als Gegenbild zum christlichen Gemeinschaftsideal. In höchst polemischer Weise kontrastiert Tertullian die christliche Praxis, die nur den ehelichen Sexualverkehr von der gemeinschaftlichen Teilhabe ausschließe, von der „disciplina“ des Sokrates, welche beim Thema Teilhabe nur die sexuelle Gemeinschaft über Ehegrenzen

7 Dass Tertullian Sokrates als exemplarischen Philosophen behandelt, wird ersichtlich in I4,7 (Taceo de philosophis, Socrate contentus) und 39,I2f. (maiorum et sapientiorum suorum disciplina, Graeci Socratis et Romani Catonis, qui uxores suas amicis communicaverunt ... O sapientiae Atticae, o Romanae gravitatis exemplum: leno est philosophus et censor).

8 Apol. I4,7f.: Plane olim, id est emper, veritas odio est.

9 Apol. 22,I: Socrate ipso ad daemonis arbitrium expectante. Quidni? Cum ipsi daemonium a pueritia adhaesisse dicatur, dehortatorium plane a bono. 
hinweg kenne. ${ }^{\text {Io }}$ Stellt man die Erwähnungen des Sokrates in 22,I und 39,I2f. in den Kontext von Tertullians Sichtweise der Philosophen, wie sie aus seinen anderen Werken - und wie sich zeigen wird, auch aus der Peroratio des apol. - hervorgeht, ${ }^{\text {II }}$ so werden an ihnen zwei Schwerpunkte seiner Kritik an den Philosophen sichtbar: einerseits ihre fehlgeleiteten Ansichten und Lehren, andererseits ihre unmoralische Lebenspraxis. ${ }^{\text {I2 }}$

Im Spannungsfeld zwischen partieller Übereinstimmung und scharfer Abgrenzung bewegen sich die Bezugnahmen auf die Philosophen in apol. I-45. Es entspricht diesem Spannungsfeld, dass die Erwähnungen einzelner Philosophen bisweilen recht ambivalent erscheinen, wie sich an zwei Hinweisen auf Plato den, wie schon gesagt, neben Sokrates prominentesten Philosophen im apol. gut zeigen lässt. In 23,13 räumt Tertullian den Dämonen und all jenen, die das jüngste Gericht durch den Gott der Christen leugnen, als vermeintliche Ausflucht die Vorstellung ein, das Gericht läge in den Händen des Minos und des Rhadamantus, wie auch Plato bezeuge. ${ }^{13}$ Unterschwellig ist hier die Kritik an Platos Konkurrenzvorstellung zum Gericht durch den einen Gott zu hören; zugleich untermauert Tertullian durch diese Vorstellung den Gerichtshorizont und seine Drohung an die Leugner des Gerichts. Eine ähnliche Ambivalenz ist in 24,3 zu vernehmen. Dort geht er - hypothetisch - von der Prämisse aus, die Vielheit der Götter existiere, und legt seinen Lesern nahe, sie sollten mit Plato von der Herrschaft eines höchsten Gottes über die anderen Götter ausgehen. ${ }^{14}$ Die Voraussetzung eines Götterpantheons ist für Tertullian freilich undenkbar und zeigt Platos Irrtum an. Indes ist Platos Gedanke eines höchsten Gottes in Tertullians Augen ein gewichtiges Argument für die unvergleichliche maiestas des - einen - Gottes der Christen.

Io Apol. 39,I2f: In isto loco consortium solvimus, in quo solo ceteri homines consortium exercent, qui non amicorum solummodo matrimonia usurpant, sed et sua amicis patientissime subministrant, ex illa, credo, maiorum et sapientiorum suorum disciplina, Graeci Socratis et Romani Catonis, qui uxores suas amicis communicaverunt ... O sapientiae Atticae, o Romanae gravitatis exemplum: leno est philosophus et censor!

II Vgl. zu Tertullians Sicht der Philosophen in seinem Gesamtwerk Braun (Anm. I), 2I-4I; Osborn, (Anm. I), Was Tertullian a Philosopher?, 322-334; Dunn, (Anm. I), 3I-34.

I2 Tertullian verschont auch Sokrates nicht vor seiner Kritik an den Philosophen. Die kritische Sichtweise des Sokrates ist gegenüber dessen positiver Bewertung in den früheren griechischen Apologien singulär. Vgl. hierzu K. Döring, Exemplum Socratis. Studien zur Sokratesnachwirkung in der kynisch-stoischen Popularphilosophie der frühen Kaiserzeit und im frühen Christentum, Wiesbaden 1979, I43-I6I; I. Opelt, Das Bild des Sokrates in der christlichen lateinischen Literatur, in: H.-D. Blume/F. Mann, (Hg.), Platonismus und Christentum (FS H. Dörrie), Münster 1983, 192-197.

I3 Apol. 23,13: Dicant hoc tribunali, si forte, Minoen et Rhadamanthum secundum consensum Platonis et poetarum esse sortitos.

I4 Apol. 24,3: Nunc ut constaret illos deos esse, nonne concederetis de aestimatione communi aliquem esse sublimiorem et potentiorem, velut principem mundi perfectae maiestatis? ... ut Plato Iovem magnum in caelo comitatum exercitu describit deourm pariter et daemonum. 
In den genannten Bezugnahmen stehen die Philosophen thematisch nicht im Zentrum; sie finden im Zusammenhang unterschiedlicher, jeweils übergeordneter Themen Erwähnung, dienen der Argumentation als Abgrenzungsfolie oder unterstützen sie, sind Adressaten von Nebenbemerkungen oder Seitenhieben. Die Aussagen und Wertungen zu den Philosophen lassen dennoch Ansätze erkennen, die Tertullian im Epilog zusammenführen und vertiefen wird, so die Verbindung der Philosophen zur Wahrheitsthematik (vgl. I4,7f.), zu den Dämonen (vgl. 22,I) und zur Gerichtsthematik (vgl. 23,13), die Kritik an der Erkenntnis (vgl. 23,13; 24,3) und Lebensführung (vgl. 39,I3f.) der Philosophen. Warum er die Philosophen in der Peroratio eigens thematisiert, und welche Sichtweise der Philosophen er dabei erkennen lässt, soll im Durchgang durch apol. 46,I-49,3 nun erläutert werden.

Tertullian resümiert in 46,I zunächst die Argumentatio und lässt in 46,2 die prägnanten Worte folgen: „Aber wenngleich unsere Wahrheit einem jeden offen sichtbar wird, erachtet doch die Ungläubigkeit - obwohl sie gezwungen ist, den guten Charakter unserer Gemeinschaft anzuerkennen, der schon durch den Umgang und vom Verkehr mit ihr her bekannt geworden ist - unsere Gemeinschaft keineswegs als eine göttliche Angelegenheit, sondern eher als eine Art Philosophie. ${ }^{\text {"II }}$ Dieser programmatischen Äußerung sind schon wesentliche Faktoren dafür zu entnehmen, dass Tertullian im Anschluss an die Argumentatio noch näher auf die Philosophen eingeht. Er wertet den Ertrag seiner bisherigen Ausführungen als Offenlegung der christlichen Wahrheit vor jedermann - genau diese Offenlegung hat er von I,If. an bezweckt -, sieht jedoch folgendes Problem: Die ungläubige Haltung - die er bei seinen paganen Hörern voraussetzt - kann zwar nicht leugnen, dass die christliche Gemeinschaft etwas Gutes ist, zieht daraus aber nicht den Schluss, diese Gemeinschaft als ,göttliche Angelegenheit“ zu verstehen, sondern wertet sie als „eine Art Philosophie.“ Er sieht somit die Gefahr einer Verwechslung zwischen christlichem Glauben und Philosophie bzw. zwischen Christen und Philosophen. ${ }^{16}$ Diese Gefahr belegt er mit dem anschließenden Hinweis auf die Gleichsetzung von Christen und Philosophen durch die Nichtchristen (Eadem, inquit, et philosophi monent atque profitentur, innocentiam, iustitiam, patientiam, sobrietatem, pudicitiam). Eine solche Verwechslung ist für ihn untragbar, eben weil sie die veritas verstellt, das divinum negotium zu einem philosophiae genus macht und damit die bestehende Grunddifferenz verschleiert.

I5 Apol. 46,2: Sed dum tamen unicuique manifestatur veritas nostra, interim incredulitas, dum de bono sectae huius obducitur, quod usu iam et de commercio innotuit, non utique divinum negotium existimat, sed magis philosophiae genus.

I6 Vom abstrakten Gegenstand „der Philosophie“ (vgl. 47,2; 50,9) ist hier erstmals im apol. die Rede; da Tertullian zumeist personal von "den Philosophen" spricht, richtet die Analyse den Fokus weiterhin mehr auf die "philosophi“ als auf die ,philosophia“. Vgl. zum personalen $\mathrm{Zu}$ schnitt auf „die Philosophen“ auch J. Lortz, Tertullian als Apologet, Bd. I, Münster 1927, $353 \mathrm{f}$. 
Durch welche Kontraste Tertullian diese Differenz geprägt sieht, lässt er im einführenden Satz in 46,2 schon anklingen, und seine folgenden Ausführungen vertiefen diese Kontraste: auf der einen Seite die christliche secta und die Christiani, auf der anderen die philosophia und die philosophi (vgl. 46,5.I8; 49,I), hier divinum negotium, dort humana res (vgl. 50,I0.I6), Wahrheit und Lüge/Irrtum (vgl. 46,6f.I8; 47,II), Glaube und Ungläubigkeit (vgl. 47,3f.rzf.), bonum und malum (vgl. 50,I2). Diese Gegenüberstellungen rufen die Grundkontraste wach, die Tertullian nicht nur zwischen den Christen und den Philosophen, sondern auch grundsätzlich zwischen den Christen und ihren Anklägern im apol. sieht (vgl. I,If.IO-I3; I5,8; 2I,3I; 23,I7-I9; 45,If.). Die Verwechslung zwischen Christen und Philosophen birgt also die Gefahr einer Einordnung der causa Christianorum in die pagane Vorstellungswelt, eines Verwischens der Grenze zwischen divina und humana res in sich, der Tertullian wehren muss.

Welche Rolle die Philosophen selber bei dieser Wahrheitsverschleierung spielen, wird im Fortgang von apol. 46 deutlich. Tertullian beschwert sich zunächst darüber, dass die Christen von den Nichtchristen zwar den Philosophen gleichgesetzt werden, aber nicht, wie es konsequent wäre, gleich behandelt bzw. in Ehren gehalten werden wie diese (vgl. 46,3f.). Vor dem Hintergrund seiner eigenen Abgrenzung zwischen Philosophen und Christen bewertet er die Ungleichbehandlung in 46,5 dann doch als berechtigt (Sed merito), freilich in ironischer Brechung: Angesichts Tertullians Begründung und seiner Wertmaßstäbe wären nicht die Philosophen, sondern die Christen besser zu behandeln. Er rechtfertigt die Ungleichbehandlung durch Verweis auf die Affinität der Philosophen zu den Dämonen (Nomen hoc philosophorum daemonia non fugiunt. Quidni? Cum secundum deos philosophi daemonas deputent), zu deren Beleg er wieder auf die Person des Sokrates verweist (vgl. 22,I). Die gottähnliche Verehrung der Dämonen durch die Philosophen ist der Frontstellung der Christen zu den Dämonen (vgl. 23,4-16; 27,5-7) diametral entgegengesetzt. Der Zusammenhang zwischen den Philosophen, den Dämonen und der Wahrheitsverschleierung erschließt sich in 46,6f., in folgendem Passus: ${ }^{17}$ „Im gleichen Maße, in dem die Wahrheit Hass entfacht, erregt auch Anstoß, wer treu für sie einsteht; wer sie aber verfälscht und erheuchelt, verschafft sich gerade damit Gunst bei denen, welche die Wahrheit verfolgen. Die Wahrheit, welche auch die Philosophen, ihre Verspötter und Verächter, feindselig erheucheln und beim Erheucheln verderben, da sie ja nach Ruhm haschen, streben die Christen sogar notwendigerweise an; und die Christen stehen ungeteilt für sie ein, da sie ja für ihr Heil Sorge tragen. ${ }^{\text {"18 }}$ Aus dieser

I7 Die vom Gedankengang her sehr komplexen Ausführungen zu Sokrates in 46,5f. werden hier nicht eigens behandelt, da sie für Tertullians Grundgedanken zu den Philosophen keine zentrale Bedeutung haben.

I8 Apol. 46,6f.: In quantum odium flagrat veritas, in tantum qui eam ex fide praestat offendit; qui autem adulterat et affectat, hoc maxime nomine gratiam pangit apud insectatores veritatis. Quam et 
Aussage ergibt sich: Die Philosophen bewirken selber die Wahrheitsverschleierung, die hinter der Gleichsetzung von Christen und Philosophen steht. Dieses wahrheitsfeindliche Agieren geht aber nicht von ihnen allein aus. Ihr Erheucheln und Verderben der Wahrheit steht im Dienste der „Verfolger der Wahrheit“ (insectatores veritatis), deren Gunst sie sich in ihrer Ruhmsucht (vgl. 47,3; 50,4.IO) erwerben wollen. Mit den insectatores veritatis sind unzweifelhaft die Dämonen gemeint (vgl. 22,I2; 47,II). Auch hinter der Wahrheitsfeindschaft der Philosophen stehen also letztlich die Dämonen. Das Verhalten der philosophi gegenüber der Wahrheit ist demjenigen der Christen direkt entgegengesetzt: Letztere stehen treu zur Wahrheit und streben nach dem ewigen Heil statt nach menschlichem Ruhm. Dieser Kontrast fügt sich trefflich in die Kontrastreihe, die aus 46,2 hervorging, ein. Die grundsätzliche Schärfe der Grenzziehung zur Philosophie hebt Tertullian von Vorgängern wie Justin und Athenagoras ab und lässt eher Bezüge zur schroffen Entgegensetzung eines Tatian erkennen. ${ }^{19}$

Stellt man von diesem Passus aus erneut die Frage, warum Tertullian abschließend die Philosophen thematisiert, so erfährt der bisherige Lösungsansatz eine wesentliche Ergänzung: Die Philosophen sind an ihrer Verwechslung mit den Christen und an der Verschleierung der bestehenden Grunddifferenz aktiv beteiligt. Als Handlanger der Dämonen teilen sie einerseits die Blindheit ihrer Anhänger gegenüber der Wahrheit und der causa Christianorum (vgl. 47,3f.), wirken aber zugleich selber auf diese hin. Bei der Wahrheitsentstellung sind sie die hervorgehobene Instanz unter den Menschen: Tertullian benennt in 39,I2 ausdrücklich die Vorbildfunktion ihrer „disciplina“ für die pagane Gesellschaft. Will er die veritas offen legen - wie es ab I,If. sein erklärtes Ziel ist -, so muss er sich mit ihnen auseinandersetzen. Die Auseinandersetzung mit ihnen ist ein zentraler Bestandteil der Beschäftigung mit der paganen Umwelt der Christen, weil die philosophi diese Umwelt nicht nur repräsentieren, sondern in ihr auch eine Führungsposition einnehmen. Der Schluss des Werks bietet sich für diese Konfrontation an. Sich mit ihnen auseinander zu setzen heißt, sich sowohl von ihnen abzugrenzen als auch sie zu entlarven.

Diese Aufgabe unternimmt er grundlegend in apol. 46,8-17. Er stellt die Minderwertigkeit der Philosophen gegenüber den Christen hinsichtlich Erkenntnis (vgl. 22,I) und Lebensführung (vgl. 39,I2f.), und damit auch die Differenz zwischen Christen und Philosophen heraus. Den Kontrast zwischen beiden untermauert er am Abschluss von apol. 46, in den Worten von 46,18, die wesentliche Kontrastelemente, die schon in 46,2 anklangen, aufgreifen und vertiefen: „Worin also gleichen sich ein Philosoph und ein Christ, ein Schüler Griechen-

illusores et contemptores inimice philosophi affectant veritatem et affectando corrumpunt, ut qui gloriam captant, Christiani et necessario appetunt et integre praestant, ut qui saluti suae curant.

Vgl. hierzu z. B. Braun, (Anm. I), 25f. 
lands und einer des Himmels, ein Händler, dessen Geschäft die Berühmtheit, und einer, dessen Geschäft das Lebensheil ist, ein Arbeiter, der Worte, und einer, der Taten hervorbringt, ferner ein Erbauer und ein Zerstörer von Dingen, ein Fälscher und ein Erneuerer der Wahrheit, ein Dieb und ein Wächter derselben? ${ }^{20}$ Am Ende dieser Gegensatzpaare steht wieder das verderbliche Einwirken des Philosophen auf die veritas und dessen Kontrast zum Einstehen des Christen für die Wahrheit (vgl. 46,6f.).

Die bis dato gefundene Antwort auf die Frage, warum Tertullian im Epilog die Philosophen zum Thema macht, bestätigt sich in den folgenden Kapiteln. Apol. 47 knüpft direkt an 46,18 an und beleuchtet die Rolle der Philosophen ${ }^{21}$ als „Diebe“ und „Fälscher" der Wahrheit anhand ihres Rückgriffs auf die „göttliche Schrift" (divina litteratura) und die in ihr enthaltene Weisheit (47,I) und Wahrheit $(47,4)$. Tertullians Grundgedanke, den er in 47,I-4 darlegt, lautet: Die Schrift ist die Quelle aller Weisheit. Die Philosophen haben in ihrer curiositas Inhalte der Schrift geraubt; in ihrer Ungläubigkeit haben sie diese Inhalte aber nicht als göttlich aufgefasst (vgl. 46,2) und daher nicht hinreichend verstanden. Infolge haben sie die Wahrheit verfälscht und Verunsicherung geschaffen, wie Tertullian in $47,5-8$ illustriert.

Nachdem er in einem kurzen Seitenblick die Brücke geschlagen hat zwischen der Schriftverfälschung der Philosophen und der Häretiker (47,9f.) - Letztere versteht er als Abkömmlinge der Philosophen -, macht er in 47,II erneut eine Aussage, die für die hier eingeschlagene Fragerichtung von großem Interesse ist: „Alles, was der Wahrheit entgegensteht, ist aus der Wahrheit selbst konstruiert worden, wobei die Irrtumsgeister diese Nachahmerei ins Werk gesetzt haben. Von diesen sind derartige Verfälschungen der Heilslehre angestiftet worden, von diesen sind auch manche Fabeln in Umlauf gebracht worden, die durch ihre Ähnlichkeit den Glauben an die Wahrheit entkräften oder mit selbiger Ähnlichkeit vielmehr den Glauben an sich reißen sollten ..." ${ }^{22}$ Vom Kontext her ist klar, dass sich diese Äußerung auf die Verfälschung der Schrift bezieht. Sie stellt zunächst klar, dass die Philosophen beim Entstellen der Schrift bzw. ihrer Wahrheit von der veritas selbst ausgegangen sind, um diese dann, in verfälschter Form, gegen die Wahrheit zu richten, um also die Wahrheit zu verstellen. Dieser Hinweis

20 Apol. 46,2: Adeo quid simile philosophus et Christianus, Graeciae discipulus et caeli, famae negotiator et salutis vitae, verborum et factorum operator, et rerum aedificator et destructor, et interpolator et integrator veritatis, furator eius et custos?

2I In apol. 47 stellt Tertullian die Dichter an die Seite der Philosophen. Sie haben in diesem Zusammenhang aber nur nachrangige Bedeutung und spiegeln das Verhalten der Philosophen wider.

22 Apol. 47,II: Omnia adversus veritatem de ipsa veritate constructa sunt, operantibus aemulationem istam spiritibus erroris. Ab his adulteria huiusmodi salutaris disciplinae subornata, ab his quaedam etiam fabulae immissae, quae de similitudine fidem infirmarent veritatis, vel eadem sibi potius fidem raperent ... 
unterstreicht einerseits die Brisanz der Auseinandersetzung mit den Philosophen, zeigt aber zugleich die Anknüpfungsmöglichkeit an: Der Ursprung der philosophischen Weisheit bei der Wahrheit selbst macht es möglich, dass die Philosophen in ihren insgesamt freilich irreführenden Lehren Anteile der veritas transportieren. ${ }^{23}$ Aus diesem Grund kann Tertullian trotz der grundsätzlich scharfen Abgrenzung partiell auf die Philosophen rekurrieren und z. B. Sokrates eine Ahnung von der Wahrheit attestieren (vgl. I4,7; 46,5). - Im Fortgang des Satzes ist die Erläuterung bemerkenswert, dass die „Irrtumsgeister" - bzw. die Dämonen (vgl. 22,I2; 27,4f.) - die Urheber der Wahrheitsverfälschung sind. Hier und in der folgenden Veranschaulichung ihres wahrheitsfeindlichen Wirkens bestätigt sich, dass sie im Hintergrund der Philosophen die eigentlichen Drahtzieher sind (vgl. 46,5-7). Die Dämonen versprechen sich durch ihr Werk, den Glauben von der Wahrheit ab- und auf sich selbst hinzulenken, um damit sich selbst zu Göttern zu machen $;^{24}$ dieses Ziel erreichen sie gerade, wenn der christliche Glaube als Philosophie missverstanden wird: Denn diese richtet sich in Tertullians Augen nicht auf den einen Gott, sondern auf die Götter bzw. Dämonen (vgl. 46,5), die eben nicht göttlich sind. Da die Philosophen in diesem Plan der Dämonen eine Schlüsselrolle spielen, tritt Tertullian ihnen entgegen.

Zur Veranschaulichung der Versuche von Seiten der Philosophen, die Wahrheit zu verstellen, stellt Tertullian im Folgenden einzelne christliche Glaubensinhalte und die jeweiligen philosophischen Konkurrenzmodelle einander gegenüber und kommt jeweils zu dem Ergebnis, dass die christlichen Lehren glaubwürdiger sind. Er beleuchtet zunächst eher knapp in 47,I2-I4 die christlichen Vorstellungen vom göttlichen Gericht, der Hölle und dem Paradies sowie die jeweiligen Äquivalente der Philosophen, in apol. 48 dann ausführlicher die christliche Vorstellung von der individuellen Auferstehung des Menschen mit Leib und Seele sowie die philosophische Seelenwanderungslehre. Überblickt man die christlichen Glaubensinhalte, so fällt deren Konzentration auf die eschatologische Perspektive und speziell auf das jüngste Gericht auf: Es bildet den Schwerpunkt in 47,I2-I4, sofern in ihm die Weichenstellung für die Ewigkeit, hin zu Hölle oder Paradies geschieht; und auch die Ausführungen zur Auferstehung haben eine deutliche Dynamik auf das Gericht hin: Gemäß 48,4 liegt „der Grund für die Wiederherstellung in der Bestimmung zum Gericht" (ratio restitutionis destinatio iudicii est), und in 48,12-15 malt Tertullian dieses iudicium einschließlich seiner für die Ewigkeit drohenden Folgen drastisch aus. Von dieser Beobachtung aus erfährt die bisherige Antwort auf die Frage, warum die Philosophen im Epi-

23 Von daher ist es auch verständlich, dass Tertullian sich in seinen Werken insgesamt nicht grundsätzlich gegen die menschliche ratio wendet, diese vielmehr als eine wesentliche Erkenntnisquelle behandelt. Seine Polemik gegen die ratio der Philosophen bezieht sich auf deren entstellte - Vernunfterkenntnis. Vgl. hierzu Dunn, (Anm. I), 32-34.

24 In Tertullians Augen sind die Götter ja nichts als Dämonen (vgl. 23,IO). 
$\log$ thematisiert werden, noch eine wesentliche Präzisierung. Die Philosophen versuchen ja gerade, mit ihren konkurrierenden Lehren die christliche Vorstellung vom Gericht zu verstellen. Mit ihrem Hinwirken auf die Verschleierung der Wahrheit verstellen sie also im Speziellen die Wahrheit vom Gericht, die Tertullian offensichtlich sehr wichtig ist. Dass es ihm mit dem Gericht um die Wahrheit geht, lässt sich unschwer erschließen: Die christliche Vorstellung vom kommenden göttlichen Gericht steht am Beginn der Ausführungen in 47,I2-I4, und in 47,I4 kommt Tertullian zu dem Schluss, dass „niemals ... die Nachbildung dem Wahren" vorausgeht (numquam ... veritatem imago praecedit), dass also die Gerichtsvorstellung ursprünglich und wahr ist.

Für die Wahrheit der christlichen eschatologischen Vorstellungen tritt Tertullian schließlich auch am Schluss der ersten Hälfte des Epilogs, in 49,I-3 ein, indem er den Nichtchristen den Nutzen der Angst vor ewiger Strafe sowie der Hoffnung auf ewige Erquickung vor Augen hält: Drohung und Verheißung bewegten Menschen zur Besserung, und schon von daher sei mit ihrer Wahrheit zu rechnen. ${ }^{25}$ Auch wenn er in seinem Argumentationsgang zweimal hypothetisch die Prämisse vorbringt, diese christlichen Lehren seien falsch (49,2: Falsa nunc sint, 49,3: Certe, etsi falsa), profiliert er letztlich nur den Kontrast zwischen wahr und falsch und lässt somit noch deutlicher hervortreten, dass seine Überzeugungen wahr, die der Philosophen hingegen falsch sind.

Der Abschnitt 49,I-3 bestätigt die oben benannte Präzisierung: Bei seiner Auseinandersetzung mit der Wahrheitsverschleierung der Philosophen geht es Tertullian speziell darum, dass die Philosophen die christliche Wahrheit vom Gericht verstellen. Von dieser Präzisierung her fällt nun Licht auf die Frage nach dem Einheit schaffenden Moment der beiden Teile der Peroratio. Die Philosophen stellen zweifellos eine verbindende Linie dar. Sie erfahren auch in 49,450,16 Erwähnung, und die Bezugnahmen auf sie spiegeln den Kontrast zwischen Christen und Philosophen, wie er insbesondere an 46,2 und 46,18 abzulesen war. So weist die Wertung in 50,IO in aller Deutlichkeit auf den Kern dieses Kontrastes hin: Tertullian hat im Vorfeld die Standfestigkeit der Christen vor ihren römischen Richtern gepriesen (50,I-3) und seine Ankläger auf den Ruhm verwiesen, den auch Heroen aus ihren eigenen Reihen, speziell Philosophen, sich durch ihre Leidens- und Todesverachtung erworben haben $(50,4-9)$. Eine substantielle Angleichung der Philosophen an die Christen wehrt er in 50,IO aber ab, indem er den Ruhm der Philosophen als „menschlichen Ruhm“ (O gloriam ... humanam) bezeichnet und ihn damit abwertet: Diese gloria ist in Tertullians Augen zwar bei den Nichtchristen anerkannt, steht dem wahren Ruhm der Christen aber entgegen; die Philosophen suchen Ruhm bei den Menschen, die Christen bei Gott ( $O$

25 Apol. 49,2: ... meliores fieri coguntur qui eis credunt, metu aeterni supplicii et spe aeterni refrigerii. Itaque non expedit falsa dici nec inepta haberi, quae expedit vera praesumi. 
gloriam licitam, quia humanam, ... cui tantum pro patria, [pro agro], pro imperio, pro amicitia permissum est, quantum pro Deo non licet). Unverkennbar ist hier wieder die Grunddifferenz zwischen Philosophie und „divinum negotium“ (46,2). Dieser Unterschied dürfte auch im Hintergrund stehen, wenn Tertullian in 50,I4 den Vorbildcharakter christlicher Martyriumsbereitschaft von der Aufforderung paganer Philosophen zur Todesverachtung abhebt: Die Philosophen lehrten nur mit Worten, die Christen hingegen mit Taten bzw. dem Martyrium, das sie ja gerade aufgrund ihrer Bindung an Gott auf sich nehmen. Letztlich bewirkt das Eintreten für die Leidensbereitschaft von philosophischer Seite wiederum die Verschleierung der christlichen Wahrheit vom Gericht. Denn während die Christen ihr Leben riskieren, weil sie glauben, sich vor dem Gericht Gottes verantworten zu müssen, rufen die Philosophen zu einer Todesverachtung auf, die bei den Menschen Beifall findet, das jüngste Gericht als Beweggrund aber ausblendet.

Repräsentieren die Philosophen somit eine wesentliche Verbindungslinie zwischen 46,I-49,3 und 49,4-50,I6, so sind sie doch selber nicht das entscheidende Einheitsmoment. ${ }^{26}$ Sie stehen im zweiten Teil der Peroratio nicht mehr im Zentrum des Interesses; diese Rolle übernimmt vielmehr das Thema der christlichen Standhaftigkeit im irdischen Gericht um des Sieges bei Gott willen. Die Klärung der Frage, warum Tertullian die Philosophen thematisiert, weist aber den Weg zum Verbindungselement dieser Schwerpunkte und zu dem Gegenstand, der den ganzen Epilog eint. Bei der Auseinandersetzung mit den Philosophen setzt Tertullian sich für die von ihnen verschleierte Wahrheit ein, und besonders für die Wahrheit des göttlichen Gerichts. Diese Wahrheit ist wiederum der Ankerpunkt seiner abschließenden Darlegungen in 49,4-50,16: Weil die Christen glauben, dass das Gericht, welches letztlich über ihr Leben entscheidet, das jüngste Gericht ist, stehen sie im Gericht vor den römischen Statthaltern zu ihrem Glauben; in Tertullians Augen erwerben sie sich durch diese Standhaftigkeit und ihre daraus folgende Verurteilung - die scheinbare Vernichtung - das ewige Leben bei Gott. Tertullian malt die christliche Haltung vor den antistites so anschaulich aus, weil für ihn im irdischen Gericht die Wahrheit des göttlichen Gerichts auf dem Spiel steht: Wie er selbst sagt, streiten die Christen vor ihren irdischen Richtern „für die Wahrheit" (50,2: pro veritate certemus) und erhoffen sich als Lohn für ihre Standhaftigkeit im göttlichen Gericht die „wahre“ Auferstehung. ${ }^{27}$ Diese

26 Auch der konkrete Anknüpfungspunkt zwischen 49,3 und 49,4 ist nicht als das entscheidende Bindeglied der zwei Teile zu betrachten. Tertullian endet in 49,3 mit der Aussage, dass die christlichen Lehren unschuldig und somit allenfalls zu verlachen sind - wie manche philosophischen Ansichten -, nicht aber grausam zu bestrafen sind; zum Beleg dieser Grausamkeit führt er diverse Hinrichtungsarten an. Auf die Ungerechtigkeit dieser Verurteilungen von Christen bezieht er sich in 49,4 und leitet von ihr her zum Thema der Martyriumsbereitschaft über. An dieser Gedankenführung wird ersichtlich, wie Tertullian vom einen zum anderen Schwerpunktthema überleitet, nicht aber, was die beiden Themen im Kern verbindet.

27 Apol. 50,II: Hanc [resurrectionem] qui veram a Deo sperat ... 
Transparenz des irdischen Gerichts auf das göttliche hin sowie die Brechung des ersteren durch das letztere ist im Schlussabschnitt unverkennbar und wird besonders deutlich in zwei Formulierungen, gleich in 49,6 sowie in dem Abschlusskontrast aus 50,16: „Demnach gehört nämlich die Freude, die er [der Pöbel] für sich beansprucht, uns, die wir lieber verurteilt werden wollen als von Gott abfallen. Wie zwischen Göttlichem und Menschlichem Rivalität besteht, so werden wir, wenn wir von euch verurteilt werden, von Gott losgesprochen. ${ }^{\text {“28 }}$

Tertullian dürfte sein Eintreten für die veritas auf die Wahrheit des jüngsten Gerichts zuspitzen, da in diesem Gericht endgültig über wahr und falsch entschieden wird. Als Christ erhofft er sich, dass seine Wahrheit durch dieses Gericht ins Recht, und das Gericht der antistites ins Unrecht gestellt wird. Vor dem göttlichen Gericht sieht er sich im Moment des Martyriums, vor ihm sieht er aber zugleich alle Menschen im Moment ihres irdischen Todes. Das göttliche Gericht ist somit der Punkt, an dem allen Menschen die Wahrheit der Christen unweigerlich vor Augen gehalten wird, an dem alle Wahrheitsverfälschungen von ihnen genommen werden. Will Tertullian der christlichen veritas zu ihrem Recht verhelfen, so muss er also insbesondere der Verschleierung der Gerichtswahrheit entgegentreten und die Drohung und Verheißung dieser Wahrheit ausmalen. Von der Offenlegung der christlichen Wahrheit im Gericht her werden zum einen die scharfen Kontraste zwischen christlichem und paganem Bereich, die Tertullian im Epilog gezeichnet hat, bestätigt und für alle sichtbar gemacht, so zwischen göttlicher und menschlicher Angelegenheit (vgl. 46,2; 50,IO.I6), sowie zwischen Gerechtigkeit und Ungerechtigkeit (vgl. 46,2.IO-I6; 50,I2). Zum anderen wird - gerade ausgehend von diesen Kontrasten - das Wertesystem der Nichtchristen auf den Kopf gestellt: Betrübnis wird zu Freude (vgl. 49,6), Niederlage wird zum Sieg (vgl. 50,I-3), Verurteilung zu Freispruch (vgl. 50,I6); die Reihenfolge ist natürlich auch umkehrbar. Da die Philosophen als Handlanger der Dämonen beim Verschleiern dieser Kontraste und beim Entstellen der Wahrheit eine Führungsrolle einnehmen, hat Tertullian sich in 46,I-49,3 speziell mit ihnen auseinandergesetzt.

Erkennt man Tertullians abschließendes Eintreten für die Wahrheit, speziell des Gerichts, als das wesentliche Einheitsmoment von apol. 46-50 an, so lässt sich auch die Funktion der Peroratio für das gesamte Werk bestimmen. Tertullians Einsatz für die Wahrheit wie auch seine Kontrastierung des irdischen und des göttlichen Gerichts sind im apol. nicht neu. Beide Motive begegnen im Epilog in gebündelter Weise, bilden aber von Beginn an Grundpfeiler des Werks; sie sind auch in den eher beiläufigen Erwähnungen der Philosophen in apol. I-45 enthal-

28 Apol. 50,16: Proinde nostrum est gaudium, quod sibi vindicat [vulgus], qui malumus damnari quam a Deo excidere. - Ut est aemulatio divinae rei et humanae, cum damnamur a vobis, a Deo absolvimur. 
ten (vgl. I4,7; 23,I3). Tertullian stellt seine Verteidigungsrede von der ersten Anrede in I,I an in den Rahmen einer Gerichtsrede vor den römischen antistites; dieses Gericht macht er transparent für das göttliche Gericht (vgl. 23,4-6.13-16), von dem her er es wiederholt konterkariert (vgl. I8,3; 4I,3-5; 45,5-7). Vor den römischen Statthaltern bittet Tertullian auch schon in I,If. darum, die veritas möge gehört werden bzw. nicht unerkannt verurteilt werden, und im Verlauf seiner Ausführungen unterstreicht er diese zentrale Zielsetzung immer wieder (vgl. z. B. I5,8; 2I,30; 39,I; 45,2). Von dieser thematischen Verbindung her liegt es schon auf der Hand, dass die Peroratio anders, als Heinze annahm, ${ }^{29}$ integraler Bestandteil des apol. ist. ${ }^{30}$ In ihr kommt die Gedankenführung des apol. zu ihrem Ziel:

Das jüngste Gericht bildet nicht nur von Anfang an den Kontrapunkt zum Gericht vor den Statthaltern, in Tertullians Augen ist es auch der Punkt, an dem die Wahrheit der Christen allen Menschen offenbar werden wird. Die veritas über dieses Gericht wird von den Philosophen im Dienste der Dämonen aber gerade verschleiert. So steht Tertullian vor der Aufgabe, am Ende seines Werks den Philosophen entgegenzutreten, welche die veritas, insbesondere die Gerichtswahrheit, verstellen. Nachdem er die Philosophen widerlegt hat, kann er alles Gewicht auf das göttliche Gericht legen, vor dem sich die Christen sehen, wenn sie von ihren irdischen Richtern aufgefordert werden, ihr Bekenntnis zu leugnen. Indem Tertullian ausmalt, wie dieses Gericht die irdischen Verhältnisse auf den Kopf stellt und die Verurteilten zu Siegern macht, appelliert er an seine Ankläger: Sie sollen jetzt schon das Gericht als das wahre anerkennen, vor dem auch sie eines Tages stehen werden, und dessen Wahrheit sie dann nicht mehr ausweichen können. Diese protreptische Verwertung der Gerichtsdrohung kann an eine breite apologetische Tradition (vgl. z. B. Aristides, Apol. I7,3; Justinus, I apol. 68,2) anknüpfen, ${ }^{3 \mathrm{I}}$ und sie weist in aller Deutlichkeit darauf hin, wie sehr Tertullian im Epilog um Affekterregung - eine der wesentlichen Aufgaben der Peroratio ${ }^{32}$ - bemüht ist.

29 Vgl. Heinze, (Anm. 4), 462-488.

30 Auch L. Swift, Forensic rhetoric in Tertullian's Apologeticum. Latomus 27 (1968) 873-877 ist dafür eingetreten, apol. 46-50 nicht wie Heinze als protreptischen Epilog zu verstehen, der von den vorhergehenden forensischen Darlegungen abgekoppelt sei. Swift zufolge sind die abschließenden Kapitel vielmehr eng mit dem Vorhergehenden verbunden, insofern als sie der forensischen Thematik eine besondere Dimension - eben die des jüngsten Gerichts - hinzufügten. Über Swift hinausgehend spricht die vorliegende Analyse aber dafür, dass diese theologische Dimension der forensischen Thematik nicht erst in apol. 46-50 wirklich zum Tragen kommt, sondern für das gesamte Werk prägend und schon für die Aufnahme der Gerichtsthematik mitbestimmend ist.

3I Vgl. zu dieser Tradition J. Ulrich, Angstmacherei. Beobachtungen zu einem polemischen Einwand gegen das junge Christentum und zur Auseinandersetzung mit ihm in der apologetischen Literatur, in: F. R. Prostmeier (Hg.), Frühchristentum und Kultur (KfA.E 2), Freiburg 2007, III-I26.

32 Vgl. zu dieser Funktion der Peroratio gemäß antiker Rhetoriktheorie Eckert, (Anm. 2), I83-190. 


\section{Literaturverzeichnis}

Becker (1954): C. Becker, Tertullians Apologeticum. Werden und Leistung, München.

Becker (1992): C. Becker (Hg.), Tertullian - Apologeticum. Lateinsch und deutsch, 4. Auflage, München.

Braun (I992): R. Braun, „Tertullien et la philosophie païenne. essai de mise au point", in: ders., Aproches de Tertullien, Paris, 2I-4I.

Dekkers (1954): E. Dekkers, Q. S. Fl. Tertulliani Apologeticum, hg. v. E. Dekkers, in: Quinti Septimi Florentis Tertulliani Opera, Bd. I, CChr.SL I, Turnhout, $85-17 \mathrm{I}$.

Döring (1979 ): K. Döring, Exemplum Socratis. Studien zur Sokratesnachwirkung in der kynisch-stoischen Popularphilosophie der frühen Kaiserzeit und im frühen Christentum, Wiesbaden.

Dunn (2004): G. D. Dunn, Tertullian, London / New York.

Eckert (1993): G. Eckert, Orator Christianus. Untersuchungen zur Argumentationskunst in Tertullians Apologeticum, Stuttgart.

Heinze (I9IO): R. Heinze, Tertullians Apologeticum, Leipzig.

Lortz (1927 ): J. Lortz, Tertullian als Apologet, Bd. I, Münster.

Opelt (1983): I. Opelt, „Das Bild des Sokrates in der christlichen lateinischen Literatur", in: H.-D. Blume u. F. Mann, (Hgg.), Platonismus und Christentum, FS H. Dörrie, Münster, 192-197.

Osborn (1997): E. Osborn, „Was Tertullian a Philosopher?“, StPatr 3I, 322-334.

Osborn (1997): E. Osborn, „Tertullian as Philosopher and Roman“, in: D. Wyrwa (Hg.), Die Weltlichkeit des Glaubens in der Alten Kirche, FS für Ulrich Wickert zum 70. Geburtstag, Berlin, 23I-247.

Sider (200I): R. D. Sider, Christian ans Pagan in the Roman Empire. The Witness of Tertullian, Washington.

Swift (1968): L. Swift, Forensic rhetoric in Tertullian's Apologeticum. Latomus 27.

Ulrich (2007): J. Ulrich, „Angstmacherei. Beobachtungen zu einem polemischen Einwand gegen das junge Christentum und zur Auseinandersetzung mit ihm in der apologetischen Literatur", in: F. R. Prostmeier (Hg.), Frühchristentum und Kultur, KfA.E 2, Freiburg, III-I26.

Waltzing (1931): J.P. Waltzing, Tertullien - Apologétique. Commentaire analytique, grammatical et historique, Paris. 


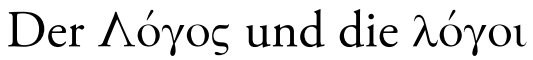

\section{Die Bedeutung der Rhetorik für die Konstituierung der christlichen Elite in der Spätantike}

\author{
JuTTA TLOKA
}

Im 4. Jahrhundert kursierte in Antiochia die Geschichte über einen jungen $M^{2} n^{\mathrm{I}}$, der früh verwaist als Sohn einer wohlhabenden und bedeutenden Familie über ein nicht unbeträchtliches Vermögen verfügte. Er aber entschied sich für ein asketisch-christliches Leben in den Bergen und machte dort beeindruckende Fortschritte in den Tugendübungen. Seine Verwandten jedoch drängten ihn, zurück in die Stadt zu kommen, wo er sich schnell wieder an das angenehme, luxuriöse und selbstverständlich auch amouröse Leben gewöhnte.

Was für die eine Seite die triumphale Rückkehr des verlorenen Sohnes bedeutete, war für die andere ein großer Verlust. Dennoch zeigt sich bald, dass der junge Mann zu keiner der beiden Welten - Stadt oder asketische Zurückgezogenheit - richtig gehörte:

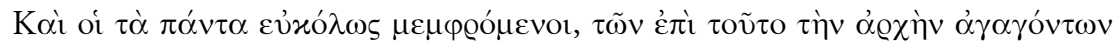

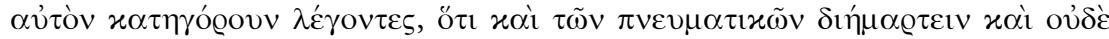

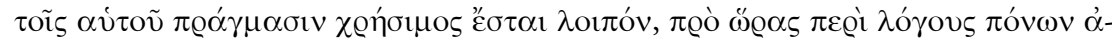

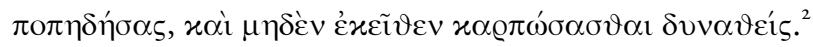

Letztlich also machte ihn der frühzeitige Abbruch seiner Ausbildung in den $\lambda$ ó$-^{-}$ rot unfähig ${ }^{3}$, ererbtes Vermögen und ererbten Status in der städtischen Welt der Spätantike adäquat einzusetzen, ebenso wie das Verlassen des asketischen Lebensweges in den Augen der christlichen Gemeinschaft, insbesondere der Mönche,

I Diese Anekdote findet sich in Johannes Chrysostomos' Traktat Ad Theodorum lapsum ii. Die meisten Handschriften bezeichnen den jungen Mann genauer als Sohn des Urbanos mit Namen Phönix. Der Name ist möglicher Weise symbolisch zu verstehen, vgl. Iohannes Chrysosto-

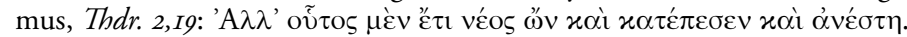

2 Iohannes Chrysostomus, Thdr. 2, I8.

3 Offensichtlich scheint die Entscheidung zu einem asketischen Leben für den Sprössling einer führenden antiochenischen Familie den Abbruch seiner rhetorischen Ausbildung im Sinne der klassischen $\pi \alpha 1 \delta$ eía bedeutet zu haben. Zumindest werden die Lebenswege als einander ausschließend wahrgenommen, wie es in der besorgten Anfrage des (fiktiven) christlichen Vaters in Johannes Chrysostomos' Werk Adversus oppugnatores und der darauf folgenden Gegenfrage

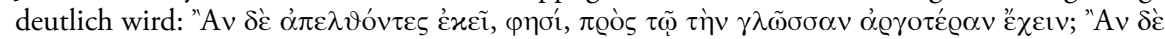

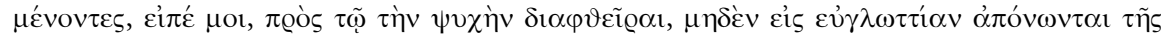

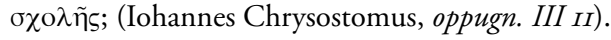


ein völliges Scheitern und größtmögliche Sünde bedeutete. Der oben zitierte Satz zeigt dabei auch die zeitgenössische Kritik an den Mönchen als Verführer der Jugend $^{4}$, die den Familien ihre hoffnungsvollen Sprösslinge unter dem - wie hier am Ende nicht eingehaltenen bzw. nicht einhaltbaren - Versprechen der Eröffnung eines Weges in den Himmel entzogen. Entsprechend geduldig versuchte die mönchische Gemeinschaft besagten jungen Mann wieder zurück in ihre Reihen zu holen, was letztlich von Erfolg gekrönt war.

\section{Die Christen und ihr Verhältnis zu Rhetorik und Philosophie}

Christentum und Rhetorik als einander ausschließende Bereiche aufzufassen hat seinen Anfang in der paulinischen Antithese von Menschenweisheit und Gotteskraft'. Schon die ersten Apologeten machten dankbar Gebrauch von dieser argumentativen Vorlage, die es ihnen ermöglichte, eine vorgebliche Schwäche in den Augen der zeitgenössischen gebildeten Kreise - fehlende Intellektualität und Widersprüchlichkeiten der Schriften der LXX und des späteren Neuen Testaments sowie mangelnde sprachliche Eleganz - zu einer Stärke des Christentums umzuwandeln bis hin zur Anwendung des Wunderbeweises, wonach das Wachstum des Christentums angesichts des demonstrativen Verzichts auf die Regeln der rhetorischen Überredungskunst nur mit göttlicher Wirkmächtigkeit zu erklären sei. So betont Minucius Felix in seinem Werk Octavius, das in jeglicher Hinsicht auf der Höhe der Bildung seiner Zeit steht, dass die Schlichtheit christlicher Verkündigung ebenso wie der über den kleinen Kreis Gebildeter hinausgehende Adressatenkreis der Beweis für die Wahrhaftigkeit der christlichen Botschaft anzusehen ist, wobei er zusätzlich auf das Schicksal paganer Philosophen verweisen kann:

Et quoniam meus frater erupit, aegre se ferre stomachari indignari dolere, inliteratos pauperes, inperitos de rebus caelestibus disputare, sciat omnes homines, sine dilectu aetatis, sexus, dignitatis, rationis et sensus capaces et habiles procreatos nec fortuna nanctos, sed natura insitos esse sapientiam, quin ipsos etiam philosophos, vel si qui alii artium repertores in memorias exierunt, priusquam sollertia mentis parerent nominis claritatem, habitos esse plebeios indoctos seminudos; adeo divites facultatibus suis inligatos magis aurum suspicere consuesse quam caelum, nostrates pauperes et commentos esse prudentiam et tradidisse ceteris disciplinam. unde apparet ingenium non dari facultatibus nec studio parari, sed cum ipsa mentis formatione generari. nibil itaque indignandum vel dolendum, si quicumque de divinis quaerat sentiat proferat, cum non

4 Diese Vorwürfe nimmt Chrysostomos selbst auf, vgl. Iohannes Chrysostomus, oppugn. II 2.

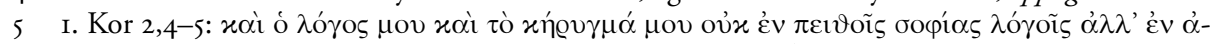

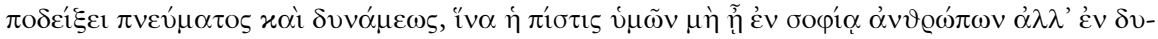

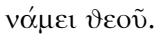


disputantis auctoritas, sed disputationis ipsius veritas requiratur. Atque etiam, quo imperitior sermo, hoc inlustrior ratio est, quoniam non fucatur pompa facundiae et gratiae, sed, ut est, recti regula sustinetur. ${ }^{6}$

Wenn auch der ostentative Verzicht auf die Regeln der Sprachkunst in den meisten uns überlieferten Schriften des frühen Christentums eher rhetorisch zu verstehen ist ${ }^{7}$, so erklärt er sich auch aus dem spezifischen Selbstverständnis des vorkonstantinischen Christentums. Das Christentum als religio illicita mit seinem absoluten und missionarischen Wahrheitsanspruch und oftmals noch eschatologischen Vorstellungen war an den gesellschaftlichen Prozessen der Zeit nicht aktiv beteiligt. Vielmehr bedeutete auch für die Angehörigen bedeutender, insbesondere kurialer Familien die Konversion eine Abkehr vom bisherigen sozialen und familiären Umfeld. Der praktische Nutzen der Rhetorik als Grundlage gesellschaftlicher Kommunikation der Eliten, Erkennungsmerkmal der $\pi \varepsilon \pi \alpha 1 \delta \varepsilon v-$ $\mu \varepsilon \dot{v} v o l$ und notwendiges Differenzkriterium zu Außenstehenden ${ }^{8}$ war damit nicht mehr gegeben. Dies bedeutet nicht, dass Herkunft und Bildung auch des vorkonstantinischen kirchlichen Führungspersonals unbedeutend gewesen sei. Es findet sich einerseits ein tiefes Misstrauen gegen ein Zuviel an Bildung und Intellektualität ${ }^{9}$, andererseits geizen die Protagonisten innerkirchlicher bzw. dogmatischer Auseinandersetzungen nicht mit ihrer hohen literarischen Bildung ${ }^{\text {I0 }}$. So ist es nicht frei von Ironie, wenn die großen christlichen Kritiker der Rhetorik sich ihrer sehr wohl zu bedienen wissen. Dennoch erforderte dieser Bereich der antiken Bildungstradition keine aktive, geschweige denn offen konstruktive Auseinandersetzung ${ }^{\mathrm{II}}$.

Zur antiken Philosophie musste dagegen von Anfang an eine Position gefunden werden. Der mit dem Johannesprolog eröffnete Weg, dem $\lambda$ ó $\gamma$ os den Vorrang vor dem $\mu$ ṽ $\theta$ o zukommen zu lassen, hatte ebenso wie das Selbstverständnis

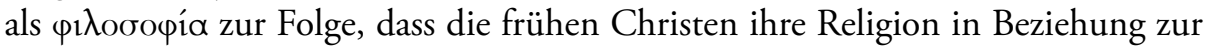
philosophischen Vernunft und damit auch zur philosophisch geprägten $\pi \alpha \delta \varepsilon i ́ \alpha$ setzen mussten ${ }^{\mathrm{r} 2}$. In der Betonung des Wertes von Bildung in philosophischer

6 Minucius Felix, Oct. 16,5-6. Vgl. dazu Aland (1983), Gemeinhardt (2007), 8I-89.

7 Zur Bildung der vorkonstantinischen christlichen Theologen vgl. Gemeinhardt (2007), 63-II3.

8 Vgl. Schmitz (1997), 27-30. 44-49.

9 Auch unter diesen Gesichtspunkten können die Auseinandersetzungen um Hippolyt und Kallist sowie Novatian und Cornelius verstanden werden, vgl. dazu Gemeinhardt (2007), I24-I25. Für den Osten sei die Kontroverse um Origenes genannt, angesichts derer sich noch Euseb genötigt sieht, Origenes' Affinität zur griechischen Bildung deutlich seinem Christsein unterzuordnen und somit zu verteidigen, vgl. Eusebius, h.e. VI 3,8-9. I9,II.

Io Vgl. die Korrespondenz Cyprians, dazu Gülzow (1975).

II Die Kritik an der Rhetorik und ihrer Anwendung durch Juristen und öffentliche Redner, die allein an ihrer Bereicherung und nicht an der Wahrheit interessiert seien, wird in besonderer Schärfe deutlich bei Commodianus, apol. 599-60o: obstrepit interea vox adornata diurnum / et saepe fit causa melior mala pluscula dando.

I2 Fiedrowicz (2000), 227-228. 
Hinsicht und der Abwertung der als inhaltsleer denunzierten rhetorischen Aspekte konnten die Christen sich auf die durch Sokrates und Platon begründete pagane Tradition der Rhetorik-Kritik berufen ${ }^{13}$, die ihrer Position mehr Plausibilität verlieh. Dies war umso notwendiger, als die normierende Funktion der Rhetorik auf intellektuell-philosophischem Gebiet, wonach das Wahre und Richtige nur in einer ästhetisch entsprechenden Sprachform ausgedrückt sein kann, von den Christen nicht geteilt werden konnte. Exemplarisch illustriert diese Abwertung zugunsten einer Aufwertung der alt- und neutestamentlichen Schriften Gregor Thaumaturgos in seinem Panegyrikos auf Origenes:

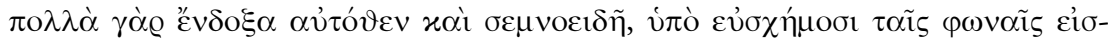

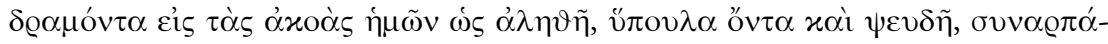

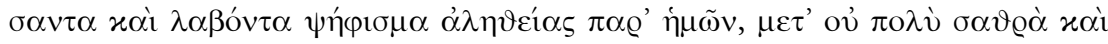

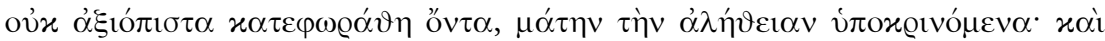

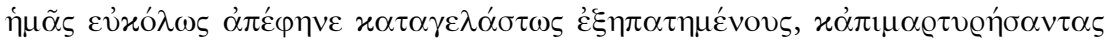

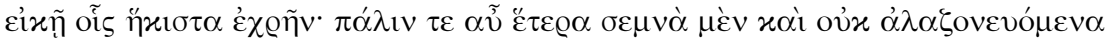

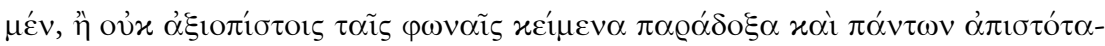

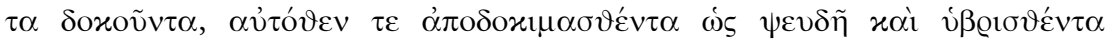

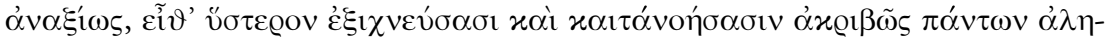

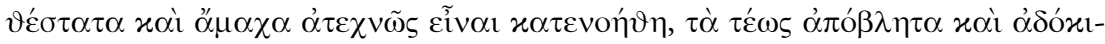

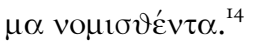

\section{Christliche Bildungsnähe und Bildungsfeindlichkeit}

Die anfangs zitierte Anekdote zeigt den Erfolg der von christlicher Seite betriebenen Abwertung der Rhetorik und der entsprechenden Bildungstradition. Gleichzeitig ist spätestens ab der sogenannten konstantinischen Wende ein zunehmend pragmatischer Zugang zur $\pi$ aı $\delta$ sía allgemein und nicht zuletzt zur rhetorischen Bildung im Besonderen zu beobachten. Dies entspricht letztlich den zunehmenden Aufgaben in sozialer und gesamtgesellschaftlicher Hinsicht. Auch werden das Christentum und damit die kirchliche Karriere zunehmend attraktiv für Angehörige der alten sozialen und intellektuellen Eliten, für die der privilegierte Klerikerstand auch eine attraktive Alternative zu den Belastungen der Angehörigen der Kurie bedeutete. Befreit von den teilweise unerfüllbaren finanziellen Lasten ${ }^{15}$ ist es für den Einzelnen mit der zunehmenden Christianisierung möglich, als Bi-

I3 Zeitgenössisch vgl. z. B. zur Rhetorik-Kritik Lukians Nesselrath (200I), 28. Themistios, der sich im 4. Jh. selbst als Philosoph sieht, betont deutlich die rein dienende Funktion der Rhetorik, vgl. Stenger (2009), 201.

I4 Gregor Thaumaturgos, pan. Or. 7,I03-I04.

I5 Vgl. u.a Cod.Theod. XVI 2, I5.19.2I.24. 
schof dennoch zum Repräsentanten der Stadt aufzusteigen und damit durchaus an die traditionelle Bedeutung der Familie anzuknüpfen. ${ }^{16}$

Das Besondere an dieser sich neu formierenden Führungsschicht war, daß sie ihre Legitimation aus Quellen herleitete, die in den herkömmlichen Kategorien von Bildung, Herkunft und Hierarchie nicht zu fassen waren. Auch wenn sie sich mit der Rhetorik zum Teil desselben Codes bedienten wie ihre paganen Standesgenossen, beruhte ihre Autorität viel stärker auf spirituellen Eigenschaften. In der asketischen, der persönlichen Vervollkommnung dienenden Lebensweise zeigte sich dem Anspruch nach, daß der Bischof von Gott spirituelle Gaben erlangt hatte. ${ }^{17}$

Diese Form der spirituell-geistlichen Selbstlegitimation der spätantiken christlichen Führungsschicht ist Ausdruck eines Unbehagens an einer tatsächlichen oder vermeintlichen Verweltlichung des Christentums, das noch deutlicher in der zunehmenden Bedeutung der Askese und der Attraktivität des Mönchtums zum Ausdruck kommt. Es ist durchaus signifikant, dass mit dem Mönch als Nachfolger des Märtyrers und mithin als erlebbarer und greifbarer Mittler zwischen Dies- und Jenseits eine neue Form der Bildungskritik Einzug hält. Die Ablehnung weltlicher Bildung, weltlichen Wissens und weltlicher Lektüre gehört zur Grundausstattung des wahren Asketen, wobei sich hier in der Hagiographie die schon in der Kindheit zutage tretende klare Entscheidung für den praktischen Analphabetismus und damit für die Bibel und das wahrhaft christliche Tugendstreben durchgesetzt hat. Stilbildend ist hier sicherlich der Antonios des Athanasios anzusehen, der schon als Kind Bildung verweigert ${ }^{18}$ und dennoch als Erwachsener aufgrund seiner spirituellen Gaben intellektuelle und rhetorische

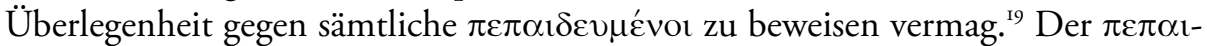
$\delta \varepsilon v \mu \varepsilon ́ v o \varsigma$ ist selbstverständlich ein Häretiker oder Heide, womit die antike Bildung weiterhin unter dem Generalverdacht der Verführung zu einem verfehlten Lebensweg steht. Der Topos der Bildungsfeindlichkeit gehörte jedoch nicht nur zu den Mönchen, die sich ja auch durchaus aus bildungsfernen Kreisen rekrutierten, sondern auch die großen Theologen dieser Zeit zeigen regelmäßig ein zumindest kritisches Verhältnis zu ihrer aufgrund ihrer Herkunft selbstverständlichen Bildung. Berühmt sind die hier exemplarisch genannten selbstkritischen Äußerungen des Hieronymus ${ }^{20}$ und Augustins ${ }^{21}$.

I6 Vgl. Rapp (2000), 382.

I7 Stenger (2009), 196.

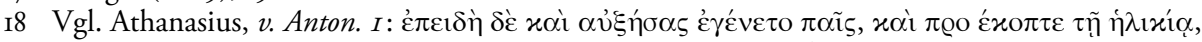

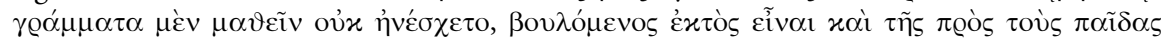

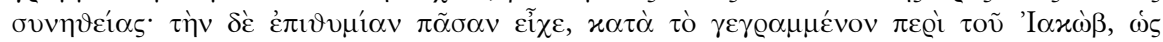

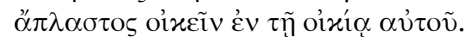

I9 Vgl. Athanasius, v. Anton. 68-69.72.89. Die Bildungsferne ist dabei als literarischer Topos des Mönchsideals zu verstehen, vgl. Gemeinharft (2009), 365 mit Anm. 68 und seine berechtigte Kritik an Klein (198I). 
Für das vierte Jahrhundert lässt sich eine insgesamt ungeklärte Haltung der Christen zum antiken Bildungserbe feststellen ${ }^{22}$, auch wenn dieses insbesondere in den dogmatischen Streitigkeiten, zu deren Lösung man sich der überlieferten philosophischen Begrifflichkeiten bediente, eine immer größere Rolle spielte. Gerade das griechisch-sprachige Christentum hat eine durchaus längere Tradition vorzuweisen in der konstruktiven Aufnahme der philosophischen Bildungsinhalte, die grundsätzlich ablehnende Haltung gegenüber der Rhetorik blieb aber bestehen.

Die eingangs zitierte Geschichte legt ein deutliches Zeugnis davon ab, wie sehr die Christen selbst und auch ihre pagane Umwelt die Erziehung zu einem asketischen Leben und die zu einem verantwortlichen Mitglied in der Gesellschaft als Gegensätze verstanden haben, die sich letztlich in der erzieherischen Al-

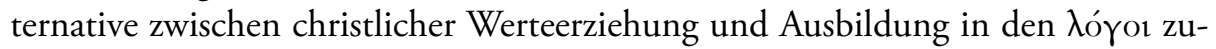
zuspitzen scheint. In seiner apologetischen Schrift Adversus Oppugnatores vitae monasticae, in der er das Mönchtum gegen christliche und pagane Angriffe verteidigt und seinen erzieherischen Nutzen für die Jugend herausstreicht ${ }^{23}$, stellt Johannes Chrysostomos noch deutlich heraus, dass der Erfolg des Christentums eher einem Abbruch der kulturellen Traditionen zu verdanken ist:

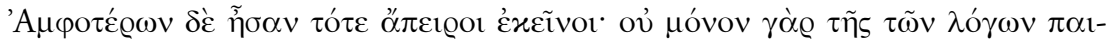

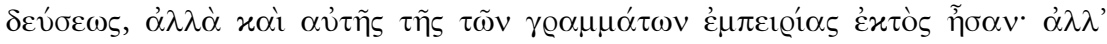

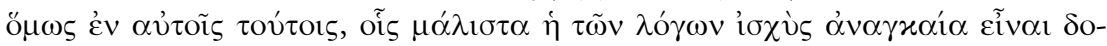

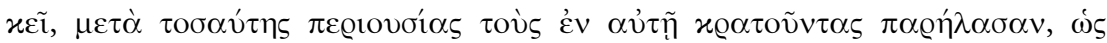

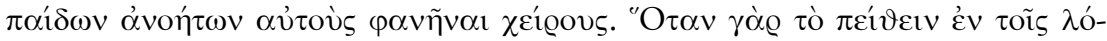

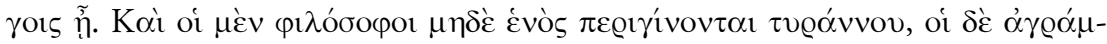

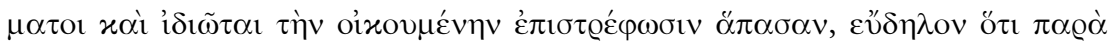

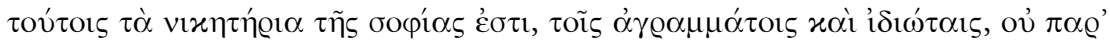

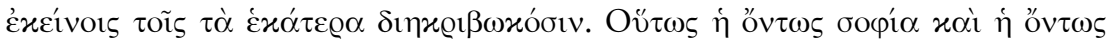

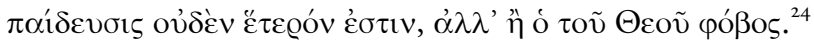

$20 \mathrm{Vgl}$. Hieronymus, ep. 22,30.

$2 \mathrm{I}$ Vgl. Augustinus, Conf. III 7-9.

22 Gemeinhardt (2007) stellt in seiner Untersuchung des lateinischen Christentums eine „Orientierungsverunsicherung" (490) im Hinblick auf die Bewertung der klassischen Bildungsinhalte in der Zeit nach der konstantinischen Wende fest.

23 Vgl. Hunter (1988), 19-65.

24 Iohannes Chrysostomus, Oppugn. III I2. 


\section{Bildung als Differenzkriterium und Statuslegitimierung aus paganer Sicht}

Gerade das Mönchtum war aus der Sicht der paganen Opposition deutlichstes Zeichen des mit dem Christentum einhergehenden kulturellen Niedergangs, der seinen Ausdruck in dem Zurückdrängen der klassischen Bildungsinhalte zu finden schien. Die zwei herausragenden östlichen Vertreter paganer Bildung und Kultur, die Jan Stenger zuletzt neben anderen einer detaillierten Analyse unterzogen hat ${ }^{25}$, Libanios und Eunap, sind alle scharfe Kritiker der Mönche, die für sie höchster Ausdruck des Barbarentums und des Untergangs der überlieferten Werte darstellen ${ }^{26}$. Die fiktiven Dialoge in Adversus Oppugnatores zeigen ebenfalls die Gefahren, die vom Mönchtum und seiner offensichtlichen Attraktivität für die Jugend auszugehen schienen. ${ }^{27}$

Zugleich überließen die Christen ihren paganen Zeitgenossen mit der Rhetorik scheinbar ein Alleinstellungsmerkmal, dessen sich beispielsweise ein Libanios selbstbewusst zu bedienen wusste.

In seiner Verteidigung der klassischen $\pi \alpha 1 \delta$ eía geht es Libanios, der sicherlich nicht als ein aktiver Feind der Christen zu verstehen ist, um ihre Bedeutung als höchstes Kulturgut der griechischen Tradition, die er fest verankert sieht in dem

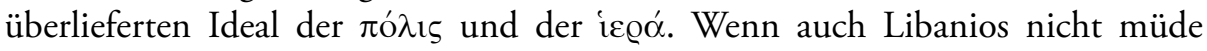
wird, die Verbindung von Bildung und paganer Religiösität zu betonen und er damit das Verständnis der $\pi \alpha \_\delta \varepsilon i ́ \alpha$ als eine Art weltanschauliches Neutrum ablehnt ${ }^{28}$, so geht es ihm darüber hinaus um die Erhaltung der gesellschaftlichen und wertsetzenden Funktionen der überlieferten Bildungsideale ${ }^{29}$, die er auch durch die wachsende Bedeutung des Lateinischen im Bereich der Jurisprudenz gefährdet sieht. ${ }^{30}$

In seiner ersten Rede, die als ,Autobiographie' des Libanios gilt, zeichnet Libanios sein Selbstbild als großer Redner, dessen Überlegenheit letztlich auf die

25 Stenger (2009).

26 Vgl. dazu eindrücklich Eunaps Schilderung der Mönche, die für ihn höchster Ausdruck von

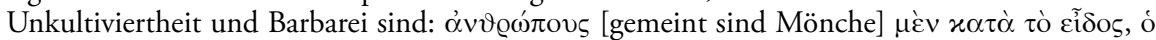

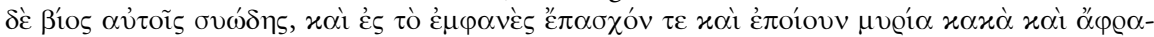

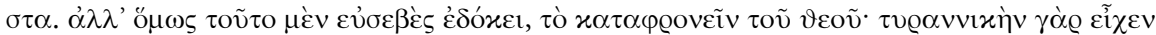

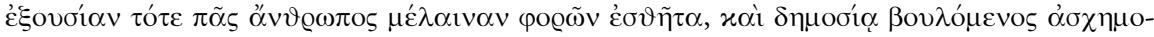

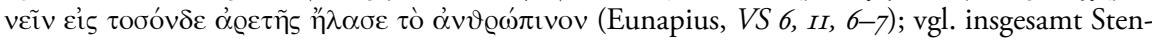
ger (2009), 194-195.203.

27 Vgl. oben, besonders Anmerkung 3.

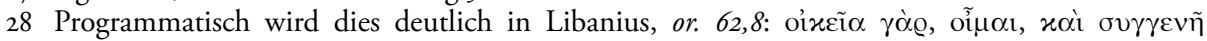

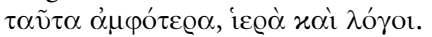

29 Vgl. Liebeschuetz (1972), II.

30 Vgl. Petit (1955), 363-365, Wolf (1954), 79-83. 
Kongruenz innerer Werte und äußerer Darstellungskunst beruht, mithin auf der

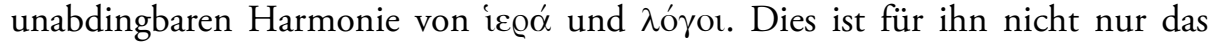
wichtigste Differenzkriterium zu jeglicher Barbarei und damit auch zum Christentum, sondern in seiner rhetorischen Fähigkeit sieht er zugleich die stärkste Waffe gegen die christliche Konkurrenz. So verhindern Christen aus Sorge vor seiner Überlegenheit, dass er Kaiser Valens mit seiner Redekunst erfreut:

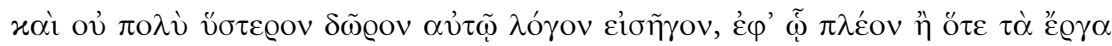

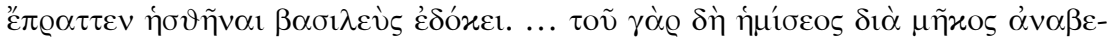

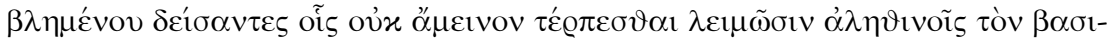

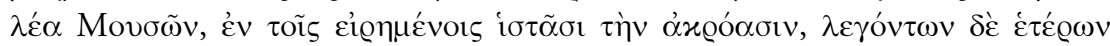

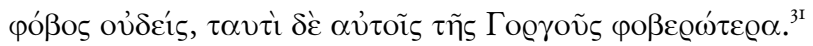

Die Unfähigkeit der Christen, Libanios in seinem eigenen Feld, der Rhetorik, zu schlagen, ist dabei im Besonderen ihrer verfehlten Religiosität, mithin der Inkon-

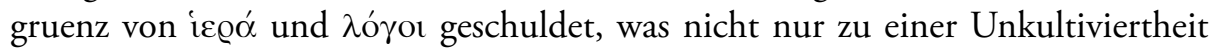
in der sprachlichen Ausdrucksfähigkeit, sondern auch des Lebenswandels allgemein führt:

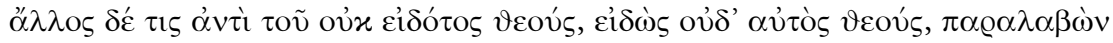

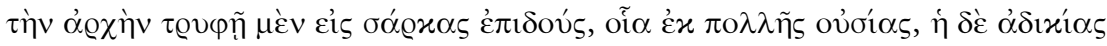

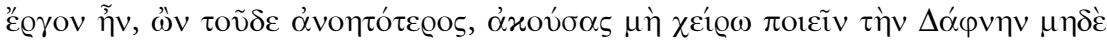

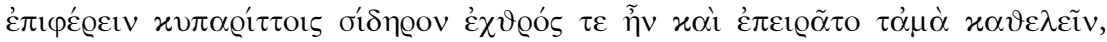

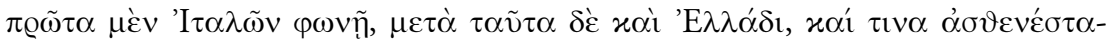

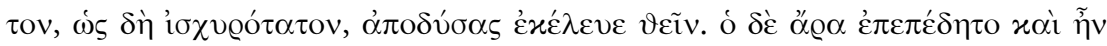

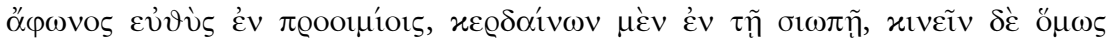
$\gamma \lambda \tilde{\omega} \tau \tau \alpha \nu \alpha \dot{\pi} \pi \vartheta \alpha \nu \circ \tilde{v} \sigma \alpha \nu \pi \varepsilon 1 \varrho \omega ́ \mu \varepsilon v o \varsigma^{32}$

Libanios stellt sich hier als Patron der Interessen der paganen Lebensweise und seiner Kultorte dar, dessen Legitimation sich aus seiner intellektuellen Autorität speist, die ihn den Mächtigen seiner Zeit ebenbürtig, oder aber, wie in diesem Fall, überlegen macht. In seiner Untersuchung der Leitbilder des Intellektuellen bei Themistios, Libanios und Eunap hat Stenger diese Legitimationsquelle neben zwei anderen erweisen. Diese beiden sind die durch einen hohen Amtsträger verliehene Autorität und die spirituelle Autorität, was bei dem paganen Intellektuellen nicht nur Einhaltung des Götterkultes, sondern auch spirituelle Auszeichnung durch die Götter bedeutet ${ }^{33}$. Die zitierte Passage zeigt hier einerseits das Oszillieren zwischen intellektueller und spiritueller Autoritätsbegründungen, andererseits wird auch die Unabhängigkeit des wahrhaft Gebildeten von den Unwägbarkeiten der Zeit und der religiös-ideologischen Vorlieben der Herrschenden deutlich.

3I Libanius, or. I,I44. Zur oratio I des Libanios vgl. Wolf (I967), 25-3I.

32 Libanius, or. $1,255-256$.

33 Vgl. Stenger (2009), 217-218. 
Die $\lambda o ́ \gamma o$ in ihrer unabdingbaren Verbindung mit den íepó sind damit für Libanios Garant für den Erhalt höchster Bildungsideale, das Überleben des eigenen Lebensideals und notwendige Voraussetzung für das Funktionieren der spätantiken Stadt, bei der sich der Rhetor als $\pi \varepsilon \pi \alpha 1 \delta \varepsilon v \mu \varepsilon ́ v o s$ für die Interessen der Bewohner als Patron einsetzt. ${ }^{34}$

Dieses Bild der Rhetorik und ihres praktischen gesellschaftlichen Nutzens deckt sich nicht mit dem Zerrbild als inhaltsleere Schönrederei, das zur christlichen Topik der Zeit gehörte. Eher passte das negative Bild auf die Betonung der vornehmen Abstammung des $\pi \varepsilon \pi \alpha 1 \delta \varepsilon v \mu \varepsilon \dot{v}$ os, wie sie von den paganen Intellektuellen als Distinktionsmerkmal - insbesondere gegen die barbarischen Mönche - betont wurde. ${ }^{35}$ Hier ist einmal mehr darauf hinzuweisen, wie sehr die Christen selbst nicht nur zur Klärung ihrer dogmatischen Fragen, sondern auch zur Bewältigung der auf das kirchliche Führungspersonal übergehenden Aufgaben zur Klärung der städtischen Angelegenheiten abhängig waren von dem traditionellen Bildungsweg gesellschaftlicher Eliten, der einen eindeutig literarischen Schwerpunkt hatte und dessen philosophische Inhalte selbstverständlich nicht ohne eine vorhergehende philologische und rhetorische Ausbildung denkbar war. Dieses uneindeutige Verhältnis zu den $\lambda$ ó $\gamma o r$ zwischen Anwendung und Ablehnung stellte letztlich eine Schwäche des Christentums des vierten Jahrhunderts dar, die nicht zuletzt Kaiser Julian mit seinem sogenannten Rhetorenedikt ${ }^{36}$ aufdeckte, mit dem er die Kongruenz der religiös-moralischen Grundhaltung des Lehrers mit den vermittelten Inhalten forderte, was für die christlichen Lehrer einem Berufsverbot bzw. Konversionszwang bedeutete. Unabhängig von der Frage nach dem exakten Ausmaß der antichristlichen Motivation dieses am I7. Juni 362 erlassenen Edikts ${ }^{37}$, zu dessen Interpretation das zugehörige Sendschreiben heranzuziehen ist ${ }^{38}$, ist es Ausdruck des Verständnisses von $\pi \alpha \iota \delta \varepsilon i ́ \alpha$ als Ausdruck höchster Kultiviertheit und untrennbare Einheit des intellektuellen, moralischen, politischen und (pagan-)religiösen Hellenismus. Es steht damit ganz im Zeichen der Restaurationsbemühungen seiner nur kurz währenden Regierungszeit. Julians Hinweis auf die Unaufrichtigkeit christlicher Lehrer, die die für den antiken Schulunterricht unentbehrlichen alten Schriftsteller der griechischen Kultur nur formal, nicht aber inhaltlich wertschätzen ${ }^{39}$, ist nicht nur moralische Anklage,

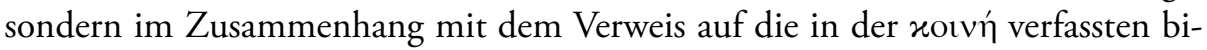

34 Vgl. Seiler (1998), I69-17I.

35 Vgl. Stenger (2009), I98-20I.

36 Vgl. Cod.Theod. XIII 3,5.

37 Das Rhetorenedikt Julians ist Objekt unzähliger Interpretationen, vgl. die wichtigsten bei Klein (198I), Pack (1986), 26I-300, Fiedrowicz (200I) und zuletzt Gemeinhardt (2007), 35I-367.

38 Vgl. Julianus, ep. 6Ic.

39 Vgl. Julianus, ep. 6Ic, 422D. $423 A-B$. 
blischen Schriften ist hier auch der intellektuelle Angriff unübersehbar, wie er ihn auch in seinem Werk Contra Galilaeos formuliert hatte:

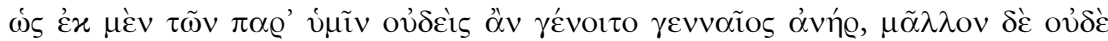

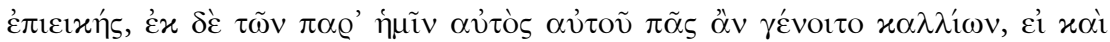

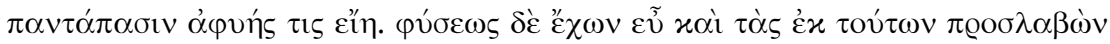

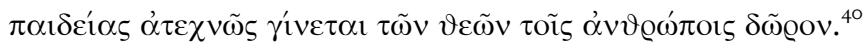

Julian versuchte letztlich legislativ zu Institutionalisieren, was pagane $\pi \varepsilon \pi \propto 1 \delta \varepsilon u-$ $\mu$ Évor wie Libanios und Eunap schon längst propagierten im Ausbau eines älteren antichristlichen Topos. Wie schon Galen, Kelsos und Porphyrios den Christen in der vorkonstantinischen Epoche Irrationalität bis hin zu quasi systemimmanenter Bildungsfeindlichkeit vorgeworfen haben ${ }^{4 \mathrm{r}}$, so schlossen die Verfechter eines auch religiös konnotierten Bildungsideals die Christen gänzlich vom Ideal des wahrhaft Intellektuellen aus. ${ }^{42}$ Das bedeutet jedoch nicht, dass die paganen $\pi \varepsilon \pi \alpha \iota \delta \varepsilon v-$

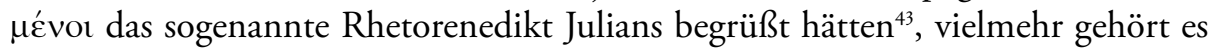
auch unter seinen Bewunderern wie Ammianus Marcellinus zu den kritisierten Maßnahmen Julians kurzer Regierungszeit ${ }^{44}$; selbst Libanios, der sich im Ver-

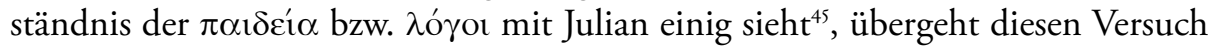
des sonst viel gelobten Kaisers mit vielsagendem Schweigen ${ }^{46}$.

40 Julianus, C. Galil. frg. 55 .

4I Vgl. u. a. Galenus, De differentiis pulsuum 2,4; Kelsos bei Origenes, z. B. Cels. I 9, IV 7; Porphyrius, Contra Christianos, frg. I. Klassisch ist die von Origenes wiedergegebene Beschreibung der

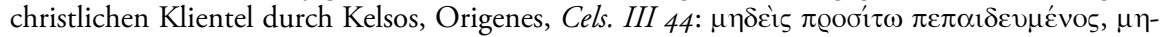

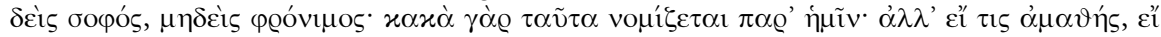

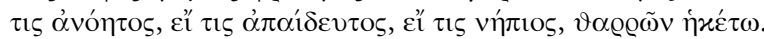

42 Vgl. Stenger (2009), 223.

43 Auch wurde nicht von jedem die religiöse Bedeutung der klassischen $\pi \alpha 1 \delta \varepsilon i ́ \alpha$ und hier insbesondere der rhetorischen Anteile in gleicher Weise bzw. in gleichem Ausmaß gesehen wie von Libanios und Julian. Als Bespiel sei der pagane Philosoph Themistios genannt, der die Rhetorik als der Philosophie lediglich dienend versteht (vgl. Stenger [2009], II7.20I) und die $\pi \alpha 1 \delta$ sí $\alpha$ „[gleichsam] säkularisiert, indem er sie von einem bestimmten Bekenntnis löst und so für Heiden wie Christen gleichermaßen verfügbar macht" (a.a.O., I23).

$44 \mathrm{Vgl}$. Ammianus XXII I0,7: Illud autem erat inclemens obruendem perenni silentio, quod arcebat docere magistros rhetoricos et grammaticos ritus Christiani cultores.

45 Vgl. die oben, Anm. 28 zitierte Äußerung des Libanios (or. 62,8) mit seiner Beschreibung Juli-

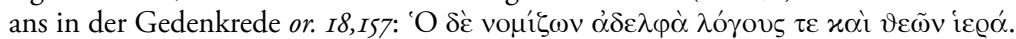

46 Die mit der in Anm. 45 wiedergegebenen Aussage eingeleitete Passage im Epitaphios auf Julian,

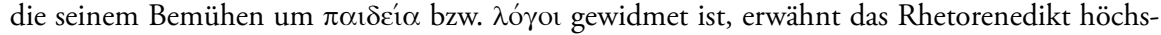
tens in Andeutung. Zur Interpretation dieser Stelle als Missbilligung des Libanios vgl. Fatouros / Krischer / Portmann (2002), 2IO-2II, Anm. I86; Wiemer (I995), IIO; Scholl (I994), II7, gegen Klein (198I), I33-I34, und Rosen (1982), 25. In der Literatur findet sich zur Erklärung dieser auf den ersten Blick überraschenden Ablehnung des Rhetorenedikts, Libanios habe wie die Christen das Edikt nicht nur als Lehr- sondern auch als Lernverbot für christliche Schüler verstanden und sich damit nicht nur in seiner Freiheit als Redner, sondern auch in finanzieller Hinsicht - nämlich in der Einschränkung seines Schülerkreises - bedrängt gesehen. Es ist jedoch wohl zunächst zu sehen, dass die legislative Zwangsdurchsetzung nicht in das Bild des Libanios von der der $\pi \alpha 1 \delta \varepsilon i ́ \alpha$ innewohnenden Überzeugungskraft passt, die ja gerade in der Bildungs- 


\section{Die Rolle der $\lambda$ ó $\gamma o r$ \\ bei der Konstituierung der christlichen Führungselite}

Die Reaktionen auf christlicher Seite zeigen deutlich, dass Julian einen wunden Punkt der Christen getroffen hatte, die nicht nur keine andere als die überlieferte Schulbildung kannten, sondern nun gezwungen waren, auch zu den den philosophischen Inhalten vorgeschalteten Bildungsgütern ein konstruktiveres Verhältnis zu finden. Der grundlegende Ansatz ist dabei sicherlich die Betonung der Areligiosität der Sprache, ihrer Grammatik und ihrer Rhetorik, wie sie von Gregor von Nazianz besonders deutlich in Kritik und Abwehr Julians formuliert wurde, der in seinem Verständnis des Griechischen einem grundlegenden Irrtum unterliege:

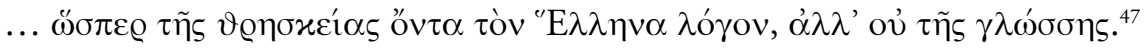

Den Christen geht es in ihrer Kritik an Julian in erster Linie um die formale Seite der $\pi \alpha \_\delta \varepsilon i ́ \alpha$, die die Bibel allein nicht zu ersetzen vermag, wie einerseits die Versuche zeigen, biblische Texte in klassische Versmaße, Dialoge und Tragödien umzusetzen $^{48}$, andererseits der Hinweis auf die durch die $\pi \alpha 1 \delta \varepsilon i ́ \alpha$ erlernte Argumentationskunst ${ }^{49}$, die nicht nur in innerchristlichen Diskussionen unabdingbares Hilfsmittel ist. Dabei ist die Einsicht in die Notwendigkeit, in formaler Hinsicht klassische Bildung und auch eine höhere Ausbildung in den Künsten der Rhetorik zu erwerben, um hier auf einem scheinbar den Heiden vorbehaltenen Gebiet bestehen zu können, nach wie vor mit einer abwertenden Charakterisierung des paganen Kontexts verbunden, wie die Einschätzung seiner rhetorischen Studien durch Gregor von Nazianz zeigt:

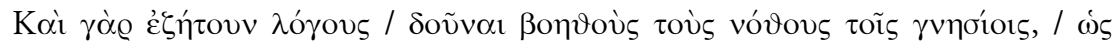

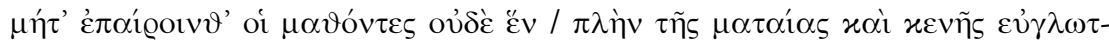

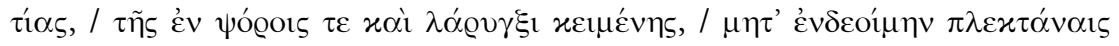

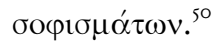

Dabei ist gerade bei Gregor von Nazianz eine positive Sicht der $\lambda$ ó $\gamma$ or aufgrund der Nähe zum $\Lambda$ ó begreift, sondern sie als Opfer an Gott ganz im Dienst der Wahrheit versteht ${ }^{\text {II }}$. In or. 6,5 jongliert Gregor geradezu mit dem Bedeutungsspektrum von $\lambda$ ó theologisch-christlichen Verständnis zum $\lambda$ ó $\gamma$ os der Vernunft, der Sprache und der Weisheit, um seine spezifische Zugangsweise deutlich zu machen:

konversion des Julians in seinen Augen den höchsten Ausdruck gefunden hatte (vgl. Libanius, or. $12,33-34$; besonders or. 18,18 ).

47 Gregorius Nazianzenus, or. 4,5.

$48 \mathrm{Vgl}$. Socrates Scholasticus, h.e. III I6,I-7; VI8,3-4.

49 Vgl. Socrates Scholasticus, h.e. III I6,8.22-27, auch Nesselrath (I999), 97.

50 Gregorius Nazianzenus, carm. 2,I,II,II3-II8.

5I Vgl. Gregorius Nazianzenus, or. 6,4. Vgl. Hartmann (2002), 297; Sieben (1996), 7. 


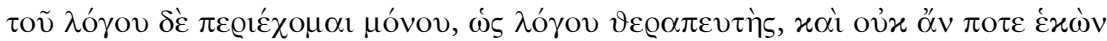

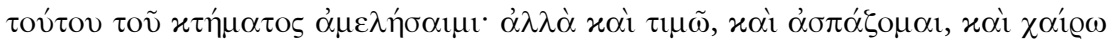

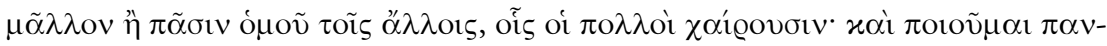

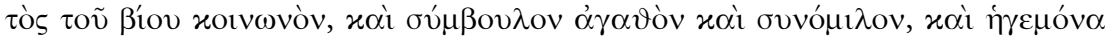

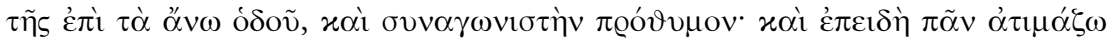

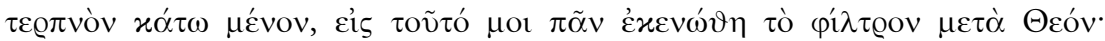

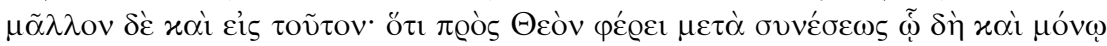

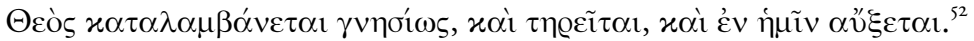

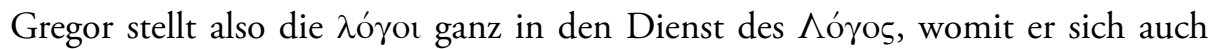
auf die Seite derjenigen stellt, die trotz der paganen Herkunft der Bildungsinhalte diese selbst areligiös, wenn nicht sogar christianisierbar verstehen. Damit bleibt jedoch weiterhin ein Bereich der $\pi \alpha$ ı $\delta$ éi $\alpha$ unberührt, auf dessen praktischen Nutzen gerade Libanios hingewiesen hat, nämlich die gesellschaftliche Funktion als Sprachcode der Eliten und damit als Mittel der Interessensvertretung für die Heimatstadt bzw. die eigene Klientel. Schließlich steht auch hinter dem Rhetorenedikt Julians eventuell auch die Überlegung, durch eine Paganisierung des Schulbetriebs den Anteil des christlichen Führungspersonals zu reduzieren und hier eingetretene Veränderungen in den Machtverhältnissen des römischen Staates rückgängig zu machen ${ }^{53}$.

An dieser Stelle sei wieder an die eingangs geschilderten Ereignisse in Antiochia erinnert, die die Auffassung, die Entscheidung zu einem tugendhaft-christlichen Leben stehe im Gegensatz zu den Notwendigkeiten einer Existenz in gesellschaftlich herausgehobener Position, als allgemein verbreitet erwiesen haben. Dabei legt die Reformschrift über das Priestertum, das Werk De sacerdotio des Johannes Chrysostomos ein deutliches Zeugnis davon ab, wie sehr die Anwendung der Rhetorik einerseits zum Handwerkszeug des Priesters gehörte, andererseits aber noch einer Rechtfertigung bedurfte.

Diese Aufgabe geht Chrysostomos an, indem er einen seelsorgerlichen Ansatz wählt, d.h. die Verantwortung des Priesters für das Seelenheil seiner Gemeindemitglieder betont. Dabei macht auch er sich das Bedeutungsspektrum von $\lambda$ ó zu Nutze, wobei $\lambda$ ó os hier sowohl „Wort Gottes“ als auch „menschliche Rede“ bezeichnet:

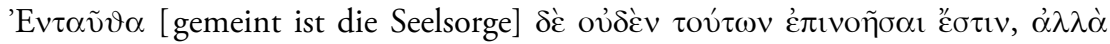

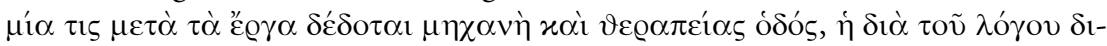

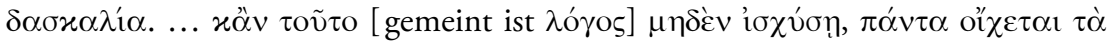

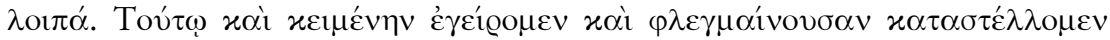

52 Gregorius Nazianzenus, or. 6,5.

53 So Klein (198I), S. 90, vgl. vor allem auch Athanassiadi-Fowden (I98I), I2I-I22, die neben intellektuellen, moralischen und religiösen auch politische Motive im $\pi \alpha 1 \delta \varepsilon i \alpha-K o n z e p t ~ J u l i a n s$ ausmacht. 


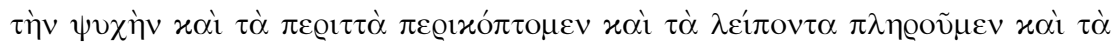

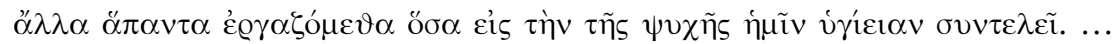

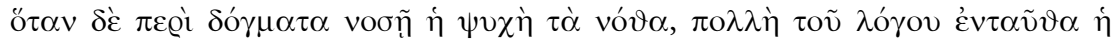

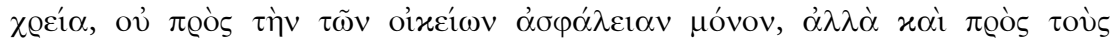

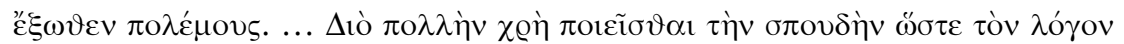

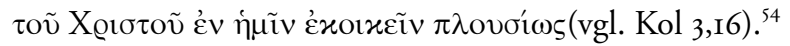

Der Vergleich mit der obigen Aussage des Gregor von Nazianz' zeigt die deutlich pragmatischere Ausrichtung des Verständnisses von $\lambda$ ó Eindrücklich macht er die Gefahren für die Christen von außen und innen, von Seiten der Heiden, Juden, Häretiker etc., deutlich, um das Wort als einzige Verteidigungswaffe des Priesters im Interesse seiner Gemeinde zu verdeutlichen. ${ }^{55} \mathrm{Er}$ nimmt jedoch nicht von hier den direkten Weg in eine einseitige Verteidigung der Rhetorik bzw. in die Forderung nach einer entsprechenden Ausbildung zukünftiger Priester, sondern geht zunächst auf die klassischen Einwände innerhalb des Christentums ein. An dieser Stelle kommt besonders die Selbstbezeichnung

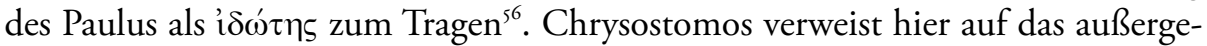
wöhnliche und unwiederbringliche Charisma des Paulus sowie auf den Unterschied, in den $\lambda$ ó $\gamma$ or oder aber der $\gamma v \tilde{\omega} \sigma ı \varsigma$ unwissend zu sein, wobei nur ersteres für Paulus galt. Die Argumentation steht in einem theologischen Zusammenhang, denn Chrysostomos betont die unabdingbare Notwendigkeit dogmatischer Wahrheitserkenntnis, und wendet sich zugleich deutlich gegen eine Übertragung des Rhetorikideals der zweiten Sophistik auf den christlichen Kontext und damit gegen den z. B. von Libanios propagierten Zusammenhang von Sprachreinheit und Vernunftschulung. Damit distanziert er sich von einem elitären Verständnis der Wahrheitserkenntnis und kann so an der zum christlichen Proprium gehörenden Behauptung des Heilszugangs für jeden unabhängig der intellektuellen und sozialen Voraussetzung weiter festhalten ${ }^{57}$. Vom Priester verlangt Chrysosto-

54 Iohannes Chrysostomus, sac. IV 3 .

55 Vgl. Iohannes Chrysostomus, sac. IV 4 .

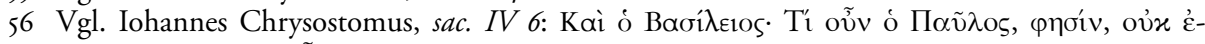

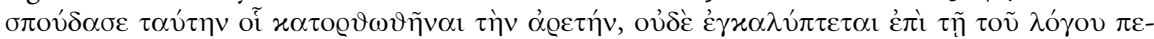

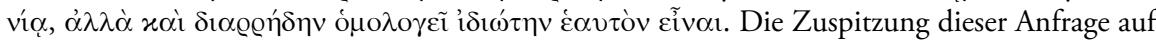
messalianische Kreise erscheint angesichts der grundsätzlichen Infragestellung des Werts rhetorischer Schulung innerhalb des Christentums nicht notwendig, so aber Staats (1992).

57 Entsprechend der Zielrichtung christlicher Existenz ist daher auch der Vorrang der Erziehung in christlichen Tugendübungen vor der intellektuellen Ausbildung bei Chrysostomos zu erklären. Während ersteres für jeden möglich ist und so das individuelle Seelenheil sicher gestellt werden kann, ist eine intellektuelle Ausbildung eher unsicher und könnte an unüberwindlichen individuellen Defiziten - intellektuell oder moralisch - scheitern, Iohannes Chrysostomus, $o p$ -

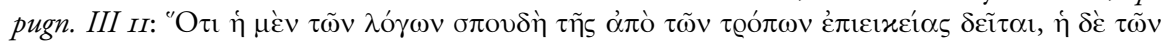

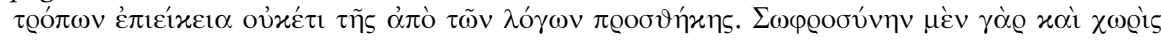

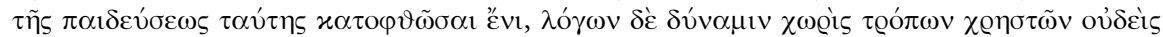

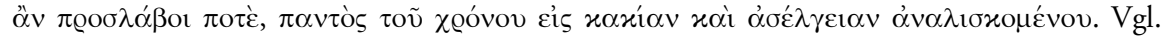
auch Iohannes Chrysostomus, hom. 2 in Eph. 
mos hier in erster Linie höchste Einsichtsfähigkeit, da er nur so die Gefahren für die Christen erkennen und abwehren kann.

Chrysostomos' Ablehnung des $\lambda$ ó $\gamma$ ot-Ideals des Libanios ist nicht nur aufgrund der von seinem Lehrer ${ }^{58}$ postulierten engen und unauföslichen Verbindung zu den iepá konsequent. Vielmehr hat Chrysostomos sich in mehreren seiner Schriften auch gegen das von Libanios ebenfalls leidenschaftliche Ideal der antiken $\pi$ ó$\lambda 1 \varsigma$ und der damit zusammenhängenden gesellschaftlichen Funktionsweisen gewandt $t^{59}$, zu denen nicht nur die $\pi \alpha i \delta \varepsilon i \alpha$ den Sprachcode der alten Eliten lieferte, sondern auch der Durchsetzung und Erhaltung überkommener Macht- und Herrschaftsstrategien diente. Chrysostomos hat dagegen sein berühmtes Bild von der "Stadt als Kloster" gesetzt ${ }^{60}$, mit dem er seine Vorstellung der Bürgerschaft im himmlischen Jerusalem und damit der Unabhängigkeit des einzelnen Christen von den gesellschaftlichen Erfordernissen des diesseitigen Lebens zu propagieren versuchte. ${ }^{61}$ Dabei sah er nicht nur in den alten Eliten allgemein eine Konkurrenz, sondern verachtete geradezu das Ensemble von Handlungsanweisungen, die bereitgestellt und propagiert durch die überlieferte Bildung die Städte in ihrem alten Lebensrhythmus weiter existieren ließen. In diesen Zusammenhang gehört seine Kritik an den Theater- und Zirkusspielen ${ }^{62}$ genauso wie die an den Strategien zur Machterlangung. Wenn Chrysostomos in seiner Schrift De sacerdotio in aller Schärfe beklagt, dass in der Kirche nicht anders als in der Gesellschaft Menschen aufgrund ihres materiellen Besitzes zu Macht und Ansehen gelangen ${ }^{63}$, so zeigt sich hier die Berechtigung der Zusammenfassung seines Anliegens in dieser Schrift unter dem Schlagwort „Verinnerlichung des Amtes" ${ }^{\text {“64. }}$.

Chrysostomos bleibt aber nicht bei der Forderung nach Verinnerlichung stehen, sondern macht vielmehr deutlich, dass die unter diesem Aspekt am geeignetsten erscheinende Gruppe der Mönche in seinen Augen eher ungeeignet ist, das Priesteramt zu übernehmen. Hier kommt seine auch in anderen Schriften vertretene Kritik am Mönchtum zum Tragen, dessen freiwillige Exilierung außerhalb der Städte einem gewissen Egoismus gleichkomme, wenn das Leben abge-

58 Das Lehrer-Schüler-Verhältnis wird von Palladius, v. Chrys., nicht erwähnt, gilt aber bei Socrates Scholasticus, h.e VI 3,I, und Sozomenus, h.e. VIII 2,5.7, als sicher. Aufgrund stilistischer Untersuchungen geht auch Fabricius, (I962),II9-I2I, von einem Lehrer-Schüler-Verhältnis aus, Gegenargumente listet Festugière (1959), 409-4IO, auf.

59 Vgl. Iohannes Chrysostomus, eleem. 6; hom. 2,5 in Rom; dazu Tiersch (2000); 52-53.

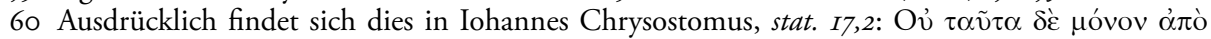

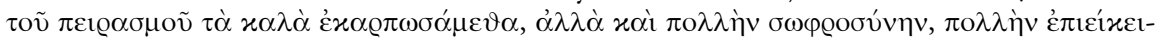

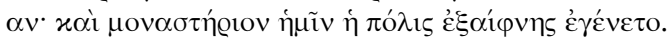

6I Vgl. Iohannes Chrysostomus, oppugn. II 9; catech 3/3,29.

62 Vgl. Iohannes Chrysostomus, Anna IVI; hom. 6,7-8 in Mt.; auch Brown (1994), 323.

63 Vgl. Iohannes Chrysostomus, sac. III Io.

64 Vgl. Dörries (1973). 
sondert von der Gemeinschaft auch für diese spezifische Lebensform geeignet erscheine $^{65}$. Für Chrysostomos ist es aber höchst fraglich, ob ein Mönch auch in der Stadt bestehen und den Gefahren für sein eigenes Seelenheil und das seiner potentiellen Gemeinde widerstehen kann. Hier geht es nicht nur um die Anfechtungen und Vergnügungen durch das städtische Gesellschaftsleben, sondern auch um die mannigfaltigen Aufgaben des Priesters bzw. Bischofs in Bereichen der Diakonie und Jurisdiktion sowie der Lehre. ${ }^{66}$ Wenn auch nicht explizit zum Ausdruck gebracht, so ist hier doch unübersehbar, dass Chrysostomos auf Bereiche verweist, zu deren kompetenter Verwaltung durch klassische Schulbildung erworbene Fähigkeiten gehören. Chrysostomos verliert trotz seiner hohen Erwartungen an Glaubensfestigkeit, Moralität und Integrität des Priesters ${ }^{67}$ die praktischen Anforderungen des Amtes nicht aus den Augen.

In seiner Argumentation wird auch deutlich, in welch hohem Maße er im Scheitern an den praktischen und alltäglichen Aufgaben des Amtes eine Gefährdung der Stabilität der Gemeinde und damit des Seelenheils der Christen sieht, dem allein der Priester zu dienen hat. ${ }^{68}$ So sieht er einerseits den Priester und die korrekte Ausübung des Amtes durch den Erwartungsdruck der Menge, die vom Amtsinhaber eine regelrechte Inszenierung erwartet und ihn unter eine hohe Sozialkontrolle stellt, gefährdet, andererseits fordert er die Bedienung der gesellschaftlichen Erwartungen im seelsorgerlichen Interesse. ${ }^{69}$ Von hier aus findet Chrysostomos dann auch den Weg zur Legitimation der Rhetorik im christlichkirchlichen Kontext. Der Priester muss sich als gleichwertig mit den paganen Sophisten erweisen und somit auch dem Bild des Intellektuellen entsprechen, um bei den Gemeindemitgliedern keinen Zweifel an seiner intellektuellen Glaubwürdigkeit aufkommen zu lassen und sie für seine Botschaft empfänglich zu machen. ${ }^{70}$ In gewisser Weise kapituliert Chrysostomos also vor dem Bild des Intellektuellen, wie es gerade von Libanios propagiert wurde, um so die Kirche nach innen wie außen konkurrenzfähig zu halten. Dass ihm dabei eine größtmögliche Distanz zu den paganen Verteidigern der $\lambda$ ó $o$ or wichtig ist, macht seine Kompro-

$65 \mathrm{Vgl}$. Iohannes Chrysostomus, sac. II I; III Io-II; VI 3-6; hom. 55, 6 in Mt.

$66 \mathrm{Vgl}$. Iohannes Chrysostomus, sac. III Io; III I2.

$67 \mathrm{Vgl}$. Iohannes Chrysostomus, sac. IV 4-5; IV 9.

68 Vgl. Iohannes Chrysostomus, sac. III I0, und dazu ähnlich Gregorius Nazianzenus, or. 2, 83-83; dazu Dörries (I973), 8.

69 Iohannes Chrysostomus, sac. III Io.I4; VI.

70 In sac. $V_{I}$ stellt Chrysostomos eindrücklich den Zwang zu sprachlicher und gedanklicher Originalität des christlichen Predigers dar. Der Prediger werde von der Gemeinde kritischer begut-

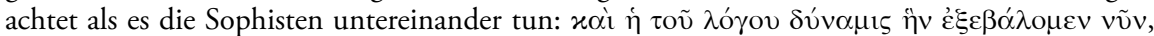

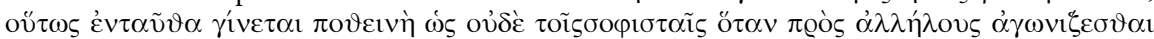
$\dot{\alpha} v \alpha \gamma \varkappa \alpha \dot{\zeta} \omega \nu \tau \alpha$. Chrysostomos zeigt seine vorhergehende Argumentation (sac. IV 6, vgl. oben), nach der es ihm nicht um das Rhetorikideal der 2. Sophistik geht, von den Anforderungen der Praxis eingeholt. 
missformel deutlich, wenn er für den Priester verlangt, die höchsten rhetorischen Fähigkeiten sollen einhergehen mit einer Verachtung des Lobs dafür:

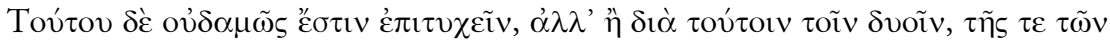

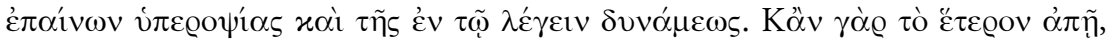

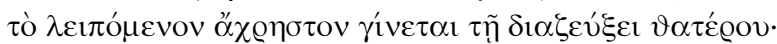

Damit wendet sich Chrysostomos gegen die von Libanios als Motivation zum intellektuellen, wohltätigen und moralischen Streben propagierte $\varphi \iota \lambda o \tau \mu \iota^{\prime 1} \alpha^{71}$, die er auch als $x \varepsilon v o \delta o \xi i \alpha$ disqualifiziert.

Unter dem Schlagwort $x \varepsilon v o \delta o \xi i \alpha$ hat Chrysostomos viele der von Libanios positiv bewerteten Funktionsweisen der spätantiken Gesellschaft kritisiert ${ }^{72}$. Dazu gehören nicht nur z. B. die Ausrichtung der von Chrysostomos scharf kritisierten öffentlichen Veranstaltungen, sondern auch die Bedeutung der $\lambda$ ó $\gamma o r$ selbst als Begründung gesellschaftlicher Differenz und Ermöglichungsgrund der Übernahme gesellschaftlicher Aufgaben. In seiner Vorstellung des einzelnen Christen als Bürger des himmlischen Jerusalems vertrat er die Vorstellung, dass ein jeder Aufgaben in der Verherrlichung Gottes und auch dem Leben in der Gemeinde zu übernehmen habe ${ }^{73}$, was ihn nicht an klar hierarchischen Vorstellungen gehindert hat. Dabei kannte Chrysostomos auch die Übernahme der Patronatsfunktion, $\pi \varrho 0 \sigma \tau \alpha \sigma i ́ \alpha$, durch die städtische Elite, zu der ja letztlich auch das kirchliche Führungspersonal gehörte, hat aber die Patronage als punktuell auszuüben verstanden und nicht als grundlegendes und beziehungsstiftendes Verhalten innerhalb eines festen Klientels und ihres Patrons ${ }^{74}$.

In der großen Krisensituation Antiochias, den Ereignissen nach dem sogenannten Säulenaufstand 387, bei dem die Bevölkerung aus Protest gegen Steuererhöhungen Standbildnisse der kaiserlichen Familie zerstört hatte ${ }^{75}$, zeigt sich jedoch, dass die kirchliche Führungselite durchaus in der Lage ist, die Funktion als Für-

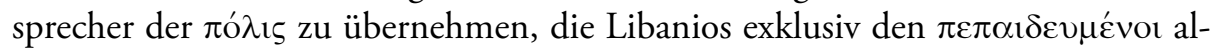
ter Prägung und ihrer Anwendung der $\lambda$ ó $\gamma o r$ zu übernehmen zugetraut hatte. In seinen 20 Homilien, die Chrysostomos in der Zeit zwischen dem Beginn der Ereignisse - das Niederreißen der Statuen des Kaisers und seiner Familie und die Ankunft seiner Gesandten - und der Ankunft der positiven Nachrichten, dass der Kaiser auf ein weiteres Strafgericht verzichtet, stellt er durchaus genüsslich das Versagen der alten Elite dar, die sich durch Flucht und Verstecken jeglichem

7I Vgl. Libanius, or. II, I37-I44; Schmitz (1997), 97-IOI.

72 Vgl. Iohannes Chrysostomus, educ. lib. 4; Anna 4,2.

73 Vgl. Iohannes Chrysostomus, hom. 58,5; 60,3 in Mt.; hom. I4,5; 4I,2 in Gen.; hom. II,I.5 in Eph.; Anna 4,I; dazu auch Ritter (1972), 79-84.

74 Insofern bevorzugt Chrysostomus die philosophische $\pi \alpha \varrho \emptyset \eta \sigma^{\alpha} \alpha$.

$75 \mathrm{Zu}$ den Ereignissen und ihren unterschiedlichen Deutungen vgl. insgesamt Leppin (1999). 
Konflikt und damit der Verantwortung entzogen hatten. ${ }^{76}$ Er betont die Rolle der Mönche, die die Gesandten von voreiligen (Todes-)Urteilen abhalten, nicht ohne den Priestern ebenfalls eine unerschrockene Ausübung der $\pi \propto \varrho \emptyset \sigma^{\prime} \alpha$ zu attestieren. Im Besonderen ist es jedoch Bischof Flavian, der zum Kaiser reist und dort erfolgreich die Rolle des Fürsprechers der Stadt Antiochia übernimmt. Der Kaiser hat damit gewisser Maßen den Bischof in seiner Rolle als Sprecher der Stadt bestätigt, womit letztlich auch eine Entmachtung bzw. Marginalisierung

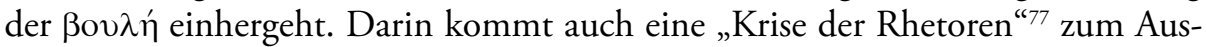
druck, was sich besonders in der Schilderung der Ereignisse bei Libanios zeigt: Einerseits behauptet er, er sei derjenige gewesen, der die Gesandten zum Einhalt bewogen habe ${ }^{78}$, andererseits stellt er sich selbst als denjenigen dar, der in Ermangelung anderer Gesandter zu Theodosios gereist und diesen auf Grundlage der gemeinsamen Bildung besänftigt habe ${ }^{79}$. Eine gewisse Hilflosigkeit des Libanios ist erkennbar, wenn er so versucht, die Rolle der Kirche gänzlich zu verschweigen, und sie erklärt sich wohl auch aus der vermutlich tatsächlich während dieser Ereignisse gehaltenen Rede or. 23, die er gegen die geflohenen Angehörigen der Oberschicht hält, die mit ihrer Flucht sein Ideal gänzlich verraten hatten.

Wenn es jedoch Chrysostomos gelungen war, mit seinen Homilien tatsächlich die Bevölkerung zu beruhigen, so ist dies sicherlich nicht zuletzt seiner rhetorischen Kunst zu verdanken. Einem Libanios kann dies nicht genug gewesen sein aufgrund des mangelnden konstitutiven Zusammenhangs mit den i̊gó, für Chrysostomos müssen die gesamten Ereignisse eine Bestätigung der Funktionalisierung der $\lambda$ ó $\gamma o$ für den kirchlichen Kontext gewesen sein. So hat er selbst ja in seiner Schrift De sacaerdotio betont, dass die Kirche und auch das Leben der Christen zwar auszurichten sind nach dem Ideal des himmlischen Jerusalems, die Christen und gerade ihr Führungspersonal aber auch in den innerweltlichen Verstrickungen zu bestehen haben. Von daher ist zu verstehen, wenn er in seiner Rechtfertigung der Rhetorik letztlich das pagane Bild des Intellektuellen und seiner gesellschaftlichen Funktion auf die kirchliche Hierarchie überträgt. Seine Versuche, dennoch durch nur punktuelle Berührungspunkte zwischen weltlichen und kirchlichen Angelegenheiten eine Unabhängigkeit von dem überlieferten Gefüge des gesellschaftlichen und politischen Diskurses zu erhalten, führten trotz seines klaren Blicks für die gesellschaftlichen Funktionsweisen letztlich auch zu seinem Scheitern. ${ }^{80}$

76 Vgl. Iohannes Chrysostomus, stat. I7,2.

77 Vgl. Hose (2000).

78 Vgl. Libanius, or. I, 253.

79 Vgl. Libanius, or. I9,I-4, vgl. Stenger (2009), 243-244.

80 Vgl. Tiersch (2000), 426-427. 


\section{Zusammenfassung}

Das Christentum hat früh ein konstruktives Verhältnis zu den philosophischen Inhalten der klassischen antiken Bildung, der $\pi \alpha \_\delta \varepsilon i ́ \alpha$, gefunden. Dieses ging häufig einher mit einer Ablehnung und moralischen Diskreditierung der Rhetorik und hier besonders dem Bildungsideal der sogenannten zweiten Sophistik. Allerdings verschärften die Situation der Kirche nach der ,Konstantinischen Wende und die Herausforderung durch Kaiser Julian die Notwendigkeit, auch der Rhetorik als konstitutivem Bestandteil höherer Bildung und als elitärem Sprachcode eine Stellung zuzuweisen, die ihre unabdingbare Anwendung legitimieren konnte ohne christliche Grundsätze aufgeben zu müssen. Im Osten haben sich u. a. Gregor von Nazianz und vor allem der als größter christlicher Redner in die Geschichte eingegangene Johannes Chrysostomos dieser Aufgabe in unterschiedlicher Weise gestellt. Dabei gehen beide über das Gebot des exakten Umgangs mit Sprache deutlich hinaus und begründen rhetorische Kunst theologisch, seelsorgerlich und nicht zuletzt pragmatisch. Die Fähigkeit zur Anwen-

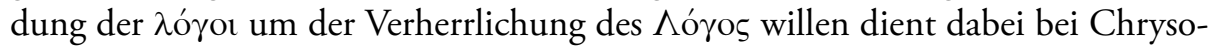
stomos nicht nur der Propagierung der christlichen Botschaft, sondern in letzter Konsequenz erfüllt er mit seiner Forderung nach rhetorischen Fähigkeiten des kirchlichen Führungspersonals auch das pagane Bild des Intellektuellen und seiner Übernahme gesellschaftlicher Aufgaben, wodurch die Rhetorik auch im christlichen Bereich die Funktion der Statuslegitimation erhält. 


\section{Literaturverzeichnis}

Aland (1983): Barbara Aland, Christentum, „Bildung und römische Oberschicht. Zum ,Octavius' des Minucius Felix“, in: Horst-Dieter Blume u. Friedhelm Mann (Hgg.), Platonismus und Christentum. FS Heinrich Dörrie, Münster, II-30.

Atthanassiadi-Fowden (198I): Polymnia Atthanassiadi-Fowden, Julian and Hellenism. An Intellectual Biography, Oxford.

Brown (1994): Peter Brown, Die Keuschheit der Engel. Sexuelle Entsagung, Askese und Körperkult im frühen Christentum, München.

Dörries (1973): Hermann Dörries, „Die Erneuerung des kirchlichen Amts im 4. Jahrhundert. Die Schrift de sacerdotio des Johannes Chrysostomus und ihre Vorlage, die Oratio de fuga sua des Gregor von Nazianz", in: Bernd Moeller u. Gerd Ruhbach (Hgg.), Bleibendes im Wandel der Kirchengeschichte. Kirchenhistorische Studien, Tübingen, I-46.

Fabricius (1962): Cajus Fabricius, $Z u$ den Jugendschriften des Johannes Chrysostomos. Untersuchungen zum Klassizismus des vierten Jahrhunderts, Lund.

Fatouros u.a. (2002): Georgios Fatouros, Tilman Krischer u. Werner Portmann, Libanios. Kaiserreden, eingeleitet, übersetzt und kommentiert, Stuttgart.

Festugière (1959): André-Jean Festugière, Antioche païenne et chrétienne. Libanius, Chrysostome et les moines de Syrie, Paris.

Fiedrowicz (2000): Michael Fiedrowicz, Apologie im frühen Christentum. Die Kontroverse um den christlichen Wabrheitsanspruch in den ersten Jahrhunderten, Paderborn / Wien / München / Zürich.

Fiedrowicz (200I). Michael Fiedrowicz, „Frühchristliche Alternativen zu paganen Bildungskonzepten“, in: Rainer Kampling (Hg.), Deus semper maior. Vom Bleibenden in den Zeiten, FS Georg Kardinal Sterzinski, Berlin, 73-87.

Gemeinhardt (2007): Peter Gemeinhardt, Das lateinische Christentum und die antike pagane Bildung, Tübingen.

Gülzow (1975): Henneke Gülzow, Cyprian und Novatian. Der Briefwechsel zwischen den Gemeinden in Rom und Karthago zur Zeit der Verfolgung des Kaisers Decius, Tübingen.

Hartmann (2002): Christoph Hartmann, „Gregor von Nazianz“, $L A C L^{3}$, Freiburg / Basel / Wien, 295-297.

Hose (2000): Martin Hose, „Die Krise der Rhetoren. Über den Bedeutungsverlust der institutionellen Rhetorik im 4. Jahrhundert und die Reaktionen ihrer Vertreter", in: Christoff Neumeister u. Wulf Raeck (Hgg.), Rede und Redner. Bewertung und Darstellung in den antiken Kulturen, Paderborn, 289299. 
Hunter (1988): David G. Hunter, A Comparison Between a King and a Monk / Against the Opponents of the Monastic Life. Two Treatises by John Chrysostoms, Lewiston.

Klein (198I): Richard Klein, „Kaiser Julians Rhetorik- und Unterrichtsgesetz“, $R Q 76,73-94$.

Leppin (1999): Hartmut Leppin, „Steuern, Aufstand und Rhetoren: Der Antiochener Steueraufstand von 387 in christlicher und heidnischer Deutung", in: Hartwin Brandt (Hg.), Gedeutete Realität. Krisen, Wirklichkeiten, Interpretationen (3. - 6. Jahrhundert n. Chr.), Stuttgart, IO3-I23.

Liebeschuetz (1972): Johann H. W. G. Liebeschuetz, Antioch. City an Imperial Administration in Later Roman Empire, Oxford.

Nesselrath (1999): Heinz-Günther Nesselrath, „Die Christen und die heidnische Bildung. Das Beispiel des Sokrates Scholastikos (Hist. Eccl. 3,I6)“, in: Jürgen Dummer u. Meinolf Vielberg, Leitbilder der Spätantike - Eliten und Leitbilder, Stuttgart, 79-Ioo.

Nesselrath (200I): Heinz-Günther Nesselrath, „Lukians Leben und Werk“, in: Martin Ebner, Holger Gzella, Heinz-Günther Nesselrath u. Ernst Ribbat (Hgg.), Lukian, Die Lügenfreunde, oder: Der Ungläubige, Darmstadt, II-3I.

Pack (1986): Edgar Pack, Städte und Steuern in der Politik Julians. Untersuchungen $z u$ den Quellen eines Kaiserbildes, Brüssel.

Petit (1955): Paul Petit, Libanius et la vie municipale à Antioche au $I V^{2}$ siècle après J.-C., Paris.

Rapp (2000): Claudia Rapp, „The Elite Status of Bishops in Late Antiquity in Ecclesiastical, Spiritual, and Social Contexts", Arethusa 33, 379-399.

Ritter (1972): Adolf Martin Ritter, Charisma im Verständnis des Johannes Chrysostomos und seiner Zeit. Ein Beitrag zur Erforschung der griechisch-orientalischen Ekklesiologie in der Frühzeit der Reichskirche, Göttingen.

Rosen (1982): Klaus Rosen, Ammianus Marcellinus, Darmstadt.

Schmitz (1997): Thomas Schmitz, Bildung und Macht. Zur sozialen und politischen Funktion der zweiten Sophistik in der griechischen Welt der Kaiserzeit, München.

Scholl (1994): Reinhold Scholl, Historische Beiträge zu den julianischen Reden des Libanios, Stuttgart.

Seiler (1998): Eva-Maria Seiler, Konstantios II. bei Libanios. Eine kritische Untersuchung des überlieferten Herrscherbildes, Frankfurt / Berlin / New York / Paris / Wien.

Sieben (1996): Hermann Josef Sieben, Gregor von Nazianz, Orationes theologicae Theologische Reden, übersetzt und eingeleitet, Freiburg / Basel / Wien.

Staats (1992): Reinhart Staats, „Chrysostomus über die Rhetorik des Apostel Paulus. Makarianische Kontexte zu ,De Sacerdotio IV, 5-6“", in: VigChr 46, 225-240. 
Stenger (2009): Jan Stenger, Hellenische Identität in der Spätantike. Pagane Autoren und ihr Unbehagen an der eigenen Zeit, Berlin / New York.

Tiersch (2000): Claudia Tiersch, Johannes Chrysostomus in Konstantinopel (398404). Weltsicht und Wirken eines Bischofs in der Hauptstadt des Oströmischen Reichs, Tübingen.

Wiemer (1995): Hans-Ulrich Wiemer, Libanios und Julian. Studien zum Verhältnis von Rhetorik und Politik im 4. Jahrbundert n. Chr., München.

Wolf (1954): Peter Wolf, „Libanios und sein Kampf um die hellenische Bildung“, in: Georgios Fatouros u. Tilmann Krischer, Darmstadt 1983, 69-83 (= MH II, I954, 23I-242).

Wolf (1967): Peter Wolf, Libanios. Autobiographische Schriften, eingeleitet, übersetzt und erläutert, Zürich / Stuttgart. 



\title{
Homöismus und Logostheologie
}

\author{
Hanns Christof Brennecke
}

\section{I.}

Die Kirchengeschichte des 4. Jahrhunderts ist theologiegeschichtlich zu großen Teilen geprägt durch die Auseinandersetzungen um die rechte und angemessene Bestimmung des Verhältnisses zwischen Vater - Sohn und Heiligem Geist in der Trinität, d.h. die Formulierung einer Trinitätslehre, die aber den christlichen Anspruch des Monotheismus bewahrt ${ }^{\mathrm{I}}$. Die dann sogenannte zweite „ökumenische Synode" von Konstantinopel ${ }^{2}$ hat 38I auf der Basis einer ab ca. 360 erstmals zu beobachtenden Differenzierung der Begriffe ov̉oí $\alpha$ und vं und Dreiheit in der Trinität bei Wahrung des Monotheismus ausgleichen können $^{3}$. Mit tatkräftiger politischer Unterstützung Kaiser Theodosius' I. und seiner Nachfolger konnte sich diese Lösung als „nizänische Orthodoxie“ durchsetzen; alle anderen Modelle galten seither als Häresie und führten zu häretischen Kirchbildungen, die z.T. mit kaiserlicher Gewalt verfolgt wurden und auch weithin verschwanden ${ }^{4}$. Die Rezeption dieser neunizänischen Trinitätslehre und des Nicaeno-Constantinopolitanum im lateinischen Abendland ist als eigener theologischer Prozess zu verstehen, der am Ende zur Entfremdung zwischen den Kirchen des Ostens und des Westens beigetragen hat 5 .

I Die angegebene Literatur soll nur die allernötigsten Informationen liefern und ist deshalb so knapp wie irgend möglich gehalten. Zum Ganzen vgl. A.M. Ritter, in: Handbuch der Dogmen- und Theologiegeschichte I, Göttingen ${ }^{2}$ I999, 99-22I; C. Piétri/Ch. Markschies, in: C. Piétri/L. Piétri, Hgg., Das Entstehen der einen Christenheit (250-430), Die Geschichte des Christentums 2, Freiburg/Basel/Wien, 1996, 27I-344; Ch. Markschies, Alta Trinità Beata, Gesammelte Studien zur altkirchlichen Trinitätslehre, Tübingen 2000.

2 A.M. Ritter, in: G. Alberigo, Hg., The Oecumenical Councils, Concilorum oecumenicorum generaliumque Decreta I, CC, Turnhout, 2006, 35-70.

3 Ch. Markschies, Art. Neunicaenismus, RGG 6 6, 2003, $232 \mathrm{f}$.

4 Mit Ausnahme der homöischen Germanen im Reichsdienst, die als Föderaten nicht den Religionsgesetzen unterlagen. Zum Homöismus der Germanen vgl. K. Schäferdiek, Art. Germanenmission, RAC Io, 1978, 492-542; ders., Schwellenzeit. Beiträge zur Geschichte des Christentums in Spätantike und Frühmittelalter, hgg. W. Löhr und H.C. Brennecke, AKG 64, Berlin / New York 1996.

5 Ch. Markschies, Ambrosius von Mailand und die Trinitätstheologie, BHTh 90, Tübingen 1995; ders., Was ist lateinischer „Neunizänismus“?, ZAC I, 1997, 73-95 (= Ch. Markschies Alta Trinità Beata (vgl. Anm. I), 238-264; R. Kany, Augustins Trinitätsdenken, Tübingen 2007. 
Theologiegeschichtlich war es vom Beginn der Auseinandersetzungen zwischen dem alexandrinischen Presbyter Arius und seinem Bischof Alexander zur orthodoxen Trinitätslehre des zweiten (ökumenischen) Konzils von Konstantinopel ein weiter, nicht selten holpriger und komplizierter Weg, der auch zu mancherlei Umwegen nötigte. Verkompliziert wurde er durch den unterennbar und nahezu unentwirrbar mit ihm verbundenen Prozess, den man sich inzwischen angewöhnt hat, als „Konstantinische Wende“ zu bezeichnen ${ }^{6}$.

Besonderes Interesse der dogmen- und theologiegeschichtlichen Forschung hat seit langem der schwierige Prozess der theologischen Ausdifferenzierung (samt dessen kirchenpolitische Folgen) der Kritiker der trinitarischen Beschlüsse der Synode von Nicaea gefunden, die das Erbe der origenistischen Logos-Theologie bewahren wollten und die Trinität strikt gestuft in drei einander (in je zu bestimmender Form) subordinierten göttlichen Hypostasen zu beschreiben versuchten und von den Vertretern der Beschlüsse von Nicaea, vor allem von Athanasius von Alexandrien in seinen polemischen Traktaten pauschal als „Arianer" diffamiert wurden 7 . Das Ende der fünfziger Jahre des vierten Jahrhunderts (357-360) kann geradezu als „Sattelzeit“ dieses Prozesses verstanden werden.

\section{II.}

Mit der Formulierung der 2. sirmischen Formel im Herbst 357 auf einer von Kaiser Constantius II. an den dortigen Hof einberufenen Synode, von der außer diesem Text so gut wie nichts bekannt ist ${ }^{8}$, beginnt üblicherweise in der modernen Kirchen- und Theologiegeschichte die Gruppe der dann nach ihrem theologi-

6 Die Folgen der konstantinischen Wende gerade für die Ausbildung des trinitarischen Dogmas zeigen vor allem die überlieferten Dokumente; vgl. H.-G. Opitz, Urkunden zur Geschichte des arianischen Streites I-2, Athanasius Werke III I,I-2; Berlin 1934-1935. Die Fortsetzung der von Opitz nur bis zur Synode von Nizäa fortgeführten Aktensammlung jetzt H.C. Brennecke/U. Heil/A. v. Stockhausen/A. Wintjes, Dokumente zur Geschichte des arianischen Streites 3, Athanasius Werke III I,3, Berlin/New York 2007 (bis 344). Die 4. Lieferung mit den Dokumenten von 344 bis 362 steht vor dem Abschluß und wird 20II erscheinen. Zur Diskussion um die „konstantinische Wende“ E. Mühlenberg, Hg., Die Konstantinische Wende, VWGTh I3, Gütersloh 1998; K.M. Girardet, Die konstantinische Wende, Darmstadt ${ }^{2} 2007$.

7 H.C. Brennecke, Hilarius von Poitiers und die Bischofsopposition gegen Konstantius II. Untersuchungen zur dritten Phase des arianischen Streites (337-36I), PTS 26, Berlin / New York 1984; ders., Studien zur Geschichte der Homöer. Der Osten bis zum Ende der homöischen Reichskirche, BHTh 73, Tübingen 1988; W. Löhr, Die Entstehung der homöischen und homöusianischen Kirchenparteien - Studien zur Synodalgeschichte des 4. Jahrhunderts, Diss.theol. Bonn 1986.

8 H.C. Brennecke, Hilarius von Poitiers (vgl. Anm. 7), 312-324; Löhr, Entstehung (vgl. Anm. 7), 44-52; J. Ulrich, Die Anfänge der abendländischen Rezeption des Nizänums, PTS 39, Berlin/ New York 1994, I6I-166; ders., Phoebadius. Contra Arianos — Streitschrift gegen die Arianer, FC 38, Freiburg etc. 1999, 42-50. 


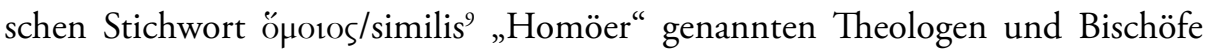
als eigenständige theologische, meist allerdings eher kirchenpolitische Größe gesehen zu werden ${ }^{\mathrm{IO}}$.

Die 2. sirmische Formel ist dann nach Protesten aus Ost und West ${ }^{\mathrm{II}}$ ganz schnell wieder aus der theologischen Diskussion verschwunden, muß aber dennoch als Schlüsseltext der homöischen Theologie angesehen werden. Später sind für die Homöer, die nach der 2. ökumenischen Synode von 38I als verurteilte Häretiker zu einer eigenen Kirche in der Illegalität wurden, die Beschlüsse der Synoden von Rimini (359) und Konstantinopel (360) als Glaubensgrundlage verbindlich geworden ${ }^{\text {I2 }}$; die homöischen Kirchen in den germanischen Nachfolgereichen auf dem Boden des ehemaligen weströmischen Reiches sind ihnen darin gefolgt und haben sich ebenfalls vor allem auf die kurze Bekenntnisformel der Synode von Rimini berufen.

Der Text der 2. sirmischen Formel ist im lateinischen Original bei Hilarius von Poitiers, in einer griechischen Übersetzung bei Athanasius von Alexandrien überliefert ${ }^{\mathrm{I}}$ :

cum nonnulla putaretur esse de fide disceptatio diligenter omnia apud Sirmium tractata sunt et discussa praesentibus sanctissimis fratribus et coepiscopis nostris Valente, Ursacio, Germinio.

unum constat deum esse omnipotentem et patrem, sicut per universum orbem creditur. et unicum filium eius Jesum Christum dominum salvatorem nostrum, ex ipso ante saecula genitum.

duos autem deos nec posse nec debere praedicari, quia ipse dominus dixit: ibo ad patrem meum et ad patrem vestrum ad deum meum et ad deum vestrum (Joh 20,17).

9 Die beiden Stichwörter tauchen hier noch nicht auf, sondern erst in den Synodaldokumenten seit 358/59.

Io Vgl. die in Anm. 8 genannte Literatur und speziell zu den Homöern H.C. Brennecke, Art. Homéisme, DHGE 24, 1993, 932-960; W. Löhr, Art. Homöer, RGG ${ }^{4}$ 3, 2000, 1880-1882.

II Als erste Reaktion eines lateinischen Theologen muß der aus den Collectanea antiariana Parisina zu rekonstruierende Liber I adversus Ualentem et Ursacium des Hilarius von Poitiers angesehen werden; vgl. Brennecke, Hilarius von Poitiers (vgl. Anm. 6). Im Osten protestierte eine von Basilius von Ankyra geleitete Synode in Ankyra Ostern 358 vor allem gegen die Zustimmung des Eudoxios, Aëtios und Eunomios zu den Beschlüssen von Sirmium; vgl. Dokumente zur Geschichte des arianischen Streites (vgl. Anm. 7), Dok. 53f.

I2 Formel von Rimini (2. sessio) bei Hieron., adv. Lucif. I7 (PL 23, I79 = Dok. 58.I2); die Formel von Konstantinopel bei Ath., syn. 30, 2-IO (258,26-259,20 Opitz = Dok. 60.5).

I3 Die aller Wahrscheinlichkeit nach originale lateinische Fassung bei Hil., syn. II (PL IO, 487A-489B). Ath., syn. 28, 2-I2 eine griechische Übersetzung. Von Ath. abhängig ist die Fassung bei Socr., h.e. II 30, 3I-4I; vgl. Dokumente (vgl. Anm. 6), Dok. 49 (nach einer ersten und noch vorläufigen Fassung hier der Text). Für die Schrift de Synodis des Hilarius von Poitiers steht bis heute keine kritische Edition zur Verfügung. K. Holl jun. hatte vor dem Krieg mit Vorarbeiten zu einer Edition begonnen, die nach seinem frühen Tod im Krieg lange keine Fortsetzung fanden. Die inzwischen lange angekündigte kritische Edition von de synodis von $\mathrm{M}$. Durst für CSEL ist bisher nicht erschienen. 
ideo omnium deus unus est, sicut apostolus docuit: an Judaeorum deus tantum? nonne et gentium? imo et gentium. quoniam quidem unus deus, qui iustificat circumcisionem ex fide et praeputium per fidem (Röm 3,29f.).

sed et caetera convenerunt, nec ullam habere potuerunt discrepantiam. quod vero quosdam aut multos movebat de substantia, quae graece usia appellatur, id est (ut expressius intelligatur) homousion aut quod dicitur homoeusion, nullam omnino fieri oportere mentionem, nec quemquam praedicare ea de causa et ratione quod nec in divinis scripturis contineatur et quod super hominis scientiam sit, nec quisquam possit nativitatem filii enarrare, de quo scriptum est: generationem eius quis enarrabit (Jes $53,8)$ ?

scire autem manifestum est solum patrum quomodo genuerit filium suum et filium quomodo genitus sit a patre.

nulla ambiguitas est, maiorem esse patrem. nulli potest dubium esse, patrem honore, dignitate, claritate, maiestate et ipso nomine patris maiorem esse filio ipso testante, qui me misit maior me est (Joh $\mathrm{I} 4,28$ ).

et hoc catholicum esse, nemo ignorat, duas personas esse patris et filii, maiorem patrem, filium subiectum cum omnibus his quae ipsi pater subiecit.

patrem initium non habere, invisibilem esse, immortalem esse, impassibilem esse.

filium autem natum esse ex patre, deum ex deo, lumen ex lumine. cuius filii generationem ut ante dictum est neminem scire nisi patrem suum. ipsum autem filium dei dominum et deum nostrum sicut legitur carnem vel corpus, id est hominem suscepisse ex utero virginis Mariae sicut angelus praedicavit. ut autem scripturae omnes docent et praecipue ipse magister gentium apostolus, hominem suscepisse de Maria virgine, per quem compassus est.

illa autem clausula est totius fidei et illa confirmatio quod trinitas semper servanda est. sicut legimus in Evangelio: ite et baptizate omnes gentes in nomine patris et filii et spiritus sancti (Mt 28,19).

integer, perfectus numerus trinitatis est.

paracletus autem spiritus per filium est, qui missus venit iuxta promissum ut apostolos et omnes credentes instrueret, doceret, sanctificaret.

Diese theologische Standortbestimmung, die man besser nicht als „Bekenntnis“ bezeichnen sollte, gilt für die ältere Forschung als Ausdruck eines radikalen „Arianismus“, teilweise sogar als eine Form des Anhomöismus ${ }^{\text {I4 }}$. Davon kann nun keine Rede sein ${ }^{15}$.

Die 2. sirmische Formel steht, wie vor allem auch die Untersuchungen von Winrich Löhr und Jörg Ulrich gezeigt haben, ganz in der Tradition der antinicae-

I4 Vgl. Ulrich, Die Anfänge (vgl. Anm. 8), I63 Anm. 44f.

I5 W. Löhr und J. Ulrich (vgl. Anm. 7f.) haben meine Thesen in dieser Hinsicht nicht unwesentlich präzisiert und auch korrigiert. 
nischen Dreihypostasentheologie. Sie konnten im einzelnen zeigen, daß und wie hier die östliche synodale Tradition der vierziger und fünfziger Jahre fortgesetzt wurde ${ }^{16}$.

Auffällig und in dieser Form nicht in der Tradition der östlichen Synodalerklärungen verankert ist nun allerdings das dezidierte Verbot der Usia-Terminologie, präzisiert durch das Verbot, die Begriffe ómoov́oıos und/oder ó die Beschreibung des Verhältnisses von Vater und Sohn in der Trinität. Bekanntlich hatte dieses Verbot in besonderer Weise die Zustimmung von Eudoxius, Aëtios und Eunomios gefunden, was zum Protest der Bischöfe um Basilius von Ankyra geführt hatte.

Aus dem Bereich der lateinischen Theologie ist die Gegenschrift des im Exil im Osten weilenden Hilarius von Poitiers bekannt ${ }^{17}$, auf dessen Anregung wohl eine Gegenschrift des Phoebadius von Agennum zurückgeht ${ }^{18}$, sowie die Ablehnung der zur Unterschrift im Westen kursierenden 2. sirmischen Formel durch eine gallische Synode um Ostern $358^{19}$. Die Kritik an der sirmischen Formel hat aller Wahrscheinlichkeit nach vor allem im Westen eine Neubesinnung auf das eigentliche Nicaenum befördert ${ }^{20}$.

Winrich Löhr und Jörg Ulrich haben gezeigt, daß und wie die 2. sirmische Formel in der östlichen Tradition der Dreihypostasentheologie steht. Darüberhinaus ist aber m. E. auch nach einem Hintergrund in der lateinischen theologischen Tradition zu fragen ${ }^{21}$.

Die 2. sirmische Formel ist nach dem Ausweis des Hilarius von Poitiers ausschließlich von abendländischen lateinischen Theologen verfaßt worden ${ }^{22}$, war offenbar für die lateinische Kirche bestimmt und nur dort zur Unterschrift vorgelegt worden ${ }^{23}$. Seit langem ist aufgefallen, daß die vermutlich in den Anfang des Jahres $358 \mathrm{zu}$ datierende Gegenschrift contra Arianos des Phoebadius von Agennum nun ganz von der lateinischen theologischen Tradition geprägt ist und von Tertullians antimonarchianischer Schrift adversus Praxean her die 2. sirmische Formel zu widerlegen sucht ${ }^{24}$. Tertullian vertritt nun bekanntlich eine (voro-

I6 Ich hatte in meiner Dissertation (Hilarius von Poitiers [vgl. Anm. 7]), 3I7, fälschlich einen Kontinuitätsbruch zwischen den theologischen Deklarationen seit der antiochenischen Kirchweihsynode und der zweiten sirmischen Formel angenommen.

I7 Vgl. Anm. II.

I8 Phoebadius, Contra Arianos (vgl. Anm. 8), 50-85 die Einleitung von J. Ulrich.

I9 Vgl. Anm. II.

20 H.C. Brennecke, Hilarius von Poitiers (vgl. Anm. 7), 248-367; Ulrich, Anfänge (vgl. Anm. 8).

2I In meiner Dissertation (vgl. Anm. 7) hatte ich diese eventuelle lateinische Tradition unter Übergehung der östlichen Tradition vor allem der Synodalbeschlüsse seit 34I zu einseitig betont. Allerdings haben Löhr und Ulrich (vgl. Anm. 7f.) diese Frage vielleicht doch etwas zu schnell abgetan.

22 Hil., syn. 3; II.

23 Hil., syn. 2; 27; c.Const. 26.

24 Ulrich (vgl. Anm. 8). 
rigenistische) Logostheologie, die nicht nur die drei Personen der Trinität distinkt unterschied, sondern auch subordinierte ${ }^{25}$. Da Tertullians Logostheologie im Westen bis Mitte des 4. Jahrhunderts eigentlich wenig Spuren hinterlassen hat, stellt sich die Frage, ob und wie der Rückgriff des Phoebadius auf eine für seine Argumentation eigentlich gar nicht so gut passende, aber eben eigene lateinische Tradition nicht dadurch motiviert war, daß auch die 2. sirmische Formel sich in die lateinische Tradition zu stellen versucht hatte?

Der Westen hatte sich ja, nachdem er seit dem Exil des Athanasius in Trier und dem Beginn der Herrschaft der Kaiser Constantin II. und Constans in den arianischen Streit hineingezogen worden war, mit wenigen Ausnahmen auf die Seite der Vertreter einer trinitarischen Einhypostasentheologie gestellt, wie es vor allem in der theologischen Deklaration der westlichen Synode von Serdika im Jahre 343 deutlich geworden war $^{26}$.

Was war nun in der Mitte des 4. Jahrhunderts die westliche abendländische trinitarische Tradition ${ }^{27}$ ?

\section{III.}

Unter „Westen“ (occidens) ist hier die juristisch und politisch bis zur Reichsteilung des Kaisers Theodosius nicht ganz eindeutig definierte westliche Hälfte des Imperium Romanum verstanden, etwa identisch mit den europäischen Provinzen des Reiches und dem westliche Nordafrika, also die lateinischsprachigen Provinzen des Reiches, wobei auf dem Balkan und in Nordafrika die Übergänge vom Griechischen zum Lateinischen fließend waren, wie im vierten Jahrhundert dann vor allem an den stärker von der griechischen Theologie geprägten illyrischen Bischöfen immer wieder deutlich wird. Eine Folge der großen Mobilität, die das frühe Christentum prägte, war die Präsenz griechischsprachiger Bevölkerungsgruppen im Westen, die als Keimzellen eines abendländischen Christentums angesehen werden müssen. Dies gilt vor allem für die Anfänge des Christentums in Rom, aber auch z. B. für die Anfänge des Christentums im südlichen Gallien, wie an den Gemeinden von Vienne und Lyon deutlich wird, und vielleicht auch in Nordafrika. Die griechischsprachigen christlichen Gemeinden im Westen nehmen so die aus dem Osten kommenden theologischen Diskurse auf und führen sie selbständig weiter.

In der Auseinandersetzung um gnostische Modelle oder den theologischen Entwurf Marcions entstand in Rom im 2. Jahrhundert ein theologischer Diskurs,

25 W. Löhr, Art. Logos, RAC 23, 2009, 327-435; zu Tertullians Logostheologie 387-39r.

26 Dokumente (vgl. Anm. 6), Dok. 43.2.

27 Vgl. H.C. Brennecke, Der Trinitarische Streit im Westen bis Ambrosius, in: V. H. Drecoll, Hg., Augustin Handbuch, Tübingen 2007, II9-I27. 
der die trinitarische Fragestellung (allerdings ging es noch lange in erster Linie um die Frage nach dem Verhältnis von Gott-Vater zu Christus als Gottes Sohn) von sehr unterschiedlichen Seiten aufnahm. Deutlich ist, daß die Träger dieses römischen Diskurses zunächst oft aus Kleinasien stammten.

Von Justin, der in Rom eine christlich-philosophische Schule leitete, wurde mit der Übernahme des aus der Stoa kommenden und vom mittleren Platonismus aufgenommenen Logosbegriffes ${ }^{28}$ theologisch eine Alternative zu gnostischen Vorstellungen und Marcion entwickelt, die intellektuelle Ansprüche zu befriedigen vermochte mit der Betonung der hypostatischen Eigenexistenz des Logos neben Gott und der daraus folgenden Subordination des Logos unter Gott, die allerdings auch als latenter Ditheismus angesehen werden konnte und auch auf Widerspruch stieß. Allerdings bot die Logostheologie die Möglichkeit, gegen alle gnostische Spekulation am Monotheismus festzuhalten. Die Wirkungen der Logostheologie Justins scheinen in Rom und überhaupt im Westen sehr begrenzt gewesen zu sein.

In der Auseinandersetzung mit gnostischen Entwürfen, die den jüdischchristlichen Monotheismus in Frage stellten und in denen Christus in einem Erlösermythos nahezu aufgelöst werden konnte, ist vor allem in Rom und dann auch sehr bald in Karthago, dem in severischer Zeit aufblühenden wirschaftlichen und intellektuellen Zentrum Nordafrikas, von sehr verschiedenen Seiten versucht worden, den Monotheismus zu wahren - mit sehr unterschiedlichen Folgen für die Beschreibung des Verhältnisses von Gott-Vater zu Gott-Sohn Christus. In Karthago hat in Tertullian christliche Theologie zuerst ihren lateinische Ausdruck gefunden.

Am Ausgang des 2. Jahrhunderts leitete ein Theodot aus Kleinasien in Rom eine Schule, in der wohl vor allem Schriftauslegung geübt wurde ${ }^{29}$. Unter Berufung auf biblische Zeugnisse lehrte er, daß Christus nur ein Mensch gewesen sei, der in der Taufe von Gott den Geist verliehen bekommen habe. Theodot lehnte also jede Göttlichkeit Christi und vor allem die Vorstellung einer Präexistenz des göttlichen Sohnes/Logos ab: Die Wahrung eines strikten Monotheismus ${ }^{30}$ geschieht durch eine Christologie, die die Göttlichkeit Christi ablehnt. Ähnlich muß etwa zur selben Zeit ein sonst unbekannter Artemon ${ }^{31}$ in Rom gelehrt haben, etwas anders akzentuiert dann Theodot der Bankier. Sicher handelte es sich bei diesen Schultheologien nicht um schlichte Gemeindefrömmigkeit, sondern um eine exegetisch argumentierende intellektuelle Auseinandersetzung mit der Gnosis auf der einen und der Logostheologie auf der anderen Seite. Eine Abhän-

28 Löhr (vgl. Anm. 25), 362-370.

$29 \mathrm{Zu}$ Theodot, dem „Lederarbeiter“ vgl. Eus., h.e. V 28; Hipp., haer. VII 35; X 23f.; vgl. W. Löhr, Theodotus der Lederarbeiter und Theodotus der Bankier, ZNW 87, I996, IOI-I25.

30 Die ursprünglich antignostische Motivation scheint bei Hippolyt noch deutlich durch.

3I Eus., h.e. V 28. 
gigkeit von judenchristlichen Vorstellungen, wie es altkirchliche Polemik behauptet, scheint eher unwahrscheinlich.

Unter Bischof Viktor bildet sich in Rom ein Monepiskopat aus, durch den die pluralen theologischen Entwürfe zurückgedrängt werden. Die Problematik gnostischer Entwürfe scheint ihm allerdings nicht deutlich geworden zu sein, wie Irenäus erkennen läßt. Auf der anderen Seite ist aber von ihm der sich offenbar breiter Zustimmung erfreuende radikale Versuch des Theodot, den christlichen Monotheismus zu wahren, aus der Kirche ausgeschlossen worden ${ }^{32}$.

Als theologische Alternative, der es ebenfalls darum ging, gegen gnostische und markionitische Vorstellungen den Monotheismus zu wahren und so den Problemen einer Logostheologie zu entgehen, ist der sog. modalistische Monarchianismus $^{33}$ anzusehen, der zur Wahrung des Monothesismus faktisch den göttlichen Christus mit Gott identifizierte. Am Ende des 2. Jahrhunderts hatte der aus Smyrna stammende Noët ${ }^{34}$ in Rom eine theologisch-philosophische Schule geleitet, die längere Zeit bestanden haben muß. Hippolyt wirft Noët polemisch vor, in Abhängigkeit von der heidnischen Philosophie (Heraklit) Gott mit Christus identifiziert zu haben. Die heftige Polemik Hippolyts zeigt, daß die römische Kirche und besonders ihre Bischöfe diese eindeutige monotheistische Absage an gnostische Spekulationen viel eher als die immer im Verdacht eines Ditheismus stehende Logos-Theologie als eine Art kirchliche Normaltheologie ansahen. Wenig später als Noët haben der Kleinasiate Praxeas (identisch mit Epigonus?) und der vielleicht aus Libyen stammende Sabellius ${ }^{35}$ ähnlich gelehrt, ohne daß wir Sicheres über den Zusammenhang mit der Schule Noëts aussagen können (ob Sabellius wirklich von Gott und Christus als "Sohnvater" gesprochen hat und die für antike Gottesvorstellung unerträgliche Aussage pater passus est gemacht hat, oder ob es sich dabei um polemische Schlußfolgerungen seiner Gegner handelt, bleibt allerdings unklar). Gegen diese in Rom und damit im Westen kirchlich rezipierte Identifikationstheologie richtete sich der Widerstand Hippolyts in Rom ${ }^{36}$ und Tertullians ${ }^{37}$ in Karthago von der Seite einer ebenfalls antignostischen Logos-

32 Löhr (vgl. Anm. 29).

33 R. Hübner/M. Vinzent, Der paradox Eine: Antignostischer Monarchianismus im zweiten Jahrhundert, VigChr.S. 50, Leiden 1999; S. Gerber Calixt von Rom und der monarchianische Streit, ZAC 5, 200I, 213-239.

34 Hipp., haer. IX 7 ff. X 27.

35 W. Bienert, Sabellius und der Sabellianismus als historisches Problem, in: H. C. Brennecke/ E. L. Grasmück/C. Markschies, Hg., Logos, FS L. Abramowski, BZNW 67, Berlin/New York 1993, I24-139 (= Werden der Kirche - Wirken des Geistes. Beiträge zu den Kirchenvätern und ihrer Nachwirkung, hg. U. Kühneweg, MThSt 55, Marburg I999, I24-I39).

36 Hipp.,haer. IXf. Zu Hippolyt vgl. C. Scholten, Art. Hippolytos II (von Rom), RAC I5, I99I, 492-55I.

37 Tert., Prax., ed. Aem. Kroymann/Ern. Evans, CC II, 1954, II58-I205. Eine lat. — deutsche Ausgabe mit ausführlicher Einleitung und Kommentar: Tertullian, Adversus Praxean/Gegen Praxeas, hg. H.-J. Sieben, FC 34, Freiburg/Basel/Wien $200 I$. 
theologie, die besonders gegen Noët, Praxeas und Sabellius an der hypostatischen Eigenexistenz des göttlichen Logos/Sohn festhielten. Vor allem Tertullian, der sich in Karthago mit Anhängern des Praxeas konfrontiert sah, hat in seiner Schrift adversus Praxean eine lateinische Trinitätslehre von der Logostheologie her entwickelt ${ }^{38}$. Den Monotheismus betont Tertullian durch den Begriff der Substanzeinheit, betont dabei aber die Eigenexistenz und Subordination der trinitarischen Personen.

Deutlich ist nun allerdings, daß die Logostheologie eines Hippolyt oder Tertullian im Westen nicht weit verbreitet war, beide waren theologisch eher Aussenseiter. Über die zeitgenössische Rezeption Tertullians ist nichts bekannt; Hippolyt wurde von Bischof Kallist (zusammen mit Sabellius) wegen Ditheismus aus der römischen Kirche ausgeschlossen ${ }^{39}$. Indem Kallist bei seiner theologischen Lösung auf der einen Seite den Logosbegriff aufnahm, ihn aber völlig anders als die Logostheologen von genuin stoischen Vorstellungen her interpretierte und so auch für Vertreter der Identifikationstheologie annehmbar macht, versucht er eine Versöhnung beider Optionen (bei Ausschluß von „Extremisten“ wie Sabellius und Hippolyt) und schafft eine offenbar nicht nur in Rom überzeugende kirchliche Normaltheologie ${ }^{40}$, bei der Theologie viel fester als bisher an das kirchliche Amt, an das Amt des Bischofs gebunden war.

Diese Form einer trinitarischen bzw. binitarischen Theologie scheint im Westen - wenn es denn überhaupt theologische Debatten in der Folgezeit gab, von denen wir allerdings keine Kenntnisse haben - weithin konsensfähig gewesen zu sein.

In der Mitte des 3. Jahrhunderts hat der römische Presbyter Novatian, ein theologisch von Tertullian und wohl vor allem von Hippolyt geprägter Vertreter der Logostheologie, der in der Vakanz nach dem Martyrium des Fabian in der decischen Verfolgung eine wichtige Rolle in der römischen Gemeinde spielte, aber wie Hippolyt nicht Bischof wurde und sich von der römischen Kirche trennte, mit seiner Schrift de trinitate (einer gegen jede Identifikationstheologie gerichtete Auslegung der regula fidei) den ersten theologischen Beitrag aus Rom in lateinischer Sprache geliefert, über dessen zeitgenössische Rezeption aber nichts bekannt is $\mathrm{t}^{4}$.

Für die weitere Entwicklung des trinitätstheologischen Diskurses im Westen erscheint wichtig, daß die Entfaltung der Logostheologie durch Origenes im Westen nicht rezipiert wurde. Auch Novatian als Vertreter einer westlichen Logostheologie zeigt keine Einflüsse des Origenes oder der die östliche Theologie

38 Löhr (vgl. Anm. 25), 387-39I; Sieben (wie vorige Anm.), I6-52.

39 Scholten (vgl. Anm. 36), 499-50I.

40 Gerber (vgl. Anm. 33).

4 I Zu Novatian vgl. H.-J. Vogt, Art. Novatian, LACL ${ }^{32003}$, 522-524; zur Trinitätstheologie Löhr (vgl. Anm. 25), 395 . 
dominierenden Diskussion um ihn. Bischof Dionys von Rom steht in seiner Auseinandersetzung mit seinem origenistischen Namensvetter aus Alexandrien in den 6oer Jahren des 3. Jahrhunderts ganz in der Tradition einer römischen kirchlichen Trinitätstheologie, wie sie seit Kallist offenbar in Rom und angesichts der Bedeutung Roms als sedes apostolica des Westens überhaupt im Abendland verbreitet war ${ }^{42}$. So verurteilt Dionys von Rom zwar Sabellius, lehnt aber gegen die Vertreter einer Logostheologie jede hypostatische Teilung der Trinität ab.

Nach den wenigen und später in einer völlig neuen Situation überarbeiteten Nachrichten über den „Streit der Dionyse“ schweigen die Quellen über einen trinitätstheologischen Diskurs im Westen für mehr als ein halbes Jahrhundert. Erst in der Konfrontation mit dem Problem des arianischen Streites in dessen zweiter Phase nach dem Tod Kaiser Constantins (337) aus eher politischen Gründen wird eine neue trinitätstheologische Debatte auch im Westen nötig, nun allerdings erzwungen durch die Vorgänge im Osten ${ }^{43}$.

Das Schweigen der abendländischen Theologie in den ersten zwanzig Jahren des arianischen Streites, bei dem es ja um eine Klärung innerhalb des Origenismus ging, erklärt sich aus der Tatsache, daß die Trinitätslehre des Origenes im Westen keine Rolle gespielt hatte. Ossius von Cordoba, der theologische Ratgeber Constantins aus der lateinischen Kirche, leistet bei seinen verschiedenen Auftritten im Osten im Auftrag des Kaisers keinen Beitrag zur Trinitätstheologie. Auf der Synode von Nicaea sind nur sechs Teilnehmer aus dem Westen anwesend $^{44}$; eine Rezeption der theologischen Beschlüsse von Nicaea im Westen ist bis in die soer Jahre des 4. Jahrhunderts nicht erkennbar ${ }^{45}$. Falls das Bekenntnis von Nicaea überhaupt irgendwo im Westen zur Kenntnis genommen worden ist, konnte es in seiner Stoßrichtung gegen jede subordinatianische Mehrhypostasentheologie als vollkommen in Übereinstimmung mit der uns bei Kallist und Dionys erkennbaren theologischen Tradition des Westens und speziell Roms angesehen werden.

Durch die Exilanten Athanasius und Markell von Ankyra wird der Westen nun auch zu einer theologischen Stellungnahme in dem ihm bisher fremden Streit genötigt. Unter der Führung von Julius von Rom (der allerdings als Theologe nicht fassbar wird) und Maximin von Trier, dem Gastgeber des Athanasius in dessen Exil, rehabilitiert eine römische Synode nicht nur Athanasius, sondern erklärt den wegen Häresie im Osten abgesetzten Markell für rechtgläubig (340). ${ }^{46}$ Die theologische Rehabilitierung Markells, des profilierten Vertreters einer antio-

42 U. Heil, Athanasius von Alexandrien, de sententia Dionysii. Einleitung, Übersetzung und Kommentar, PTS 52, Berlin/New York 1999.

43 Ulrich, Anfänge (vgl. Anm. 8).

44 Ulrich, ebd., I9-25.

45 Hilarius von Poitiers (vgl. Anm. 7); Ulrich, Anfänge (vgl. Anm. 8).

46 Dokumente (vgl. Anm. 6), Dok. 4O; 4I. 
rigenistischen Einhypostasentheologie, ist von der römischen Tradition einer Auffassung der Trinität, wie sie bei Kallist und Dionys deutlich geworden war, leicht erklärlich und eigentlich selbstverständlich. Die in Rom versammelten Bischöfe halten also Markell nicht für rechtgläubig, weil sie seine Position als in Übereinstimmung mit den Beschlüssen von Nicaea ansehen, sondern weil sie mit der römischen Tradition seit Kallist vereinbar war. Diese Option wurde noch dadurch verstärkt, daß der Begriff substantia, die direkte Übersetzung des griechi-

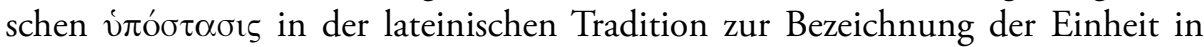
der Trinität (so schon Tertullian) benutzt wurde, was mancherlei Verwirrung stiftete.

Auf der von Kaiser Constans seinem Bruder Constantius nahezu abgepreßten Reichssynode von Serdica (343) konnten daher die westlichen Teilnehmer auf ihrer Teilsynode eine von der Theologie Markells her formulierte theologische Deklaration, die jede Mehrhypostasentheologie als arianisch verurteilte und sich als die wahre Interpretation von Nicaea verstand, von ihrer Tradition her als orthodox anerkennen ${ }^{47}$.

Die gescheiterte Synode von Serdica hatte de facto zu einer Spaltung zwischen den Kirchen des Ostens und des Westens geführt. Aber im kulturellen Überschneidungsgebiet von griechischer und lateinischer Sprache in Illyrien und auch sonst gab es auch im Westen Anhänger einer sich nun lateinisch definierender Dreihypostasentheologie in der Tradition des Euseb von Nikomedien/Konstantinopel, die allerdings für die Mehrzahl der westlichen Theologen und Kirchenmänner als „arianisch“ galt. Mit der Ermordung Kaiser Constans' (350) und der Erlangung der Alleinherrschaft Constantius' II. (353), der bisher im Osten die „Eusebianer“, also die Vertreter der origenistischen Tradition, gestützt hatte, mußte es zu neuen theologischen Konflikten kommen.

Das war die Situation, als Kaiser Constantius nach der Absetzung und Flucht des Athanasius in Sirmium die Initiative zu einer Einigung der Kirche ergriff.

M. E. läßt sich nun zeigen, daß die Verfasser der 2. sirmischen Formel, nicht nur in der Tradition der östlichen Synodalen Bekenntnisse seit der antiochenischen Kirchweihsynode standen ${ }^{48}$, sondern auch auf die noch nicht origenistisch beeinflußte Tradition der lateinischen Logostheologie eines Tertullian und Novatian zurückgegriffen haben, wie schon die intensive Benutzung Tertullians durch Phoebadius vermuten ließ.

Es kann sich in diesem Rahmen weder um einen ausführlichen und vollständigen Vergleich noch um eine Kommentierung des ganzen Textes handeln ${ }^{49}$, nur

47 Dokumente (vgl. Anm. 6), Dok. 43.2.

48 Dokumente (vgl. Anm. 6), Dok. 41.4; 42; 43.12; 44; 47.3.

$49 \mathrm{Zu}$ den Parallelen in der östlichen Tradition seit der antiochenischen Kirchweihsynode vgl. Löhr und Ulrich (vgl. Anm. 7f.). 
auf einige auffällige Parallelen eben auch zur lateinischen Tradition bei Tertullian und Novatian sei hingewiesen ${ }^{50}$ :

Die Betonung des einen Gottes und seines einzigen Sohnes, unseres Heilandes ist so allgemein, daß sich daran keine Beobachtungen im einzelnen machen lassen. Zur Aussage duos autem deos nec posse nec debere praedicari in Sirm. 2 vgl. Tert., Prax. 13,6 (II75,4If. Kroymann/Evans): duos tamen Deos et duos Dominos nunquam ex ore nostro proferimus; 19,8 (II85,45-47): et tamen ne de isto scandalizentur, rationem reddimus qua Dii non duo dicantur nec Domini sed qua Pater et Filius duo, ... Nov., trin. XXVI 2I (63,58f. Diercks): ne, si Pater esse credatur, alteri iam Deo Patri Christus subiectus esse dicatur.

Vgl. auch Nov., trin. XXXI 6-II (76,33-48 Diercks) die ausführliche Argumentation gegen eine Zweigötterlehre vom Gegensatz natus - innatus/genitus ingenitus her mit der Formulierung der sirmischen Formel: scire autem manifestum est solum patrum quomodo genuerit filium suum et filium quomodo genitus sit a patre.

$\mathrm{Zu}$ dem von der sirmischen Formel herangezogenen Testimonium Joh 20,17 vgl. Tert., Prax. 28,9 (I20I,39-44 Kroymann/Evans): Postremo quam caecus qui nec in Christi nomine intellegit alium Deum portendi si Christi nomen Patri adscribat. Si enim Christus Pater Deus est qui dicit: Ascendo ad Patrem meum et Patrem vestrum et Deum meum et Deum vestrum, utique alium Patrem super se et Deum ostendit.

$\mathrm{Zu}$ Sirm. 2: nulla ambiguitas est, maiorem esse patrem. nulli potest dubium esse, patrem honore, dignitate, claritate, maiestate et ipso nomine patris maiorem esse filio ipso testante, qui me misit maior me est (Joh I4,28). Et hoc catholicum esse, nemo ignorat, duas personas esse patris et flii, maiorem patrem, filium subiectum cum omnibus his quae ipsi pater subiecit; vgl. Tert., Prax. 9,2 (II68, I3-I8 Kroymann/ Evans): sicut ipse profitetur: quia pater maior me est (zu Joh I4,28 vgl. auch Prax. I4,IO); Nov., trin. XXVI 8f. (62,25-63,28 Diercks): Aut cum legit: Non descendi de caelo ut faciam uoluntatem meam, sed uoluntatem eius qui misit me (Joh 6,38)? Aut dum inuenit positum: Quoniam qui me misit, maior me est (Joh I4,28)?; XXVII 2 (64,4-8 Diercks): At cum ego dicit, deinde patrem infert dicendo Ego et Pater, proprietatem personae suae, id est Filii, a paterna auctoritate discernit atque distinguit, non tantummodo de sono nominis, sed etiam de ordine dispositae potestatis, ... ; XXVII I2 (65,54-56 Diercks): Dum ergo accipit sanctificationem a Patre, minor Patre est; minor autem Patre consequenter snon Pater est, sed Filius. Pater enim si fuisset, sanctificationem dedisset, non accepisset,

50 Sowohl die Verfasser der 2. sirmischen Formel als auch Phoebadius, der diese aus Tertullian heraus widerlegen will, benutzen Tertullian selektiv. Ein Verbot der Usia/Substantia-Terminologie ließ sich aus Tertullian gerade nicht ableiten; vgl. Tert., Prax. 2,4; I2 u. ö. 
XXXI I8 (77,79-84 Diercks): Cuius sic diuinitas traditur, ut non aut dissonantia aut inaequalitate dininitatis duos deos reddidisse nideatur. Subiectis enim ei quasi Filio omnibus rebus a Patre, dum ipse cum his quae illi subiecta sunt Patri suo subicitur, Patris quidem sui Filius probatur, ceterorum autem et Dominus et Deus esse reperitur.

Da sowohl Tertullians Schrift gegen Praxeas als auch Novatians de trinitate gegen Vertreter einer Identifikationstheologie gerichtet sind, finden sich in beiden Schriften zahlreiche Aussagen über die Unterscheidung der Personen in der Trinität, wobei es hier natürlich in erster Linie um die Betonung der Distinktion der Eigenpersönlichkeit Christi geht. Eine Eigenpersonalität des Geistes spielt in Sirm. 2 noch keine Rolle; auch hier geht es nur um die Betonung der Personalität Christi gegenüber Gott.

Zu Sirm. 2: Et hoc catholicum esse, nemo ignorat, duas personas esse patris et filii, maiorem patrem, filium subiectum cum omnibus his quae ipsi pater subiecit vgl. Tert., Prax. 4,4 (II63,22-26 Kroymann/Evans): Hoc uno capitulo epistolae apostolicae potuimus iam et Patrem et Filium ostendisse duos esse, praeterquam ex nominibus Patris et Filii etiam ex quo quod qui tradidit regnum et cui tradidit, item qui subiecit et cui subiecit duo sint necesse est; 9, I (II68,3f. Kroymann/Evans): Ecce enim dico alium esse Patrem et alium Filium et alium Spiritum, ...; I4,I (II76,If. Kroymann/ Evans): Adhuc et illa nobis regula adsistit duos uindicantibus Patrem et Filium, ....

Novatian widmet die Kapitel XXVI-XXVIII von de trinitate grundsätzlich dem Argument, daß in der Trinität die Personen vor allem des Vaters und des Sohnes unterschieden werden müssen.

\section{IV.}

Die zweite sirmische Formel, die offenbar im Auftrag des Kaisers ganz für den lateinischen Westen formuliert worden war, steht natürlich in der Tradition der griechischen antinicaenischen Logostheologie in der Folge des Origenes, wie sie seit der theologischen Opposition gegen Nicaea und dann vor allem gegen die Einhypostasentheologie Markells von Ankyra im Osten in den verschiedenen theologischen Synodalerklärungen seit der antiochenischen Kirchweihsynode formuliert worden war. Aber im lateinischen Westen konnte sie eben auch auf die lateinische, in erster Linie antisabellianisch ausgerichtete Logostheologie des frühen 3. Jahrhunderts vor Origenes zurückgreifen und der lateinischen Kirche damit demonstrieren, daß eine die Einheit bis zur Identifikation der trinitarischen Personen betonende Trinitätslehre nicht die einzige lateinische theologische Tradition war, daß es eben auch im lateinischen Westen eine Tradition einer die Eigenexistenz der drei göttlichen Personen betonende Logostheologie gegeben hatte, die eben weit hinter Origenes zurückgriff. So ist für mich zu erklären, daß 
Phoebadius bei dem Versuch, die zweite sirmische Formel theologisch zu widerlegen, ausgerechnet auf Tertullians Schrift gegen Praxeas zurückgriff. Vielleicht erklärt der Rückgriff auf eine westliche Tradition auch, warum z. B. Ossius von Cordoba und auch Liberius offenbar ohne große Probleme diese Erklärung unterzeichnen konnten.

Die Wirkungsgeschichte von Tertullians Schrift adversus Praxean ist in vieler Hinsicht unklar ${ }^{\text {SI }}$. Mir scheint jedenfalls wahrscheinlich, daß eben auch eine Wirkungsgeschichte im lateinischen antinicaenischen Milieu anzunehmen ist. Dasselbe gilt für Novatians Schrift de trinitate, die in der vorliegenden patristischen Tradition kaum Spuren hinterlassen hat ${ }^{5^{2}}$. Interessant ist eine Bemerkung Rufins, daß diese Schrift, als deren Verfasser er übrigens Tertullian annimmt, in makedonianischen Kreisen Konstantinopels unter dem Namen Cyprians beliebt und verbreitet war ${ }^{53}$. Damit gäbe es zumindest einen Beleg für die Rezeption eines vornizänischen lateinischen Logostheologen durch die Gegner der Beschlüsse von Nicaea $^{54}$.

Die Rezeption der vornizänischen Väter, gerade der Logostheologen vor Origenes in den großen dogmatischen Kontroversen des 4. und 5. Jahrhunderts ist wenig erforscht und hält vermutlich noch viele Überraschungen bereit, die zu mancherlei Korrekturen an dem uns vertrauten Bild der dogmen- und theologiegeschichtlichen Entwicklung des vierten und fünften Jahrhunderts Anlaß geben könnten.

5I Sieben (vgl. Anm. 37), 78-94.

52 Novatianus De Trinitate - Über den dreifaltigen Gott, hg. H. Weyer, Darmstadt 1962, I9.

53 Ruf., de adult. Libr. Orig. I2 (CC XX, ed. M. Simonetti, Turnolt I96I, I5).

54 Zur Rezeption Cyprians bei den lateinischen Homöern vgl. den Schriftstellerindex bei R. Gryson, Scripta Arriana Latina, CC 87, Turnholt 1982, 282. 


\section{Literaturverzeichnis}

Bienert (1993): W. Bienert, „Sabellius und der Sabellianismus als historisches Problem“, in: H. C. Brennecke, E. L. Grasmück u. C. Markschies (Hgg.), Logos, FS L. Abramowski, BZNW 67, Berlin / New York, I24-I39 (= Werden der Kirche - Wirken des Geistes. Beiträge zu den Kirchenvätern und ihrer Nachwirkung, hg. v. U. Kühneweg, MThSt 55, Marburg 1999, I24-I39).

Brennecke (1984): H.C. Brennecke, Hilarius von Poitiers und die Bischofsopposition gegen Konstantius II. Untersuchungen zur dritten Phase des arianischen Streites (337-36I), PTS 26, Berlin / New York.

Brennecke (1988): H. C. Brennecke, Studien zur Geschichte der Homöer. Der Osten bis zum Ende der homöischen Reichskirche, BHTh 73, Tübingen.

Brennecke (1993): H. C. Brennecke, Art. „Homéisme“, DHGE 24, 932-960

Brennecke (2007):H.C. Brennecke, „Der Trinitarische Streit im Westen bis Ambrosius“, in: V. H. Drecoll (Hg.), Augustin Handbuch, Tübingen, II9I27.

Brennecke u. a. (2007): H. C. Brennecke, U. Heil, A. v. Stockhausen u. A. Wintjes, Dokumente zur Geschichte des arianischen Streites 3, Athanasius Werke III $\mathrm{I}, 3$, Berlin / New York.

Gerber (200I): S. Gerber, "Calixt von Rom und der monarchianische Streit“, $Z A C_{5}, 213-239$.

Girardet (2007): K.M. Girardet, Die konstantinische Wende, 2. Auflage, Darmstadt.

Gryson (1982): R. Gryson, Scripta Arriana Latina, CC 87, Turnholt.

Heil (I999): U. Heil, Athanasius von Alexandrien, de sententia Dionysii, Einleitung, Übersetzung und Kommentar, PTS 52, Berlin / New York.

Hübner u. Vinzent (I999 ): R. Hübner u. M. Vinzent, „Der paradox Eine: Antignostischer Monarchianismus im zweiten Jahrhundert", VigChr, Leiden, 50.

Löhr (1986): W. Löhr, Die Entstehung der homöischen und homöusianischen Kirchenparteien - Studien zur Synodalgeschichte des 4. Jahrhunderts, Diss.theol. Bonn.

Löhr (2000): W. Löhr, Art. „Homöer“, $R G G^{4} 3$, I880-I882.

Löhr (2009): W. Löhr, Art. „Logos“, RAC 23, 327-435.

Markschies (1995): Ch. Markschies, Ambrosius von Mailand und die Trinitätstheologie, BHTh 9o, Tübingen.

Markschies (1997): Ch. Markschies, „Was ist lateinischer ,Neunizänismus?", $Z A C$ I, 73-95.

Markschies (2000): Ch. Markschies, Alta Trinità Beata. Gesammelte Studien zur altkirchlichen Trinitätslehre, Tübingen.

Markschies (2003): Ch. Markschies, Art. „Neunicaenismus“, $R G G^{4}$ 6, $232 \mathrm{f}$. 
Mühlenberg (1998): E. Mühlenberg (Hg.), Die Konstantinische Wende, VWGTh I3, Gütersloh.

Novatianus (1962 ): Novatianus, De Trinitate - Über den dreifaltigen Gott, hg. v. H. Weyer, Darmstadt.

Opitz (1935): H.-G. Opitz, Urkunden zur Geschichte des arianischen Streites I-2, Athanasius Werke III I,I-2, Berlin.

Piétri u. Markschies (1996 ): C. Piétri u. Ch. Markschies, „Theologische Diskussionen zur Zeit Konstantins: Arius, der ,arianische Streit' und das Konzil von Nizäa, die nachnizänische Auseinandersetzungen bis 337", in: C. Piétri u. L. Piétri (Hgg.), Das Entstehen der einen Christenheit (250-430), Die Geschichte des Christentums 2, Freiburg / Basel / Wien, 27I-344.

Ritter (1999): A. M. Ritter, „Dogma und Lehre in der Alten Kirche“ in: C. Andresen (Hg.), Handbuch der Dogmen- und Theologiegeschichte I, 2. Auflage, Göttingen, 99-283.

Ritter (2006): A. M. Ritter, „Concilium Constantinopolitanum I - 38I“ in: G. Alberigo (Hg.), The Oecumenical Councils, Concilorum oecumenicorum generaliumque Decreta I, CC, Turnhout, 35-70.

Rufin (I96I): Rufin, de adult. Libr. Orig. I2, CC XX, ed. M. Simonetti, Turnolt. Schäferdiek (1978): K. Schäferdiek, Art. „Germanenmission“, $R A C$ 10, 492-542.

Schäferdiek (1996): K. Schäferdiek, Schwellenzeit. Beiträge zur GRuf., de adult. Libr. Orig. I2 (CC XX, ed. M. Simonetti, Turnolt I96reschichte des Christentums in Spätantike und Frühmittelalter, W. Löhr u. H.C. Brennecke (Hgg.), AKG 64, Berlin / New York.

Scholten (I99I ): C. Scholten, Art. „Hippolytos II (von Rom)“, $R A C$ I5, 492-55I.

Sieben (200I): H.-J. Sieben, Tertullian, Adversus Praxean/Gegen Praxeas, FC 34, Freiburg / Basel / Wien.

Tertullian, Prax., ed. Aem. Kroymann u. Ern. Evans, CC II, 1954.

Ulrich (1994): J. Ulrich, Die Anfänge der abendländischen Rezeption des Nizänums, PTS 39, Berlin / New York.

Ulrich (1999): J. Ulrich, Phoebadius. Contra Arianos - Streitschrift gegen die Arianer, $\mathrm{FC} 38$, Freiburg.

Vogt (2003): H.-J. Vogt, Art. „Novatian“, ${ }^{3} L A C L$. 